\title{
MASTER
}

\section{$\therefore$ MASTER}

31
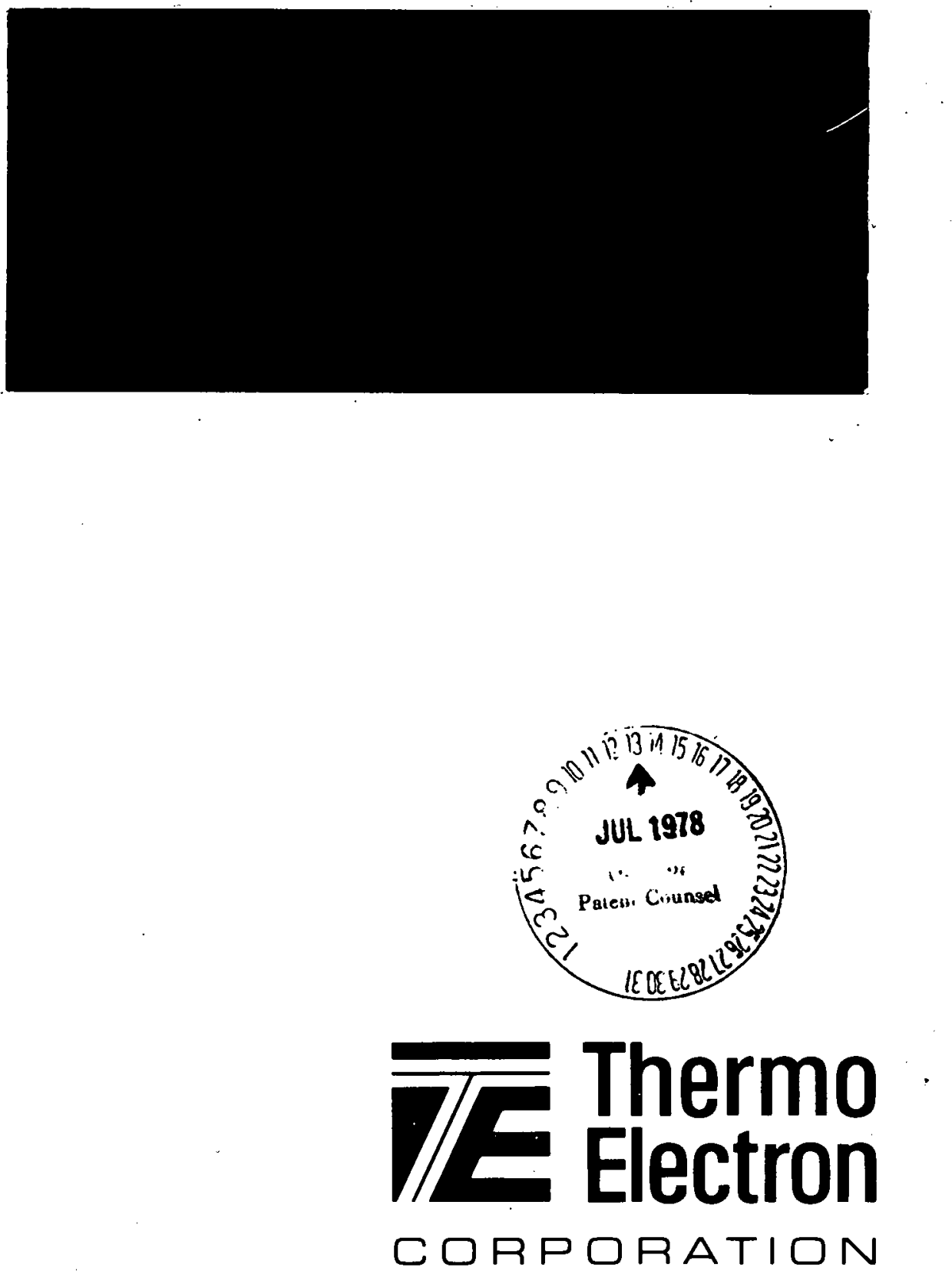


\section{DISCLAIMER}

This report was prepared as an account of work sponsored by an agency of the United States Government. Neither the United States Government nor any agency Thereof, nor any of their employees, makes any warranty, express or implied, or assumes any legal liability or responsibility for the accuracy, completeness, or usefulness of any information, apparatus, product, or process disclosed, or represents that its use would not infringe privately owned rights. Reference herein to any specific commercial product, process, or service by trade name, trademark, manufacturer, or otherwise does not necessarily constitute or imply its endorsement, recommendation, or favoring by the United States Government or any agency thereof. The views and opinions of authors expressed herein do not necessarily state or reflect those of the United States Government or any agency thereof. 


\section{DISCLAIMER}

Portions of this document may be illegible in electronic image products. Images are produced from the best available original document. 
NOTICE

PORTIONS OF THIS REPORT ARE ILLEGIBLE IT has been ropreduced from the best avalibilo copy to permit the breadest possible availability.

\author{
DESIGN AND DEVELOPMENT OF AN \\ AUTOMOTIVE OR GANIC RANKINE-CYCLE \\ POWERPLANT WITH A \\ RECIPROCATING EXPANDER \\ FINAL REPORT: \\ VOLUME 2 \\ DETAILED DISCUSSION \\ Thermo Electron Corporation \\ 101 First Avenue \\ Waltham, Masșachusetts 02154
}

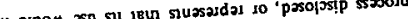

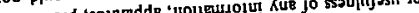
50 lompodd so ssomidus

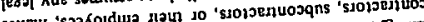

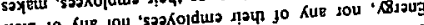

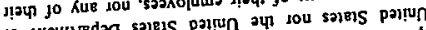

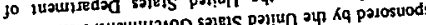

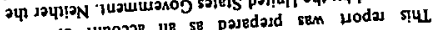
YHom jo junojos ue se pajed

September 1977

Department of Energy

Under Contract No, EY-76-C-02-2670 
TABLE OF CONTENTS

Chapter

Page

INTRODUCTION

$1-1$

2

SYSTEM DEVELOPMENT .............. 2-1

2. 1 SYSTEM DESCRIPTION .............. 2-1

2. 2 TEST CONFIGURATION .............. 2-7

2. 3 . PREPROTOTYPE SYSTEM TEST FACILITY .. 2-12

2.3. I System Power Measurements....... 2-12

2.3.2 Ram Air Facility ............ 2- 14

2.3.3 Combustion Air-Fuel Facility....... 2-14

2. 3.4 Instrumentation ............. 2-17

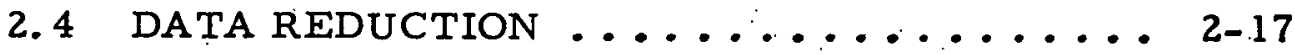

2. 5 INITIAL TEST RESULTS AND PERFORMANCE EVALUATION .................... 2-20

2.6. FUEL ECONOMY IMPROVEMENT ....... 2-26

2.6. 1 Implemented Fuel Economy Improvements .............. 2-... 2-29

2.6.2 Test Results for Improved Preprototype System ................... 2-... 2-...

2.6.3 Future Fuel Economy Improvements ... 2-52

3 COMPONENT DEVELOPMENT ........... 3-1

3. 1 INTRODUCTION ..................... 3-1

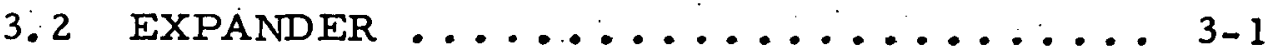

3.2.1 Four-Cylinder Expander ............. 3-1

3. 2,2 Single-Cylinder Expander ........ 3-13

3.2.3 Intake Valving ................. 3-28

3. 2. 4 Expander Test Facility ......... 3-55

3.2.5 Expander Test Results and

Performances Evaluation ........ 3-58

3.3 REGENERATOR ................... 3-72

3.3.1 Regenerator Design ........... 3-72

3.3.2 Test Results and Performance

Evaluation ............. 3- 80 
TABLE OF CONTENTS (continued)

Chapter

3. 4 FAN AND CONDENSER ............... 3-86

3.4.1 Fan and Condenser Design........ 3-86

3.4.2 Condenser and Fan Testing; and

Performance Evaluation ......... 3-93

3.5. BOOST PUMP ........................ 3-98

3.5. 1 Boost Pump Design ........... 3-98

3.5.2 Test Results and Performance

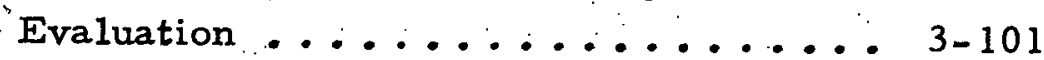

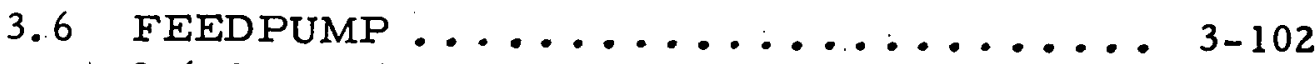

3.6.1 Feedpump Design ................. 3-102

3.6.2 Feedpump Test Facility .............. 3-113

3.6.3. Test Results and Performance

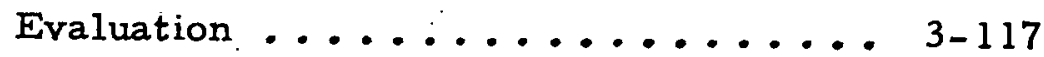

3.7 BUNER/VAPOR GENERATOR ......... 3-127

3.7.1 Burner/Vapor Generator Design..... 3-127

3.7.2 Vapor Generator Testing and

Performance Evaluation ......... 3- 134

3.7.3 Burner Testing and Performance

Evaluation ................. 3-139

3.8 CONTROL SYSTEM .................... 3-156

3. 8. 1 Condenser Fan Drive and Control .... 3-158

3.8.2 Combustion Controls .................. 3-162

3. 8. 3 Combustion Controls - Test Results and

Performance Evaluation ........ 3-178

3. 8.4 Feedpump Displacement Control..... 3-184

3.9 TRANSMISSION EVALUATION .......... 3-... 187

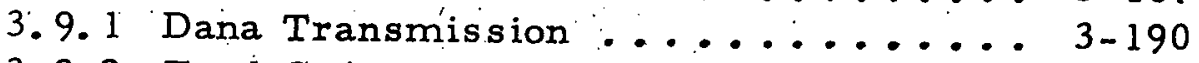

3.9.2 Ford C-4 Transmission ................ 3-190

3. 9. 3. Comparison of Transmission Units ... 3-19.1

4 COMPACT CAR DESIGN .................. 4-1

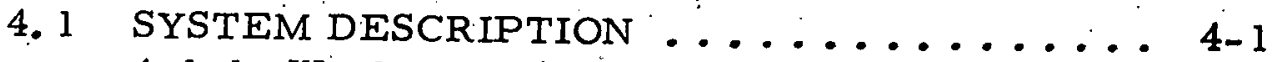

4. 1. 1 Working Fluid ............... 4-.

4. 1.2 Expander-Feedpump Assembly Design.. 4-7

4. 1.3 Expander and Feedpump Detail Design.. 4-11 
TABLE OF CONTENTS (continued)

Chapter

Page

4. 1.4 Compact Car Burner/Vapor Generator 4-18

4. 1.5 Compact Car Condenser/Regenerator

$4-27$

4. 2 IMPROVEMENTS RELATIVE TO THE

PREPROTOTYPE SYSTEM AND FERFORMANCE

PROJECTIONS ................... 4-32

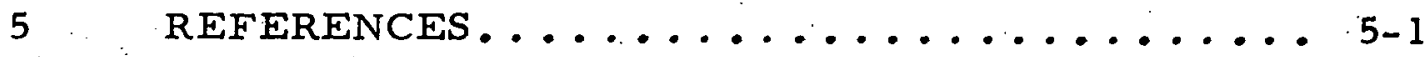

APPENDIX

A

ROAD LOAD FUEL ECONOMY CALCULATIONS .... A A- 1

A. 1 COMBUSTION SYSTEM POWER

REQUIREMENT $\ldots \ldots \ldots \ldots \ldots \ldots$ A -1

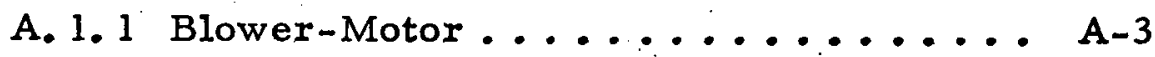

A. 1.2 Fuel Cup Atomizer Power ........ A-3

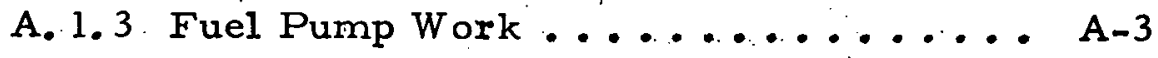

A. 2 BOOST PUMP REQUIREMENTS .......... A-6

A. 3 NET ORCS POWER .................. A-6

A. 4 POWER TRAIN INPUT POWER $\ldots \ldots . . . .$. A-7

A. 5 POWER STEERING .................... A-7

A. 6 ELECTRICAI ACCESSORIES ............ A-7

A. 7 DRIVELINE REQUIREMENTS .......... A-7

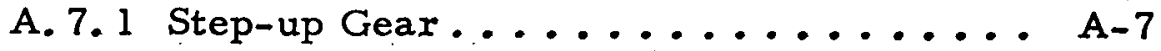

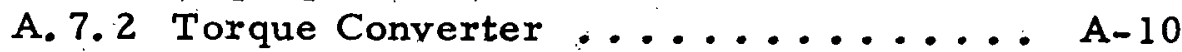

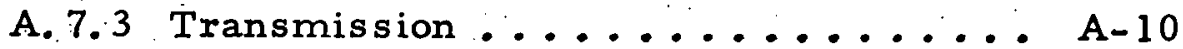

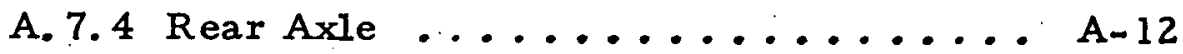

A. 8 ROAD LOAD POWER ....................... A-14

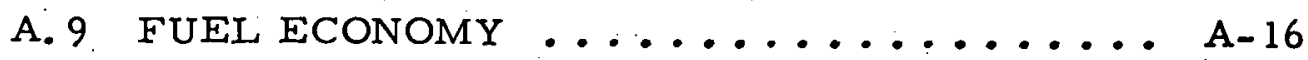

B IDEAL CYCLE MODEL FOR EXPANDER ........ B-1

B. 1 Case $1\left(m_{6}-m_{R E S} \leq m_{N E T}\right) \ldots \ldots . \ldots$ B- 1

B. 2 Case $2\left(m_{6}-m_{R E S}>m_{N E T}\right) \ldots \ldots . . . . .8-4$ 


\section{ABSTRACT}

This final report, written under ERDA Contract EY-76-C-02-2670, presents the work performed at Thermo Electron Corporation from November 1971 to December 1974 under the Environmental Protection Agency Contract No. 68-01-0409 for the design and development of an organic Rankine-cycle engine for automobile propulsion.

An automotive powerplant using an organic Rankine-cycle system with a reciprocating expander has been designed, built, and tested on an engine dynamometer in a preprototype configuration. The system is designed to provide performance approximately equivalent to that of a 351-CID internal combustion engine in the reference car, a 1972 Ford Galaxie 500. A description of the preprototype system, major components, and results from component and system testing are presented. The fuel economy based on steady-state measurements is estimated to be $10.2 \mathrm{mpg}$ over the federal driving cycle with a maximum of $16 \mathrm{mpg}$ at $30 \mathrm{mph}$. Projections of steady-state emission measurements show compliance with the 1970 Clean Air Act standards for 1978 vehicle emissions. The levels for unburned hydrocarbons, carbon monoxide, and oxides of nitrogen were 41 percent, 6 percent, and 69 percent of the standards, respectively.

At the conclusion of the preprototype phase of the program, a prototype design effort was initiated to upgrade and improve the performance of the preprototype system. The reference vehicle for this prototype design is a compact car in the weight class of a 1974 Ford Pinto. The results of this design study, including performance projections, are also presented in this report. 


\section{INTRODUCTION}

Emphasis on reducing automotive exhaust emissions has led to research on many alternative powerplants to replace the internal combustion engine. The Rankine-cycle engine is an inherently clean engine due to the use of a continuous combustion process and the separation of the power cycle frpm this process, and has received attention as a potentially desirable long-term solution to the emissions problem.

Moreover, the Rankine-cycle engine offers the potential for high reliability, low maintenance requirements, moderate cost, good driveability, and good fuel economy. Because of the strong potential of the Rankine-cycle engines, the Environmental Protection Agency (EPA) initiated development at Thermo Electron Corporation of a Rankine-cycle engine. The program was subsequently transferred to the Energy Research and Development Administration (ERDA), now Department of Energy (DOE). The Ford Motor Company, under a joint development program with Thermo Electron Corporation, has contributed financial and technical resources to the development effort.

This report (Volume 2) describes in detail the work performed in the design, development, and testing of a Rankine-cycle powerplant capable of powering a full-size (4500-1b) automobile. This preprototype engine system is described in detall in the system development section, and performance results are reported from initial road load tests through the final off-road load (ORL) system characterization tests. The component development, including design and testing, is included in this report. The design of a prototype (compact car) system is presented showing the potential improvement relative to the prototype system. 


\section{SYSTEM DEVELOPMENT}

\subsection{SYSTEM DESCRIPTION}

The Thermo Electron Rankine-cycle engine is a completely.sealed system using an organic working fluid. Figure 2.1 is a schematic diagram of the engine. The major system components consist of the burner, vapor generator (boiler), expander, feedpump, condenser, and regenerator. Organic fluid (at high pressure and temperature) from the vapor generator is expanded in a reciprocating expander to produce power to drive the vehicle and all auxiliaries and accessories. Low-pressure superheated vapor exhausts from the expander into the regenerator where part of the energy in the exhaust vapor is transferred to the feed liquid going to the vapor generator. The vapor leaves the vapor side of the regenerator slightly superheated and passes into the air-cooled condenser where the remaining superheat is removed and the vapor is condensed to a slightly subcooled liquid. The condensed liquid pressure is then raised from the condenser pressure to the vapor generator inlet pressure by the system feedpump. The liquid then passes through the regenerator and into the vapor generator, where energy is transferred to the working fluid by fuel combustion providing high pressure and temperature vapor to the expander, thus completing the cycle. The system is completely sealed with 100 percent of the vapor condensed under all operating conditions.

The working fluid used is Fluorinol-85, a mixture of 85 mole percent trifluoroethanol and 15 mole percent water. The characteristics of the fluid are summarized in Table 2.1. This fluid has excellent characteristics as the working fluid for low-cost Rankine-cycle engines oriented toward commercial applications. Its thermodynamic 


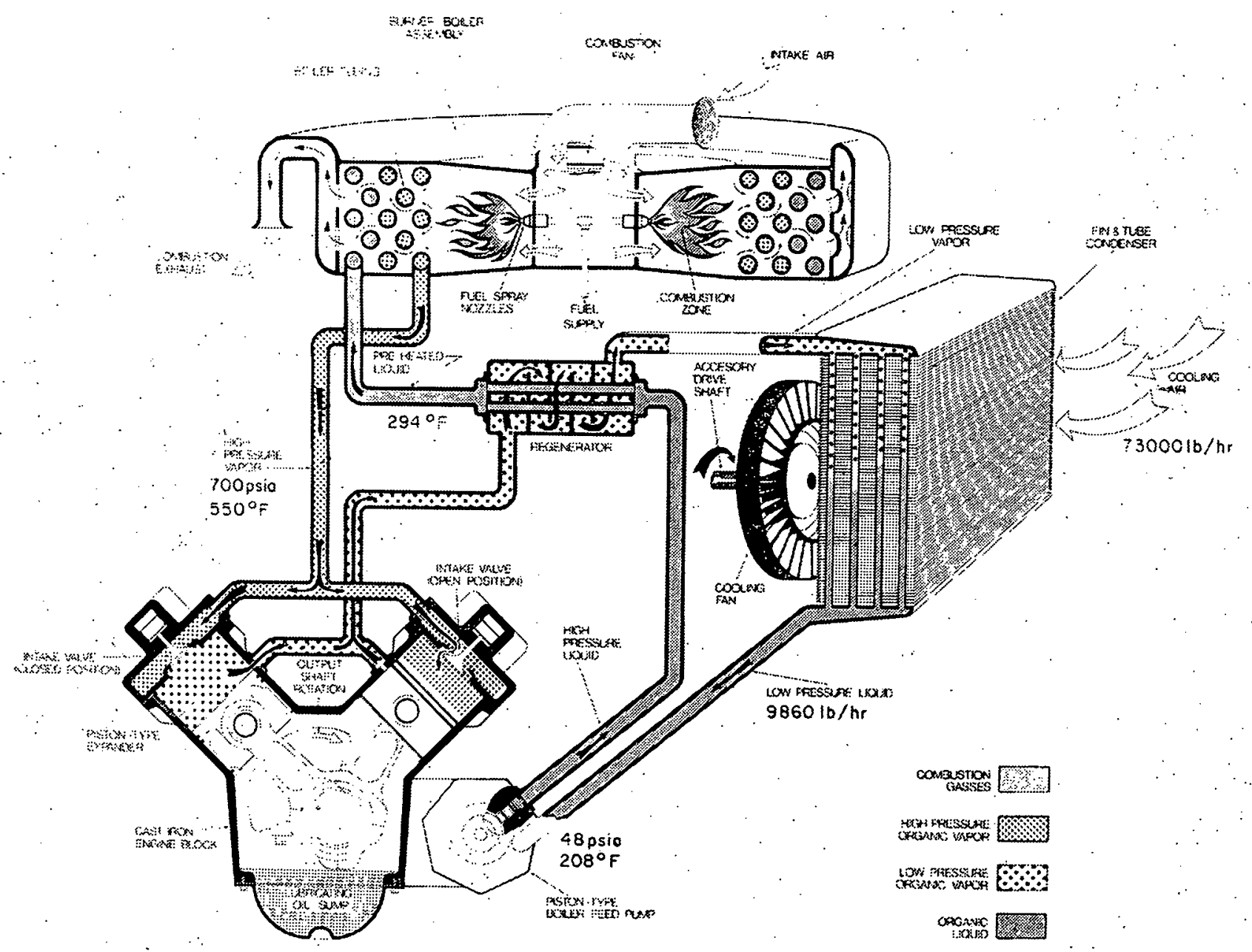

Figure 2.1. Thermo Electron Rankine-Cycle Engine Schematic Diagram 
TABLE 2. 1

WORKING FIUID AND LUBRICANT CHARACTERISTICS

A-1588

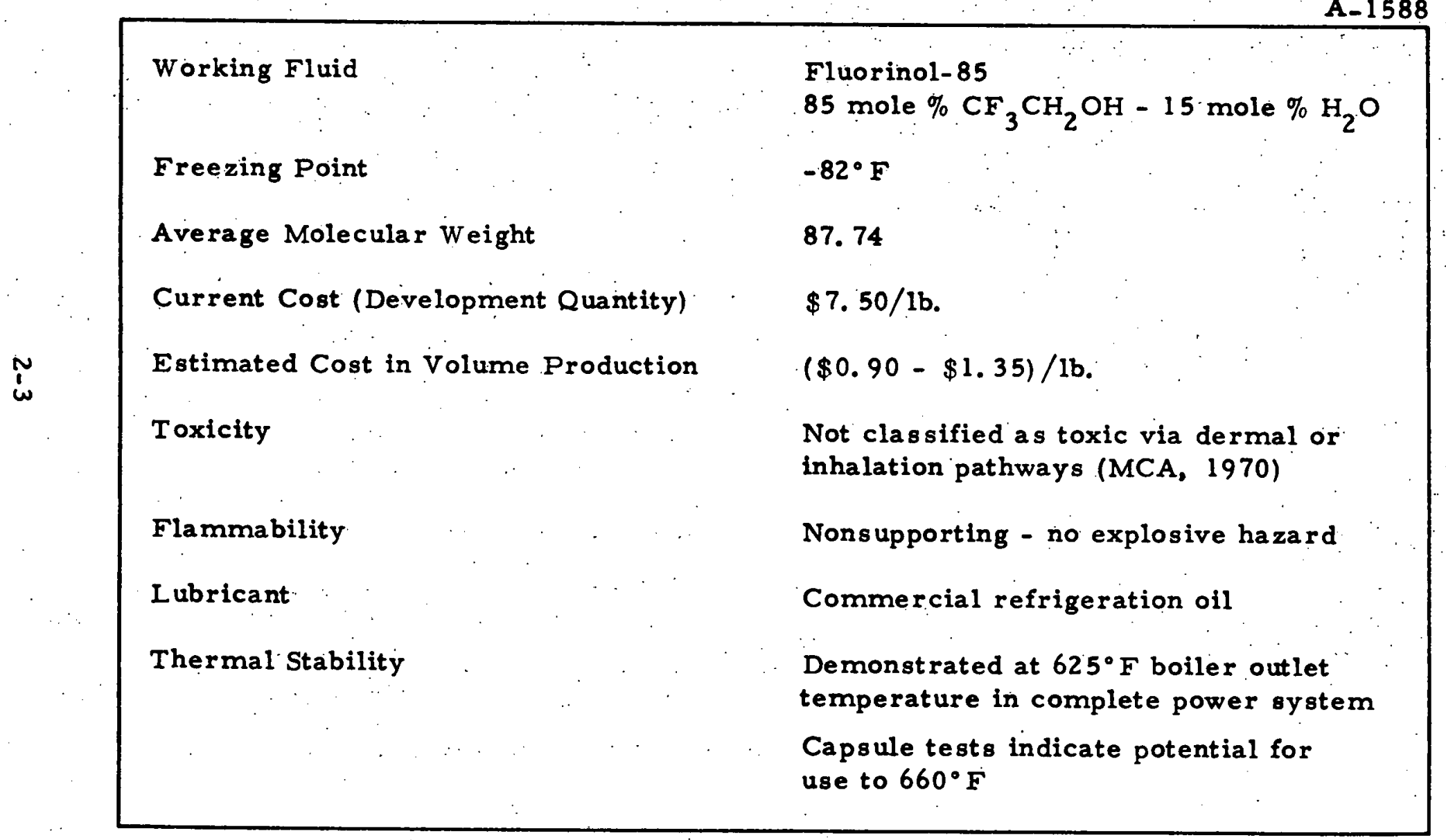


characteristics provide an acceptable cycle efficiency at moderate boiler outlet temperature levels of 500 to $625^{\circ} \mathrm{F}$. At the se temperatures, low-cost lubricants are avallable that are thermally stable and compatible with the working fluid at the peak cycle temperature. Because the lubricant:is sealed in the system with the working fluid, there is no need for complete separation of the lubricating oil from the working fluid before it enters the vapor generator. All internal moving parts of the system are well lubricated, leading to the potential for long life. The moderate vapor generator outlet temperature, coupled with the noncorrosiveness of the working fluid, permits the use of low-cost materials of construction, such as carbon steel vapor generator tubing and a cast iron expander block, minimizing the system cost. Another key characteristic for the automotive application is the low freezing point of $-82^{\circ} \mathrm{F}$.

In the design of the components and the system, an essential consideration has been packaging the complete system into a 1972 Ford Galaxie engine compartment with only minor modifications to the vehicle. The Ford Motor Company assisted in the integration and packaging of the system within the vehicle. The complete system layout is illustrated in Figure 2.2, which shows a side view looking from the passenger's side of the engine compartment.

Performance calculations indicated that a system designed to provide 146 gross shaft power from the expander at a vehicle speed of $107 \mathrm{mph}$ and expander speed of $1800 \mathrm{rpm}$ provided acceptable performance when installed in the reference vehicle, a 1972 Ford Galaxie. All component sizes are thus based on this peak power design point condition. The major system characteristics at the peak power operating point are summarized in Table 2.2 . 


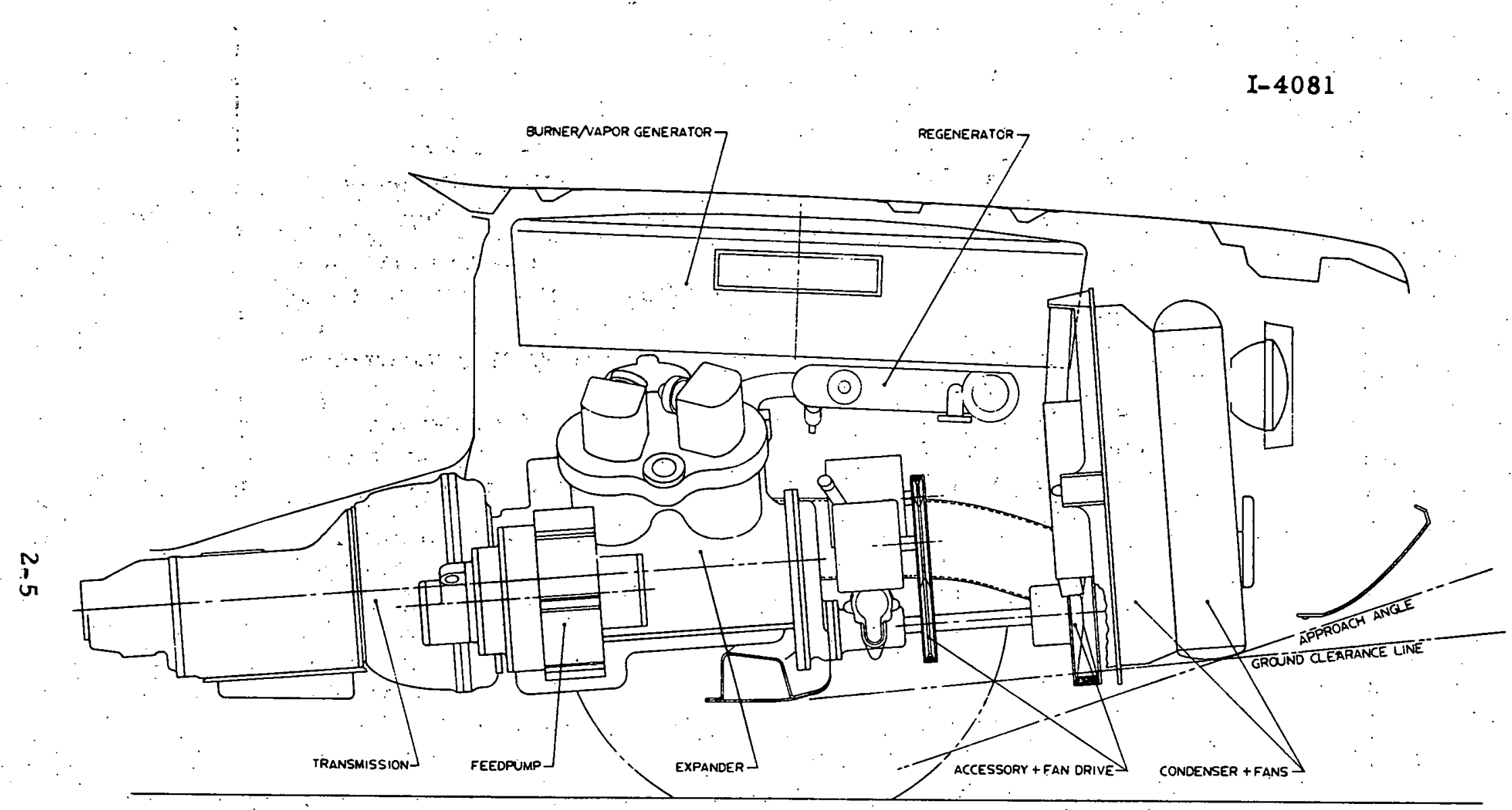

Figure 2.2 1972 Ford Galaxie Engine Compartment 
TABLE 2.2

MAJOR SYSTEM CHARACTERISTICS AT PEAK POWER

Reference Car and Transmission

Curb Weight

Expander Gross Shaft Power

Expander Speed

Net Shaft Power to Torque Converter

Heat Transfer Rates

Vapor Generator

Condenser

Regenerator

Combustion Rate (HHV)

Accessory and Auxilia ry Powers

(Shaft from Expander)

\section{Feedpump}

Condenser Fans

Combustion System

Other

Total
1972 Ford Galaxie 500

3 -speed automatic

$4318 \mathrm{lbs}$

145. $5 \mathrm{hp}$

$1800 \mathrm{rpm}$

$111.1 \mathrm{hp}$

$2.17 \times 10^{6} \mathrm{Btu} / \mathrm{hr}$ 1. $79 \times 10^{6} \mathrm{Btu} / \mathrm{hr}$ $435,600 \cdot \mathrm{Btu} / \mathrm{hr}$

$2.67 \times 10^{6} \mathrm{Btu} / \mathrm{hr}$
$11.2 \mathrm{hp}$
$13.6 \mathrm{hp}$
$5.2 \mathrm{hp}$
$4.4 \mathrm{hp}$
$34.4 \mathrm{hp}$ 


\subsection{TEST CONFIGURATION}

The preprototype test system, including all the components, plumbing, support equipment, and instrumentation that were used in the engine dynamometer tests, is shown in Figure 2.3. The components are placed in exactly the same position relative to each other as they would be in the vehicle. Additional figures are included to show more clearly some of the components hidden from view in Figure 2.3. The condenser, two condenser fans, and the variablespeed condenser fan drive are shown in Figure 2.4. The variablespeed drive consists of a pair of variable-pitch diameter pulleys that can vary the fan speed independent of the expander speed for optimum condenser operation. Also shown in this photograph is a view of the four-cylinder expander-feedpump subassembly.

Figure 2.5 shows the plate-fin regenerator prior to installation in the system. The regenerator serves two purposes. Its main function is to preheat the working fluid entering the boiler by desuperheating the vapor entering the condenser. Its secondary function is to trap oil droplets contained in the exhaust vapor from the expander and return the oil to the crankcase. The small unflanged tube in the lower right of the photograph is the oil return line.

Another component installed in the system, but not visible in Figure 2.3, is the boost pump. During certain operating conditions, the net positive suction head (NPSH) required by the main feedpump is higher than that available at the condenser. The boost pump, shown in Figure 2.6, is a centrifugal pump that can operate at the low NPSH coming out of the condenser and provide up to 20 psig into the main feedpump. 


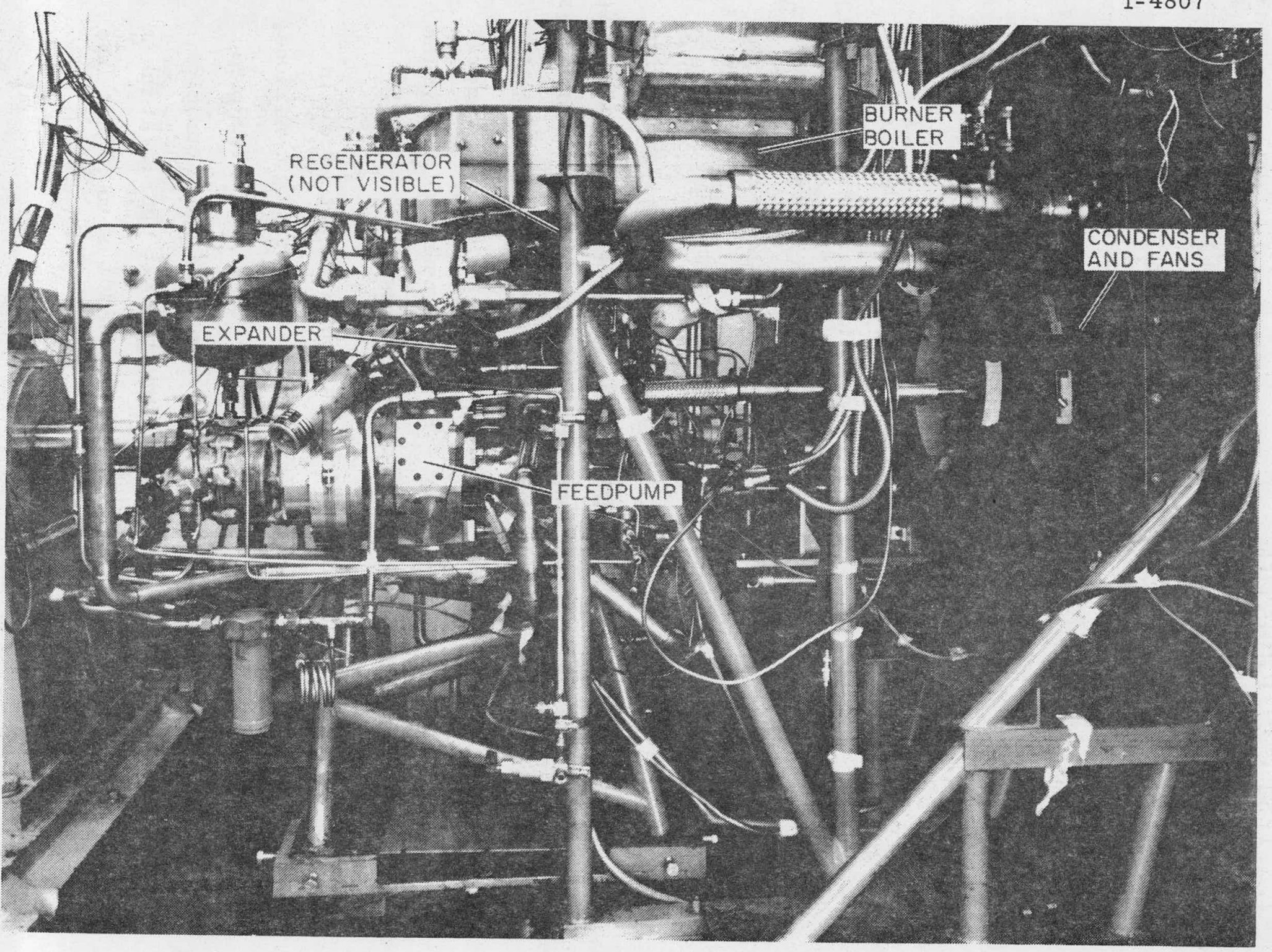

Figure 2.3 Preprototype System - Side View 


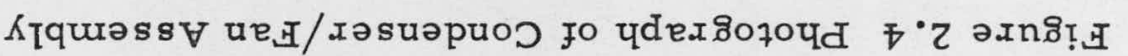

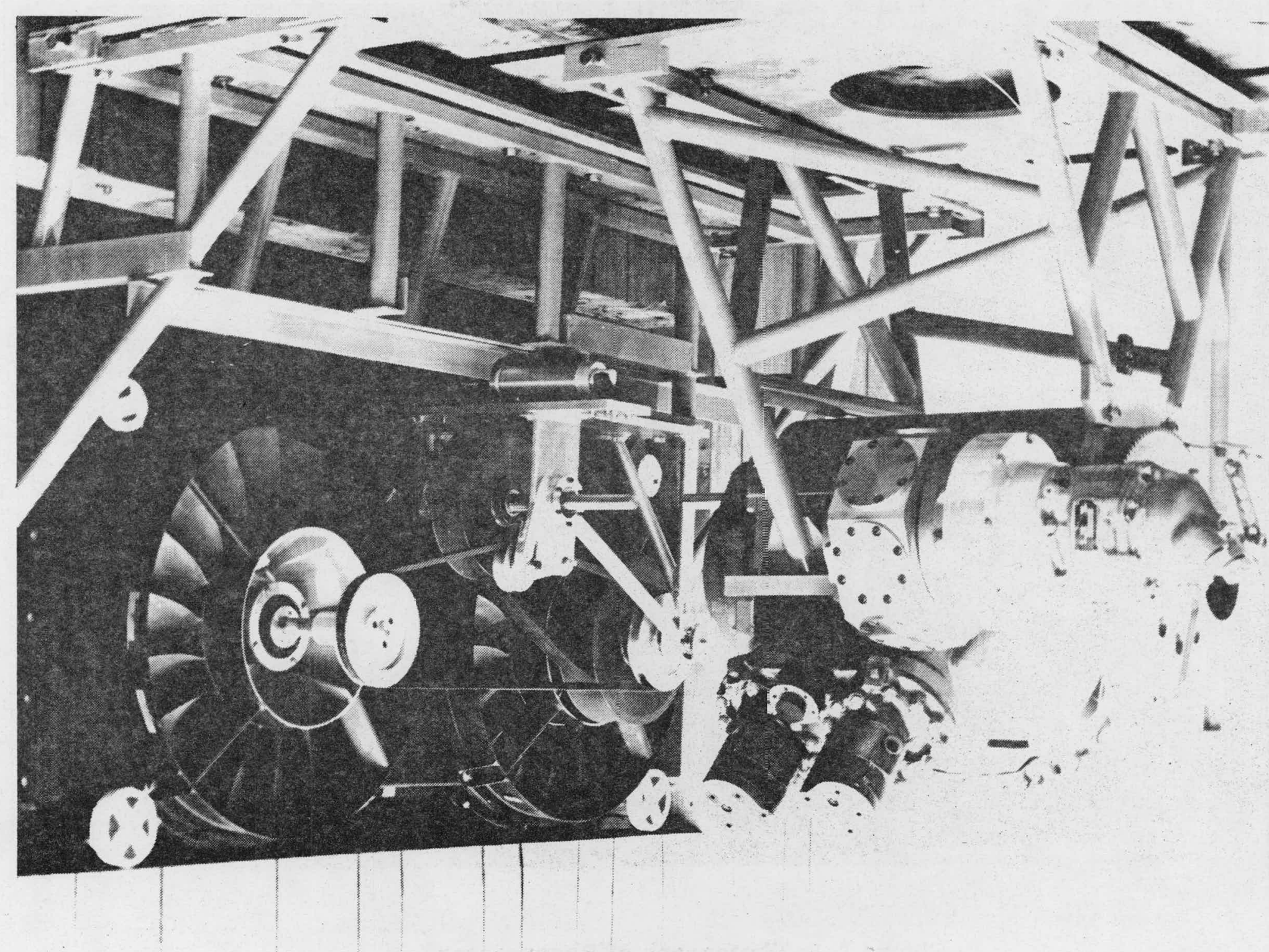

ZII万-I 


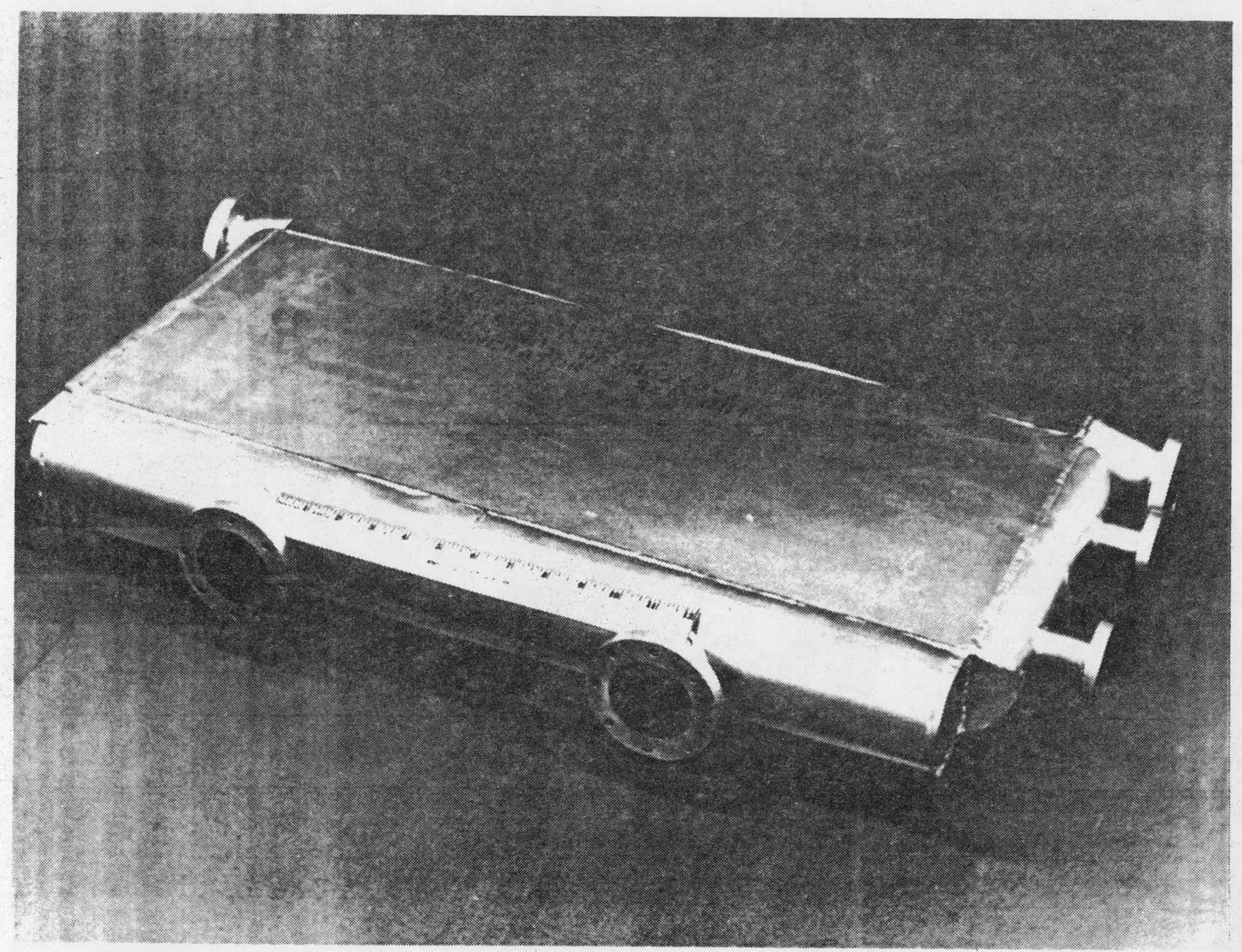

Figure 2.5 Photograph of Regenerator 


\section{3 PREPROTOTYPE SYSTEM TEST FACILITY}

The preprototype engine was tested on a dynamometer at Thermo Electron's Rankine-cycle engine development facility. A schematic of the facility with the preprototype system is presented in Figure 2.7. The facility is designed to conduct steady-state tests over the entire operating range of the preprototype engine. Instrumentation was installed to determine accurately the preprototype engine performance, fuel consumption, and exhaust emissions, as well as the performance of individual components. In the preprototype system tests, the expander was coupled directly to the dynamometer, which measured the torque and speed that would occur at the expander-to-transmission stepup gear interface in an automotive installation.

Test plans ${ }^{1,2}$ were prepared prior to the start of the system tests in order to define the test runs required to meet the program objective. The objective was to characterize the preprototype system performance over the normal operating range. The test plans identified the number of road load and ORL operating points required to obtain an approximation of the performance over the normal operating range. The test plans also contain a complete listing of the instrumentation used for the tests, including the range and accuracy.

\subsubsection{System Power Measurements}

System power was measured using a 350-hp Eaton Dynamatic (Mode1 1519DG) eddy-current dynamometer,capable of handling speeds from 0 to $4500 \mathrm{rpm}$ and torques from 0 to $1000 \mathrm{ft} / 1 \mathrm{~b}$. The dynamometer can be operated using either torque or speed control. During the preprototype tests, the speed control function was used and the desired 


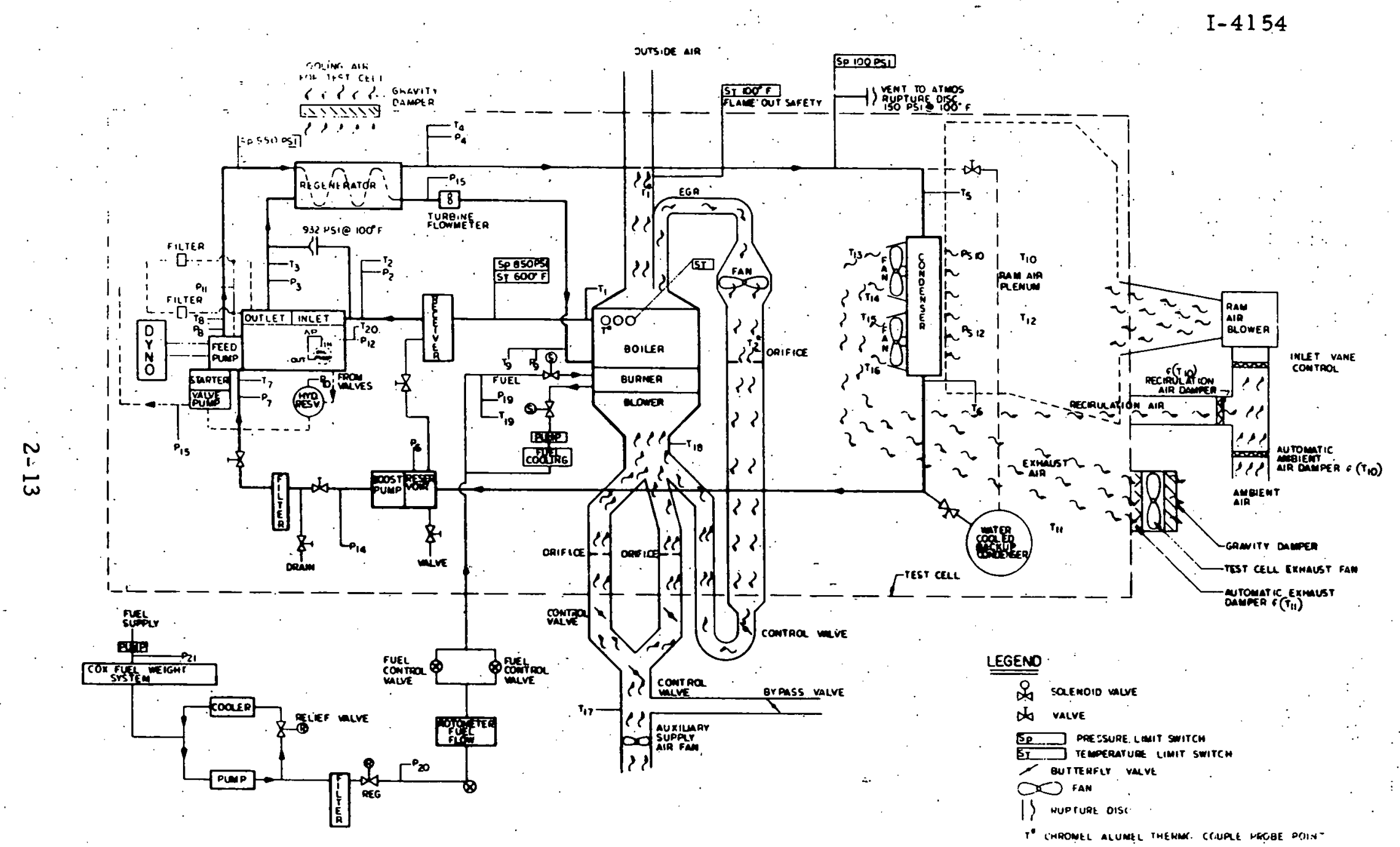

Figure 2. 7 Schematic of Preprototype System Test Facility 
speed was set with the controls. The dynamometer than automatically varied the torque on the expander to maintain the set speed. A photograph of the dynamometer is shown in Figure 2.8. Instrumentation included with the dynamometer allows speed and torque to be read within \pm 0.5 percent accuracy.

\subsubsection{Ram Air Facility}

A facility to simulate condenser ram air was constructed as part of the system test facility. It can simulate ram air velocities up to $85 \mathrm{mph}$. Warm atr from the condenser outlet can be recirculated to the ram air blower inlet in order to maintain the condenser cooling air temperature at a minimum of $68^{\circ} \mathrm{F}$, regardless of the ambient temperature. The ram air blower and recirculation ducting are shown in Figure 2.9. A water-cooled condenser was also installed as a backup unit for the system air condenser and fans, but its use was not required during the system tests.

\subsubsection{Combustion Air-Fuel Facility}

Air required for the burner was supplied by an auxiliary blower through two four-inch ASME-designed orifice lines. This auxiliary blower could not supply sufficient airflow at the rated pressure to run the preprototype combustion system at full capacity. As a result of this, the preprototype expander operation was limited to a maximum of $95 \mathrm{hp}$. Equipment was also installed for measuring barometric pressure and relative humidity during system operation. A separate blower was used with a 3-inch orifice line for measuring exhaust gas recirculation flow to the inlet of the burner. 
I- 4467

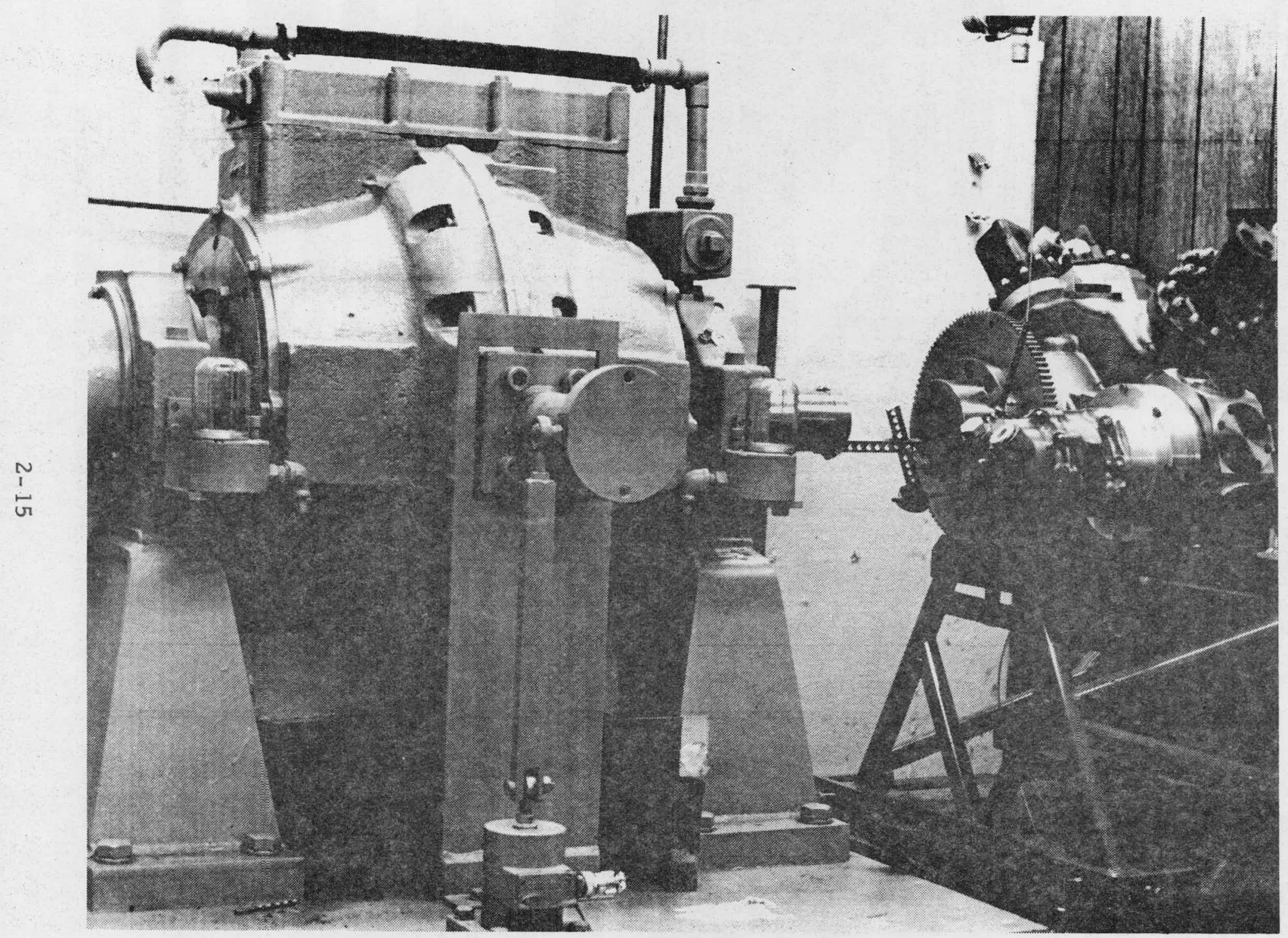

Figure 2.8 Preprototype Engine System Test Stand 
I- 4810

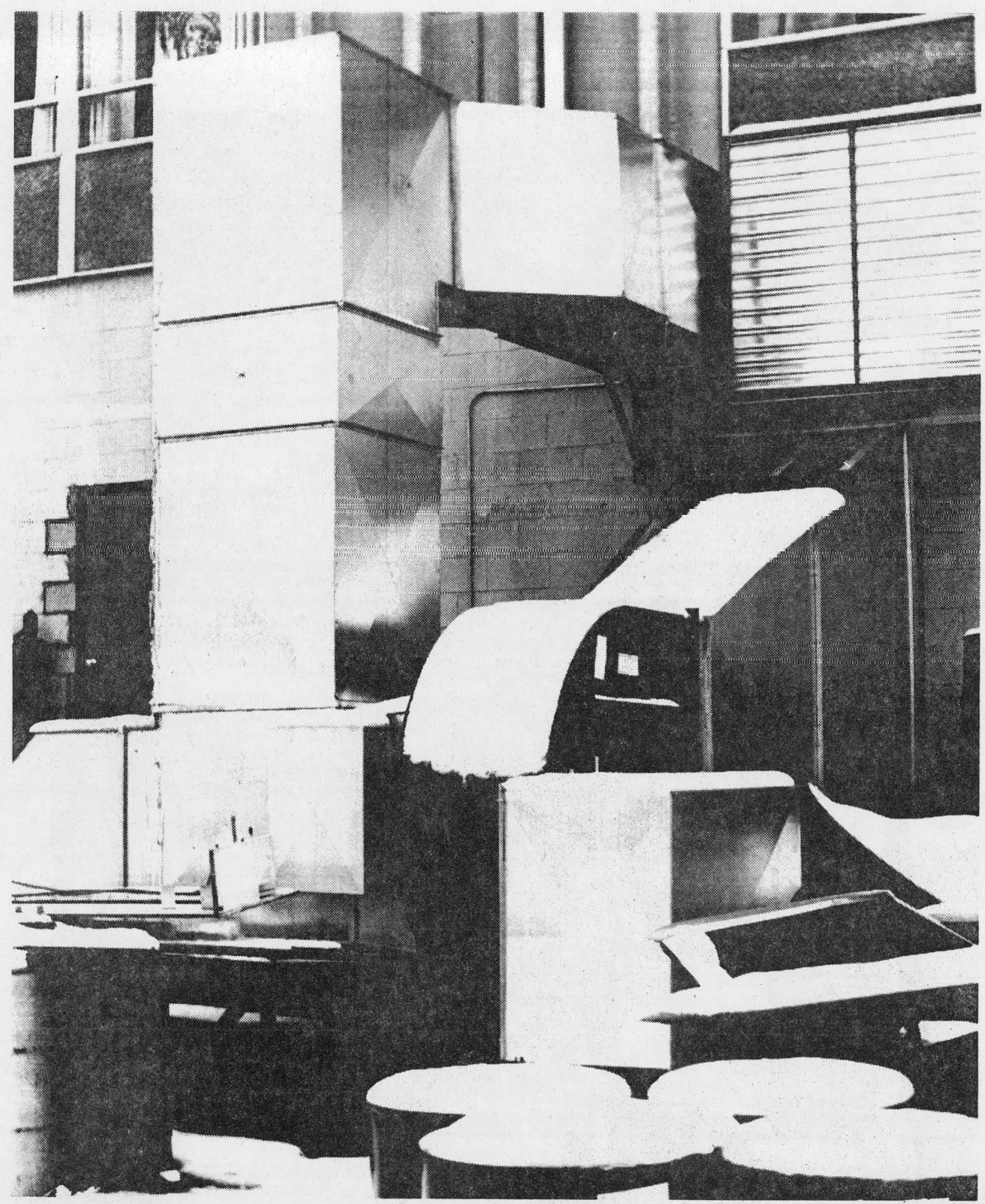

Figure 2.9 Ram Air Blower and Recirculation Ducting 
Two 1000-gallon fuel tanks were installed to provide fuel for testing. One tank contained fuel supplied by EPA for preprototype system testing. Specifications for this fuel are given in Table 2:3. The other contained a commerctal low-lead regular gasoline and was used for system and instrumentation checking. Fuel flow was measured using a Cox Model 402 batch weighting system, which has a range of 5 to $600 \mathrm{lb} / \mathrm{hr}$ at an accuracy of \pm 0.5 percent. Calibrated rotameters were used for instantaneous readings of the fuel flow rate.

\subsubsection{Instrumentation}

The system test facility was instrumented with all the required temperature and pressure measurement equipment to define the thermodynamic state at the entrance and exit of the various components. Working fluid flow rates were measured using a Fisher Porter turbine meter with a batch totalizer having an accuracy of \pm 0.5 percent. Figure 2.10 shows a view of the control panel containing the instrumentation along with the Cox fuel weighing system, dynamometer controls, and the preprototype engine on its test stand.

\subsection{DATA REDUCTION}

A data reduction program was used, which took as input the temperatures, pressures, flow rates, and power measurements in the preprototype system, and calculated brake specific fuel consumption (BSFC), component efficiencies, emissions, flow rates, pressure drops, and heat exchanger efficiencies. The program took measured dynamometer power, which is equal to the expander shaft power after the feedpump and condenser fan work is subtracted. The blower work, fuel work, boost pump, and alternator work was then subtracted. 
TABIE 2. 3

EPA FUEL SPECIFICATION

\begin{tabular}{|c|c|c|}
\hline Item & $\begin{array}{c}\text { ASTM } \\
\text { Designation }\end{array}$ & Specification \\
\hline Octane, Research, min & D2699 & $91-93$ \\
\hline $\mathrm{Pb}$ (Organic) gm/U.S. ga1 & D524 & $<0.02$ \\
\hline Distillation Range & $\mathrm{D} 86-\mathrm{D} 67$ & -- \\
\hline $\begin{array}{l}\text { I. B. P., , }{ }^{\circ} \mathrm{F} \\
10 \text { percent point. }{ }^{\circ} \mathrm{F}\end{array}$ & -- & $100-115$ \\
\hline $\begin{array}{l}10 \text { percent point, }{ }^{\circ} \mathrm{F} \\
50 \text { percent point, }{ }^{\circ} \mathrm{F}\end{array}$ & -- & $\begin{array}{l}140-150 \\
240-250\end{array}$ \\
\hline 90 percent point, $: F$ & -- & $330-340$ \\
\hline E. P., ${ }^{\circ} F(\max )$ & - & 425 \\
\hline Sulfur, Wt. percent max. & D1266 & 0.10 \\
\hline Phosphorous, Theory & -- & 0.0 \\
\hline R. V.P., lb & D323 & $5.5-7.5$ \\
\hline Washed Gum $(\max \dot{\operatorname{mgm}} / 100 \mathrm{ml})$ & D381 & 4.0 \\
\hline Corrosion (not lower than) & D130 & $1 \mathrm{~B}$ \\
\hline Oxidation Stability (not less than) & D525 & $240+$ \\
\hline Hydrocarbon Composition & D1319 & $: \quad--$ \\
\hline $\begin{array}{l}\text { Olefins, percent max } \\
\text { Aromatics, percent max } \\
\text { Saturates }\end{array}$ & $\begin{array}{l}- \\
-- \\
-\end{array}$ & $\begin{array}{l}30 \\
40 \\
\text { Remainder }\end{array}$ \\
\hline Nitrogen, Wt. percent max & -- & 0.005 \\
\hline Density* & $\therefore$ & $6.35 \mathrm{lbm} / \mathrm{gal}$ \\
\hline Higher Heating Value*** & -- & $20,130 \mathrm{Btu} / \mathrm{lbm}$ \\
\hline
\end{tabular}

\footnotetext{
* Mea sured at Thermo Electron Corporation.

*** Calculated from Density Measurement.
} 


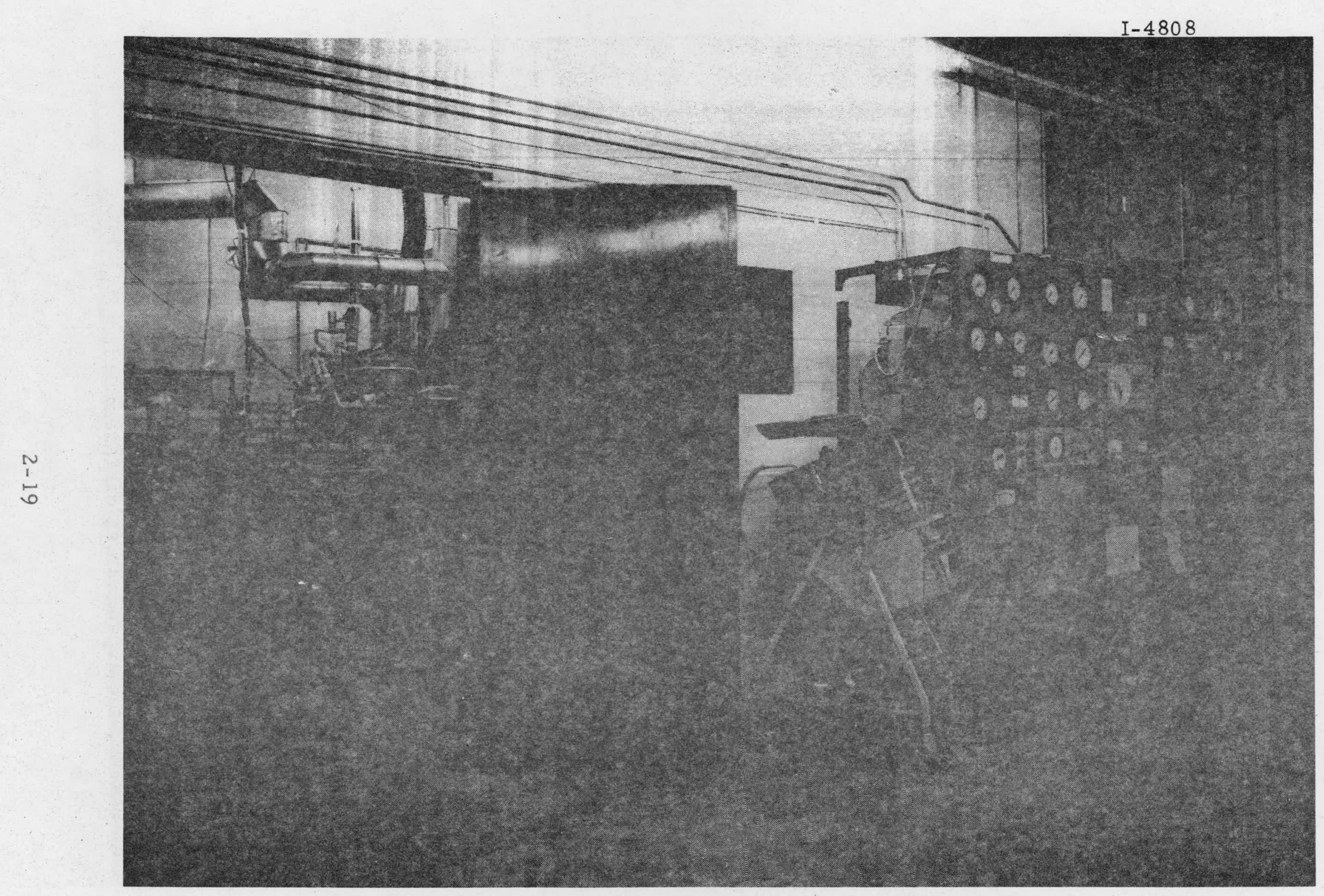

Figure 2. 10 Preprototype Engine Installed in Test Facility 
The power thus obtained was the Rankine-cycle net system power after all the auxiliaries had been subtracted. This power was used to define cycle efficiency. The power steering and accessory power was then subtracted so that torque converter input power would be obtained. Transmission and driveline efficiencies obtained from Ford Motor Company were then used to calculate the power available at the wheels. Gross expander power was obtained by taking the dynamometer power and adding the condenser fan and feedpump power. The power of these auxiliaries was calculated from manufacturer and TECO test data. A detailed outline of the procedure used to calculate fuel economy is included in Appendix A.

\section{5 INITIAL TEST RESULTS AND PERFORMANCE EVALUATION}

During the initial preprototype system testing of approximately 48 hours, data were taken at vehicle road load power conditions corresponding to vehicle speeds of 6 to $70 \mathrm{mph}$.

The correct expander speed, torque, and ram air speed equivalent for these road load cases were maintained during the tests. All auxiliaries, except for the combustion air blower and a fractional horsepower boost pump, were driven by the expander. These road load test results are listed as Runs 24 through 113 in Table 2. 4. Nomenclature for those items in Table 2.4 that are not self-explanatory is listed in Table 2.5. The fuel economy measured in the se initial road load tests was between 50 and 65 percent of the predicted fuel economy goal, as can be seen in Figure 2.11. The curve labeled May 1973 in the figure includes these first data taken on the preprototype system. Test results from the single-cylinder expander indicated the expander efficiency in the preprototype system was not as high as expected. For this reason, the expander was disassembled. 
TABLE 2.4

PREPROTOTYPE SYSTEM TEST RESULTS: INITIAL TESTS

A -1612

\begin{tabular}{|c|c|c|c|c|c|c|c|c|c|c|c|c|c|c|c|c|c|c|c|c|}
\hline \multicolumn{8}{|c|}{ SY STEM } & \multicolumn{6}{|c|}{ EXPANDER } & \multicolumn{4}{|c|}{ DRIVE TRAIN } & \multirow{3}{*}{\begin{tabular}{|c|} 
FAN \\
$\begin{array}{c}\text { Power } \\
\text { (hp) }\end{array}$ \\
\end{tabular}} & \multirow{3}{*}{\begin{tabular}{|c|} 
RAM \\
$\begin{array}{c}\text { Air } \\
\text { (mph) }\end{array}$ \\
\end{tabular}} & \multirow{3}{*}{ Comment $\mathrm{B}$} \\
\hline \multirow{2}{*}{ Rug } & \multirow[b]{2}{*}{$\begin{array}{c}\text { Power } \\
\text { (bp) }\end{array}$} & \multirow{2}{*}{$\begin{array}{l}\text { Cycle } \\
\text { Eff. } \\
\text { (\%) }\end{array}$} & \multirow{2}{*}{ BSFC } & \multirow{2}{*}{$\begin{array}{c}\text { Fuel } \\
\text { Economy } \\
\text { (mpg) }\end{array}$} & \multirow{2}{*}{$\begin{array}{l}\text { Vehicle } \\
\text { Speed } \\
\text { (mph) } \\
\end{array}$} & \multirow{2}{*}{$\begin{array}{c}\text { Fuel } \\
\text { Flow: } \\
\text { (lb.hr) }\end{array}$} & $F-85$ & & In & & Outlet & & & & & Power at & & & & \\
\hline & & & & & & & $\begin{array}{c}\text { Flow: } \\
(1 \mathrm{~b} / \mathrm{h} r)\end{array}$ & $\mathrm{rpm}$ & $\begin{array}{l}\text { Temp: } \\
\left({ }^{\circ} F\right)\end{array}$ & $\begin{array}{l}\text { Press. } \\
\text { (psia) }\end{array}$ & $\begin{array}{l}\text { Press. } \\
\text { (psia) }\end{array}$ & $\begin{array}{c}\text { Power } \\
\text { (hp) }\end{array}$ & (\%) & $\begin{array}{c}\text { meter } \\
(\mathrm{bp})\end{array}$ & $\begin{array}{l}\text { Input } \\
\text { (hp) }\end{array}$ & $\begin{array}{c}\text { Wheels } \\
\text { (hp) }\end{array}$ & Gear & & & \\
\hline 24 & 42.04 & 8.93 & 1.55 & 6.37 & 63.9 & 63. 7 & 4472 & 1011 & 544 & 540 & 22.0 & -- & -. & 43.30 & 39.16 & 35.154 & 3 & .- & 59.0 & Initial Test 5 \\
\hline 27 & 30.42 & 10.69 & 1. 30 & 8.97 & 54.4 & 38.5 & 2746 & 853 & 564 & 485 & 13.0 & .. & -. & 31.35 & 27.78 & 24.650 & 3 & $\therefore$ & 50.2 & 1. Bosch \\
\hline 30 & 11.50 & 9.74 & 1.45 & 11.76 & 29.6 & 16.0 & 1109 & 532 & 522 & 415 & $-\cdot$ & -- &.- & 11.65 & 9.33 & B. 04 & 3 & -. & 29.0 & Valving \\
\hline 36 & 25.80 & 10.58 & 1.31 & 9.65 & 50.15 & 33:0 & 2305 & 848 & 526 & 390 & 13.0 & -- & -- & 26.64 & 23.17 & 20.8 & 3 & -. & 49.6 & 2. Auxillary \\
\hline 50 & 32.95 & 10.35 & 1.34 & 8.33 & 56.5 & 43.0 & 2894 & 849 & 566 & 410 &.- & $\ldots$ & -. & 33.95 & 30.32 & 26.71 & 3 &.- & 50.0 & Exhaust \\
\hline 59 & 35.04 & 9.04 & 1.52 & 7.13 & 58.86 & 52.5 & 4038 & 1011 & 556 & 490 & -- & $-\cdot$ & -- & 36.6 & 32.15 & 29.23 & 3 & -- & 59.5 & $\begin{array}{l}\text { Valve } \\
\text { lat }\end{array}$ \\
\hline 61 & 36.63 & 8.61 & 1.60 & 6.63 & 60.1 & 57.6 & 4268 & 1009 & 580 & 485 & $\cdots$ & $\cdots$ & --- & 37.85 & 33.75 & -30.59 & 3 & .. & 59.5 & \\
\hline 65 & 18. 12 & 9.76 & 1.42 & 10.28 & 40.7 & 25.1 & 1620 & 688 & 560 & 435 & $\ldots$ & $\ldots$ & $\ldots$ & 18. 34 & 15. 73 & 13.88 & 3 & -. & 39.5 & \\
\hline 71 & 9.02 & 8. 03 & 1.78 & 9.92 & 23.8 & 15.2 & 903 & 450 & 540 & 405 & 6.0 & 9.9 & 35.8 & 9.25 & 6.96 & 5. 79 & 3 & 0.07 & 25.0 & $\begin{array}{l}\text { Problem Areas } \\
\text { 1. Cycleto- }\end{array}$ \\
\hline 78 & 48. 44 & 8.71 & 1.58 & 5. 78 & 68. 5 & 75.3 & 5451 & $\$ 179$ & 537 & 475 & 18.5 & 56.32 & 43.6 & 50.3 & 45.3 & 41.26 & 3 & 1.28 & 68.3 & Cycle Varia- \\
\hline 81 & 7.67 & 6.67 & 2.16 & 8.15 & 19.98 & 15.6 & 953 & 822 & 580 & 295 & 4.0 & 8.75 & 27.5 & 7. 83 & 5.08 & 4.57 & 1 & 0.26 & 20.4 & tion in Bosch \\
\hline 82 & 19.59 & 9.82 & 1.42 & 10.00 & 42.5 & 27.0 & 1793 & 692 & 533 & 415 & 6.2 & 21.33 & 39.44 & 19.9 & 17.19 & 15. 09 & 3 & 0.18 & 39.5 & Valving \\
\hline 83 & 18. 77 & 9.42 & 1.49 & 9.78 & 41.5 & 27.0 & 1782 & 692 & 518 & 375 & 6.2 & 20.5 & 39.3 & 19.1 & 16.37 & 14.42 & 3 & 0.2 & 39.5 & 2. Auxiliary \\
\hline 84 & 18. 78 & 9.41 & 1.48 & 9.77 & 41.54 & 27.0 & 1875 & 691 & 508 & 395 & 6.0 & 20.52 & 37.5 & 19.08 & 16.39 & 14.43 & 3 & 0.19 & 39.5 & Exhaust \\
\hline 85 & 8. 20 & 7.44 & 1.98 & 9.17 & 21.5 & 14.9 & 1031 & 822 & 533 & 285 & 5.3 & 8.99 & 29.4 & 8.37 & 5.61 & 5. 04 & 1 & 0 & 47.7 & $\begin{array}{l}\text { Valve } \\
\text { Valust }\end{array}$ \\
\hline 86 & 8.05 & 7.20 & 1.99 & 8.85 & 21.1 & 15.1 & 1003 & 821. & 516 & 285 & 5.0 & 8.81 & 30.0 & 8.21 & 5.46 & 4.91 & $i$ & 0 & 47.6 & Springs \\
\hline 87 & 5. 40 & 6.78 & 2.19 & 8.24 & 14.0 & 10.8 & 654 & 416 & 527 & 220 & 3.5 & 5.82 & 28.9 & 5. 54 & 3.39 & 2.93 & 1 & 0.03 & 30.9 & Failure \\
\hline 91 & 11.43 & 8. 82 & 1.60 & 10.67 & 29.4 & 17.5 & 1139 & 530 & 544 & 375 & 4.5 & 12.39 & $33.6^{\circ}$ & 11.61 & 9.26 & 7.97 & 3 & 0.07 & 28. 8 & 3. Piston- \\
\hline 92 & 7.96 & 7. 42 & 1.94 & 9.25 & 21.1 & 14.5 & 896 & 426 & 571 & 360 & 5.0 & 8.67 & 29.7 & 8.11 & 7.95 & 4.92 & 3 & 0.04 & 29.2 & Cylinder \\
\hline 93 & 18.78 & 9.74 & 1.43 & 10.10 & 41.5 & 26.1 & 1571 & 689 & 572 & 400 & 6.5 & 20.26 & 41.1 & 19.02 & 16.39 & 14.42 & 3 & 0.13 & 39.6 & $\begin{array}{l}\text { Cylinder } \\
\text { Scoring }\end{array}$ \\
\hline 94 & 18.19 & 9.53 & 1.46 & 10.03 & 40.76 & 25.8 & 1638 & 687 & 548 & 360 & 8.5 & 19.62 & 42.6 & 18. 44 & 15.8 & 13.93 & 3 & 0.13 & 39.6 & \\
\hline 96 & 34.70 & 7.90 & 1.77 & 6.26 & 58.6 & 59.4 & 4230 & 1012 & 544 & 465 & 25.0 & 39.8 & 43.2 & 36.23 & 31.8 & 28.93 & 3 & 0.33 & 59.7 & \\
\hline 98 & 47.33 & 8.71 & 1.60 & 5.70 & 66.0 & 73.5 & 4935 & 863 & 571 & 455 & 27.5 & 53.03 & 49.3 & 48.97 & 44.68 & 37. 84 & 3 & 0.38 & 69.7 & \\
\hline 99 & 17.62 & 9.24 & 1.51 & 9.85 & 40.0 & 25.8 & 1608 & 685 & 571 & 450 & 7.0 & 19.25 & 38.14 & 17.87 & 15.23 & 13.46 & 3 & 0.13 & 39.8 & \\
\hline 101 & 4.54 & 6.23 & 2.41 & 6. 82 & 10.6 & 9.9 & 570 & 300 & 558 & 185 & 3.5 & 4.86 & 27.6 & 4.68 & 2.67 & $2.13^{\circ}$ & 1 & 0.01 & 32.3 & \\
\hline 102 & 3.28 & 5.65 & 2.77 & 5. 09 & 6.3 & 7.9 & 487 & 300 & 596 & 235 & 6.5 & 3. 8 & 26.7 & 3.43 & 1.4 & 1.21 & 1 & 0.14 & 20.0 & \\
\hline 103 & 5. 79 & 6. 53 & 2.25 & 7.00 & 13.2 & 12.0 & 697 & 297 & 498 & 270 & 3.0 & 6.41 & 29.2 & 5.94 & 3.93 & 2.73 & 1 & 0.15 & 20.3 & \\
\hline 107 & 18.52 & 9.72 & 1.43 & 10.14 & 41.18 & 25.8 & 1597 & 687 & 557 & 205 & 11.8 & 19. 34 & 53.14 & 18.77 & 16.13 & 14.2 & 3 & 0.13 & 39.9 & \\
\hline 108 & 19.30 & 10.64 & 1.31 & 10.91 & 42.2 & 24.6 & 1565 & 689 & 553 & 345 & 13.0 & 20.64 & 52.4 & 19.55 & 16.91 & 14.84 & 3 & 0.12 & 38.9 & \\
\hline 110 & 19.34 & 10.93 & 1.27 & 11.20 & 42.2 & 23.9 & 1552 & 689 & 547.5 & 402 & 11.8 & 20.74 & 50.58 & 19.55 & 16.95 & 14.87 & 3 & 0.12 & 38.9 & \\
\hline 111 & 19.16 & 10.67 & 1.30 & 10.97 & 42.0 & 24.3 & 1582 & 688 & 560.8 & 490 & 11.5 & $20: 78$ & 46.91 & 19.39 & 16.77 & 14.73 & 3 & 0.12 & 38. 8 & \\
\hline 112 & 36.57 & 8.91 & 1.55 & 6.86 & 60.0 & 55.5 & 3938 & 1008 & 546.7 & 333 & 21.5 & 40.91 & 49.13 & 37.81 & 33.7 & 30.54 & 3 & 0.42 & 59.1 & \\
\hline 113 & 35. 50 & 8.95 & 1.55 & 7.00 & 59.2 & 53.7 & 3752 & -1011 & 552.4 & 540 & 20.8 & 40.53 & 44.99 & 36.77 & 32.6 & 29.63 & 3 & 0.44 & 59.2 & \\
\hline 114 & 25. 18 & 10.07 & 1.38 & -- & NR L & 33.9 & 2329 & 799 & 542 & 540 & 19.0 & $\therefore$ & - & 26.0 & 22.63 & 20.09 & 3 & -- & 35.75 & \\
\hline 115 & 44.57 & 9.19 & 1. 50 & -. & NRL & 65.6 & 4317 & 800 & 552 & 405 & 20.3 & 49.27 & 50.05 & 46.15 & 42.01 & 34.3 & 3 & 0.26 & 104.2 & \\
\hline 116 & 47.92 & 9.91 & 1.39 & -- & NRL & 65.5 & 4283 & 806 & 557 & 503 & 20.0 & 52.93 & 51.21 & 49.42 & 45.36 & 36.78 & 3 & 0.27 & 104.4 & \\
\hline 117 & 34.12 & 7.30 & 1.90 & $\because \cdot$ & NRL & 63.3 & 4364 & 805 & 549 & 215 & 20.0 & 38.05 & 45.97 & 35.56 & 31.55 & 27.27 & 3 & 0.22 & $04.9^{\circ}$ & \\
\hline 118 & 50.02 & 10.01 & 1.38 & -- & NRI & 67.6 & 4553 & 684 & 552 & 440 & 21.0 & 54.95 & 52.52 & 51.7 & 47.63 & 34.21 & 3 & 0.21 & 505.3 & \\
\hline 119 & 49.27 & 9.95 & 1.39 & $\cdots$ & NRL & 67.0 & 4451 & 686 & 555 & 535 & 21.0 & 54.5 & 51.02 & 50.94 & 46.89 & 34.81 & 3 & 0.20 & 15. 05 & \\
\hline 120 & 50.66 & 10.44 & 1.32 & -. & NRL $L$ & 65.7 & 4450 & 687 & 549 & 630 & 20.3 & 56.12 & 51.25 & 52.2 & 48.27 & 34.66 & 3 & 0.20 & 505.6 & \\
\hline 121 & 50.40 & 10.43 & 1.32 & -- & NR L & 65.4 & 4428 & 685 & 546 & 687 & 20.0 & 56.0 & 50.96 & 51.91 & 48.0 & 34.3 & 3 & 0.20 & 05.5 & \\
\hline 122 & 50.21 & 10.57 & 1.30 & -- & NRL & 64.3 & 4421 & 685 & 548 & 520 & 20.0 & 55.0 & 51.91 & 51.65 & 47.82 & 34.37 & 3 & 0.11 & 86.0 & \\
\hline 124 & 45.93 & 9.63 & 1.43 & -- & NRL & 64.6 & 4454 & $684^{\circ}$ & 546 & 520 & 19.8 & 54.82 & 51.37 & 47.41 & 43. 54 & 34.26 & 3 & 3.56 & 50.4 & \\
\hline 125 & 35. 14 & 10.76 & 1.29 & -. & NR I & 44.2 & 3058 & 682 & 554 & 520 & 19.7 & 38.49 & 51.84 & 36.1 & 32.76 & 26.78 & 3 & 0.11 & 50.4 & \\
\hline 126 & 31.16 & 9.70 & 1.43 & -- & NRL & 43.5 & 3064 & 684 & 553 & 540 & 19.0 & 39.1 & 51.74 & 32.04 & 28. 78 & 23.26 & 3 & 4. 11 & 0 & \\
\hline 127 & 34.91 & 11.01 & 1.26 & -- & NR L & 42.9 & 3098 & 686 & 542 & 540 & 19.7 & 38.24 & 51.46 & 35. 79 & 32.53 & 26.52 & 3 & 0.09 & 52.6 & \\
\hline 128 & 53.80 & 9.88 & 1.40 & -. & NR L & 73.7 & 5144 & 693 & 549 & 539 & 21.0 & 63.1 & 51.5 & 55.55 & 51.36 & 34.59 & $\therefore$ & 3.08 & 94.0 & \\
\hline 129 & 11.70 & 9.19 & 1.47 & 11.22 & 30.4 & 17.2 & 1116 & 533 & 558 & 375 & 10.0 & 13.1 & 42.6 & 12.38 & 9.83 & 8.42 & 3 & 0.05 & 32.0 & \\
\hline 131 & 7.74 & 8.07 & 1.68 & 10.62 & 20.0 & 11.9 & 743 & 419 & $553^{\circ}$ & 307 & 14.0 & 8.15 & 45.8 & 7.74 & 5.45 & 4.56 & 3 & 0.03 & 20.4 & \\
\hline
\end{tabular}


TABLE 2. 5

NOMENCLATURE FOR TABLE 2.4

\section{System}

System Powe $r$ (hp)

Cycle. Efficiency (\%)

Expander

rpm

Power (hp)

Efficiency (\%)

Drive Train

Dynamometer (hp)

TC Input (hp)

Power at Wheels (hp)

Fan Power (hp)

Ram Air (mph)
Rankine-cycle system power (auxiliaries such as the feedpump, combustion system, condenser fans, and boost pump are subtracted from the gross expander power to obtain this value).

Rankine system cycle efficiency is the system power divided by the fuel input expressed as horsepower.

Brake specific fuel consumption is the fuel flow divided by the system power.

Expander shaft speed.

Gross expander power before a uxiliaries and accessories are subtracted.

Expander efficiency based on gross expander power divided by maximum isentropic work available to the expander.

Power measured at the dynamometer during the test.

$\therefore$ Torque converter input power - power available to the drive train of the vehicle.

Power which exists at the wheels after the drive line losses are subtracted from the TC input power.

Power required for condenser fans.

Ram air setting to simulate road load speed. 


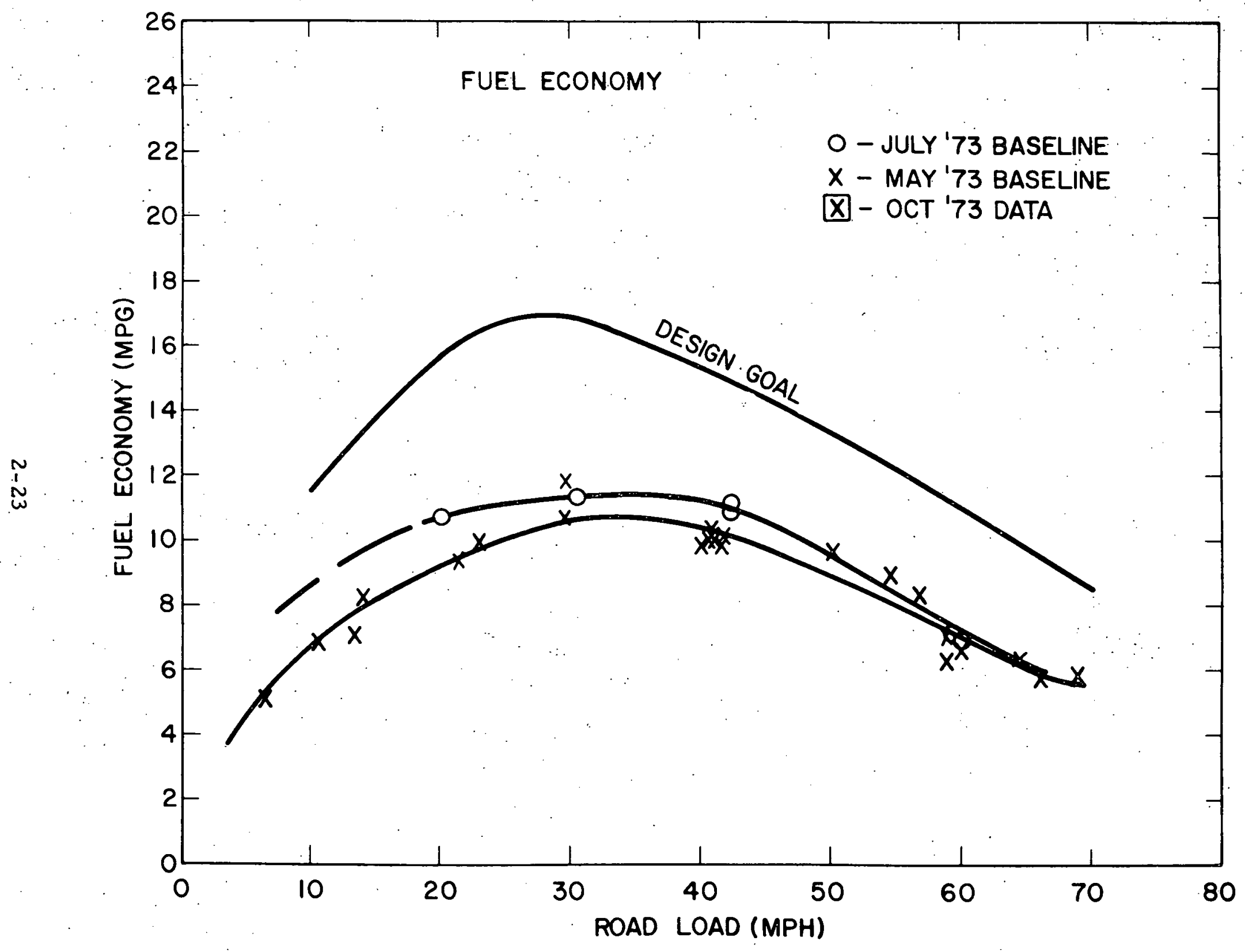

Figure 2.11 Fuel Economy versus Road Load Speed (Initial Tests) 
The auxiliary exhaust valve springs and a piston ring were broken, and the cylinder walls were scored. Some design changes were made and the expander was rebuilt. A second set of road load data was taken in. July 1973. These data are also shown in Figure 2.11 as the July 1973 baseline. Although there was a small improvement, the results were still far from the design goal. This can be seen more clearly in Figure 2.12, which shows the expander efficiency measured in the preprototype system as compared.with the predicted performance. The remaining system components, 1.e., boller, condenser, feedpump, were all operating close to the predicted performance.

Examination of the expander parts and an analysis of the expander with a computer model revealed the reasons for the low expander efficiency. The main problems were valye leakage, erratic intake valve behavior, excessive clearance volume, and high mechanical losses due to the hydraulic power requirements of the intake valves. Each of these problems was in some manner associated with the intake valve or auxiliary exhaust valve.

The expander used in these preprototype system tests contained an intake valve system developed for Thermo Electron by American Bosch. It consisted of a double-acting hydraulically driven poppet valve, which provided the ability to control cutoff. (The percentage of time the valve was open to high pressure and temperature vapor during each revolution of the expander.) This valye event was controlled through an electrical signal that acted on a solenoid to control the valve hydraulic action. An auxiliary exhaust valve was provided in addition to the main exhaust ports at the bottom of the cylinder. This auxlliary exhaust valve, actuated by cylinder pressure; allowed the cylinder to continue to exhaust the vapor even as the piston returned to top dead center. 


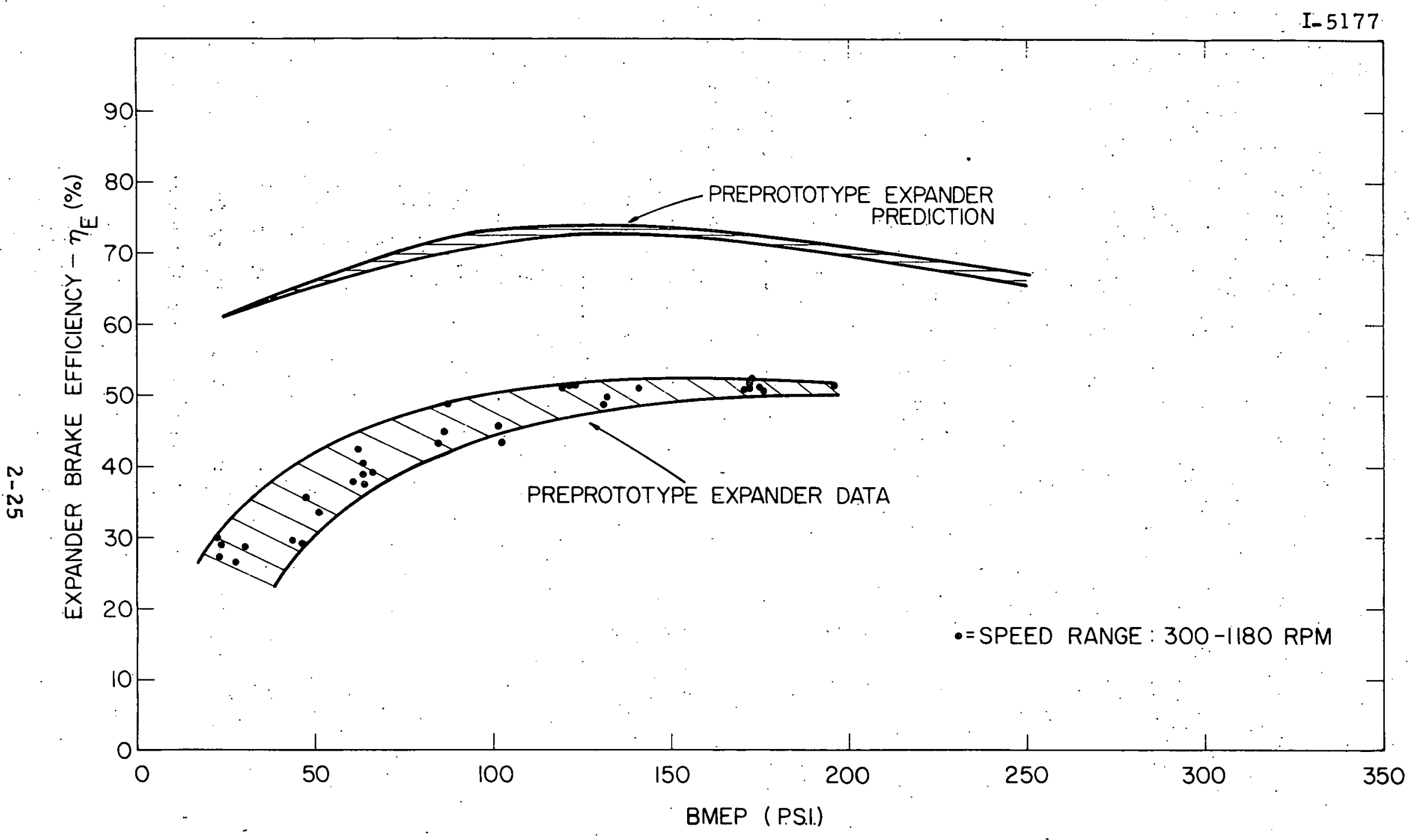

Figure 2.12 Expander Efficiency versus BMEP (Initial Preprototype System Testing) 
In the initial roadload tests, it was found that the system optimized at an expander inlet pressure of 400 to 500 psia, as opposed to the design value of 700 psi. Since the cycle efficiency improves with increasing pressure for a Fluorinol-85 system (assuming constant component efficiency), a loss that could explain the decreasing cycle efficiency as the pressure increased was leakage. Leakage at the inlet valves results in a direct loss in efficiency because, on the expansion stroke, it manifests itself as a throttling loss, whereas, on the return stroke, it results in negative work. Leakage losses increase with pressure and, if great enough, offset any thermodynamic gain in efficiency due to the higher pressure. In addition, at the design inlet pressure, most road load conditions require valve intake cutoffs lower than the optimum. This would mean that at lower pressures, higher cutoffs would be required resulting in higher expander, and consequently cycle, efficiencies.

A series of tests were performed to study the effect of intake valve cutoff on optimum pressure (Run Nos. 114-120 of Table 2.4). During these tests, condenser pressure and expander speed were maintained constant, and cycle efficiency was measured at two different rpm levels with approximately the same combustor firing rate. The optimum pressure was found to be higher for the high flow rate cases (or high cutoff), as shown in Figures 2.13 and 2.14, and it was observed that the intake valving exhibited erratic behavior at low intake cutoff (also referred to as cycle-to-cycle variations).

\subsection{FUEL ECONOMY IMPROVEMENT}

At the conclusion of the initial preprototype system tests, a study was undertaken to evaluate methods for improving the fuel economy. Included in this study. was an examination of both the thermodynamic 


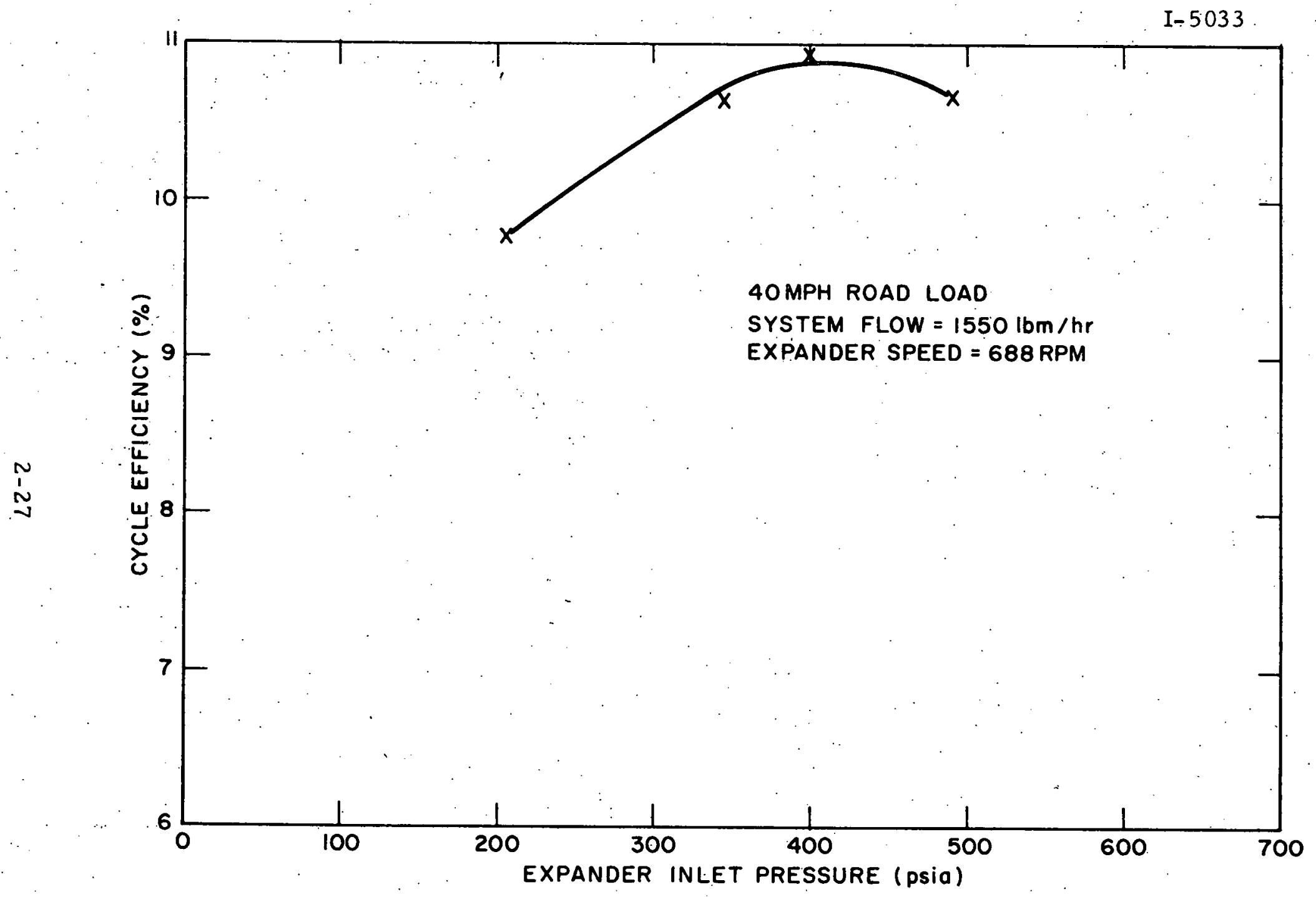

Figure 2.13 Cycle Efficiency versus Pressure - Low System Flow 


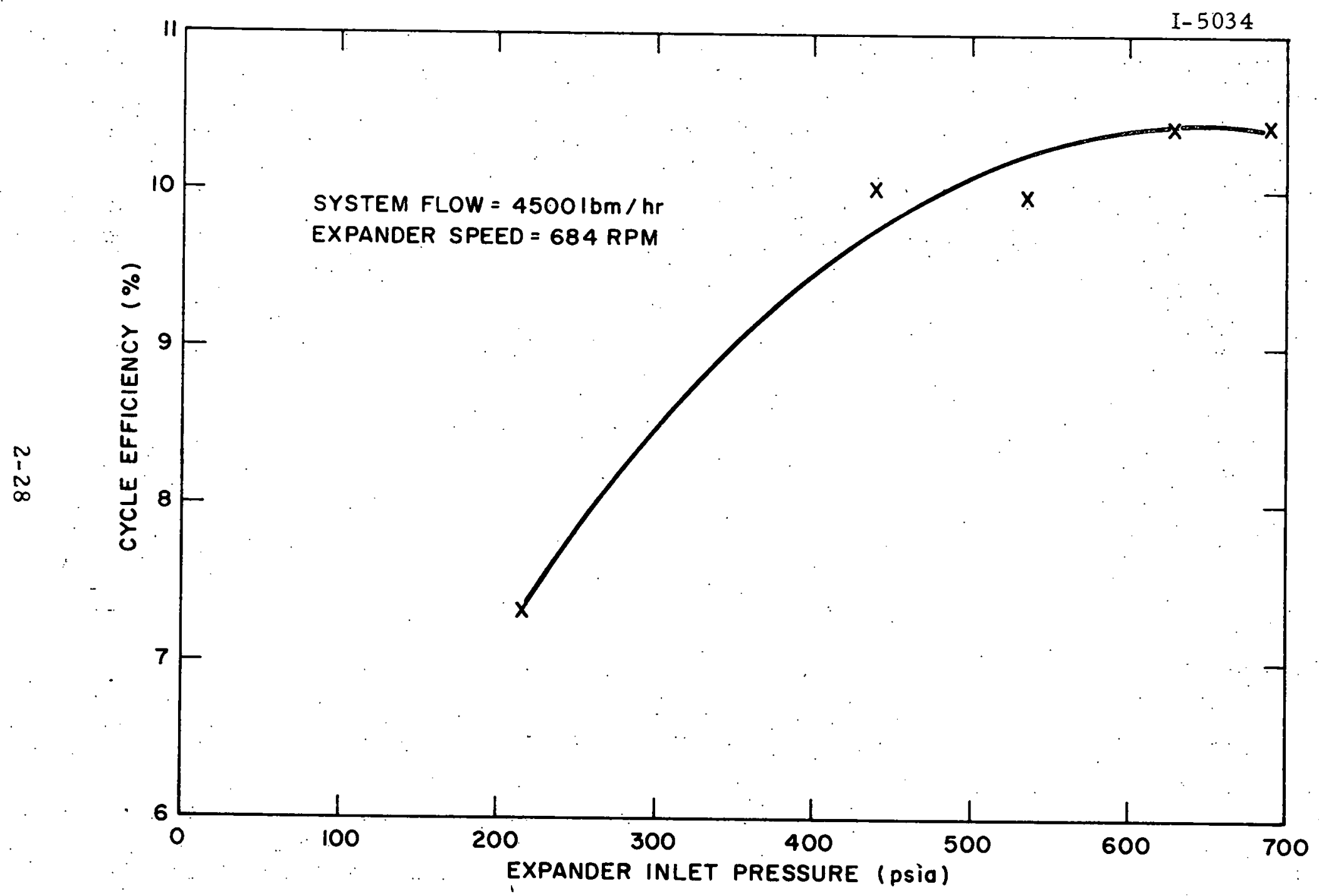

Figure 2.14 Cycle Efficiency versus Pressure - High System Flow 
cycle chosen for the system, as well as the efficiency of each component. The improvements included both those that could be implemented within the scope of this program and some that would be recommended for future study.

\subsubsection{Implemented Fuel Economy Improvements}

There were really very few options available that would not involve making extensive hardware changes in the preprototype system, and the schedule did not allow time for new hardware developments. Two changes were implemented. The expander valving, both intake and exhaust, was modified and the inlet temperature to the expander was raised.

\subsubsection{Expander Valving}

As previously mentioned, the performance of the expander was below expected values. Most of the deficiencies were thought to be due to the valving systems. The American Bosch variable cutoff intake valving was replaced by the less complex BICERI single-acting hydraulic system described in the expander design section (Section 3.2). This development effort with BICERI in England was funded by Thermo Electron. The auxiliary exhaust valve system was also eliminated, and the exhaust system became a simple uniflow exhaust with cylinder ports.

As with all modifications to the expander, new valving concepts were first tested on the single-cylinder expander to evaluate performance before installation on the four-cylinder expander. The singlecylinder was operatep for 70 hours with the new valving approaches. The new inlet valve system exhibited extremely steady behavior with 
well controlled valve events over the entire cutoff range. Improved reliability was also obtained with the simpler BICERI system. In addition, mechanical losses were less because the hydraulic power requirement of the new valving system was only 40 percent of the old system. Figure 2.15 shows the improved results using the singlecylinder with BICERI valving and uniflow exhaust, as compared with the initial preprototype expander tests using the Bosch valving.

Since the mechanical losses per cylinder on the four-cylinder expander are lower than on the single-cylinder expander, higher brake efficiency was anticipated from tests of the four-cylinder expander.

\subsubsection{Higher Vapor Generator Outlet Temperature}

In the Rankine-cycle engine, as in any cyclical heat engine, increasing the mean temperature at which energy is added to the working fluid increases the cycle efficiency. With a fixed condenser size and airflow rate, the condensing temperature is also lowered, thereby reducing the mean temperature of heat rejection with a resulting additional improvement in the cycle efficiency. For the initial preprototype system testing and design, a vapor generator outlet temperature of $550^{\circ} \mathrm{F}$ was selected, due to the extensive test experience at Thermo Electron with complete small horsepower systems at this temperature. Since this selection, the Monsanto Company, under its EPA-supported working fluid evaluation program, concluded that Fluorinol-85 could be used at peak temperatures at least as high as $660^{\circ} \mathrm{F}$, based on capsule tests. In addition, Thermo Electron accumulated 500 hours of testing on a small horsepower system at a vapor generator outlet temperature of $600^{\circ} \mathrm{F}$ with no 
I- $51.81 \mathrm{r}$

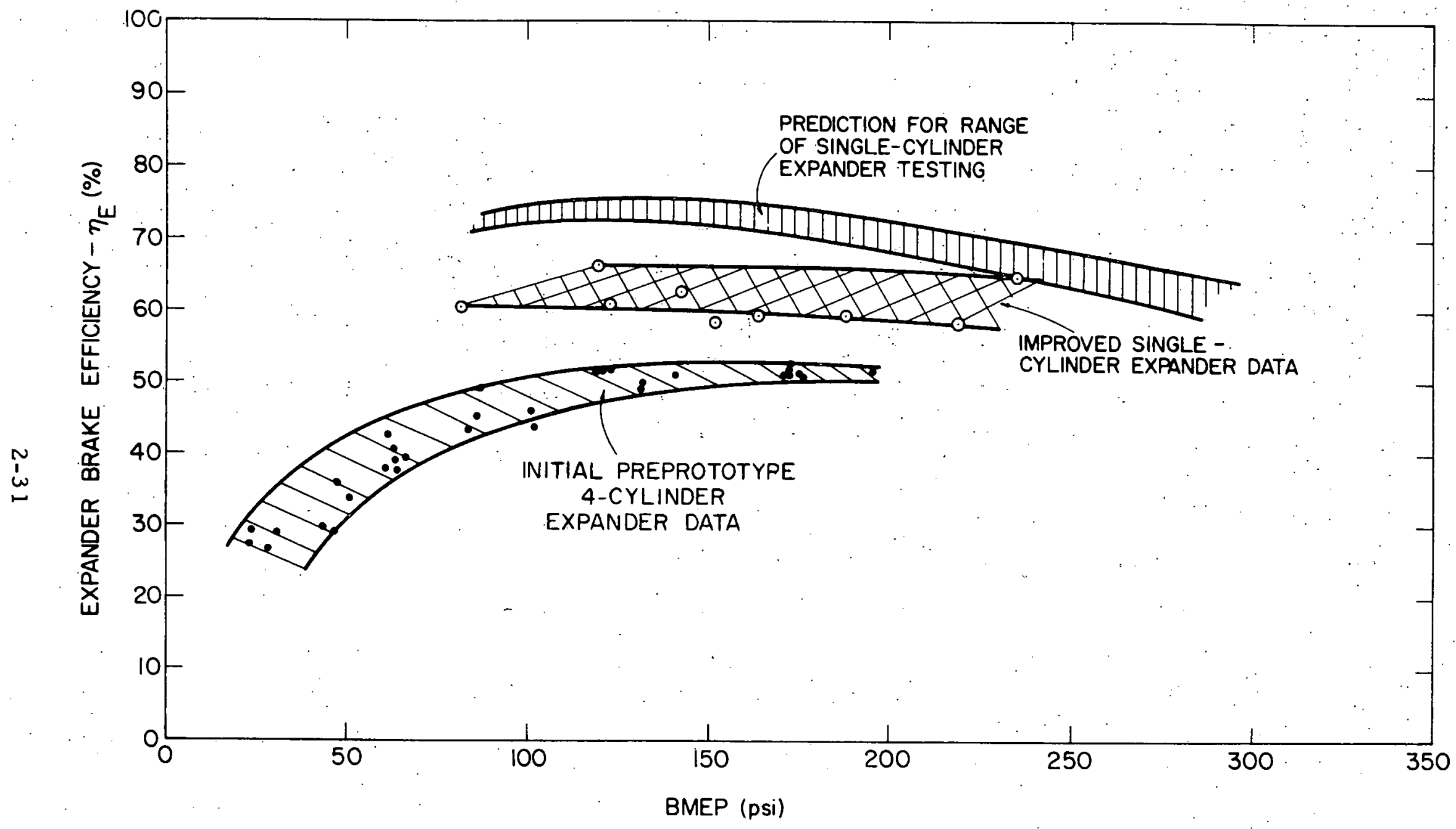

Figure 2.15 Expander Efficiency versus BMEP with BICERI Intake Valving and Uniflow Exhaust 
measurable fluid degradation. It thus appeared that the boiler outlet temperature could be safely raised to at least $625^{\circ} \mathrm{F}$, resulting in a significant improvement in the system fuel economy.

The effect of a higher vapor generator outlet temperature was evaluated for the same component design and the same maximum combustor firing rate $\left(2.7 \times 10^{6} \mathrm{Btu} / \mathrm{hr}\right)$. The performance comparison is shown in Table 2.6. Raising the vapor generator outlet temperature from 550 to $625^{\circ} \mathrm{F}$ improves the performance, i.e., acceleration characteristics, of the system by 10 to 12 percent. The fuel economy over the federal driving cycle is improved by 10 percent. This modification provides a substantial improvement in fuel economy and is incorporated very easily into the system testing, requiring only adjustment of the vapor generator outlet temperature control.

Figure 2.16 shows the calculated efficiency of the preprototype engine as a function of intake ratio for temperatures of 550 and $625^{\circ} \mathrm{F}$. As can be seen from the graph, the efficiency is about 10.0 percent higher at the elevated temperature.

\subsubsection{Test Results for Improved Preprototype System}

The emphasis for this phase of preprototype testing was to obtain a new road load fuel economy baseline for the preprototype system with the following modifications:

- BICERI intake valving on the V-4 expander

- Uniflow exhaust porting

- Peak cycle temperature of $625^{\circ} \mathrm{F}$ 
TÄBL 2.6

COMPARISON OF CALCULATED VEHICLE PERFORMANCE AS A FUNCTION OF BOILER OUTLET CONDITIONS

\begin{tabular}{|l|l|l|}
\hline Driving Condition & $700 \mathrm{psia}, 550^{\circ} \mathrm{F}$ & $700 \mathrm{psia}, 625^{\circ} \mathrm{F}$ \\
\hline $0-60 \mathrm{mph}$ & $14.257 \mathrm{sec}$ & $12.815 \mathrm{sec}$ \\
$25-70 \mathrm{mph}$ & $17.1 \mathrm{sec}$ & $15.117 \mathrm{sec}$ \\
$50-80 \mathrm{mph}$ & $18.529 \mathrm{sec}$ & $15.957 \mathrm{sec}$ \\
$(1400) \mathrm{ft}$ & $15.7 \mathrm{sec}$ & $14.5 \mathrm{sec}$ \\
$30 \mathrm{mph}$ & $18.73 \mathrm{~m} / \mathrm{gal}$ & $20.48 \mathrm{~m} / \mathrm{gal}$ \\
$40 \mathrm{mph}$ & $17.05 \mathrm{~m} / \mathrm{gal}$ & $18.63 \mathrm{~m} / \mathrm{gal}$ \\
$50 \mathrm{mph}$ & $14.69 \mathrm{~m} / \mathrm{gal}$ & $16.195 \mathrm{~m} / \mathrm{gal}$ \\
$60 \mathrm{mph}$ & $12.46 \mathrm{~m} / \mathrm{gal}$ & $13.667 \mathrm{~m} / \mathrm{gal}$ \\
$70 \mathrm{mph}$ & $10.45 \mathrm{~m} / \mathrm{gal}$ & $11.514 \mathrm{~m} / \mathrm{gal}$ \\
$80 \mathrm{mph}$ & $8.68 \mathrm{~m} / \mathrm{gal}$ & $9.59 \mathrm{~m} / \mathrm{gal}$ \\
Federal Driving & $11.12 \mathrm{~m} / \mathrm{gal}$ & $12.3 \mathrm{~m} / \mathrm{gal}$ \\
Cycle & & 1.
\end{tabular}




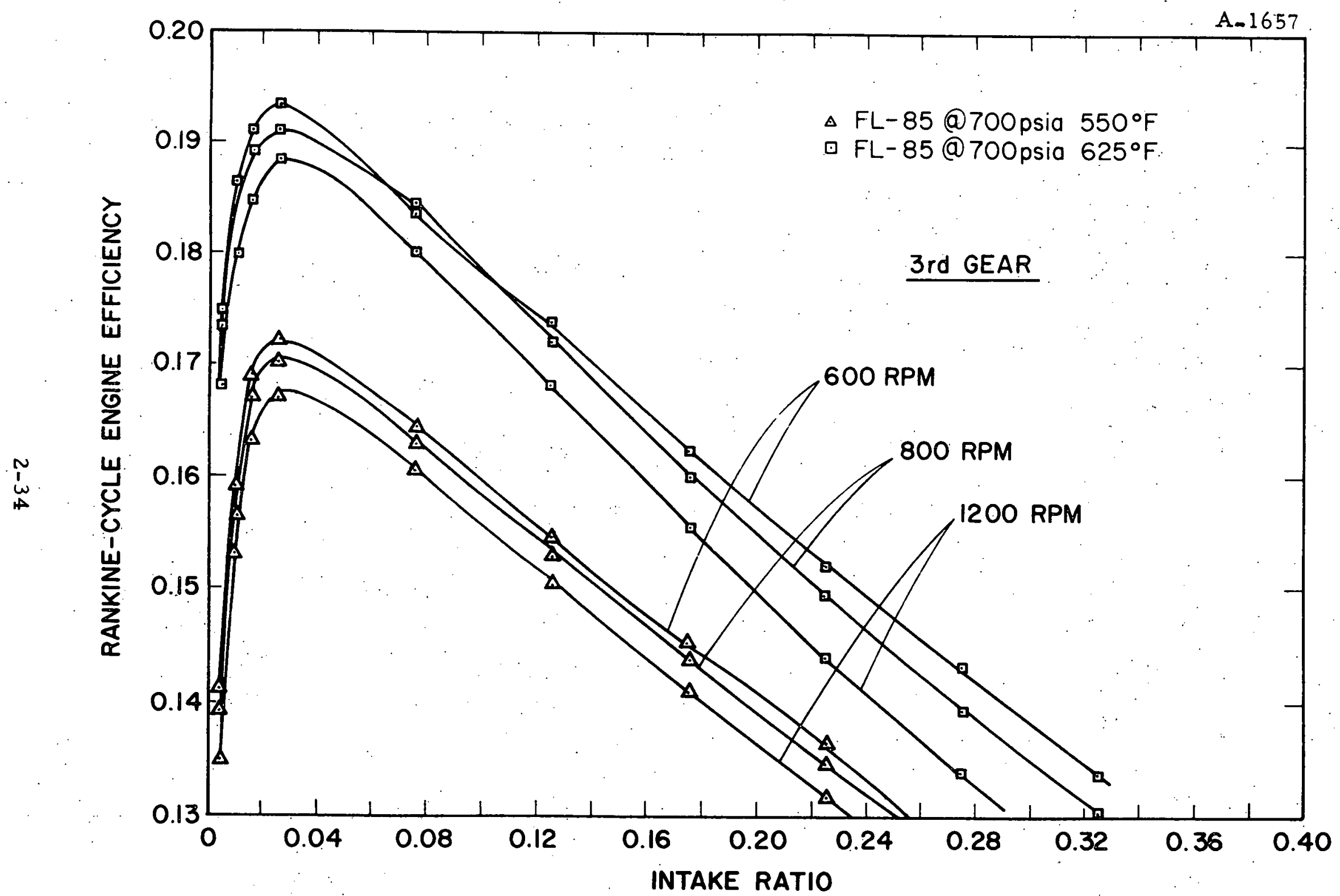

Figure-2.16 Rankine-Cycle Engine Efficiency 


\subsubsection{Road Load Test Results}

The first series of road load tests performed on the system with the BICERI valving were run at an inlet temperature of $550^{\circ} \mathrm{F}$, with speeds from 340 to $1200 \mathrm{rpm}$. Figure 2.17 shows these data as the baseline data taken in January 1974. The improvement in fuel economy compared to the initial tests in the May to July 1973 period ranges from 25 percent in the $20-$ to $40-\mathrm{mph}$ speed range up to a maximum of 50 percent at a road load speed of $70 \mathrm{mph}$.

Although the improvement in fuel economy with the new valving was quite significant, the January 1974 baseline still fell short of the goal. Still further improvement in fuel economy could be attained by decoupling the Bendix hydraulic pump used to supply the high-pressure oil for the BICERI valves. This pump, which was directly coupled to the expander, was initially used to supply the high-pressure oil for the American Bosch valving. Since the pump was oversized for the BICERI valving oil.requirements, it operated at very low displacement where the pump operation is inefficient. Since the pump designed for the V-4 BICERI system was not available for installation, the Bendix pump was decoupled from the expander and a facility pump was used to supply the oil requirements for the valving. The oil requirements were measured and the power was approximated and deducted from the system power during the data reduction calculations.

Another major improvement instituted at this time was to raise the boiler outlet temperature to $625^{\circ} \mathrm{F}$. The improved fuel economy due to these two changes can be seen in Figure 2.17. as the February 1974 baseline (solid line). It should be noted that this curve intersects the curve. representing the design goal at approximately $50 \mathrm{mph}$, and 


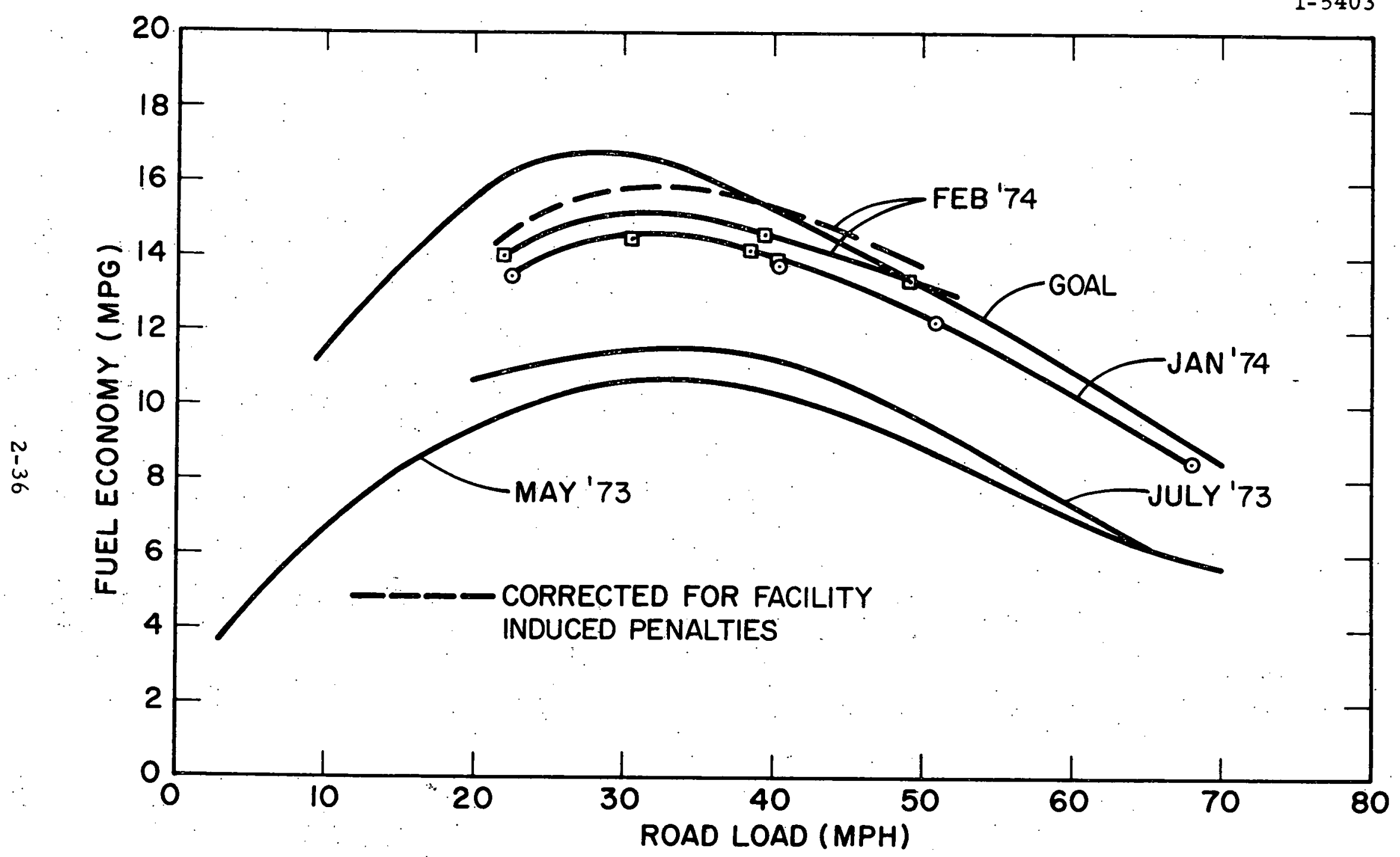

Figure 2.17 Preprototype System Fuel Economy - FL-85 Baseline 
indications are that it exceeds the goal at higher speeds. The data used to plot the January and February 1.974 baselines are listed in Table 2.7.

Also included in Figure 2.17 is the February 1974 baseline (dashed line) curve corrected for facility-induced penalties. These corrections were made to reflect the differences that exist between running the system in a laboratory environment and running it in a vehicle compartment. They include corrections for excessive heat losses, equipment limitations, and nonoptimized runping conditions. For example, there were two heat losses that would not be as great in a packaged vehicle; first, the plumbing between the boiler and the expander would be shorter than that used in the preprototype system and, second, the air entering the combustor would be hotter if the compartment were shrouded. Another loss involved the use of high excess air rates in the burner instead of low excess air combined with exhaust gas recirculation (EGR). During the fuel economy tests, the EGR hardware was not operational on the preprototype burner. In order to simulate the full flow through the burner, high rates of excess air were used. This resulted in higher fuel consumption due to colder air entering the burner than would have been present if EGR were used. This did require less blower power than if the EGR system were used, but the net result was a poorer fuel economy when EGR was not used. The last correction that was applied to the data occurred because some of the data were not at the correct expander inlet temperature of $625^{\circ} \mathrm{F}$. Some of the data were at a slightly lower temperature, and a correction was applied to them. 
TABLE 2.7

PREPROTOTYPE SYSTEM TEST RESULTS:

FUEL ECONOMY IMPROVEMENT PHASE

A-1 1596

\begin{tabular}{|c|c|c|c|c|c|c|c|c|c|c|c|c|c|c|c|c|c|c|c|c|}
\hline \multicolumn{8}{|c|}{ SYSTEM } & \multicolumn{6}{|c|}{ EXPANDER } & \multicolumn{4}{|c|}{ DRIVE TRAIN } & \multirow{3}{*}{$\begin{array}{c}\text { FAN } \\
\begin{array}{c}\text { Power } \\
(\mathrm{hP})\end{array}\end{array}$} & \multirow{3}{*}{$\begin{array}{l}\text { RAM } \\
\begin{array}{l}\text { Air } \\
(\mathrm{mph})\end{array}\end{array}$} & \multirow[b]{3}{*}{$\begin{array}{c}\text { Comments } \\
-\end{array}$} \\
\hline \multirow[b]{2}{*}{ Run } & \multirow[b]{2}{*}{$\begin{array}{l}\text { Power } \\
\text { (hp) }\end{array}$} & \multirow{2}{*}{$\begin{array}{l}\text { Cycle } \\
\text { Eff. } \\
(\%):\end{array}$} & \multirow[b]{2}{*}{ BSFC } & \multirow{2}{*}{$\begin{array}{c}\text { Fuel } \\
\text { Economy } \\
\text { (mpg) }\end{array}$} & \multirow{2}{*}{$\begin{array}{l}\text { Vehicle } \\
\text { Speed } \\
\text { (mph) }\end{array}$} & \multirow{2}{*}{$\begin{array}{c}\text { Fuel } \\
\text { Flow } \\
(1 \mathrm{~b} / \mathrm{hr})\end{array}$} & \multirow{2}{*}{$\begin{array}{c}F-85 \\
\text { Flow } \\
\text { (lb/hr) }\end{array}$} & \multirow[b]{2}{*}{$\mathrm{rpm}$} & \multicolumn{2}{|c|}{ Inlet } & \multirow{2}{*}{$\begin{array}{l}\text { Outlet } \\
\text { Press. } \\
\text { (psia). }\end{array}$} & \multirow[b]{2}{*}{$\begin{array}{l}\text { Power } \\
\text { (hp) }\end{array}$} & \multirow[b]{2}{*}{$\begin{array}{l}\text { Eff. } \\
(\%)\end{array}$} & \multirow{2}{*}{$\begin{array}{l}\text { Dynamo- } \\
\text { meter } \\
\text { (hp) }\end{array}$} & \multirow{2}{*}{$\begin{array}{c}\text { TC } \\
\text { Input } \\
\text { (hp) }\end{array}$} & \multirow[b]{2}{*}{$\begin{array}{c}\text { Power at } \\
\text { Wheels } \\
\text { (hp) }\end{array}$} & \multirow[b]{2}{*}{ Gear } & & & \\
\hline & & & & & & & & & $\begin{array}{l}\text { Temp. } \\
\left({ }^{\circ} \mathrm{F}\right)\end{array}$ & $\begin{array}{l}\text { Press. } \\
\text { (psia) }\end{array}$ & & & & & & & & & & \\
\hline 132 & 11.55 & 10.53 & 1.28 & 12.81 & 30.7 & 15.2 & 877. & 534 & 543 & 510 & 7.5 & 13.33. & 50.3 & 12.51 & 9.97 & 8. 53 & 3 & & & \\
\hline 133 & 27.68 & 13.62 & 0.99 & 12.35 & 50.8 & 26.1 & 1642 & 850 & 552 & 510 & 9.5 & 29.42 & 61.6 & 27.68 & 23.86 & 21.38 & 3 & 0.305 & $\begin{array}{l}20.7 \\
49.8\end{array}$ & Fuel Fconomy \\
\hline 134 & 47.24 & 12: 61 & 1.07 & 8. 50 & 67.9 & 50.7 & 3190 & 1174 & 568 & 510 & 16.5 & 52.55 & 63.5 & 49. 18 & 44.07 & 40.43 & 3 & 0.502 & 70.1 & $\begin{array}{l}\text { Fuel Economy } \\
\text { Improvement }\end{array}$ \\
\hline 135 & 17.54 & 12.34 & 1.10 & 13.28 & 40.2 & 19.2 & 1109 & .688 & $550^{\circ}$ & 515 & 7.5 & 19.33 & 57.0 & 18.21 & 15.38. & 13.59. & 3 & 0.153 & 28.8 & Road Load \\
\hline 136 & 17.69 & 12.77 & 1.06 & 13.69 & 40.4 & 18.8 & 1096 & 689 & 553 & 523 & 6.5 & 19.52 & 56.2 & 18.37 & 15.53 & 13.72 & 3 & 0.176 & 39.6 & Tests \\
\hline 137 & 16.75 & 12.53 & 1.08 & 13. 76 & 39.2 & 18. 1. & 1059 & 688 & 550 & 415 & 6.8 & 18.44 & 57. & 17.42 & 14.60 & 12.96 & 3 & 0.200 & 39.6 & Uniflow \\
\hline $\begin{array}{l}138 \\
139\end{array}$ & $\begin{array}{r}12.04 \\
7.89\end{array}$ & $\begin{array}{l}11.43 . \\
10.09\end{array}$ & 1.18 & 13.81 & 31.0 & 14.3 & 848 & 534 & 541 & 430 & 7.2 & 13.41 & 53.1 & 12. 71 & 10.16 & 8.67 & 3 & 0.091 & 28.9 & Expander \\
\hline 140 & $\begin{array}{l}7.89 \\
7.34\end{array}$ & $\begin{array}{r}10.09 \\
9.47\end{array}$ & 1.34 & 13.46 & 22.4 & 10.6 & 623 & 503 & 533 & 415 & 7.5 & 9.11 & 50.3 & 8. 52 & 6.10 & 5. 33 & 2 & 0.120 & 28.8 & \\
\hline 141 & 17.89 & 12.98 & $\begin{array}{l}1.43 \\
1.04\end{array}$ & 11.68 & 19.3 & 10.5 & 618 & 343 & 531 & 415 & 8.0 & 8.45 & 47.9 & 7.97 & 5. 76 & 4.36 & 3 & 0.070 & 30.6 & \\
\hline 142 & 16.35 & 12.82 & $\begin{array}{l}1.04 \\
1.06\end{array}$ & $\begin{array}{l}13.85 \\
14.21\end{array}$ & $\begin{array}{l}40.7 \\
38.6\end{array}$ & 18.7 & $\begin{array}{l}1041 \\
1006\end{array}$ & 687 & 585 & 445 & 4.8 & 19.71 & 54.9 & 18.58 & 15.73 & 13.87 & 3 & 0.282 & 39.4 & \\
\hline 143 & 11.71 & 11.84 & 1.14 & 14.46 & $\begin{array}{l}38.6 \\
30.5\end{array}$ & $\begin{array}{l}17.3 \\
13.4\end{array}$ & $\begin{array}{r}1006 \\
811\end{array}$ & $\begin{array}{l}688 \\
533\end{array}$ & 564 & 420 & 4.5 & 18.12 & 53.3 & 17.03 & 14.21 & 12.63 & 3 & 0.282 & 39.5 & \\
\hline 144 & 24.47 & 14.19 & 0.95 & 13.33 & 49.0 & $\begin{array}{r}23.7 \\
23.4\end{array}$ & $\begin{array}{r}811 \\
1364\end{array}$ & $\begin{array}{l}533 \\
850\end{array}$ & $\begin{array}{l}529 \\
619\end{array}$ & $\begin{array}{l}390 \\
425\end{array}$ & $\begin{array}{l}5.2 \\
7.5\end{array}$ & $\begin{array}{l}13.08 \\
27.19\end{array}$ & 52.1 & 12.38 & 9.84 & 8.43 & 3 & 0.13 .7 & 28.9 & \\
\hline 145 & 17.07 & 13. 38 & 1.01 & 14.57 & 39.6 & 17.3 & 1041 & 689 & 614 & 430 & 7.0 & $\begin{array}{l}27.19 \\
18.73\end{array}$ & $\begin{array}{l}61.3 \\
54.7\end{array}$ & 25.73 & 22.04 & 19.86 & 3 & 0.305 & 50.4 & \\
\hline 146 & 7. 72 & 10.44 & 1.30 & 13.97 & 22 & 10 & 533 & 506 & 608 & 405 & 6.0 & $\begin{array}{r}18.73 \\
8.81\end{array}$ & $\begin{array}{l}54.7 \\
49.4\end{array}$ & $\begin{array}{r}17.71 \\
8.29\end{array}$ & $\begin{array}{r}14.92 \\
5.92\end{array}$ & $\begin{array}{r}.13 .22 \\
5.19\end{array}$ & $\begin{array}{l}3 \\
2\end{array}$ & $\begin{array}{l}0.176 \\
0.112\end{array}$ & $\begin{array}{l}40.3 \\
29.3\end{array}$ & \\
\hline
\end{tabular}


In this later testing of the preprototype system, the following was established and demonstrated:

- Fluorinol-85 baseline fuel economy curve

- Up to 50 percent improvement in fuel economy from the initial test results

- System operation at $625^{\circ} \mathrm{F}$

- Reliable operation of BICERI valving

- Reduced noise level of the system

- Measured fuel consumption within 10 percent of the original goal

- Simulation of the system idle condition

\subsubsection{System Characterization - ORL Test Results}

The system characterization tests consisted of a number of ORL test points: The range of test data taken is shown in Figure 2.18 together with an outline of the federal driving cycle.

The basic operating conditions of the system are listed below:

- Expander Inlet Pressure

- Expander Inlet Temperature

- Expander. Speed Range

- Fuel Firing Rate 500 psta $600^{\circ} \mathrm{F}$ 400 to $1200 \mathrm{rpm}$ 10 to $105 \mathrm{lb} / \mathrm{hr}$

These ORL characterization test results are shown in Table 2. 8 . Performance results are given for each gear in each of the se tests. Various cooling airflow rates across the condenser were run so that performance of the system could be maximized at each fuel firing rate and expander speed. Figure 2.19 is an example of a set of tests that show the effect of fan horsepower (directly related to cooling airflow) on BSFC, cycle efficiency, and condenser pressure. From 


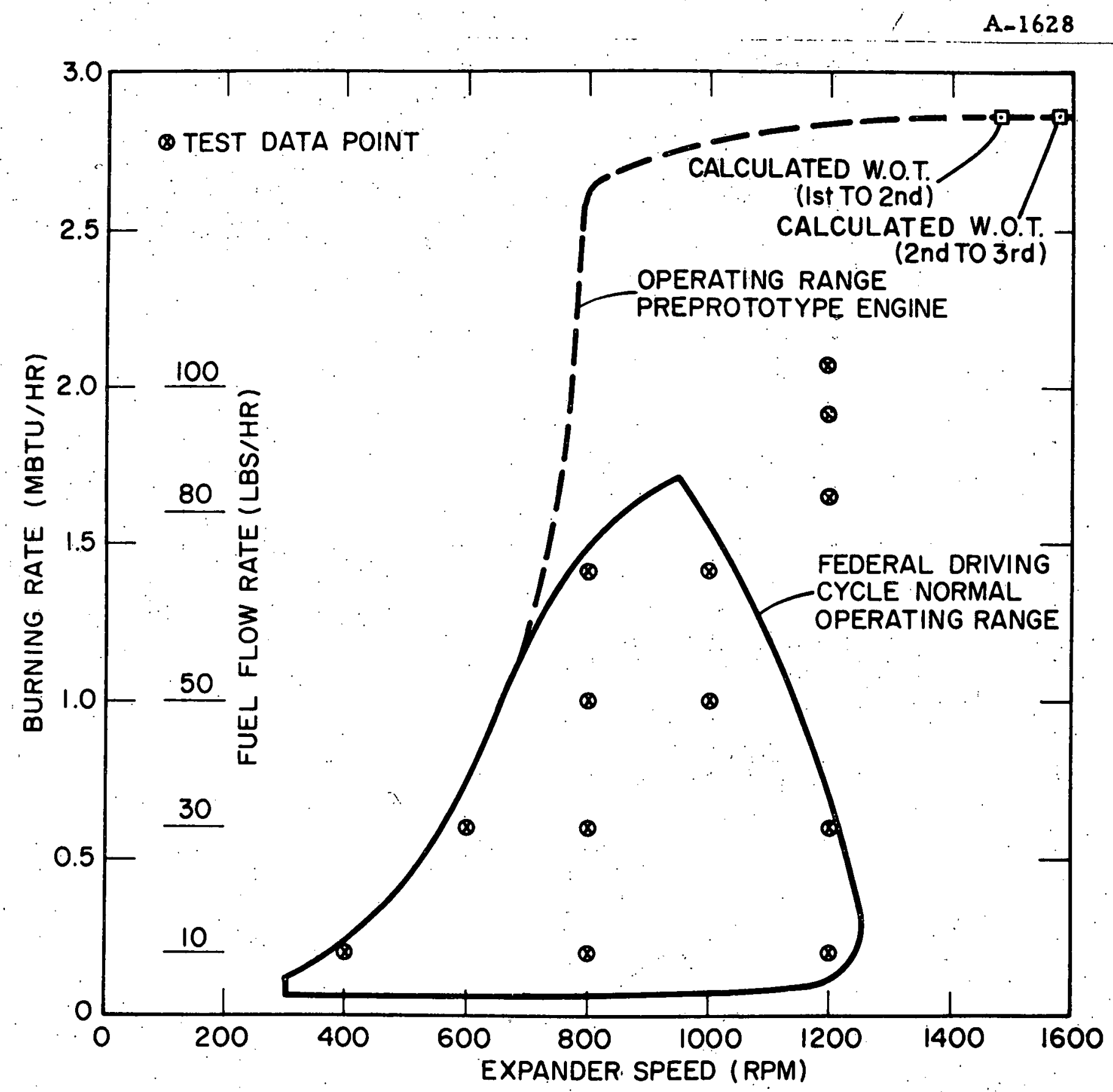

Figure 2.18 Range of Test Data Taken 
TABLE 2.8

PREPROTOTYPE SYSTEM TEST RESULTS:

SYSTEM CHARACTERIZATION TESTS

A-1597a

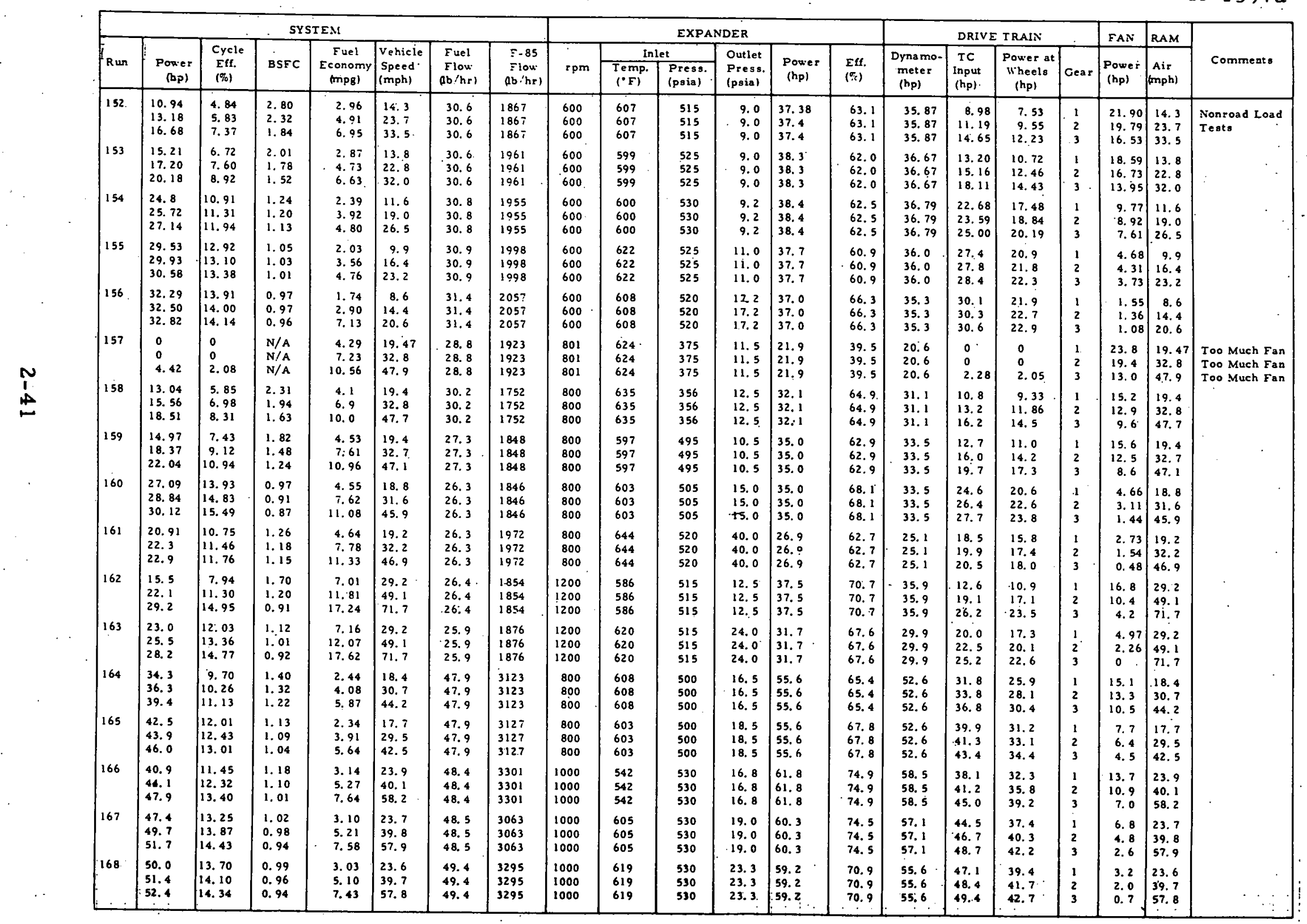


TABLE 2.8 (cont'd)

PREPROTOTYPE SYSTEM TEST RESULTS: SYSTEM CHARACTERIZATION TESTS

$A-1597 b$

\begin{tabular}{|c|c|c|c|c|c|c|c|c|c|c|c|c|c|c|c|c|c|c|c|c|}
\hline \multicolumn{8}{|c|}{ SYSTEM } & \multicolumn{6}{|c|}{ EXPANDER } & \multicolumn{4}{|c|}{ DRIVE TRAIN } & \multirow{2}{*}{\begin{tabular}{|c|} 
FAN \\
$\begin{array}{c}\text { Power } \\
\text { (mp) }\end{array}$ \\
\end{tabular}} & \multirow{2}{*}{\begin{tabular}{|l} 
RAM \\
$\begin{array}{c}\text { Air } \\
\text { (mph) }\end{array}$
\end{tabular}} & \multirow[b]{2}{*}{ Comments } \\
\hline Run & $\begin{array}{l}\text { Power } \\
\text { (hp) }\end{array}$ & $\begin{array}{l}\text { Cycle } \\
\text { Eff. } \\
(\%)\end{array}$ & BSFC & $\begin{array}{c}\text { Fuel } \\
\text { Economy } \\
\text { (mpg) }\end{array}$ & $\begin{array}{l}\text { Vehicle } \\
\text { Speed } \\
\text { (mph) }\end{array}$ & $\begin{array}{l}\text { F.uel } \\
\text { Flow: } \\
\left(1 \mathrm{~b}^{\prime} \mathrm{hr}\right)\end{array}$ & $\begin{array}{c}F-85 \\
\text { Flou } \\
(\mathrm{b} / \mathrm{hr})\end{array}$ & rpm & $\begin{array}{l}\frac{\text { In }}{\text { Temp. }} \\
\left({ }^{\circ} \mathrm{F}\right)\end{array}$ & \begin{tabular}{|l|} 
Press. \\
(psia)
\end{tabular} & $\begin{array}{l}\text { Outlet } \\
\text { Press. } \\
\text { (psia) }\end{array}$ & $\begin{array}{c}\text { Power } \\
\text { (hp) }\end{array}$ & $\begin{array}{l}\text { Eff. } \\
\left(\sigma_{c}^{\circ}\right)\end{array}$ & $\begin{array}{c}\text { Dynamo- } \\
\text { meter } \\
\text { (hp) }\end{array}$ & $\begin{array}{c}\text { TC } \\
\text { Input } \\
\text { (hp) }\end{array}$ & $\begin{array}{c}\text { Power at } \\
\text { Wheels } \\
\text { (hp) }\end{array}$ & Gear & & & \\
\hline 169 & $\begin{array}{l}0 \\
3.86 \\
7.24\end{array}$ & $\begin{array}{l}0 \\
5.30 \\
9.95\end{array}$ & $\begin{array}{l}N^{\prime} A \\
2.55 \\
1.36\end{array}$ & $\begin{array}{l}12.54 \\
21.12 \\
30.8\end{array}$ & $\begin{array}{l}19.4 \\
32.8 \\
47.8\end{array}$ & $\begin{array}{l}9.9 \\
9.9 \\
9.9\end{array}$ & $\begin{array}{l}516 \\
516 \\
516\end{array}$ & $\begin{array}{l}800 \\
800 \\
800\end{array}$ & $\begin{array}{l}595 \\
595 \\
595\end{array}$ & $\begin{array}{l}525 \\
525 \\
525\end{array}$ & $\begin{array}{l}3.5 \\
\text { 3. } 5 \\
3.5\end{array}$ & $\begin{array}{l}10.1 \\
10.1 \\
10.1\end{array}$ & $\begin{array}{l}52.0 \\
52.0 \\
52.0\end{array}$ & $\begin{array}{l}9.7 \\
9.7 \\
9.7\end{array}$ & $\begin{array}{l}0 \\
1.64 \\
5.03\end{array}$ & $\begin{array}{l}0 \\
1.47 \\
4.53\end{array}$ & $\begin{array}{l}1 . \\
2 \\
3\end{array}$ & $\begin{array}{l}8.7 \\
5.1 \\
1.6\end{array}$ & $\begin{array}{l}19.4 \\
32.8 \\
47.8\end{array}$ & $\begin{array}{c}\text { To.o Much Fan } \\
.\end{array}$ \\
\hline 170 & $\begin{array}{l}7.12 \\
8.62 \\
8.73\end{array}$ & $\begin{array}{r}9.83 \\
11.90 \\
12.05\end{array}$ & $\begin{array}{l}1.38 \\
1.14 \\
1.12\end{array}$ & $\begin{array}{l}12.59 \\
21.2 \\
31.0\end{array}$ & $\begin{array}{l}19.4 \\
32.8 \\
4 i .8\end{array}$ & $\begin{array}{l}9.8 \\
9.8 \\
9.8\end{array}$ & $\begin{array}{l}465 \\
465 \\
465\end{array}$ & $\begin{array}{l}800 \\
800 \\
800\end{array}$ & $\begin{array}{l}609 \\
609 \\
609\end{array}$ & $\begin{array}{l}550 \\
550 \\
550\end{array}$ & $\begin{array}{l}\text { 3. } 0 \\
\text { 3. } 0 \\
\text { 3. } 0\end{array}$ & $\begin{array}{l}9.9 \\
9.9 \\
9.9\end{array}$ & $\begin{array}{l}53.9 \\
53.9 \\
53.9\end{array}$ & $\begin{array}{l}9.6 \\
9.6 \\
9.6\end{array}$ & $\begin{array}{l}4.88 \\
6.37 \\
6.52\end{array}$ & $\begin{array}{l}4.23 \\
5.70 \\
5.87\end{array}$ & $\begin{array}{l}1 \\
2 \\
3\end{array}$ & $\begin{array}{l}1.9 \\
0: 6 \\
0\end{array}$ & $\begin{array}{l}19.4 \\
32.8 \\
46.3\end{array}$ & . \\
\hline 171 & $\begin{array}{l}9.15 \\
9.70 \\
9.2\end{array}$ & $\begin{array}{l}12.60 \\
13.36 \\
12.65\end{array}$ & $\begin{array}{l}1.07 \\
1.01 \\
1.07\end{array}$ & $\begin{array}{l}12.57 \\
21.2 \\
30.9\end{array}$ & $\begin{array}{l}19.4 \\
32.8 \\
47.8\end{array}$ & $\begin{array}{l}9.8 \\
9.8 \\
9.8\end{array}$ & $\begin{array}{l}510 \\
510 \\
510\end{array}$ & $\begin{array}{l}800 \\
800 \\
800\end{array}$ & $\begin{array}{l}608 \\
608 \\
608\end{array}$ & $\begin{array}{l}530 \\
530 \\
530\end{array}$ & $\begin{array}{r}4.5 \\
\because 4.5 \\
4.5\end{array}$ & $\begin{array}{l}10.4 \\
10.4 \\
10.4\end{array}$ & $\begin{array}{l}55.6 \\
55.6 \\
55.6\end{array}$ & $\begin{array}{l}10.1 \\
10.1 \\
10.1\end{array}$ & $\begin{array}{l}6.9 \\
7.4 \\
7.0\end{array}$ & $\begin{array}{l}5.97 \\
6.6 \\
6.3\end{array}$ & $\begin{array}{l}1 \\
2 \\
3\end{array}$ & $\begin{array}{l}0.53 \\
0.06 \\
0\end{array}$ & $\begin{array}{l}19.4 \\
32.8 \\
35.8\end{array}$ & Ram Too Low \\
\hline 172 & $\begin{array}{c}4.99 \\
8.93 \\
10.5\end{array}$ & $\begin{array}{r}6.92 \\
12.39 \\
14.56\end{array}$ & $\begin{array}{l}1.95 \\
1.09 \\
0.93\end{array}$ & $\begin{array}{l}19.0 \\
32.0 \\
46.7\end{array}$ & $\begin{array}{l}29.2 \\
40.1 \\
71.7\end{array}$ & $\begin{array}{l}9.8 \\
9.8 \\
9.8\end{array}$ & $\begin{array}{l}556 \\
555 \\
556\end{array}$ & $\begin{array}{l}1200 \\
1200 \\
1200\end{array}$ & $\begin{array}{l}583 \\
583 \\
583\end{array}$ & $\begin{array}{l}500 \\
500 \\
500\end{array}$ & $\begin{array}{l}3.8 \\
3.8 \\
3.8\end{array}$ & $\begin{array}{l}11.8 \\
11.8 \\
11.8\end{array}$ & $\begin{array}{l}58.3 \\
58.3 \\
58.3\end{array}$ & $\begin{array}{l}11.4 \\
11.4 \\
11.4\end{array}$ & $\begin{array}{l}2.2 \\
6.1 \\
7.6\end{array}$ & $\begin{array}{l}1.9 \\
5.4 \\
6.9\end{array}$ & $\begin{array}{l}1 \\
2 \\
3\end{array}$ & $\begin{array}{l}5.2 \\
1.3 \\
0\end{array}$ & $\begin{array}{l}29.2 \\
49.1 \\
65.4\end{array}$ & Ram Too Low \\
\hline 173 & $\begin{array}{l}10.5 \\
10.0 \\
10.0\end{array}$ & $\begin{array}{l}14.24 \\
13.7 \\
13.7\end{array}$ & $\begin{array}{l}0.95 \\
0.99 \\
0.99\end{array}$ & $\begin{array}{l}18.6 \\
31.4 \\
45.8\end{array}$ & $\begin{array}{l}29.2 \\
49.1 \\
71.7\end{array}$ & $\begin{array}{l}10.0 \\
10.0 \\
10.0\end{array}$ & $\begin{array}{l}524 \\
524 \\
524\end{array}$ & $\begin{array}{l}1200 \\
1200 \\
1200\end{array}$ & $\begin{array}{l}587 \\
587 \\
587\end{array}$ & $\begin{array}{l}520 \\
520 \\
520\end{array}$ & $\begin{array}{l}4.5 \\
4.5 \\
4.5\end{array}$ & $\begin{array}{l}11.3 \\
11.3 \\
11.3\end{array}$ & $\begin{array}{l}60.6 \\
60.6 \\
60.6\end{array}$ & $\begin{array}{l}11.0 \\
11.0 \\
11.0\end{array}$ & $\begin{array}{l}7.6 \\
7.2 \\
7.2\end{array}$ & $\begin{array}{l}6.6 \\
6.4 \\
6.5\end{array}$ & $\begin{array}{l}1 \\
2 \\
3\end{array}$ & $\begin{array}{l}0.13 \\
0 \\
0\end{array}$ & $\begin{array}{l}29.2 \\
35.8 \\
35.8\end{array}$ & $\begin{array}{l}\text { Ram Too Low } \\
\text { Ram Too Low }\end{array}$ \\
\hline 174 & $\begin{array}{l}0 \\
0 \\
0\end{array}$ & $\begin{array}{l}0 \\
0 \\
0\end{array}$ & $\begin{array}{l}\text { N/A } \\
\text { N/A } \\
\text { N/A }\end{array}$ & $\begin{array}{r}6.2 \\
10.5 \\
15.3\end{array}$ & $\begin{array}{r}9.7 \\
16.4 \\
23.9\end{array}$ & $\begin{array}{l}9.9 \\
9.9 \\
9.9\end{array}$ & $\begin{array}{l}528 \\
528 \\
528\end{array}$ & $\begin{array}{l}400 \\
400 \\
400\end{array}$ & $\begin{array}{l}590 \\
590 \\
590\end{array}$ & $\begin{array}{l}525 \\
525 \\
525\end{array}$ & $\begin{array}{l}4.5 \\
4.5 \\
4.5\end{array}$ & $\begin{array}{l}9.9 \\
9.9 \\
9.9\end{array}$ & $\begin{array}{l}52.1 \\
52.1 \\
52.1\end{array}$ & $\begin{array}{l}9.5 \\
9.5 \\
9.5\end{array}$ & $\begin{array}{l}0 \\
0 \\
0\end{array}$ & $\begin{array}{l}0 \\
0 \\
0\end{array}$ & $\begin{array}{l}1 \\
2 \\
3\end{array}$ & $\begin{array}{r}12.5 \\
11.1 \\
8.9\end{array}$ & $\begin{array}{r}9.7 \\
16.4 \\
23.9\end{array}$ & $\begin{array}{l}\text { Too Much Fan } \\
\text { Too Much Fin } \\
\text { Too Much Fan }\end{array}$ \\
\hline 175 & $\begin{array}{l}7.46 \\
7.83 \\
8.28\end{array}$ & $\begin{array}{l}10.20 \\
10.70 \\
11.32\end{array}$ & $\begin{array}{l}1.33 \\
1.26 \\
1.20\end{array}$ & $\begin{array}{r}5.4 \\
8.8 \\
12.4\end{array}$ & $\begin{array}{r}8.5 \\
13.8 \\
19.3\end{array}$ & $\begin{array}{l}9.9 \\
9.9 \\
9.9\end{array}$ & $\begin{array}{l}532 \\
532 \\
532\end{array}$ & $\begin{array}{l}400 \\
400 \\
400\end{array}$ & $\begin{array}{l}593 \\
593 \\
593\end{array}$ & $\begin{array}{l}535 \\
535 \\
535\end{array}$ & $\begin{array}{l}4.5 \\
4.5 \\
4.5\end{array}$ & $\begin{array}{l}9.65 \\
9.65 \\
9.65\end{array}$ & $\begin{array}{l}50.3 \\
50.3 \\
50.3\end{array}$ & $\begin{array}{l}9.3 \\
9.3 \\
9.3\end{array}$ & $\begin{array}{l}5.77 \\
6.14 \\
6.6\end{array}$ & $\begin{array}{l}4.35 \\
4.80 \\
5.3\end{array}$ & $\begin{array}{l}1 \\
2 \\
3\end{array}$ & $\begin{array}{l}1.37 \\
1.03 \\
0.63\end{array}$ & $\begin{array}{r}8.5 \\
13.8 \\
19.3\end{array}$ & $x^{2}+2-5$ \\
\hline 176 & $\begin{array}{l}54.7 \\
57.7 \\
61.3\end{array}$ & $\begin{array}{l}10.79 \\
11.37 \\
12.09\end{array}$ & $\begin{array}{l}1.25 \\
1.19 \\
1.12\end{array}$ & $\begin{array}{l}2.17 \\
3.63 \\
5.27\end{array}$ & $\begin{array}{l}23.4 \\
39.3 \\
57.0\end{array}$ & $\begin{array}{l}68.7 \\
68.7 \\
68.7\end{array}$ & $\begin{array}{l}4583 \\
4583 \\
4583\end{array}$ & $\begin{array}{l}1000 \\
1000 \\
1000\end{array}$ & $\begin{array}{l}605 \\
605 \\
605\end{array}$ & $\begin{array}{l}480 \\
480 \\
480\end{array}$ & $\begin{array}{l}20.2 \\
20.2 \\
20.2\end{array}$ & $\begin{array}{l}79.1 \\
79.1 \\
79.1\end{array}$ & $\begin{array}{l}67.9 \\
67.9 \\
67.9\end{array}$ & $\begin{array}{l}74.3 \\
74.3 \\
74.3\end{array}$ & $\begin{array}{l}51.8 \\
54.7 \\
58.3\end{array}$ & $\begin{array}{l}43.0 \\
46.6 \\
49.7\end{array}$ & $\begin{array}{l}1 \\
2 \\
3\end{array}$ & $\begin{array}{r}13.7 \\
11.1 \\
7.4\end{array}$ & $\begin{array}{l}23.4 \\
39.3 \\
57.0\end{array}$ & $\cdots$ \\
\hline 177 & $\begin{array}{l}62.1 \\
63.6 \\
65.6\end{array}$ & $\begin{array}{l}12.38 \\
12.68 \\
13.08\end{array}$ & $\begin{array}{l}1.09 \\
1.07 \\
1.03\end{array}$ & $\begin{array}{l}2.16 \\
3.63 \\
5.28\end{array}$ & $\begin{array}{l}23.1 . \\
38.8 \\
56.5\end{array}$ & $\begin{array}{l}67.9 \\
67.9 \\
67.9\end{array}$ & $\begin{array}{l}4756 \\
4756 \\
4756\end{array}$ & $\begin{array}{l}1000 \\
1000 \\
1000\end{array}$ & $\begin{array}{l}621 \\
621 \\
621\end{array}$ & $\begin{array}{l}500 \\
500 \\
500\end{array}$ & $\begin{array}{l}24.8 \\
.24 .8 \\
24.8\end{array}$ & $\begin{array}{l}80.4 \\
80.4 \\
80.4\end{array}$ & $\begin{array}{l}68.7 \\
68.7 \\
68.7\end{array}$ & $\begin{array}{l}75.0 \\
75.0 \\
75.0\end{array}$ & $\begin{array}{l}59.1 \\
60.6 \\
62.6\end{array}$ & $\begin{array}{r}48.4 \\
51.1 \\
.52 . .9\end{array}$ & $\begin{array}{l}1 \\
2 \\
3\end{array}$ & $\begin{array}{l}7.9 \\
6.5 \\
4.4\end{array}$ & $\begin{array}{l}23.1 . \\
38.8 \\
56.5\end{array}$ & $\because$ \\
\hline 178 & $\begin{array}{l}54.8 \\
55.7 \\
57.3\end{array}$ & $\begin{array}{l}11.00 \\
11.18 \\
11.50\end{array}$ & $\begin{array}{l}1.23 \\
1.21 \\
1.18\end{array}$ & $\begin{array}{l}1.49 \\
2.47 \\
3.54\end{array}$ & $\begin{array}{l}15.8 \\
26.3 \\
37.6\end{array}$ & $\begin{array}{l}67.4 \\
67.4 \\
67.4\end{array}$ & $\begin{array}{l}4778 \\
4778 \\
4778\end{array}$ & $\begin{array}{l}800 \\
800 \\
800\end{array}$ & $\begin{array}{l}624 \\
624 \\
624\end{array}$ & $\begin{array}{l}505 \\
505 \\
505\end{array}$ & $\begin{array}{l}23.0 \\
23.0 \\
23.0\end{array}$ & $\begin{array}{l}77.9 \\
77.9 \\
77.9\end{array}$ & $\begin{array}{l}64.4 \\
64.4 \\
64.4\end{array}$ & $\begin{array}{l}72.7 \\
72.7 \\
72.7\end{array}$ & $\begin{array}{l}52.2 \\
53.1 \\
54.6\end{array}$ & $\begin{array}{l}40.3 \\
42.4 \\
44.0\end{array}$ & $\begin{array}{l}1 \\
2 \\
3\end{array}$ & $\begin{array}{l}12.4 \\
11.6 \\
10.2\end{array}$ & $\begin{array}{r}15.8 \\
26.3 \\
37.6\end{array}$ & \\
\hline 179 & $\begin{array}{l}58.6 \\
59.4 \\
60.5\end{array}$ & $\begin{array}{l}11.76 \\
11.93 \\
12.15\end{array}$ & $\begin{array}{l}1.15 \\
1.13 \\
1.11\end{array}$ & $\begin{array}{l}1.42 \\
2.36 \\
3.39\end{array}$ & $\begin{array}{l}15.0 \\
25.0 \\
36.0\end{array}$ & $\begin{array}{l}67.4 \\
67.4 \\
67.4\end{array}$ & $\begin{array}{l}4766 \\
4766 \\
4766\end{array}$ & $\begin{array}{l}800 \\
800 \\
800\end{array}$ & $\begin{array}{l}634 \\
634 \\
634\end{array}$ & $\begin{array}{l}520 \\
520 \\
520\end{array}$ & $\begin{array}{l}26.5 \\
26.5 \\
26.5\end{array}$ & $\begin{array}{l}77.4 \\
77.4 \\
77.4\end{array}$ & $\begin{array}{l}65.7 \\
65.7 \\
65.7\end{array}$ & $\begin{array}{l}72.0 \\
72.0 \\
72.0\end{array}$ & $\begin{array}{l}55.9 . \\
56.8 \\
57.8\end{array}$ & $\begin{array}{l}43.4 \\
45.6 \\
46.7\end{array}$ & $\begin{array}{l}1 \\
2 \\
3\end{array}$ & $\begin{array}{l}8.4 \\
7.7 \\
6.7\end{array}$ & $\begin{array}{l}15.0 \\
25.0 \\
36.0\end{array}$ & \\
\hline 180 & $\begin{array}{l}45.2 \\
48.3 \\
52.2\end{array}$ & $\begin{array}{l}7.20 \\
7.69 \\
8.31\end{array}$ & $\begin{array}{l}1.88 \\
1.76 \\
1.63\end{array}$ & $\begin{array}{l}2.18 \\
3.67 \\
5.36\end{array}$ & $\begin{array}{l}29.2 \\
49.1 \\
71.8\end{array}$ & $\begin{array}{l}85.0 \\
85.0 \\
85.0\end{array}$ & $\begin{array}{l}5219 \\
5219 \\
5219\end{array}$ & $\begin{array}{l}1200 \\
1200 \\
1200\end{array}$ & $\begin{array}{l}635 \\
635 \\
635\end{array}$ & $\begin{array}{l}395 \\
395 \\
395\end{array}$ & $\begin{array}{l}24.0 \\
24.0 \\
24.0\end{array}$ & $\begin{array}{l}66.5 \\
66.5 \\
66.5\end{array}$ & $\begin{array}{l}53.6 \\
53.6 \\
53.6\end{array}$ & $\begin{array}{l}61.5 \\
61.5 \\
61.5\end{array}$ & $\begin{array}{l}42.1 \\
45.1 \\
48.9\end{array}$ & $\begin{array}{l}36.4 \\
40.3 \\
43.7\end{array}$ & $\begin{array}{l}1 \\
2 \\
3\end{array}$ & $\begin{array}{r}11.4 \\
8.2 \\
4.9\end{array}$ & $\begin{array}{l}29.2 \\
49.1 \\
71.8\end{array}$ & $\begin{array}{l}\text { Expander Effcy. } \\
\text { is Too. Low }\end{array}$ \\
\hline 181 & $\begin{array}{l}56.2 \\
58.8 \\
63.2\end{array}$ & $\begin{array}{l}7.96 \\
8.33 \\
8.95\end{array}$ & $\begin{array}{l}1.70 \\
1.62 \\
1.51\end{array}$ & $\begin{array}{l}1.94 \\
3.25 \\
4.73\end{array}$ & $\begin{array}{l}29.1 \\
49.0 \\
71.1\end{array}$ & $\begin{array}{r}95.5 \\
95.5 \\
95.5\end{array}$ & $\begin{array}{l}6848 \\
6848 \\
6848\end{array}$ & $\begin{array}{l}1200 \\
1200 \\
1200\end{array}$ & $\begin{array}{l}595 \\
595 \\
595\end{array}$ & $\begin{array}{l}515 \\
515 \\
515\end{array}$ & $\begin{array}{l}32.0 \\
32.0 \\
32.0\end{array}$ & $\begin{array}{l}84.8 \\
84.8 \\
84.8\end{array}$ & $\begin{array}{l}56.0 \\
56.0 \\
56.0\end{array}$ & $\begin{array}{l}75.4 \\
75.4 \\
75.4\end{array}$ & $\begin{array}{l}53.0 \\
55.6 \\
59.9\end{array}$ & $\begin{array}{l}45.4 \\
49.1 \\
53.0\end{array}$ & $\begin{array}{l}1 \\
2 \\
3\end{array}$ & $\begin{array}{r}12.4 \\
9.7 \\
5.9\end{array}$ & $\begin{array}{l}29.1 \\
49.0 \\
71.1\end{array}$ & \\
\hline 182 & $\begin{array}{l}66.0 \\
68.2 \\
72.1\end{array}$ & $\begin{array}{l}8.49 \\
8.76 \\
9.28\end{array}$ & $\begin{array}{l}1.59 \\
1.54 \\
1.46\end{array}$ & $\begin{array}{l}1.74 \\
2.92 \\
4.25\end{array}$ & $\begin{array}{l}28.8 \\
48.5 \\
70.5\end{array}$ & $\begin{array}{l}105.3 \\
105.3 \\
105.3\end{array}$ & $\begin{array}{l}7076 \\
7076 \\
7076\end{array}$ & $\begin{array}{l}1200 \\
1200 \\
1200\end{array}$ & $\begin{array}{l}575 \\
575 \\
575\end{array}$ & $\begin{array}{l}535 \\
535 \\
535\end{array}$ & $\begin{array}{l}30.0 \\
30.0 \\
30.0\end{array}$ & $\begin{array}{l}93.0 \\
93.0 \\
93.0\end{array}$ & $\begin{array}{l}59.4 \\
59.4 \\
59.4\end{array}$ & $\begin{array}{l}83.2 \\
83.2 \\
83.2\end{array}$ & $\begin{array}{l}62.7 \\
64.8 \\
68.8\end{array}$ & $\begin{array}{l}53.3 \\
56.7 \\
60.3\end{array}$ & $\begin{array}{l}1 \\
2 \\
3\end{array}$. & $\begin{array}{r}10.5 \\
8.2 \\
4.8\end{array}$ & $\begin{array}{l}28.8 \\
48.5 \\
70.5\end{array}$ & . \\
\hline
\end{tabular}


A- 1636

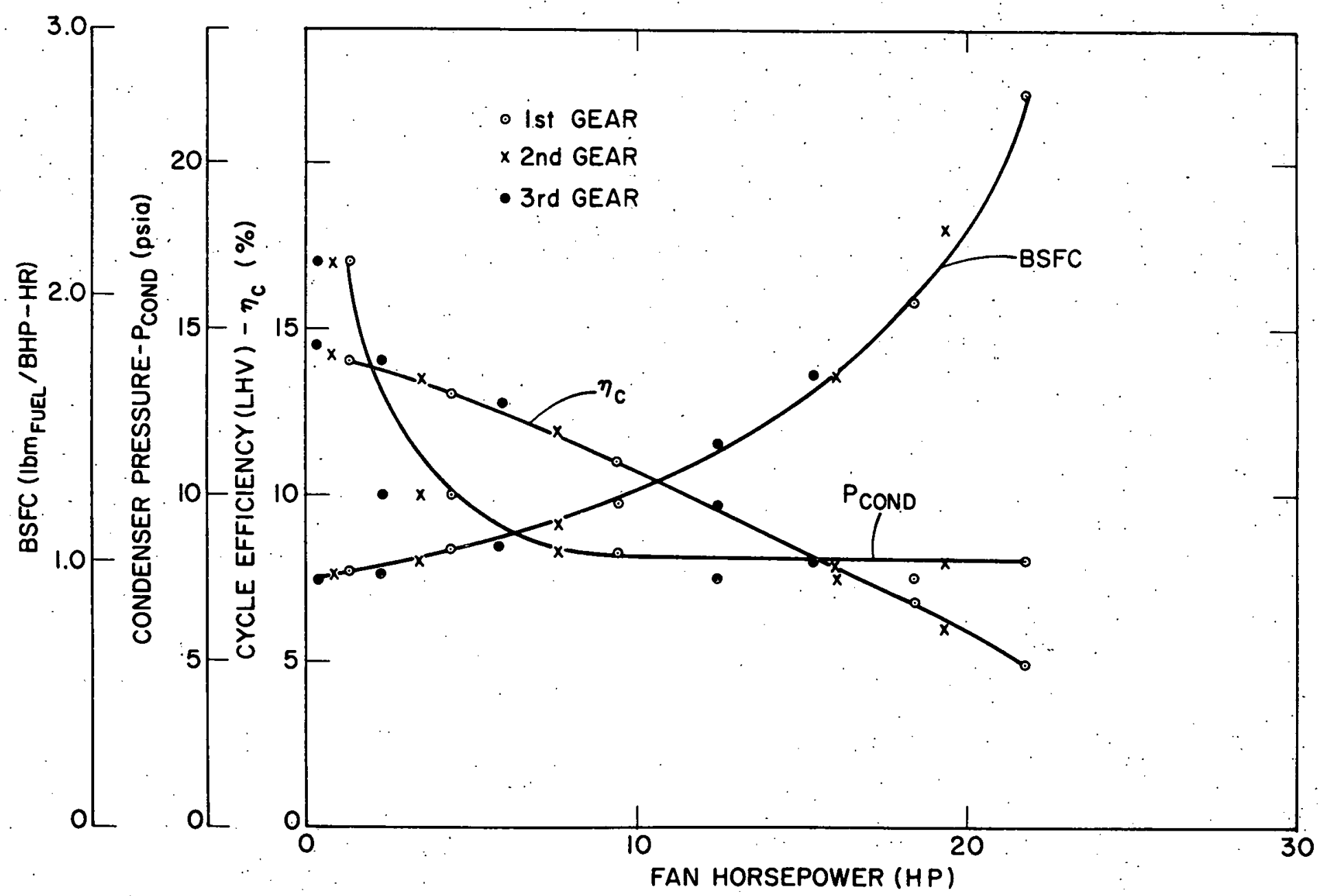

Figure 2.19 BSFC, Cycle Efficiency, and Condenser Pressure versus Fan Horsepower for Preprototype System ORL Tests 
each set of tests a maximum performance point was established (BSFC and cycle efficiency) at a particular fan horsepower. A maximum performance condition is the reby defined for each firing rate and expander speed for the required pressure and temperature operating conditions of the system. BSFC can then be related to system power at various expander speed levels for each gear. These relationships are shown for gears 1,2, and 3 in Figures $2.20,2.21$, and 2. 22 , respectively. The best $B S F C$ for the system, achieved in the se ORL characterization tests, was 0.87 (lbm/bhp-hr) at a speed of $800 \mathrm{rpm}$ in third gear. The BSFC based on the gross expander power for this run was 0.7.5. The BSFC over the normal operating range of the system falls generally between 0.90 and $1.0(\mathrm{lb} / \mathrm{bhp}-\mathrm{hr})$.

The BSFC in the preceding was based on system power. The BSFC, when based on expander power before various parasitic loads are considered, is understandably lower. Figure 2.23 shows fuel consumption as a function of both system and expander brake power for the preprototype system road load baseline data of January and February 1974. This same data are presented in Figure 2. 24 as a function of vehicle speed.

A complete characterization map of system efficiency versus expander speed was not obtained because, although many data points were run and evaluated, it would have been necessary to test the system over the same operating cycle in much finer increments of firing rate and expander speed. This would have meant many more test points, and time did not permit running the system in this manner. However, a limited map of the expander power as a function of fuel flow and expander speed is shown in Figure 2.25. This map was 


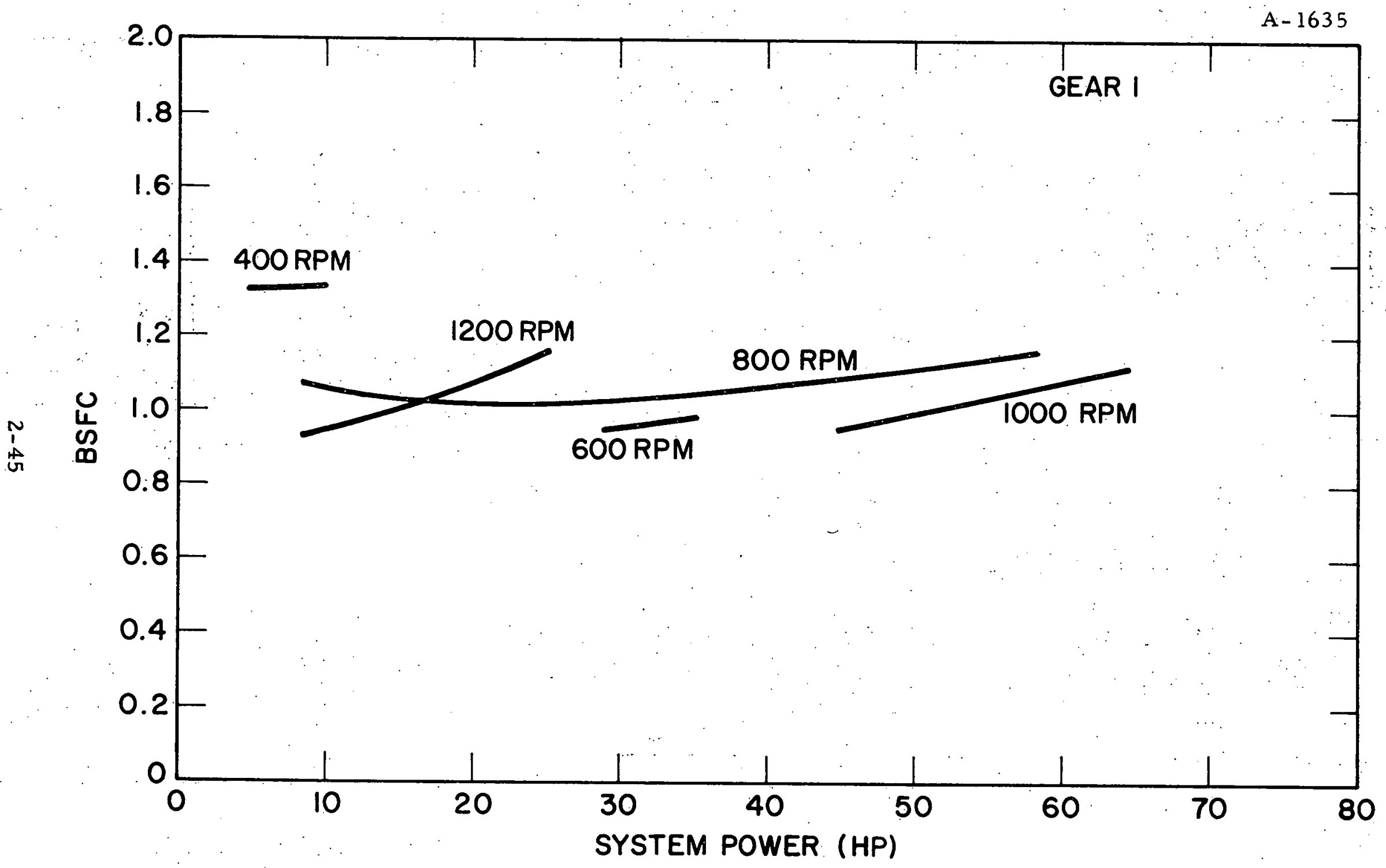

Figure 2.20 BSFC Versus System Power - lst Gear 


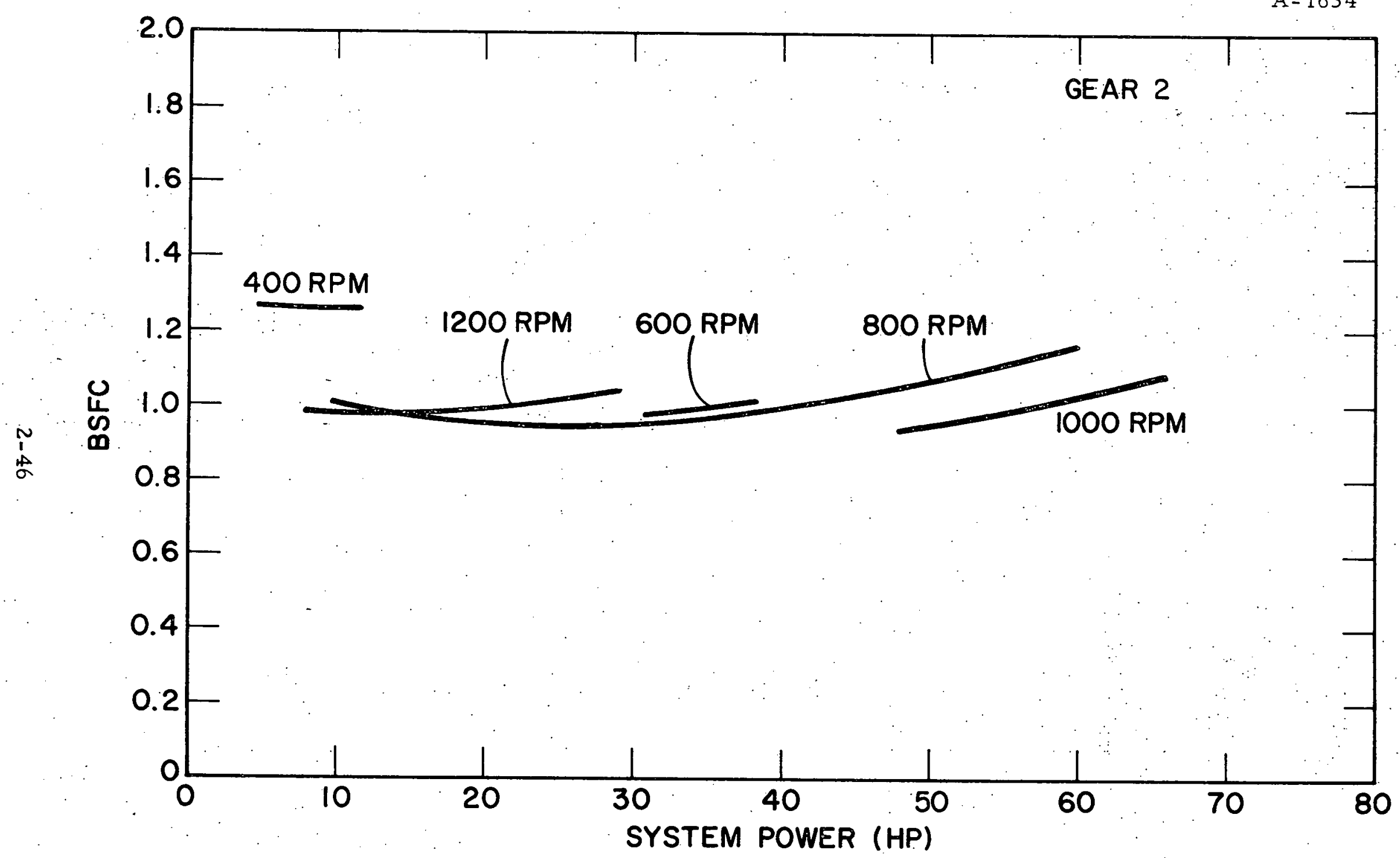

Figure 2.21 BSFC Versus System Power - 2nd Gear 


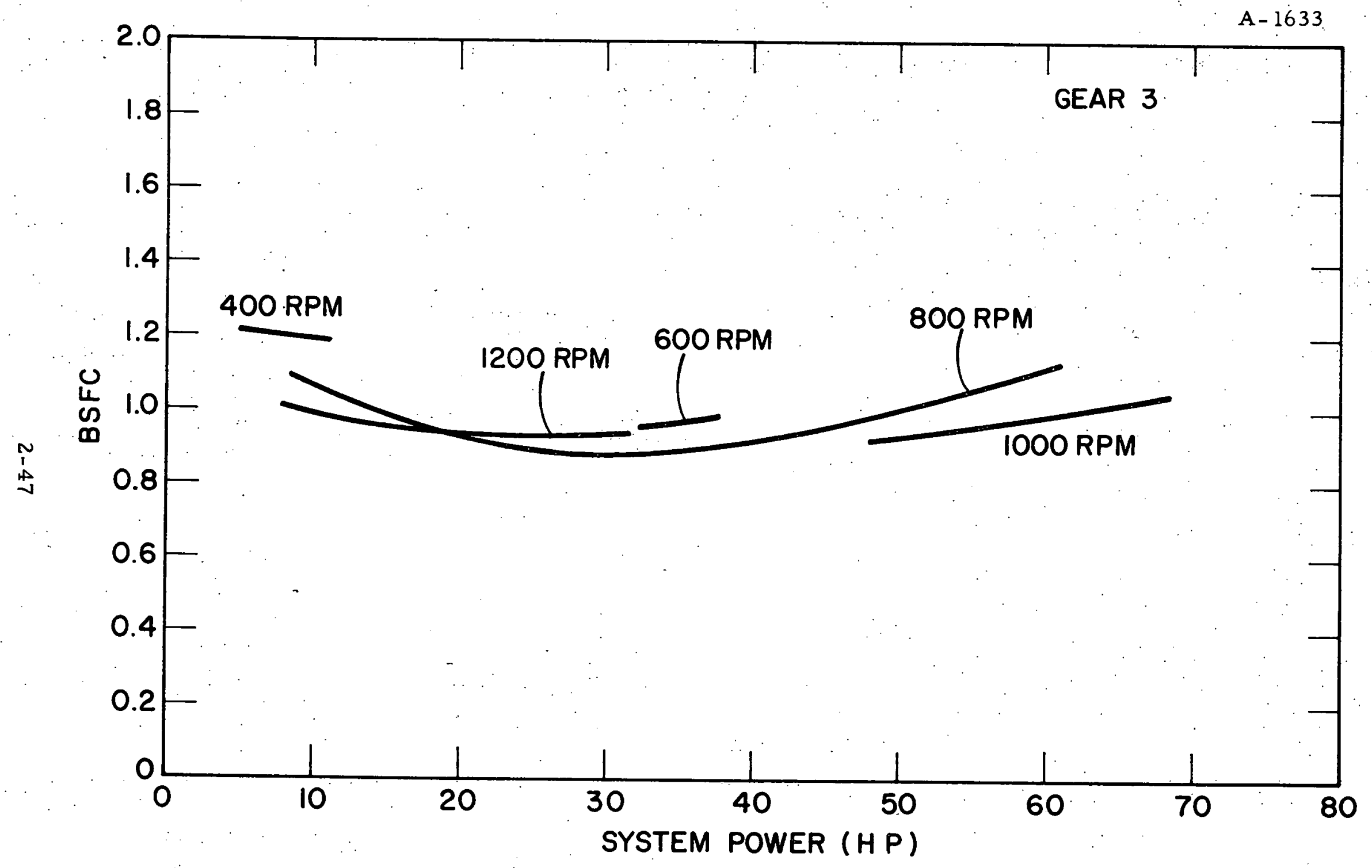

Figure 2.22. BSFC Versus System Power - 3rd Gear 


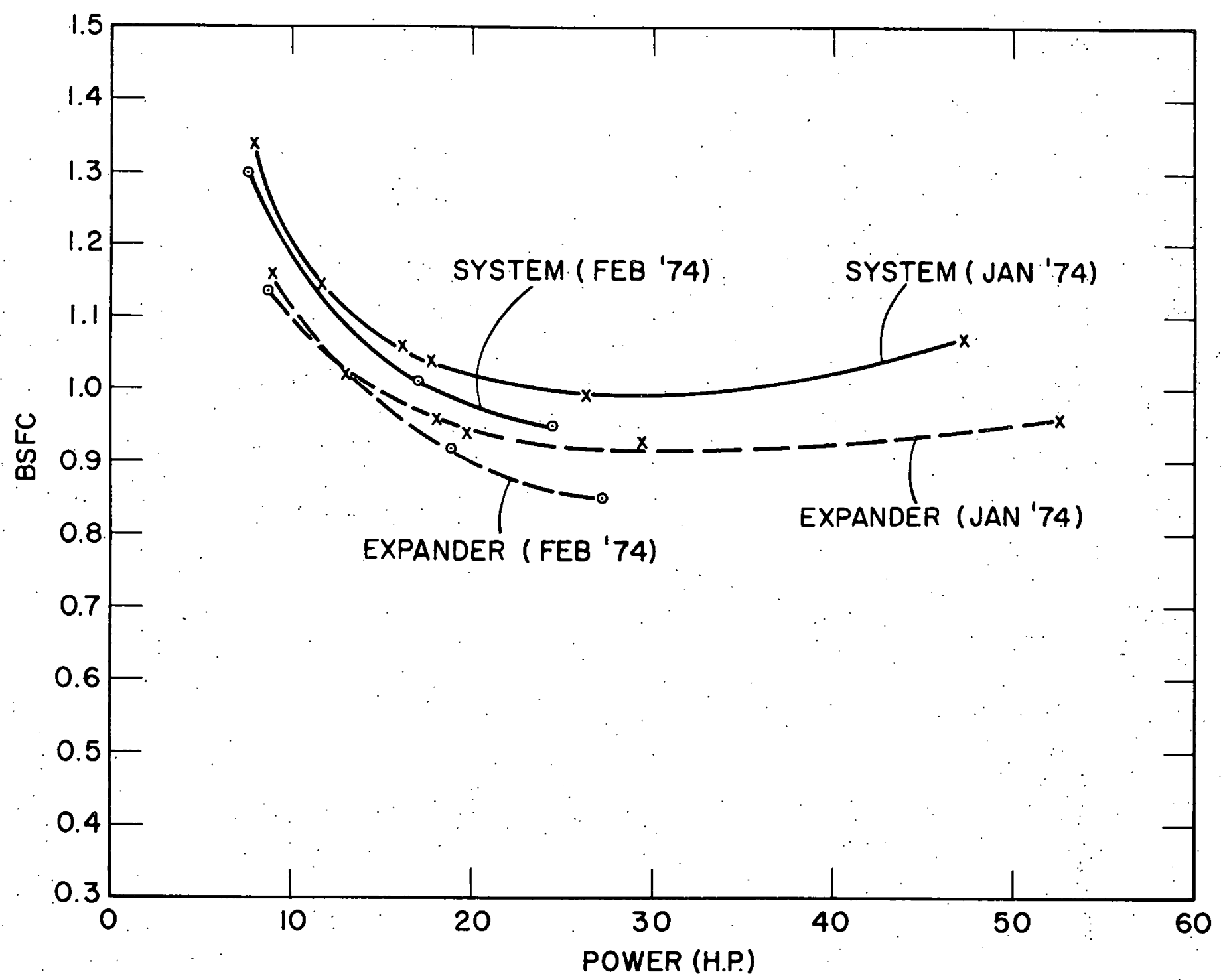

Figure 2.23 Road Load BSFC versus System Power for Preprototype System 


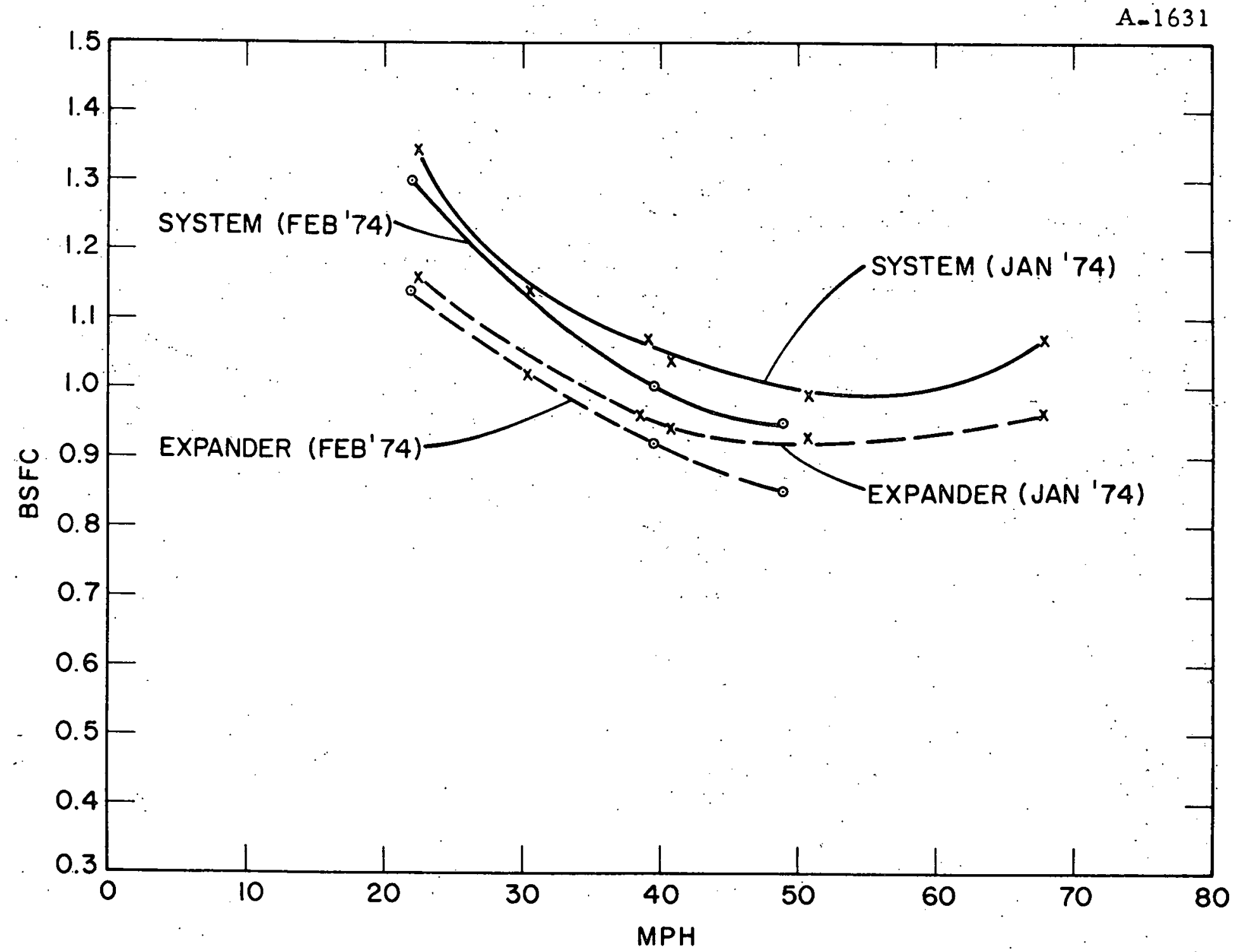

Figure 2.24 Road Load Fuel Consumption versus Vehicle Speed for the Preprototype System 
A-1616

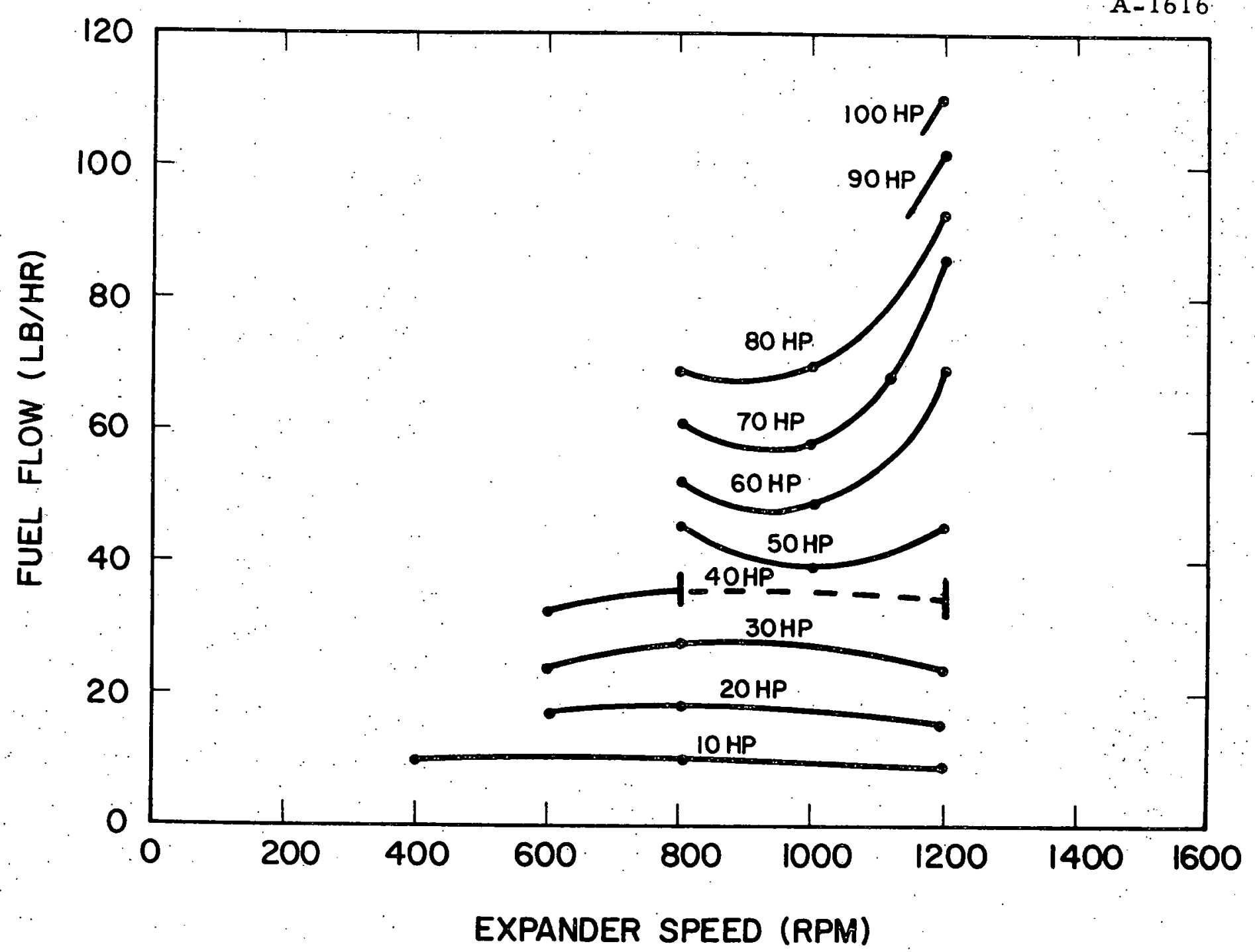

Figure 2.25 Preprototype Expander Map 
made by plotting the data and then cross-plotting even increments of power. An attempt was made to plot a map of BSFC for the system using Figure 2.25, but it could not be done due to insufficient data. It should be noted that it was not possible to separate condenser pressure as a variable; so the data represent various condenser pressures and, consequently, has some scatter.

\subsubsection{Emission Results}

Although transient emission testing of the preprototype system over the federal driving cycle was not included in this program, some estimates of the expected emission levels of the system were made based on computer calculations using steady-state emission measurements.

The driving-cycle fuel economy based on steady-state fuel economy measurements was projected to be $10.2 \mathrm{mpg}$. Measurements were also taken of the various pollutant levels (parts per million) corresponding to the fuel firing rates expected over the federal driving cycle. The steady-state emission measurements were used as an input to a computer program to project emission levels over the federal driving cycle used by the EPA. The emission levels appearing below include 30 seconds firing at $56 \mathrm{lb} / \mathrm{hr}$ for startup simulation, and show pollution levels well below the 1970 Clean Air Act federal standards.

\section{STEADY-STATE EMISSION MEASUREMENTS}

\section{Clean Air Act}

Pollutant Federal Standard

$$
\text { (grams/mile) }
$$

Emissions (grams $/ \mathrm{mile}$ )

UHC

0.41

3.40

0.40

0.17

0.21

0.275 


\subsubsection{Future Fuel Economy Improvements}

A study was performed with the objective of increasing the fuel economy of the preprototype system. Some of the changes (described in previous sections) did not require extensive hardware modifications so they were implemented in the system. There were also some improvements that were not included because they were considered to be beyond the scope of this program. They are discussed in the following sections, and their impact on the fuel economy is estimated.

\subsubsection{Auxiliary and Accessory Optimization}

Auxiliaries and accessories require $34.4 \mathrm{hp}$ at the design point, which represents 23.6 percent of the design point expander power output $(145.5 \mathrm{hp})$. Since this is a sizable fraction of the expander output, an attempt was made to determine the extent of improvement that could be realized in the fuel economy of the system by improving various auxiliaries and accessories, thereby reducing the parasitic power requirements. The following components were investigated:

- Feedpump

- Condenser Fans

- Boost Pump

- Combustion Blower

a. Feedpump

The main feedpump is a radial, seven-cylinder, reciprocating piston pump. The pump is directly driven by the expander and is integrated with the expander. Since at any speed the required system pumping rate can vary from zero to a maximum of about $16 \mathrm{gpm}$, depending on the intake valving cutoff point (or system power output), the pump has variable displacement to minimize the feedpump power 
requirement at part-load conditions. An important development goal was maintaining high pump efficiency over a wide speed and pumping rate range. The overall pump efficiency at maximum flow rate varied from 85 percent at low speeds to 72 percent at the highest pump speed of $1800 \mathrm{rpm}$. Further improvement will be slight since the maximum possible improvement in the fuel economy that can be realized with an ideal 100-percent efficient pump is 2 to 2.5 percent. The following modifications to the pump would reduce losses and improve fuel consumption by 0.8 percent:

- Reduction of frictional losses

- Streamlining of flow passages

- Decrease in valve weight

- Reduction of valve cracking pressure

b. Condenser Fans

The condenser fans represent the largest parasitic power loss from the system at high power levels. At the design point, the condenser fans require $13.57 \mathrm{hp}$, which represents 9.32 percent of the expander power.

A gain in fuel economy by increasing the efficiency of the fans is not very probable; however, since the design point total efficiency is already 70 percent, reoptimization of the fan control may lead to some slight savings in the fuel economy $(0.3$ percent over the federal driving cycle and 1 percent at the design point).

\section{c. Boost Pump}

The current boost pump is electrically driven through a magnetic coupling to provide a hermetic pump. The boost pump motor has an 
efficiency of 50 percent; whereas the pump has an efficiency of 56 percent. The motor efficiency can be increased from 50 to 90 percent using a specially fabricated"electric motor. The use of a high-efficiency motor results in an improvement in fuel economy of 1.6 percent of the federal driving cycle. The improvement at design point, however, is only 0.2 percent. The improvement in fuel economy is small because the boost pump is not required below road load speeds of $50 \mathrm{mph}$.

\section{d. Combustion Blower}

The present combustion blower is motor driven and uses a commercially avallable impeller with a vaneless radial diffuser. The total efficiency of the blower at the maximum flow condition is 50 percent. The combustion blower at design point delivers $788 \mathrm{cfm}$ at 10 in. water column (WC) static pressure rise corresponding to an ideal power of $1.24 \mathrm{hp}$.

The use of the high-efficlency combustion blower results in a 0.65 -percent improvement in fuel economy at the design point and a 0.7 -percent improvement over the federal driving cycle. Another advantage is the reduction in blower motor size from 2.48 to $1.77 \mathrm{hp}$.

\section{e. Summary - Auxiliary and Accessory Optimization}

A summary of the improvements possible in reducing the parasitic power requirements is shown in Table 2.9." Included in the table is the impact on fuel economy, both over the federal driving cycle and the design point. Also shown is the impact on packaging of the various improvements. 
TABLE 2.9

REDUCTION IN PARASITIC POWER - SUMMARY

A-1589

\begin{tabular}{|l|c|c|c|}
\hline \multirow{2}{*}{\begin{tabular}{c} 
Reason \\
\cline { 2 - 4 }
\end{tabular}} & $\begin{array}{c}\text { Improvement in Fuel Economy, \% } \\
\text { Cycle }\end{array}$ & $\begin{array}{c}\text { Packaging } \\
\text { Impact }\end{array}$ \\
\cline { 2 - 5 } $\begin{array}{l}\text { Improved Feedpump } \\
\text { Efficiency }\end{array}$ & 0.8 & 0.6 & Nesign Point \\
$\begin{array}{l}\text { Improved Condenser } \\
\text { Fan Efficiency }\end{array}$ & 0.3 & 1.0 & Nil \\
$\begin{array}{l}\text { Improved Boost Pump } \\
\text { Operation and } \\
\text { Efficiency }\end{array}$ & 1.6 & 0.2 & Better \\
$\begin{array}{l}\text { High Efficiency } \\
\text { Combustion Blower }\end{array}$ & 0.7 & 0.65 & Packaged \\
\hline
\end{tabular}




\subsubsection{Alternative Drives for Auxiliaries and Accessories}

The current preprototype system uses a conventional, three-speed transmission, which permits the expander to idle at zero vehicle speed. All accessory and auxiliary components are directly driven by the propulsion expander as indicated in Figure 2.26. Although many different means can be considered for driving the auxiliaries and accessories, four alternative means of driving the system auxiliaries and the vehicle accessories were considered.

\section{a. Alternative A - Auxiliary Expander}

In this approach, a separate and smaller reciprocating or turbine expander is used to drive all auxiliaries and accessories. The only auxiliaries driven electrically are the startup cranking motor and the system electric controls. Since the cranking motor is used only on startup and the system electric controls represent a very small power drain, the alternator load is primarily that required for operation of the vehicle accessories such as lights and radio. Even the blower for heating/cooling of the passenger compartment can be driven directly from the auxiliary power unit. This approach would have two advantages; first, it would eliminate the use of electric motors and, second, it would drive the hydraulic pumps, such as the power steering pump, at a constant speed.

\section{b. Alternative B - Constant-Speed Accessory Drive}

In this scheme, the accessories are driven at a constant speed by using a variable-speed drive between the expander and the accessories. Since the fans are driven already by a variable-speed drive, the main advantage of this alternative would be the ability to drive the 


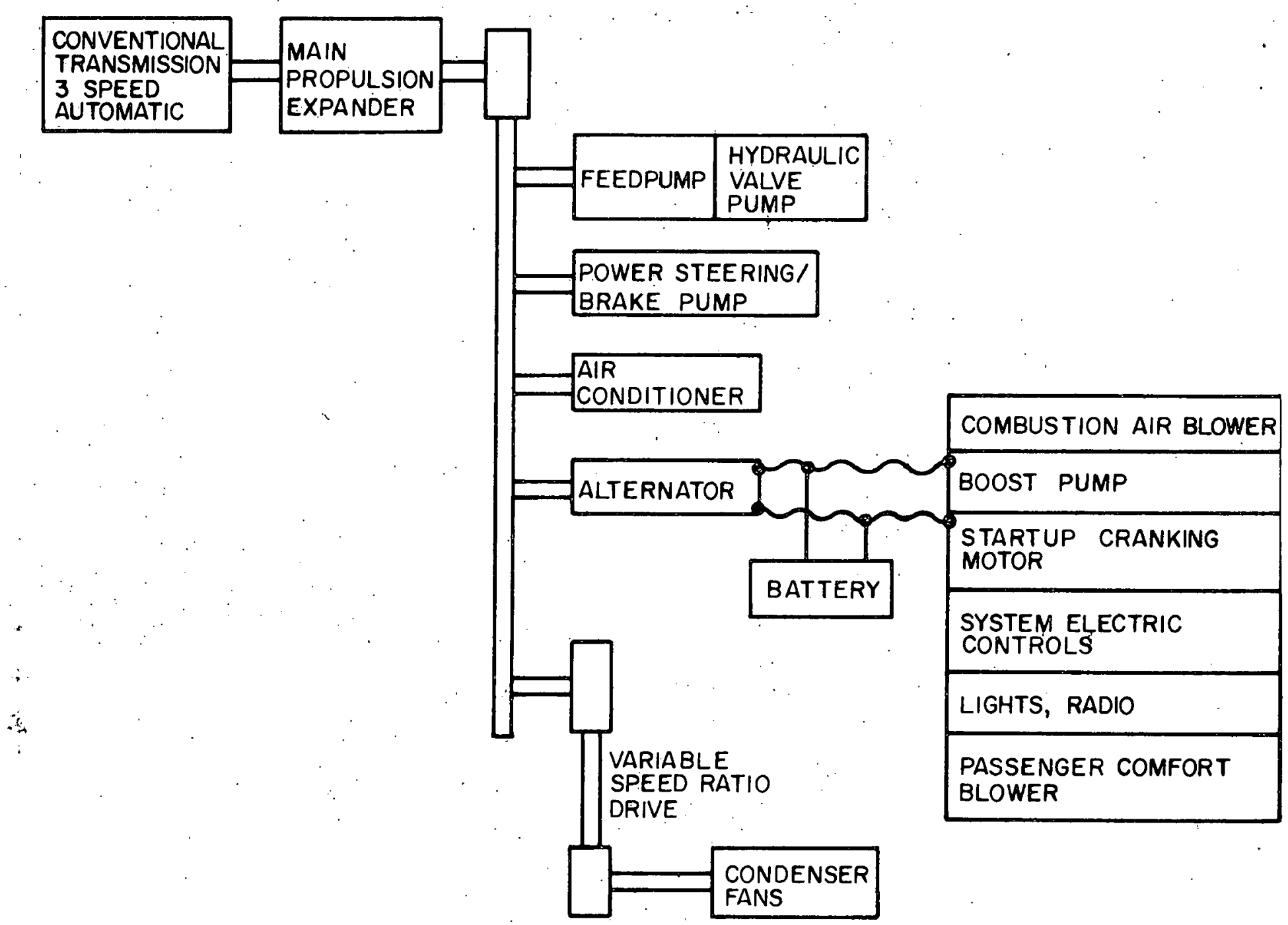

Figure 2.26 Current Approach for Driving Auxiliaries and Accessories 
alternator, power steering pump, and air-conditioning compressor at a constant speed.

\section{c. Alternative C - Auxiliary Turbine}

At very. low power levels, almost complete expansion ts obtained in the expander; however, at intermediate and high power levels, incomplete expansion occurs in the expander. A turbine operating on the reciprocating expander exhaust to drive the condenser fans can be used to recover some of this lost expansion work. This would be a suitable match since, under high power operation, when the condenser fan power is highest, the shaft output from the auxiliary turbine expander would also be the highest.

\section{d. Alternative D - Small Auxiliary Expander}

This is a variation of Alternative $A$ that reduces the peak auxiliary expander power requirements to approximately $20 \mathrm{hp}$. Instead of driving all the auxiliaries and accessories as with Alternative $A$, this scheme would drive the boost pump, alternator, power steering pump, air conditioning compressor, and condenser fans. The feedpump and hydraulic pump would be driven by the main expander. The combustion blower is electric-motor driven to reduce its power requirements at low system power levels and to simplify air ducting, blower drives, system controls, and system startup. The passenger comfort blower is also driven by an electric motor to simplify the drive system and air ducting.

\section{e. Conclusions - Alternative Drives}

All of the drive systems described would require extensive changes to the automotive installation in order to realize their potential advantages, and they are more complex then the current approach. None of 
these alternatives could be incorporated into the preprototype system under the time limits of the program. Alternative $C$, with the lower pressure exhaust turbine, has many interactions with the main expander and would complicate the controls and add a variable-speed drive. Most of the benefits would occur at high power on vehicle acceleration and not in the road load power range. Alternative $B$ requires the addition of a constant-speed drive and the redesign of many components, drive systems, and controls. Alternative D would appear to be the most promising alternative to the present system. However, a detailed systems analys is is required to determine whether fuel consumption would be improved as compared to the present approach over the federal driving cycle. Since these systems required extensive analysis and could not be incorporated within the time limits of this program, no further study or design efforts were devoted to the alternative drive systems.

\subsubsection{Transmission Optimization}

The transmission characteristics have a strong effect on both fuel economy and acceleration performance. The current system uses a conventional three-speed automatic transmission selected because of its off-the-shelf avallability and because its acceleration performance: meets the specifications. Relatively minor modifications to the transmission, such as changing gear ratios and shift points, provide some improvement in fuel economy at the expense of wide-open throttle (WOT) acceleration performance. Design of the current system was based more on meeting the acceleration performance specifications than on maximizing fuel economy. 
In reoptimizing for maximum fuel economy, more consideration was given to the federal driving cycle. The federal driving cycle was analyzed statistically to provide at least a qualitative indication of the improyement that might be expected. The analysis points out the areas where optimization of the accessory and auxiliary components should be concentrated by indicating where the highest percentages of fuel are consumed.

The statistical analysis was performed based on vehicle speed, acceleration, power, and intake ratio. The results of the analysis are shown in Table 2.10.

This statistical analysis indicates that the bulk of operation during the federal driving cycle is at low horsepower and low intake ratios. In order to minimize the low intake ratio operation, the expander speed at the same horsepower levels would have to be reduced. One way to accomplish this is to increase the engine stepup gear ratio (SHRA). The design value of the SHRA is 2.7. Increasing the SHRA to 3.0 (keeping the rear axle ratio constant at 3.5 ) yields an improvement in fuel economy of 1.1 percent over the federal driving cycle, as shown in the fourth column of Table 2.11. Reducing the SHRA to 2.5 resulted in a degradation of fuel economy. Changing the SHRA does not alter the torque converter efficiency over the federal driving cycle.

Another way to reduce the speed of the expander is by reducing the rear axle ratio (DSRA). However, this results in alteration of the speed ratio and torque ratio across the torque converter. As shown in Table 2.11, contrary to expectations, reducing DSRA from a baseline value of 3.5 to 3.0 resulted in 1 percent poorer fuel economy over the federal driving cycle. This is because the improvement in 
TABLE 2.10

FEDERAL DRIVING CYCLE FUEL CONSUMPTION ANALYSIS

\begin{tabular}{|l|c|c|}
\hline Variable & $\begin{array}{c}\text { High Fuel } \\
\text { Consumption Range }\end{array}$ & $\begin{array}{c}\text { Percent of Total } \\
\text { Fuel Consumed }\end{array}$ \\
\hline Vehicle Speed & $20-30 \mathrm{mph}$ & 40 \\
Acceleration & -5 to $1 \mathrm{mph} / \mathrm{sec}$ & 54 \\
Power & $20-30 \mathrm{hp}$ & 61 \\
Intake Ratio & $<0.025 *$ & 75 \\
\hline
\end{tabular}

* Intake ratio at full power is 0.325 . 
TABLE 2.11

COMPARISON OF VEHICLE PERFORMANCE AS A FUNCTION OF

REAR-AXLE RATIO AND ENGINE STEP-UP GEAR RATIO*

\begin{tabular}{|c|c|c|c|c|c|c|c|}
\hline & $\begin{array}{l}\text { SHRA }=2.7 \\
\text { DSRA }=3.5\end{array}$ & $\begin{array}{l}2.7 \\
3.0\end{array}$ & $\begin{array}{l}3.0 \\
4.0\end{array}$ & $\begin{array}{l}3.0 \\
3.5\end{array}$ & $\begin{array}{l}3.0 \\
3.0\end{array}$ & $\begin{array}{l}2.5 \\
4.0\end{array}$ & $\begin{array}{l}2.5 \\
3.5\end{array}$ \\
\hline $0-60 \mathrm{mph}(\mathrm{sec})$ & 12.815 & 13.31 & 12.7 & 13.21 & 13.77 & 12.43 & 12.7 \\
\hline $25-70 \mathrm{mph}(\mathrm{sec})$ & 15.117 & 15.56 & 15.14 & 15.41 & 15.9 & 14.75 & 15.0 \\
\hline $50-80 \mathrm{mph}(\mathrm{sec})$ & 15.957 & 16.17 & 15.86 & 16.38 & 16.49 & 15.3 & 15.78 \\
\hline $1400 \mathrm{ft}(\mathrm{sec})$ & 14.5 & 14.6 & 14.5 & 14.5 & 14.7 & 14.5 & 14.6 \\
\hline $30 \mathrm{mph}(\mathrm{m} / \mathrm{gal})$ & 20.48 & 20.0 & 20.98 & 21.0 & 20.4 & 19.85 & 20.01 \\
\hline $40 \mathrm{mph}(\mathrm{m} / \mathrm{gal})$ & 18.63 & 18.63 & 18.93 & 19.17 & 19.0 . & 17.88 & 18.21 \\
\hline $50 \mathrm{mph}(\mathrm{m} / \mathrm{gal})$ & 16.2 & 16.32 & 16.33 & 16.69 & 16.7 & 15.4 & 15.84 \\
\hline $60 \mathrm{mph}(\mathrm{m} / \mathrm{gal})$ & 13.67 & 13.8 & 13.62 & 14.07 & 13.99 & 12.845 & 13.35 \\
\hline $70 \mathrm{mph}(\mathrm{m} / \mathrm{gal})$ & 11.51 & 11.62 & 11.49 & 11.79 & 11.8 & 10.8 & 11.23 \\
\hline $80 \mathrm{mph}(\mathrm{m} / \mathrm{gal})$ & 9.59 & 9.64 & 9.53 & 9.83 & 9.66 & 8.85 & 9.42 \\
\hline $\begin{array}{l}\text { Federal Cycle } \\
\text { (m/gal) }\end{array}$ & 12. 3 & 12.17 & 12.52 & 12.44 & 12.27 & 12.18 & 12.16 \\
\hline$\%$ Improvement & -- & -1 & +1.8 & +1.1 & -0.2 & -1.0 & -1.1 \\
\hline
\end{tabular}

FL-85 with boiler outlet at 700 psia and $626^{\circ} \mathrm{F}$ was used in the above calculations.

SHRA Engine Step-up Gear Ratio - 2. 7 Design Value.

DSRA Rear-Axle Ratio - 3.5 Design Value. 
expander efficiency was nullified by deterioration in torque converter efficiency. A review of Table 2.11.indicates that the best fuel economy was obtained with SHRA $=3.0$ and DSRA $=4.0$. This combination yitelds a net efficiency improvement of 1.8 percent over the federal driving cycle.

\subsubsection{Effect of Two-Cylinder Expander Operation}

The system uses a V-4 reciprocating expander with hydraulically actuated valves. System power is controlled by varying the intake valve cutoff on all four cylinders. At very low power levels, the valve event is very short and full valve lift does not occur, resulting in throttling of the vapor to the cylinder. As the cutoff is increased, the valve lift increases, reducing throttling with an improvement in expander efficiency. Less efficient expansion occurs in the cylinder, however, as the cutoff is increased. For each speed, a cutoff (and expander power) exists at which the expander and engine efficiencies are maximized. For low power cycles, such as the federal driving cycle, the expander cutoff is generally less than that corresponding to the most efficient expander operation. A procedure that may improve the driving cycle fuel economy is to use only two of the four expander cylinders at low power levels so that a higher intake valve cutoff is used. A comparison of the fuel economy calculated for four- and two-cylinder operation indicates a 4 percent reduction in fuel consumption using two cylinders.

Use of two cylinders at low power levels is easily implemented with the American Bosch valving system, since the intake valves are electrically controlled. Implementation with the BICERI valving 
system will be considerably more difficult, since these valves are controlled by a rotating port in the hydraulic system. This approach requires that the efficiency improvement not be counterbalanced by compressor work in the two ldling cylinders. The compressor effect should be small due to both the low condenser pressure at low power operation and the partial recovery of the compression work in the expansion stroke.

\subsubsection{Evaluation of Air Preheating}

The design point efficiency of the current vapor generator, based on the higher heating value of the fuel, is 80.6 percent with the exhaust gas temperature at $600^{\circ} \mathrm{F}$. At 5 percent of firing rate, the efficiency rises to 88 percent with an exhaust gas temperature of $325^{\circ} \mathrm{F}$. The incoming combustion air is as sumed to be at $85^{\circ} \mathrm{F}$. Some of the waste. heat lost in the exhaust can be recovered by preheating the incoming air into the combustor. Use of an air preheater will result in direct improvement in fuel economy.

Two alternative methods were evaluated in conjunction with an air preheater:

a. Preheating combustion air by extracting heat from exhaust gases... The advantage of this method is that the blower is pumping denser air at the design point than Alternative 2, and the blower-motor size is smaller. However, the net improvement, especially at part load, is smaller due to the small $\Delta \mathrm{T}$ between the cold and hot side. 
b. Preheating with condenser exhaust air (at $130-190^{\circ} \mathrm{F}$ ). The blower induces condenser exhaust air through the cold side of the heat exchanger. The advantage of this scheme is that the system is taking advantage of the condenser reject heat; and the efficiency gain (especially at part-load conditions) is significantly higher. However, because the air is preheated, the pumping power requirements of the combustion blower are higher, and a larger combustion blower motor is required.

A comparison of two alternative schemes with a preheater is shown in Table 2.12. As shown, Alternative 2 is superior to Alternative 1, especlally at low firing rates, which is mostly the case for the federal driving cycle. Alternative 2 is also more compact than Alternative 1 as far as packaging is concerned. Alternative $l$ is more prone to leakage, since it has higher pressure air on the cold side and lower pressure exhaust gas on the hot side. Since Alternative 2 offers larger improvements in fuel economy and no leakage problems, it was selected as the prime approach, even though it calls for a larger motor. Incorporation of the air preheater would result in 9.73 percent improvement at design point and 3.50 percent over the federal driving cycle.

The effect of preheated air on emission characteristics, particularly $\mathrm{NO}_{x}$, would have to be studied in order to confirm the acceptability of using a preheater. 
TABLE 2. 12

COMPARISON OF PREHEATER SCHEMES

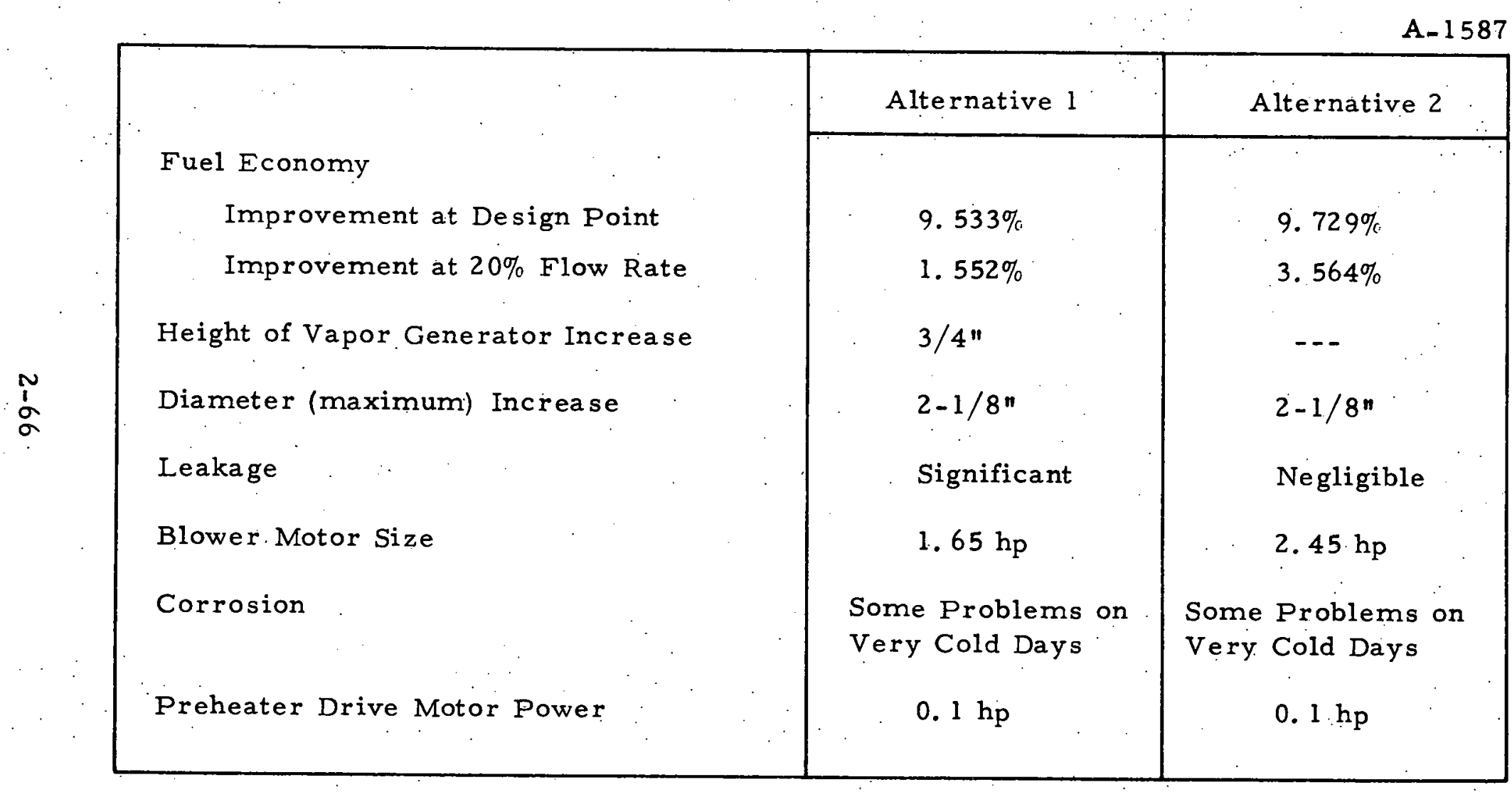




\section{COMPONENT DEVELOPMENT}

\subsection{INTRODUCTION.}

The Thermo Electron Rankine-cycle engine is a completely sealed system using an organic working fluid. Figure 2.1 is a schematic diagram of the engine. The major system components are the burner, vapor generator, expander, feedpump, condenser, and regenerator. A small additional component, the boost pump, is required to prevent cavitation of the main feedpump during conditions of low subcooling at the condenser outlet. Thermo Electron designed and developed the burner, vapor generator, expander, feedpump and condenser fan drive as well as fabricating and testing these items in component test facilities. The expander valving, the condenser and fans, the boost pump, and the regenerator were bullt to Thermo Electron's specifications by manufacturers of similar equipment.

\subsection{EXPANDER}

The following sections describe the V-4 and single-cylinder expander designs, including their mechanical development during the course of the program and a summary of their performance.

\subsubsection{Four-Cylinder Expander}

The basic design of the expander (number of cylinders, bore, stroke, type of valving; etc.) was determined during a previous contract and is described in Reference 3. The expander has 4 cylinders, arranged in a 90 degree $\mathrm{V}$, a 4.42-in. bore by 3.00-in. stroke, and is designed to use a hydraulically operated, variable cutoff intake valving system. The maximum design speed of the expander is $1800 \mathrm{rpm}$. 
The design layout of the expander is shown in Figures 3.1 through 3.4. The main cylinder block and cylinder head are cast iron, the crankshaft cast steel, the pistons are cast aluminum alloy, and the connecting rods are forged aluminum. Castings and forgings were obtained from local vendors, except for the pistons, which were purchased from Jahn's Company. Later in the program, pistons were made from bar stock at Thermo Electron.'

Needle bearings and caged rolle $r$ bearings were used throughout the expander. These were sized for a life of approximately 1500 hours, based on an expander speed and load equivalent to a vehicle speed of $60 \mathrm{mph}$. The crankshaft bearings, both main and connectingrod big end, were split for Thermo Electron by the supplier, the Torrington Company. Lubrication is by pressure spray at various locations in the crankcase through the use of a gear pump.

A drive is taken off the front of the expander for the condenser fans and other accessorles (see Figure 3.3). This eliminated the complexity of running a drive shaft from the back to the front of the expander at the expense of an additional shaft seal at the front of the crankshaft. The timer for the intake valve is driven off the front of the gear case as shown in Figure 3.3. For reasons of compactness, a one-inch reduction in the length of the expander was achieved by tightening clearances and reducing radii on the crankshaft, connecting rod, and main bearing assemblies. The oil reservoir for the valving system would ultimately be part of the cylinder block casting, but it was removed in the final preprototype design for reasons of flexibility in testing. Bolt-on cross braces were added to the crankcase after excessive deflections were discovered during hydrostatic testing. 


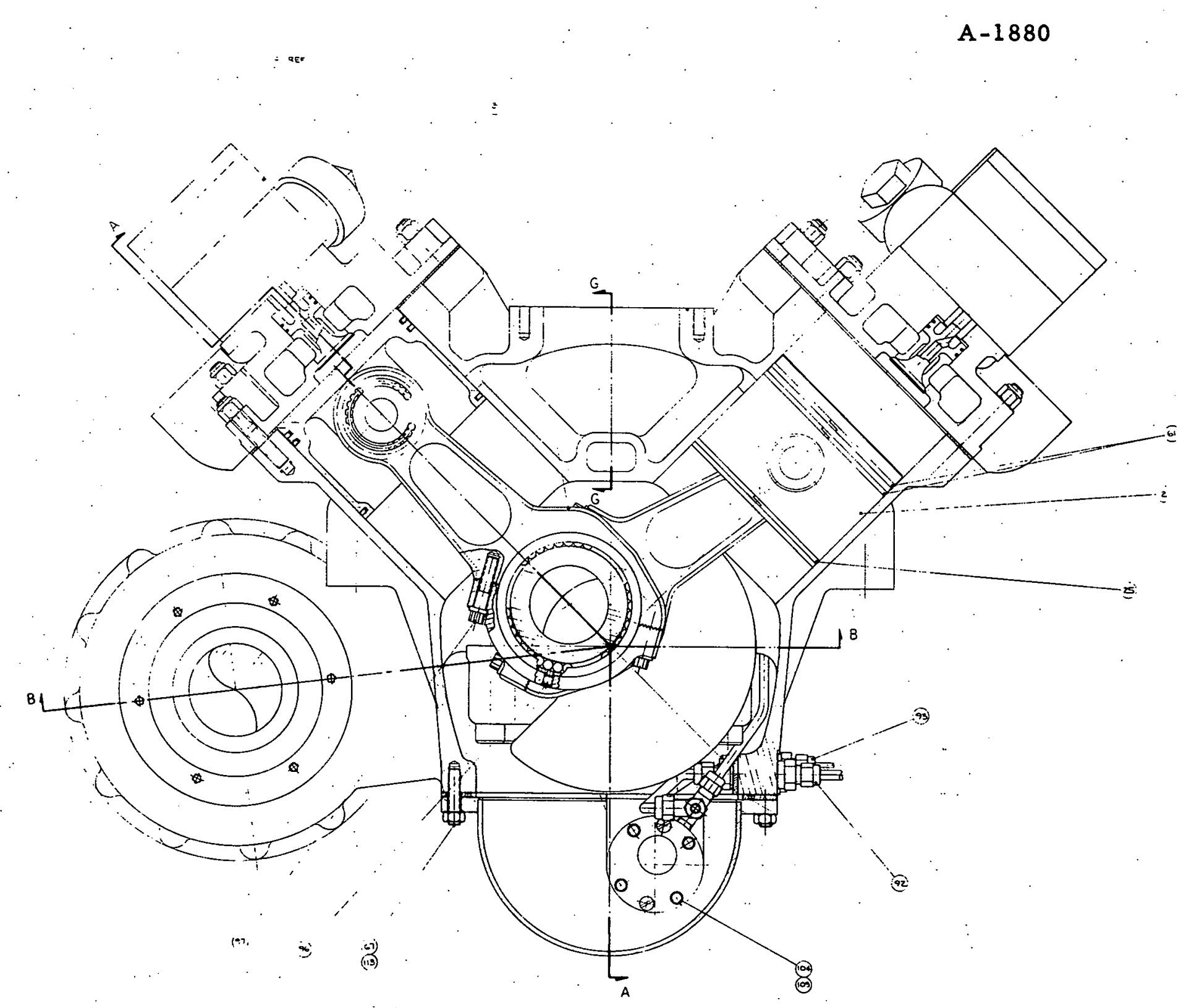

Figure 3.1 End Cross-Sectional Vlew - Expander 


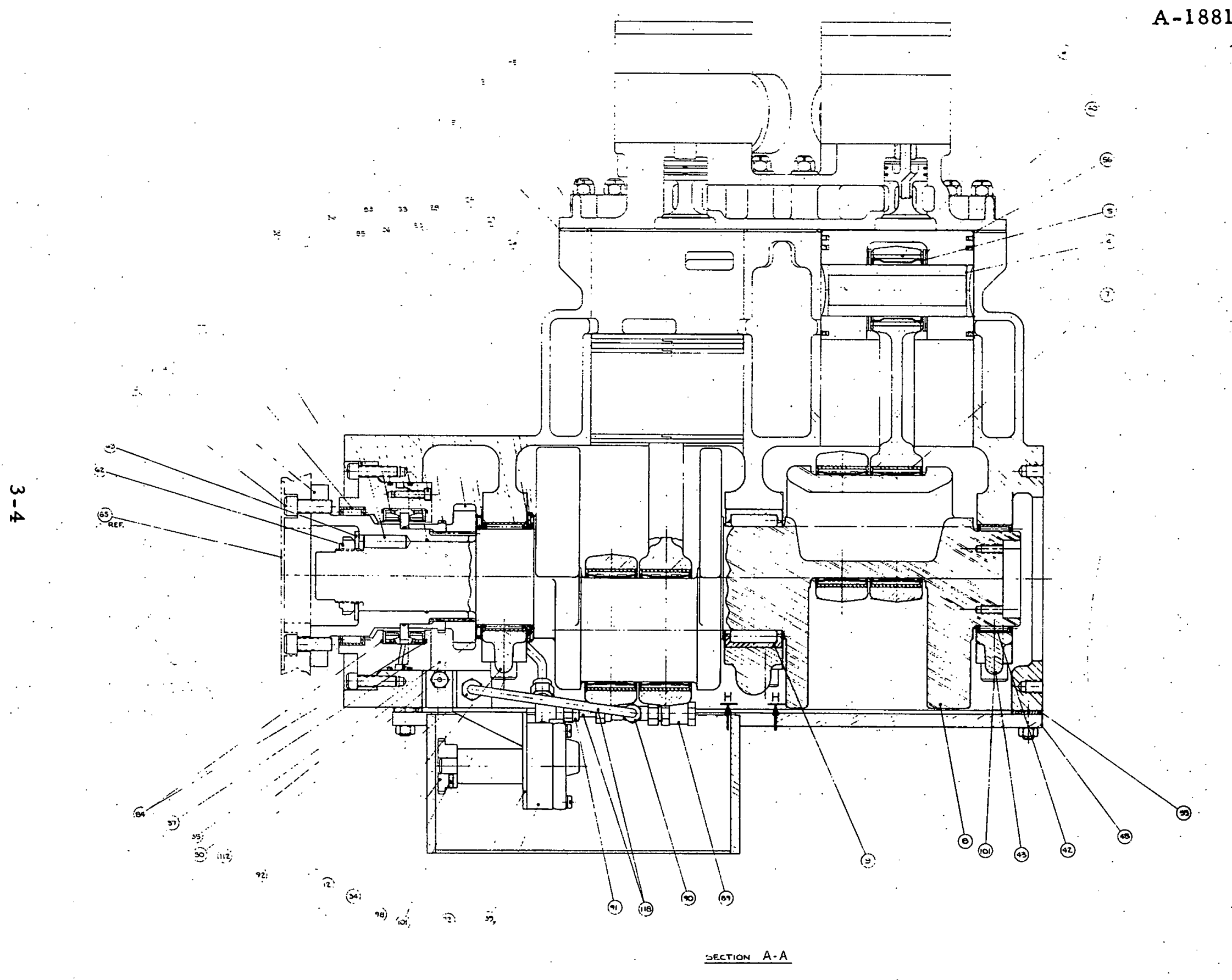

Figure 3.2 Side Cross-Sectional View - Expander 


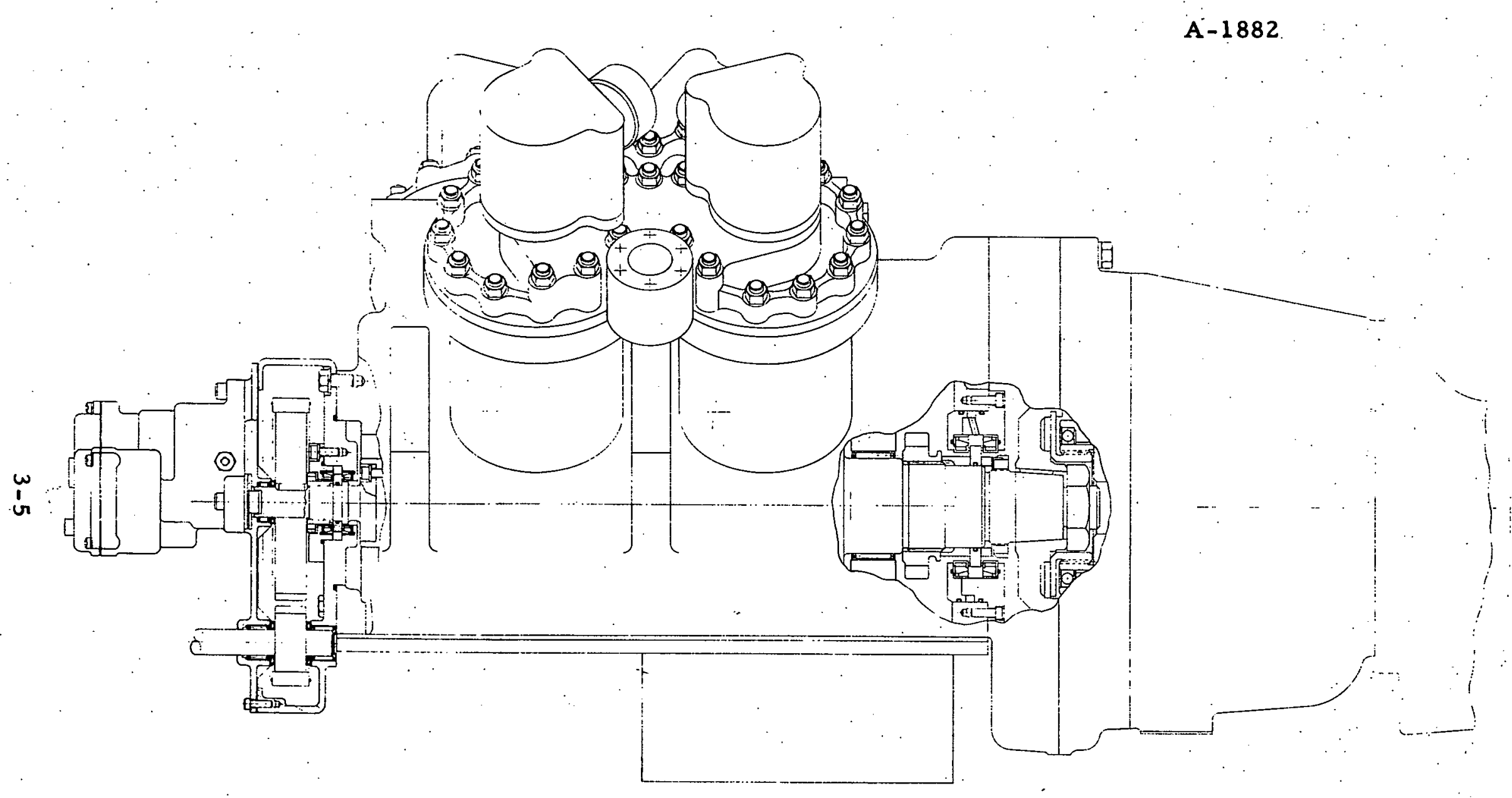

Figure 3:3a Expander Power Train - Side View 
$A-1883$

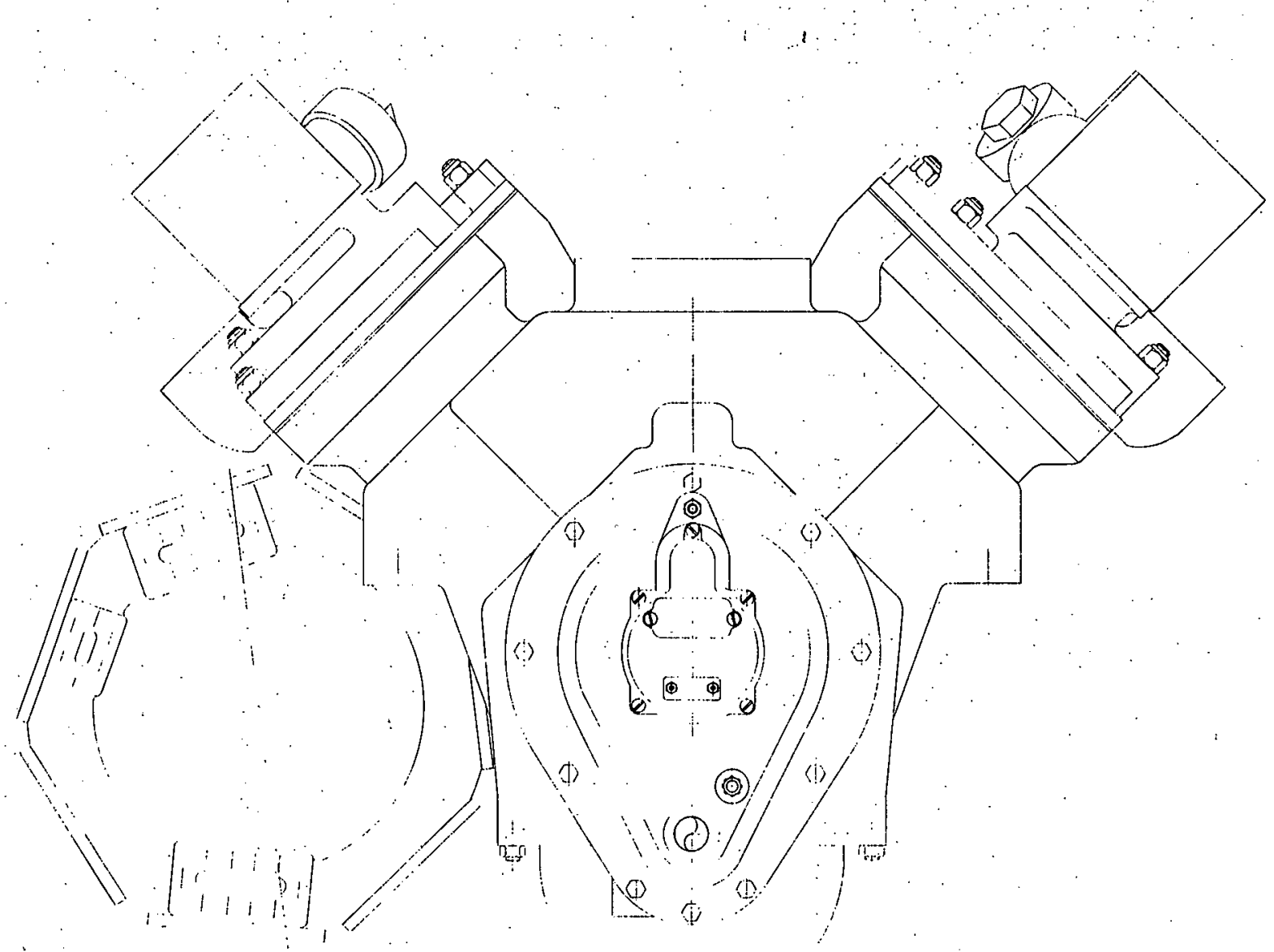

Figure 3.3b Expander Power Train - End View 


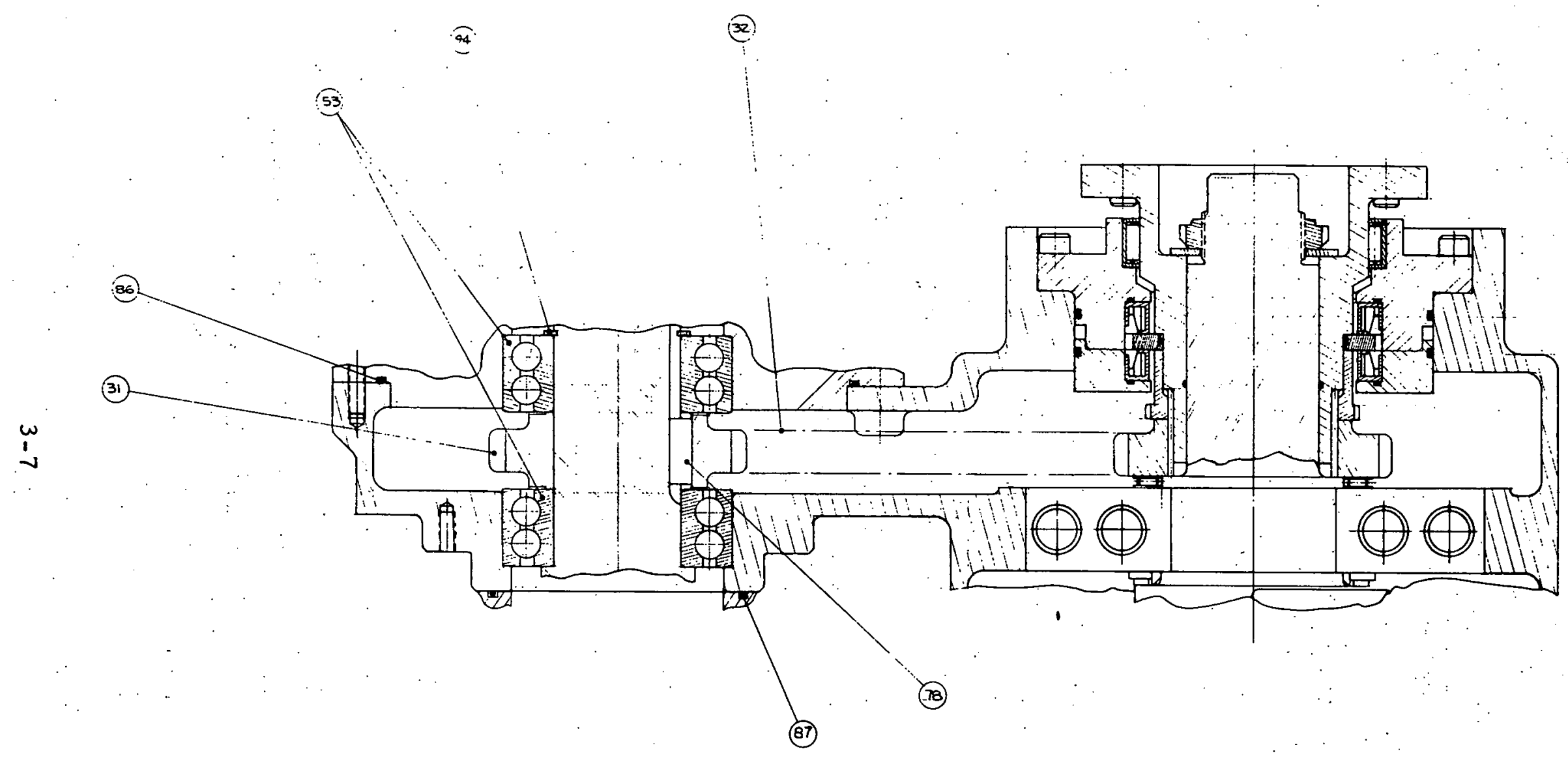

SECTION B-B

Figure 3.4 Cross-Sectional View of Expander Auxiliary Drive Unit 
The cylinder heads are designed to minimize the area exposed to the high pressure vapor and to provide good flow area around the intake valve. Figure 3.4 shows the feedpump and hydraulic valve pump drive. A Bendix pressure-compensated variable-displacement piston pump was used for all testing with the American Bosch intake valving system.

Figures 3.5 and 3.6 show the expander cylinder block and most of the internal parts.

A number of changes in the design of the expander.were made during the program. The most significant was the change from the American Bosch intake-valving system to the BICERI system. These systems and the reasons. for the change are discussed in Section 3.2.3. Figure 3.7 shows the expander cylinder heads with BICERI valving installed. Note the lower profile as compared to Figure 3,.1 which shows the expander with the American Bosch valving.

The detall changes to the piston, rings and the eventual elimination of the auxiliary exhaust ports occurred during testing of the singlecylinder expander and will be discussed in detail in the following section.

Compression relief valyes were added to the V-4 cylinder heads and were located on the bottom side of the cylinders, where liquid had a tendency to collect, particularly during startup. These relief valves are shown in Figure 3.7.

Most of the mechanical problems that resulted. in design changes showed up on the single cylinder expander and will be discussed in Section 3.2.2. The change from the American Bosch intake-valving system to the BICERI system required a redesign of the cylinder 


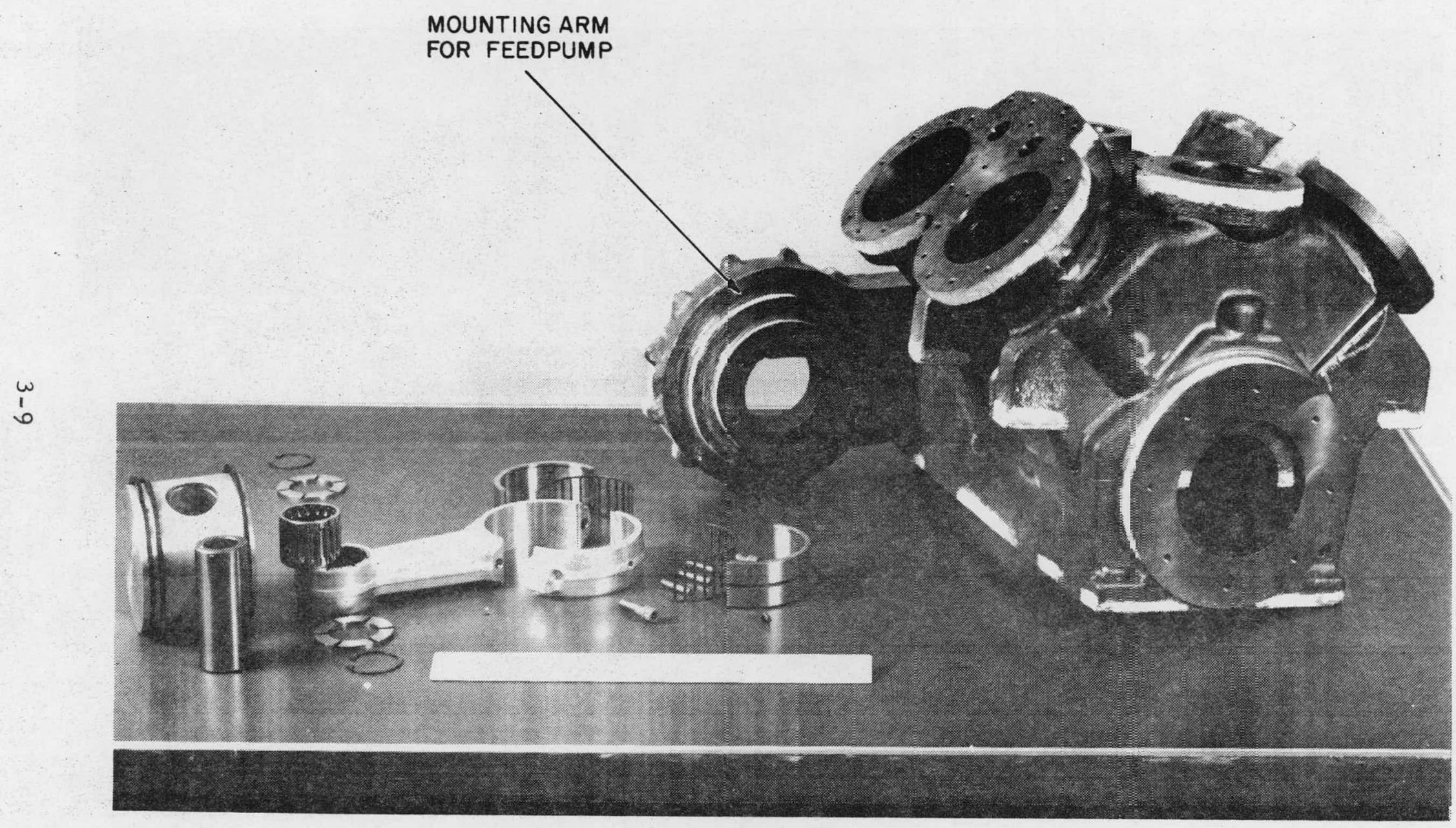

Figure 3.5 Four-Cylinder Expander Block and Piston-Connecting Rod Parts 


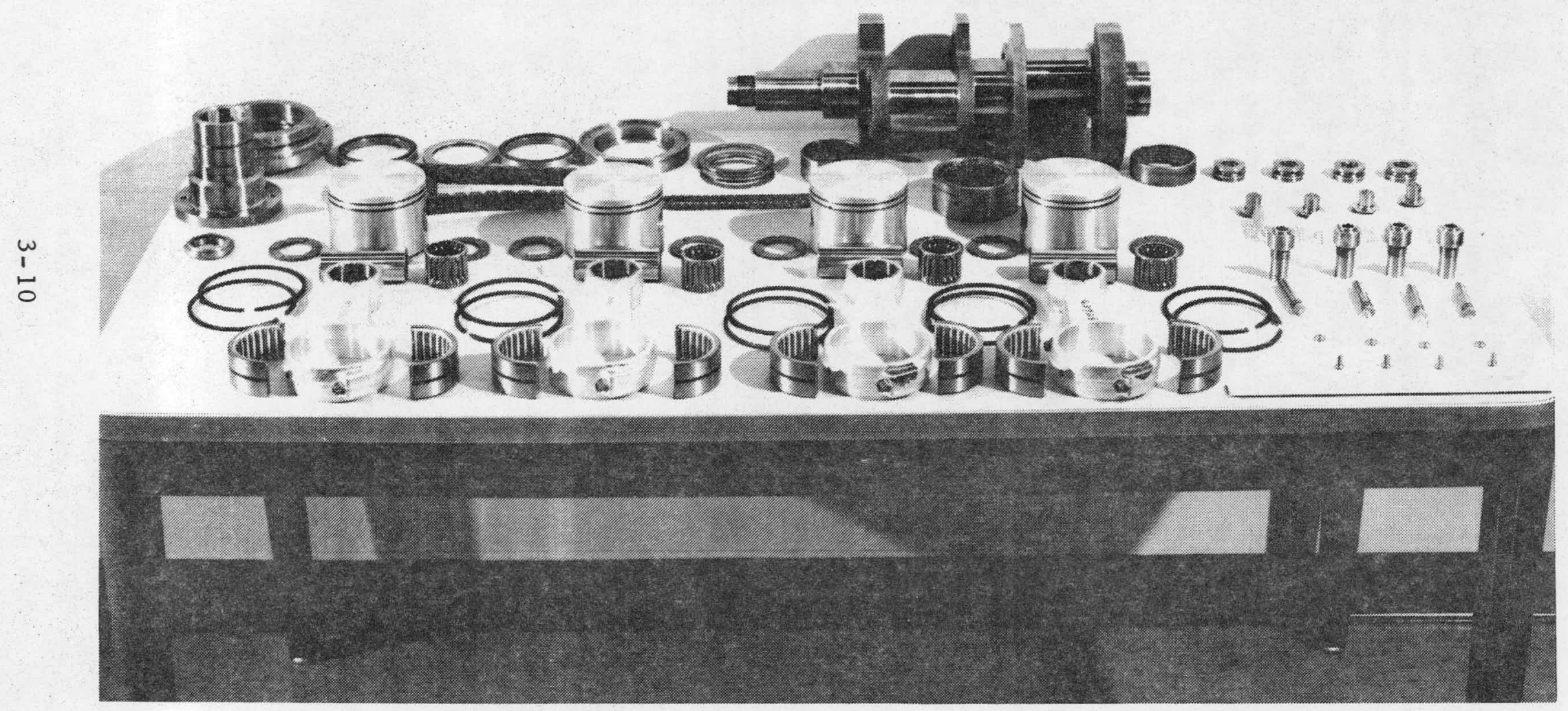

Figure 3.6 Internal Parts for Four-Cylinder Expander 


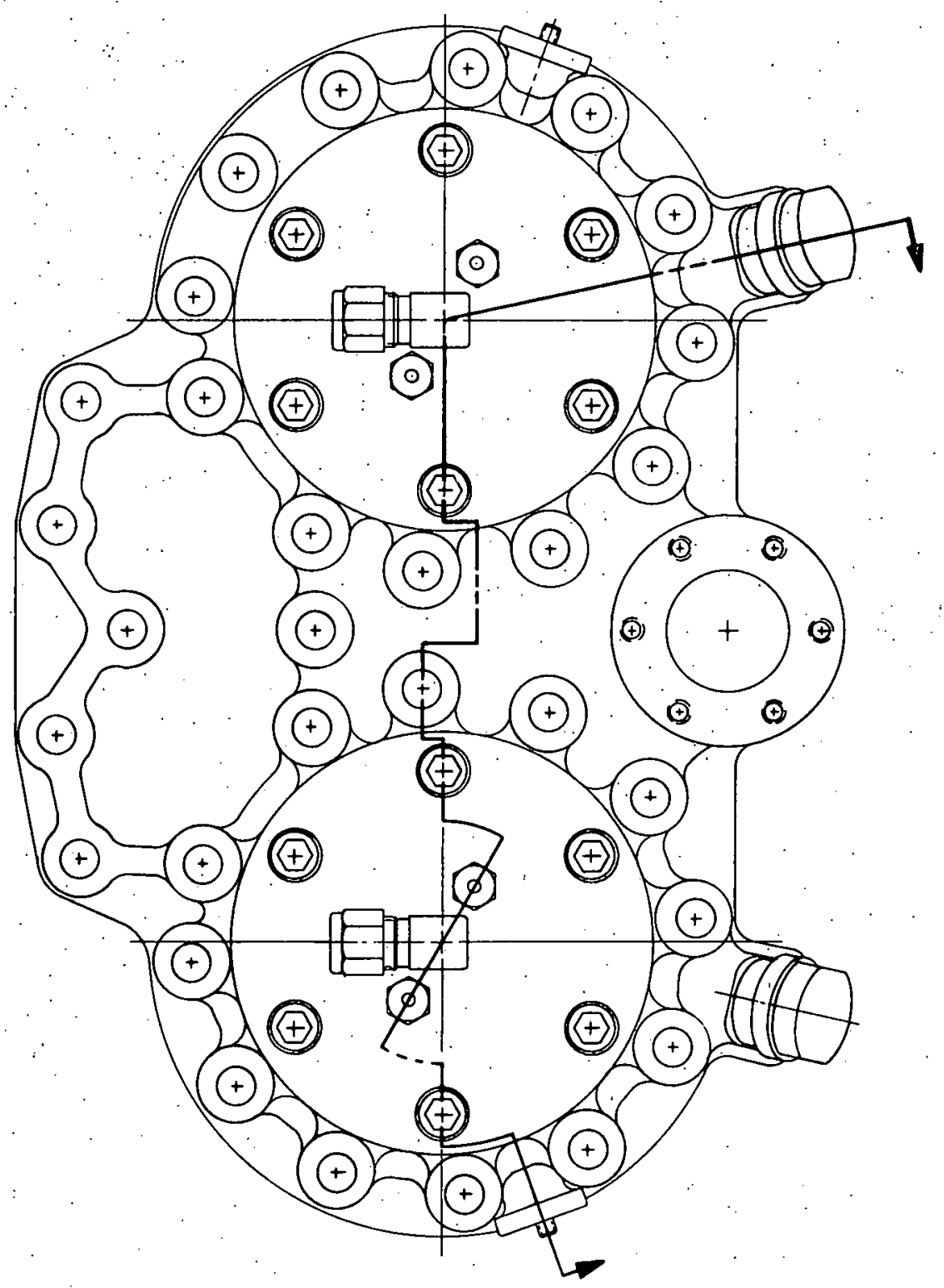

Figure 3.7a BICERI Cylinder Head with Recompression Valves - Front View 


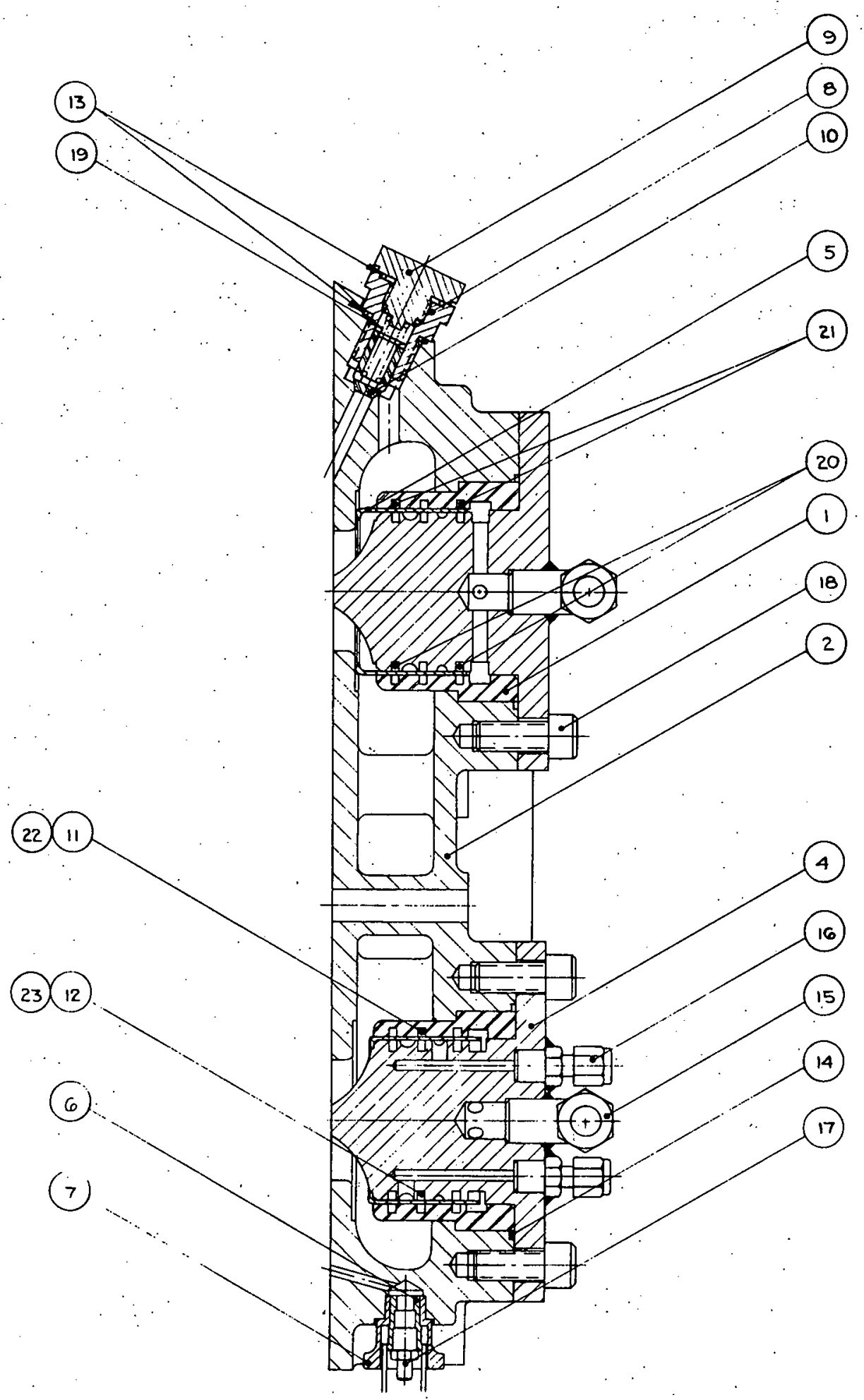

Figure 3.7b BICERI Cylinder Head with Recompression Valves - Side Cross-Sectional View 
head and provision of a drive system for the BICERI distributor. These changes are discussed in detail in Section 3.2.3. During one of the early runs, a fracture occurred on one bank of a V-4 expander block, about on the plane of the lower exhaust ports. A metallurgical investigation revealed a coarse-grained structure in the area of the failure. It is also worth noting that this particular expander was the only one bored out to accept cylinder sleeves, and therefore the casting thickness at the point of fracture was about $0.032 \mathrm{in}$. thinner than normal. While a single source of the failure could not be determined, it was felt that the combination of the coarse-grain structure and the thinner wall section caused the failure. Hydrolocking also had occurred during early attempts to start this expander and may have contributed to the failure.

This problem did not occur in any of the other V-4 expanders.

\subsubsection{Single-Cylinder Expander}

A single-cylinder test expander was constructed because it provides greater flexibility than a multicylinder expander during development work. Performance measurements are more readily made, it is easier to isolate expander difficulties which result in poor performance and/or mechanical failure, and modifications to the expander can be made much more rapidly, reducing development time.

The single-cylinder expander layout is presented in Figures 3.8 through 3.10. It was designed to provide a flexible test expander with the basic bore and stroke of the V-4 expander. The singlecylinder expander has three main castings: crankcase, cylinder, and cylinder head. The connecting rod and piston assembly are the 

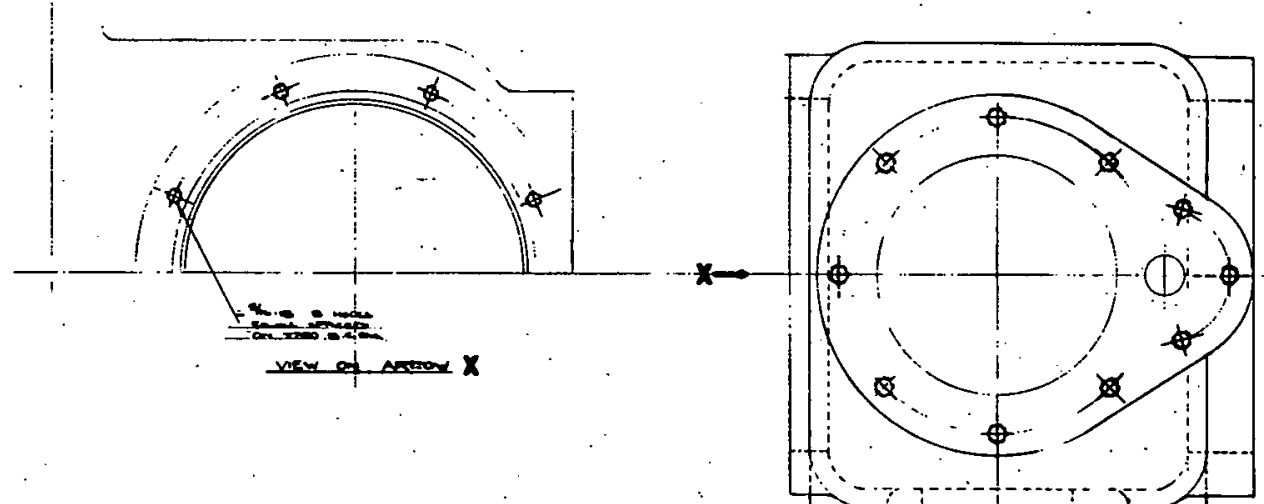

$\therefore$
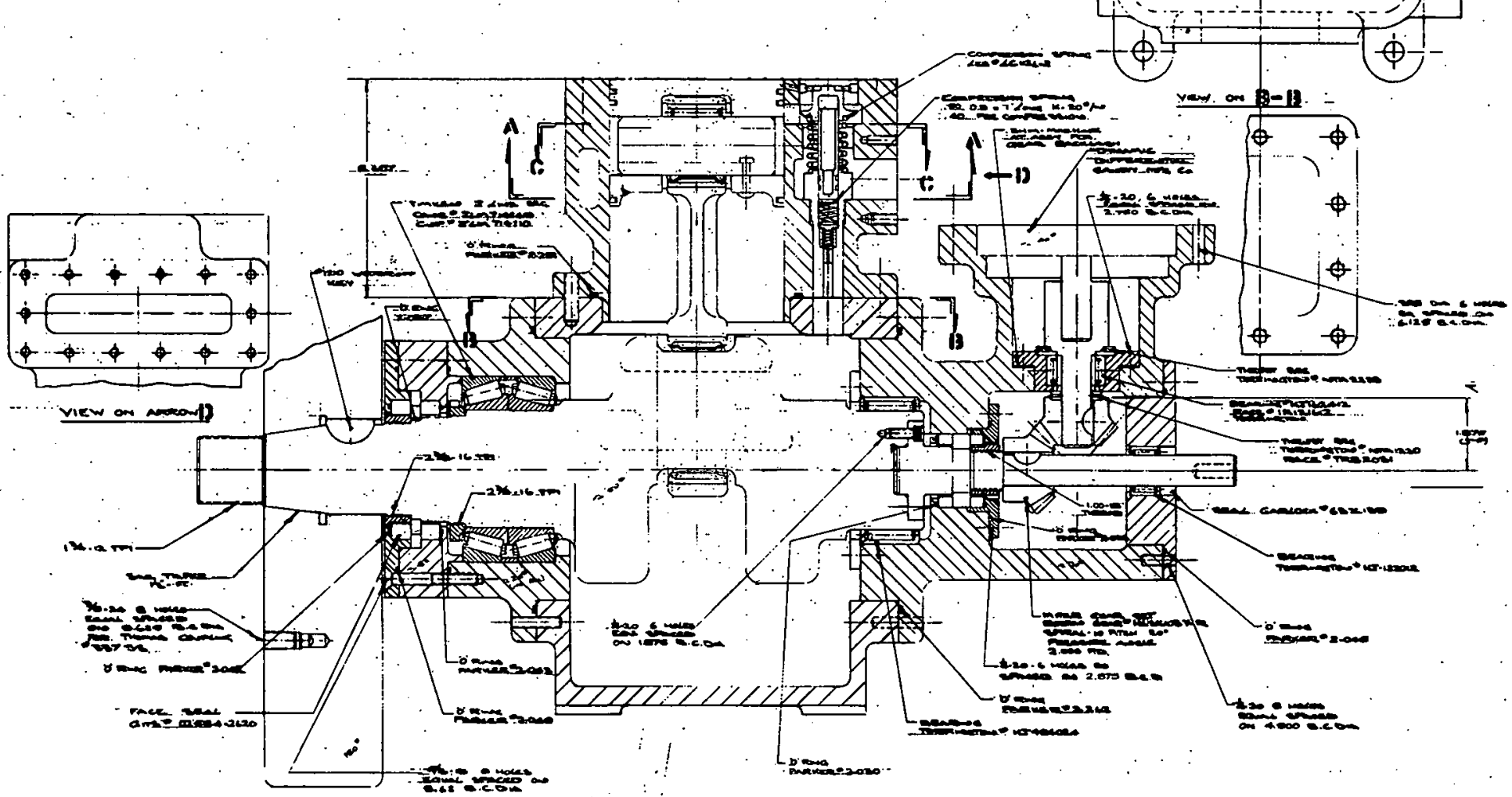

Figure 3.8. Side Cross-Sectional View - Single-Cylinder Expander 

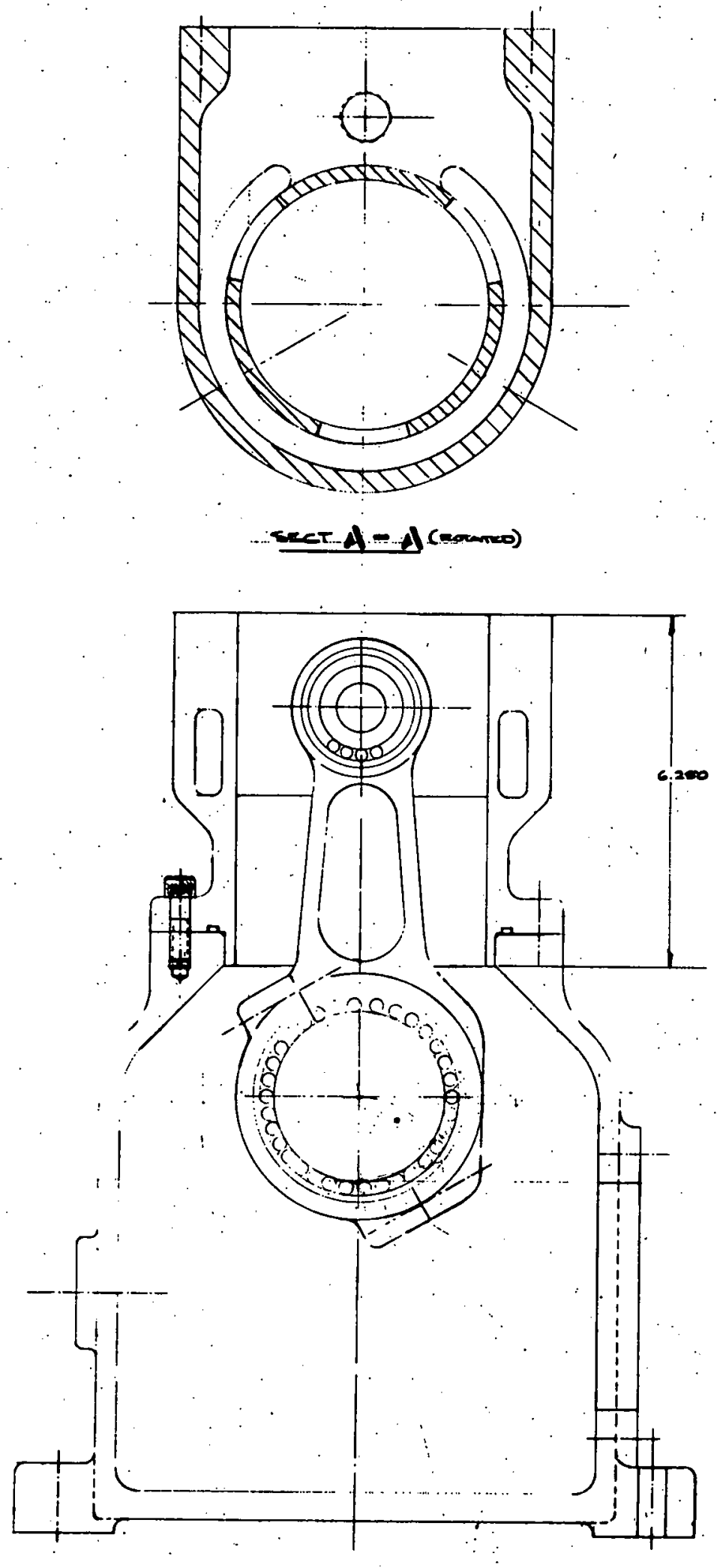

Figure 3.9 Front Cross-Sectional View - Single-Cylinder Expander 


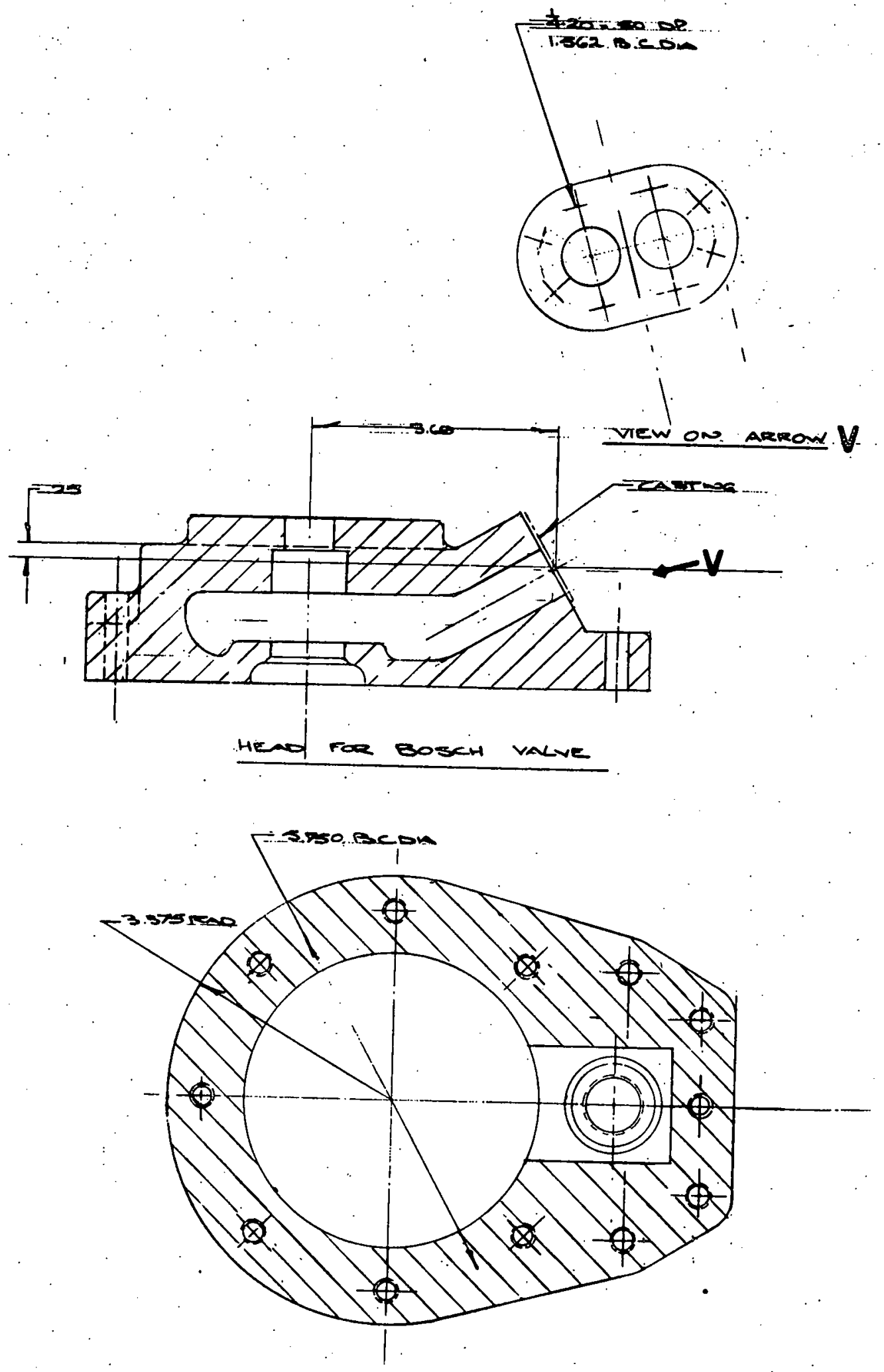

Figure 3.10 Head Assembly for American Bosch Valve Single-Cylinder Expander. 
same as those used in the V-4 expander. The cylinder head is designed to accommodate either the American Bosch or the BICERI intake valving mechanisms.

The exhaust porting was designed to permit as much flexibility as possible in the testing of exhaust valves. For the main exhaust ports near Bottom Dead Center (BDC), the cylinder block incorporates an exhaust port plenum around the circumference, allowing complete freedom in selecting the number and location of the main exhaust ports. The auxiliary exhaust ports permit approximately a $60^{\circ}$ variation in the crank angle at which these ports are closed by the piston. The auxiliary exhaust ports were located so that a cam-operated exhaust valve could have been tested if desired. The self-operating auxiliary exhaust valve, as planned for the expander, is illustrated in Figure 3.8.

The crankcase uses shaft seals (see Figure 3.8 ) at both ends of the crankshaft so that valve timing mechanisms can be directly driven from one end of the expander and the flywheel, and load driven from the other end. This procedure eliminates the bulky gear or chain drive required if the timing drive is taken from the flywheel side of the expander. The timing mechanism for both the American Bosch and BICERI intake valving systems is driven from the crankshaft through a right-angle miter gear and a differential arrangement so that the phase angle between the expander crank and the timing mechanism can be changed to vary the intake valve opening crank angle. The stub shaft extending from the front of the expander, where the timing mechanism is driven, is also used to drive the volume signal for generating P-V diagrams on an oscilloscope. 
As illustrated in Figure 3.8, the valve timing mechanism for the American Bosch valving approach is outside the shaft seal. For the BICERI pump-timer, the differential is removed and the pump bolted directly to the flange shown. The main forward shaft seal is then moved to the stub shaft where a Garlock seal is used, thus incorporating the BICERI pump-timer inside the hermetic seal as on the preprototype V-4 expander.

The flywheel is sized to keep the cyclic speed variation within $\pm 1 / 2$ percent over the operating speed range.

Figure 3.11 shows the complete expander; assembled, and Figure 3.12 shows the expander components before assembly.

During the initial shakedown tests of the expander, it was determined that the piston-to-bore clearance and some of the piston ring gaps and side clearances were too tight. After these problems were corrected and the piston was hard anodized, most of the subsequent problems were related to the auxiliary exhaust valve and its porting. The auxiliary exhaust-valve assembly is shown in Figure 3.13. The valve is shown in the open position.

Excessive wear of the cast iron piston rings was observed, particularly in the upper port area, indicating that the piston rings were expanding into the exhaust ports causing fracture of the rings and piston. This problem was solved by modifying the rings, piston, and cylinder. First, the rings were chrome plated and the end-gap dimension was increased to 0.014 inches. Next, the top exhaust port configuration was changed by cutting down the circumferential length of the port by placing two ports (ribbed port) in place of the 


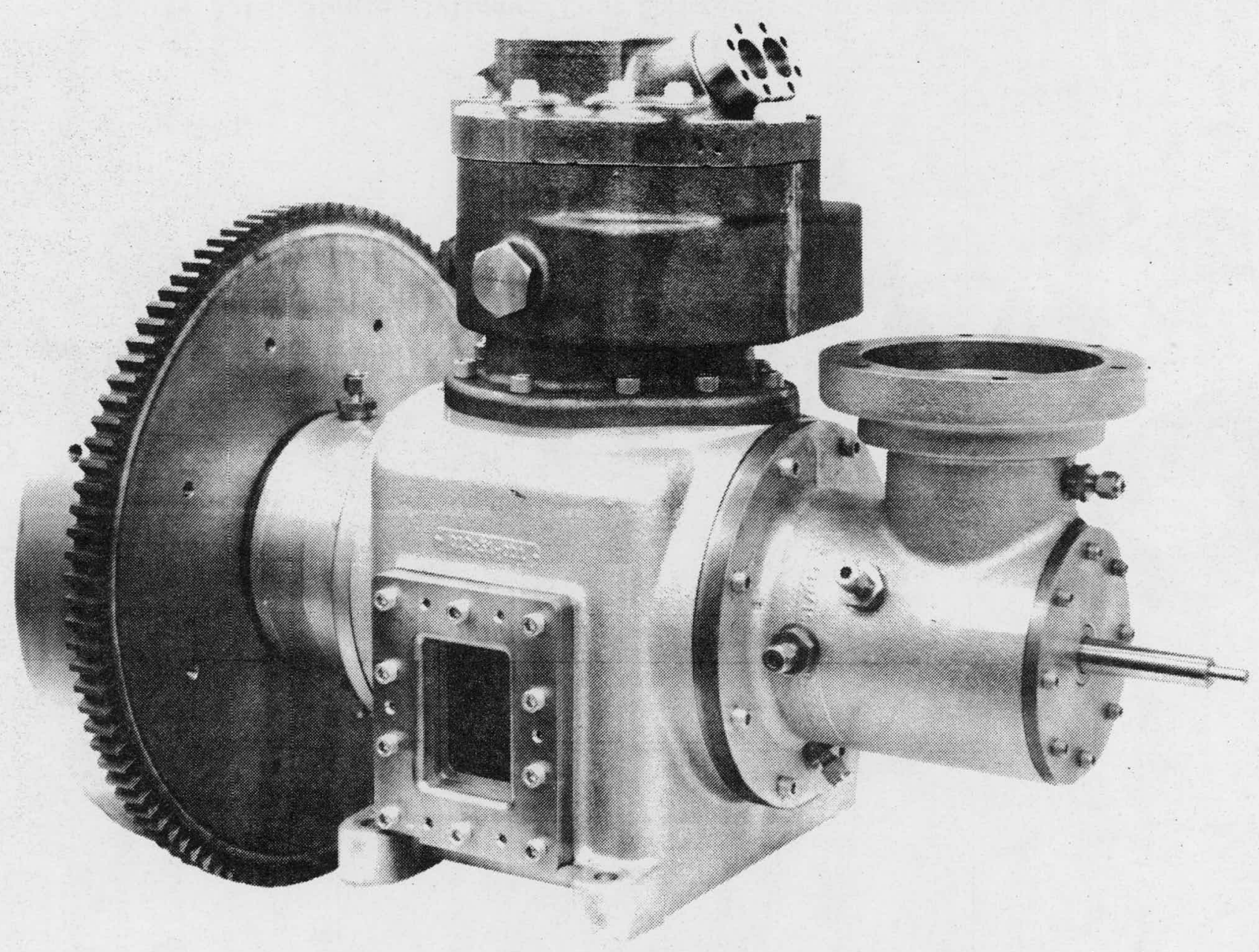

Figure 3.11 Complete Single-Cylinder Test Expander 


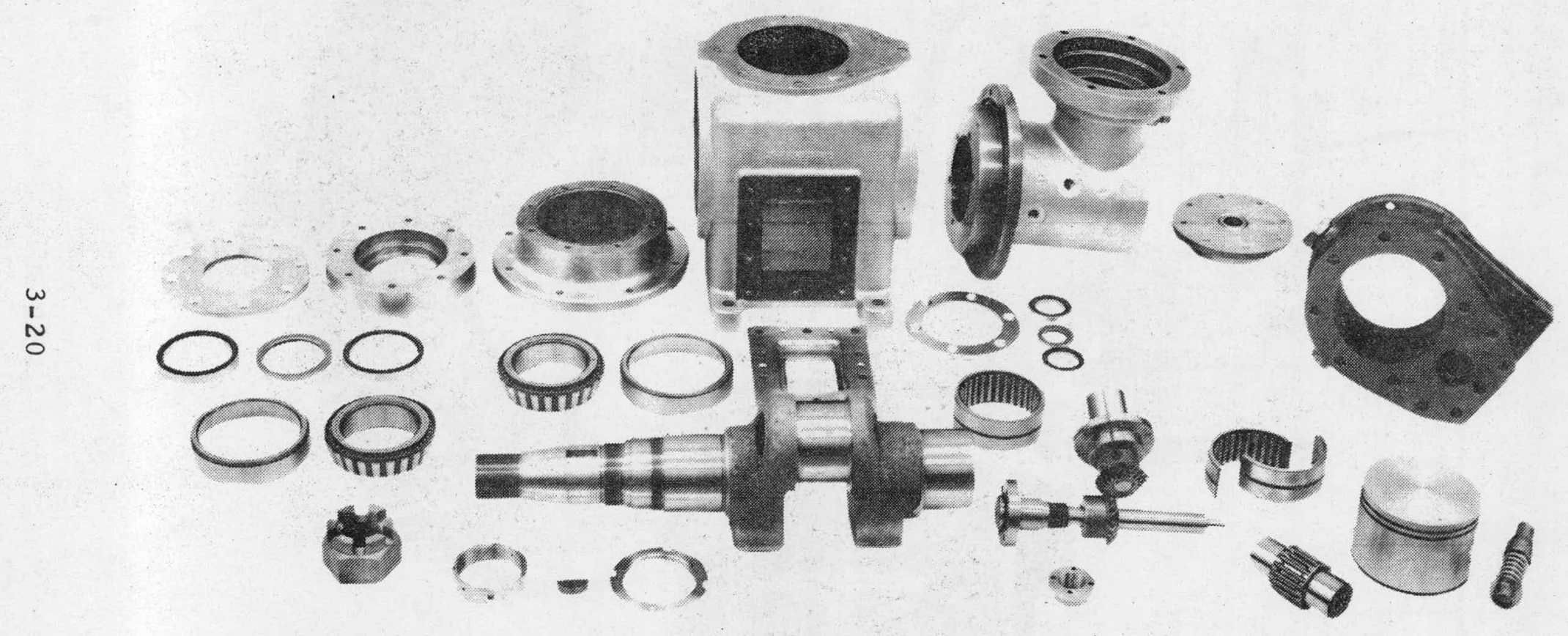

Figure 3.12 Single-Cylinder Test Expander Components 


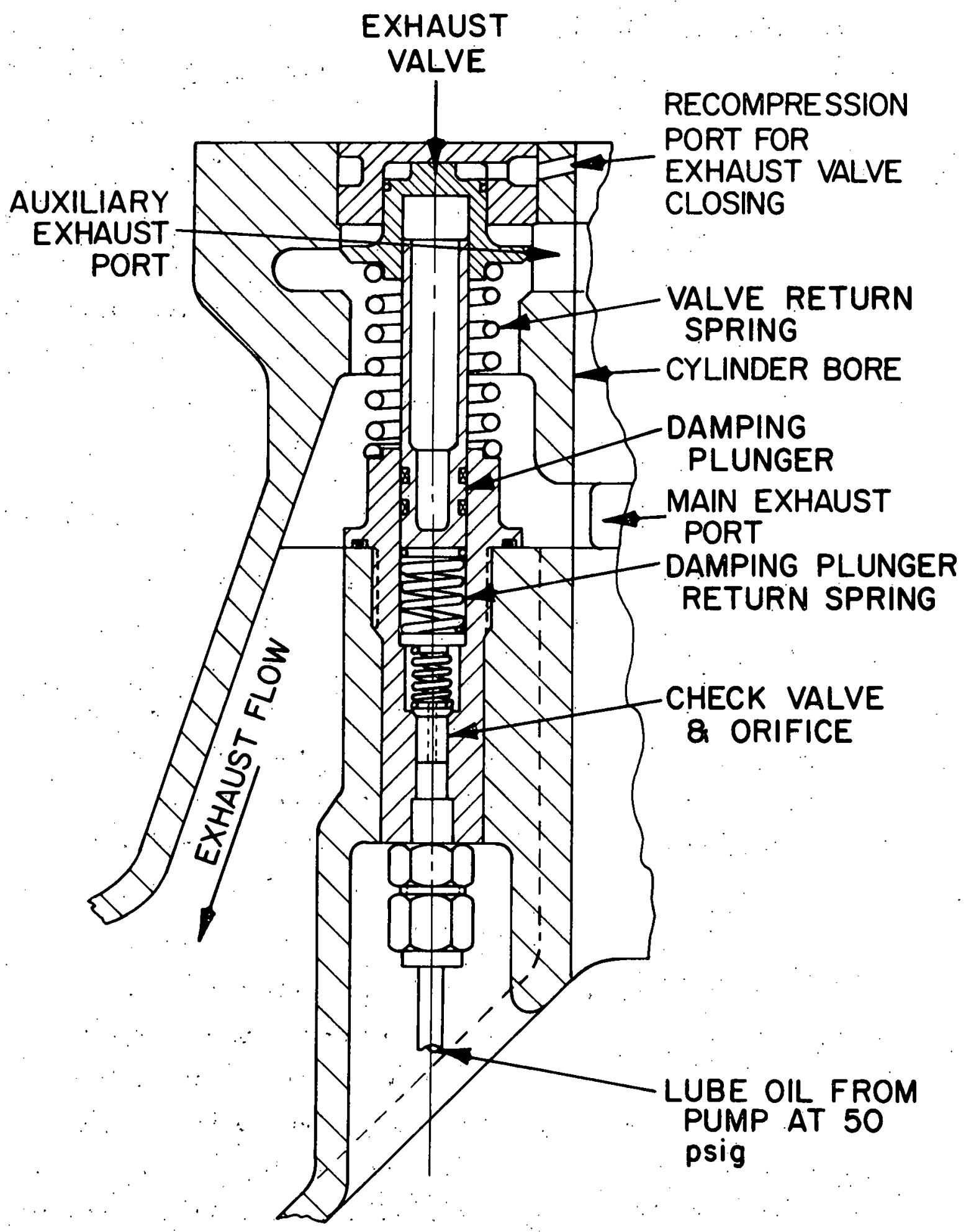

Figure 3.13 Exhaust Valve Design with Hydraulic Damper 
single one. Third, a new full-skirted piston design was incorporated to insure that both top rings did not fall within the upper port area at the same time, eliminating a leak path for the: high pressure vapor. Figure 3.14 shows the original piston geometry, and Figure 3.15 shows the pressure-balancing approach using the full-skirted piston.

After the above modifications were made on the expander, the same rings were used for 27-1/2 hours of tests. Table 3.1 shows the wear rates of the chrome-plated piston rings after 9 hours and 58 minutes of testing. Table 3.2 shows the wear rates of the se same rings after 27 hours and 33 minutes. The wear rates in the tables were determined by measuring the ring thickness after each period of test time. A second method, using the change in the ring end gap was also used to verify the wear rates. The wear rate, using the end gap method, is equal to the change in end gap divided by 6 times the test time. For one set of conditions, the wear rate was 0.303 $\times 10^{-4} \mathrm{in} . / \mathrm{hr}$ using the end gap method and $0.308 \times 10^{-4}$ in. $/ \mathrm{hr}$ using the ring thickness method. The agreement between the two methods is quite good. A comparis on of wear rates for the first 10 hours with the wear rate for the subsequent 27 hours shows a declining wear rate with time.

Following this, the single-cylinder expander was run over one hundred additional hours during which much data were taken. At the end of this test period a connecting rod fallure occurred because a piston seized and a connecting rod big end cap bolt snapped. This failure occurred at fairly high speed and load due to the inertia of the expander flywheel and dynamometer pulling the rod against the seized piston. It is felt that foreign particles entered the cylinder causing the piston to seize. 


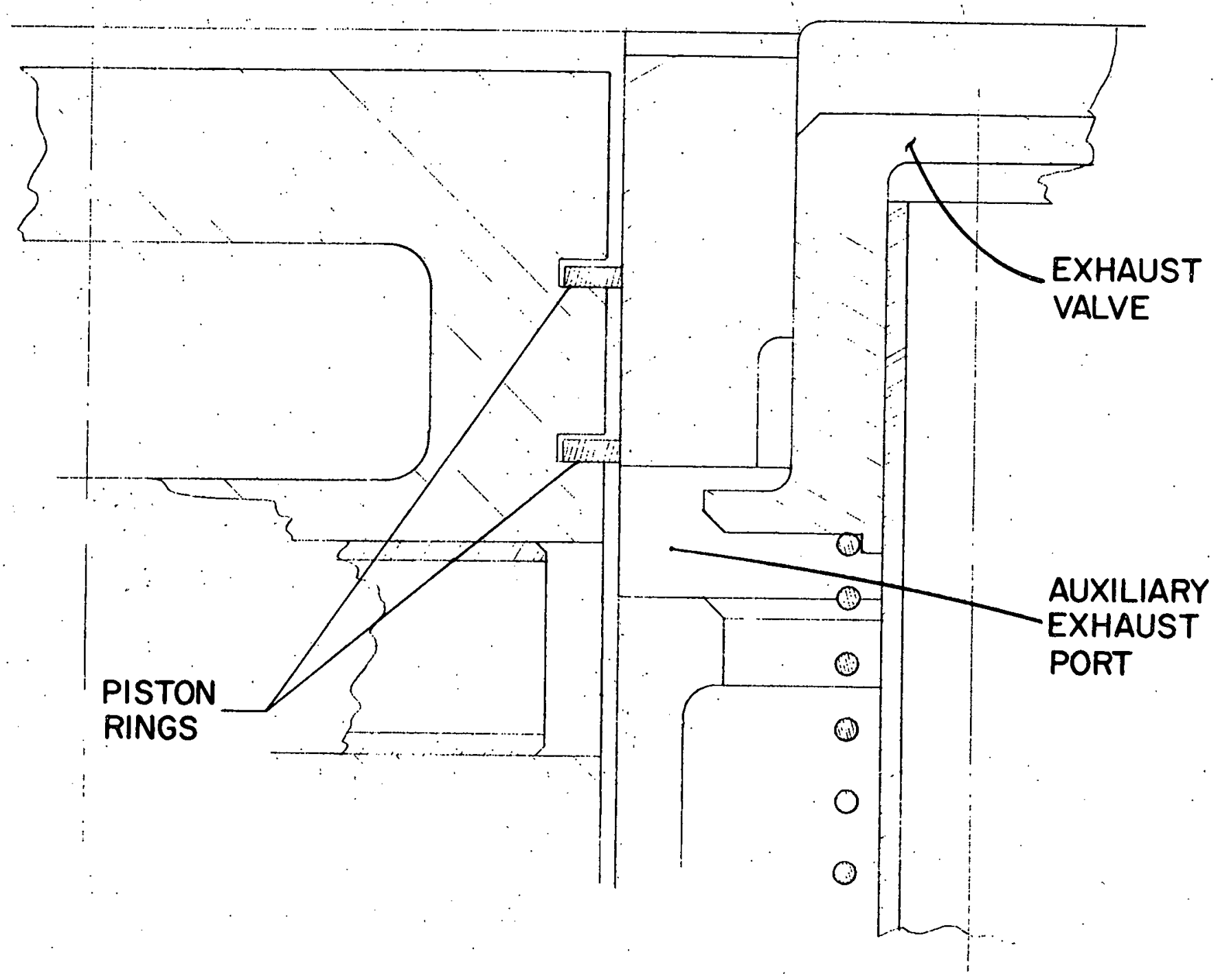

Figure 3.14. Piston at Top Dead Center Showing Ring and Pin Location Relative to Auxiliary Exhaust Port in Original Piston Geometry 


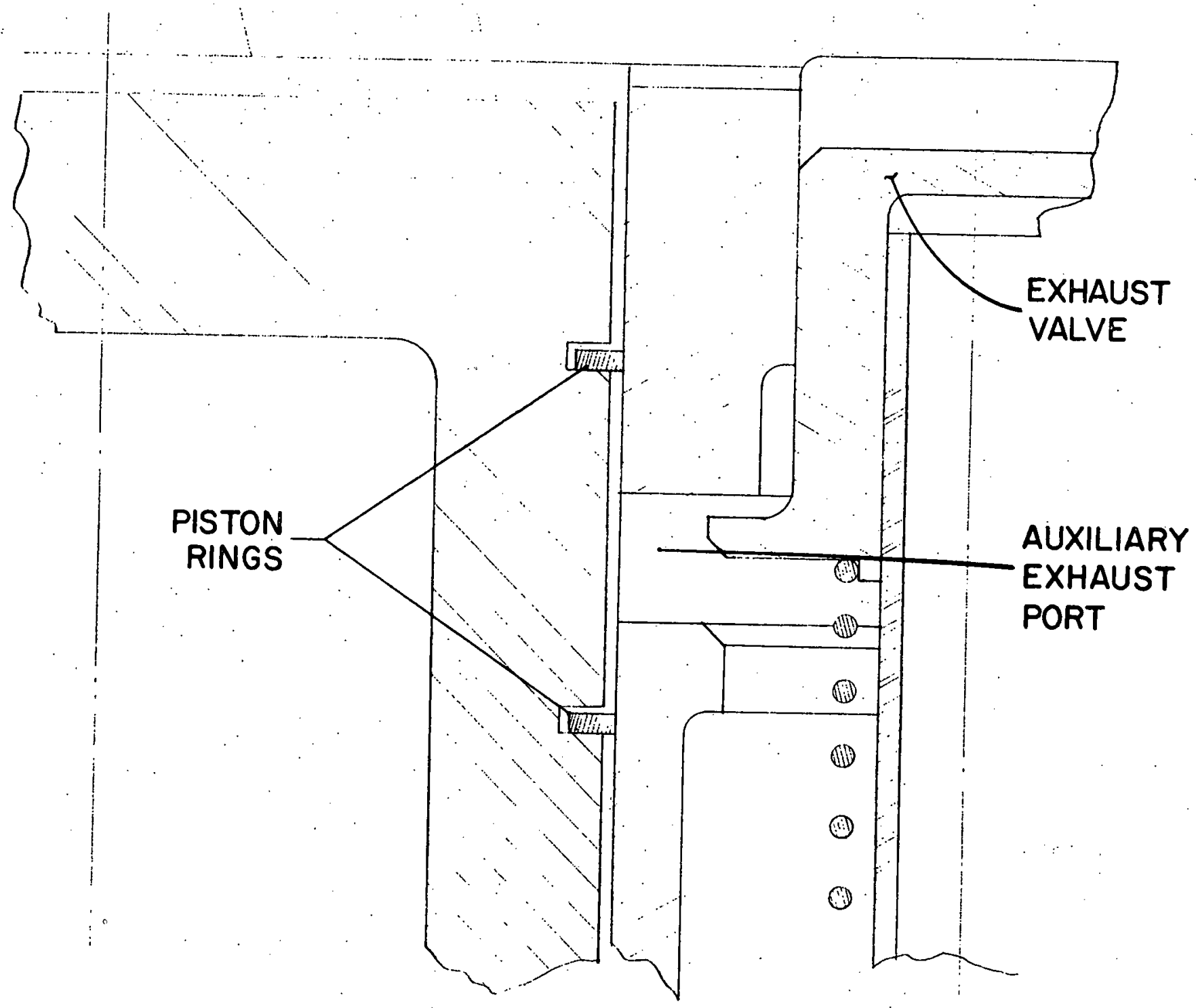

Figure 3.15 Full-Skirted Piston at Top Dead Center Showing Pressure Balancing Approach 
TABLE 3.1

CHROME-PLATED PISTON RINGS - WEAR AFTER 9 HOURS, 58 MINUTES

\begin{tabular}{|c|c|c|c|c|}
\hline \multirow{2}{*}{$\begin{array}{c}\text { Ring } \\
\text { Position }\end{array}$} & \multicolumn{3}{|c|}{ Average Ring Wear Dimensions } \\
\cline { 2 - 5 } & \multicolumn{2}{|c|}{ Wear (in.) } & \multicolumn{2}{|c|}{ Wear Rate (in./hr) } \\
\cline { 2 - 5 } & Minimum & Maximum & Minimum & Maximum \\
\hline Top & 0.0002 & 0.0011 & $0.201 \times 10^{-4}$ & $1.129 \times 10^{-4}$ \\
Middle & 0.0001 & 0.0014 & $0.100 \times 10^{-4}$ & $1.405 \times 10^{-4}$ \\
Bottom & 0 & 0.0006 & 0 & $0.602 \times 10^{-4}$ \\
\hline
\end{tabular}




$$
\text { A- } 1580
$$

TABLE 3.2

CHROME-PLATED PISTON RINGS - WEAR AFTER 27 HOURS, 33 MINUTES

\begin{tabular}{|c|c|c|c|c|}
\hline \multirow{2}{*}{$\begin{array}{c}\text { Ring } \\
\text { Position }\end{array}$} & \multicolumn{4}{|c|}{ Average Ring Wear Dimensions } \\
\cline { 2 - 5 } & \multicolumn{2}{|c|}{ Wear (in.) } & \multicolumn{2}{|c|}{ Wear Rate (in./hr) } \\
\cline { 2 - 6 } & Minimum & Maximum & Minimum & Maximum \\
\hline Top & 0.0004 & 0.0013 & $0.145 \times 10^{-4}$ & $0.472 \times 10^{-4}$ \\
Middle & 0.0004 & 0.0016 & $0.145 \times 10^{-4}$ & $0.581 \times 10^{-4}$ \\
Bottom & 0.0001 & 0.0007 & $0.036 \times 10^{-4}$ & $0.254 \times 10^{-4}$ \\
\hline
\end{tabular}


The introduction of hard anodized aluminum pistons and chromeplated rings in the single-cylinder expander appeared to eliminate the piston- and ring-scoring problems. These measures were also taken with the V-4 expanders, but score marks and scratches appeared again when these expanders were put into operation. Under a microscope it appeared that the piston rings had surface imperfections, some of which appear to be as much as 0.001 " high. It was felt that this might be a contributing factor because the scratch marks that appeared in the bores were at random positions. Consequently, a set of rings was hand lapped and put into the single-cylinder expander. After several hours of running, the bore was examined. Only one scratch was apparent; this went to the top of the piston travel, indicating that a foreign particle had entered the cylinder. The relatively trouble-free experience with the single-cylinder expander, which has accumulated many more hours than any system with a V-4 expander, tends to lead one to the conclusion that the random scratches that occur:are more likely caused by foreign material from some other part of the system than by any fundamental lubrication problems. Hundreds of hours of testing are required to prove a piston, ring, bore, and lubrication system, and since this was beyond the program scope, nothing like this amount of time was ever accumulated on a single combination.

Auxiliary exhaust valve spring failures, apparently due to spring surging, occurred frequently in both the single- and 4-cylinder expanders. A number of materials and various operating stress levels were tested, but with little or no improvement. This reinforced the theory that the spring was surging and that some direct action to stop or reduce intercoil vibration was necessary. A number of progressively 
wound springs and a damper were obtained from the Associated Spring Company in Ann Arbor, Michigan. The damper itself was a flat wire coil wound to fit inside the valve spring in such a way that the coils are damped through friction on the inner flat coil. This type of damper is standard for automotive use. A various pitch spring with a damper ran for 32.5 hours in the single-cylinder expander without breaking or taking a noticeable set. Previous spring combinations ran only 3 to 10 hours before failing. Further testing with the auxiliary exhaust valve was stopped when a decision was made to switch to uniflow operation, thus eliminating the exhaust valve.

\subsection{Intake Valving.}

In order to maintain high efficiency over the wide speed and power range of the expander, a variable cutoff intake valving approach was chosen over a simpler but less efficient fixed cutoff valving approach which would need a throttle valve to control expander power. Two different variable cutoff valving systems were used during the program. The first, a hydraulic valving system, was developed by American Bosch under a subcontract from. Thermo Electron. The second, also a hydraulic type, was simultaneously developed at the British Internal Cumbustion Engine Research Institute (BICERI) under a contract funded by Thermo Electron.

Initially, the expander development work was carried out with the American Bosch valving. Later in the program it was replaced by the BICERI valving. There were several reasons for this change. Very briefly, the American Bosch valving exhibited excessive cycleto-cycle variation in valve event at reduced cutoff. This prevented 
operation at lower power levels with high inlet pressure and made it necessary to reduce expander inlet pressure in order to reduce power. However, reducing inlet pressure to lower power output also reduces cycle efficiency. The American Bosch system also required about twice the hydraulic power to operate the valves as the BICERI system. Another reason for switching was the simpler and quieter mechanism used in the BICERI system.

\subsubsection{American Bosch Intake Valve System}

The valve actuating mechanism is illustrated in Figure 3.16 and consists of the following basic elements: a double-spool servo valve, a spool check valve, the driving plunger and piston, and a solenoid or magnetic actuator (not shown in Figure 3.16).

Referring to Figure 3.16, the right-hand sketch shows the valve in the closed position. High-pressure fluid is applied to the top of the small spool of the servo valve. A bleed line equipped with an orifice and a spool-type check valve is provided across the two spools of the servo valve. This line produces pressure force equalization across the spools when the solenoid valve is closed. The servo spools are thus maintained in their closed position by the force differential generated by the difference in spool diameters. The high-pressure fluid is ducted through the servo valve passages and applied to the underside of the valve actuating piston. This fluid pressure holds the valve in its closed position.

Referring to the left-hand sketch, when the solenoid-actuated valve is opened, the fluid pressure under the large spool valve is sharply reduced, and a large pressure drop occurs across the two 


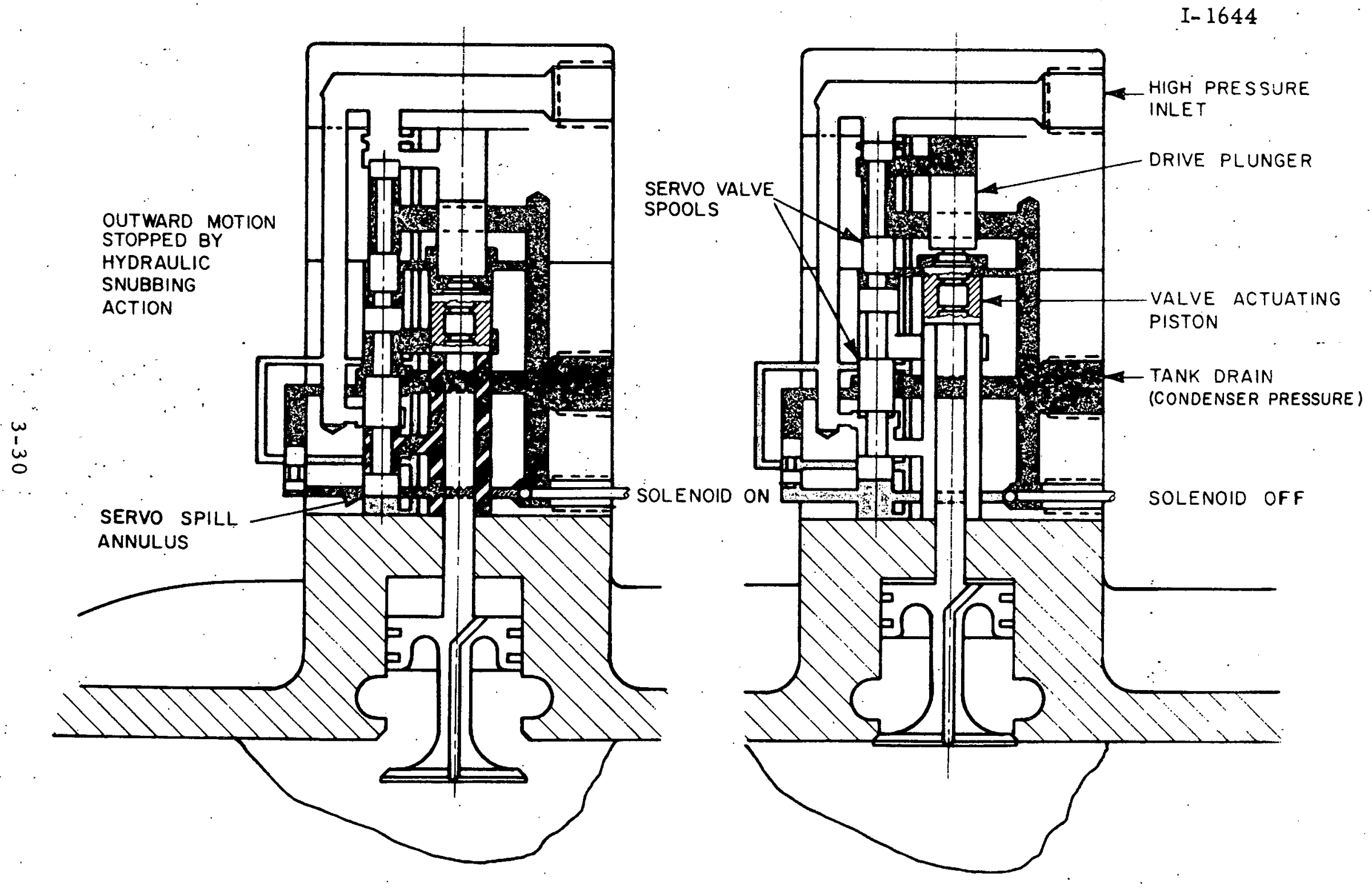

Figure 3.16 Servo Actuated Inlet Valve (American Bosch)

$\#$ 
spools, which causes them to more downward and the spool check valve to close by spring action. When the servo spools have moved to the point where the spill annulus is closed off (position shown in sketch), the pressure under the large spool increases sufficiently to stop the motion of the spools. Since the bleed line is open, the pressure under the spools will increase, and they will start to move upward. Motion in this direction, however, will cause the spill annulus to be reopened slightly, which re-establishes flow through the solenold control valve. When this flow exactly matches the flow through the bleed orifice, the spools become stabilized in their "open" position.

With the servo valve spools in their open position, the area under the valve actuating piston is switched from high pressure to "tank" pressure $\Leftarrow$ condenser pressure), and the area above the drive plunger is switched from tank pressure to high pressure. The resultant high pressure drop across the drive plunger and valve actuating piston drives the intake valve open. When the valve actuating piston moves to the point where its spill annulus is closed off (position shown in sketch), the pressure under the piston increases sufficiently to stop the motion of the valve. This "snubbing" pressure is indicated by the dot-dash area. The valve will remain open as long as the solenoid valve is energized.

When the solenoid valve is closed, flow through the bleed line causes the pressure under the large servo spool to increase. This forces the spool check valve upward, thus opening a large parallel feed passage under the servo spools for fast response. The servo spools are driven upward to the point where the top end of the small 
spool closes off the bleed line annulus (position shown in right-hand sketch of Figure 3.16). Further slight upward motion causes the pressure under the servo spools to decrease to a value which will achieve force balance, at which point all motion will cease and the servo spools will be in their "closed" position. If, in this condition, there is leakage into the bleed line, the servo spools will move slowly upward until they contact a mechanical stop (not shown). During operation the spools will never contact the stop because there is not sufficient time for this leakage to occur. When the servo valve is in: this closed position, the area above the drive plunger. will be switched from high pressure to tank pressure, and the area below the valve actuating piston will be switched from tank pressure to high pressure. The resultant pressure drop across these members will now drive and hold the valve closed.

A drawing of the actuator assembly and intake valve is shown in Figure 3.17 and a photograph of a disassembled unit is shown in Figure 3.18 .

A schematic diagram of the complete intake valving system is. shown in Figure 3.19. Control of the valve actuating mechanism is accomplished by a speed-sensitive phototransistor timer, shown in Figure 3.20, which energizes the capacitor discharge circuit that feeds the solenoid at the proper time in the expander cycle. A circuit is also required to turn this signal off at the proper time to control the length of time that the valve is open. The timer is equipped with a speed-sensitive automatic advance mechanism that maintains the valve opening at the optimum point relative to crank angle as a function of speed. Also built into the valve duration control is an 


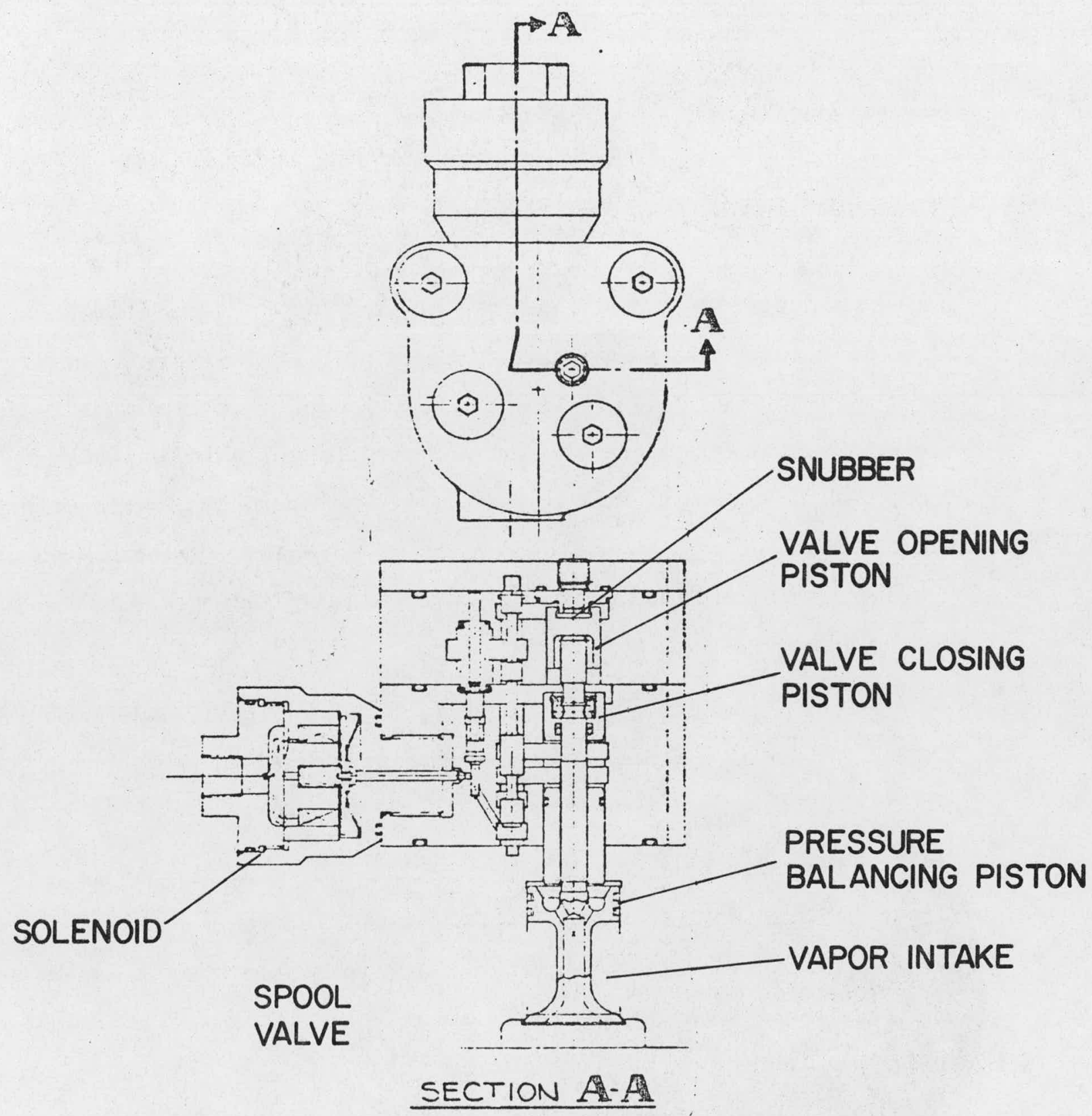

Figure 3.17 Actuator Assembly Intake Valve 


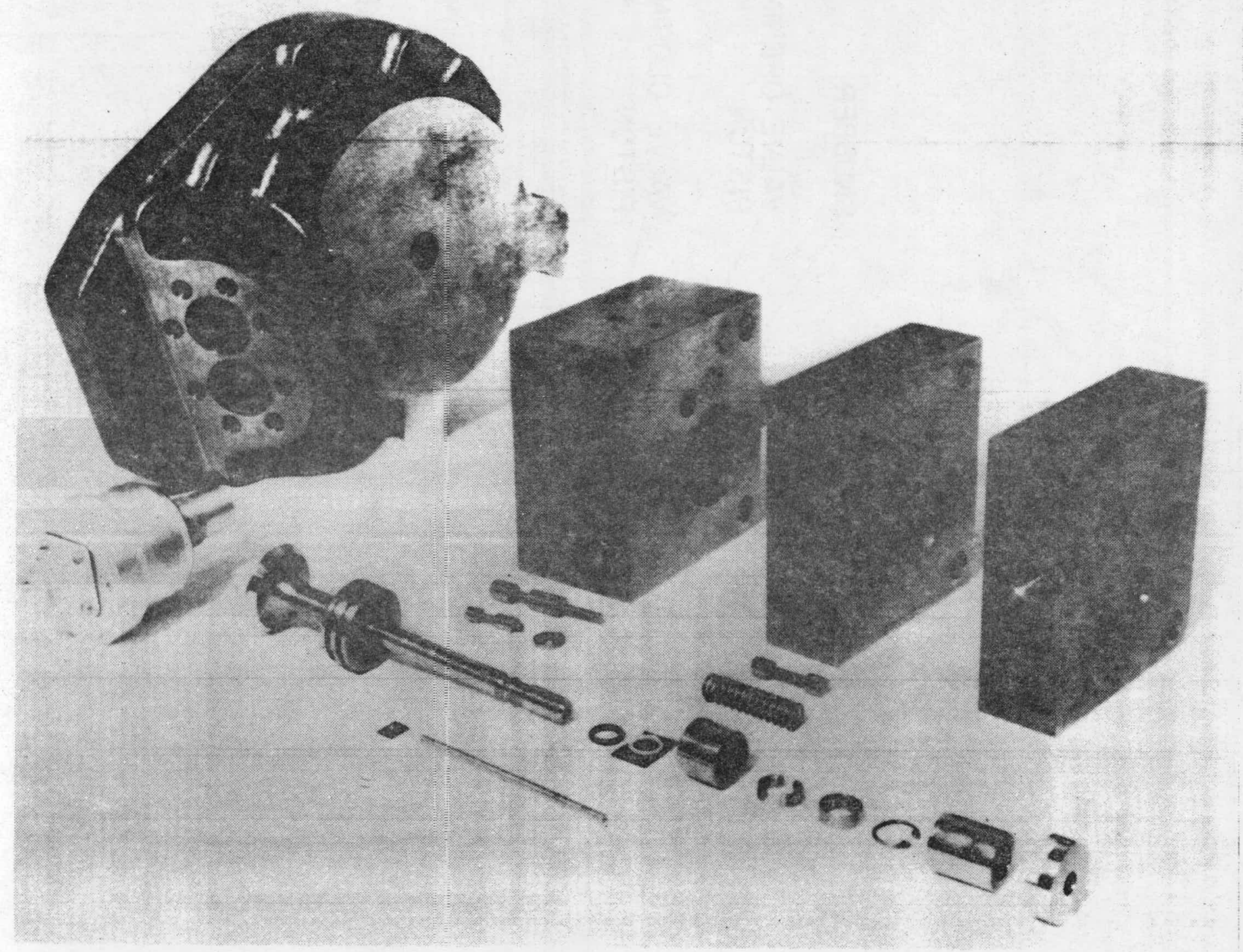

Figure 3.18 Photograph of Disassembled Actuator and Intake Valve for Single-Cylinder Expander 


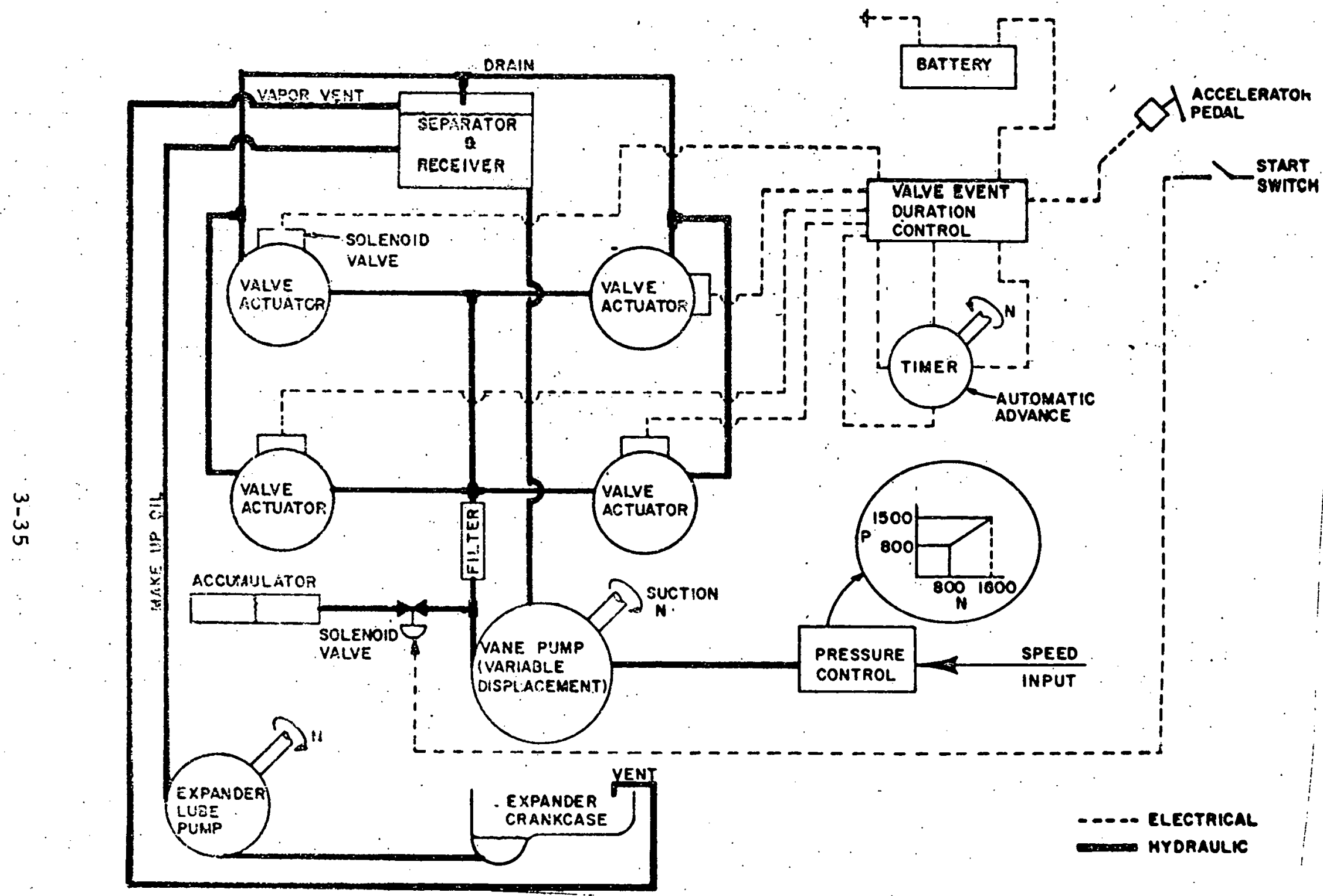

Figure 3.19 American Bosch Intake Valving Schematic 
A- 1878

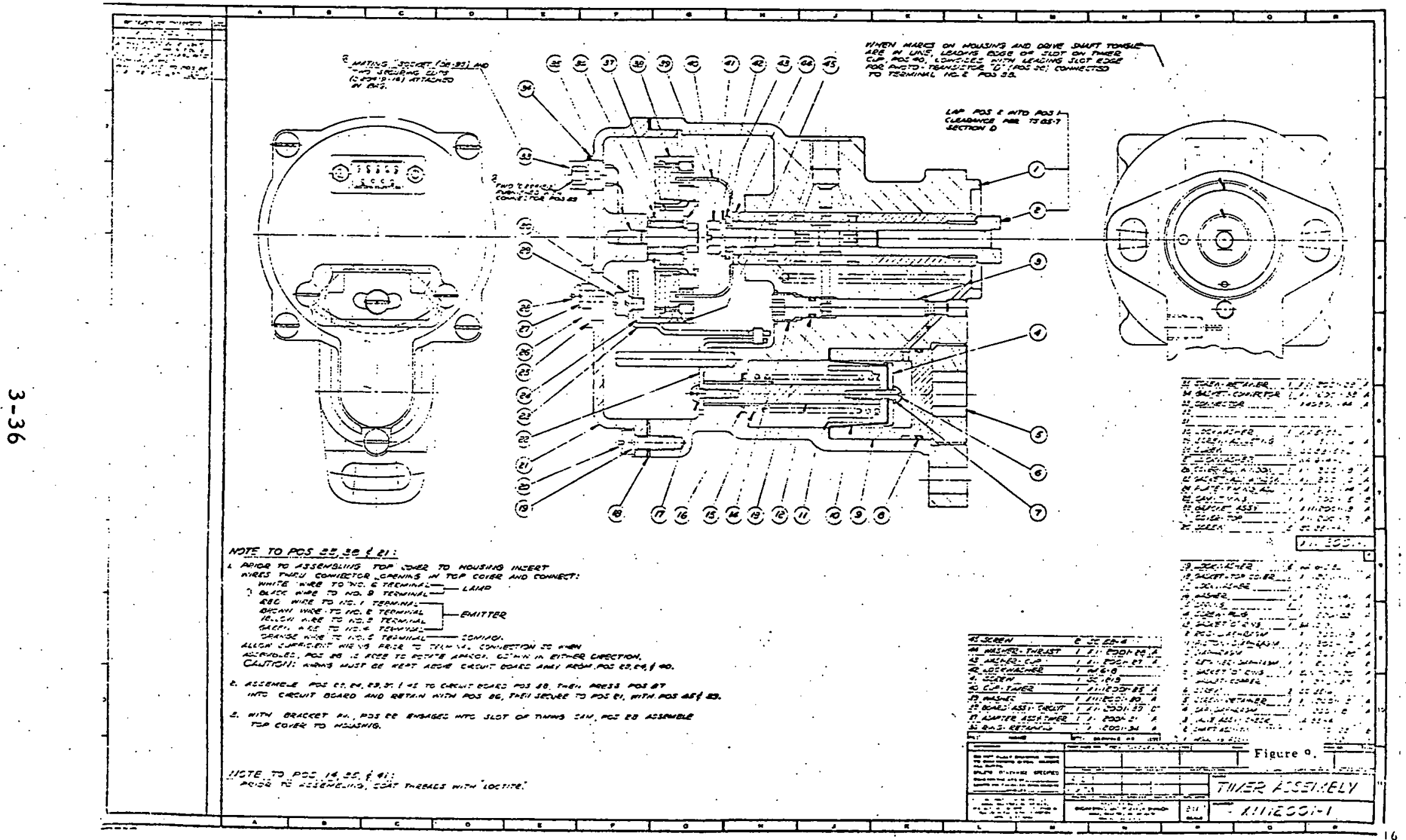

Figure 3.20 Timer Assembly 
electronic speed sensor, which is used to limit the maximum intake ratio as a function of speed, so that the expander cannot overdraw the capacity of the boiler. It can be seen from Figure 3.19 that the hydraulic receiver for the valving is separate from the lube oil sump in the crankcase. The lube oil pump provides only enough oil for makeup of leakage out of the valve system. Leakage occurs only down the valve stem around the vane pump and is quite small. A separate reservoir is used to insure that the oil used for the valving system is free of Fluorinol-85, which may be present in the crankcase, particularly during startup. The qutput pressure of the supply pump was controlled with a speed sensitive pressure regulating valve. The response time required by the actuators is less at lower speeds, and by dropping the pressure level the power required to operate the inlet valving system was reduced.

The actuator used in the initial bench tests conducted at American Bosch did not have a valve seat, but did have a mass equal in weight to the valve used in the design. Consequently, a snubber had to be built into the closing portion of the valve cycle. This snubber can be seen in Figure 3.17 as a recess in the opening plunger, which engages a close fitting projection on the valve actuator cover on the return stroke of the valve. Initial testing attempted to determine the correct engagement length and clearances to provide a valve seating velocity in the range of 3 to $6 \mathrm{ft} / \mathrm{sec}$.

Aside from minor problems with clearances and surface hardness, the only significant mechanical problem with the actuators was the method of attaching the valve closing piston to the valve stem. An intake valve with closing piston assembly is shown in Figure 3.21. 
$w$
$\vdots$
$\infty$

\section{C.8.}

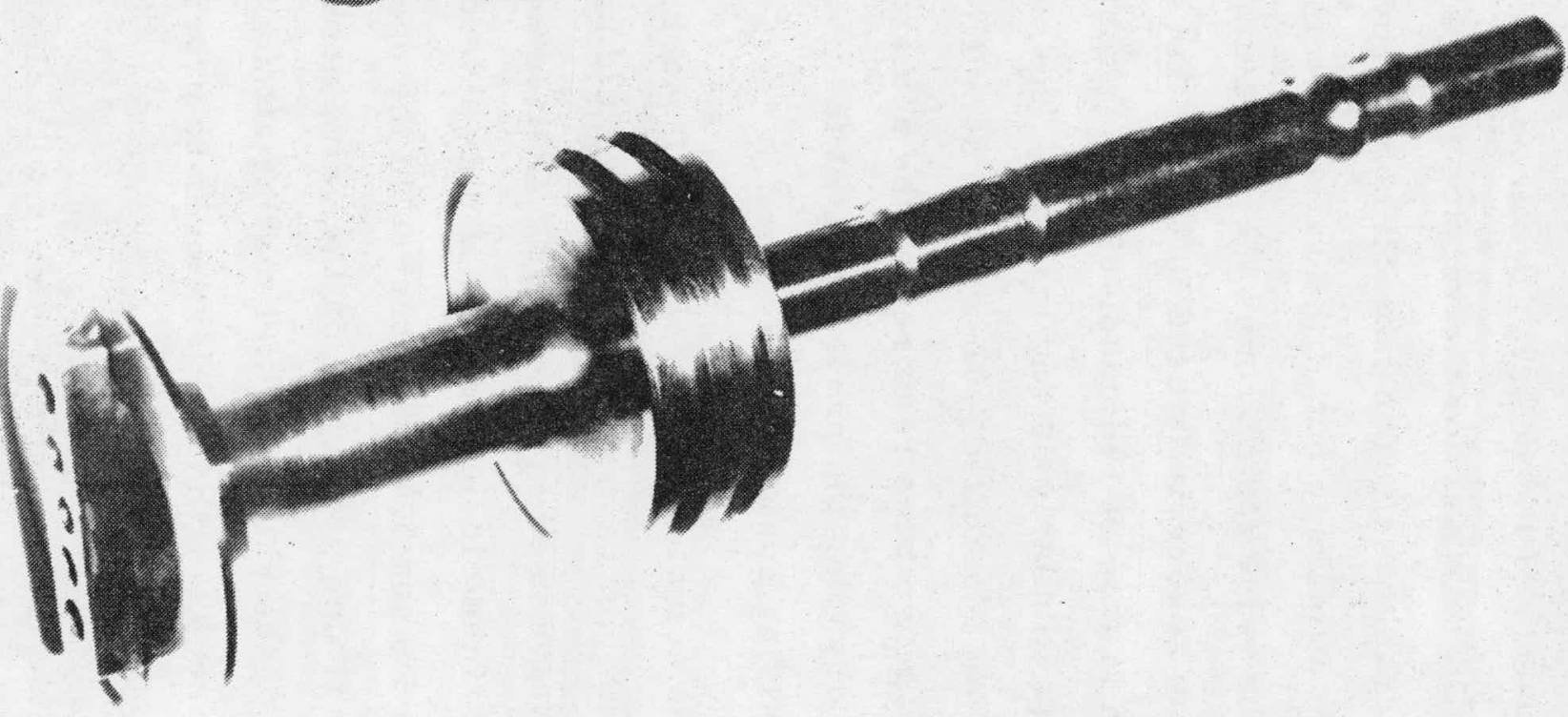

Figure 3.21 Photograph of Intake Valve and Keeper System 
The actuating piston must be rigidly attached in the axial direction, and this attachment must be capable of withstanding the shock of the plston engaging the opening snubber. At the same time, the piston must have reasonable lateral clearance so that concentricity problems with the close-fitting valve stem do not arise. The original design used a bowed snap ring for attachment. This method, and variations of it, resulted in either scored actuating pistons or broken snap rings. The attachment method finally adopted is shown in Figure 3.22. This method used a valve lock retainer nut threaded directly to the valve. This permits the piston and valve to operate freely on their respective bore centers and eliminates the need for a spring interface between the securing nut and the valve lock retainer. With this design, the valve lock retainer was secured with much greater force, which precluded valve lock and retainer breakage. No further problems in this area were encountered once this design change was implemented.

American Bosch also fabricated a skid mounted test bench of the entire valving system that was to be used to shake down various system components, especially the recelver-separator assembly. The test bench was completed and shipped to TECO, but was not used extensively since most of the valving effort was spent trying to resolve unexpected problems with the valve actuators. American Bosch also evaluated various commercially available vane and gear pumps for use in the system. However, a pressure-compensated, variable-displacement piston pump was used in expander and preprototype system testing. This action was taken to minimize parasitic losses and to provide the flexibility required to determine the optimum valve actuating pressure versus expander speed. 


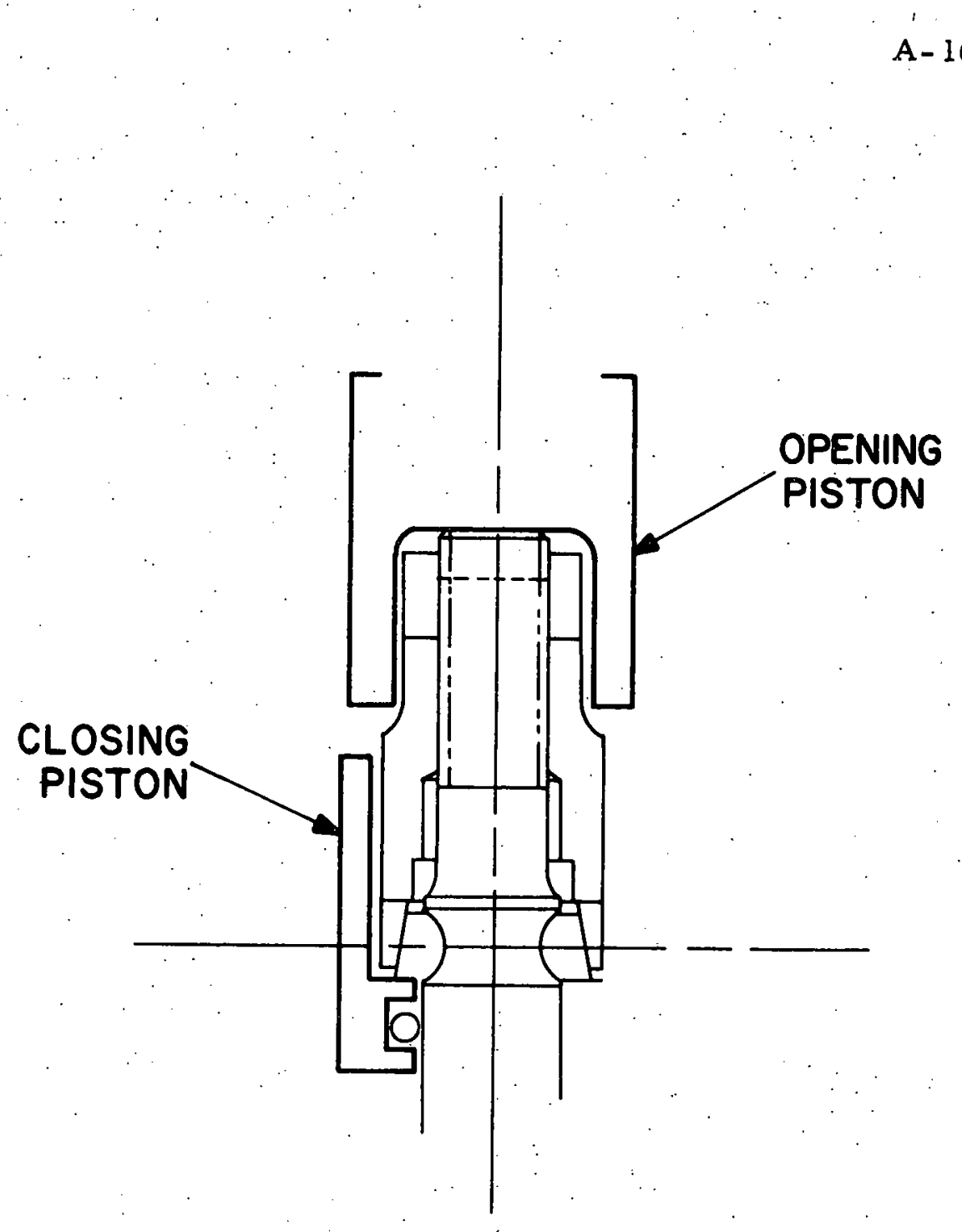

Figure 3.22 Attachment Method Used for Actuating Pistons 
After the actuators were delivered to TECO, several minor problems occurred when the actuators were exposed to the hightemperature fluorinol for the first time. These problems were related to materials for the solenoids and were easily corrected. Testing uncovered some minor difficulties with the cutoff control circuitry, but these were easily eliminated. A still-existing problem that became apparent early in the testing was that of cycle-to-cycle variation in valve event, as well as valve-to-valve variation in the case of the four cylinder unit. A typical example of this variation for the single-cylinger expander is shown in Figure 3.23. The addition of an accumulator in the drain line significantly reduced the cycle-to-cycle variation as shown in Figure 3.24.but did not eliminate it. American Bosch supplied a new control circuit for the 4-cylinder system which eliminated the tendency of the system to drift from higher to lower cutoffs and vice versa. However, the new circuit had no noticeable effect on cycle-to-cycle and valve-to-valve variations in valve event. At this point, individual accumulators were added to the inlet and drain of each actuator, but performance improvement was only marginal. Since all of the road load operation requires relatively low-flow rates, the cutoff required to maintain $700 \mathrm{psi}$ at the inlet to the expander was relatively short. As a result, the system could not be made to operate at the optimum pressure of $700 \mathrm{psi}$; in fact, the cycle efficiency peaked at lower pressures and declined as the pressure was increased. This penalty was ascribed to the valving problem at reduced cutoff because no such optimum pressure was observed when the flow rate was increased so that the system operated at 700 psi without excessive cycle-to-cycle and cylinder-to-cylinder variation. 


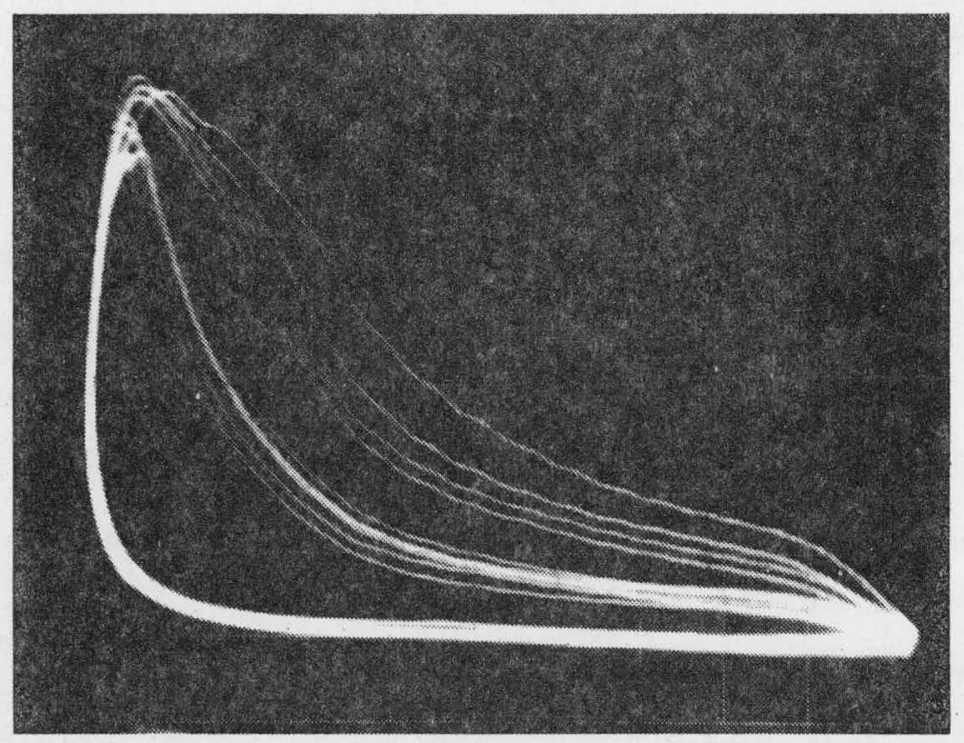

Figure 3.23 P-V Diagram Illustrating Large Cycle-toCycle Variation Prior to Installation of Accumulator on the Oil Discharge Line from the Actuator 
I- 4753

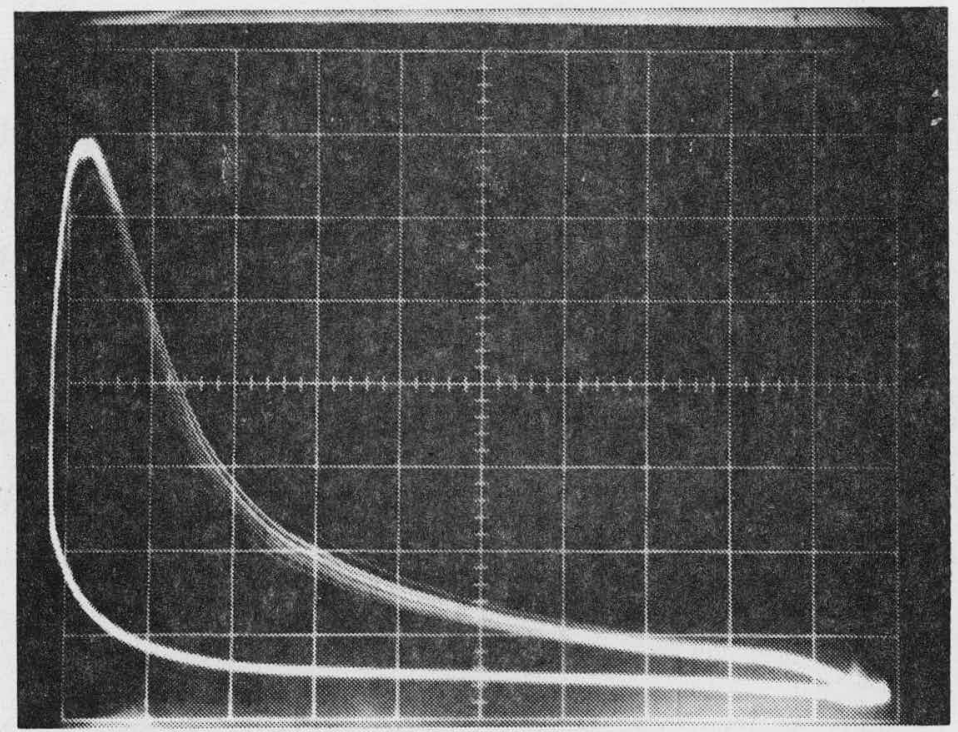

Figure 3.24 P-V Diagram Illustrating Low Cycle-to-Cycle Variation After Installation of Accumulator on the Oil Discharge Line from the Actuator 
Another problem was also evident in the form of "cross-talk" in either the electronic circuitry or hydraulics, or possibly both. Although American Bosch studied the problem at length, they were unable to resolve it.

\subsubsection{BICERI Intake Valving System}

\section{a. Initial Valve Design (Sleeve Valve)}

The BICERI system is a purely hydraulic system comprising a high-pressure (1000 psi) pump, an accumulator, a distributor, and vapor inlet valves. The initial vapor inlet valve design, shown in Figure 3.25 is a thin-walled sleeve valve which is closed by highpressure oil from the engine-driven distributor and opened by inlet vapor acting on the unbalanced area at the seat end of the valve. The distributor alternately applies pressure to the hydraulic end of the valve and removes it for a variable period corresponding to the valve open event.

At the time the BICERI valving was adopted as the primary approach, the only significant problem was that of sealing the high pressure and temperature working fluid from the hydraulic end of the valve. The original concept was to bleed from two locations between sealing rings, as shown in Figure 3.25, thereby preventing either Fluorinol from entering the hydraulic end during the period when the valve is open or oil from leaking into the Fluorinol end while the valve is closed. It was expected that the upper bleed would produce mostly oil, with a small quantity of Fluorinol, and the lower bleed would produce mostly Fluorinol, with a small quantity of oil. This was indeed the case with the early system, built and tested at 


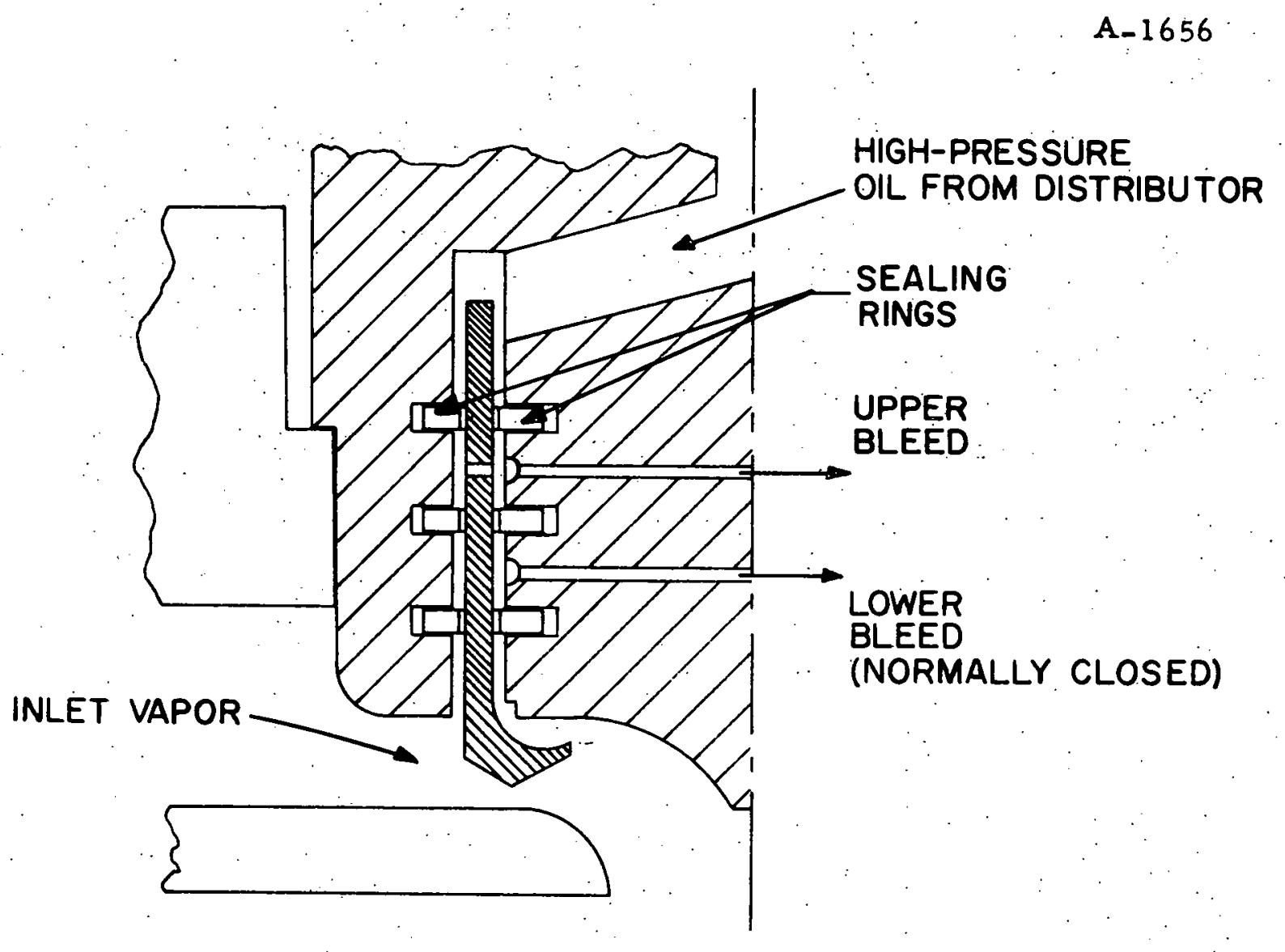

Figure 3.25 BICERI Sleeve Valve, Half Section 
BICERI, which used simple one-piece cast iron rings as both inner and outer seals. However, the rings did not seal well and, in order to prevent Fluorinol (simulated with high-pressure air at BICERI) from getting into the hydraulic system, a special pressure control valve was fitted to the distributor; this maintained the control pressure well above atmospheric pressure during the valve open period. This dial, however, impaired the performance of the valve slightly. Improved cast iron sealing rings (two-piece rings with a lapped joint) were obtained from the Koppers Company and shipped to BICERI. The tests with these rings indicated that both bleed lines could be closed, and the valve could function well with some oil leakage from the hydraulic end into the system. Elimination of the bleeds was desirable because it eliminated the problem of separating oil and Fluorinol in fairly large quantities, and it also reduced the pumping power for the oil. This valve configuration was tested on the singlecylinder expander at Thermo Electron, and the oil leakage rate into the system was measured at $0.5 \mathrm{gal} / \mathrm{hr}$. The valve performed quite well; i.e., no sticking or erratic behavior was noted. This leakage rate was deemed high but tolerable, providing there was an adequate separation system at the regenerator so that oil could be returned to the valving system from the lube oil pump.

In order to improve the valve operation further, BICERI performed some tests with a Teflon ring backed with a Viton "O" ring. These tests indicated.very low leakage in both directions, and good valve performance with no bleed. The probable reas on for the improved leakage performance was the fact that the valves, which are thin-walled and must be hardened, are very difficult to make perfectly 
round, and the teflon rings are better able to conform to this slight out-of-roundness. Teflon rings were then tested on the single-cylinder expander at TECO and, although the valve functioned well, the leakage was erratic, amounting at times to almost nothing and at other times approaching the two-plece cast iron rings in leakage rate.

Further tests were carried out on the V-4 expander instead of the single-cylinder expander. The valves were equipped with a Teflon ring in the top position and an iron ring in the bottom position, which also served as a heat shield. In this series of tests, both leakage and a random sticking of the valves occurred. After a number of ways of making the rings had been explored and tested, it was concluded that the erratic leakage could be attributed to the binding of the valve caused by the high-pressure differential on the Teflon ring. BICERI also encountered this problem, particularly in tests conducted at air temperatures corresponding to the Fluorinol temperatures in. the TECO system. In addition, BICERI found that extended.running with the Teflon rings tended to increase their clearances, producing higher leakage with time; hence, they recommended a return to two (inner and outer) single iron rings with Viton backing and some bleed between the two rings.

An attempt was made to reduce the pressure differential on the teflon rings by placing the Viton-backed Teflon ring in the center position, with the two-piece castiron rings in top and bottom positions, and testing it on the V-4 expander at TECO. Erratic valve behavior and random sticking still occurred, so the upper bleed vent was opened. This resulted in acceptable, although somewhat sluggish, valve behavior at small intake ratios when the vent pressure 
was maintained at 500 psig. Fortunately, the bleed produced very little, if any, Fluorinol, thereby eliminating any need for oil-Fluorinol separation.

In summary, it is concluded that a no-leakage seal on the valve is as detrimental to its performance as a poor seal. With no leakage, the combination of high-pressure differential on the seals and a deadheaded hydraulic line causes erratic valve behavior. The final configuration used the Teflon ring in the center and the two-piece cast iron rings at the top and bottom with the upper bleed open. All of the preprototype V:4 expander data presented in Section 3.2.4 for the BICERI valving is for this sealing arrangement:

\section{b. Advanced Valve Design (Poppet Valve)}

A considerable effort was devoted, both at BICERI and Thermo Electron, toward evaluating a new intake valve design for the BICERI variable-cutoff valving system. This new concept uses exactly the same pump and distributor already developed. The only changes to the system are in the valve itself. The original BICERI sleeve valve performs well in terms of its response, gives reasonably good expander efficiency, and is very quiet. The new valve design, however, attempts to overcome the problem of leakage past the seals and the associated complexity of sealing rings (six per valve). Also, the sealing a rea was reduced to one tenth the area that existed in the sleeve valve. BICERI proposed a poppet valve of roughly the same seat diameter and with somewhat more lift than the sleeve valve. A similar arrangement was devised at Thermo Electron. TECO's poppet valve design differs from BICERI's in that it has the same flow area as the sleeve valve but is much smaller in diameter and, 
in an attempt to keep the weight down, has a larger lift. A summary of the various configurations run and some of the results are given in Table 3.3. In one of the configurations tested, a projection was left on the valve which interfered with the piston by 0.016 in. This was done to insure that the valve would always open, since some difficulty was experienced in providing enough back pressure to open the valve with inlet pressures in the 500- to:700-psi range.

The expander efficiency achieved with the poppet vallve was about the same as that achieved with the sleeve valve. There was no cycleto-cycle variation problem with these valves and they operated in a stable manner over a good range of speed and torque. There was no leakage of working fluid into the oil circuit with any of the valves tested; oil leakage down the stem was slight, and was not amenable to measurement in the time duration within which any one configuration was tested. Due to the reduced leakage, the oil pump power requirement was reduced, but precise measurements were not made.

Examining Table 3.3 , it can be seen that the opening and closing times of the sleeve valve are higher than those of valves that weigh more and have less unbalanced area, contrary to what would be expected. Evidently, the drag of the seals slows the sleeve valve down and eliminates the advantage of light weight inherent in its design. All of the poppet valves tested were noisier than the sleeve valve. This is attributed to the higher mean kinetic energy these valves possess when they hit their seats. The kinetic energy shown in Table 3.3 is calculated on the basis of a velocity derived from the lift of the valve and the time for the valve to close, which assumes an average velocity during closing. In the case of the sleeve valve, 
TABLE 3.3

SUMMARY OF VALVE CHARACTERISTICS TESTED ON THE SINGLE-CYLINDER EXPANDER

A-1581

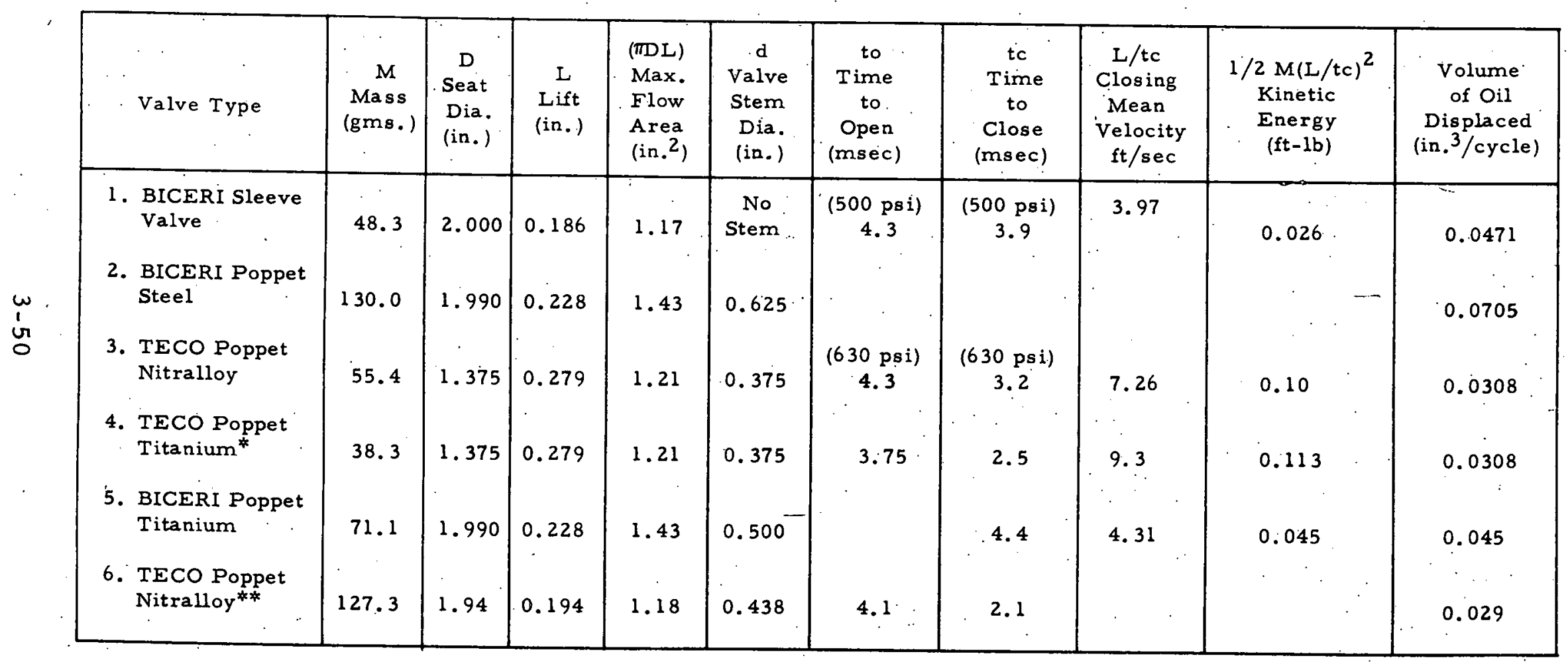

* 0.016 interference between piston and valve projection

Titanium valves have a 0.005 to 0.010 thick coating of tungsten carbide sprayed on the stem and seat in the case of the TECO design and on the seat in the case of the BICERI design.

* Hydraulically snubbed; mean closing velocity and kinetic energy not relevant. 
this assumption may be true, but there is evidence that the poppet type valves are accelerating rapidly when they hit their seat due to the force caused by the rapidly increasing pressure drop through the valve.

Figure 3.2.6 shows some indicator cards taken from the expander at $800 \mathrm{rpm}$. These diagrams show cylinder pressure versus crank angle and hydraulic pressure on the valve versus crank angle. $A$ short study of Figure 3.2.7 will aid in the interpretation of these diagrams. In Figure 3.2.6 (Run No. 188, a sleeve valve çase, and Run No. 221, a poppet valve case), the hydraulic trace during valve closing illustrates an almost constant closing velocity for the sleeve valve and a very high pressure drop for the poppet valve, indicating a rapidly accelerating condition. The "hydraulic hammer" of the oil column when the valve hits its seat was consistently more severe with the poppet valve than with the sleeve valve, although the quantity of oil moving is up to 40 percent less. This is further confirmation that the poppet valves are moving at much higher velocity when they hit their seats. Run No. 230 of Figure 3.26 indicates that the valve was not fully open. This was probably because too little clearance existed between the valve rim and dashpot $(0.008$ in. diametrical clearance).

An advanced poppet valve design was also tested and is shown in Figure 3.28. This valve is made of Nitralloy. with a carbon steel seat. (The tungsten carbide sprayed titanium valve tested previously was found to cause excessive wear in the carbon steel seats.) This valve has a snubber as part of the stem. To accommodate this, a split collar must be used. The head of the valve is designed to be more streamlined than previous valves and projects into the cylinder, 

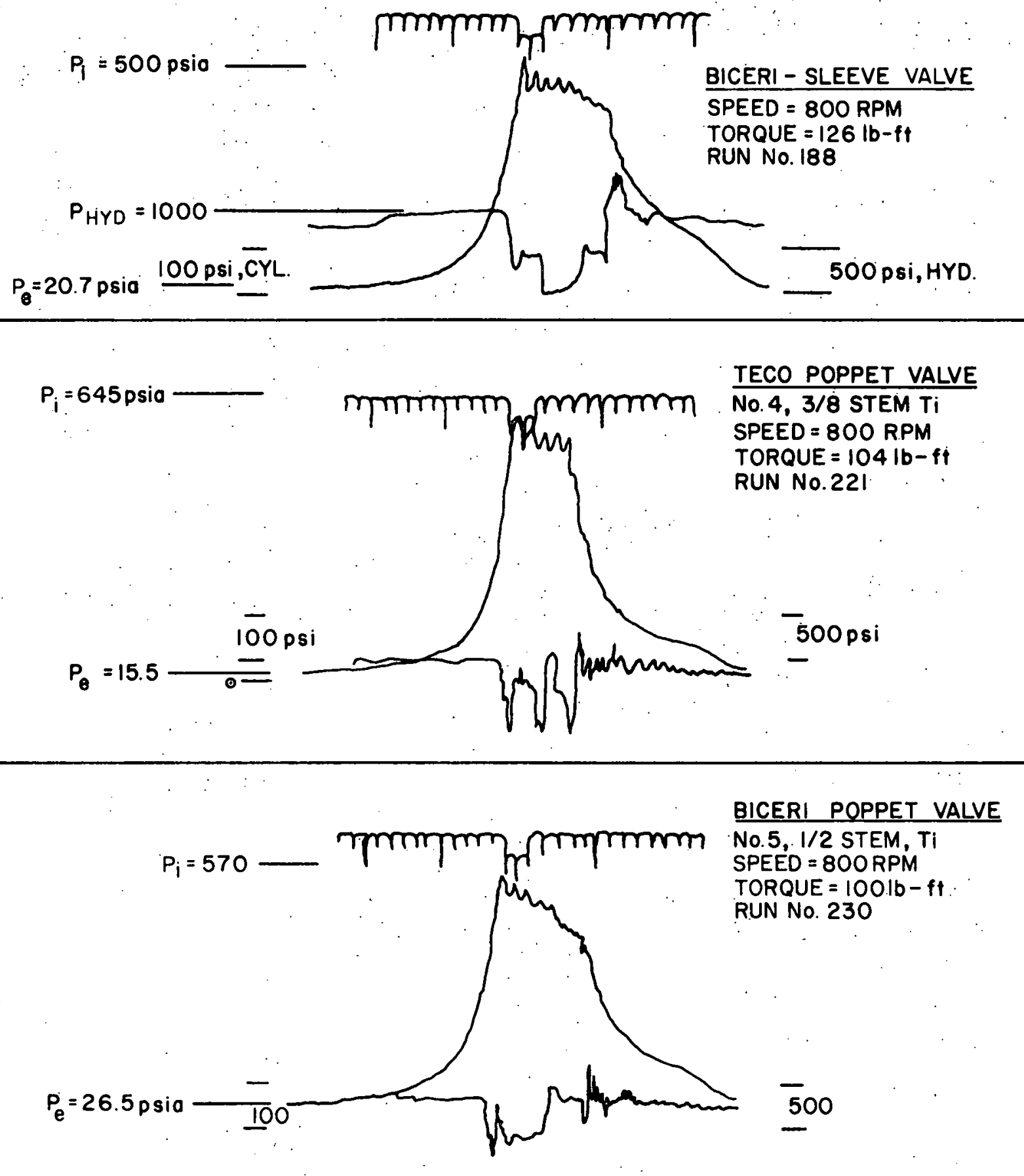

Figure 3.26 Cylinder Pressure versus Crank Angle, and Hydraulic Pressure on the Valve versus Crank Angle. (Indicator Cards Taken from the Expander.at $800 \mathrm{rpm}$ ) 


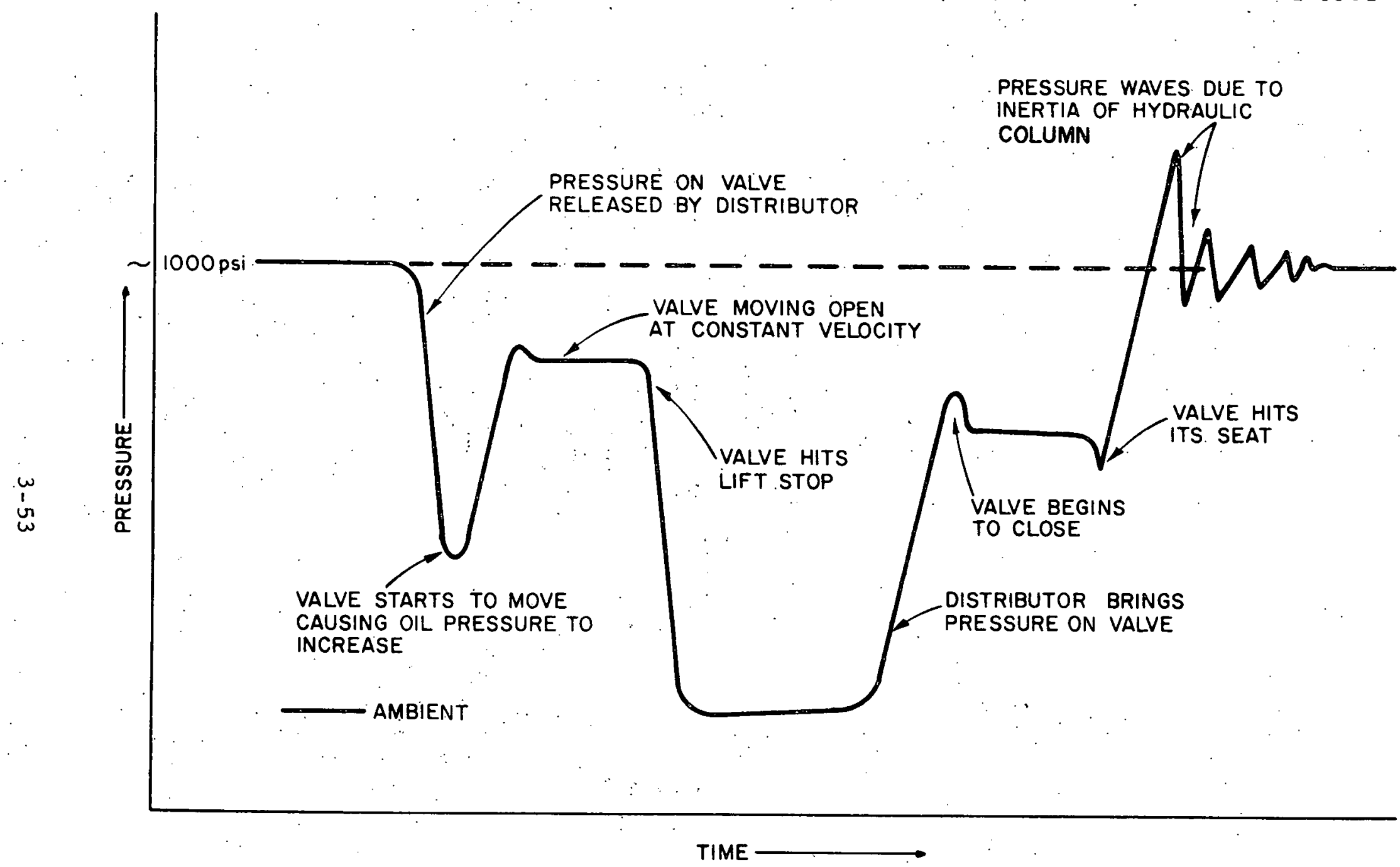

Figure 3.27 Interpretation of Hydraulic Traces from BICERI Valving 


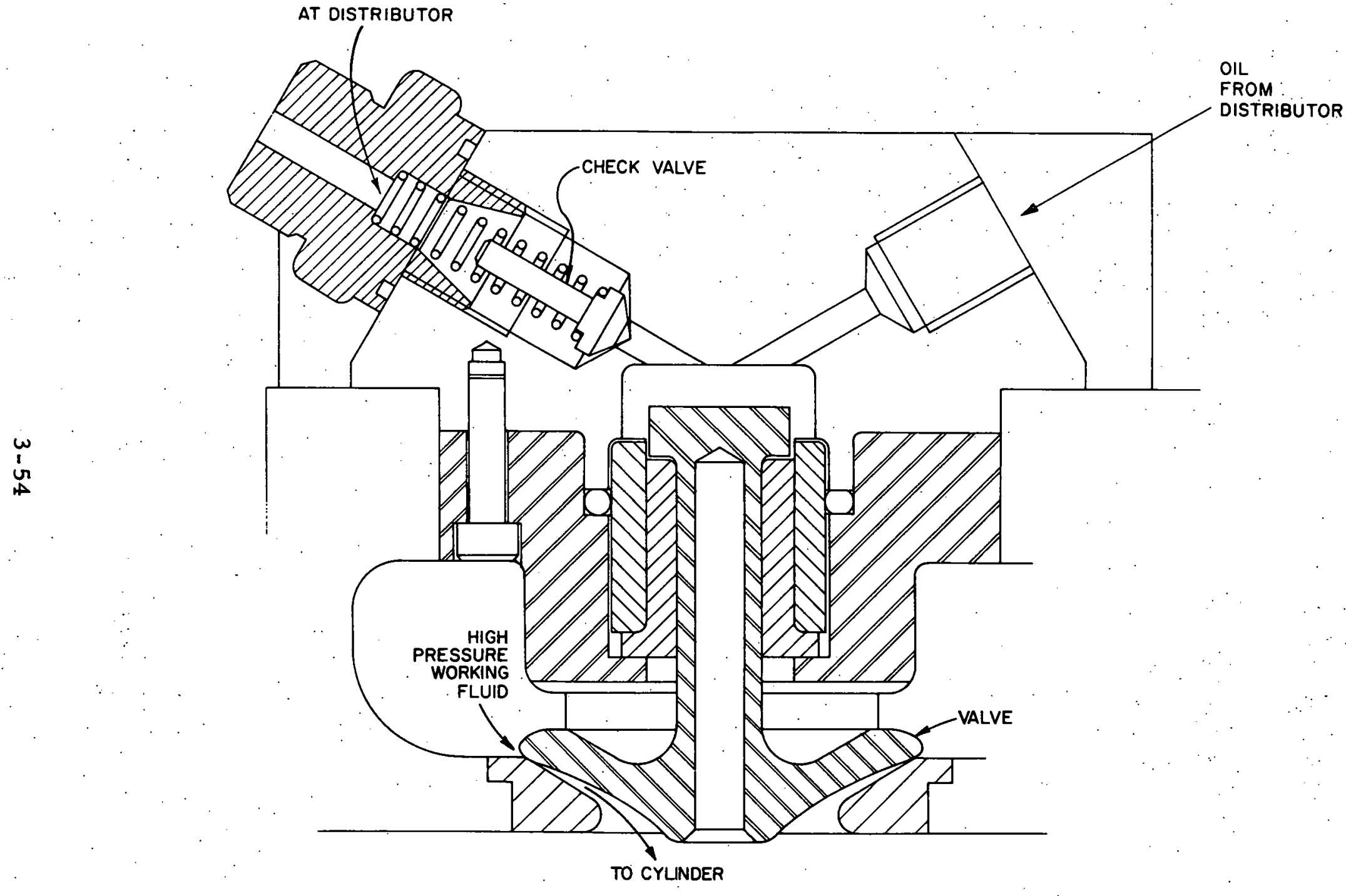

Figure 3.28 Adranced Poppet Valve Design Showing Pressure Relief Valve 
interfering with the piston by about 0.020 in. This provides for positive opening when recompression pressure is less than inlet pressure. The valve guide is split so that the valve can be made in one piece. With a diametrical clearance of about 0.0022 on the snubber and an engagement of 0.040 , this valve had about the same noise level in the single-cylinder expander as did the original BICERI sleeve valve and a slight improvement in efficiency. When the snubber engageme nt was reduced to 0.016 in., the nolse level was substantially increased and even began to show up on the oscilloscope trace of cylinder pressure in the form of vibrations transmitted to the pressure transducer. The material of the valve guide was Nitralloy. The valve of Figure 3.28 together with the servo unit (pump, accumulator, distributor assembly), represents a viable, variable-cutoff valving system for Rankine-cycle engines operating with organic working fluids. Close to 400 hours of testing were accumulated on the servo unit at BICERI.

\subsubsection{Expander Test Facility}

The single-cylinder and four-cylinder preformance test were conducted in Thermo Electron's expander test facility. A schematic of the facility is shown in Figure 3.29. The expanders were mounted on either end of a 350-hp Eaton eddy-current dynamometer. The expanders and the dynamometer were mounted on a 13 -ton concrete inertia mass, which was isolated from the floor using compressed air lift pads. This isolation was necessary to prevent building vibrations from transferring to the single-cylinder expander. This test stand is shown in Figure 3.30. The facility included a $2 \times 10^{6} \mathrm{Btu} / \mathrm{hr}$ gas-fired vapor generator to provide superheated vapor to the expander. This allowed full-power testing of the single-cylinder expander, but limited the 4-cylinder 


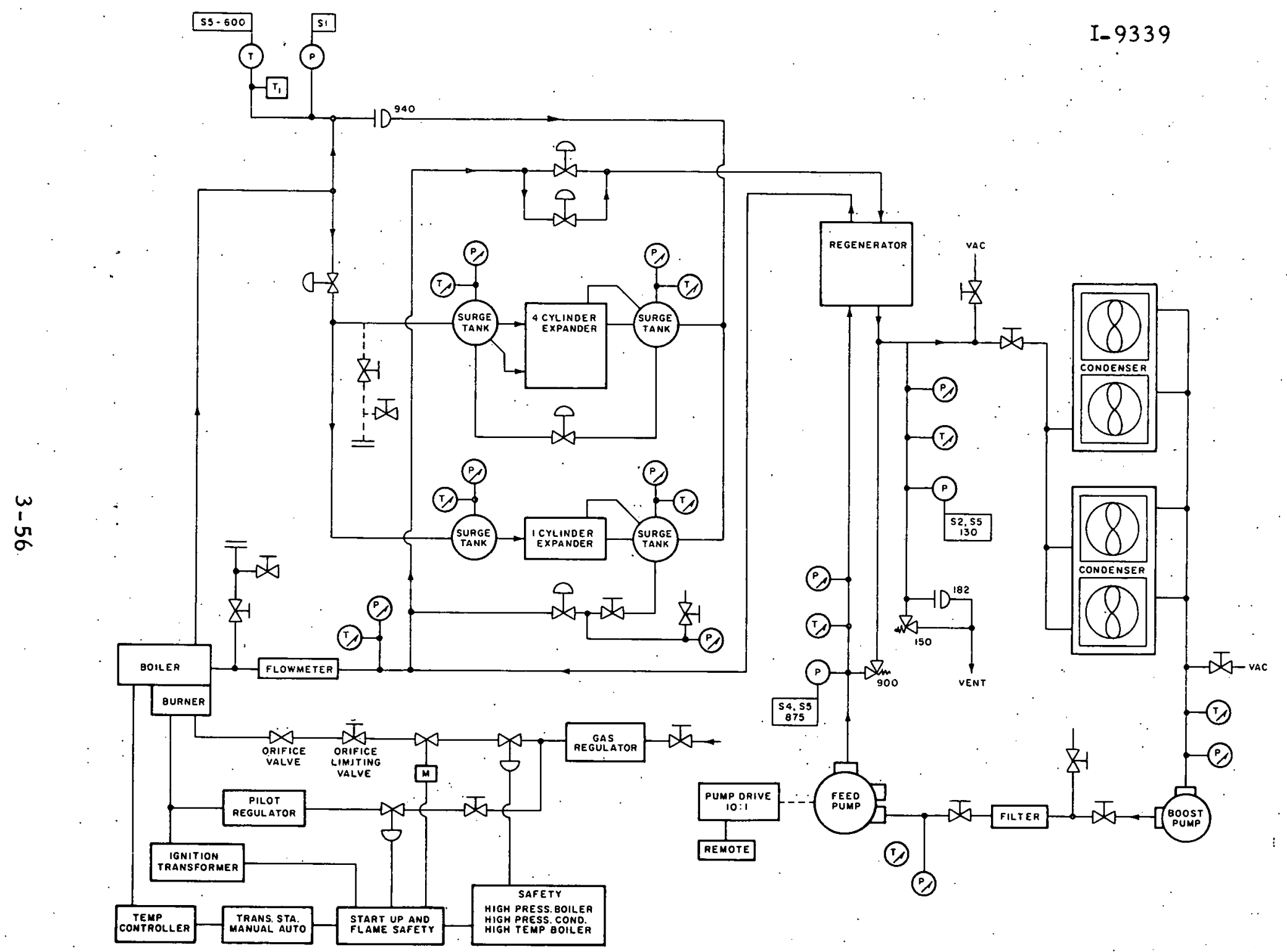

Figure 3.29 Thermo Electron Engine Test Facility Schematic 


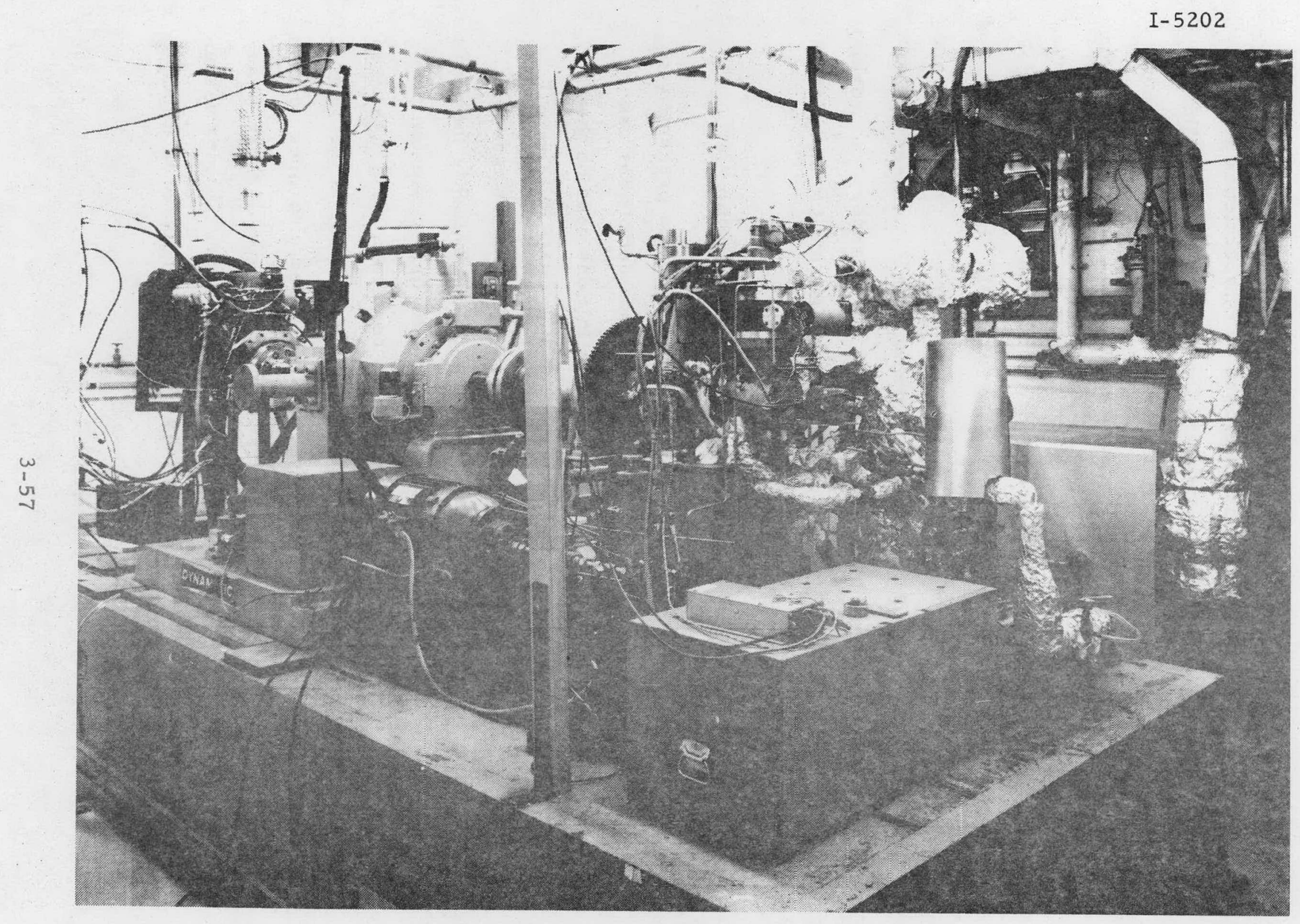

Figure 3.30 Expander Test Stand 
tests to 90 to $100 \mathrm{hp}$. A stainless-steel finned-tube regenerator was also provided in the facility to avoid excessive temperatures at the inlet of two large air-cooled condensers located outside the building. A variable displacement pump similar to the preprototype feedpump was installed, together with a variable-speed motor, allowing a wide range of flow rates to be used. All of the equipment was installed in. side an enclosed test cell. The tests were conducted from a test panel (shown in Figure 3.31) located outside the test cell. This panel included both controls for test operation and instrumentation for data taking and monitoring. The loop instrumentation provided for P-V traces in the cylinder, torque and speed measurements of the expander, and working fluid pressures, temperatures, and flow rates, so that the complete expander characteristics could be determined.

\subsubsection{Expander Test Results and Performance Evaluation}

In order to understand the performance information presented in the following sections, a discussion of the various definitions used is included here. Figure 3.32 illustrates the definitions used on the basis of $\mathrm{P}-\mathrm{V}$ diagrams or mean effective pressure (MEP). Overall efficiency is always defined as BMEP divided by TMEP, where BMEP is the measured brake mean effective pressure and TMEP is the mean effective pressure which would result in an isentropic expansion of the measured flow rate from measured inlet condition to the measured exhaust pressure. The SMEP, as shown in Figure 3.32, is the highest value of MEP the expander with the actual measured clearance volume, exhaust port timing, and expansion ratio could achieve, if there were no friction, mixing, valving, and heat transfer losses. The derivation of the expressions used to calculate the SMEP are included in Appendix B. 


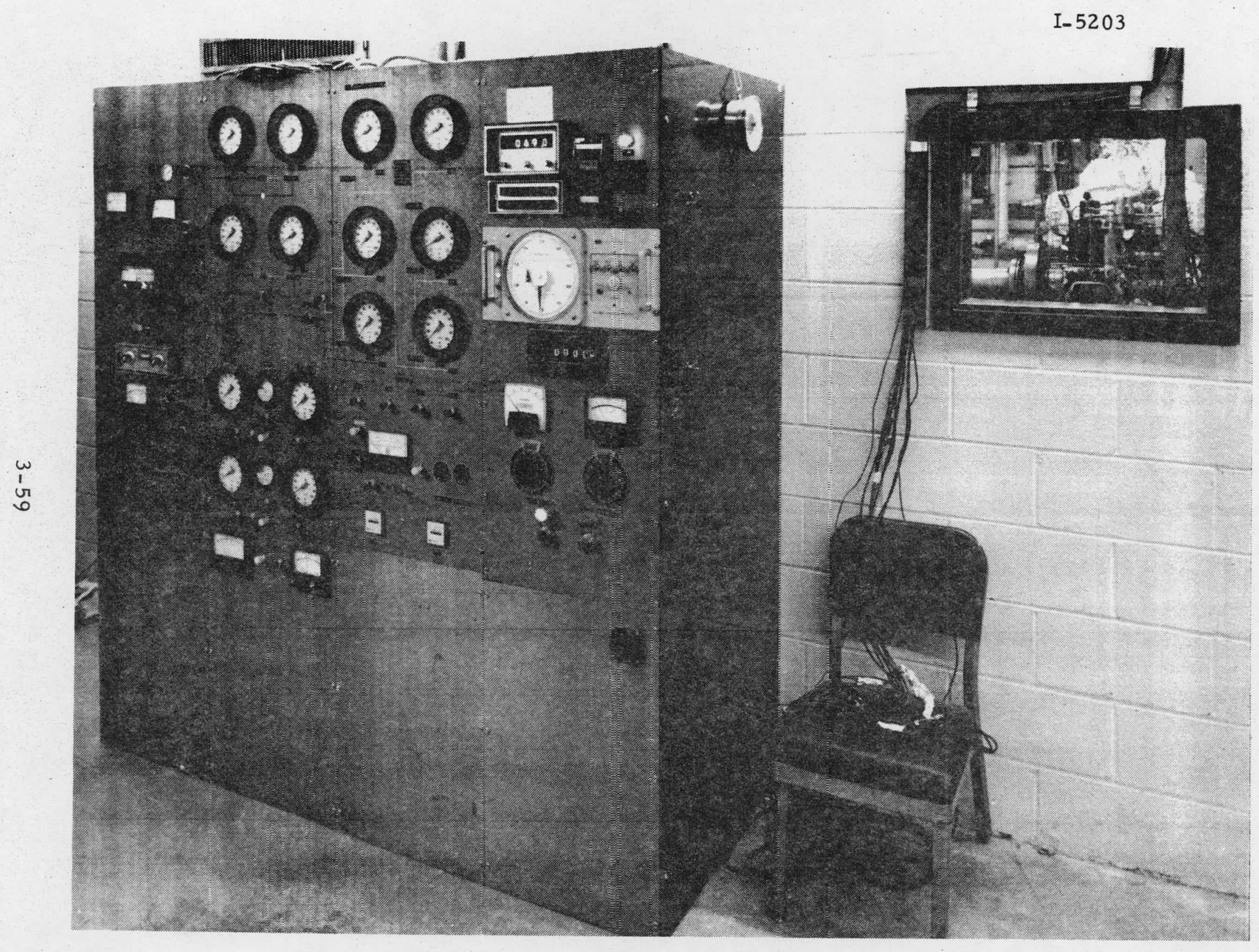

Figure 3.31 Expander Test Loop Instrumentation Panel 

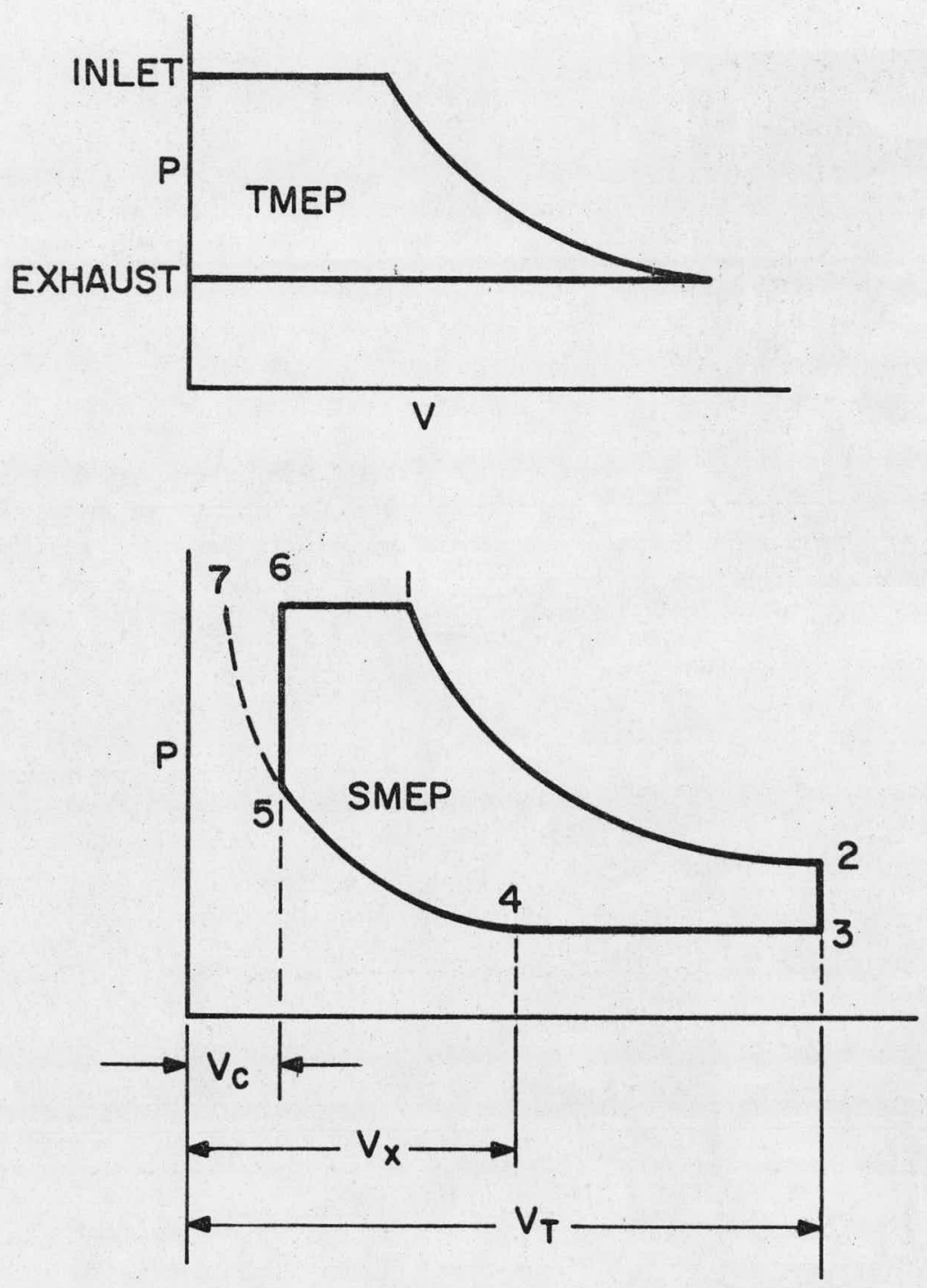

Figure 3.32 Illustrations Defining the Terms Used in Expander Performance Analysis.

The SMEP is calculated by assuming that the gas remaining in the cylinder after blowdown has expanded isentropically $(2-3)$ and been compressed isentropically by the incoming fluid at the end of recompression $(5-7)$. The entropy is therefore constant through the cycle. 
None of the single-cylinder data include the power to operate the inlet valve; since this was supplied by a separate hydraulic system. All of the V-4 expander data do include the valve power, either because the valve hydraullc pump was being driven by the expander (as in the case of the American Bosch valving) or the valve oll flow rate was measured and power for the pump calculated, assuming an 80-percent pump efficiency (as in the case of the BICERI valving).

The performance data presented in the following sections will include only the data with BICERI valving, the chosen approach. Figure 2.15 of Chapter 2 shows a comparison of the two valving schemes using preprototype system data and single-cylinder data and will not be repeated here. Single-cylinder data with the American Bosch valving can be found in Reference 4.

\subsubsection{Single-Cylinder Performance}

After the BICERI intake valving system had been selected, the single-cylinder development effort turned to optimizing the exhaust valve and clearance volume. Figure 3.33 shows the performance of the single-cylinder expander with the auxiliary exhaust valve and BICERI intake sleeve valve.

An analysis of the expander performance showed that the biggest advances in expander efficiency could be made by reoptimizing the auxiliary exhaust port timing and reducing the clearance volume. The location (relative to the piston stroke) and size of the auxiliary exhaust port originally had been established at the "design point", where the BMEP for the expander was 180 psi. This condition required that the auxiliary exhaust be placed very close to the end of the piston stroke 


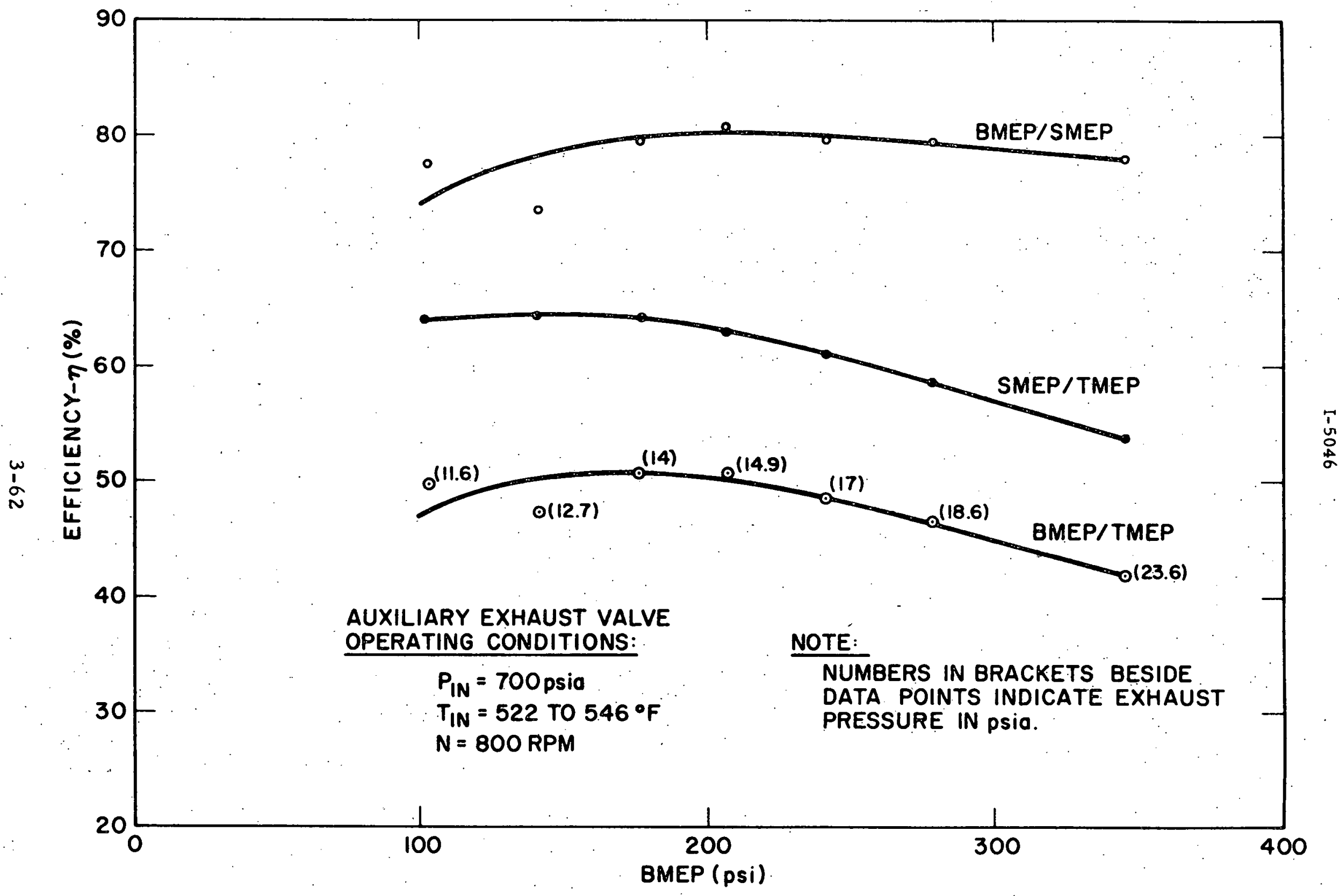

Figure 3.33. Single-Cylinder Expander, Efficiency vs. BMEP (BICERI sleeve valve) 
(40 ${ }^{\circ}$ BTDC) and be almost as large as the inlet valve. Also, in order to reduce the tendency of the piston rings to be forced into the ports, the auxiliary exhaust valve pocket was vented to the cylinder clearance space, thereby balancing the pressure between the cylinder and the auxiliary exhaust valve pocket. Thus, the clearance volume was increased by more that 50 percent over the value used in the original expander prediction program. Figure 3.34 shows the effect of clearance volume on efficiency for an exhaust port closing of $40^{\circ}$ B TDC. Since both the size and the location of the auxiliary exhaust port affect the clearance volume, it is not possible to vary these parameters independently in a real expander. Figure 3.35 shows the effect on efficiency of the cylinder volume when the exhaust valve closes $\left(V_{x}\right)$. This curve indicates that the efficiency improvement in going from an auxillaxy exhaust valve with a.0.00184-in. 3 clearance volume to uniflow exhaust with a $0.000658-$ in. $^{3}$ clearance volume should give about a 5 -point improvement in ideal efficiency (SMEP/TMEP). A uniflow configuration was tested on the single-cylinder expander without the auxiliary exhaust pocket so that the clearance volume was considerably reduced. The result, shown in Figure 3.36, was a 10-point improvement in overall efficiency above that shown in Figure 3.33, rather than the 5 points predicted. The difference was initially attributed to reduced mixing losses from the smaller clearance volume; but modification of the analysis to include mixing showed this to be a negligible effect for the range of clearance volume used. Some of the difference could be due to reduced leakage losses, since with the auxiliary exhaust valve there could be a short but finite period when incoming vapor might escape out of the clearance volume through the vent passages around the exhaust valve and out the exhaust port before the valve was sealed. 


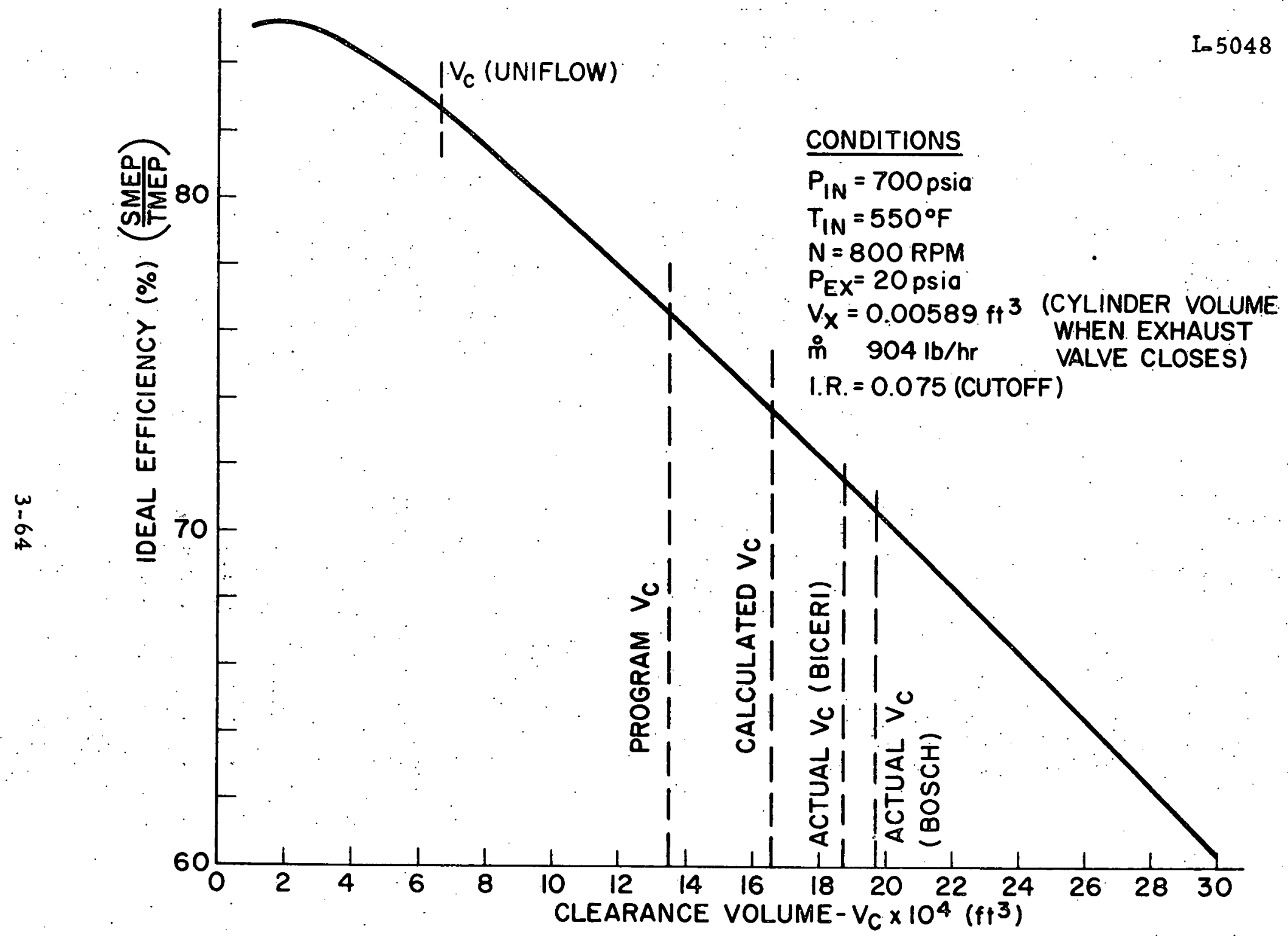

Figure 3.34 Single-Cylinder Expander, Computed Efficiency versus Clearance Volume 


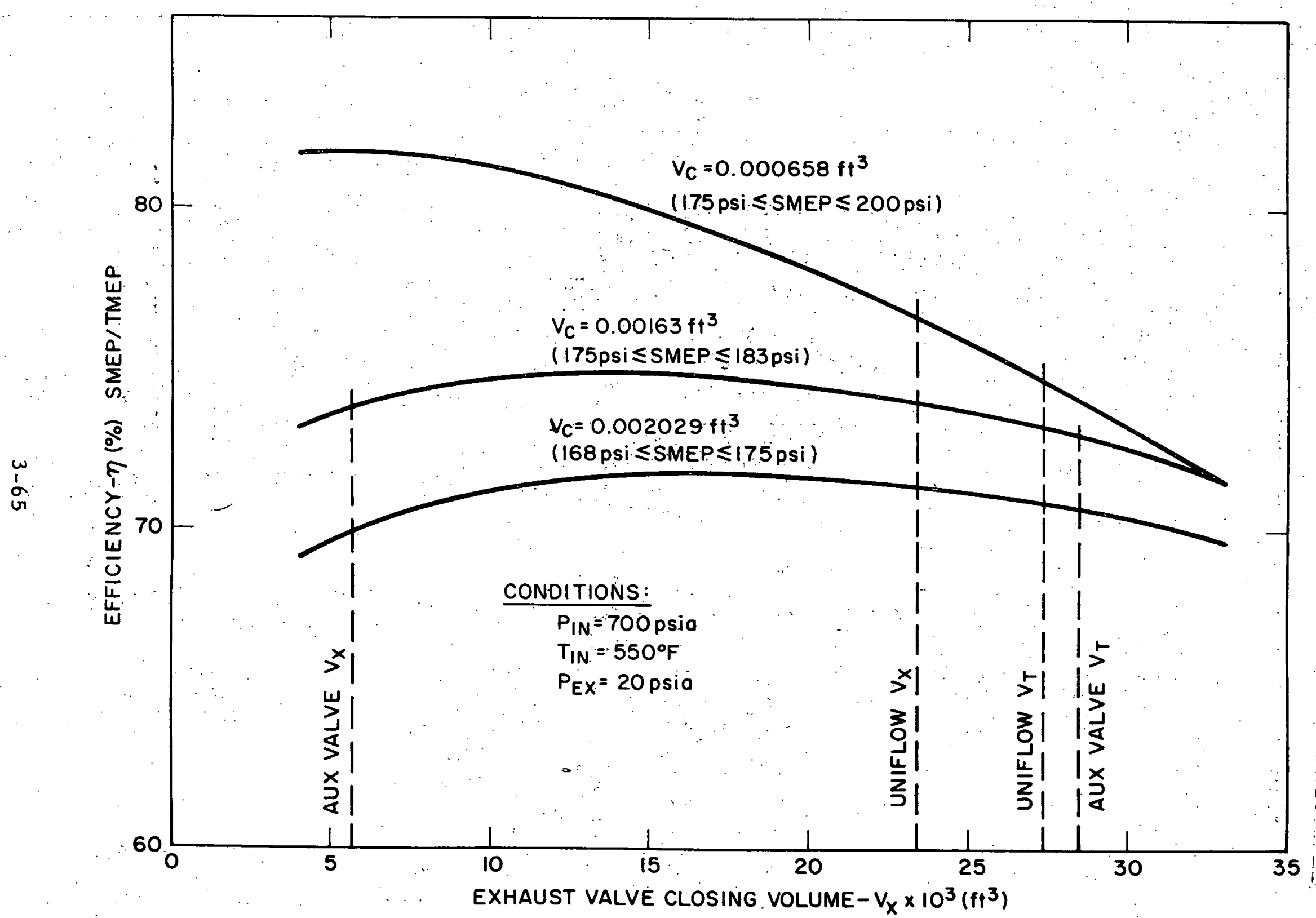

Figure 3.35 Single-Cylinder Expander, Computed Efficiency versus Exhaust Valve Closing Volume 


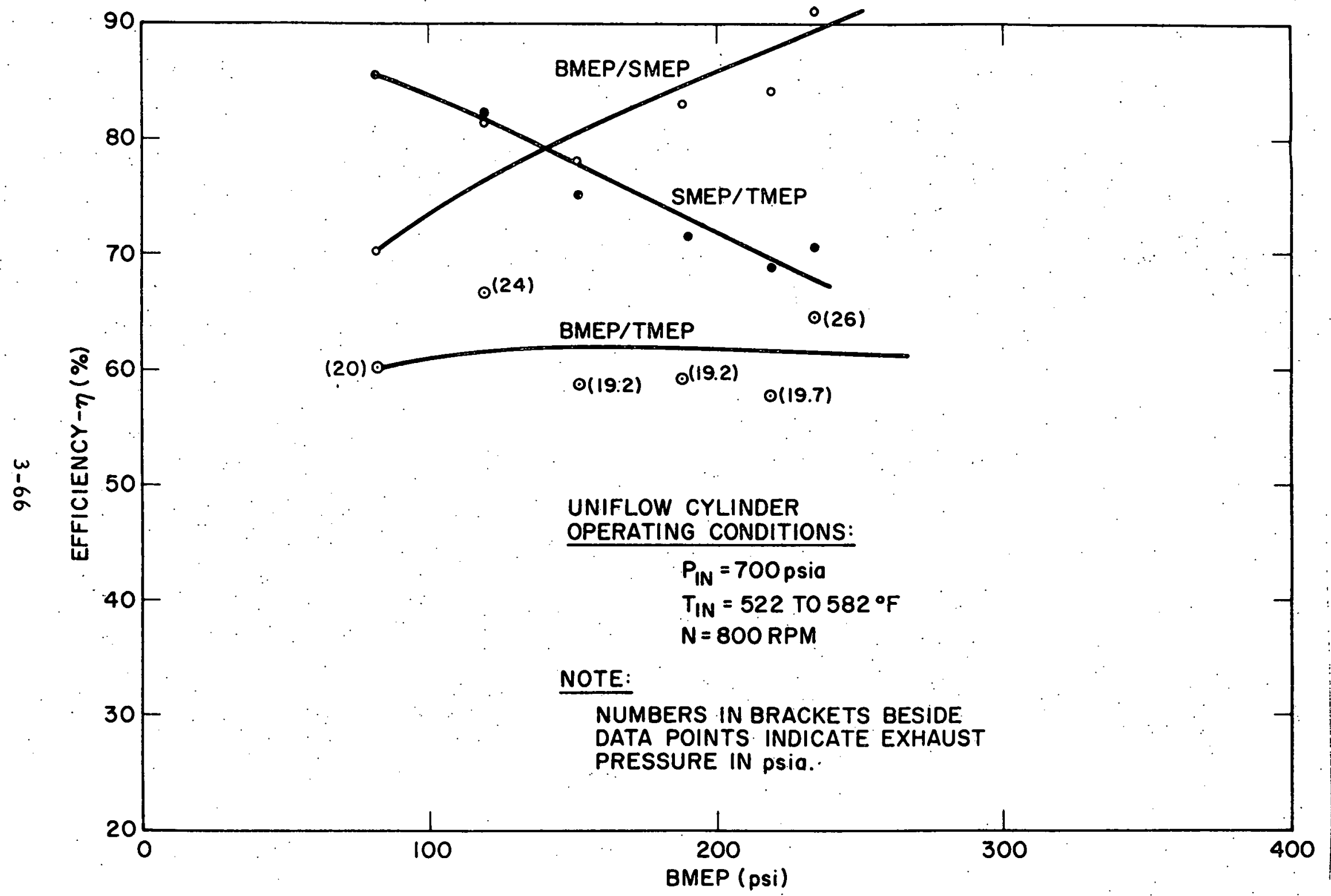

Figure 3.36 Single-Cylinder Expander, Efficiency versus BMEP (BICERI Sleeve Valve) 
The data shown in Figures 3.33 and 3.36 were taken with the BICERI sleeve valve shown in Figure 3.25. The expander performance did not change appreciably when other inlet valve designs were tested. Typical performance data with an inlet valve of the poppet type shown in Figure 3.28 are shown in Figures 3.37 and 3.38 . The power, in terms of hydraulic pumping power, is not significantly different from .. one valve type to the other.

An appreciation for the relative magnitude of the various losses can be gained from thalues of BMEP/SMEP given in Figures 3.33 and 3.37. If the mechanical efficiency is taken into account, then the Indicated mean effective pressure can be compared to the SMEP, and an estimate of the losses due to heat transfer, valving, and mixing with the residuals during the inlet process may be obtained. Attempts to get accurate indicator cards did not result in consistent values for the friction mean effective pressure. But even so, Willans lines and P. V cards indicated mechanical efficiencies of at least 90 percent at $800 \mathrm{rpm}$ and $B M E P$ values above $100 \mathrm{psi}$. This indicates that the above mentioned losses can only be in the order of 10 percent.

\subsubsection{Four-Cylinder Expander Performance}

A summary of the final V-4 expander data is shown in Figures 3.39 and 3.40. All of the changes that resulted in improved performance for the single-cylinder expander were incorporated into the fourcylinder expander used to take these data. The data shown in the figures are for the expander installed in the preprototype engine sys tem. The efficiency shown in the figures is based on the gross expander horsepower. This is the power of the expander shaft after the power to run the valving system is subtracted. 


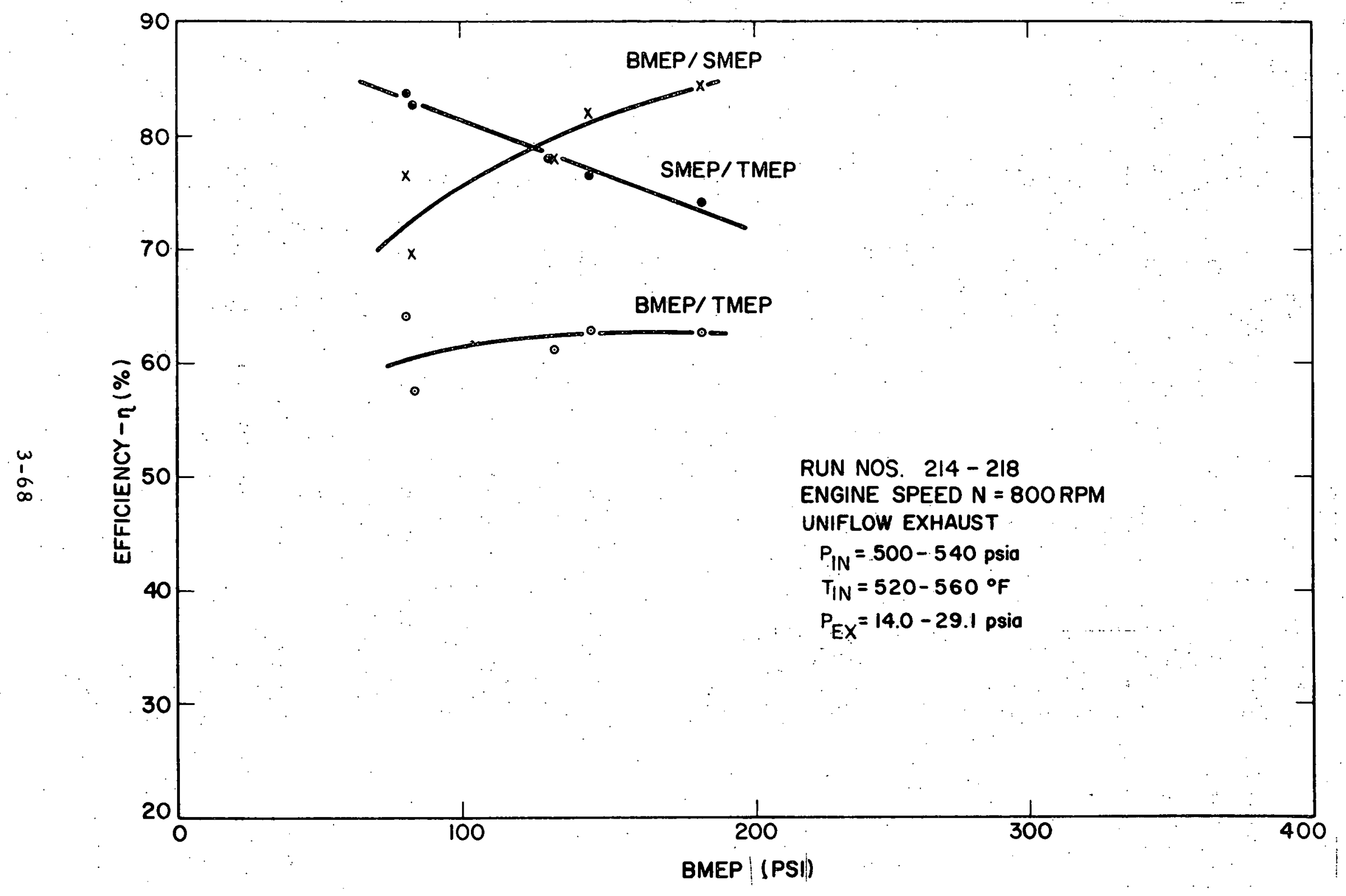

Figure 3.37 Single-Cylinder Expander Efficiency versus BMEP: BICERI Poppet Valve (TECO Design) 3/8" Stem-Nitralloy without Snubber 
A. 1646

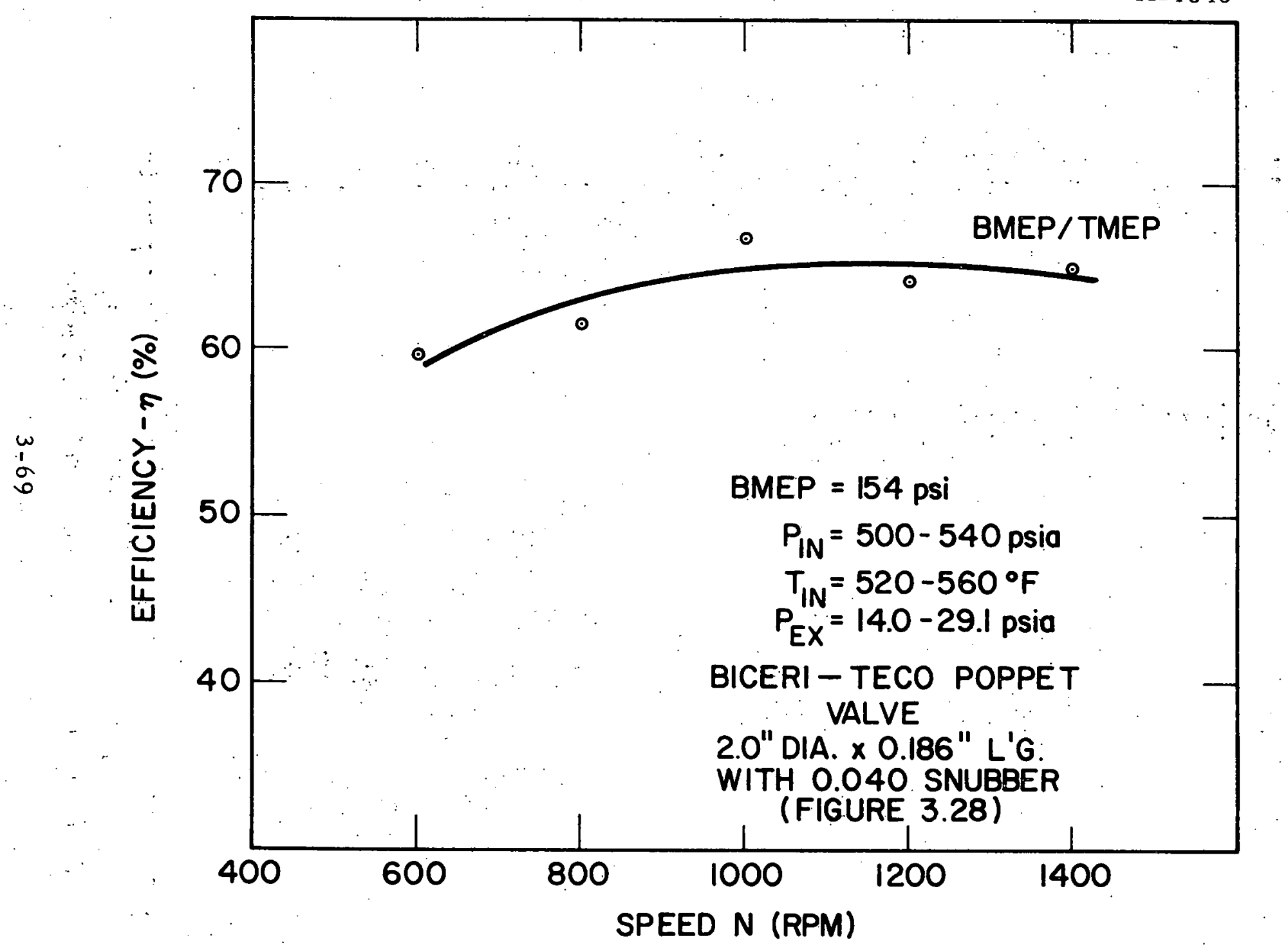

Figure 3.38 Single-Cylinder Expander Overall Efficiency versus Speed 


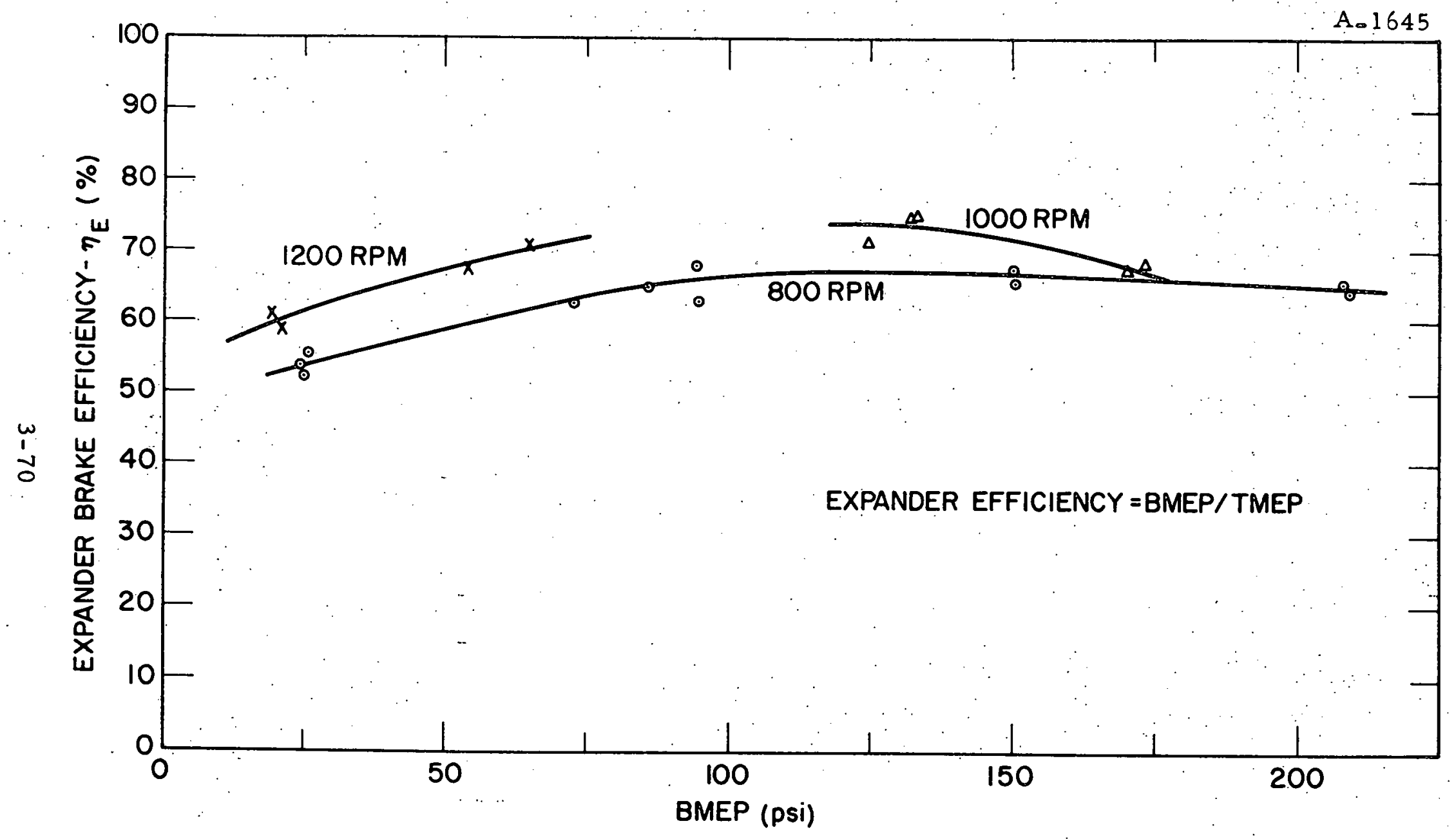

Figure 3.39 Four-Cyllnder Expander Efficiency versus. BMEP 
A- 1617

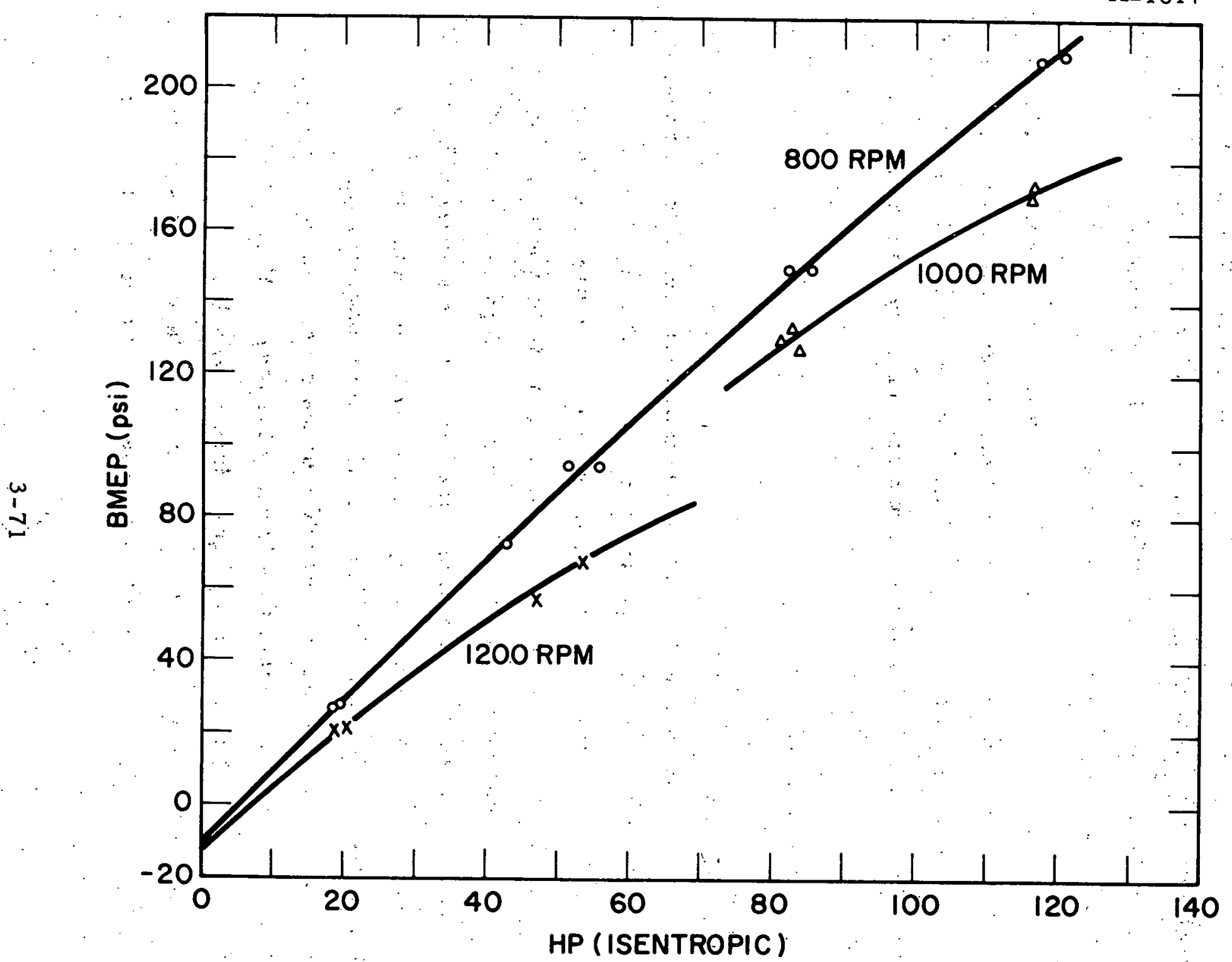

Figure 3.40 BMEP versus Isentropic Horesepower (Preprototype Expander) 
Note that the overall efficiency achieved was somewhat higher than that of the single-cylinder expander. This is due to the lower friction mean effective pressure (FMEP) of the four-cylinder expander. Figure 3.40 is a modified Willan's line, which indicates an FMEP (BMEP at an 1sentropic power of $0 \mathrm{hp}$ ) in the range of 15 to $18 \mathrm{psi}$; this is very close to original estimates.

The expander was run from $3.8 \mathrm{hp}$, which is close to the idle condition, to $93 \mathrm{hp}$, which is in excess of the steady-state power requirement at $85 \mathrm{mph}$. The efficiency of the expander was quite good, varying from 52 percent at a BMEP of 25 to a high of 75 percent at a BMEP of 132.

\subsection{REGENERATOR}

\section{3 .1 Regenerator Design}

The regenerator was designed and fabricated by United Aircraft Products to specifications provided by TECO. The regenerator assembly is shown in Figures 3.41 and 3.42 . The heat exchanger core is of plate-and-fin construction. It is made by stacking alternate layers of vapor circuit and liquid circuit fins, separated by divider plates, and brazing the assembly together. The flow arrangement is cross-counterflow, with one vapor pass, and two liquid passes. A flow schematic is shown in Figure 3.43. The vapor-side fins are faced so that flow is across the width of the core, whereas the liquidside fins are faced so that flow is along the length. Each liquid layer of the core is divided into two equal circuits by a bar placed along the length of the layer: There are seven vapor layers and six liquid layers. Vapor from the expander exhaust enters a common header 


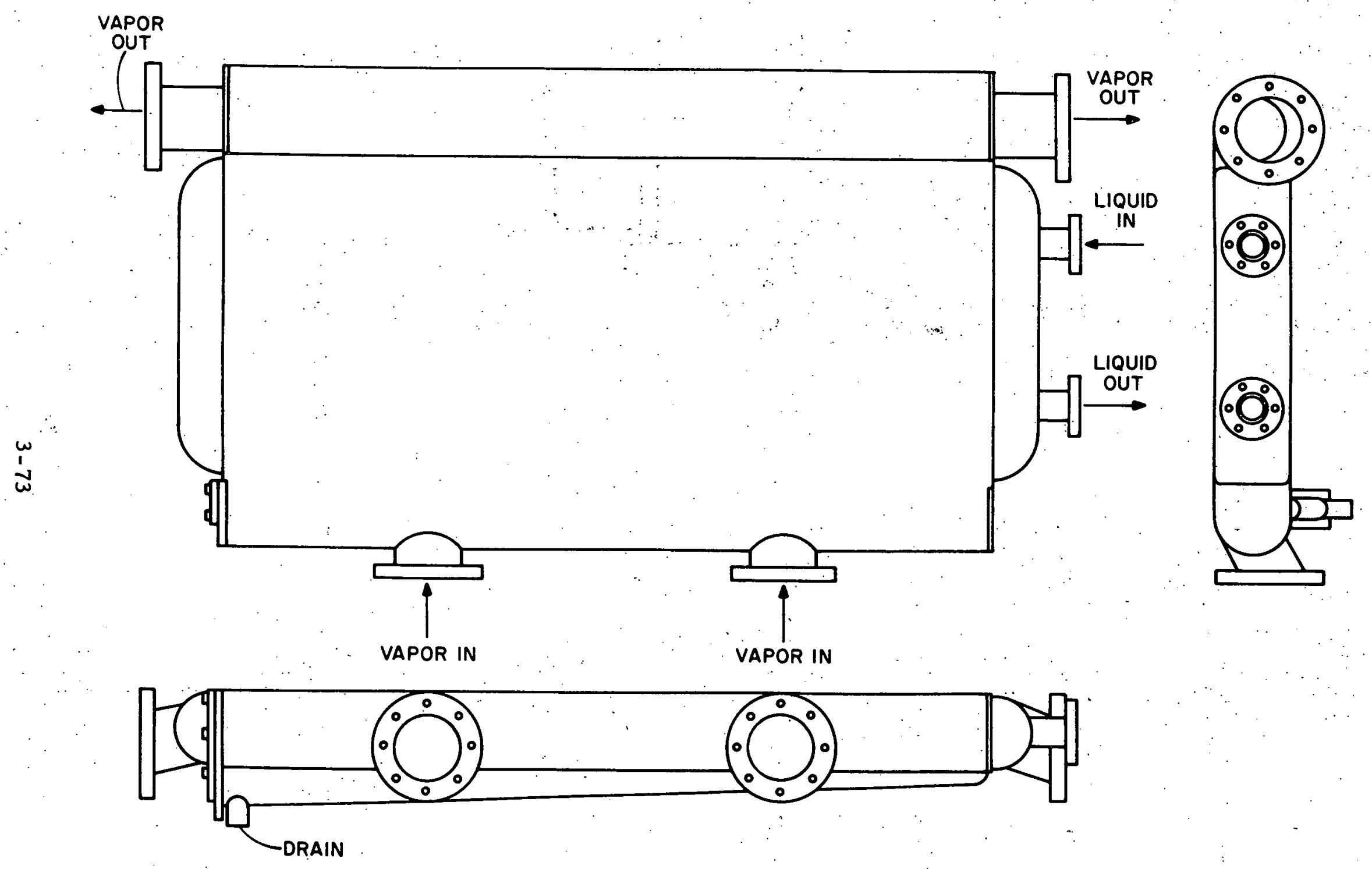

Figure 3.41 Regenerator Assembly 


$$
\text { A- } 1644
$$

FILTER SCREEN

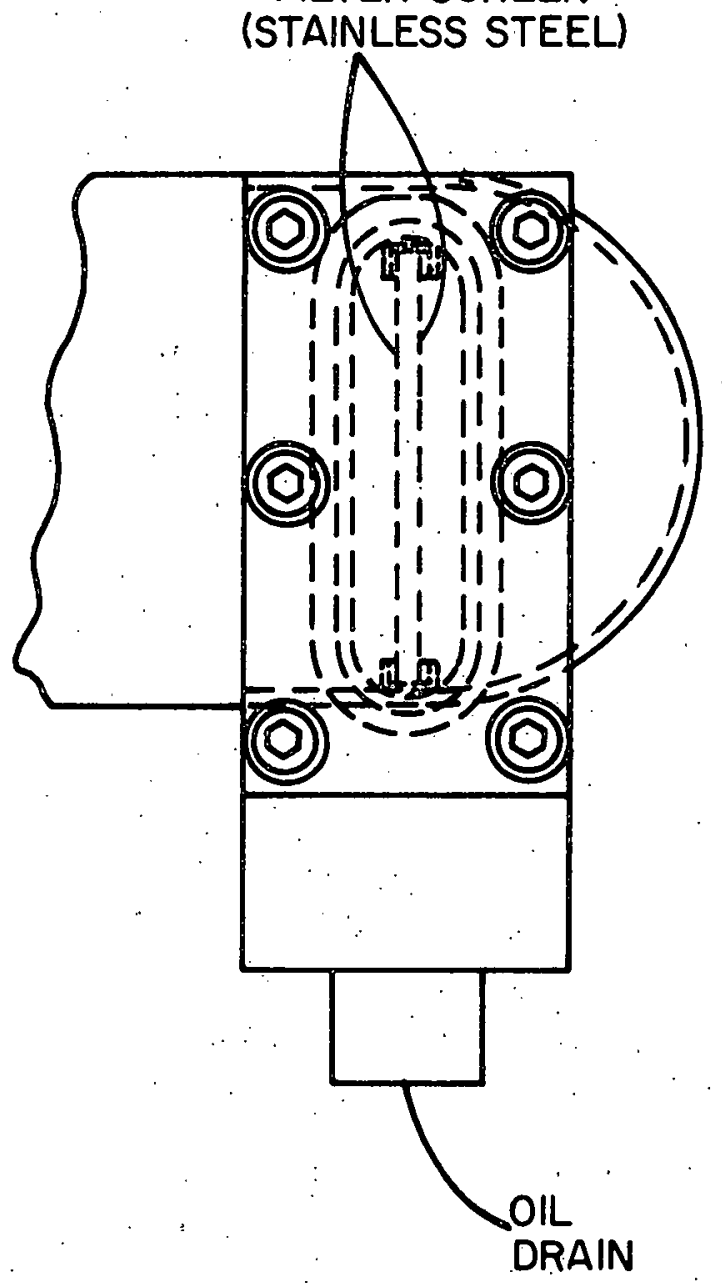

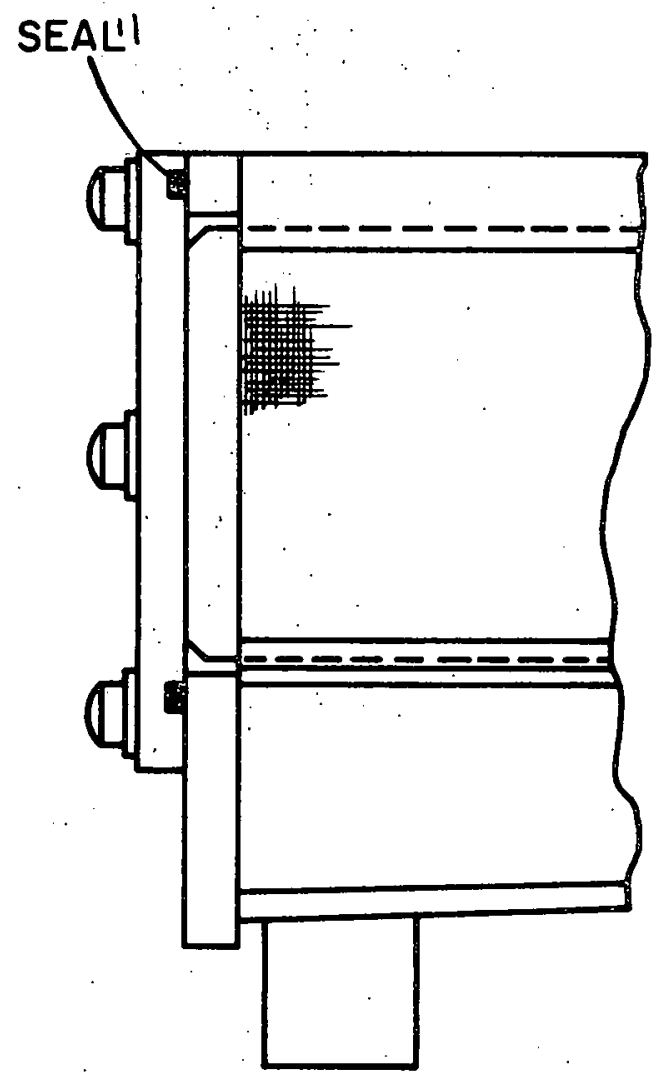

Figure 3.42 Regenerator End Detail 
A-1643

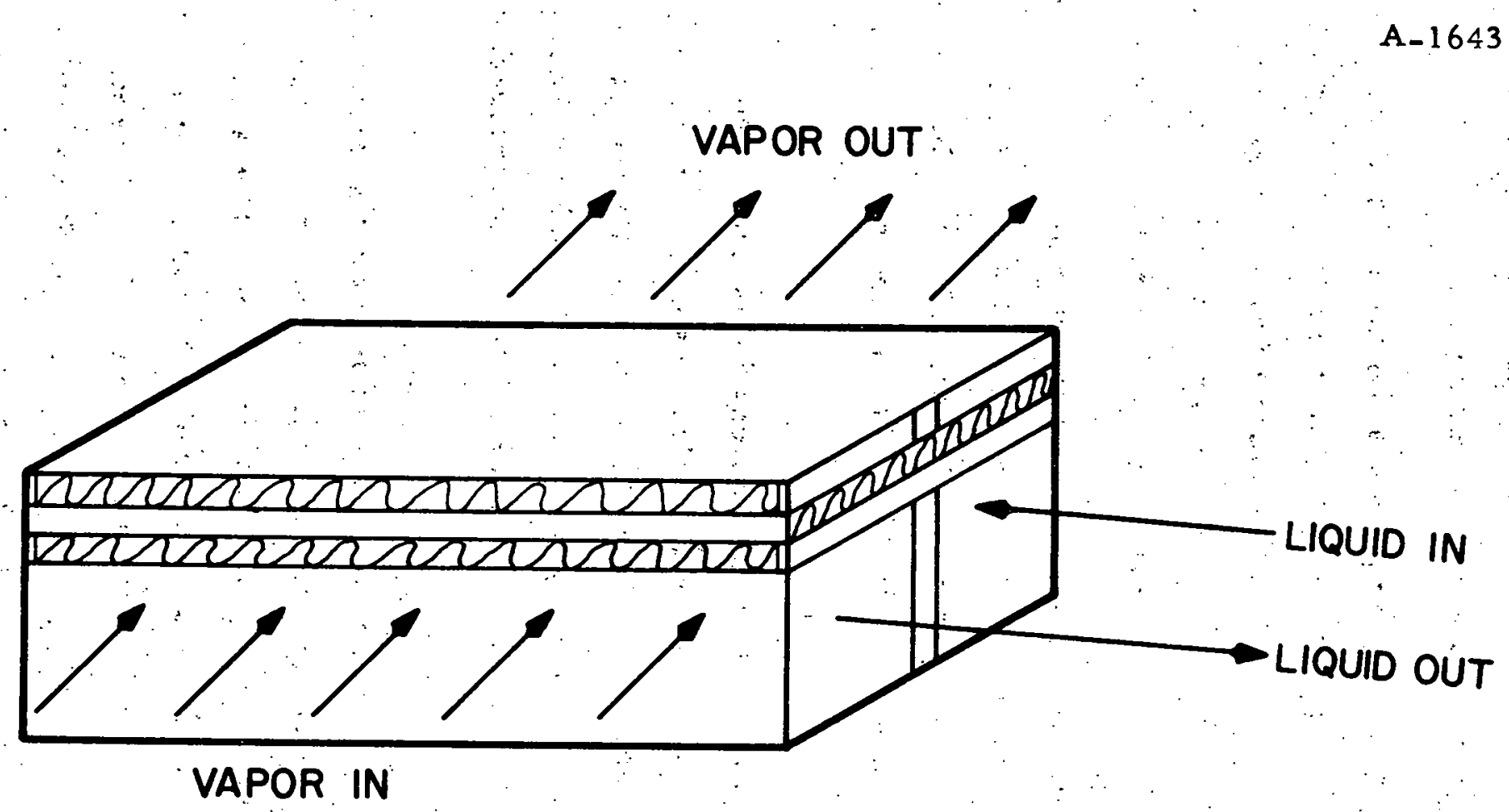

Figure 3. 43 Flow Schematic 
from two inlet ports. It passes through the seven parallel vapor layers to be collected in the outlet header. Vapor exits the regenerator by two ports located at opposite ends of the header.

Liquid from the feedpump enters a header, which connects to the gix parallel liquid circuits on the side of the regenerator nearest the vapor exhaust. After traveling the length of the regenerator, the flow is reversed by a header at the opposite end. It returns the length of the regenerator, by way of the second liquid circuit, to the outlet header.

The regenerator is designed for an effectiveness of 0.815 at the maximum flow of $9860 \mathrm{lbm} / \mathrm{hr}$ and transfers $414,000 \mathrm{Btu} / \mathrm{hr}$ at an expander exhaust temperature of $375^{\circ} \mathrm{F}$ and a liquid inlet temperature of $208^{\circ} \mathrm{F}$. The design-point performance parameters are summarized in Table 3.4.

The heat exchanger is 26.50 in. long by 11.20 in. wide by 2.62 in. thick and weighs $103 \mathrm{lb}$. The vapor-side fins are $0.233 \mathrm{in}$. high, of a ruffled design, $0.007 \mathrm{in}$. thick, and are spaced $24 \mathrm{fins}$ per inch. The liquid-side fins are a lanced type 0.1 in. high and 0.005 in. thick. Physical characteristics of the regenerator are summarized in Table 3.5.

The assembly procedure for the regenerator was as follows. All parts were cleaned first by vapor degreasing using trichloroethylene as the solvent, and then dipping in a solution of Oakite super ruststripper. The fins were then coäted with Nicroblaze type LM alloy, the composition of which is given in Table 3.6, and the core was laid up for brazing by alternately stacking vapor-side fins, divider plates, and liquid-side fins. Bars were also placed to seal the edges of each 
TABLE 3.4

REGENERATOR DESIGN POINT PERFORMANCE

Rate of Heat Transfer

Flow Rate of Fluorinol-85

Fluorinol-85 Conditions

\section{Liquid:}

Inlet Temperature

Inlet Pressure

Outlet Temperature

Outlet Pressure

Vapor

Inlet Temperature

Inlet Pressure

Outlet Temperature

Outlet Pressure

Regenerator Effectiveness
414,400 Btu/hr

$9860 \mathrm{lbm} / \mathrm{hr}$

$208^{\circ} \mathrm{F}$

831 psia

$287^{\circ} \mathrm{F}$

826.5 psia

$375^{\circ} \mathrm{F}$

42. 5 psia

$239^{\circ} \mathrm{F}$

41.2 psia

$81.5 \%$ 
TABLE 3.5

REGENERATOR PHYSICAL CHARACTERISTICS

Flow Pattern

Material

Weight

Braze Alloy

Core Dimensions

Fin Surface

Liquid Side

Fin Type

UAP Number

Fin Density

Helight

Thickness

Transfer Area/Volume

Free Flow Area/Frontal Area

Hydraulic Diameter $\left(4 \dot{\tau}_{h}\right)$

Vapor Side

Fin Type

UAP Number

Fin Density

Height

Thickness

Transfer Area/Volume

Free Flow Area/Frontal Area

Hydraulic Diameter $\left(4 \tau_{h}\right)$
2 pass cross-counter flow

1015 carbon steel

103 lbs

Nicrobraze LM

$26.50 \times 11.20 \times 2.62$
Lanced
Uं-52681 9-7
18.5 FPI
$0.1 \mathrm{in}$.
0.005 in.
$650 \mathrm{ft}^{2} / \mathrm{ft}^{3}$
0.860
$0.00529 \mathrm{ft}$

Ruffled

Similar to U-405649

24 FPI

0.233 in.

$0.007 \mathrm{in.}$

$700 \mathrm{ft}^{2} / \mathrm{ft}^{3}$

0.832

$0.00473 \mathrm{ft}$

Number of Layers

Liquid

Vapor

Frontal Area

Liquid

Vapor:

Volume Between Plates

Liquid

Vapor
6

7

0.0226

$0.294 \mathrm{ft}^{2}$

$0.098 \cdot \mathrm{ft}^{3}$

$0.275 \mathrm{ft}^{3}$ 
A- 1572

TABLE 3.6

COMPOSITION OF NICCROBRAZE ALIOY LM

$\begin{array}{ll}\text { Cr } & 12.0 \% \\ \mathrm{~B} & 2.9 \% \\ \mathrm{Si} & 4.5 \% \\ \mathrm{Fe} & 3.0 \% \\ \mathrm{C} & 0.1 \% \\ \mathrm{Ni} & \text { Balance }\end{array}$


layer and to separate the liquid layers into two circuits. The stacked core was then brazed in a dry hydrogen atmosphere $\left(-90^{\circ} \mathrm{F}\right.$ dewpoint) at $1900^{\circ} \mathrm{F}$. After being allowed to cool, the core was leak checked, and then manifolds and auxiliary ports were TIG welded in place using argon as the inert gas. The finished regenerator assembly was pressure and vacuum leak checked, as outlined in the procedure of Table 3.7. Upon completion of these tests, the exterior surfaces were painted with a high-temperature paint and the interior was charged with argon for protection during shipping and storage. The completed regenerator is shown in Figure 3.44.

Two stainless-steel screens were installed in the inlet header to intercept and coalesce droplets of oil entrained in the exhaust vapor. The screens were made of 5-mil wire and had a pore size of $10 \mathrm{mil}$. They were accessible through a cover plate at one end of the header, as shown in Figure 3.42. Oil separated by the screens drained into a gutter and was returned to the expander crankcase by a 3/4-in. diameter tube. A plat of interception efficiency against droplet size is given in Figure 3:45.

The regenerator was connected to the expander, feedpump, and condenser of the preprototype system by bolted flanges sealed with Viton "0" rings. After installation, the exterior of the regenerator was covered with a minimum of one inch of Fiberfrax ceramic fiber insulation and a layer of aluminum foil.

\subsubsection{Test Results and Performance Evaluation}

The temperature of the working fluid entering and leaving the vapor and liquid sides of the regenerator was measured by thermocouples inserted into the manifold connecting the regenerator with 


\section{A- 1573}

TABLE 3.7

PRESSURE AND VACUUM LEAK TESTS

The completed regenerator was proof tested for the following maximum design conditions.

Liquid Side

Maximum Pressure Maximum Temperature

Vapor Side

Maximum Pressure

Maximum Temperature
850 psig

$350^{\circ} \mathrm{F}$

106 psig

$412^{\circ} \mathrm{F}$

\section{Leak Test}

After pressure testing, the regenerator was checked for leaks on a helium mass spectrometer. The leakage rate with the interior passages of the regenerator vapor side evacuated and the exterior flooded with helium was less than $10^{-7} \mathrm{scc} / \mathrm{sec}$. The leakage rate with the interior passages of the liquid side of the regenerator evacuated was less than $10^{-7} \mathrm{scc} / \mathrm{sec}$. 


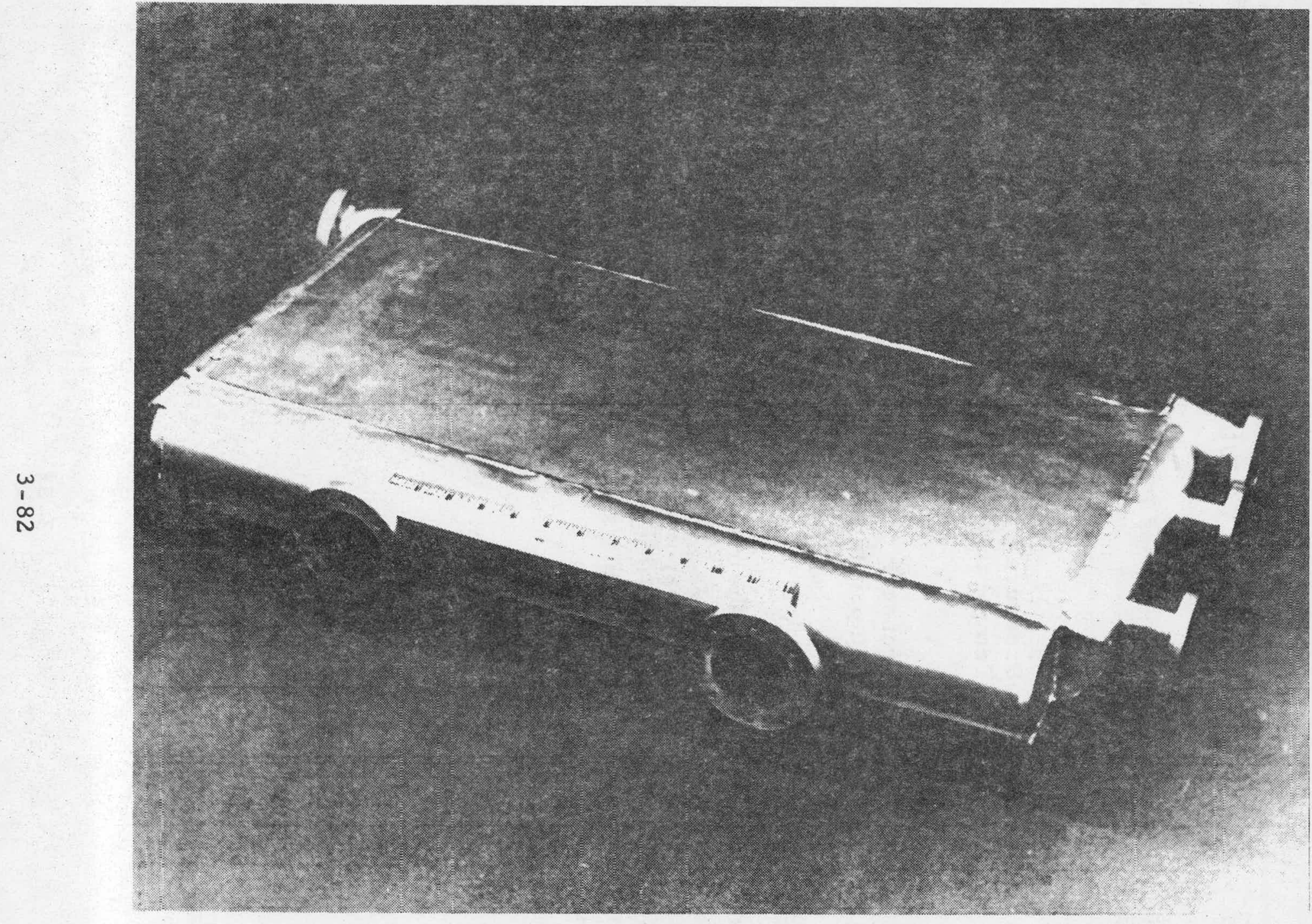

Figure 3.44 Photograph of Regenerator 


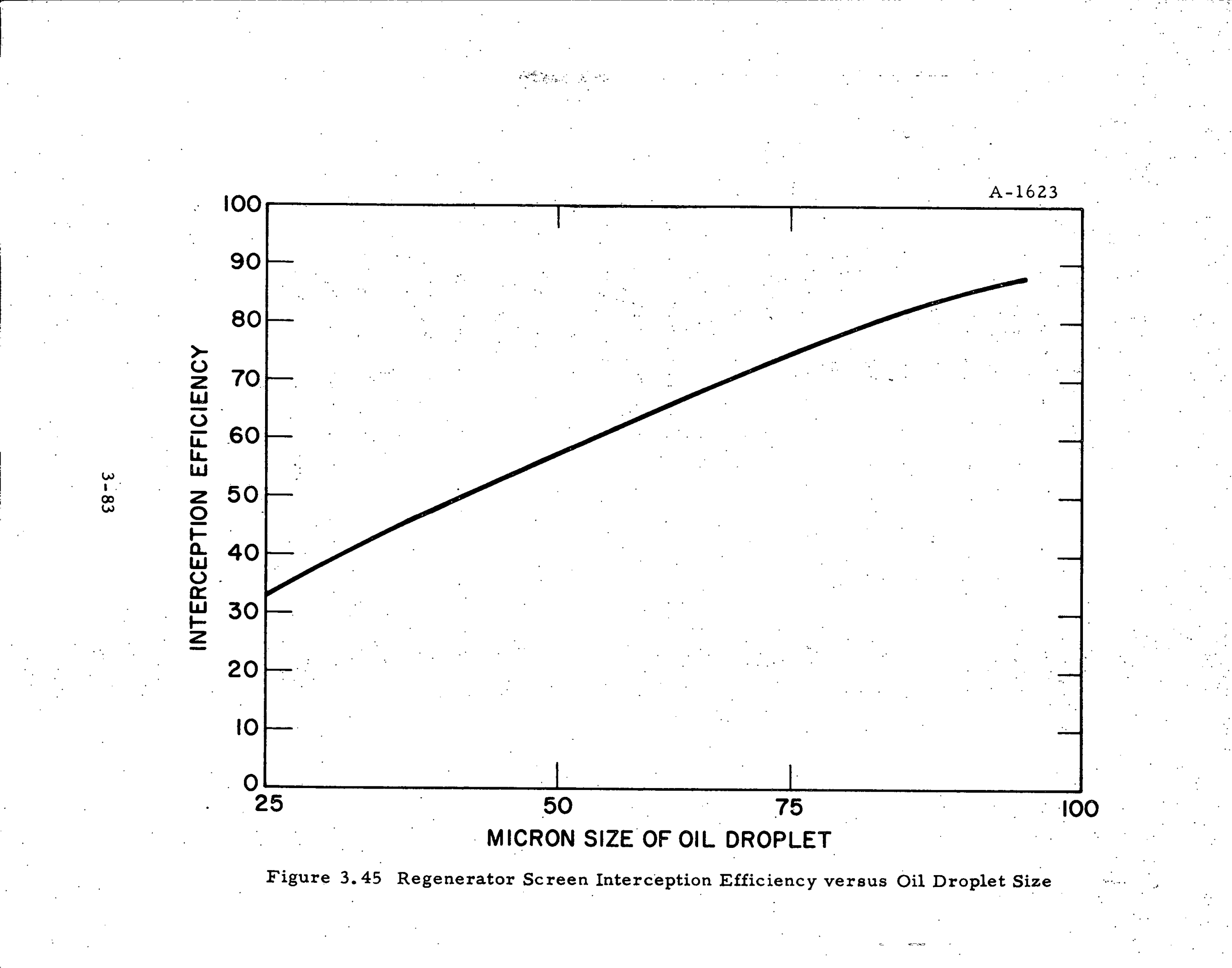


various components of the system. The pressures into and out of the regenerator were also measured and used to determine the pressure drop.

Under a number of operating conditions, particularly at low flow rates, the regenerator condenses some of the organic vapor. This condition is detected by attempting a heat balance between the liquid and vapor sides of the regenerator, assuming no condensation. In those cases where a large discrepancy exists, it is found that the liquid has absorbed more heat than the vapor could have given up had it not begun to condense. Also, in these cases, the measured vapor outlet temperature is found to be within a few degrees of the condensing temperature for the measured pressure. The measured effectiveness plots in Figure 3.46 are for cases in which no condensation occurred. Early in the testing of the regenerator in the preprototype test loop, the oll separation screen was severely damaged, possibly by debris entrained in the high-velocity vapor flow. As a result, the screen was removed and, for all subsequent runs, the regenerator was operated without an oil separator at the inlet.

The liquid-side pressure drop of the regenerator was obtained by subtracting the boller inlet pressure from the feedpump outlet pressure. Since both of the pressures were obtained by reading 1000 psia pressure gauges with $10 \mathrm{psi}$ graduations, it is not possible to obtain the fine resolution necessary to measure the small pressure drops involved. At the higher flow rates run in the system tests 160 to 70 percent of the design point flow) the difference was in the vicinity of $10 \mathrm{psi}$. The predicted drop at the design point was 6.3 psi. 


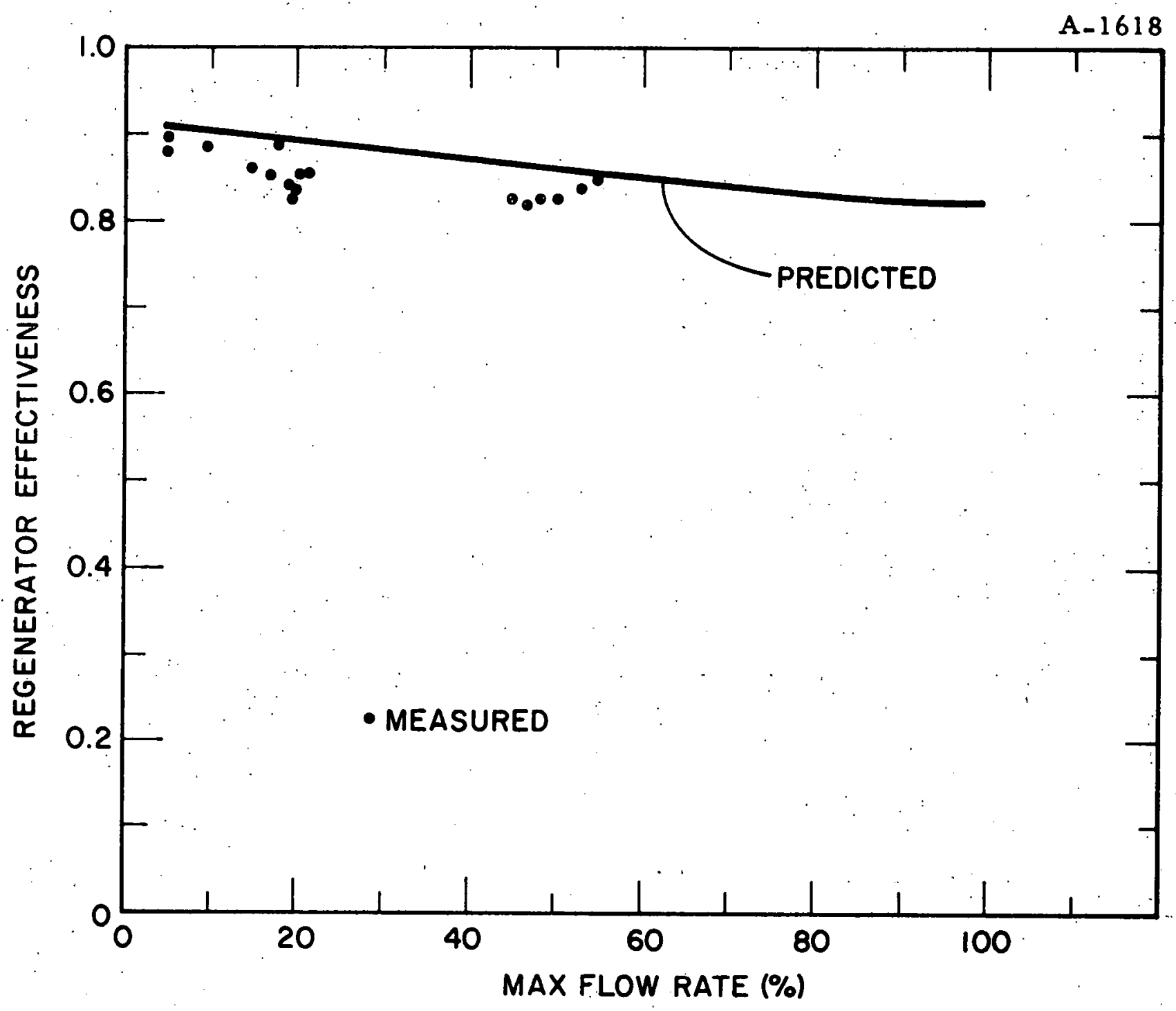

Figure 3.46 Regenerator Effectiveness 
The predicted pressure drop of the vapor side, together with plumbing, 1s $2.7 \mathrm{psi}$. In order to minimize the accumulation of errors in measuring this small difference, the inlet pressure taps were conm nected to a single-pressure gauge through a selector valve. The gauge read from 0 to 200 psia with 1 -psi subdivisions. Duiring the testing, the regenerator was operated over a wide range of pressures and temperatures, with a resultant wide variation in mean density. To allow comparison of these points, the data were referenced to a pressure drop.at the design point density. This was accomplished by multiplying the measured pressure difference by a correction factor obtained by dividing the density at measured conditions by the design point density. These data are plotted in Figure 3.47.

\subsection{FAN AND CONDENSER}

\subsubsection{Fan and Condenser Désign}

The fan and condenser used in the preprototype system tests were designed by AiResearch Manufacturing Company under Contract Number 68-01-0407 for the Environmental Protection Agency. The design and testing program carried out at AiResearch is reported in Reference 5. A photograph of the condenser-fan assembly is shown in Figure 3.48.

The frontal area of the condenser was made as large as possible consistent with the requirement that the condenser fit in a 1972 Ford Galaxie engine compartment. Then, assuming a constant frontal area and a constant condensing coefficient, the relationships between condenser effectiveness and condenser volume were derived. These relationships are plotted in Figure 3.49. As can be seen from the graph, 


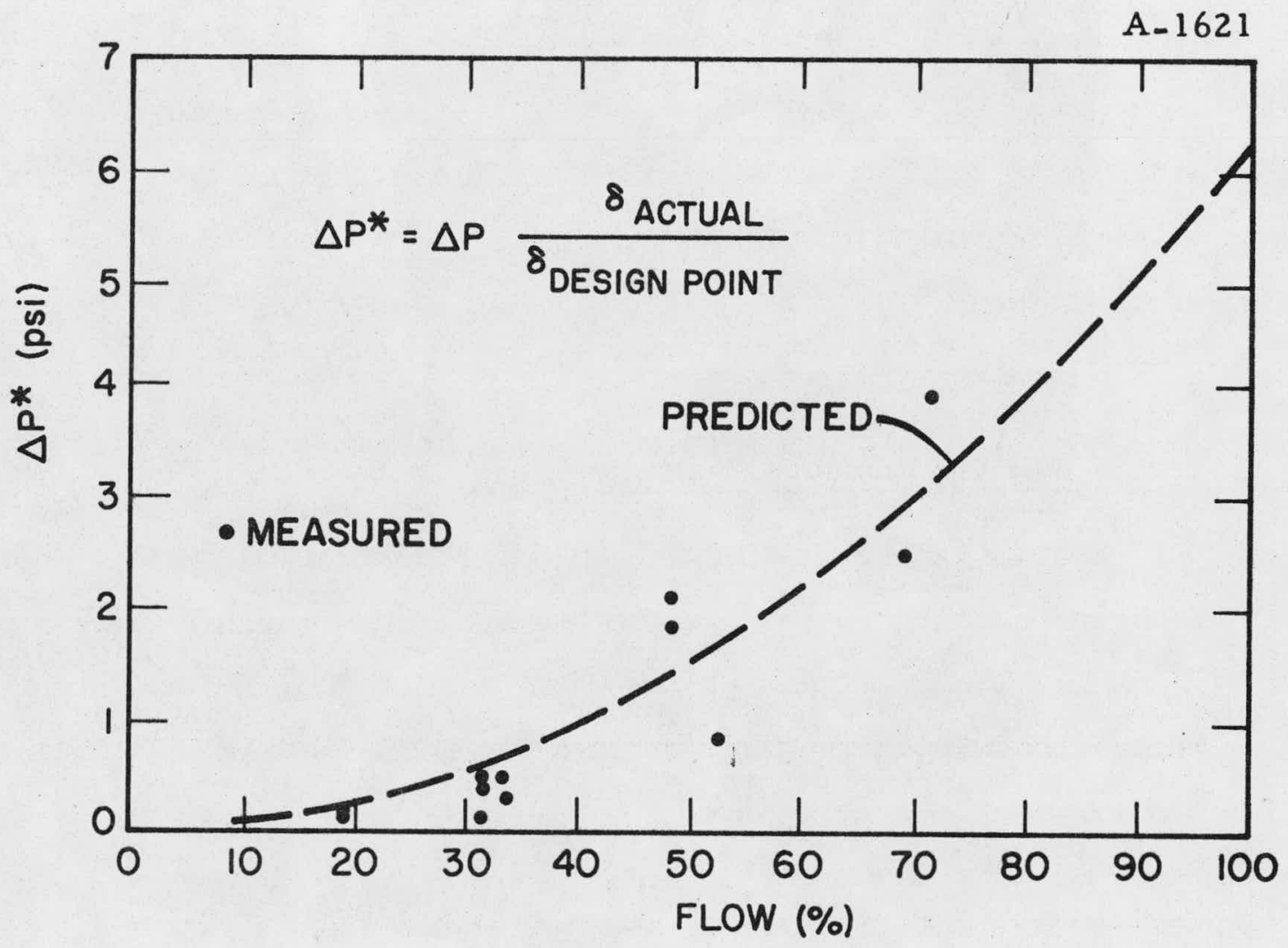

Figure 3.47 Regenerator Vapor-Side Pressure Drop 
I-4112

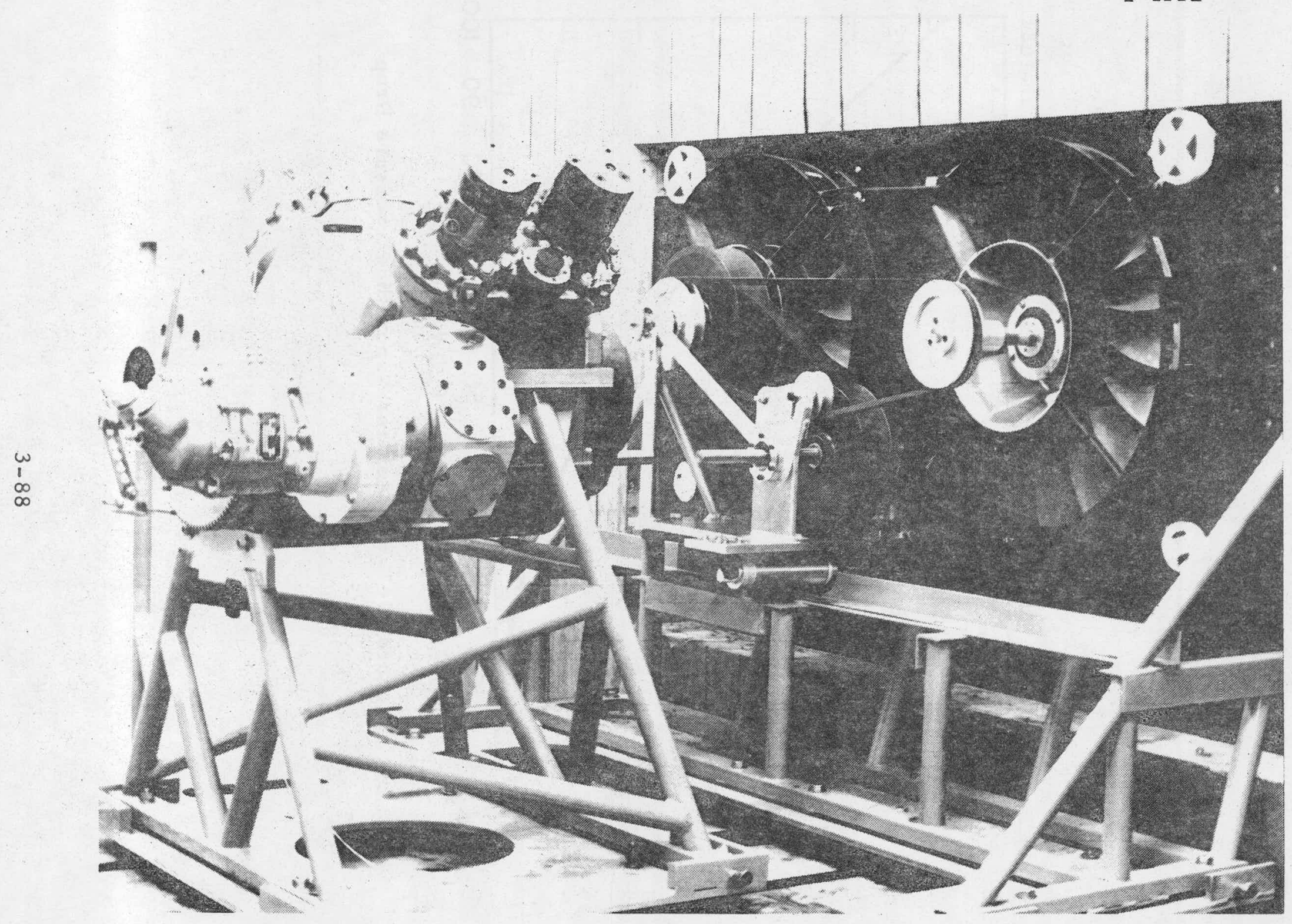

Figure 3.48 Rear View of Condenser with Fans 


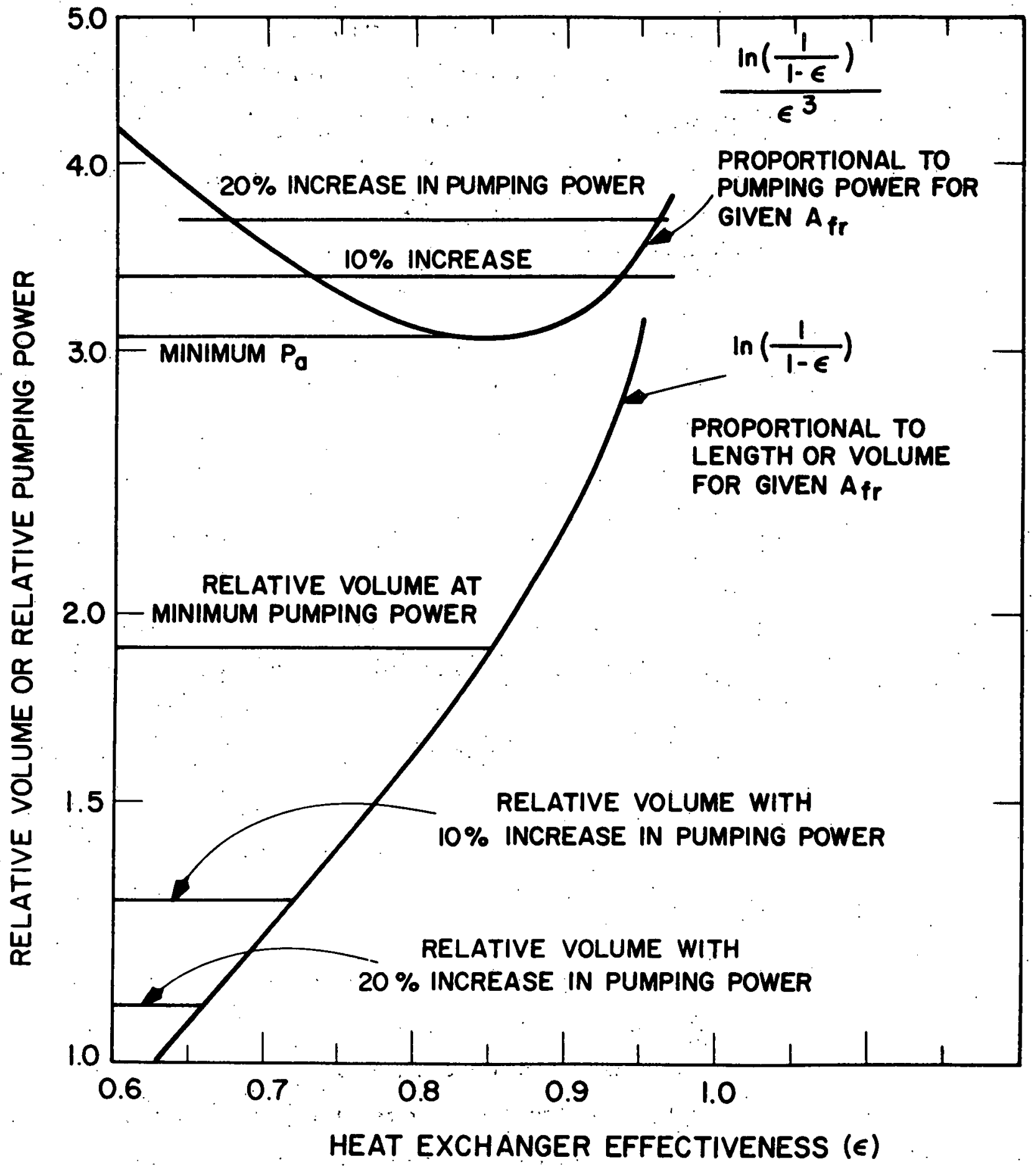

Figure 3.49 Variation of Relative Volume and Relative Fan Power with Heat Exchanger Effectiveness 
the pumping power goes through a minimum at a heat exchanger effec- ? tiveness of 0.85 , whereas condenser volume always increases for increased effectiveness. Decreases in volume can be obtained by decreasing the effectiveness and increasing ideal pumping power. An effectiveness of 0.8 was chosen as the condenser design point. This value gives a volume 15 percent lower than an effectiveness of 0.85 with an increase in pumping power of only 1.8 percent. Using this value of effectiveness, and the package restraints imposed by the system, AiResearch designed a condenser requiring minimum air pumping power. The design requirements for the condenser are given in Table 3.8 and a design summary in Table 3.9.

The condenser was assembled using a fluxless brazing process. Fluxless brazing was chosen over the more conventional salt-bath brazing to avold entrapment of flux in the small vapor passages. The fin material, both air and vapor side, is 3003 aluminum. The tube sheets were Reynolds MD-151 clad sheet. The base material for this sheet is 6951 aluminum, and it is clad with type X4003 cladding. Rein. forcement bars were type 6951 aluminum alloy. The use of the heattreatable 6951 alloy was dictated by the high working pressure in the condenser. Tofacilitate brazing, the cores were assembled as four modules. After brazing, these modules were assembled by TIG welding. Following testing of these welds, the pan assemblies, shrouds, support brackets, and ducts were welded in place. The final machining was done and the assembly pressure leak checked. The exterior surfaces of the core were then coated with an epoxy ester material prior to helium leak testing. Helium leakage of the core was less than $4.8 \times 10^{-9} \mathrm{scc} / \mathrm{sec}$. 
TABLE 3.8

CONDENSER DESIGN REQUIREMENTS

Vapor Side

Working Fluid

Fluorinol- 85

Total heat rejection, Btu/hr

$1.88 \times 10^{6}$

Flow; 1b/hr

9860

Inlet temperature, ${ }^{\circ} \mathrm{F}$

238

Inlet pressure, psia

40.0

Condensing temperature (avg), ${ }^{\circ} \mathrm{F}$

212

Condensing pressure (avg), psia

36.4

Liquid outlet temperature, ${ }^{\circ} \mathrm{F}$

193

Subcooling, ${ }^{\circ} \mathrm{F}$

17.0

Core Pressure drop, psi

2. 6

Overall pressure drop, psi

5. 0

Maximum operating conditions

100 psig at. $300^{\circ} \mathrm{F}$

Maximum allowable leakage, scc/sec

$1 \times 10^{-6}$

of helium :.. .

\section{Air Side}

Flow, lb/hr

75,300

Inlet temperature, ${ }^{\circ} \mathrm{F}$

85

Inlet pressure, psia

14.7

Outlet temperature, ${ }^{\circ} \mathrm{F}$

189

Temperature effectiveness

0.80

Overall core pressure drop, in. $\mathrm{H}_{2} \mathrm{O}$

4.1 


\section{A-1575}

TABLE 3.9

\section{CONDENSER DESIGN SUMMARY}

Weight

Airflow length

Vapor-side flow length (core only)

Width

Air-side fins (nominal)

Height

Thickness

Fins/inch

Vapor-side fins

Height

Thickness

:Fins/inch
$137 \mathrm{1b}$

$4.50 \mathrm{in}$. $20.8 \mathrm{in}$.

57.8 in.

Perforated ( -13$)$

0.326 in.

$0.004 \mathrm{in}$.

22

Offset rectangular

$0.050 \mathrm{in}$.

$0.004 \mathrm{in}$.

20 
The condenser fans were also designed, fabricated, and tested by AiResearch under the same EPA contract and this work i.s reported in Reference 5. The fans are of a tube axial design. The blades are aerodynamically shaped to maximize the fan efficiency and are shaped so that the air leaving the blade tips has a radial velocity component. This was done to minimize the blockage effect of the expander and vapor generator, both of which are mounted close behind the fans. The impeller housing was designed for a fan tip-to-housing clearance of $0.030 \mathrm{in}$. The housing centerbody, which supports the fan, is held by four struts. The struts are aligned with the average air angle leaving the impeller for minimum resistance, and spaced so that only one blade wake strikes a strut at any given instant. The latter was, done to minimize noise levels. Each fan is held by a pair of ball bearings in the centerbody. The bearings are preloaded and lubricated for their 3000-hr life with a high-temperature grease.

The housing assembly was welded of sections of 6061 aluminum and heat treated to a T-6 condition. The impeller was cast 356 aluminum, also treated to a T-6 condition. Extra material was allowed on two planes of the impeller hub to facilitate balancing. After balancing, each impeller was run to $5400 \mathrm{rpm}$, which is 1.5 times the maximum rated speed. The fans were tested for aerodynamic performance and noise levels prior to shipment to TECO. The fan design requirements are given in Table 3.10 and the fan parameters in Table 3.11 .

\subsubsection{Condenser and.Fan Testing, and Performance Evaluation}

For various operating conditions, the amount of desuperheating and subcooling that takes place in the condenser varies considerably. 


\section{FAN DESIGN REQUIREMENTS}

Total number of fans

Design point vehicle speed, mph

Ambient temperature, ${ }^{\circ} \mathrm{F}$

Ambient pressure, psia

Air temperature at fan inlet, ${ }^{\circ} \mathrm{F}$

Total airflow, $1 \mathrm{~b} / \mathrm{hr}$

Volumetric airflow per fan, cfm

Inlet flow dynamic pressure, in. $\mathrm{H}_{2} \mathrm{O}$

Inlet recovery factor, percent

Net ram pressure rise, in. $\mathrm{H}_{2} \mathrm{O}$

Predicted condenser air-side pressure drop, in. $\mathrm{H}_{2} \mathrm{O}$

Installation loss, in. $\mathrm{H}_{2} \mathrm{O}^{(1)}$

Required fan total pressure rise, in. $\mathrm{H}_{2} \mathrm{O}$

Calculated air horsepower

Specified efficiency, percent

Fan rotation (2)

Fan drive mechanism ${ }^{(3)}$

Maximum overall length, in.

Fan noise level, dbA maximum
2

107

85 :

$14: 7$

189

75,300

10,300

3.79

100

3.79

4.09

2. 80

3.10

5.0

70

ccw

V-belt

4.0

(1) Installation loss includes losses across the bumper, grille, transition section between condenser and fans, and the engine compartment.

(2). Fan rotation as viewed from driver's seat.

(3) V-belt drive mechanism supplied by Thermo Electron' Corporation.

(4) Fan noise levels are not specified. However, overall vehicle noise level, of which the fans are a major portion, shall not exceed $77 \mathrm{dbA}$ at $40 \mathrm{ft}$; according to the EPA vehicle specifications. 
TABLE 3.11

FAN PARAMETERS

\begin{tabular}{|ll|}
\hline Speed & $2400 \mathrm{rpm}$ \\
Tip Diameter & $22 \mathrm{in}$ \\
Number of Blades & 17
\end{tabular}

FAN BLADE PARAMETERS

\begin{tabular}{|c|c|c|c|}
\hline \multicolumn{1}{|c|}{ Streamline } & Hub & Mean & Tip \\
\hline Leading edge radius, in. & 4.0 & 8.3 & 1.0 \\
Trailing edge radius, in. & 5.5 & 8.7 & 11.0 \\
Camber angle, deg & 45.0 & 19.4 & 11.9 \\
Chord along streamline, in. & 3.48 & 3.77 & 3.84 \\
Thickness; percent & 1.2 .0 & 8.5 & 6.0 \\
Incidence angle, deg & -3.8 & 1.1 & -0.8 \\
Stagger angle, deg & 21.0 & 57.3 & 68.6 \\
\hline
\end{tabular}


In order to allow a comparison of predicted to actual performance over a wide range of operating conditions, the effectiveness of the condensing portion of the condenser was plotted against predicted values. The average condensing temperature was determined by averaging the inlet and outlet pressures of the condenser and taking the corresponding condensing temperature from the fluid properties tables. In order to determine the outlet air temperature corresponding to the condensing section, several thermocouples were placed in the air stream at various locations. Since condensation is essentially a constant temperature process, the thermocouples measuring air temperature over the conderising region agree within a few degrees, whereas those above and below the condensing section differ significantly. To ensure that the air temperature profile was identified accurately, those cases in which partial condensation had taken place in the regenerator were not included in the analysis. A plot of predicted condenser effectiveness and of the test results is given in Figure 3.50. The effectiveness was defined as:

$$
\epsilon_{c}=\frac{T_{\text {air, out }}-T_{\text {air, in }}}{T_{\text {cond }}-T_{\text {air, in }}}
$$

In almost all cases, the difference between the condensing temperature and ambient air was less than $100^{\circ} \mathrm{F}$. The small temperature difference involved made the effectiveness extremely sensitive to small variations in temperature. This sensitivity to temperature measurement is evidenced by the large amount of scatter in the data of Figure 3.50. However, the results do tend to confirm the curve of predicted effectiveness. 


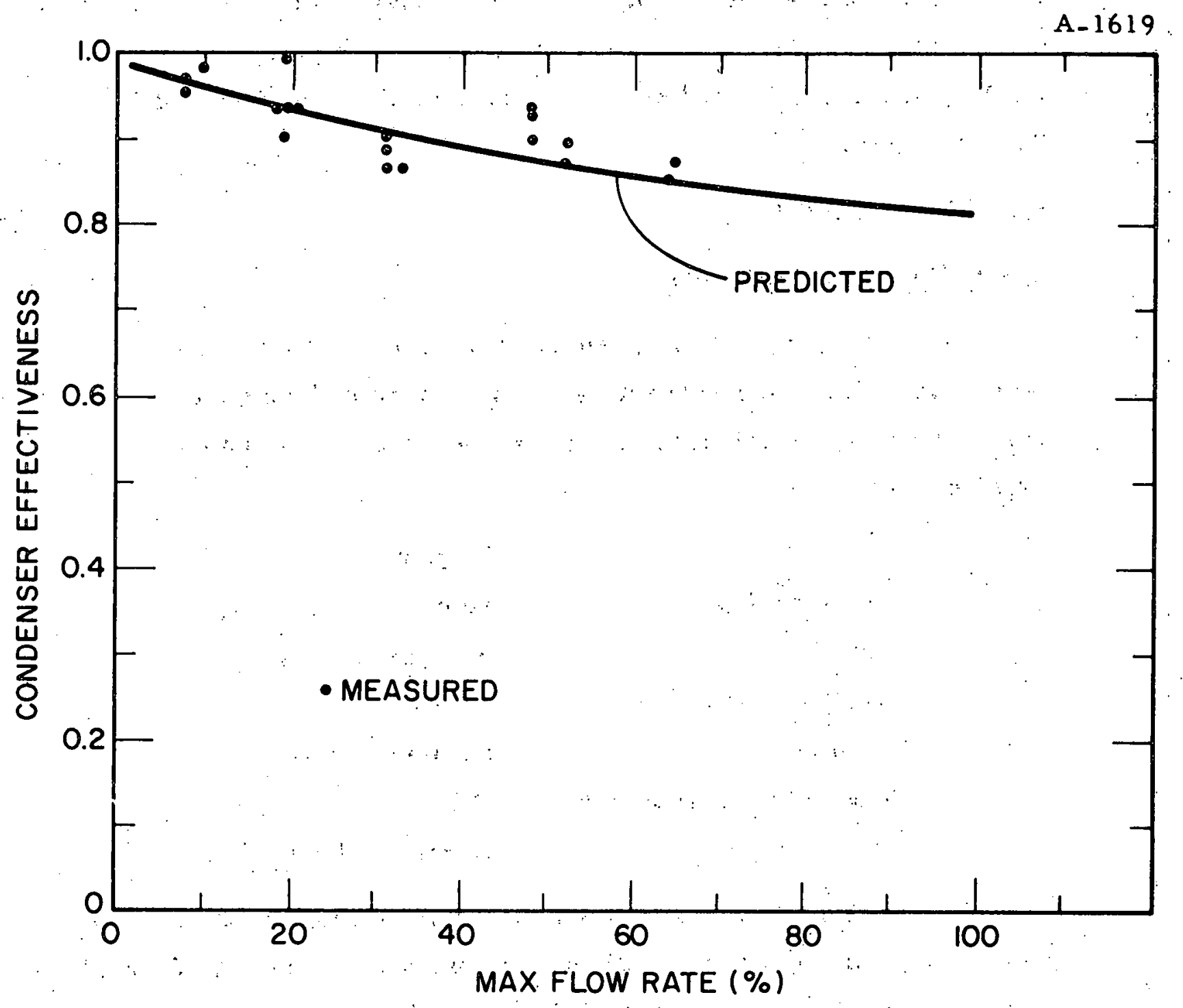

$\therefore$ Figure 3.50. Condenser Effectiveness

$3-97$ 
The air-side pressure drop of the condenser and the performance of the fans were tested extensively at AiResearch as part of the development contract. Figure 3.51 gives the performance characteristics of the fan, and Figure 3.52 shows the AiResearch condenser and fan airflow test results.

\subsection{BOOST PUMP}

\subsubsection{Boost Pump Design}

The boost pump for the preprototype system was designed and developed under a subcontract by Barber Nichols Engineering Company and is shown in Figure 2.6. The primary design requirements are listed below:

$\begin{array}{ll}\text { Flow } & 17 \mathrm{gpm} \\ \text { Pressure Rise } & 10 \mathrm{ps} ! \\ \text { NPSH } & \sim 0 \mathrm{psi} \\ \text { Power Source } & 24 \mathrm{~V} \mathrm{dc} \\ \text { Fluid } & \text { Fluorinol-85 } \\ \text { Max. Fiuid Temperature } & 300^{\circ} \mathrm{F} \\ \text { Construction } & \text { Hermetically sealed }\end{array}$

The impeller is a $\mathrm{Nash}$ design with a liquid ring on one side and a centrifugal impeller on the other. The purpose of the liquid ring is to remove vapor and noncondensibles from the impeller eye, thus preventing the centrifugal pump from cavitating.: This impeller has the capability of delivering the flow at the required outlet pressure at basically 0 psi of NPSH. The impeller design was modified slightly and designed into a new housing, drive unit, and electric motor-driven pump assembly. 


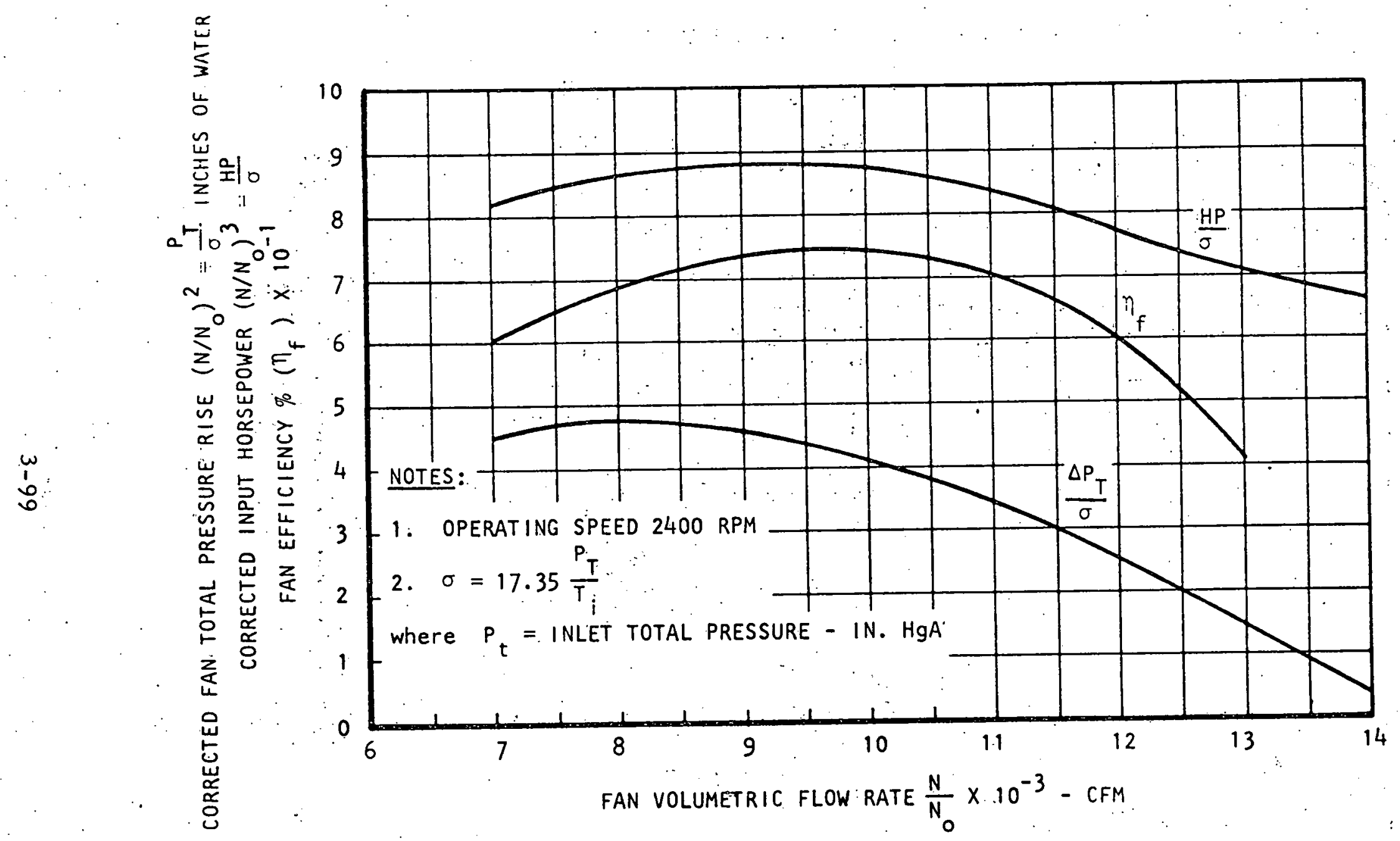

Figure 3.51. Performance of the TECO Shaft-Driven Fan, AiResearch PN 605977-1-1 


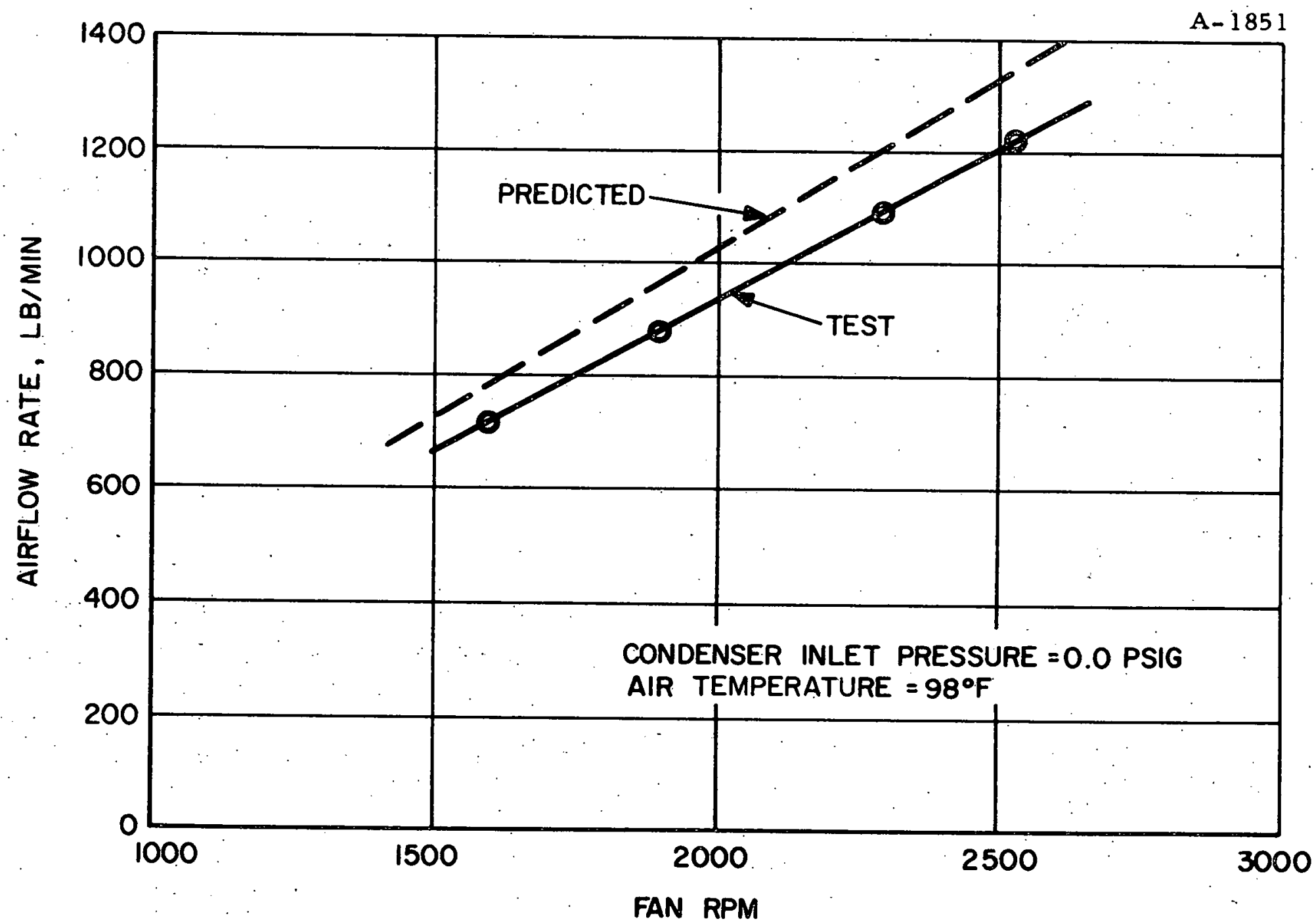

Figure 3.52. Condenser and Fan Airflow Test Results 
To eliminate the need for a rotary shaft seal, a magnetic coupling was selected to couple the drive of the pump to the electric motor. The drive assembly is made up of two sets of Indiana General Indox I magnets, with the inner set rotating inside a stainless-steel shell, which is sealed to the pump housing. All sealing is done through the use of Viton $A$-rings at the static surfaces in the pump assembly. A Carter EMU series motor was selected, which delivers $1 / 3 \mathrm{hp}$ at 5500 rpm with à $24-V$ de supply.

During development testing, some modifications were made in the boost pump design. There was a wear problem on the rear journal bearing for the magnetic drive shaft assembly (bearing farthest from the impeller) after several hours of running at vacuum conditions with water. This bearing is in a trapped a rea and, at vacuum conditions, was operating in vapor. To provide a path for fluid back to this bearing, the pump drive shaft was bored out, which allowed liquid from the front bearing (which is slightly pressurized) to flow through the shaft back to the rear bearing and out into the eye of the impeller. Grooves were added to the Rulon bearings to ensure fluid flow to all the Rulon running surfaces for film lubrication. These provide a trap for particles to keep them from imbedding in the Rulon and wearing the metal running surfaces.

\subsubsection{Test Results and Performance Evaluation}

Much of the initial testing performed at Barber-Nichols was to onsure proper operation of the pump in handling vapor and noncondensibles without causing the pump to lose prine. Of course, durability was another important factor and the modifications described above were incorporated to improve the life of the boost pump. 
In tests performed on their test stand; Barber-Nichols obtained the characteristic curves for the boost pump shown in Figure 3.54. Data were taken using Fluorinol-85 at three levels of NPSH. The overall efficiency ranges from a high of 22.5 percent at an NPSH of 4.5 in. of Fluorinol-85, to a high of 35.5 percent at an NPSH of 1.94 in. of Fluorinol-85. Data were also taken on the 24-V de motor chosen to drive the boost pump. The motor characteristics for the same tests reported in Figure 3.54 are shown in Figure 3.55 for the three levels of NPSH,

During all the testing on the preprototype system, the boost pump performance was continually monitored. Some results at various Fluorinol-85 flow levels are plotted in Figure 3.56. The NPSH on the boost pump in these preprototype tests generally fell within the range between 7 in, and 19.4 in. of Fluorinol-85, and agreed with the per:formance measured by Barber-Nichols in their testing. The agreement in performance is quite consistent and remained that way throughout all preprototype testing, indicating no major difficulties in the mechanical durability of the boost pump.

\subsection{FEEDPUMP}

\subsubsection{Feedpump Design}

A piston type feedpump was selected based on Thermo Electron's past experience with pumping organic fluids. Although the pump work at the design point was only 5 percent of the expander output, the pump work at high shaft speeds and low expander output power would have been excessive if a fixed displacement pump were used. For this reason, a variable-displacement design was selected. One additional 


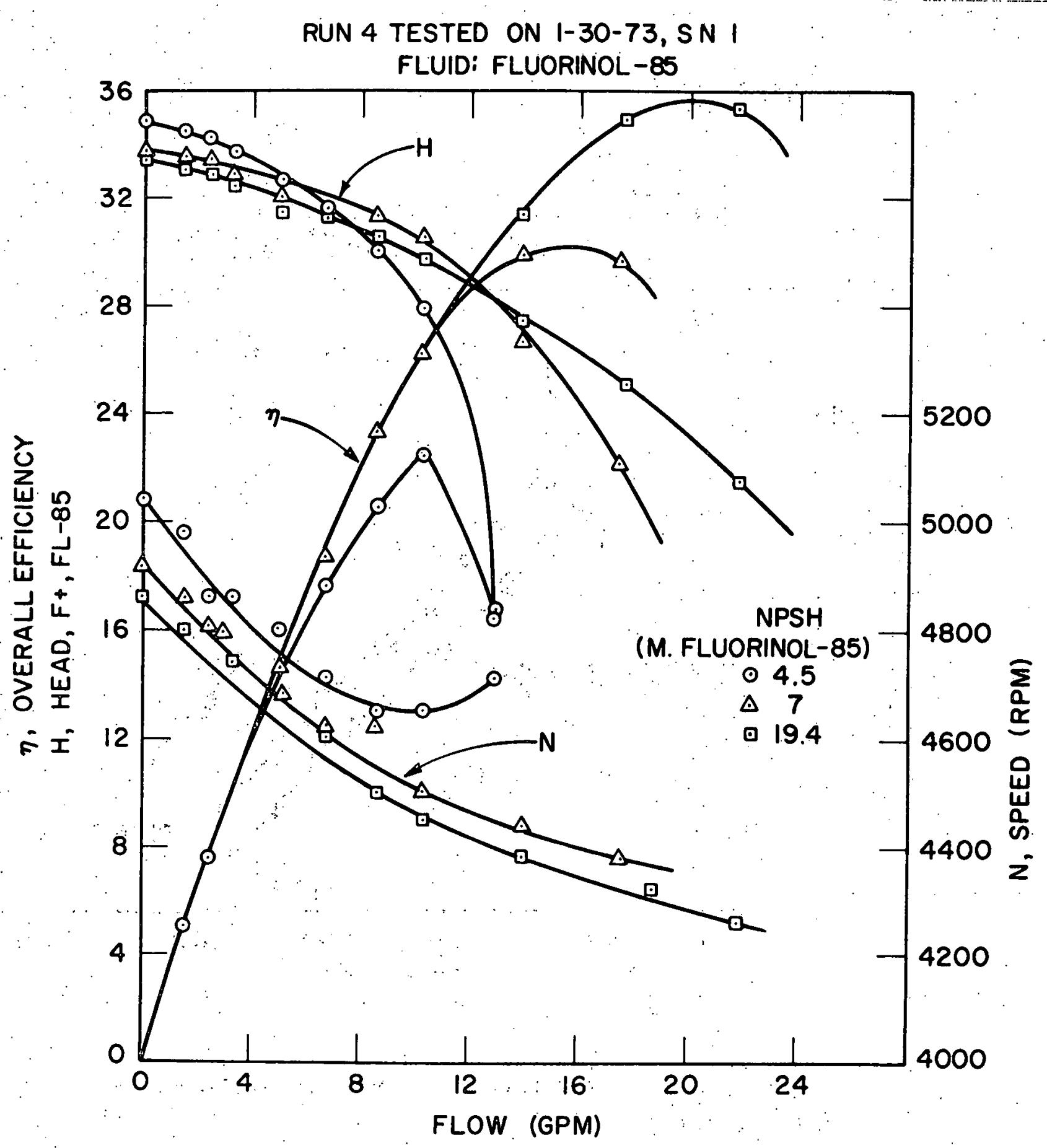

Figure 3. 54 Boost Pump, Barber-Nichols Data 


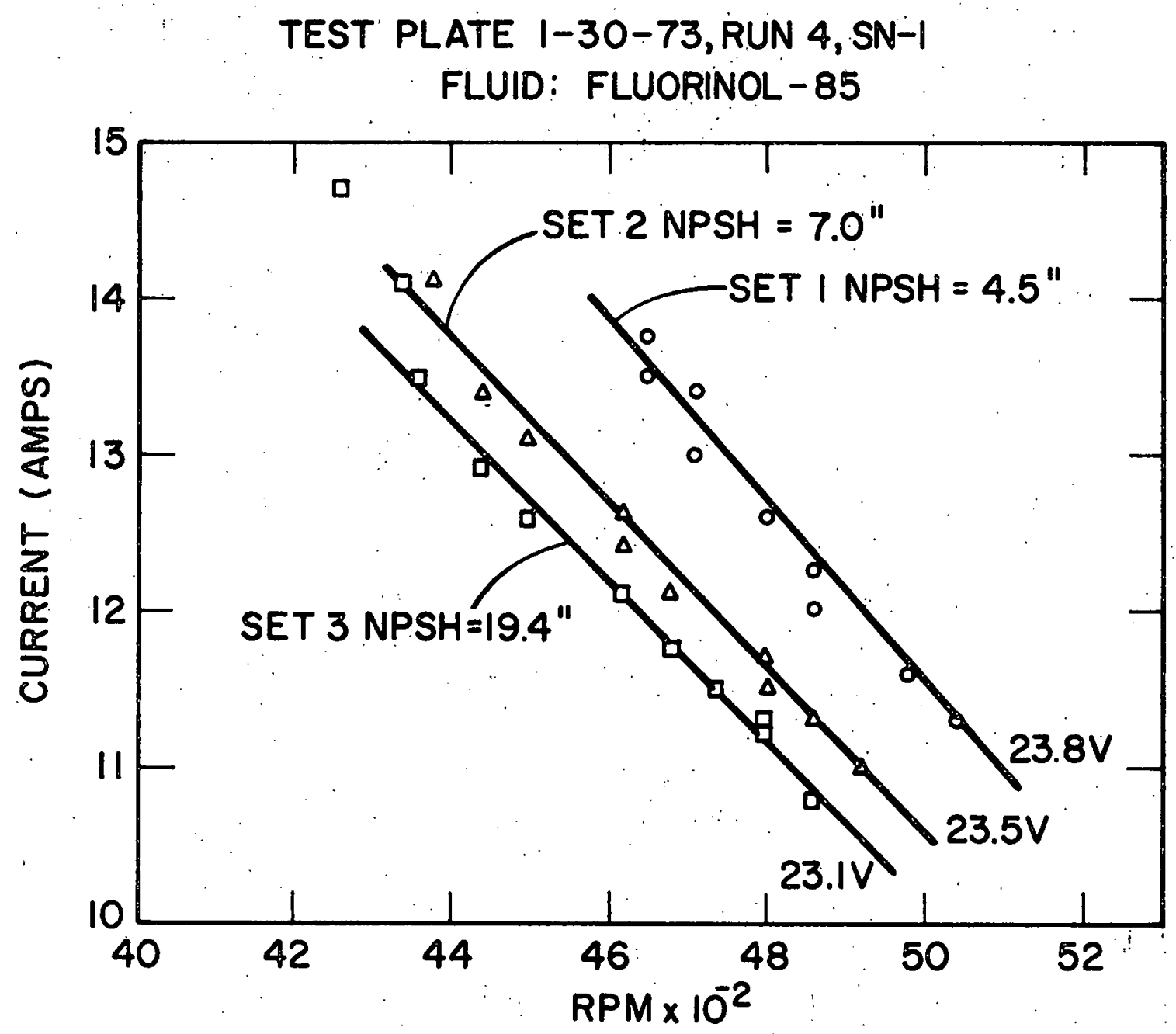

Figure 3.55 Boost Pump Motor Characteristics 


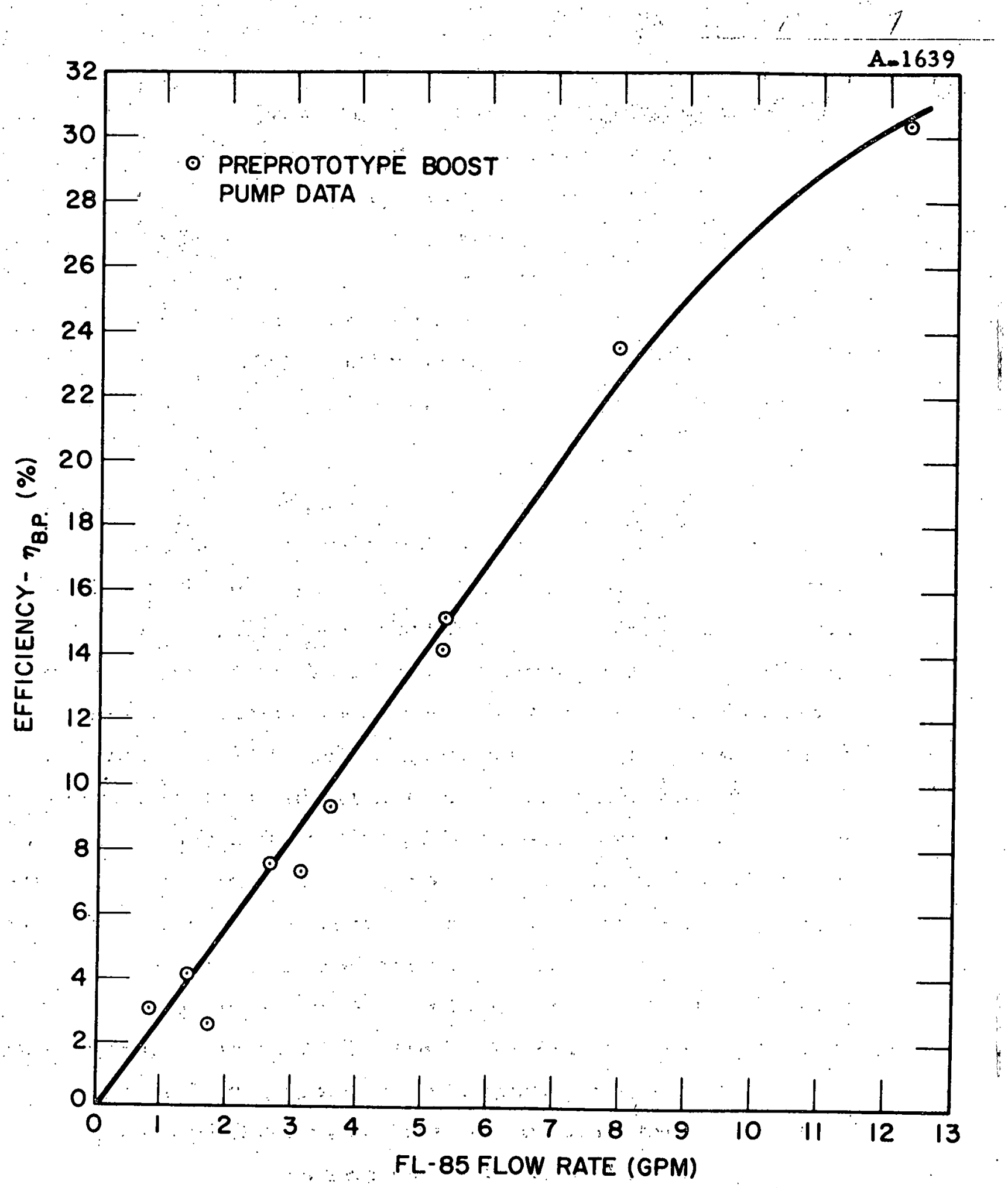

Figure 3. 56 Boost Pump Performance During Preprototype System Tests 
requirement, based on analysis and tests carried out at TECO, was that the pump have at least five cylinders to avoid cavitation. The performance requirements of the pump are given in Table 3.12. The pump was designed to be directly driven by the main propulsion expander. It was impractical to drive the pump by other means, such as an electric motor, because the relatively high peak power requirement of approximately $10 \mathrm{hp}$ would make the cost prohibitive and the size of the motor impractical, and would result in a reduction in overall efficiency.

A side cross-sectional view of the feedpump can be seen in Figure 3.57. The pump has seven cylinders with a bore of 1.5 in. located radially about the axis of the rotating shaft. Each cylinder houses pistons that can be varied from zero to full stroke (0.466 in.) by moving the angled portion of the shaft axlally through the center eccentric ring. Rulon rings are used on the pistons. The maximum displacement of the pump is 5.76 in. $^{3}$. The cylinders receive fluid from a common inlet plenum and discharge into a common outlet plenum. The inlet valve is a spring-loaded washer type, whereas at the outlet there is a disc spring-loaded valve. The piston shoes ride on a septagonal ring, with a circular ring used to return the pistons. Figure 3.58 is a photograph of the septagonal ring with an attached piston. It also shows the tongued shaft ends at either side of the shaft with the grooved cam-follower. Figure 3.59 is a photograph showing most of the major components of the feedpump, and Figure 3.60 shows the assembled feedpump, which has overall dimensions of $13-5 / 8$ in. in length by $10-1 / 8$ in. in diameter. 
TABLE 3.12

Working Fluid

Outlet Pressure

Flow Rate

Inlet Pressure-Operation

Pumping Slew Rate

Flat Frequency Response

Overall Efficiency (minimum)

Ambient Temperature Range

Operating Temperature Range
Fluorinol-85

850 psia

$0-17$ gpm

4- 90 psia

$100 \mathrm{gpm} / \mathrm{sec}$

To $6 \mathrm{~Hz}$

$75 \%$ at full flow and full speed $60 \%$ at $30 \%$ of full flow at any speed

$-40^{\circ} \mathrm{F}$ to $150^{\circ} \mathrm{F}$ ambient

Fluid inlet temperature from

$100-250^{\circ} \mathrm{F}$

Startup temperature from $-20^{\circ} \mathrm{F}$ 


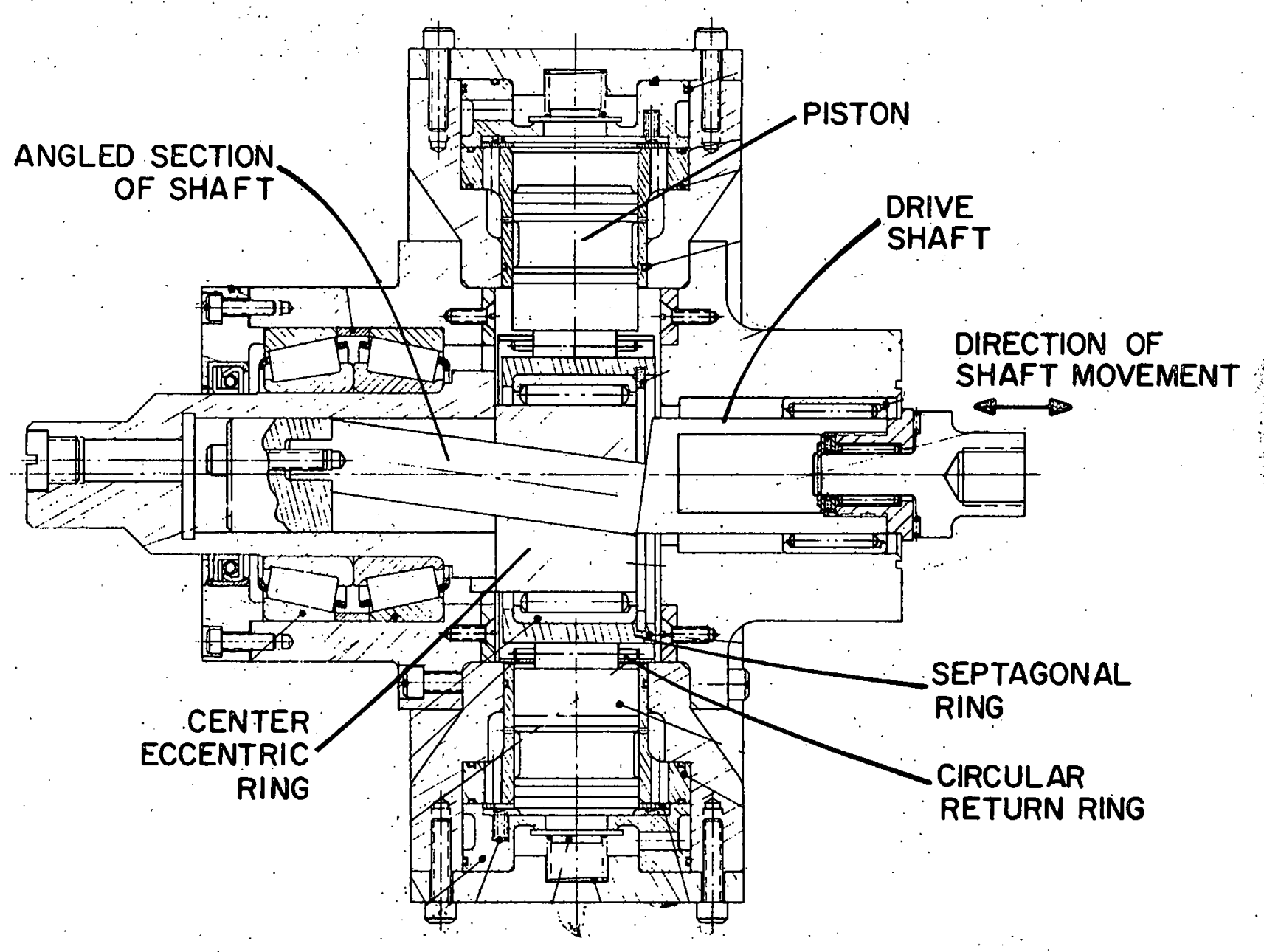

Figure 3.57 Side Cross-Sectional View: 7-Cylinder Feedpump 


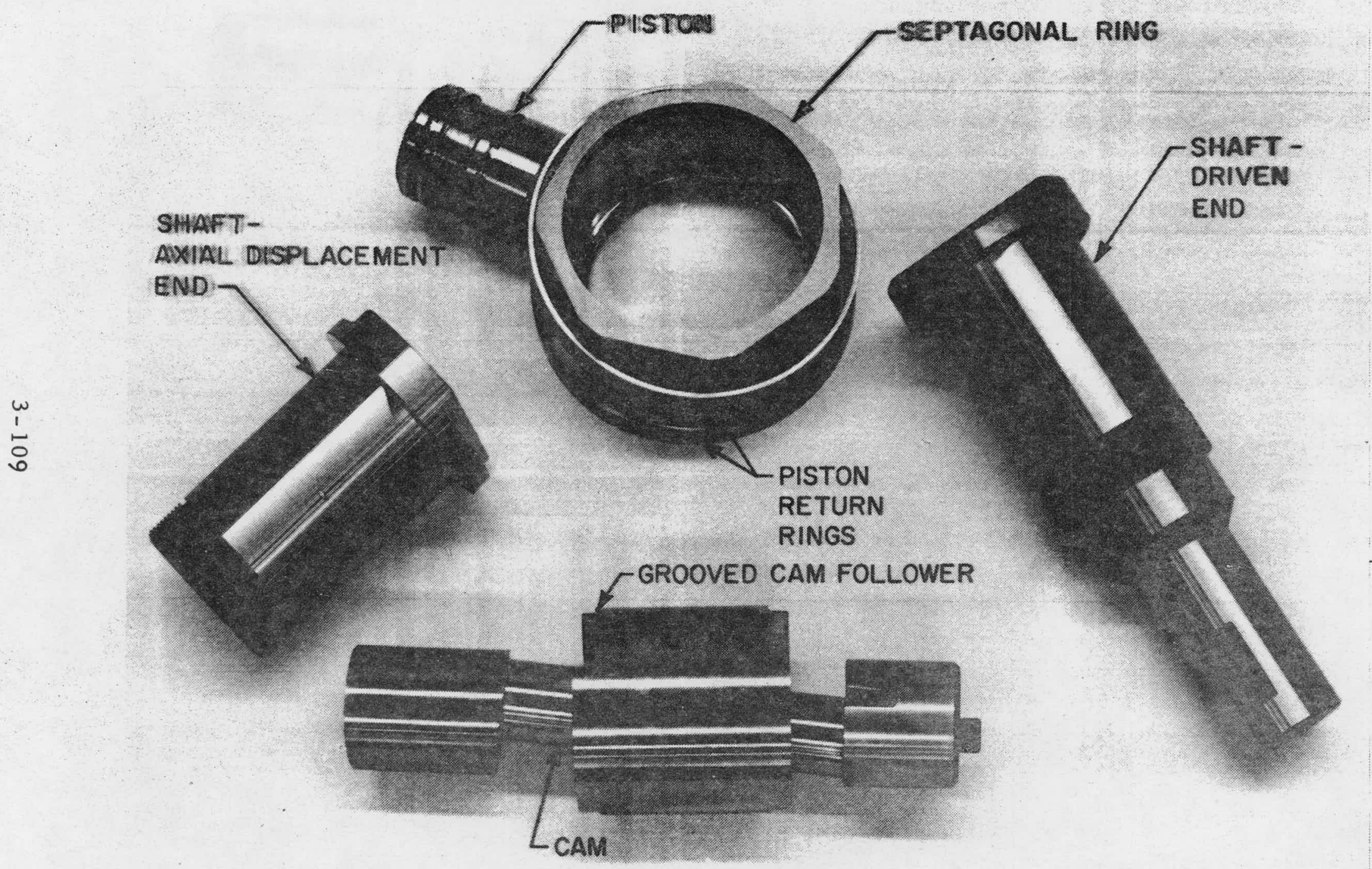

Figure 3.58 Photograph of a Septagonal Ring with an Attached Piston 


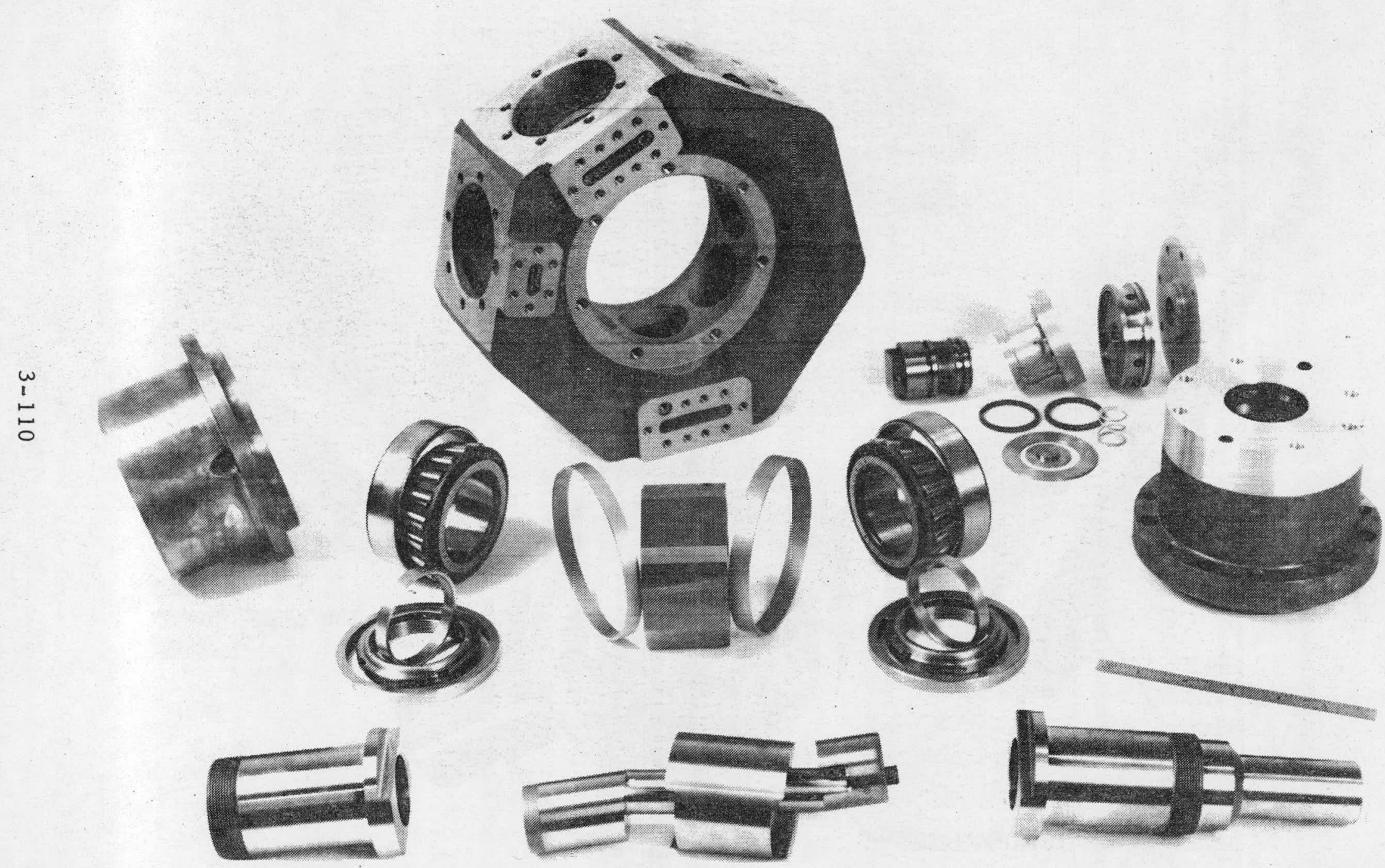

Figure 3.59 Feedpump Parts 


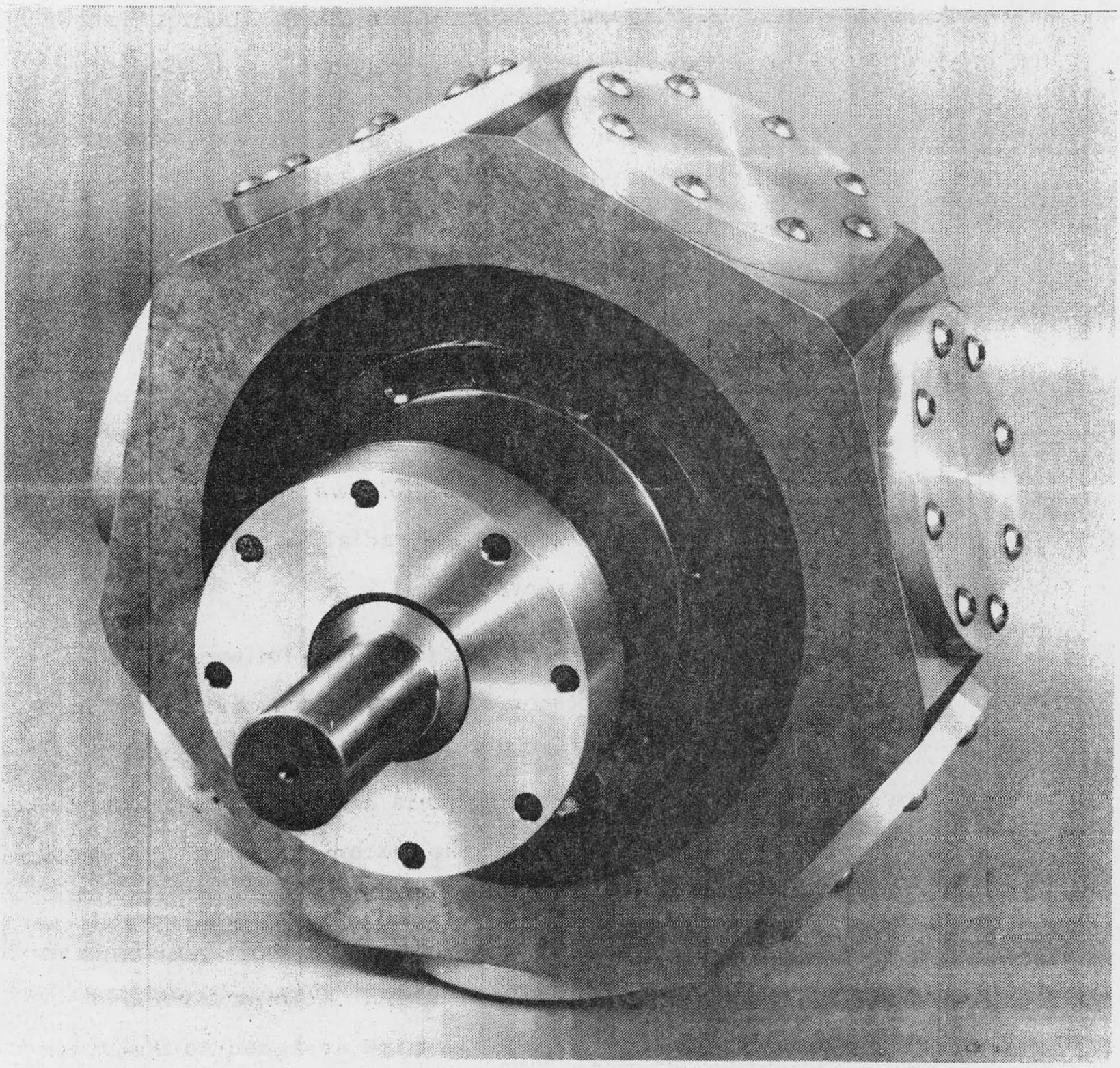

Figure 3.60 Assembled Feedpump 
As development testing was performed on the feedpump, certain design modifications were incorporated to improve the durability of the pump.

- The bearings were rearranged on the driven end of the pump to increase the span of support between the bearings, eliminating unacceptable runout of the shaft.

- The cam-follower was redesigned to incorporate a tongueand-groove configuration on both ends, eliminating the possibility of high stress concentration found in the prior singledovetail arrangement on the cam-follower. At the same time, the new configuration reduces the radial load being taken by the tongue-and-groove sections.

- Modifications were made on the feedpump following a failure that occurred when a piston shoe pin, on which the piston return rings ride, fell out due to an inadequate press fit and wedged against the return ring; this caused the ring and other piston shoe pins to fracture. The piston shoe pins are encompassed on either side by the return rings. To prevent repetition of this type of failure, all piston pins were pressed into the shoes and inspected for a minimum holding force. In addition, the piston return rings were designed so that their cross section is "L" shaped. The "L"-shaped return ring prevents a pin from falling out if it does become loose, and also increases the stiffness of the ring.

Modifications were also incorporated to improve the pump performance during development testing. To reduce the feedpump NPSH 
requirements, modifications were made on the inlet area of the feedpump. First, the spring preload on the inlet valve was reduced by decreasing the amount of spring precompression. Second, the valve exposure area at the inlet was increased. Both of these modifications reduced the inlet valve cracking pressure. Inlet flow paths were .... smoothed out at the same time with grooves machined from the inlet valve spring holes to relieve any possible pressure buildup behind the inlet valve itself.

\subsubsection{Feedpump Test Facility}

The feedpump test stand comprised two systems: the mechanical drive system and the fluid system. The feedpump itself was the connecting link between these systems.

Since the pump was tested over a speed range of 300 to $1800 \mathrm{rpm}$, a variable-speed drive (Reeves, Model 400) was required to drive the feedpump. The drive unit was supplied with a tachometer for speed indication; in addition, a strobotac was used to check the tachometer. A rotating through-shaft torque sensor was used to measure driving torque. To protect the torque sensor from.overload in the event of pump seizure, a torque limiting clutch was used to couple the drive unit to the torque sensor.

The fluid system, or the pump loop, is shown schematically in Figure 3.61. A photograph of the feedpump test facility is shown in Figure 3.62. The test loop could be isolated from the pump by closing the ball valve in the discharge line and the shutoff valve in the intake line. The pump inlet reservoir was heated by strip heaters so that the pump suction pressure could be controlled by varying the fluid temperature in the reservoir. 


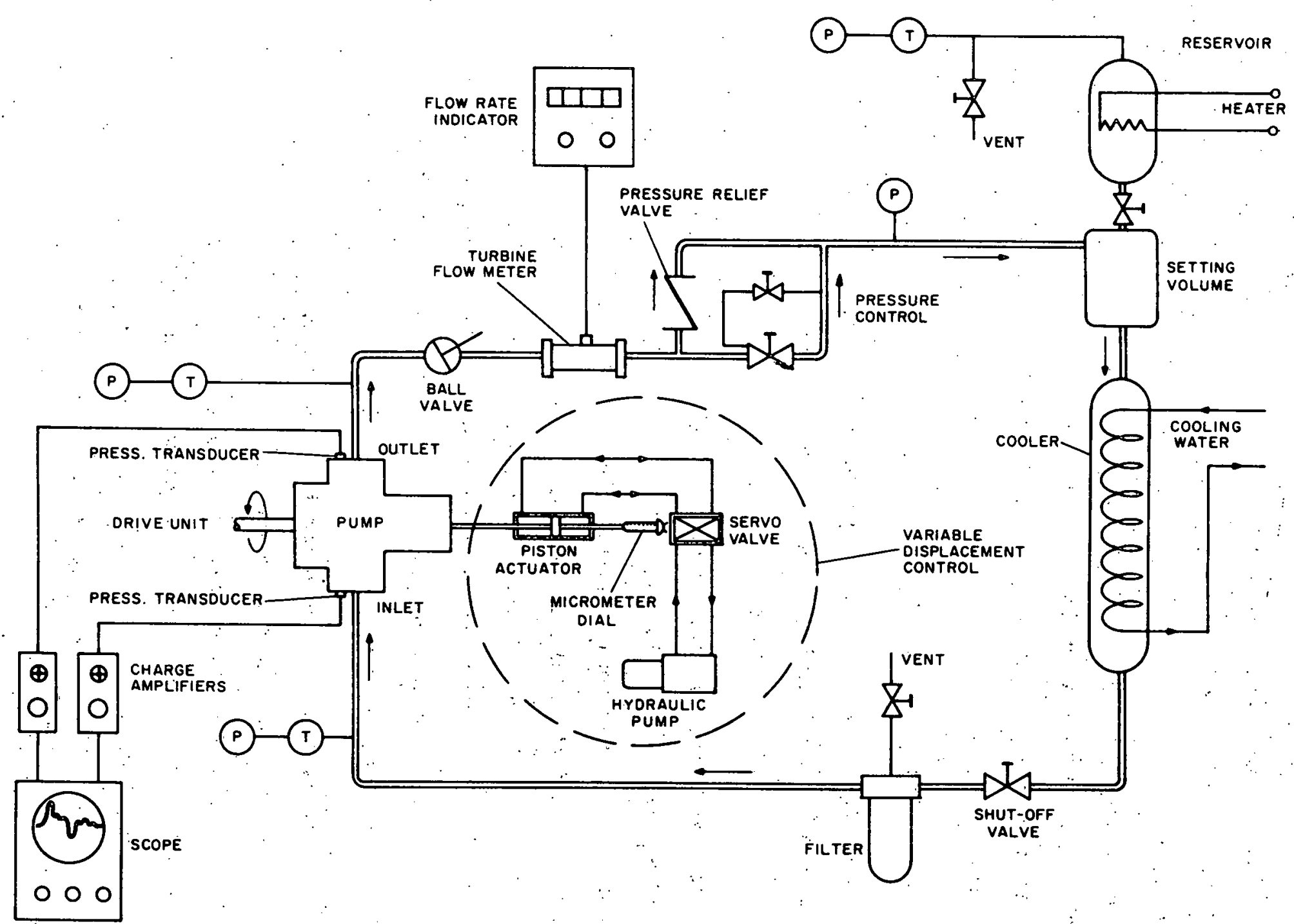

Fgiure 3.61 Schematic of Feedpump Test Loop 
I-1631

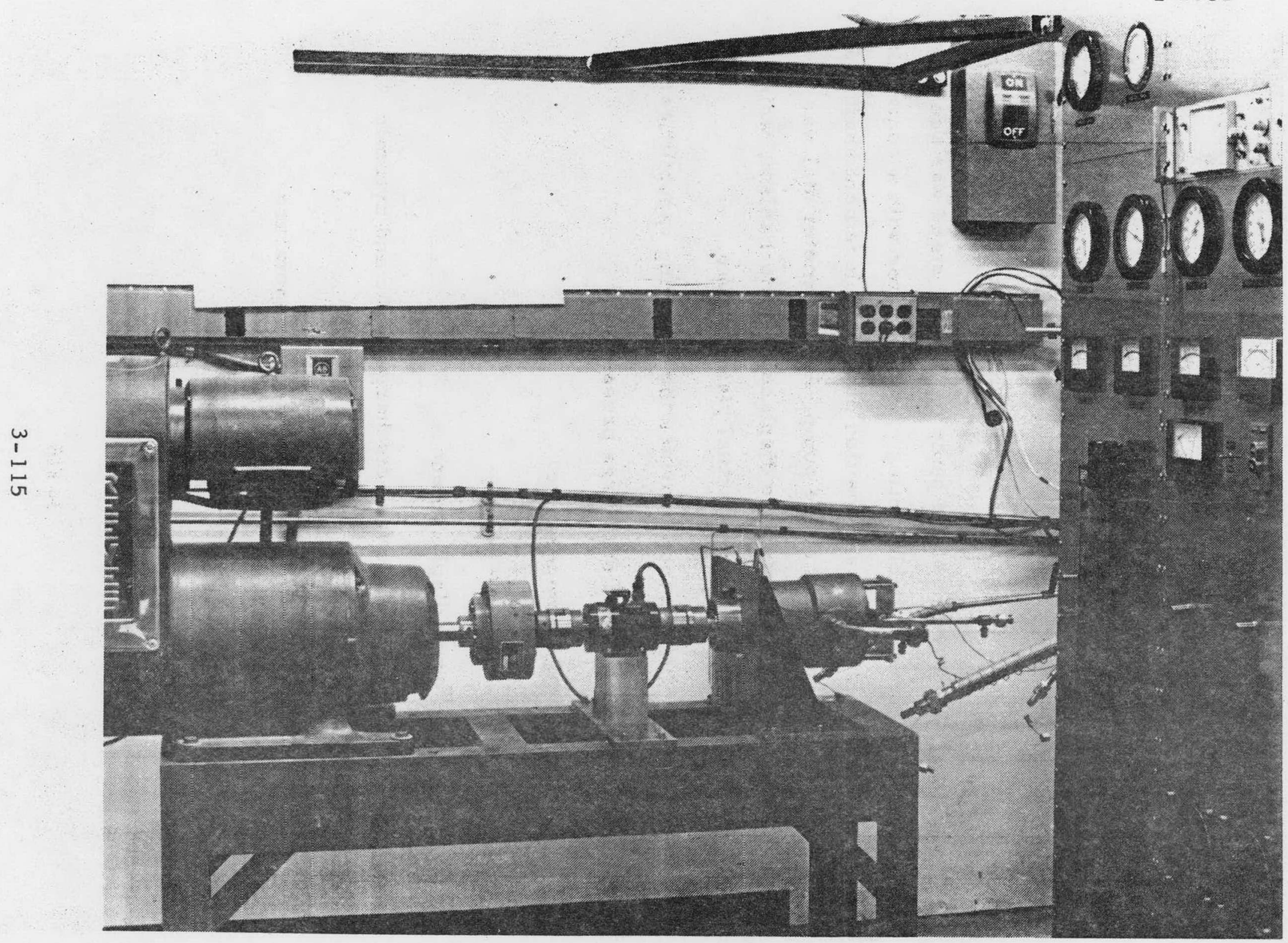

Figure 3.62 Feedpump Test Facility 
The most critical aspect of operation of the test loop was to ensure that all air and vapor had been removed from the loop, particularly the intake system. Vents were provided at all possible gas traps to ensure that any air could be removed from the system.

A turbine flowmeter with an associated digital readout was used to measure the flow-rate output of the pump. The rating of the turbine flowmeter was 1.8 to $18.4 \mathrm{gpm}$, and suitable calibration curves were provided by the manufacturer, Fischer \& Porter Instrument Company.

Variable displacement of the pump on the test stand was achieved by utilizing an external double-acting piston actuator with a controlling servo valve to maintain the set position of the displacement shaft and, therefore, the displacement of the pump. A micrometer dial was used to measure the axial setting on the displacement mechanism, which allowed for precise indication of actual piston stroke.

In summary, the test loop provides the following capabilities:

- Variable inlet and discharge pressure

- Variable inlet temperature

- Variable pump speed

- Variable pump displacement

- Mea surement of inlet and discharge static and dynamic pressures

- Measurement of inlet and discharge temperature

- Measurement of pump delivery rate 
- Measurement of actual pump displacement

- Measurement of pump speed and torque to drive the pump

\subsubsection{Test Results and Performance Evaluation}

Over 600 hours of operating time was accumulated on the radial feedpump, including development time on the test feedpump and actual operating time with feedpumps utilized in the expander test facility and on the preprototype system.

Performance measurements were made on the pump at various' speeds and displacements at the required operating discharge pressure of 850 psig. A summary of the efficiency measurements is given in Figure 3.63. The overall pump efficiency varies from approximately 87 percent at low speed to 72 percent at $1800 \mathrm{rpm}$. The top cuirve in Figure 3.64 is the maximum flow-rate conditions that the pump had to meet at: each speed up to the maximum of $1800 \mathrm{rpm}$. The data points show the power requirements and precentage of full displacement of the feedpump needed to achieve these maximum operating conditions. The lower curve shows pump requirements at a lower flow rate corresponding to low-power system operation. The variation of efficiency with displacement is presented in Figure 3.65 for various speeds and ait an operating discharge pressure of 865 psia. Figure 3.66 shows the outlet pressure effect on efficiency for various speeds. The overall efficiency, although decreasing with increasing rpm, does improve with higher pump discharge pressures.

Another important mea surement made on the feedpump during testing was the inlet pressure effect. Some initial test results summarized in Figures 3.67 and 3.68. For an operating discharge pressure 


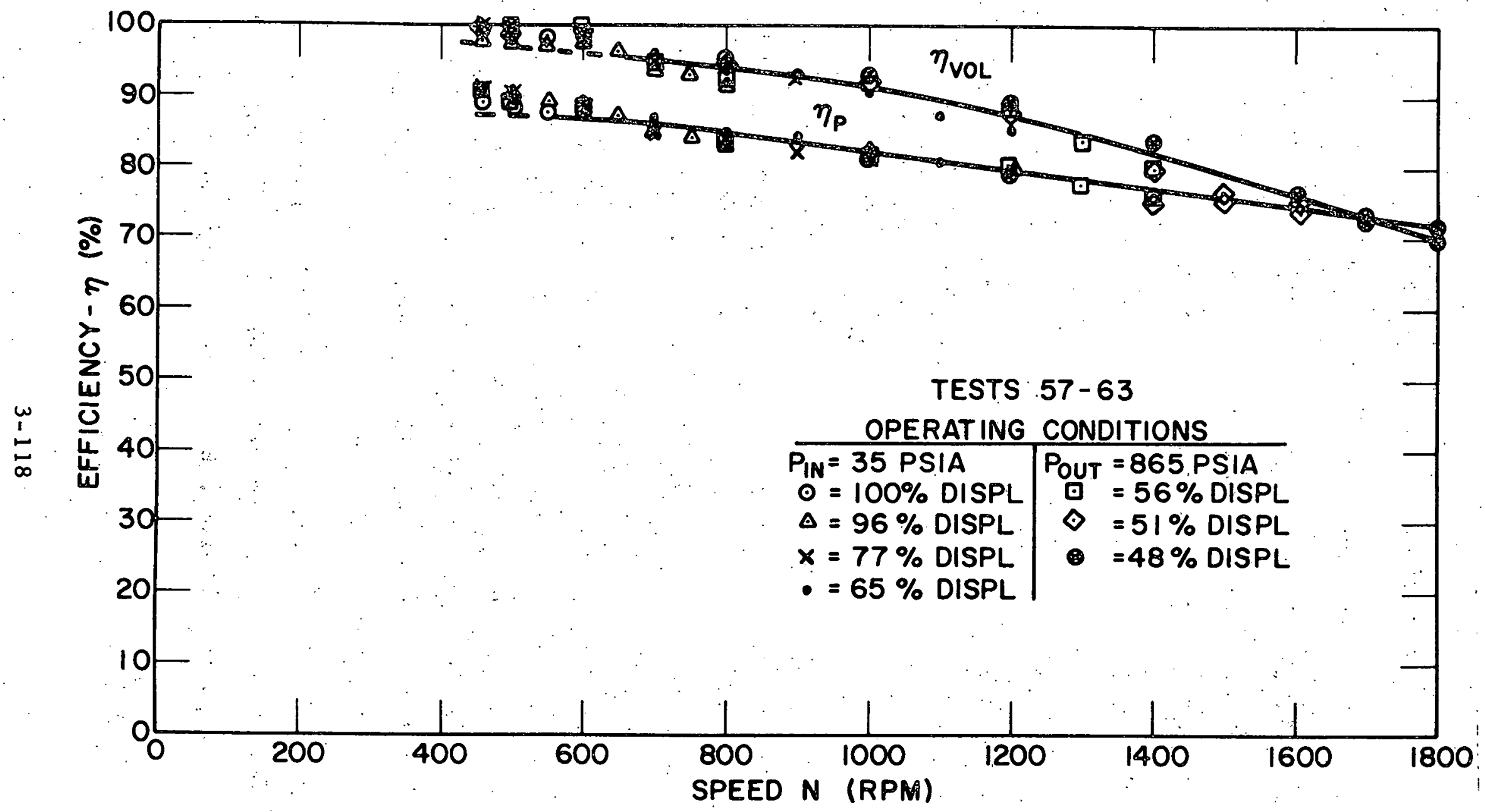

Figure 3.63 Volumetric and Overall Pump Efficiencies as a Function of rpm and Displacement 


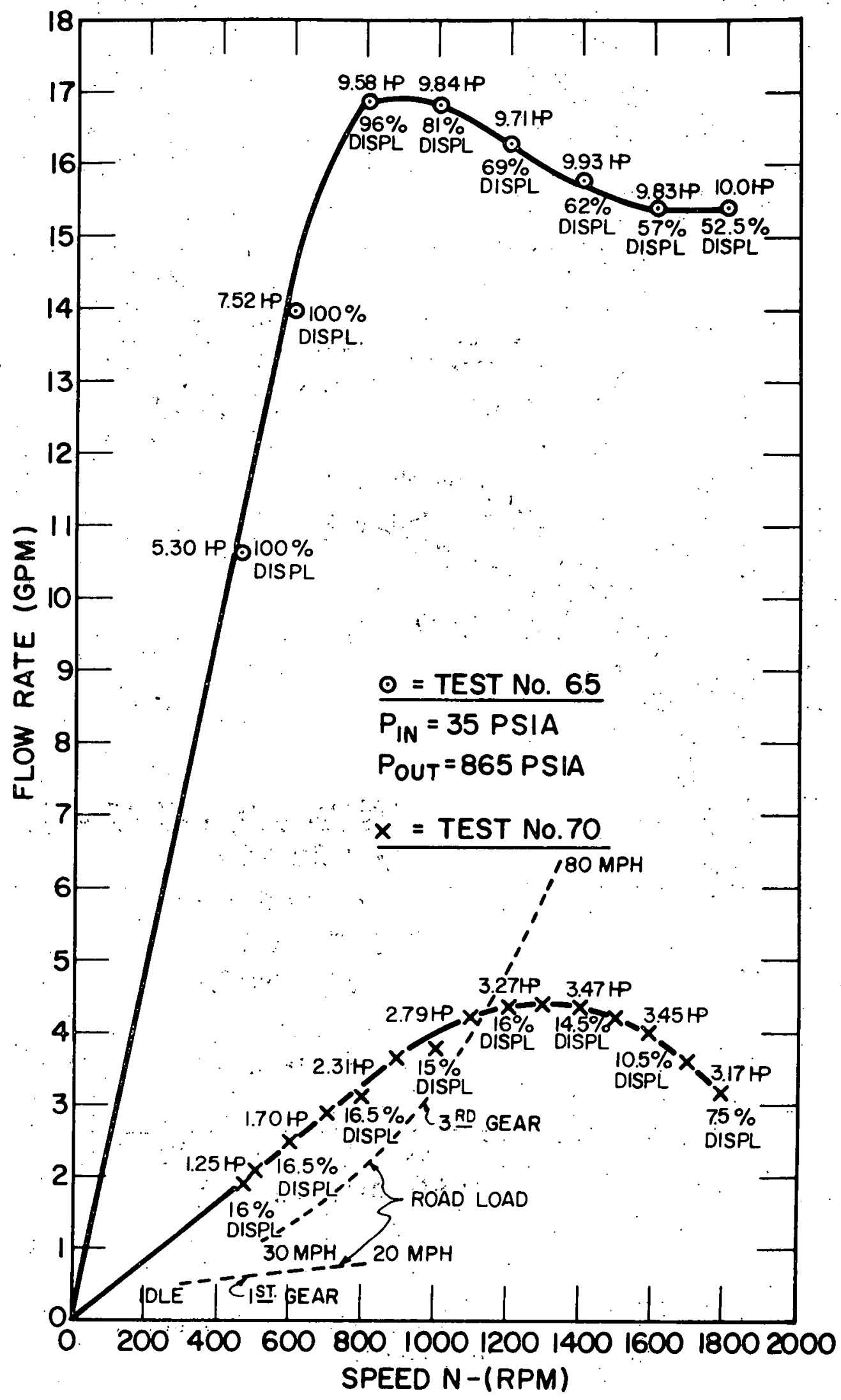

Figure 3.64 Pump Operating Conditions for Maximum Flow Rate Requirement and for Part-Load Flow Rate Requirement 


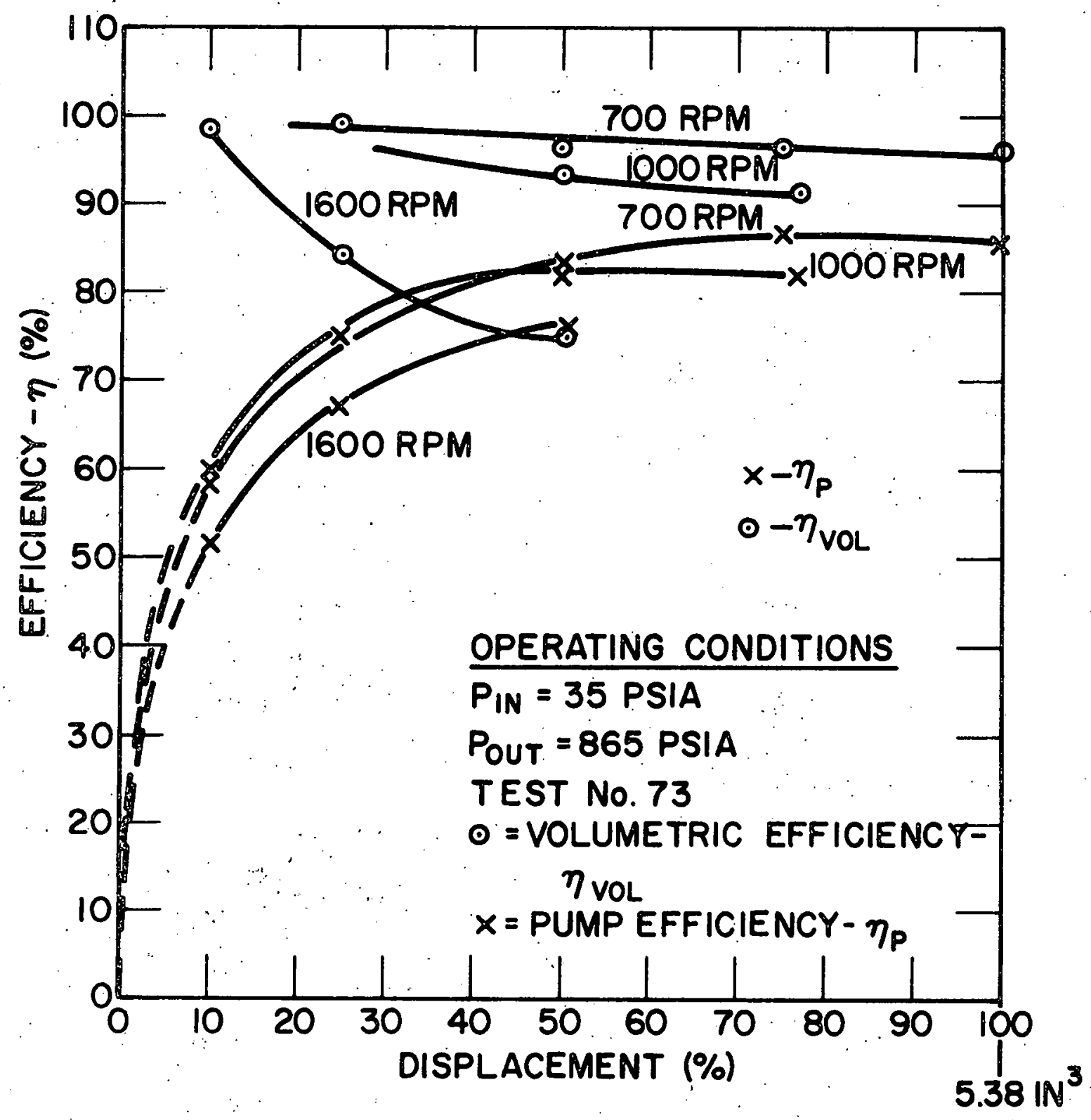

Figure 3.65 Variation of Pump Efficiency with Displacement 
I -3388

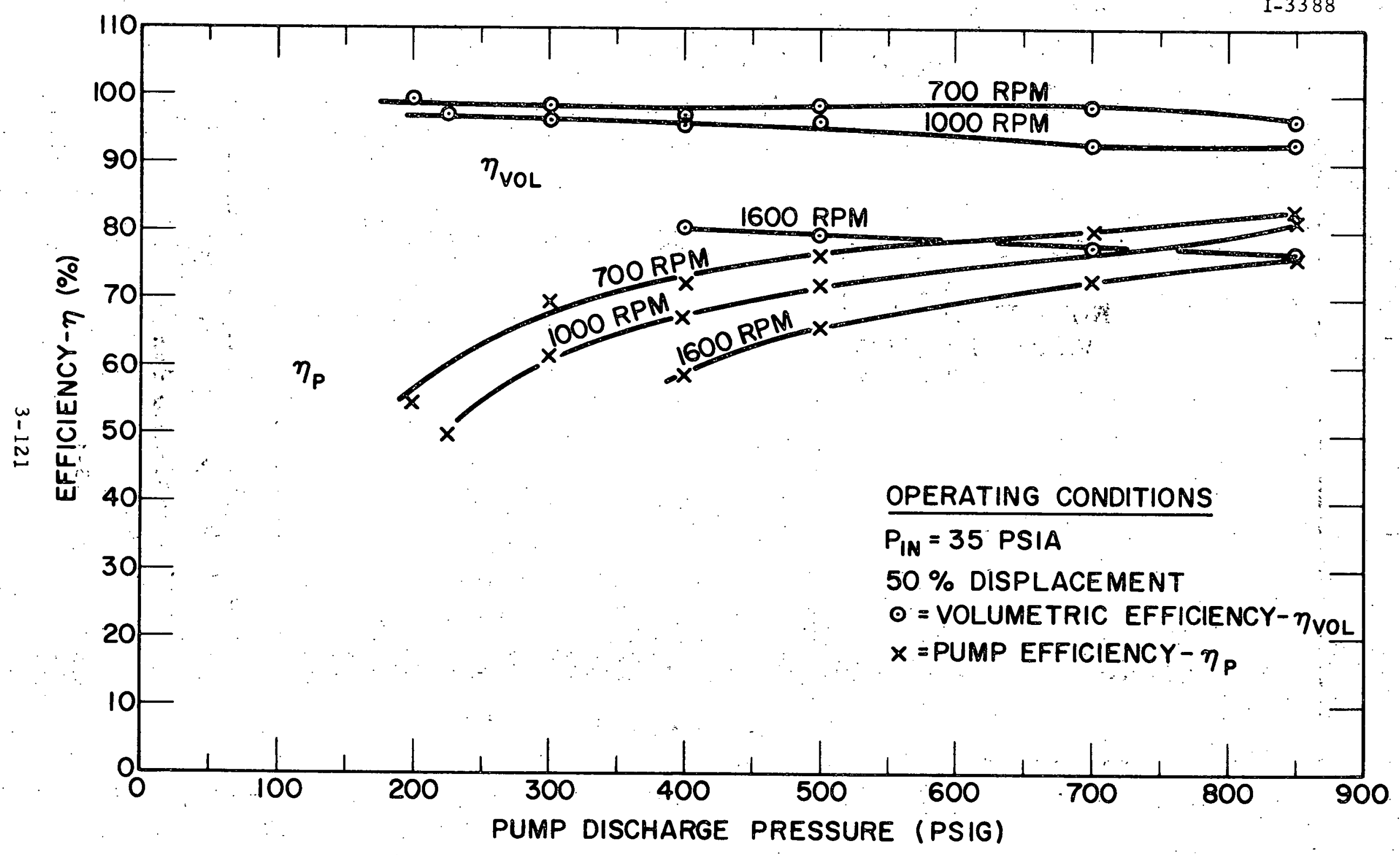

Figure 3.66 Effect of Discharge Pressure on Pump Efficiency 


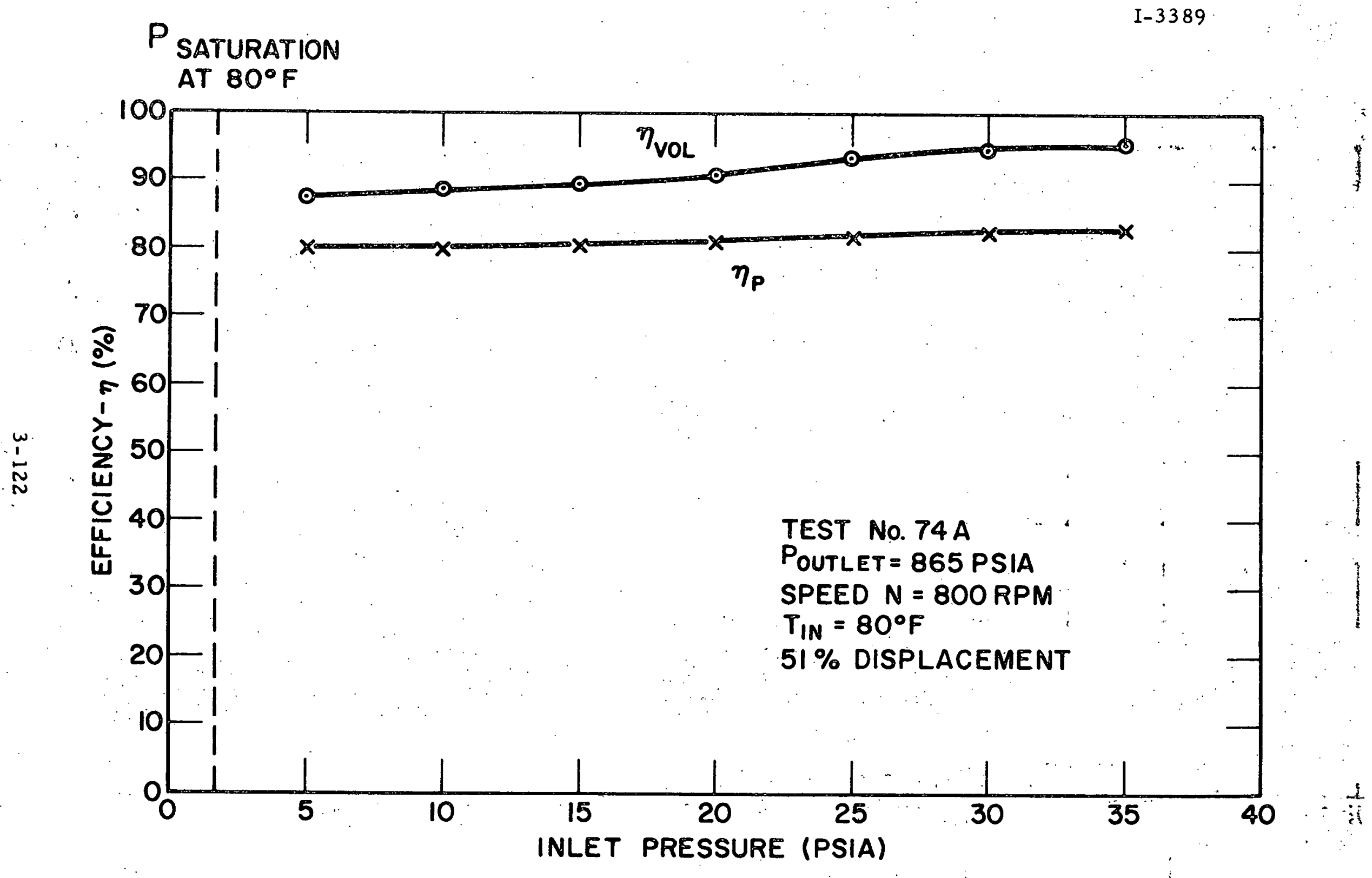

Figure 3.67 Variation of Pump Efficiency with Inlet Pressure - $800 \mathrm{rpm}$ 


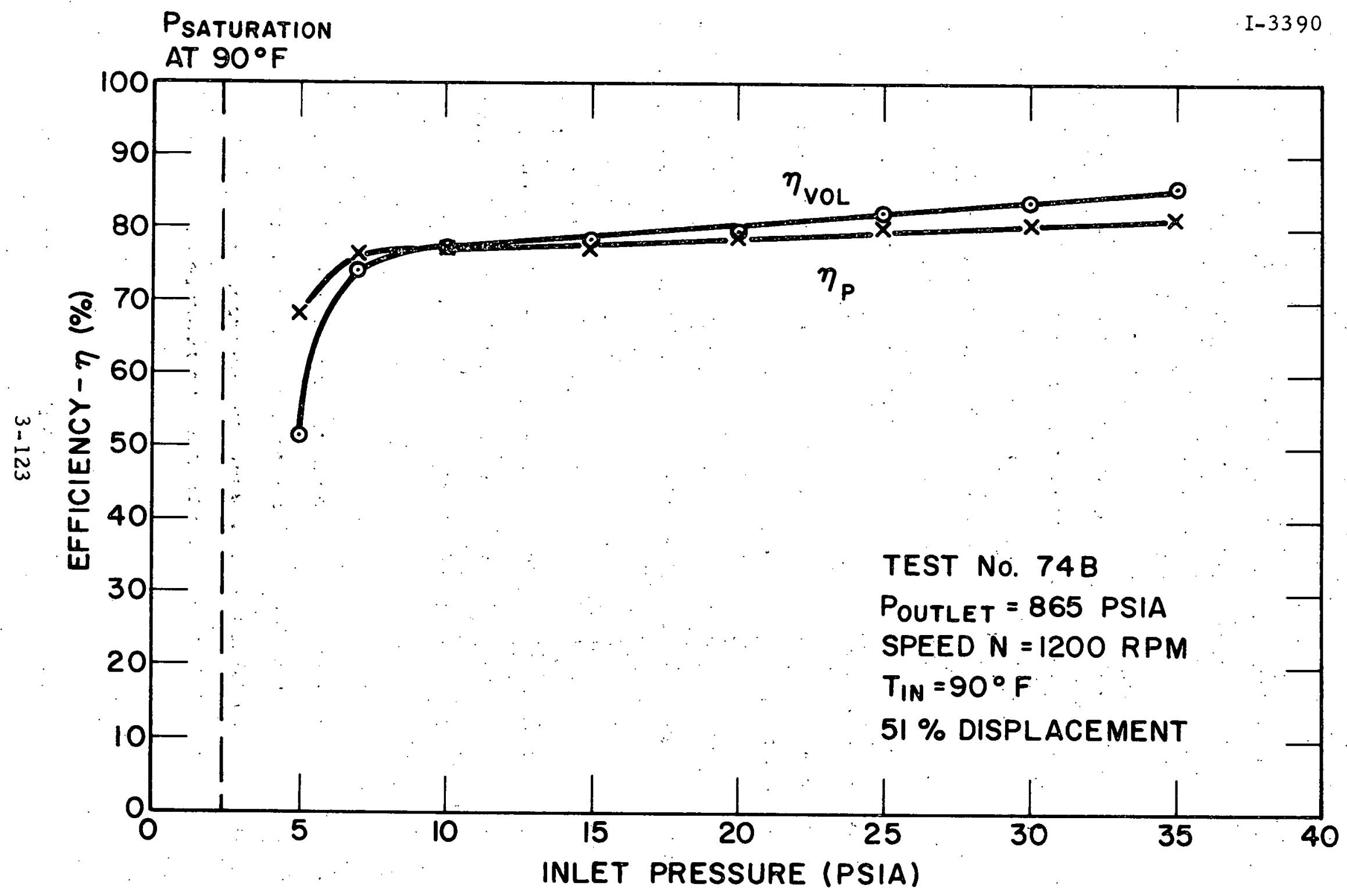

Figure 3.68 Variation of Pump Efficiency with Inlet Pressure $-1200 \mathrm{rpm}$ 
of 865 psia at 51 percent pump displacement, Figure 3.67 shows the efficiency as a function of inlet pressure at a speed of $800 \mathrm{rpm}$; Figure 3.68 shows the efficiency at a speed of $1200 \mathrm{rpm}$. At $800 \mathrm{rpm}$, the efficiency remains high to $5 \mathrm{psia}$ inlet pressure. At $1200 \mathrm{rpm}$, the efficiency of the pump falls off below an inlet pressure of 7 psia, indicating cavitation. These measurements provided a preliminary indication of the NPSH required for the feedpump. In subsequent tests, more data were taken over a wider temperature and speed range to establish complete NPSH requirements for the pump. The pump was run at speed conditions up to $1800 \mathrm{rpm}$, and. Figure 3.69 shows the NPSH profile obtained on the pump from the initial tests. These results were unacceptable at the high speed, high flow-rate conditions. At 1800 rpm; the NPSH was almost 30 psi at $15 \mathrm{gpm}$.

As previously described in the design section, modifications were made on the inlet area of the feedpump to reduce the NPSH requirements.

After the modifications were incorporated, the feedpump was again tested for NPSH requirements; the results are shown in Figure 3.70. In comparison with the initial experiments for NPSH requirements, which were very high (close to $30 \mathrm{psi}$ at $1800 \mathrm{rpm}$ and $15 \mathrm{gpm}$ ), these test results show an NPSH of less than $10 \mathrm{psi}$ at $16 \mathrm{gpm}$ and $1800 \mathrm{rpm}$. The curve gives experimental values of the NPSH requirements for the feedpump at various speeds up to the maximum of: $1800 \mathrm{rpm}$. The intersecting line shows the maximum flow conditions that the feedpump had to meet at the various speed conditions. This NPSH performance was satisfactory for the system operation and represented the final step in development of the pump for the preprototype engine test. 
I-353 I

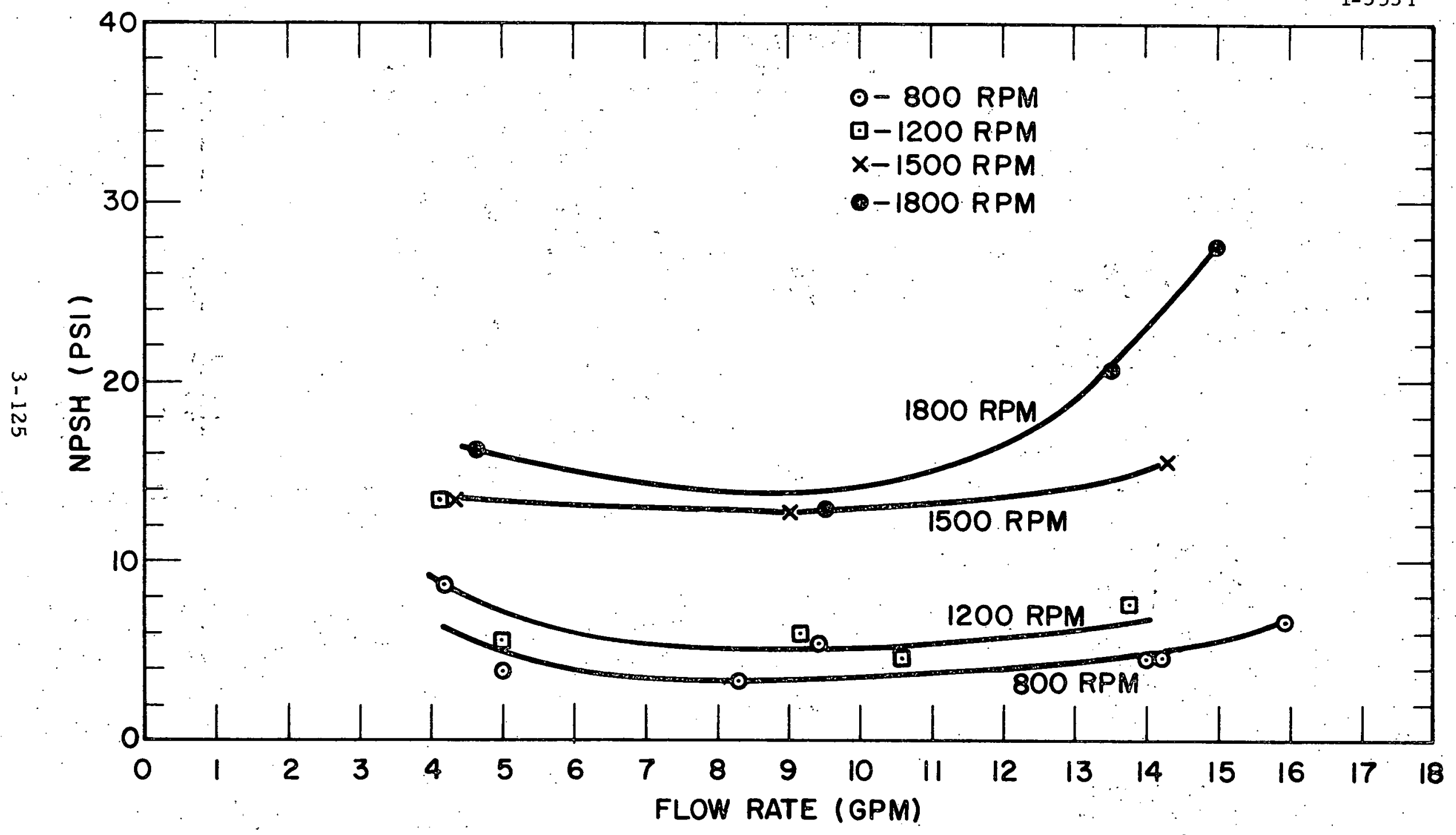

Figure 3.69 Seven-Cylinder Feedpump, NPSH Versus Flow Rate, Initial Design 
I- 3732

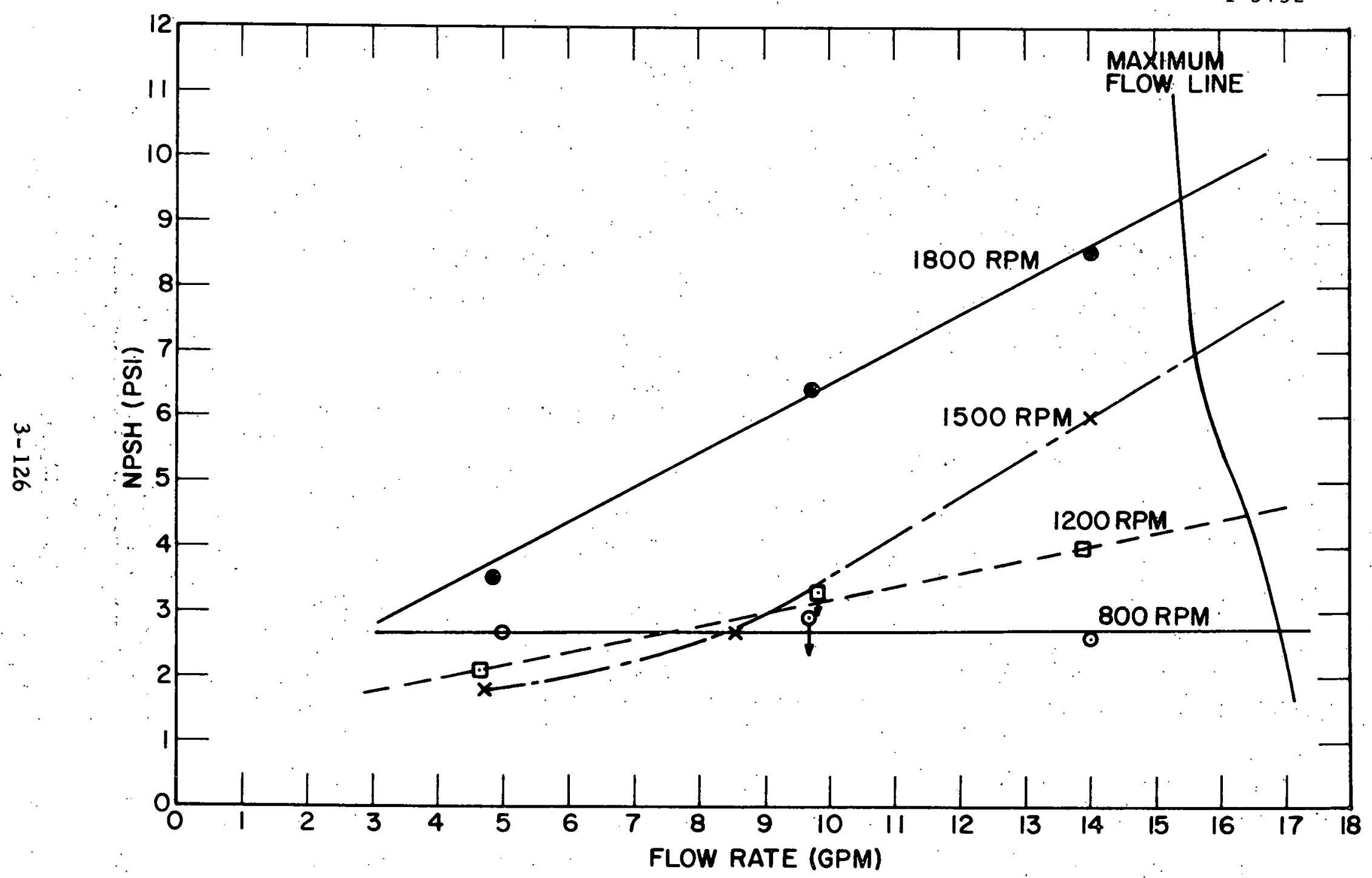

Figure 3. 70 Seven-Cylinder Feedpump, NPSH versus Flow Rate, Improved Design 


\subsection{BURNER/VAPOR GENERATOR}

Of all the components, the burner/vapor generator has undergone the greatest amount of change from the original design. It began as an axial combustion firing into a rectangular boiler, and in its final version consisted of a radial burner firing into a circular boiler. Extensive emission testing was done on all the different configurations. The burner/vapor generator was designed and developed with Thermo Electron funding.

\subsubsection{Burner/Vapor Generator Design}

The automotive burner was originally designed to be an axial-flow device, exhausting into a diffuser connected to a vapor generator consisting of a rectangular array of parallel tubes. An axial burner.was developed and tested to demonstrate that a burner could operate on automatic controls over an automobile driving cycle with its steep transients while still maintaining good emission levels. The test results and details of the axial burner were reported in Reference 6.

The performance of this axial burner was quite good and was designed for a lo0-hp automotive system (Maverick-size car). When the reference car.was changed to full size (Galaxie 500), the packaging studies indicated that the increased depth of this larger burner/vapor generator assembly was not amenable to installation in an automobile engine compartment. A pancake-shaped, radial-flow, burner/vapor generator would, however, fit fairly easily into the space available between the top of the expander and the hood. Furthermore, the fabrication of the vapor generator was greatly simplified, since the parallel tubes with a la rge number of return bends were replaced by 
a series of five coils with only four crossovers. Elimination of parallel passes removed any possibility of parallel-flow instability due to maldistribution of flow, which could result in overheating of the organic fluid. For these reasons, development work was begun on a radial-flow burner/vapor generator.

The first radial burners used an array of air-atomizing nozzles facing radially outward from the center of the burner'. Maintaining an even fuel flow to each of several nozzles, located in the hightemperature environment of the combustion zone, proved to be extremely difficult. At the same time, tests made with a rotating atomizer looked very promising. Not only did the rotating atomizer provide inherent radial symmetry, but it eliminated the need for an atomizing air compressor - a bulky, noisy, and power-consuming device.

As testing with the rotating atomizer and radial burner continued, it became evident that the atomizer, which had been driven by its own motor, could be allowed to rotate at the same rate as the combustion blower with a negligible effect on emissions. The atomizer was mounted on the blower shaft, and the atomizer motor shaft and controls were eliminated. The atomizer bearing assembly was retained since it contained the fuel distribution system. During this testing period, the burner design was also modified to provide better air distribution and to reduce distortion of the combustion chamber walls. This distortion was due to stresses induced as a result of the extreme temperature cycling to which the walls were exposed," as well as to large temperature gradients along the radius of the burner. A crosssectional view of the radial burner/vapor generator is shown in Figure 3.71. 


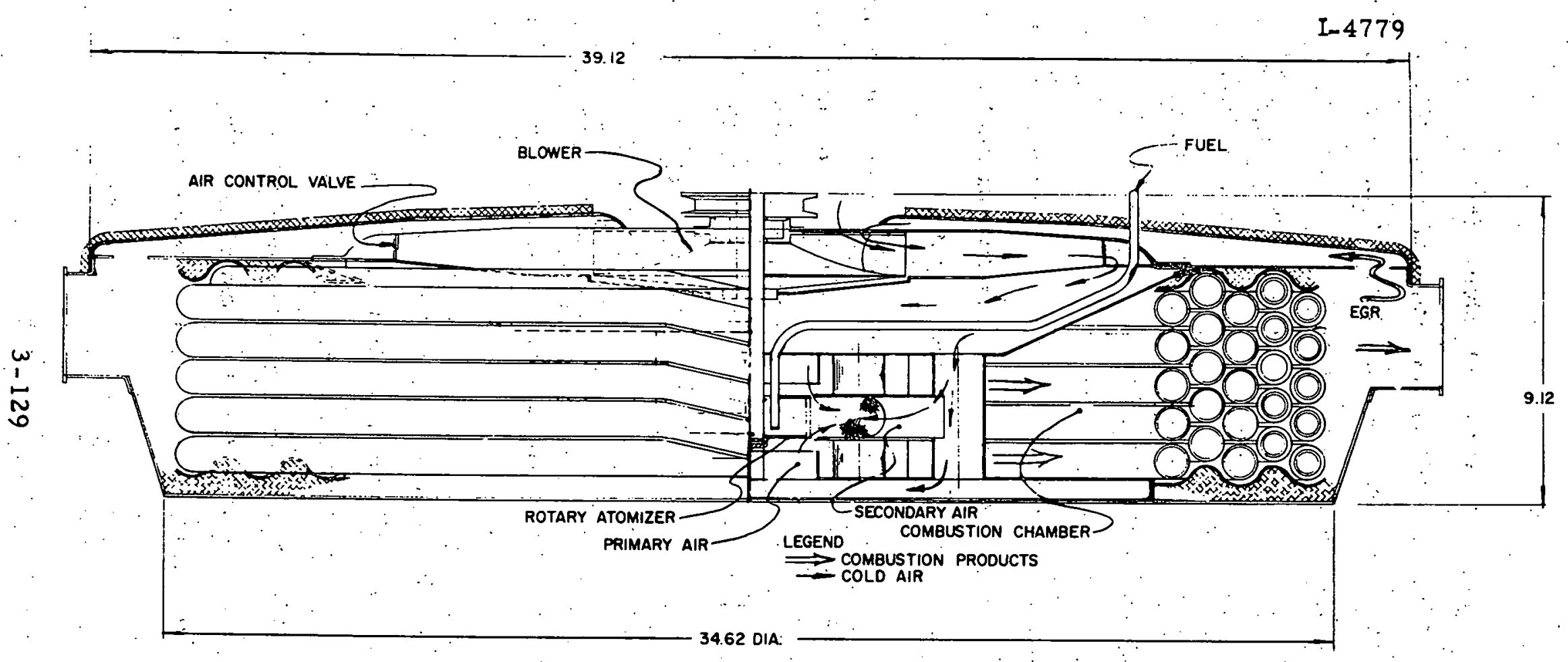

Figure 3.71 Cross-Sectional View of Radial Burner/Vapor Generator 
In the present design, air is introduced into the combustion zone from three directions - radially inward, and vertically above and below the rotating atomizer. A schematic of this flow, together with an approximate flow breakdown, is shown in Figure 3.72. The 24 outer tubes carry air to the bottom air chamber, whereas the twelve inner tubes carry air to the reverse flow ducts. A small amount of air also flows to the bottom air chamber through holes in the bottom cover plate of each inner tube. This flow cools the inner tube and keeps its temperature within acceptable limits. The reverse flow duct is faced by perforated metal screening. This screen is directly in line with the rotating atomizer, and any large fuel droplets thrown from the atomizer are intercepted and vaporized by it.

All walls and components of the burner are cooled by incoming air to the point where oxidation is well within acceptable limits. There are, however, large temperature differences between sections of the burner, and there are large radial temperature differences along the burner walls. To accommodate the resulting differences in the thermal expansion, slots were provided at various locations to minimize distortion. The expansion slots were kept to a minimum in order to optimize the air flow distribution. A photograph of the burner is shown in Figure 3.73.

The vapor generator is a five-pass design. The organic fluid enters the outermost (fifth) row in the liquid state and exits from the middle (third) row in the superheated vapor state. The flow schematic of the organic fluid in the vapor generator is shown in Figure 3.74. The organic liquid undergoes partial sensible heating in the fourth and fifth row while flowing in cross-counter arrangement. These coils 


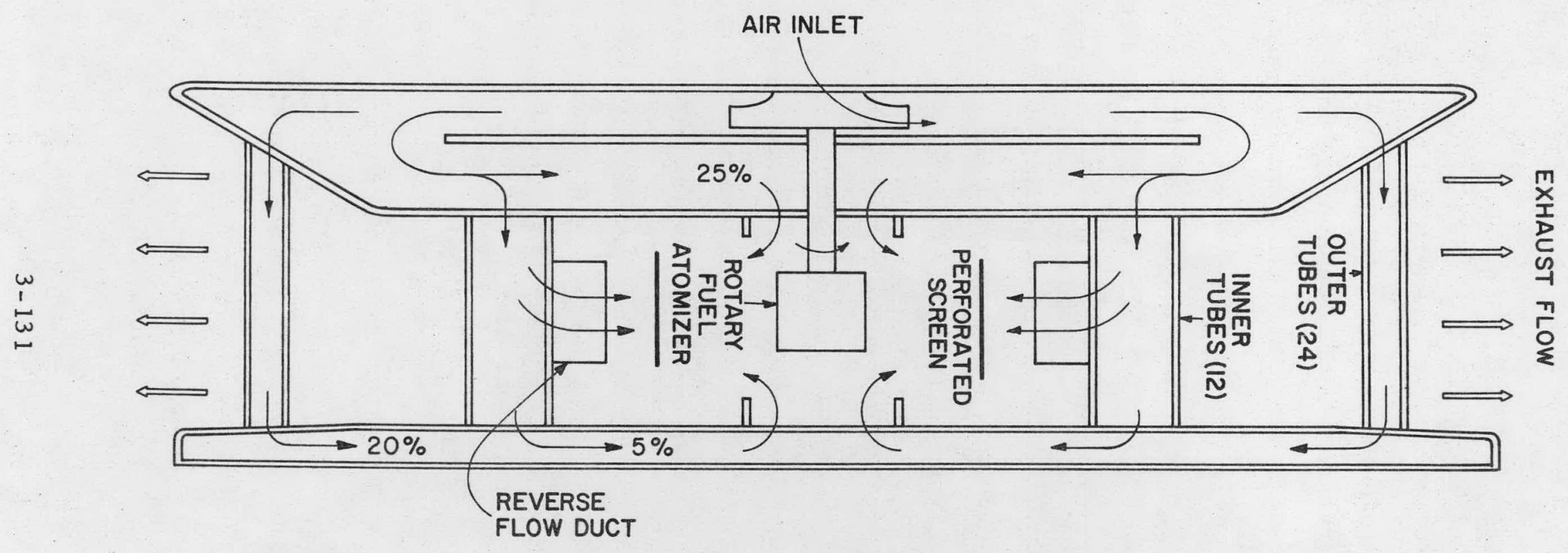

Figure 3.72 Burner Airflow Schematic 


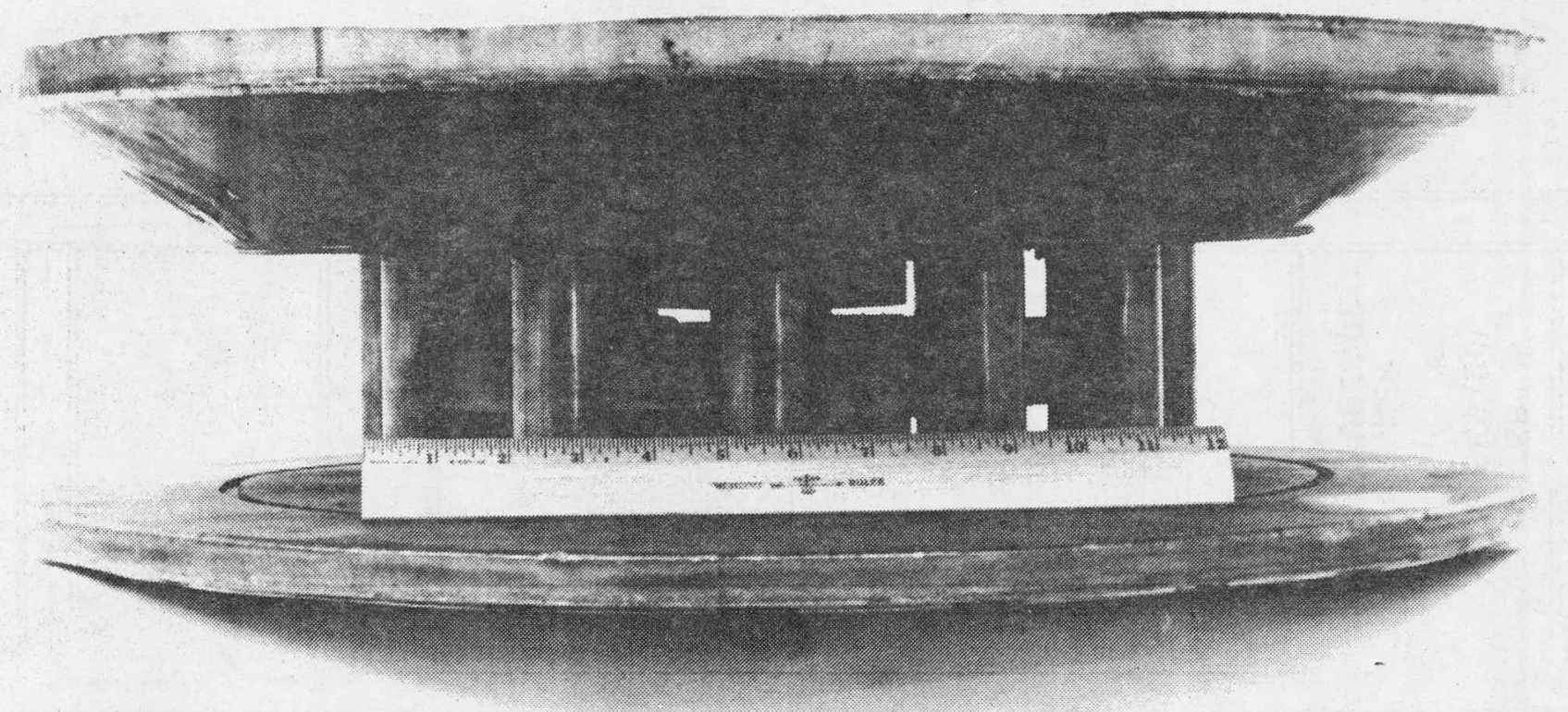

Figure 3.73 Photograph of Radial Burner 


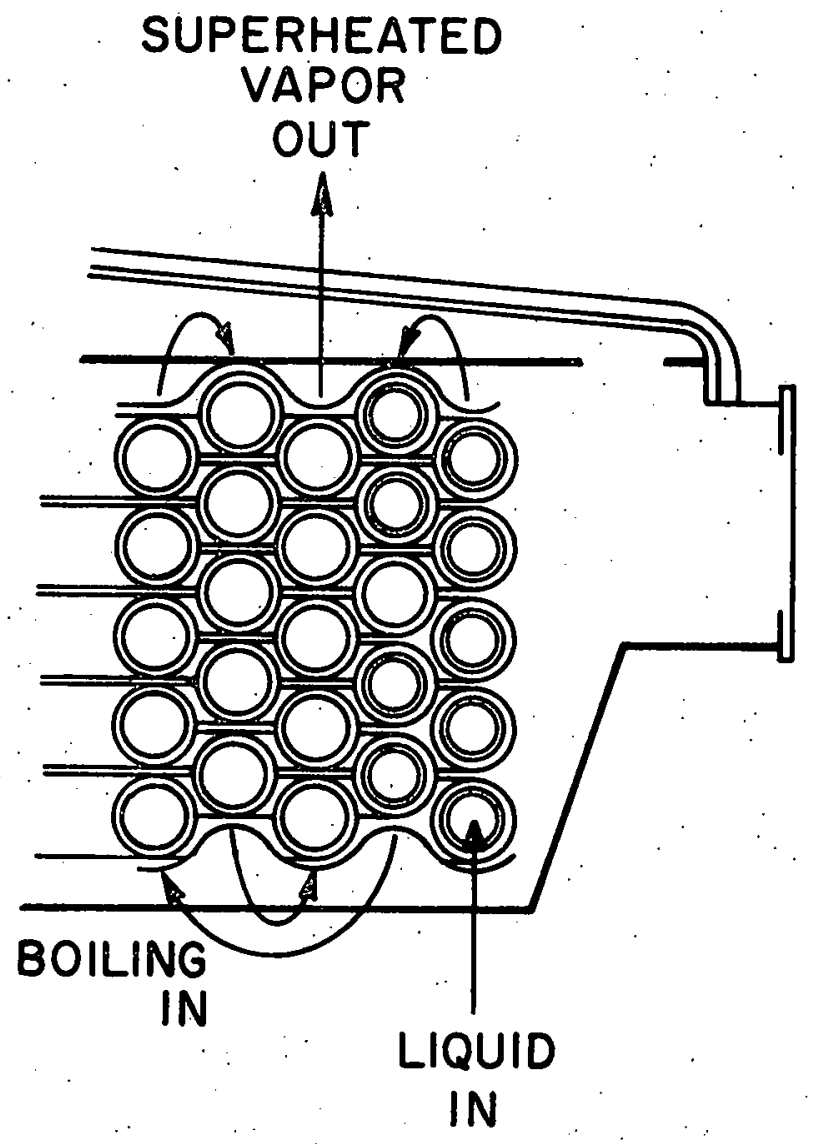

Figure 3.74 Vapor Generator Flow Schematic 
are externally finned to yield a high effectiveness for the vapor generator. From the fourth row the organic liquid enters the first row and, subsequently, flows through the second and third rows in a crossparallel fashion. This arrangement is tailored to keep the wall temperature from exceeding the maximum safe organic fluid temperature, thus preventing the organic fluid from overheating. The organic fluid leaves the first row in a two-phase state and the second row in a partially superheated vapor state. In the third row, the vapor attains the required superheating before exiting into the expander.

For the design operating temperature of $550^{\circ} \mathrm{F}$, the maximum internal wall temperature was maintained at $580^{\circ} \mathrm{F}$. To maintain this level, it was necessary to use internally finned tubing on the last twelve feet of the third row. The remainder of the first three rows are plain-walled steel tubing. A photograph of the vapor generator is shown in Figure 3.75 .

The design polnt characteristics of the burner/vapor generator are given in Table 3.13. One key feature of the unit is recirculation of the EGR to the inlet of the burner after the gas has been cooled by the tube bundle. This can be seen in Figure 3.71. This was done primarily to minimize oxide of nitrogen emissions. A photograph of the assembled burner/vapor generator is shown in Figure 3.76. The predicted performance, design temperatures, and pressures for each row can be found in Table 3.14.

\subsubsection{Vapor Generator Testing and Performance Evaluation}

During operation of the vapor generator, the inlet and outlet conditions of the working fluid were obtained by measuring the pressure and temperature at these points. The temperature of the fluid was 


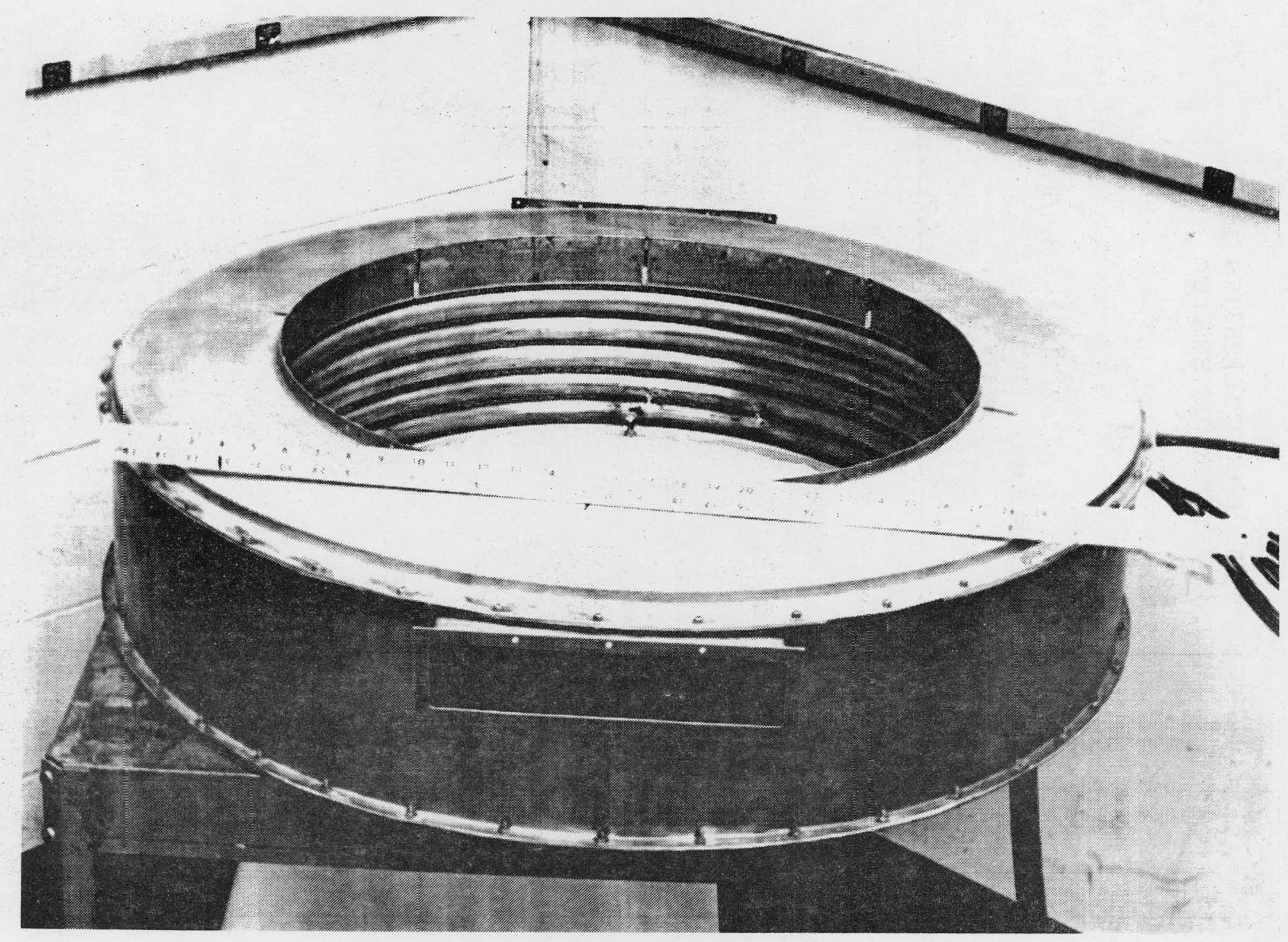

Figure 3.75 Photograph of Vapor Generator Tube Bundle 


\section{DESIGN POINT CHARACTERISTICS OF} BURNER/VAPOR GENERATOR

\section{Burner}

Firing Rate

Fuel (EPA Reference) Flow Rate

Airflow Rate

EGR Flow Rate

Combustor Space Rate

Combustor Pressure Drop

Control Pressure Drop

Vapor Generator

Efficiency

Heat Transfer Rate

Exhaust Gas Temperature

Gas-Side Pressure Drop

Organic Fluid Side

Inlet Pressure

Inlet Temperature

Outlet Pressure

Outlet Temperature

Flow Rate

Maximum Tube Inner Wall

Temperature

Number of Stages (Rows)
$2.78 \times 10^{6} \mathrm{Btu} / \mathrm{hr}$

$138 \mathrm{lb} / \mathrm{hr}$

$2473 \mathrm{lb} / \mathrm{hr}$

$522 \mathrm{lb} / \mathrm{hr}$

$1.94 \times 10^{6} \mathrm{Btu} / \mathrm{hr}-\mathrm{ft}^{3}$

4.5" WC

2.0" WC

$81 \%$

$2.25 \times 10^{6} \mathrm{Btu} / \mathrm{hr}$

$600^{\circ} \mathrm{F}$

2.75" WC

816 psia

$287^{\circ} \mathrm{F}$

700 psia

$550^{\circ} \mathrm{F}$

$10,000 \mathrm{lb} / \mathrm{hr}$

$580^{\circ} \mathrm{F}$

5 




Figure 3.76 Photograph of Assembled Burner-Vapor Generator 
TABLE 3.14

DESIGN POINT STAGEWISE PERFORMANCE OF VAPOR GENERATOR

A- 1611

\begin{tabular}{|c|c|c|c|c|c|c|c|c|c|c|}
\hline \multirow{2}{*}{$\begin{array}{l}\text { Row } \\
\text { No. }\end{array}$} & \multicolumn{4}{|c|}{ Fluorinol- 85} & \multicolumn{2}{|c|}{$\begin{array}{c}\text { Exhaust } \\
\text { Gas }\end{array}$} & \multirow{2}{*}{$\begin{array}{c}\text { Heat } \\
\text { Transferred } \\
\text { (Btu/hr) }\end{array}$} & \multirow{2}{*}{$\begin{array}{l}\text { Maximum } \\
\text { Heat Flux } \\
\left(\mathrm{Btu} / \mathrm{hr}-\mathrm{ft}^{2}\right)\end{array}$} & \multirow{2}{*}{$\begin{array}{c}\text { Maximum } \\
\text { Wall } \\
\text { Temperature } \\
\left({ }^{\circ} \mathrm{F}\right)\end{array}$} & \multirow{2}{*}{$\begin{array}{r}\text { Weight } \\
\text { (lbs) }\end{array}$} \\
\hline & $\begin{array}{l}P_{\text {in }} \\
\text { (psia) }\end{array}$ & $\begin{array}{l}\mathrm{T}_{\text {in }} \\
\left({ }^{\circ} \mathrm{F}\right)\end{array}$ & $\begin{array}{c}\mathrm{P}_{\text {out }} \\
\text { (psia) }\end{array}$ & $\begin{array}{l}T_{\text {out }} \\
\left({ }^{\circ} \mathrm{F}\right)\end{array}$ & $\begin{array}{l}\mathrm{Tg}_{\text {in }} \\
\left({ }^{\circ} \mathrm{F}\right)\end{array}$ & $\begin{array}{l}\mathrm{Tg} \text { out } \\
\left({ }^{\circ} \mathrm{F}\right)\end{array}$ & & & & \\
\hline I & 774.46 & 427.5 & 753.18 & $\begin{array}{l}446^{\circ} \mathrm{F} \\
(69 \% \text { Qual. })\end{array}$ & 2975 & 2437 & 544,500 & 74,100 & 566 & 16.02 \\
\hline II & 753.18 & $\begin{array}{l}446^{\circ} \mathrm{F} \\
(69 \% \text { Qual. })\end{array}$ & 727.48 & 474 & 2437 & 2011 & 427,000 & 47,000 & 542 & 17.3 \\
\hline III & 727.48 & 474 & 700 & 550 & 2011 & 1600 & 398,000 & 39,000 & 580.6 & 19.7 \\
\hline IV & 795.26 & 355 & 774.46 & 427.5 & 1600 & 963 & 568,000 & 71,000 & 495.3 & 21.7 \\
\hline $\mathrm{V}$ & 816.46 & 287 & 795.26 & 355 & 963 & 600 & 323,000 & 37,800 & 386 & 23.1 \\
\hline
\end{tabular}

Rows I, II, III are fabricated out of 1.000" od, 0.049" wall

1015 Carbon Steel. Last 12 feet of Row $\amalg$ have internal

finning 1 " od 0.049 "Wall 32 fins, $0.020 "$ base, $0.041 "$

high, 1 in. 5" spiral also 1015 carbon steel.

Rows IV \& V are fabricated out of $3 / 4$ " od, $0.035^{\prime \prime}$ Wall, $18 \mathrm{fpi}$.

0.009 " thick, 0.170" high, 1015 carbon steel. 
measured by sheathed thermocouples inserted through the tube wall and immersed in the flow. The static pressure and temperature of the exhaust gas at the vapor generator outlet was also measured. The combustion gas inlet temperature was not measured directly, but was determined by performing a heat balance between the working fluid and the combustion gas sides of the exchanger. In this balance; heat losses to the surroundings, which are quite small, were neglected. A plot of predicted and measured vapor generator effectiveness is shown in Figure 3.77. The design-point gas-side pressure drop proved to be considerably higher than the 8-in. WC predicted. Extrapolation of the curve of Figure 3.78 indicates an actual pressure drop of about 12 in. WC cold flow tests indicated that the discrepancy was probably caused by insufficient clearance between the outside diameter of the outermost coil and the vapor generator housing. The Fluorinol-85 pressure drop through the vapor generator is shown in Figure 3.79 .

\subsubsection{Burner Testing and Performance Evaluation}

The burner has undergone extensive testing during its development at TECO. Although burner data have been taken during runs of the preprototype system, the bulk of the testing was done in a separate combustion test facillty. This facility, shown in Figure 3.80 , contained a water-cooled heat exchanger into which the burner was installed, and it had the capability of supplying and measuring air, fuel, and recirculated exhaust gas. Emissions were measured using the same portable test stand (shown in Figure 3.81) that was used for the preprototype testing. 


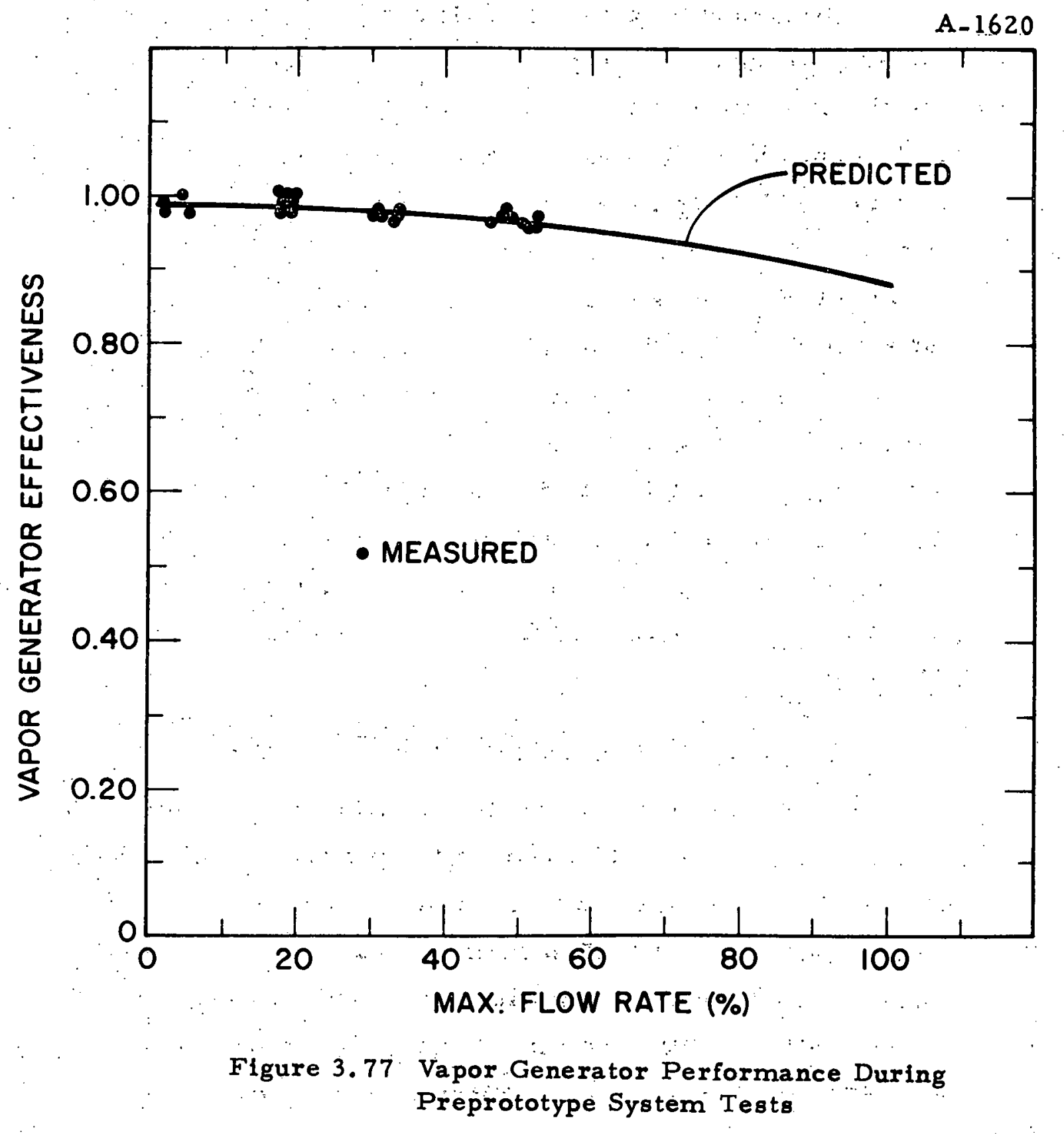




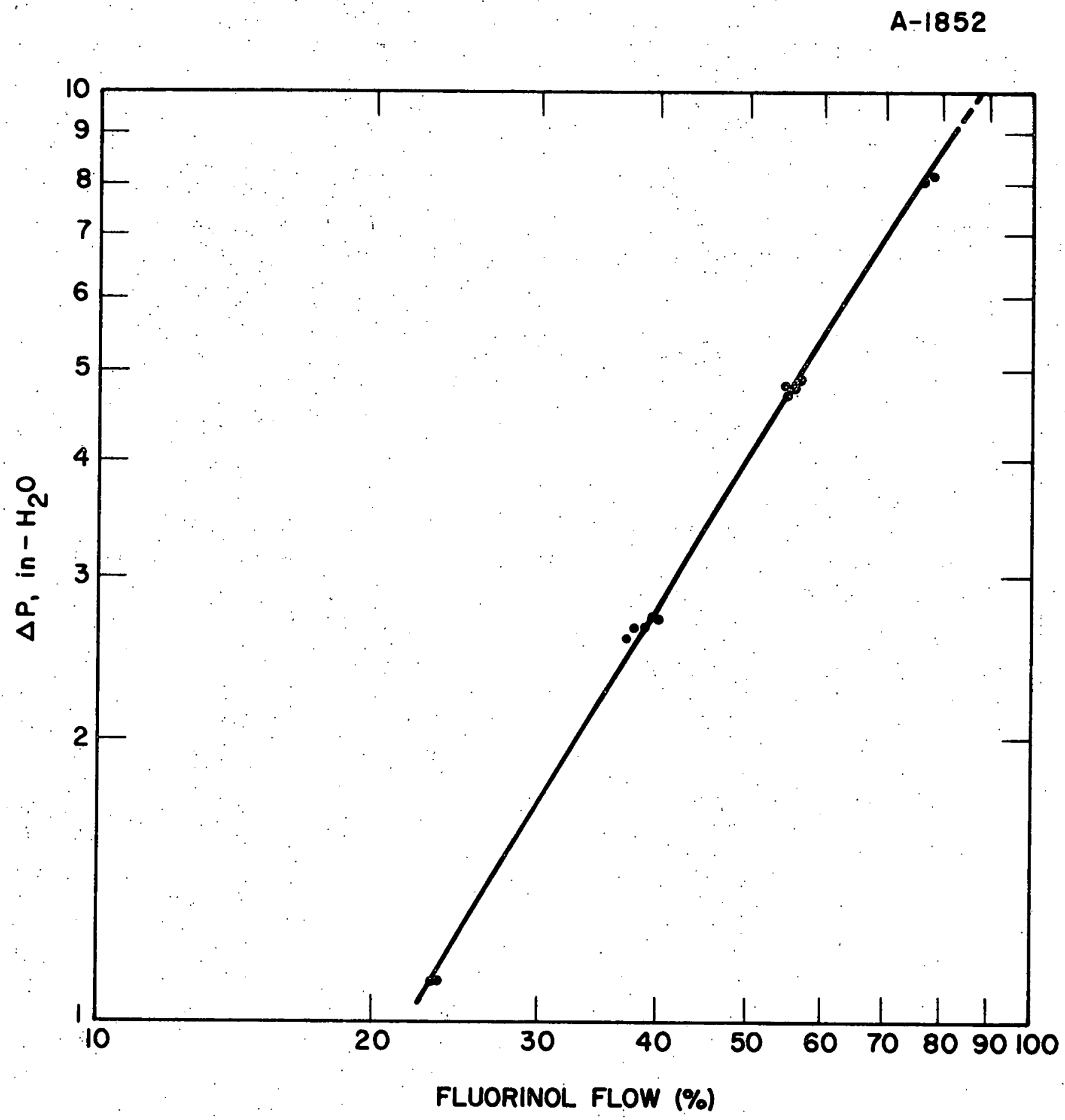

Figure 3. 78 Burner-Vapor Generator Gas-Side Pressure Drop 


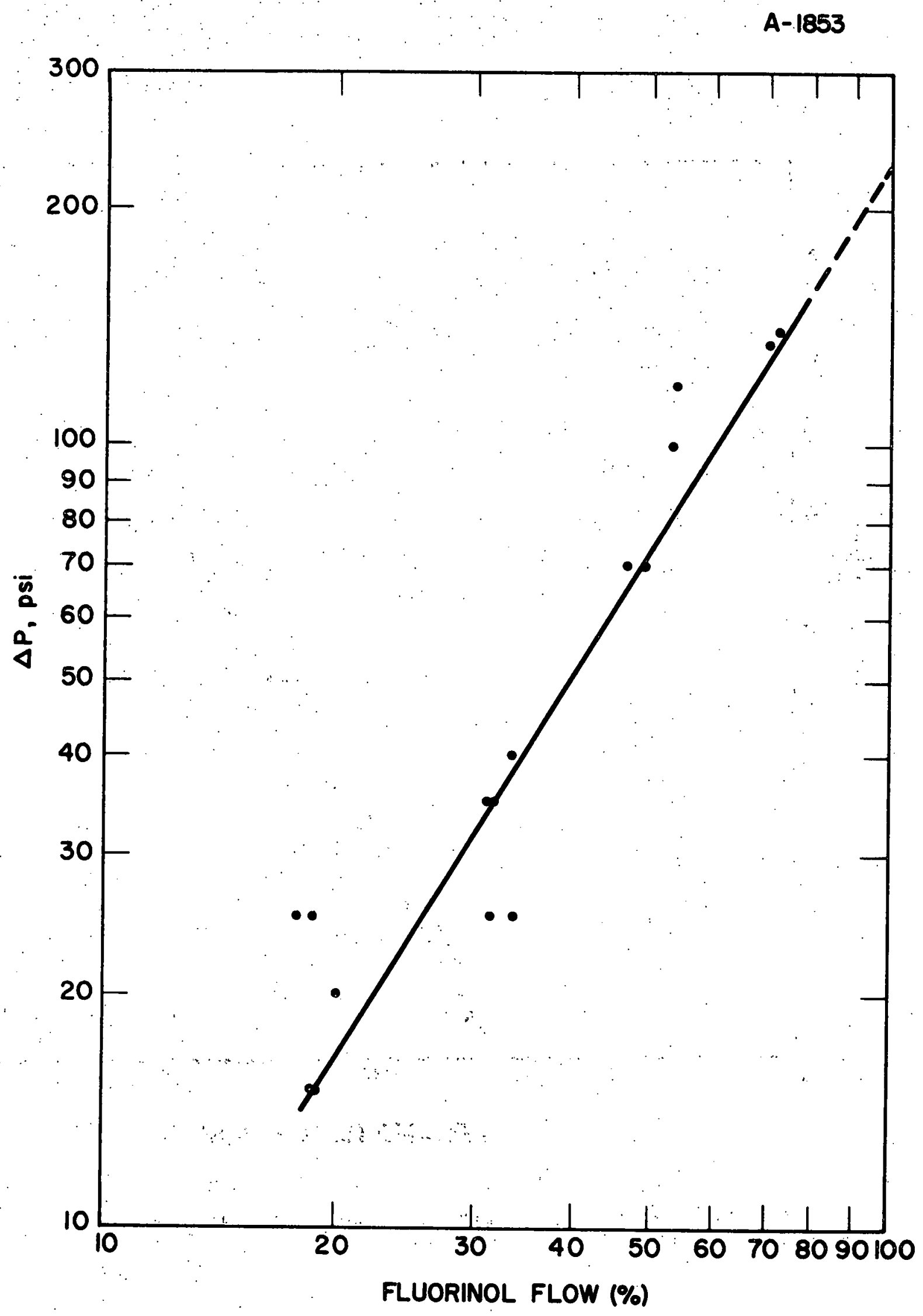

Figure 3. 79 Vapor Generator Fluid-Side Pressure Drop 


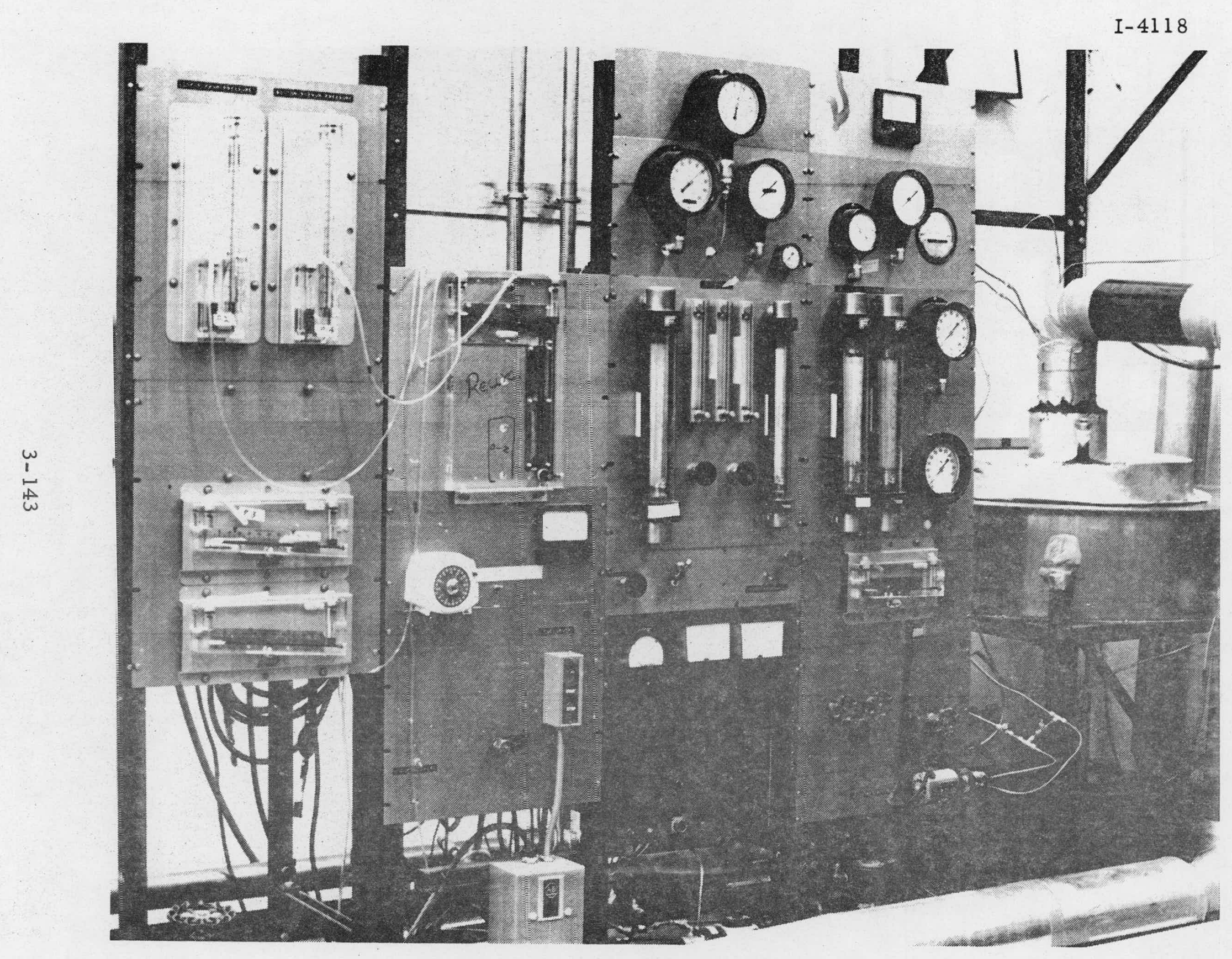

Figure 3.8C Combustion Test Facility 


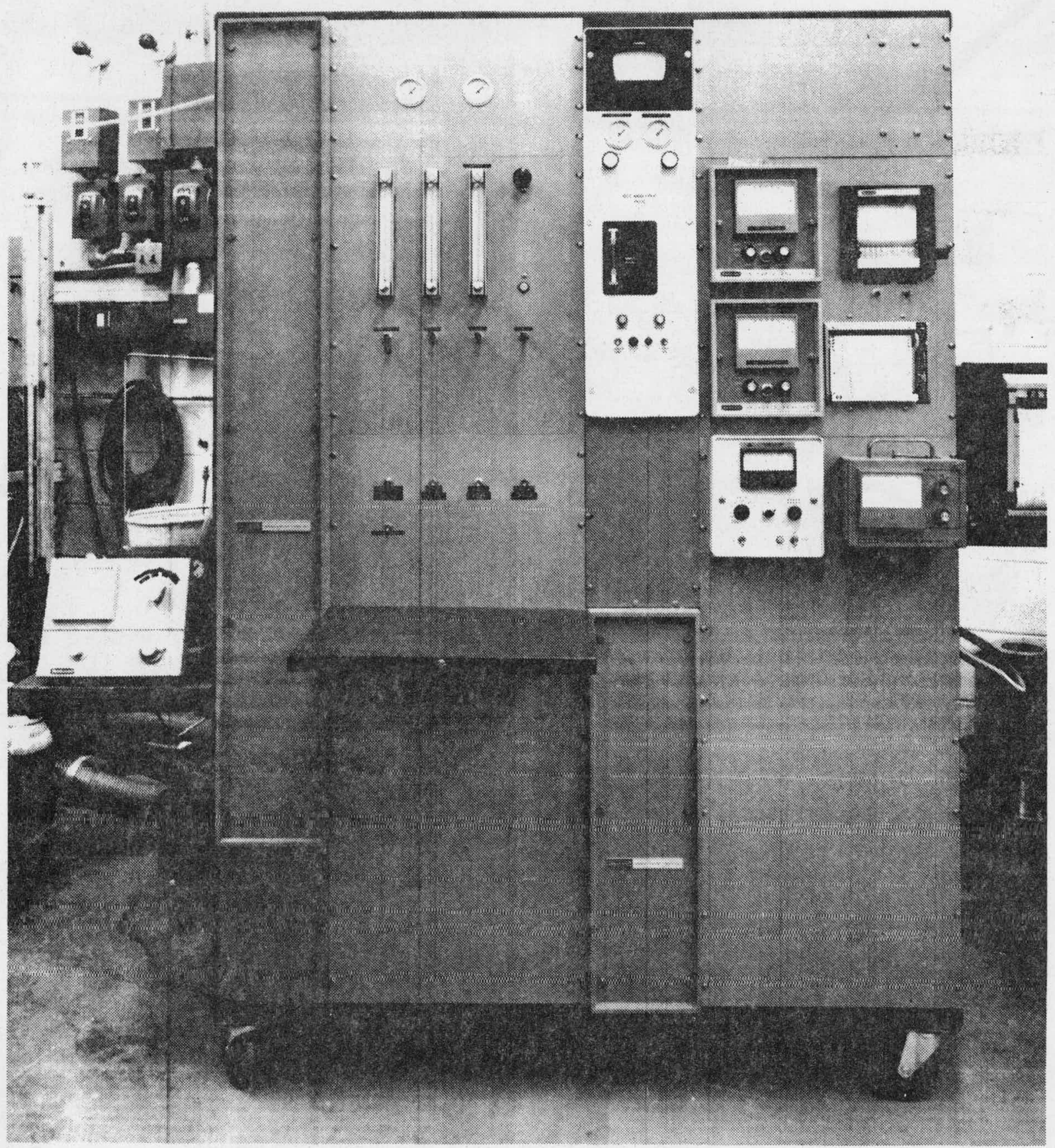

Figure 3.81 Emission Measuring Instruments 
Combustion air was provided by a Buffalo Forge blower driven by a Reeves variable-speed drive motor. Air from the blower was ducted to the burner through two parallel 4-in.-diameter orifice lines. Airflow to each line was controlled by a butterfly valve and could be shut off or throttled as needed. A range of orifice plates were used in conjunction with inclined verticle manometers to provide an airmeasuring system. EGR was provided by a second blower installed between the burner exhaust and the air inlet. The rate of EGR flow was measured in a 3 -in. orifice line. Orifice plates were available to provide accurate measurement over a wide flow range. The temperature of the recirculated exhaust gas was measured downstream of the orifice plate by a thermocouple immersed in the flow. Fuel, provided by the EPA, was stored in a 1000-gal underground tank. Fuel specifications are given in Table 3.15. Fuel flow to the burner was measured by three Fischer-Porter flowmeters connected in parallel. The smallest flowmeter had been calibrated to a maximum flow of $150 \mathrm{lb} / \mathrm{hr}$. The analyzers used for measuring emissions, as well as the calibration gases used, are described in Table 3.16.

In the TECO combustion test facility, testing of various design configurations, as well as the effect of various fuel, air, and EGR ratios upon emission levels, were evaluated. This evaluation was done by conducting tests over the range of fuel flow predicted for the federal driving cycle. Operating time of the burner was also recorded during these tests and used to evaluate the life of various components, As a result of these life tests, some changes. were made to eliminate vulnerable sections of the burner. This was done by strengthening them, by providing better cooling and insulation, or, as in the case of bearings in the combustion zone, by eliminating them. 
TABLE 3.15

EPA FUEL SPECIFICATION

\begin{tabular}{|c|c|c|}
\hline Item & $\begin{array}{c}\text { ASTM: } \\
\text { Designation }\end{array}$ & Specification \\
\hline 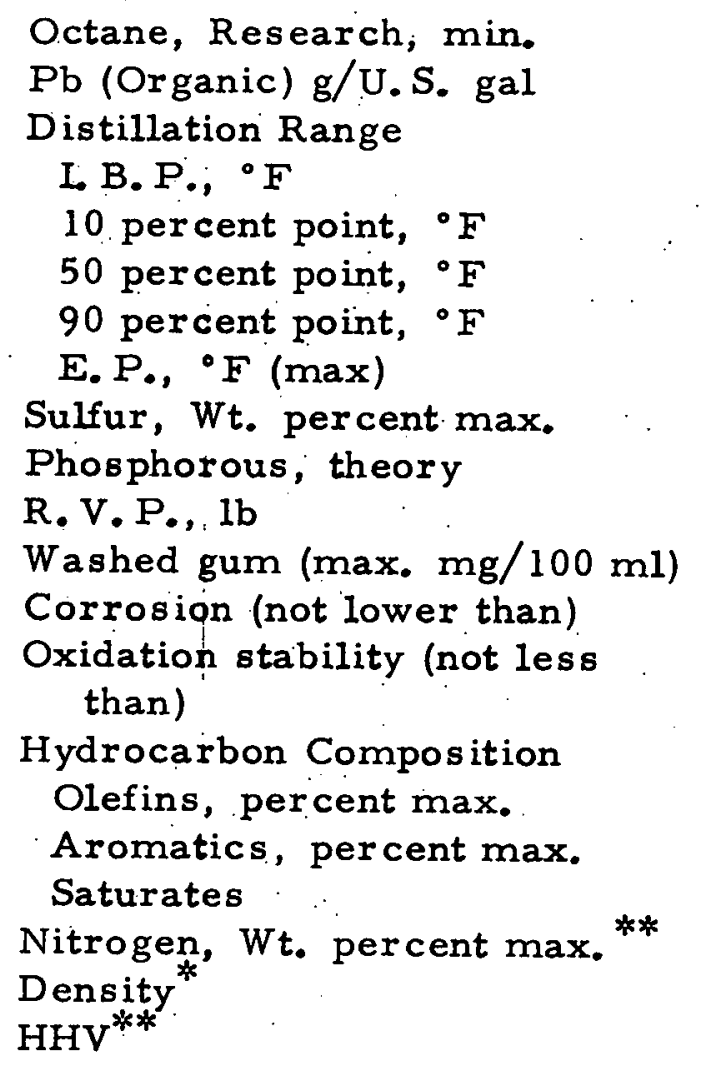 & $\begin{array}{l}\text { D2699 } \\
\text { D524 } \\
\text { D86-67 } \\
- \\
- \\
- \\
- \\
- \\
\text { D 1266 } \\
- \\
\text { D323 } \\
\text { D381 } \\
\text { D130 } \\
\text { D525 } \\
\text { D1319 } \\
- \\
- \\
- \\
-\end{array}$ & $\begin{array}{l}91-93 \\
<0.02 \\
\quad- \\
100-115 \\
140-150 \\
240-250 \\
330-340 \\
425 \\
0.10 \\
0.0 \\
5.5-7.5 \\
4.0 \\
1 B \\
240+ \\
- \\
30 \\
40 \\
\text { Remainder } \\
0.005 \\
6.35 \mathrm{lbm} / \mathrm{gal} \\
\text { Btu/1bm }\end{array}$ \\
\hline
\end{tabular}

Octane, Res
Pb (Organic)
Distillation
I. B. P., ${ }^{\circ} \mathrm{F}$
10 percent
50 percent
90 percent
E. P., ${ }^{\circ} \mathrm{F}$
Sulfur, Wt.
Phosphorous
R. V. P., lb
Washed gum
Corrosion (n
Oxidation st
than)
Hydrocarbon
Olefins, per.
Aromatics
Saturates
Nitrogen, W
Density
H

Measured at Thermo-Electron

**

Calculated from Density Measurement 
TABLE 3.16

\section{EMISSION ANALYZERS}

\section{Hydrocarbon Analyzers}

Beckman Models 109A and 402 (high temperature) Hydrocarbon Analyzers are used. Both analyzers are flame ionization detectors. The instruments are capable of reading from $4 \mathrm{ppm}$ full scale to $120,000 \mathrm{ppm}$ full scale. Repeatability is $\pm 1 \%$ full scale for successive samples. Response time is less than one second for $90 \%$ of final reading.

\section{Carbon Monoxide}

Carbon monoxide is measured using a Beckman Model IR-3 15AL nondispersive infrared analyzer: The analyzer has three ranges: $0-100$ ppm, $0-250 \mathrm{ppm}$, and $0-1000 \mathrm{ppm}$. Accuracy is $\pm 1 \%$ of full scale.

\section{Carbon Dioxide}

A Beckman Model IR-3 15A nondispersive infrared analyzer is used to measure $\mathrm{CO}_{2}$ : The analyzer has three ranges: $0-4 \%, 0-10 \%$, and $0-20 \%$. Accuracy is $\pm 1 \%$ of full scale.

\section{Oxides of Nitrogen}

Oxides of nitrogen are measured using a Thermo Electron Model 10A NO-NO Chemiluminescent Analyzer. This instrument is capable of measuring $\mathrm{NO}_{\mathrm{x}}$ from $10 \mathrm{ppm}$ to $10,000 \mathrm{ppm}$ full scale. Accuracy and linearity is $\pm 1 \%$ full scale. Response time is 1 second.

\section{Calibration Gases}

Two grades of gases are used for calibration. Span gases are "primary standard gases," which have a certification accuracy of $\pm 1 \%$.

Certified gases, which have a certification accuracy of $\pm 2 \%$ above $50 \mathrm{ppm}$ and $\pm 5 \%$ below $50 \mathrm{ppm}$, are used to check linearity. 
Initial testing indicated that over a fairly wide range of rotary atomizer speeds, the emission levels remained relatively constant. Since the predicted speed range of the preprototype combustion blower fell within this range, it was decided to mount both the blower and the atomizing cup on the same shaft. All further testing was done with the blower in place. Air was still provided by the facility supply system so that the orifice lines could be used for measurement. The preprototype blower was operated in series with this system, and the system blower throttled until the preprototype blower was operating at $\pm 200 \mathrm{rpm}$ of its predicted speed at a given airflow. The operating parameters and emission levels for the burner are given in Figures 3.82 through 3.85. All of these data was taken with the EPA specified fuel.

NO $\mathrm{x}_{\mathrm{x}}$ emission data are shown in Figures 3.82 and 3.83. Figure 3.82 shows the range of $\mathrm{NO}_{\mathrm{x}}$ data taken. Of the three emissions, $\mathrm{NO}_{x}$ was the most difficult to eliminate. The most effective $\mathrm{NO}_{\mathbf{x}}$ control was EGR. This lowered the flame temperature in the burner enough to reduce $\mathrm{NO}_{x}$ emissions below the federal standard. Excess air would also have lowered the flame temperature, but EGR was more effective since the oxygen concentration of EGR is much lower than that of excess air, and high oxygen concentration increased $\mathrm{NO}_{\mathrm{x}}$ emissions. The final operating parameter selected for the control of $\mathrm{NO}_{\mathrm{x}}$ emissions is shown in Figure 3.83. 'Excess air was set at 25 percent, and EGR varied from about 70 percent at low firing rates to 30 percent at the maximum firing rate. 


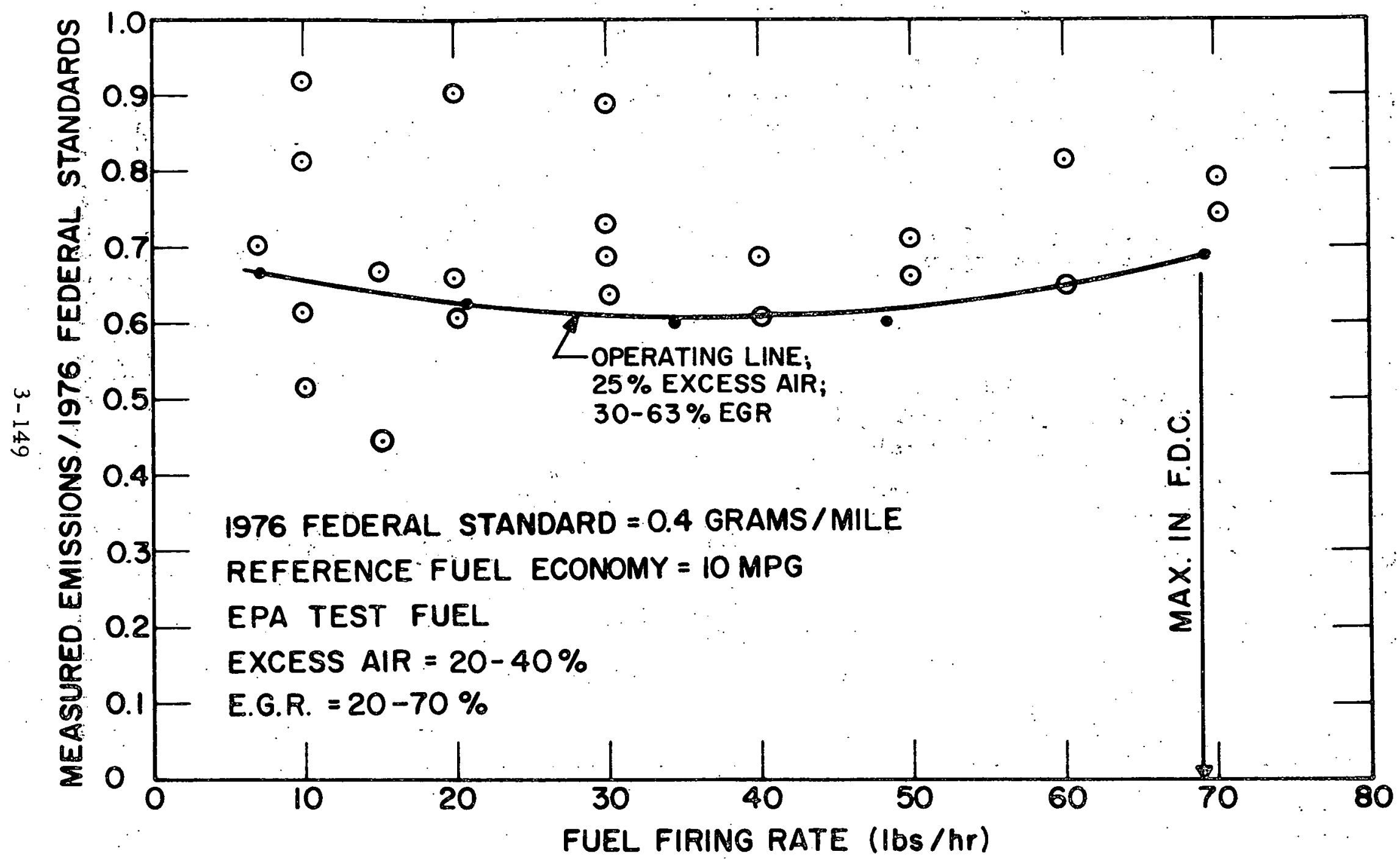

Figure 3.82 NO Emissions as a Function of Fuel Firing Rate for Various Excess Air and EGR Flows 


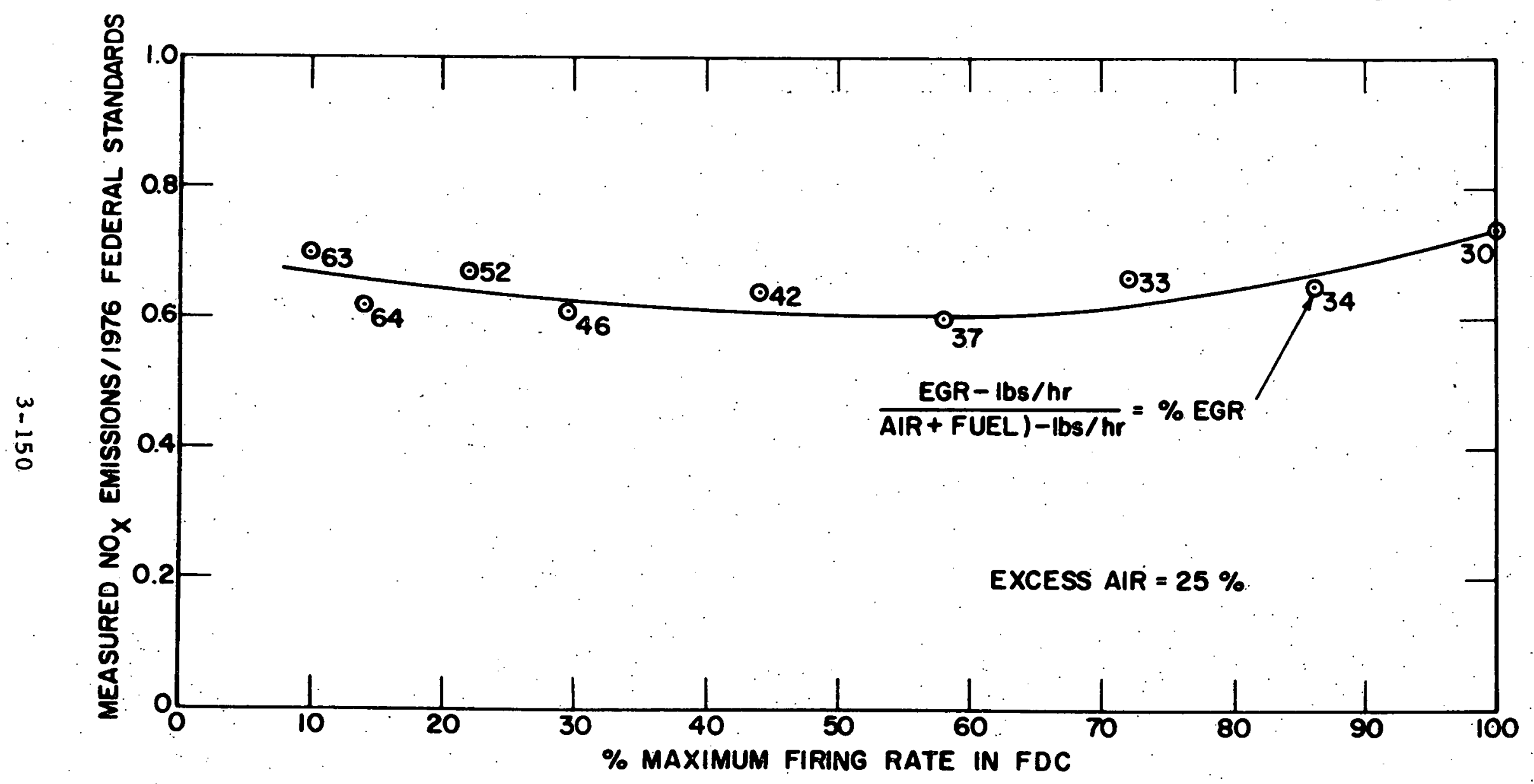

Figure 3.83 $\mathrm{NO}_{\mathbf{x}}$ Emissions as a Function of Firing Rate 


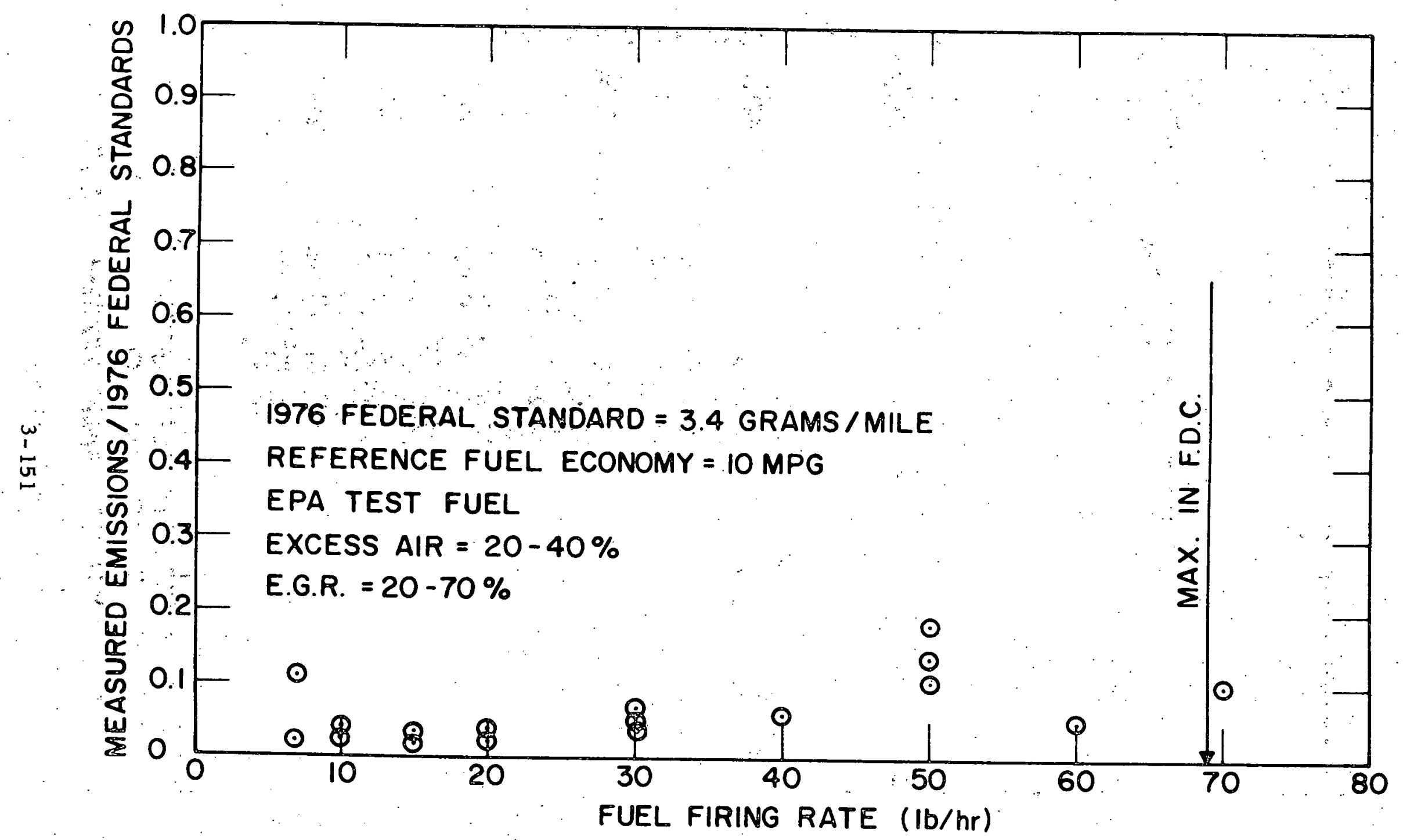

Figure 3.84 CO Emissions as a Function of Fuel Firing Rate 
I -4120

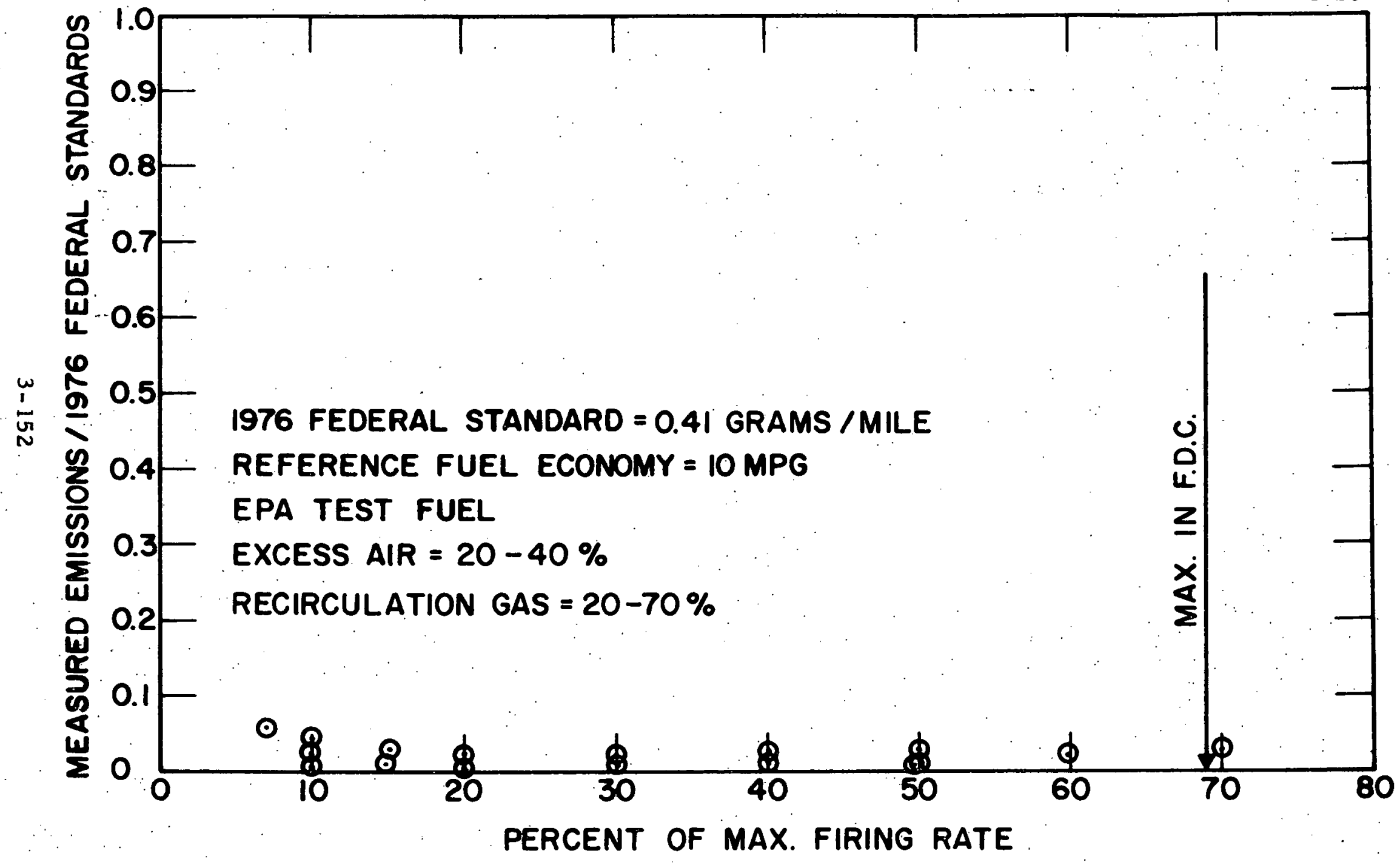

Figure 3.85 HC Emissions as a Function of Fuel Firing Rate 
The control of CO was not difficult. Testing showed that as long as excess air was kept above 15 to 20 percent and a moderate amount of EGR was used, CO emissions stayed well below the federal standard. This can be seen in Figure 3.84. The operating parameters chosen for the control of $\mathrm{NO}_{\mathbf{x}}$ emis sions coincided nicely with the requirements for controlling CO emissions.

HC emissions were the easiest of the three to control. They were less than 5 percent of the federal standards under all test conditions, as can be seen in Figure 3.85. HC emissions were insensitive to moderate amounts of both excess air and EGR. Excess air had to be increased above 75 percent before $\mathrm{HC}$ increased due to flame quenching.

The permissible federal emission levels for a fuel economy of 10 mpg are shown in Figure 3.86. The steady-state emis sion data were used, and a projection of the emission levels was made using a.simulated federal driving cycle. The results of this computation are shown in Table 3.17 .

In the final phase of the burner testing, the burner assembly was installed in the preprototype loop and operated with the rest of the system. At this time, a startup problem was encountered. During startup, with no exhaust gas present, air entered the blower inlet through the EGR ducts, resulting in a very lean air/fuel ratio. This ratio proved to be too lean for reliable ignition. The startup problem could be overcome either by physically blocking the EGR ducts on startup, or by altering the initial fuel signal. Because time and schedule commitments were an important consideration, the least time consuming method (blocking the EGR ducts) was chosen, and the system was run with exhaust gas recirculation. This resulted 


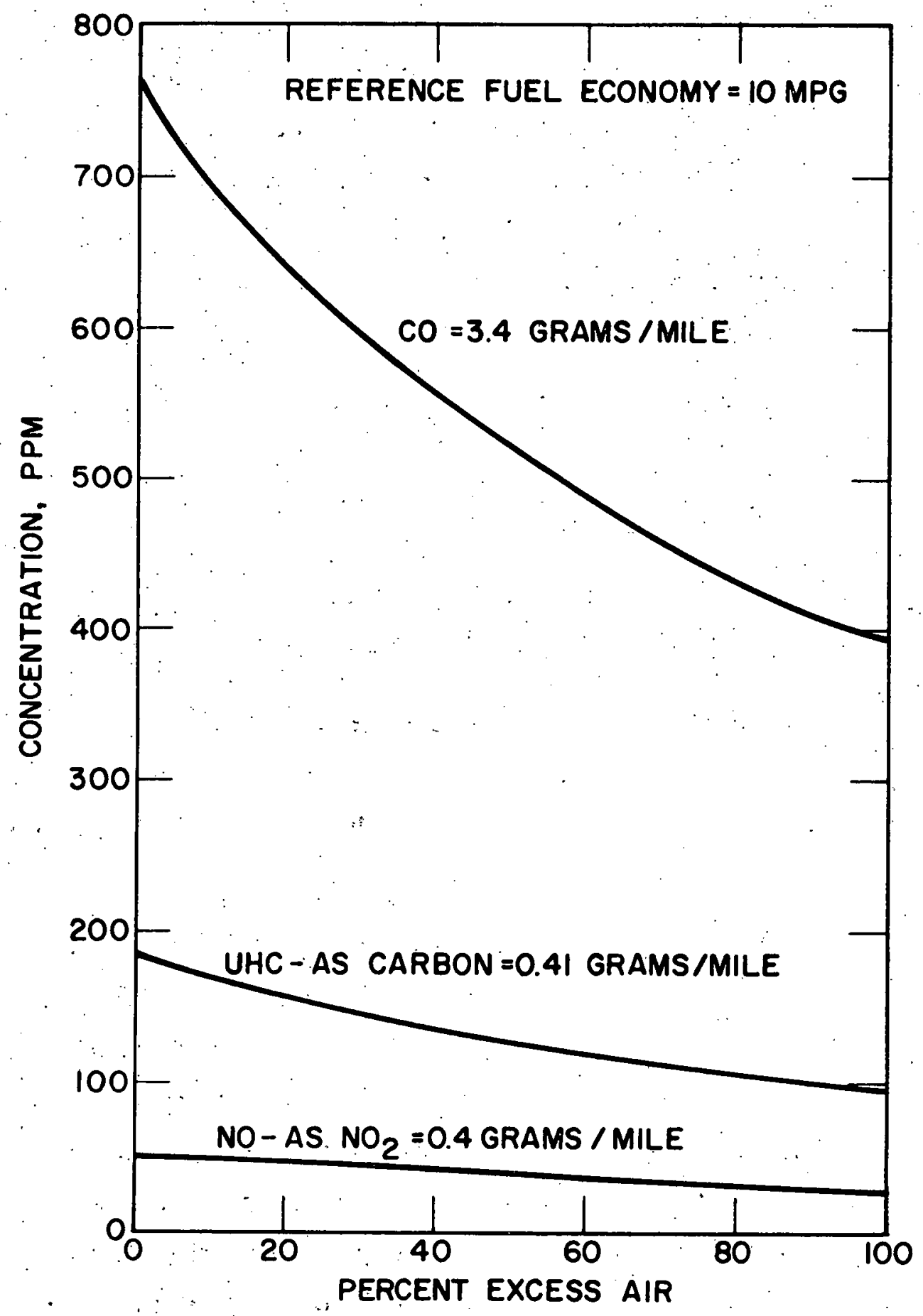

Figure 3.86 1976. Federal Emission Standards 
TABLE 3.17

\section{COMPUTER CALCULATED EMISSIONS OF RADIAL BURNER FOR. \\ FEDERAL DRIVING CYCLE}

\begin{tabular}{|c|c|c|}
\hline Pollutant & $\begin{array}{c}1976 \\
\text { Federal } \\
\text { Standard } \\
(\mathrm{g} / \mathrm{mile})\end{array}$ & $\begin{array}{c}\text { Calculated } \\
\text { Emissions } \\
(\mathrm{g} / \mathrm{mile})\end{array}$ \\
\hline $\mathrm{UHC}$ & 0.41 & 0.17 \\
$\mathrm{CO}$ & 3.4 & 0.21 \\
$\mathrm{NO}$ & 0.4 & 0.27 \\
\hline
\end{tabular}

1. Based on Steady-State Test Data

2. Includes 30 Seconds Firing at $56 \mathrm{lb} / \mathrm{hr}$ for Startup Simulation.

3. Computed Fuel Consumption $10 \mathrm{mpg}$ for Federal Driving Cycle 
in increased oxides of nitrogen and reduced CO during the preprototype tests. These levels, as would be expected, are about the same as. those experienced in the burner test loop without EGR:

\subsection{CONTROL SYSTEM}

A schematic illustrating the main features of the control system is shown.in Figure 3.87. The control system operated in the following manner.: Depressing the accelerator pedal increased expander intake ratio. A signal proportional to intake ratio then changed feedpump displacement causing an increase in organic flow rate. Simultaneously, air and fuel flow rates increased as a function of this intake ratio signal and expander speed. The controller was preprogrammed to give the organic, fuel, and air flow rates corresponding to the intake ratio and speed of the expander. This control scheme required some additional features to prevent excessive pressure and temperature in the vapor generator, so two secondary systems.were added. Vapor generator outlet pressure was used to trim feedpump displacement, and vapor generator outlet temperature was used to trim air and fuel flow rates, thereby keeping these parameters within acceptable limits. A separate control signal corresponding to the condenser pressure was used to keep the fan speed at an optimum value.

The following sections describe the three basic elements of the control system. An analog computer simulation of the control system was made by Bendix Corporation under a subcontract from Thermo Electron. This work is reported in Reference 7. 

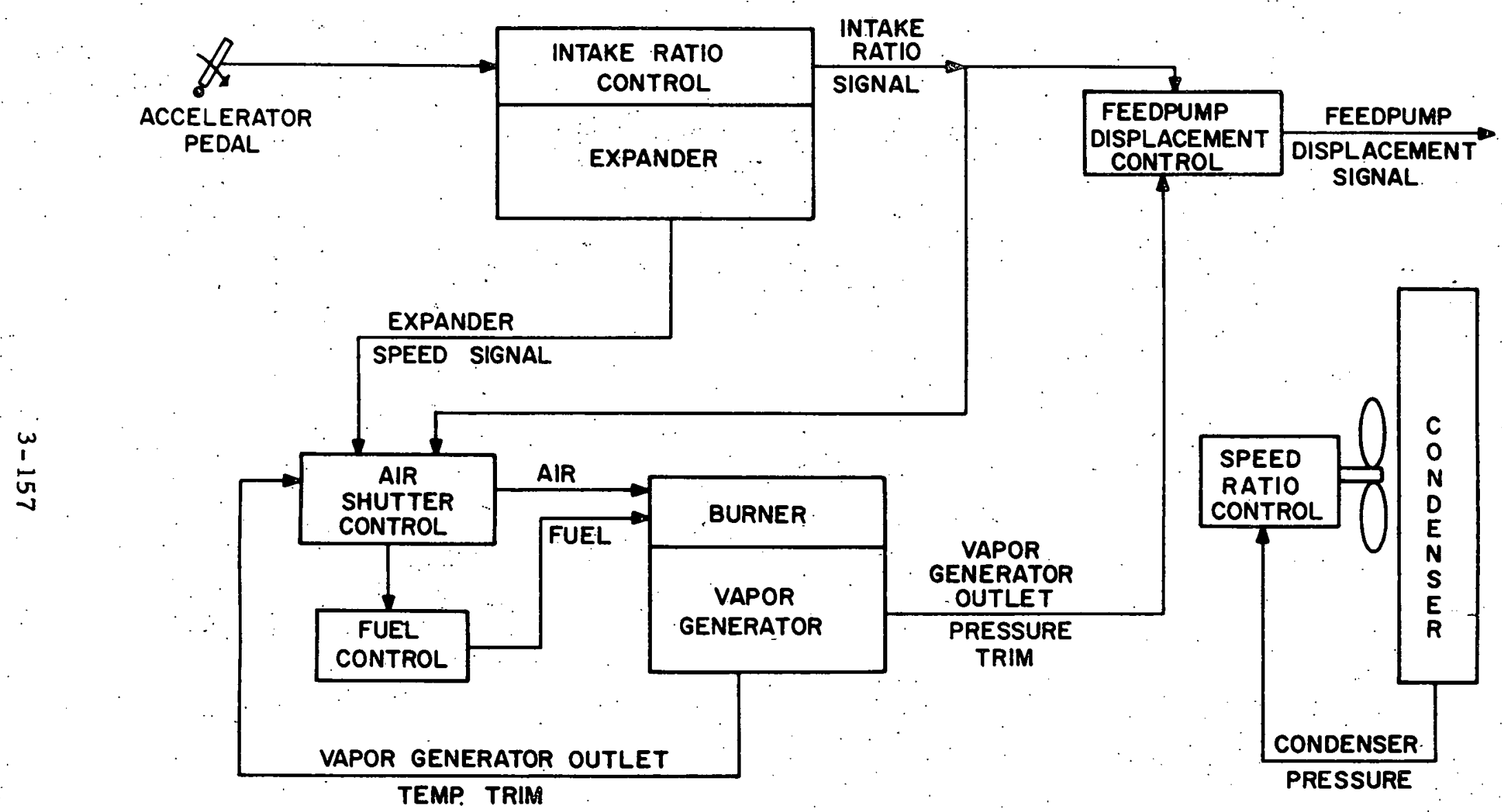

Figure 3.87 Preprototype System Control Schematic 


\subsubsection{Condenser Fan Drive and Control}

The fan drive and speed control were designed for maximum system efficiency"at low power outputs and maximum system performance at high power outputs. The system efficiency, performance, packaging, reliability, and cost were all considered in the selection of the fan speed control and drive.

Early in the program, a study to determine the optimum ratio of fan speed to expander speed at various expander intake ratios demonstrated the necessity of varying the fan speed relative to the expander speed. The study results are indicated in Figure 3.88. The study indicated that, at an expander speed of $800 \mathrm{rpm}$ with the expander intake ratio varying from the minimum to the maximum, the optimum fan speed varies from 1300 to $2700 \mathrm{rpm}$. The power requirement of the fan at $2700 \mathrm{rpm}$ is 8.9 times the requirement at $1300 \mathrm{rpm}$. It is obvious that a constant ratio of the fan speed to expander speed is not desirable if the best system efficiency is to be obtained.

After considering several types, we selected a variable-speed drive manufactured by Speed Selector, Inc. (shown in Figure 3.89). The drive was modified for use in the preprototype system by removing the hand control on the drive pulley, which changes the speed ratio, and replacing it with an air-cylinder actuator. Figure 3.90 is a schematic of the modified drive.

The controller. set the drive pulley to obtain the optimum speed ratio by using the condenser pressure as the control parameter. The effects of ram air, expander power output, ambient air temperature and humidity, and condenser fan speed are reflected in the condenser. 
I-2737

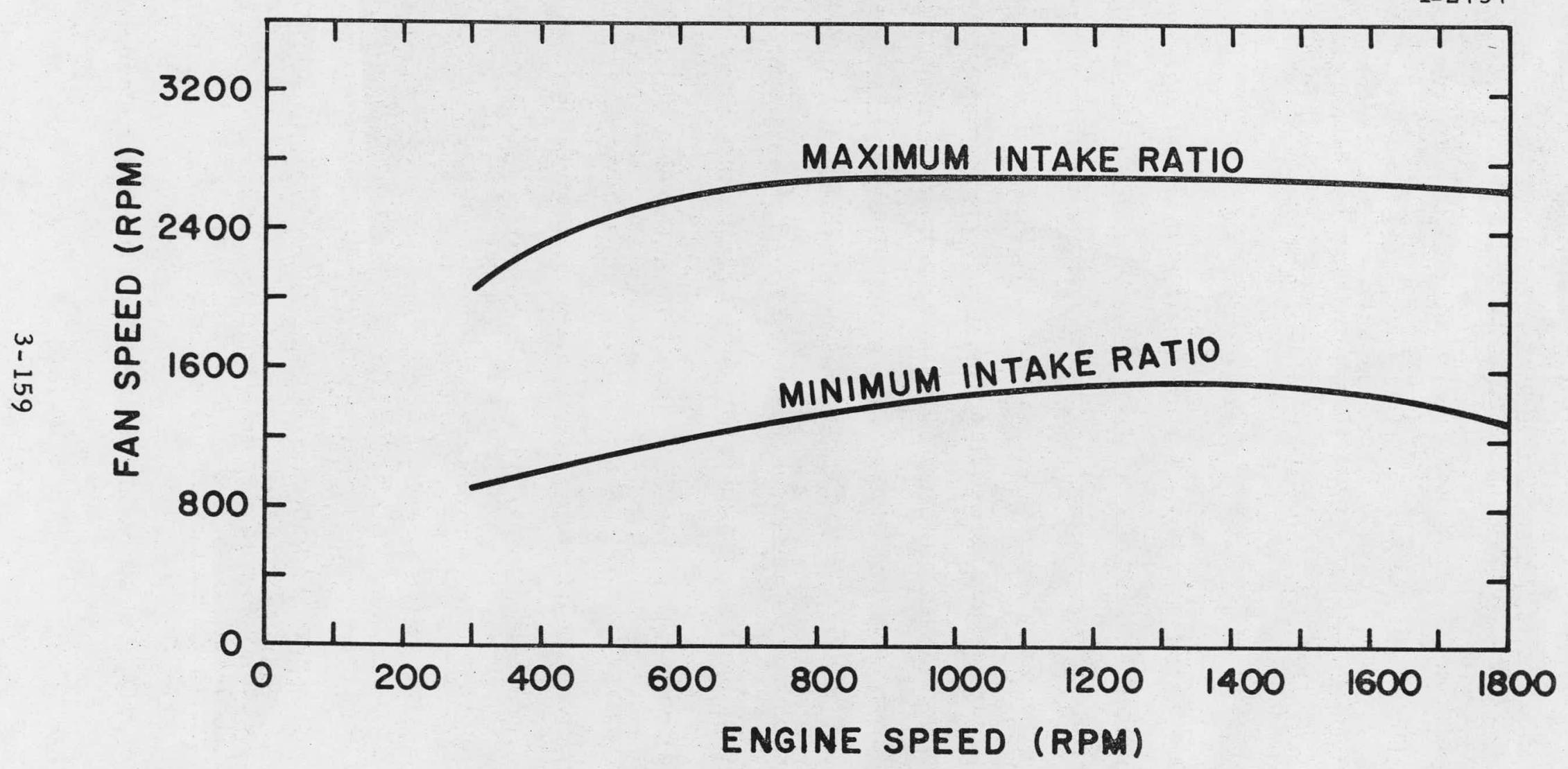

Figure 3.88 Optimum Fan Operating Range 
I- 3745

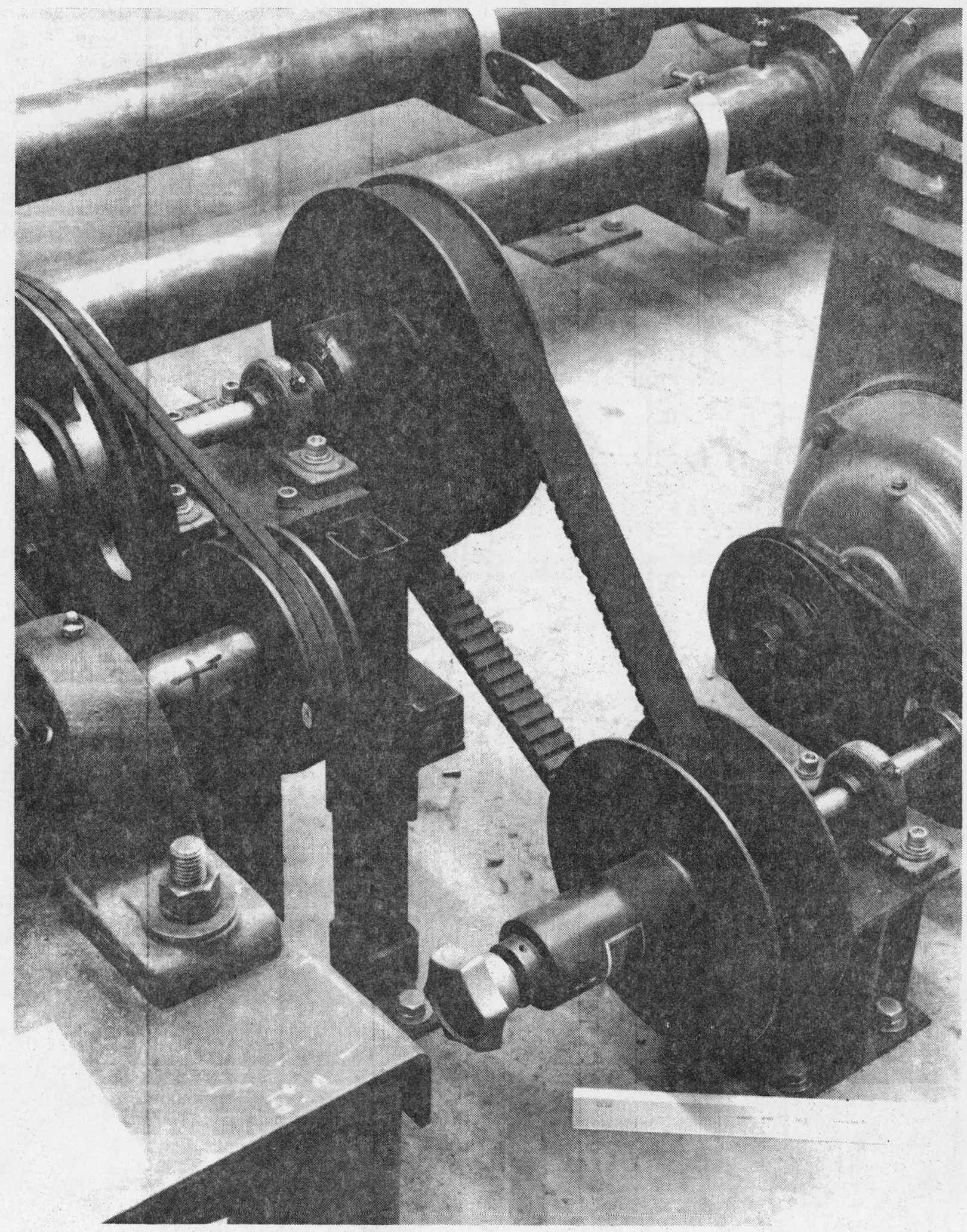

Figure 3.89 Variable-Speed Ratio Belt Drive for Condenser Fans 


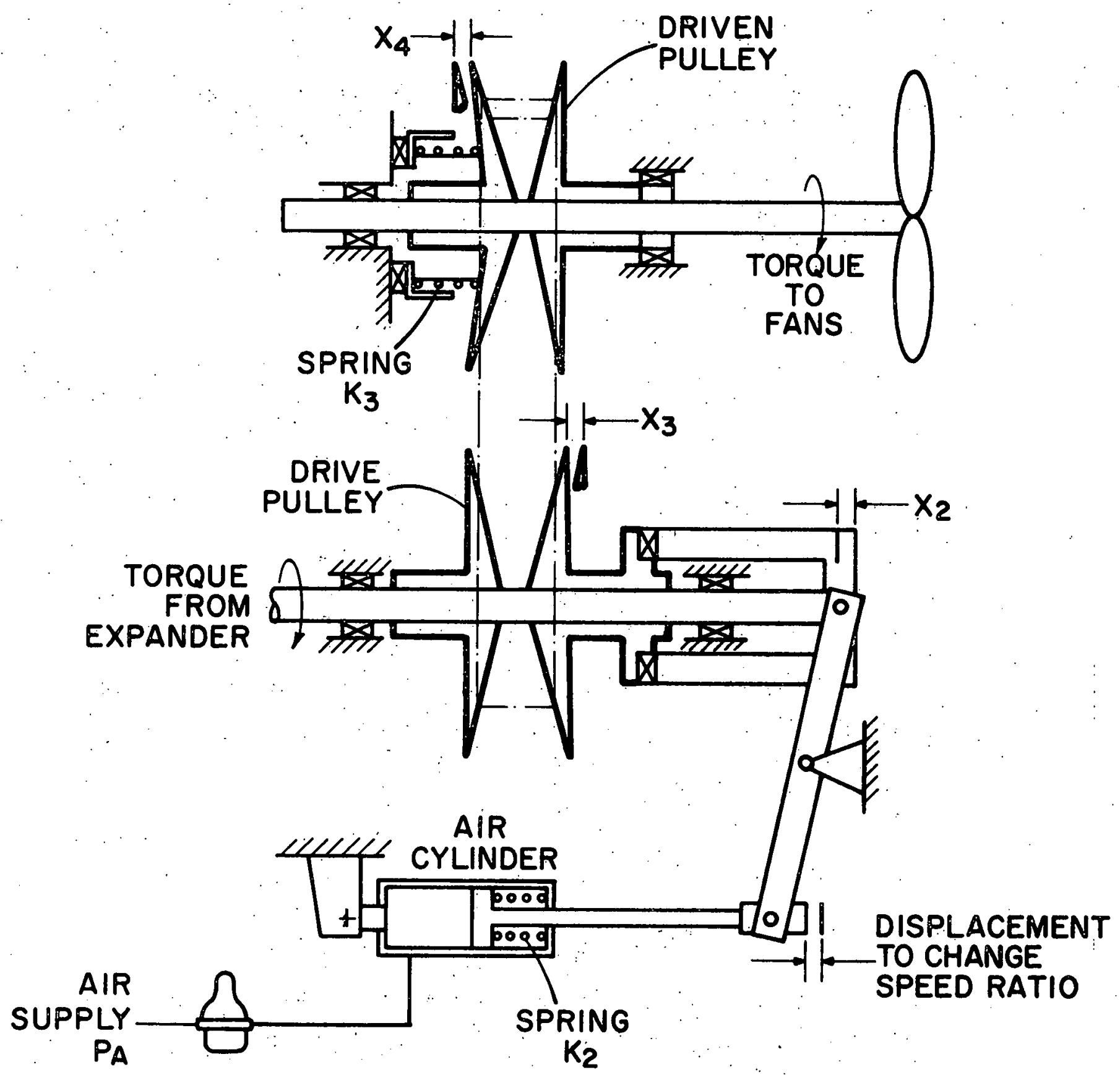

Figure 3.90 Preprototype Variable-Speed Drive 
pressure. A computer study was used to determine the optimum relationship of the ratio of fan rpm to expander rpm versus the condenser pressure. This is shown in Figure 3. 91.

Although this manual air control was adequate for the preprototype system testing, the intent was to replace it later with an electrical controller operating with the condenser pressure as input. This control system is shown schematically in Figure 3.92. The electrical controller consisted of a 1/65-hp gear motor driving a ball screw, which actuated the drive pulley. A potentiometer sensed the drive-pulley position and provided a feedback signal indicating the speed ratio of the belt drive. The electronic controller received a voltage signal from the pressure transducer in the condenser, indicating a speed ratio setting. The electronic controller moved the : gear motor until the feedback signal matched the transducer signal at the correct speed ratio.

The electrical control system was designed and built, but was never installed on the preprototype system because test priorities did not allow time for the incorporation of the electronic controller. 3. 8.2 Combustion Controls

The initial combustion control concept used a throttling valve in combination. with a constant-speed blower for modulating air and fuel flow. At low flows, this arrangement resulted in excessive blower power. This problem was overcome by using a variable-speed blower motor in combination with a variable area valve to control airflow. In this scheme, the pressure drop across a variable-flow area shutter was sensed, and the area was adjusted to maintain a constant pressure 


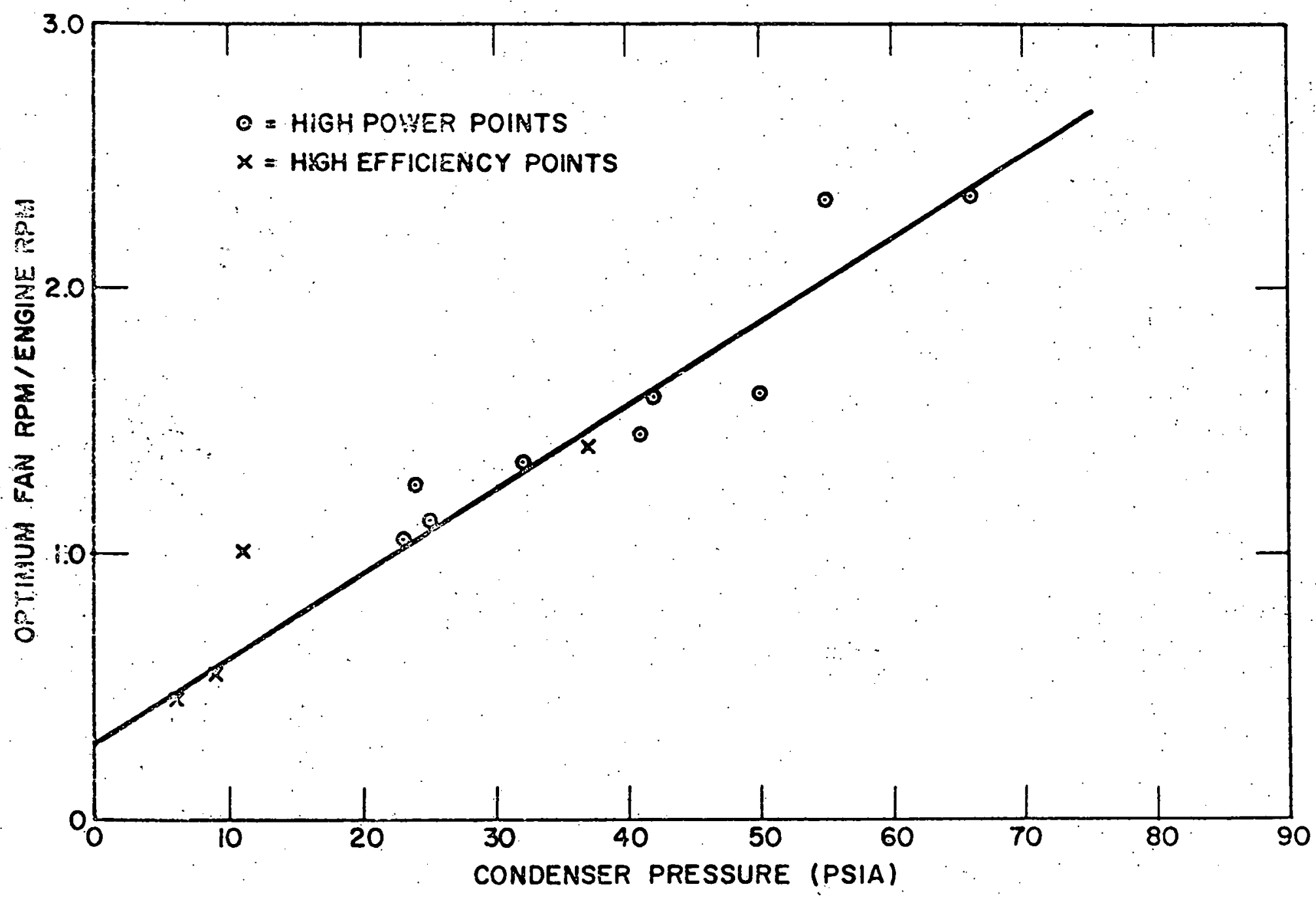

Figure 3.91 Condenser Fan Speed Control Optimization and Characteristic 


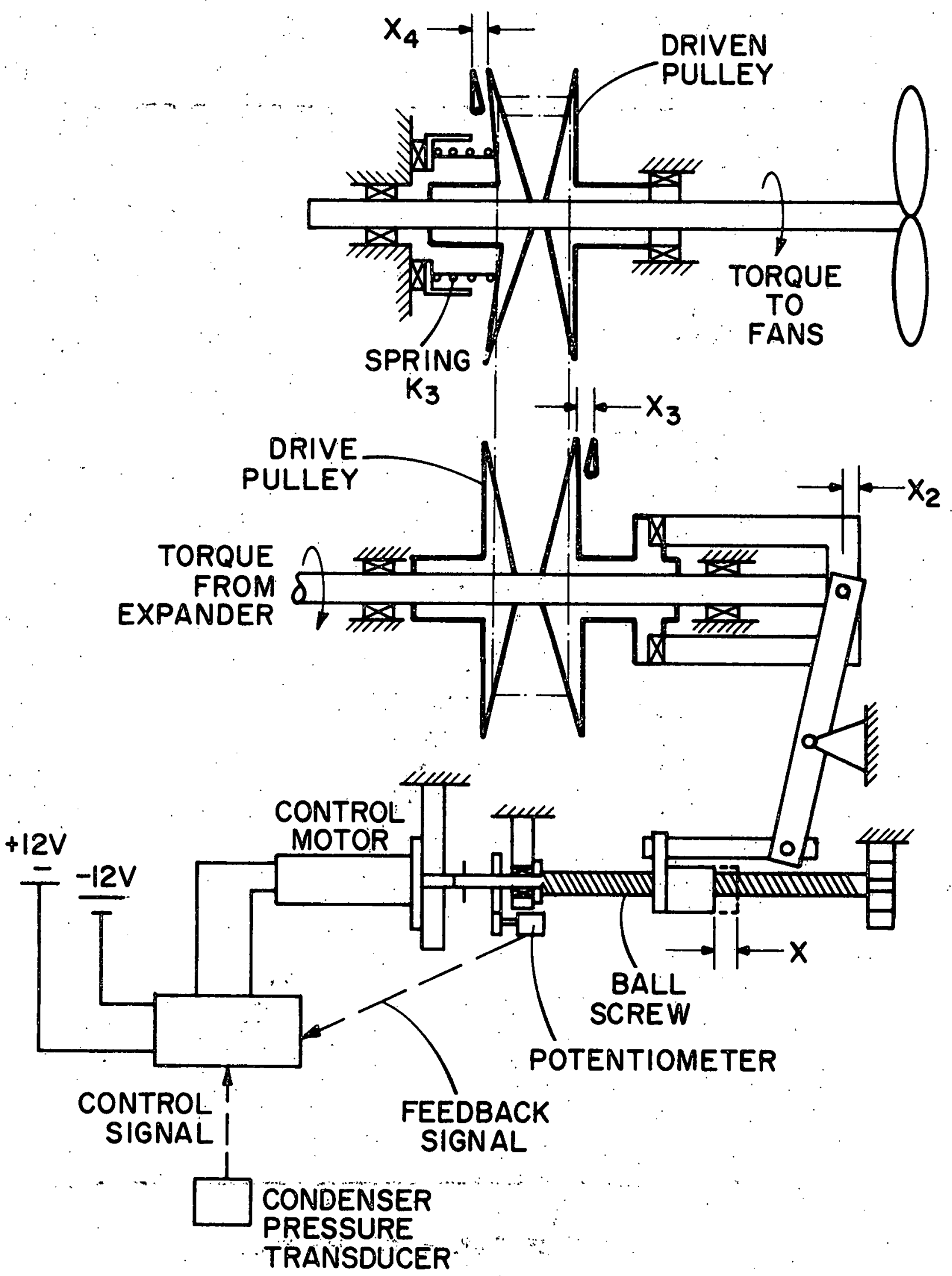

Figure 3.92 Electrically Controlled Eondenser Fan Drive 
drop across the shutter. The blower speed was set by the organic flow rate. The position of the shutter determined the fuel flow rate. The main problem with this concept occurred at low air flow rate. Due to the relatively flat pressure drop versus flow rate characteristics of the blower in this region, the pressure signal was ambiguous. In the final configuration, both the blower speed and the shutter position were set to correspond to a predicted organic flow rate using the expander speed and intake-valve cutoff position. Air-shutter pressure drop was used as a secondary trim on the blower speed. This resulted in the airflow rate being a function of shutter position only; thus, using shutter position to modulate fuel flow rate resulted in accurate control of the air/fuel ratio.

\subsubsection{Air-EGR Metering System}

The air shutter consisted of two flat aluminum plates, one fixed and one free to rotate. As the bottom plate rotated, it opened or closed six identical cutouts in the top plate. These cutouts were shaped to provide an equal percentage increase in open area versus rotation. This was necessitated by the requirement that positioning errors have an equal effect at all firing levels. The contour enhanced loop stability by providing low shutter gain at low flows.

Originally; the shutter was located on the blower outlet. However, due to the high temperature encountered in this area of the burner with the resultant differential expansion and distortion, it was decided that a shutter on the inlet would be more reliable. Also, in the first sys tem it was necessary to provide a restriction in the exhaust to provide a driving force to bring the recirculated exhaust gas to the blower inlet, especially at low firing rates. With the shutter at the inlet, 
the control-pressure differential reduced the blower inlet pressure below ambient; and no exhaust restriction was necessary to provide EGR. This reduced the power requirement of the blower significantly.

With the shutter, idle to full power required a rotation of $30^{\circ}$. Since the area of the shutter increased as an exponential function of the angle of rotation, it was not practical to have the area of the curve go to zèro. In the shutter assembly, the shutters were fully closed at idle, and the required area for idle conditions was provided by fixed openings into the chamber below the shutters. One of these openings was a round the blower drive shaft, eliminating the need for a' seal at this point.

A second shutter was provided for control of EGR. It was located below the atr shutter and was attached to it so that they rotated together. - The pressure differential across the EGR shutter was not constant, but was the sum of the control pressure in the chamber and the back pressure of the exhaust duct downstream of the EGR opening. Also, the exhaust temperature varied.with the firing rate. The effects of variable pressure drop and temperature were sufficiently repeatable to be taken into account, and the area of the openings was adjusted to allow for them. Thus shutter allowed for a continuously varying percentage of EGR, and optimum emission levels throughout the entire firing range.

The shutter control concept is shown in Figure 3.93. It employed a de gear motor to rotate the shutter through a worm gear drive. The expander organic flow rate signal voltage was the primary control input to the gear motor. A potentiometer was used for feedback in 


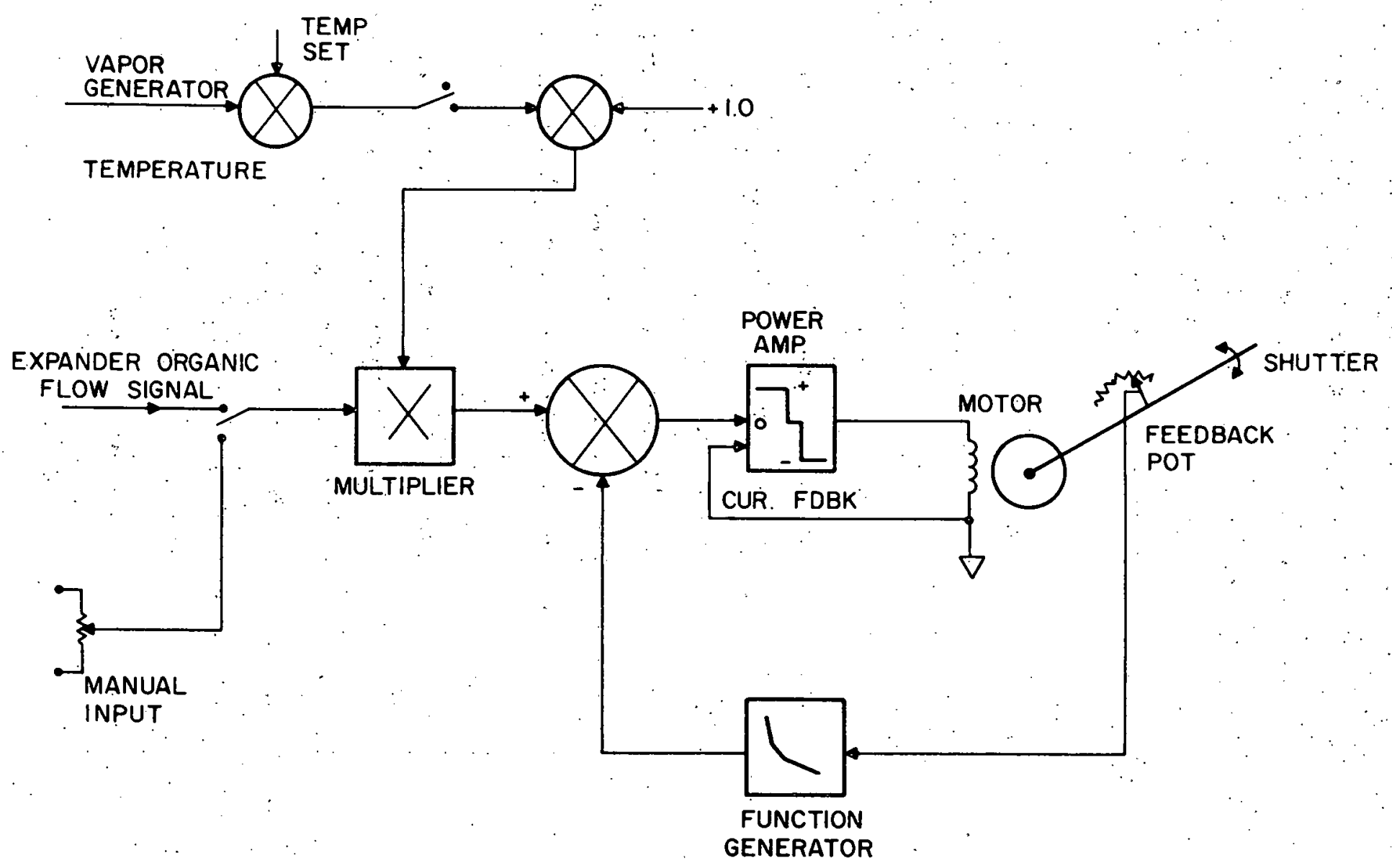

Figure 3.93 Shutter Control Schematic 
this position control loop. An additional temperature trim signal is also applied to the shutter control. Deviation of vapor generator outlet temperature from a preset value caused an error voltage to be added to the primary signal, which rotated the shutter to adjust burning rate for the correct vapor generator outlet temperature. Vapor generator temperature was sensed by a thermocouple brazed to the boiler tube wall.

Although the combustion air and EGR flow rates through the shutters were calculated, it was necessary to measure them to obtain the actual shutter characteristics. To facilitate testing, the shutter assembly was mounted on the blower test rig. The test setup is illustrated in Figure 3.94. Inlet air entered through the six evenly s.paced air inlet openings, View A. The EGR passed through the six EGR openings, View B. The alrflow was controlled by moving the shutter to meter the air across the opening, while maintaining a constant pressure drop across the shutter. The EGR and inlet air flowed through the combustion blower and out through the turbine flowmeter.

To establish the percentage EGR flow compared to the air inlet flow, tests were run at a constant pressure drop across the shutter with either EGR or inlet air shutter blocked. Figure 3.95 shows the EGR and inlet airflow at two inches of WC pressure drop across the shutter. Then, to establish whether the two flows were additive, tests were conducted with both shutters open. Some interaction of the flows existed, as indicated in the two plots. 


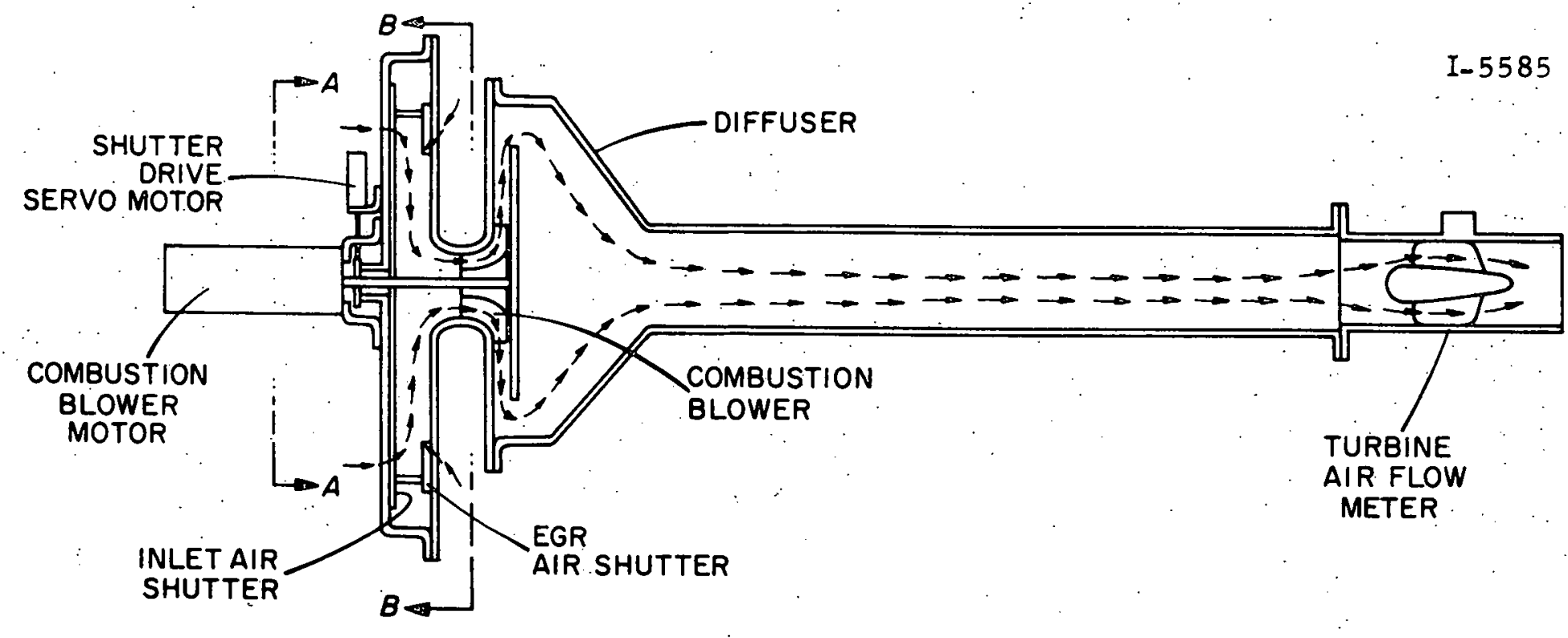

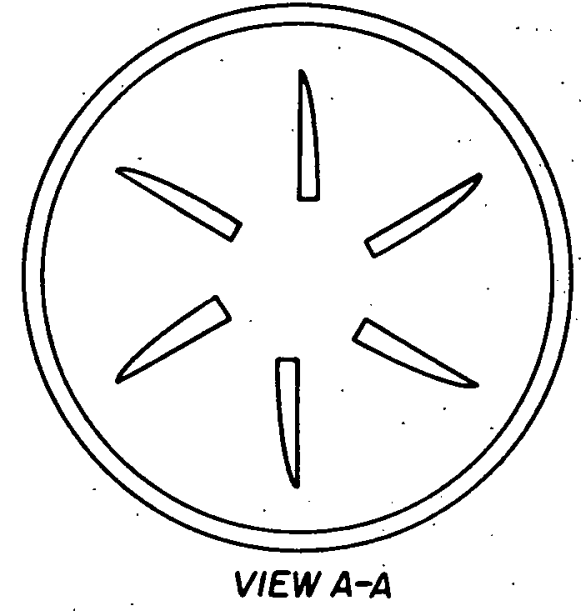

INLET AIR METERING OPENINGS

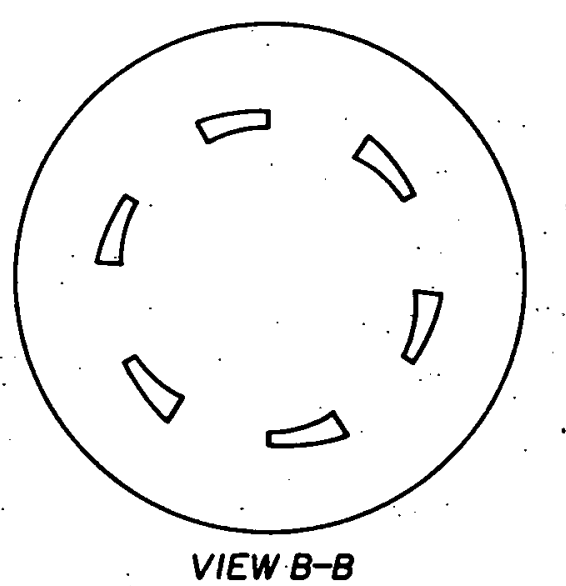

EGR INLET METERING OPENINGS

Figure 3.94 Alr-EGR Flow Test Fixture 
I- 5587

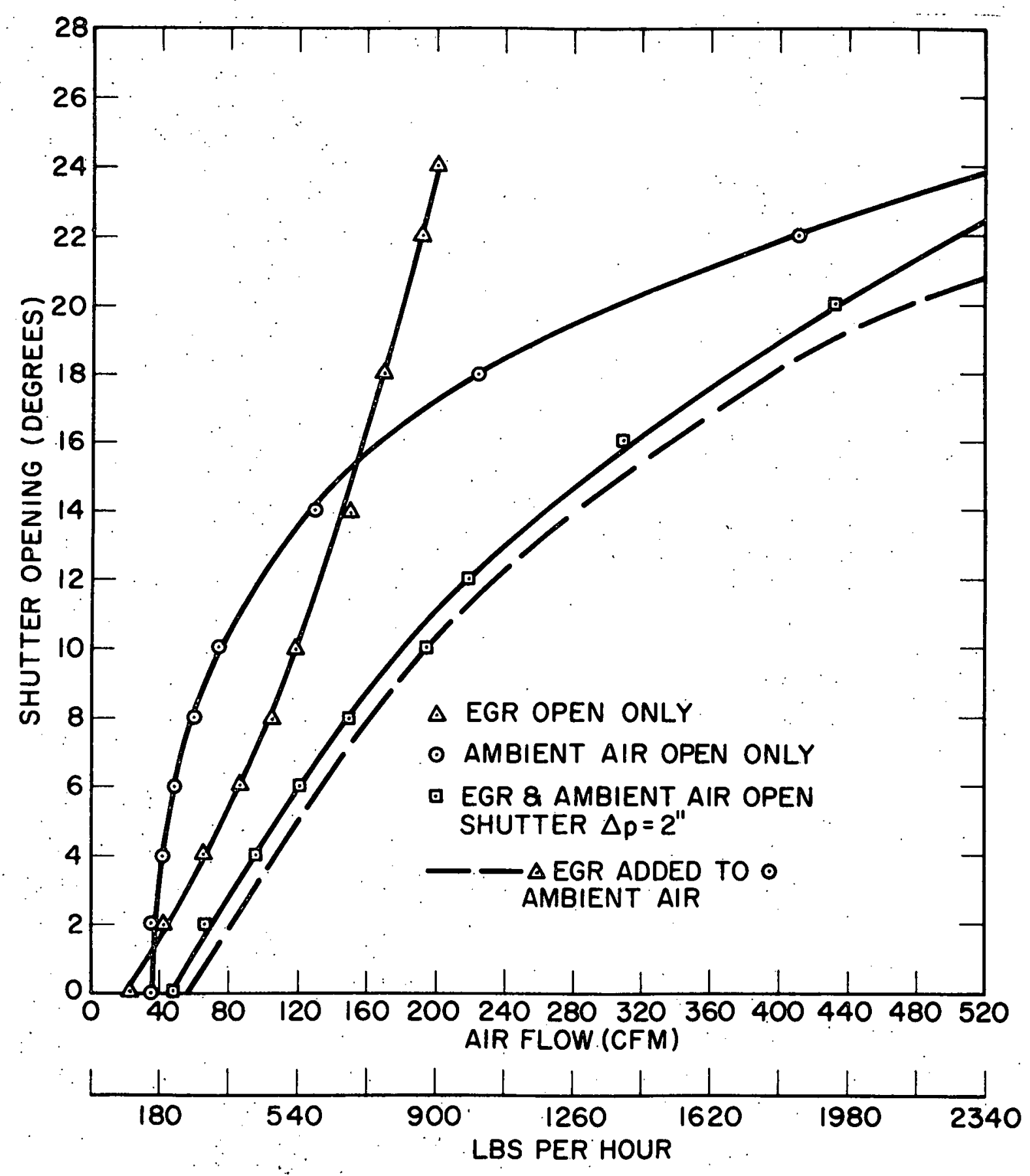

Figure 3.95 Air Shutter Test: $2 " \mathrm{H}_{2} \mathrm{O}$ Across the Shutter 
Since it was required that airflow be proportional to expander organic flow, a nonlinear function was necessary to match the logarithmic airflow stroke characteristic to the organic flow. This measured function plotted versus the theoretical function is shown in Figure 3.96: The calibration of input signal versus shutter area is shown in Table 3.18. Also shown is the hysteresis or error band of the shutter area. The response time of the shutter was obtained by applying a step input to the shutter and measuring its rotation as a function of time. A rotational slew rate of $5^{\circ} / \mathrm{sec}$ was measured in this manner.

\subsubsection{Combustion-Blower Speed Control}

The combustion-blower speed control must.vary blower speed in order to match burning rate with organic flow rate. A schematic of the control system is shown in Figure 3.97. The primary mode of control was open-loop scheduling of blower speed in response to the expander organic flow $\left(W_{F}\right)$ signal. In addition, the pressure drop across the air shutter was sensed and used as a closed-loop trim on blower speed to maintain a design $\Delta P$. An interface circuit was necessary to match blower speed characteristics to the $W_{F}$ signal. The measured function is plotted with the desired function in Figure 3.98.

The $W_{F}$ input signal, or a manual input signal, together with any signal due to a $\Delta P$ error, was applied to a pulse-width modulation circuit, which produced a pulse train with an amplitude switched from 0 to 24 volts. The "on" time of the pulse, or duty cycle, was proportional to the magnitude of the input signal. The pulses switched a power transistor network, capable of carrying $100 \mathrm{amps,} \mathrm{which}$ 
I -5283

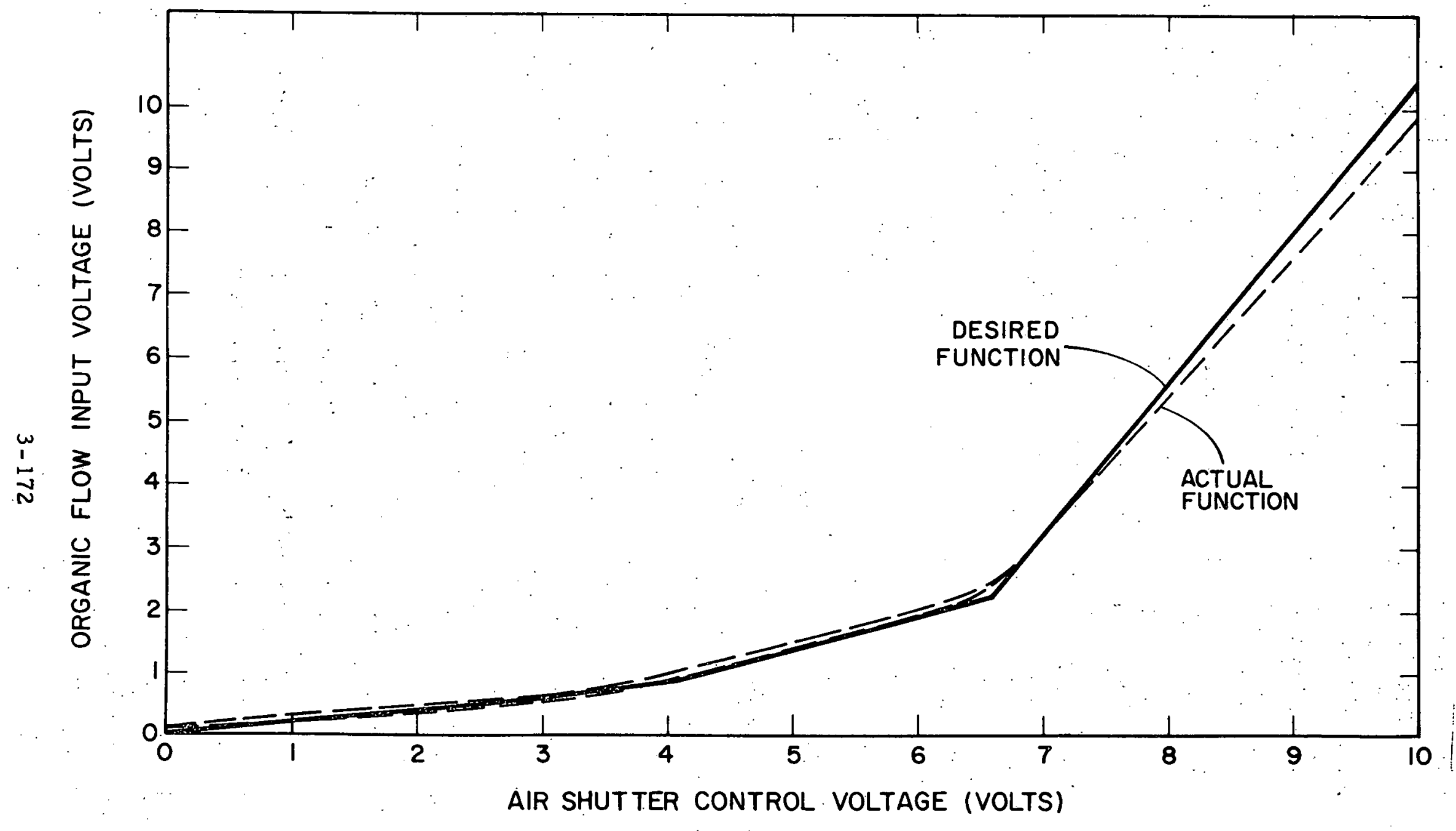

Figure 3.96 Air Shutter Actuator Control Voltage versus Input Flow Signal 
TABLE 3.18

CALIBRATION OF INPUT SIGNAL VOLTAGE TO SHUTTER POSITION

\begin{tabular}{|c|c|c|c|}
\hline $\begin{array}{l}\text { Input } \\
\text { Signal } \\
\text { (Volts) }\end{array}$ & $\begin{array}{l}\text { Shutter } \\
\text { Opéning } \\
\text { (Deg.) }\end{array}$ & $\begin{array}{l}\text { Shutter } \\
\text { Area } \\
(\text { in. } 2)\end{array}$ & $\begin{array}{c}\text { Total Error Band } \\
\text { Repeatability } \\
\text { Hysteresis } \\
\text { (\% F.S. Area) }\end{array}$ \\
\hline 0.000 & 0 & 0.75 & - \\
\hline 0.502 & 5.75 & 1.41 & 1.06 \\
\hline$\cdots 1.000$ & 11.68 & 2.90 & 1.87 \\
\hline 1.500 & 14.45 & 4. 35 & 1.35 \\
\hline 2.000 & 17.20 & 6.24 & $1: 55$ \\
\hline 2.500 & 19.75 & 8.80 & 0.73 \\
\hline 3.000 & 20.90 & 10.24 & 0.22 \\
\hline 3.500 & 21.50 & 11.00 & 0.30 \\
\hline 4.000 & 22.20 & 12.20 & 0.25 \\
\hline 4.500 & 22.80 & 12.80 & $0: 42$ \\
\hline 5.000 & 23.50 & 13.75 & 0.31 \\
\hline 5.500 & 24.10 & 14.60 & 0.24 \\
\hline 6.000 & .24 .60 & 15.55 & 0.16 \\
\hline 6.500 & 25.30 & 16.80 & 0.46 \\
\hline 7.000 & 25.90 & 18.00 & 0.16 \\
\hline 7.500 & 26.20 & 18.80 & 0.16 \\
\hline 8.000 & 27.00 & 20.80 & 0.16 \\
\hline 8.500 & 27.75 & 22.18 & 0.09 \\
\hline 9.000 & 28.40 & 23.38 & 0.00 \\
\hline 9.500 & 29.20 & 24.86 & 0.09 \\
\hline $10: 000$ & 29.60 & & : \\
\hline 10.372 & 30.00 & 30.00 & - \\
\hline
\end{tabular}




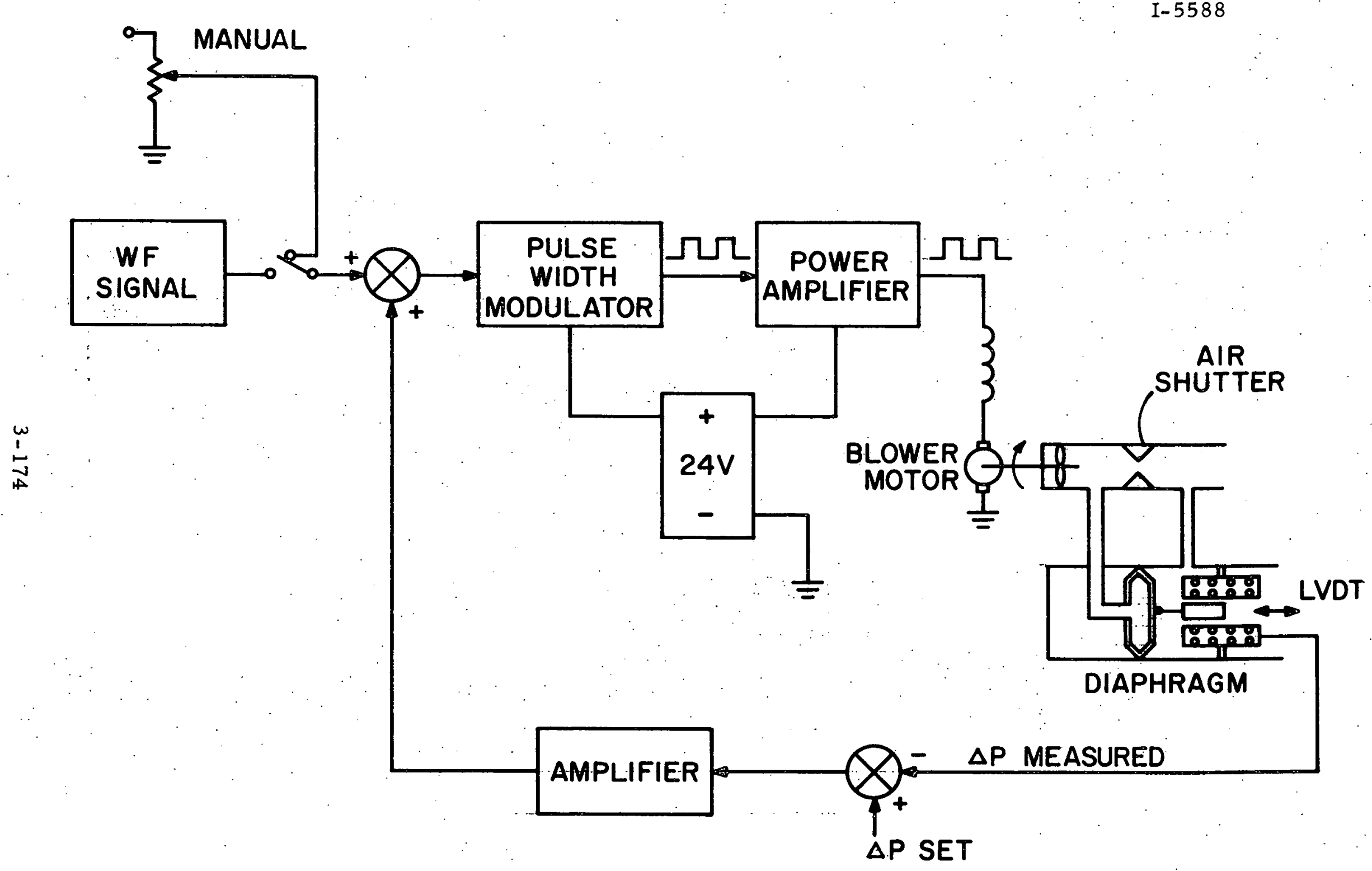

Figure 3.97 Combustion Blower Speed Control. 


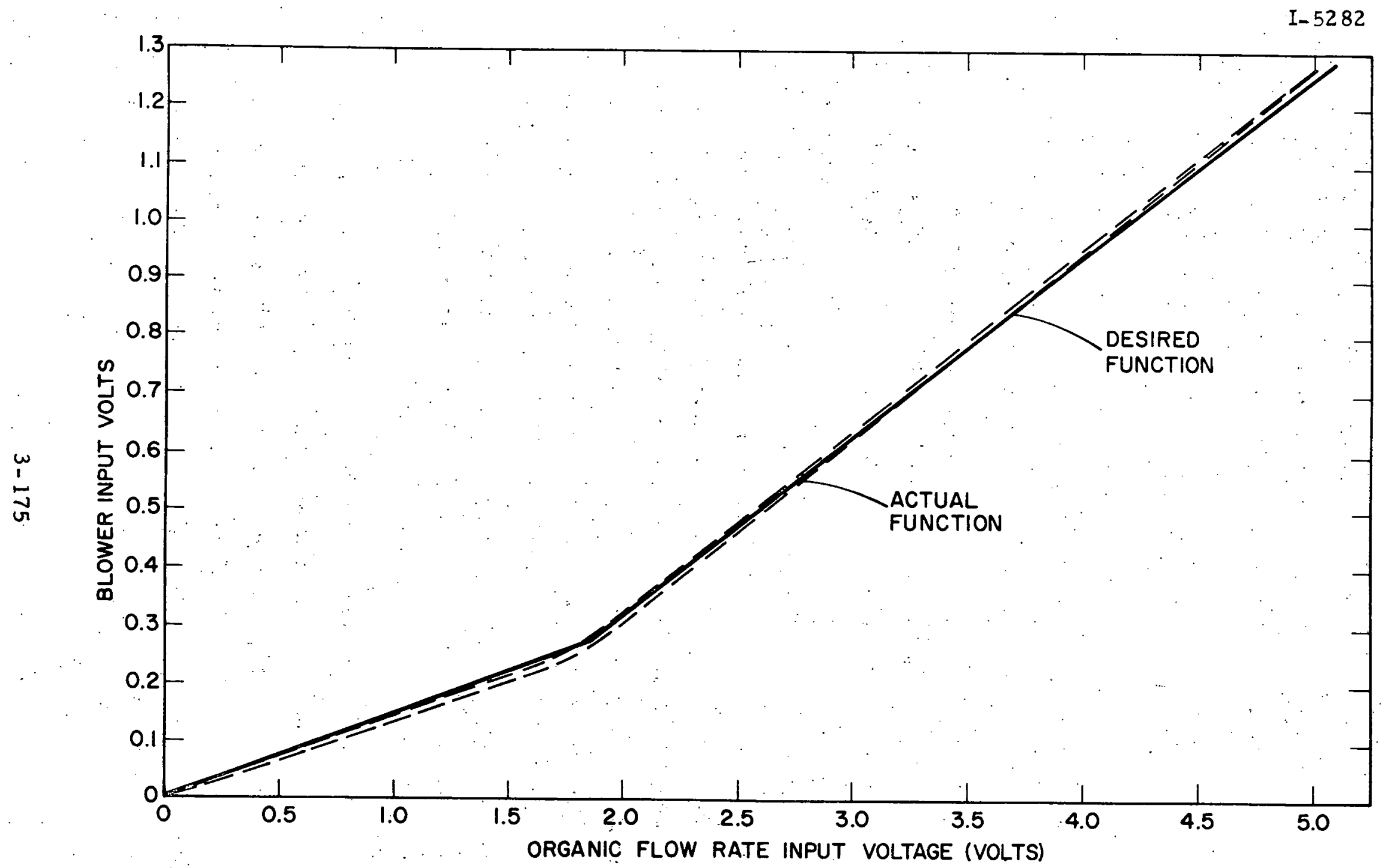

Figure 3.98 Blower Motor Control Voltage versus Input Flow Rate Signal 
drove the series-wound blower motor. The motor was rated for 2.25. $\mathrm{hp}$ at $6500 \mathrm{rpm}$. The pulse width modulated control was capable of a speed turn-down ratio of approximately $2.5: 1$.

\subsubsection{Fuel Control System}

The fuel control must meter fuel to the burner such that the air/ fuel ratio remains constant over the firing range. Ideally, a transient change in airfiow should be followed by a matching fuel flow change.

The chosen concept required that the fuel flow rate be slaved to shutter angular displacement. A schematic of the fuel system and control is shown in Figure 3.99. A potentiometer attached to the shutter provided an input signal to a voltage-controlled oscillator. The output frequency of the oscillator was proportional to the magnitude of the input signal. This frequency was applied to a phase-locked loop where it was compared to a feedback frequency generated by a motor-driven tachometer. The frequency error was rectified and amplified to vary motor speed until the frequency error was eliminated. Motor speed was, therefore, proportional to the potentiometer input signal. A single-piston fixed-displacement pump was driven by the motor, making fuel flow rate proportional to motor speed and the input signal.' Pulsations at low flows were dampened by a needlevalve restriction and diaphragm.

Due to the wide variation in inlet air temperature under preprototype operating conditions, a temperature compensation circuit was also provided. A thermistor, as one arm of a Wheatsone bridge, was mounted in the inlet air stream. A temperature deviation from. a calibrated set point trimmed fuel flow to maintain the correct air/ fuel mass flow ratio. 


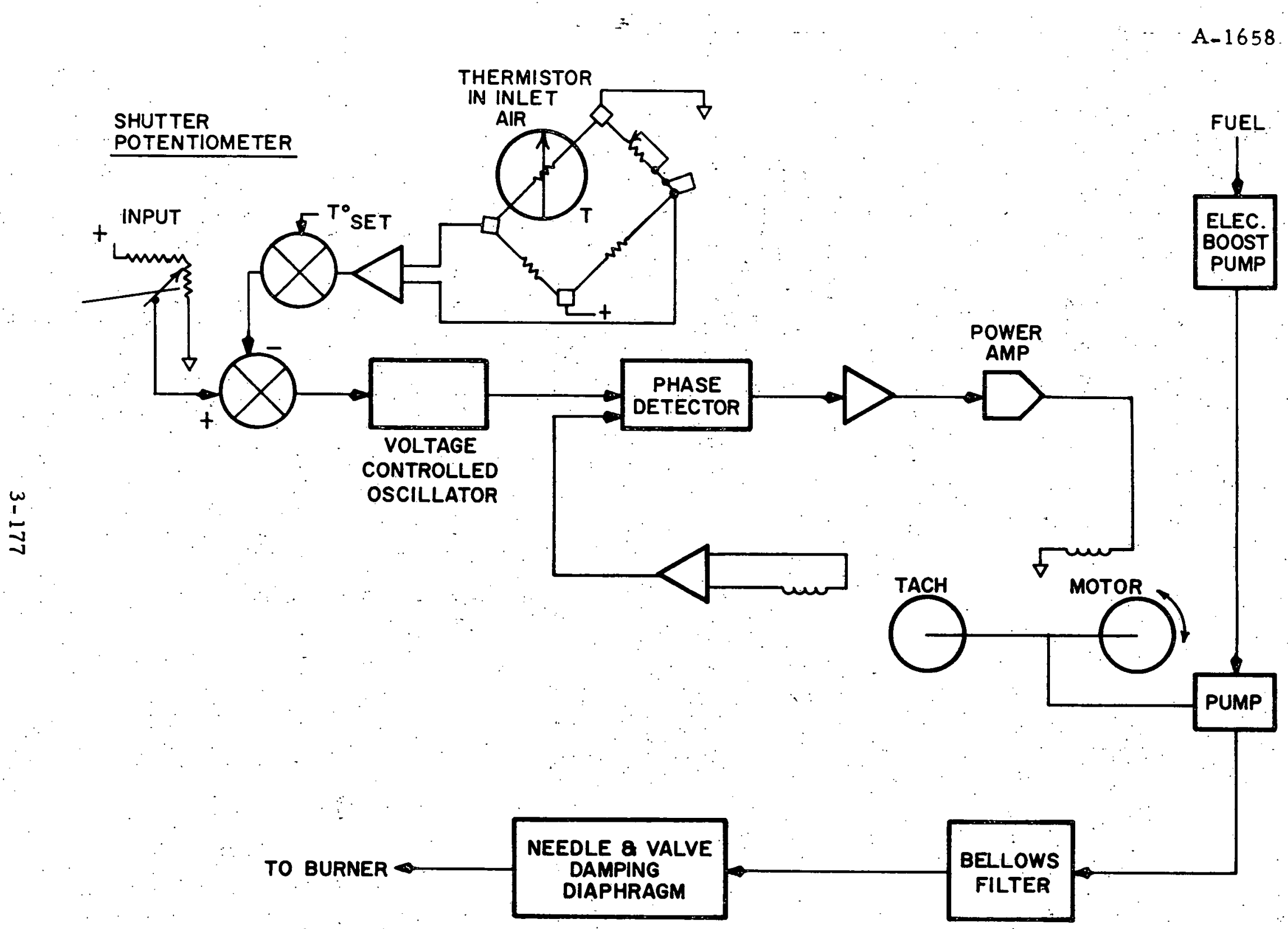

Figure 3.99 Fuel Control Schematic 
3. 8.3 Combustion Controls - Test Results and Performance Evaluation

\subsubsection{Combustor Controls Operational Tests.}

The combustor controls were initially tested outdoors without the vapor generator to determine if gross mismatches or instability occurred during combustion. : It was found that close manual control could be maintained, and the system was installed in the combustor test loop. A test schematic of the system is shown in Figure 3.100.

Initially, the air-shutter position was set to provide a desired airflow as determined from previous test data. Fuel flow rate was then trimmed by varying fuel-pump speed to obtain the desired air/fuel ratio. The EGR was blocked off for these series of tests; therefore, a higher air/fuel ratio of $22: 1$ was used to compensate for this. A potentiometer was used to trim blower speed to provide a 2 -in. WC pressure drop across the air shutters. Once the stable operating point had been reached, the various parameters determining shutter position and blower speed were recorded. The fuel flow range from 10 to $70 \mathrm{lb} / \mathrm{hr}$ was covered in this test.

The values determined at each operating point were then used to correct the curve fits for shutter position and blower speed based on the actual operating conditions. The entire flow range could then be covered with one manual input potentiometer. There were some mismatch and deadband between air and fuel settings due to a hysteresis in the shutter drive. Attaching the feedback and fuel input potentiometer directly to the shutter eliminated the mismatch between air and fuel. However, this moved the deadband inside the shutter closed-loop control, which caused stability problems, resulting in a limit at high flow 


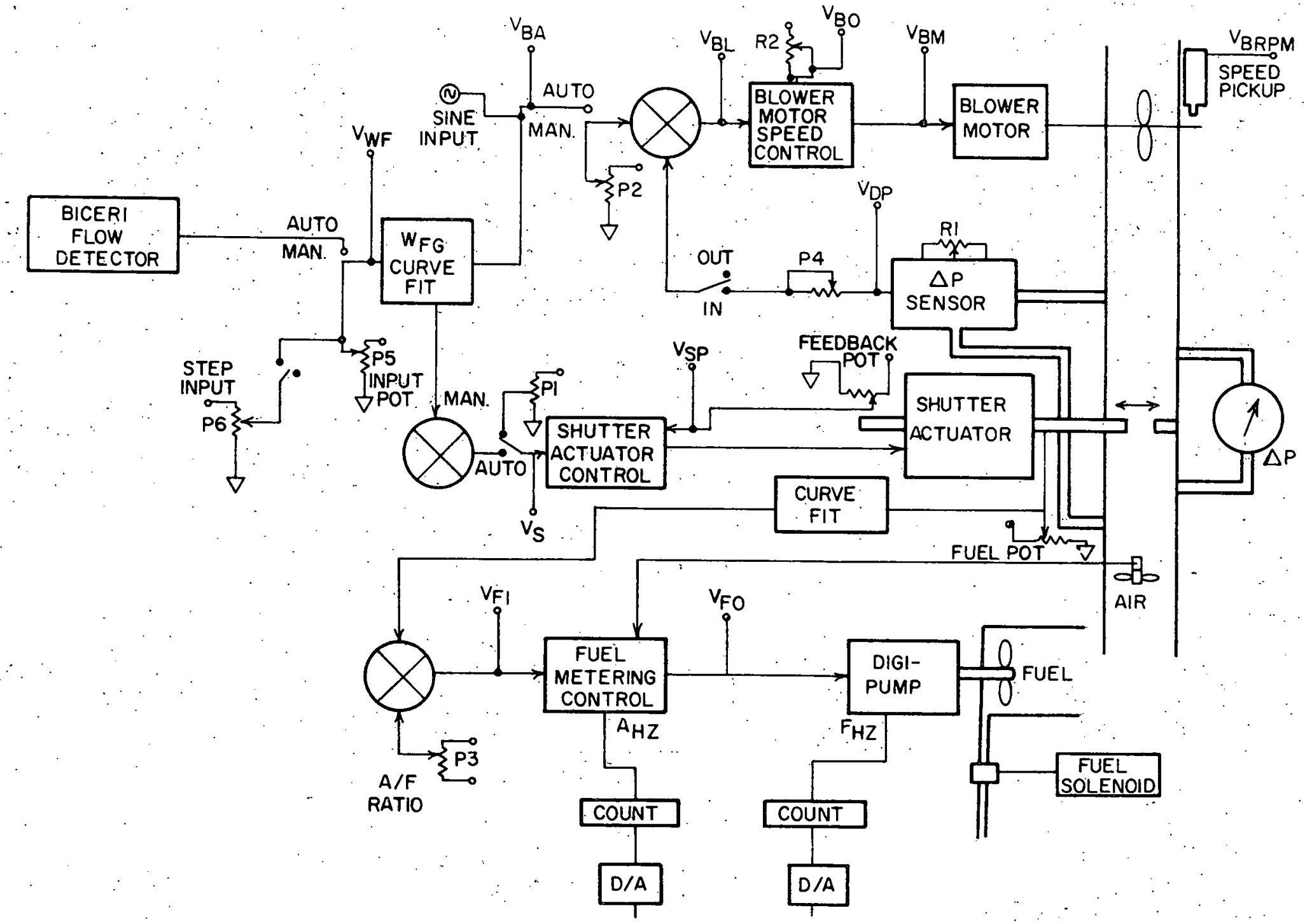

Figure 3.100 Combustion Controls Test Schematic 
settings. Compensation techniques were unsuccessful without reducing system gain to an unacceptable value. The feedback potentiometer attached to the shutter drive was retained within the control closed loop. Another potentiometer was attached to the shutter and used as the input signal to the fuel control. This required another curve fit similar to the shutter position function.' Mismatch between air and fuel flow rate was thus eliminated, and the control was stable for any input setting.

The deadband now occurred in the organic flow rate input signal where it: could be reduced by the vapor generator pressure and temperature feedback or overridden by the accelerator pedal input. The burning rate range of 10 to $70 \mathrm{lb} / \mathrm{hr}$ fuel was covered with one manual input signal; the results are shown in Figure 3.101 .

Transient testing of the combustor controls was accomplished by using step and ramp changes to the fuel flow rate and recording the changes as a function of time. The combustor was set to a steadystate operating point of about $25 \mathrm{lb} / \mathrm{hr}$ and subjected to step and ramp inputs to $35 \mathrm{lb} / \mathrm{hr}$, and from 25 to $50 \mathrm{lb} / \mathrm{hr}$. A typical response of the air and fuel flow to a step input is shown in Figure 3.102 , and to a ramp input in Figure 3.103. For the worst case; a step input from 25 to $50 \mathrm{lb} / \mathrm{hr}$, the maximum error in the fuel/air ratio was $2.5 \mathrm{per}$. cent. The blower speed and $\Delta P$ feedback controls were also tested and found to be stable.

The transient air/fuel error may be decreased by more closely matching shutter and blower motor response times. The overall burning-rate response time may be decreased by frequency-compensation techniques, but is probably fast enough due to the large thermal inertia of the vapor generator. 


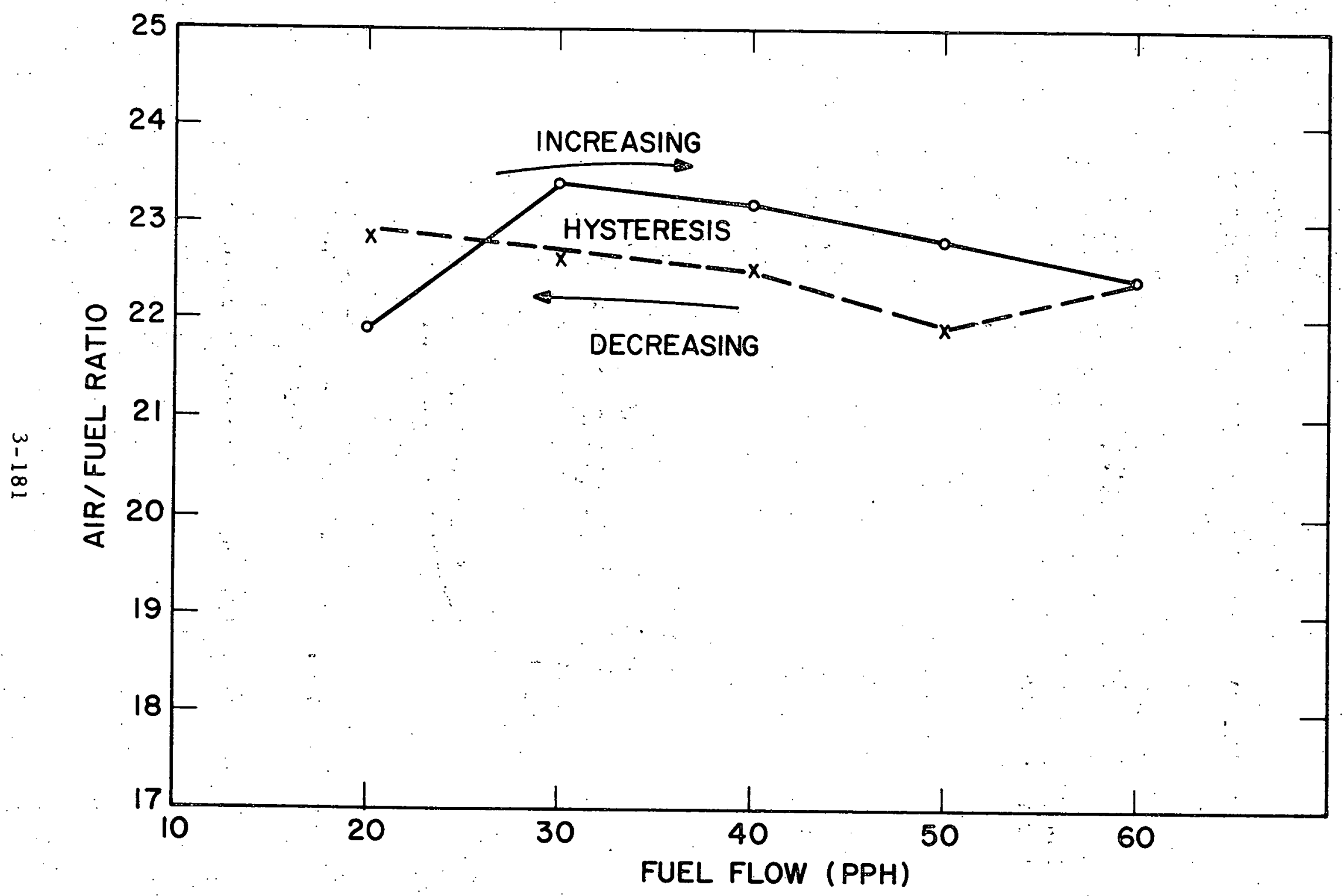

Figure 3.101 Fuel-Air Control Characteristics 


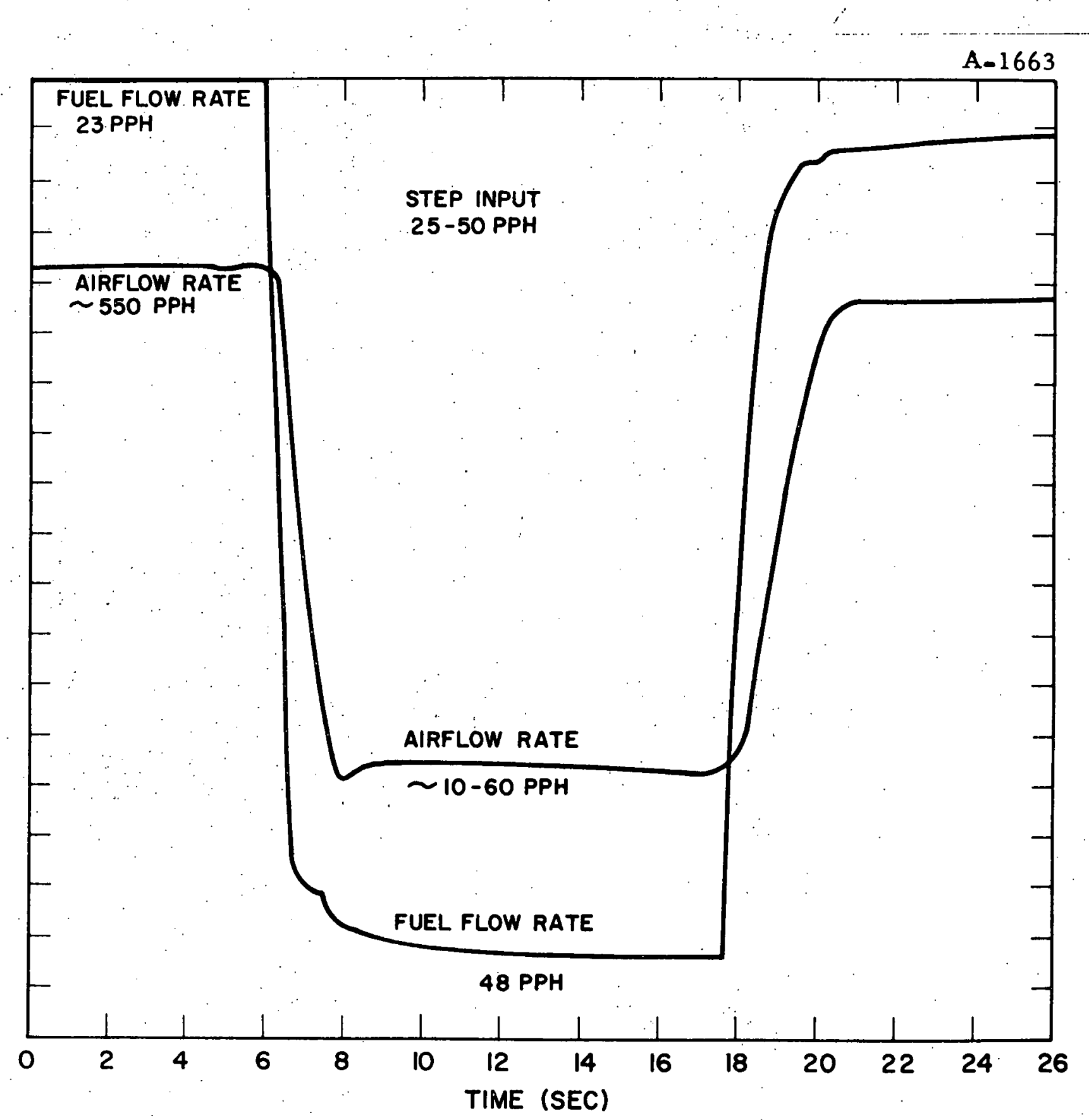

Figure 3.102 Response of Combustion Controls to Step Input 


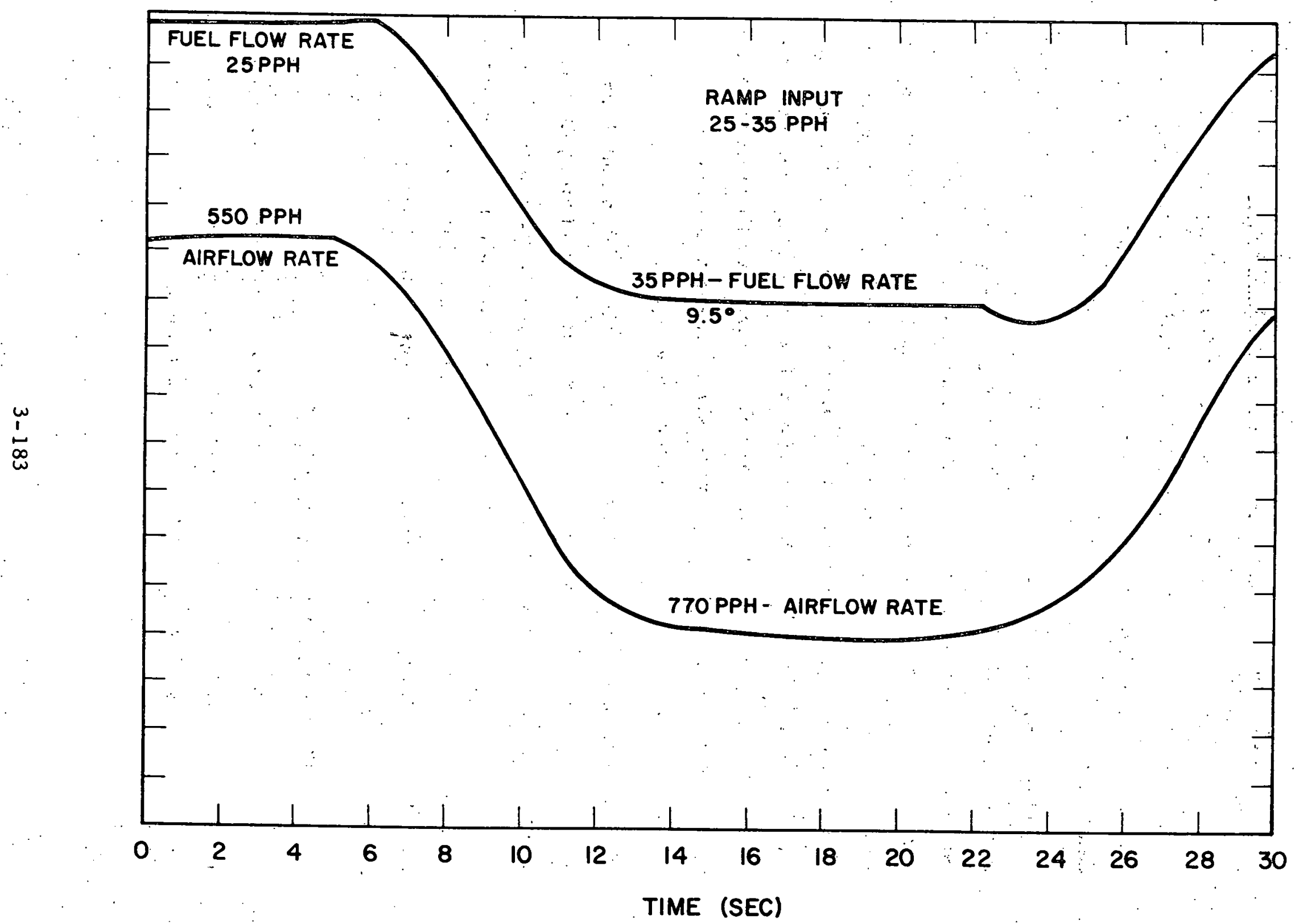

Figure 3.103 Response of Combustion Controls to a Ramp Input 


\subsubsection{Combustor-Controls Test in Preprototype System}

The combustor and controls were installed in the preprototype vapor generator. The test runs were primarily to obtain system performance data and secondarily to obtain control system development data.

Organic flow rate was set manually, and burning rate was matched to it with one manual input. Since the preprototype boiler characteristics were not matched to the control characteristics, some air/fuel ratio errors occurred. Where necessary, fuel flow was independently adjusted to provide the correct ratio. The major parameter monitored was the airmass flow reading. This signal was provided by a turbinetype flowmeter, which had been calibrated in airflow ( $\mathrm{ft}^{3} / \mathrm{min}$ ) versus speed $(\mathrm{Hz})$. A frequency-to-analog voltage signal was processed and combined with signals from a temperature sensor and atmospheric pressure transducer to provide a mass flow signal.

The combustor was operated over the range of 10 to $100 \mathrm{lb} / \mathrm{hr}$ fuel. At each point, data were taken to enable the control system to be matched to the expander, as well as to system parameters, Unfortunately, timing and priorities did not permit testing of the system operated by the control system. The development of the control system stopped with the acquisition of data required for further development.

\subsubsection{Feedpump Displacement Control}

A displacement control was required to provide proper feedpump flow regardless of pump speed. The variation of displacement and flow rate with feedpump speed is shown in Figure 3.64. The pump 
displacement was varied by axial movement of the drive shaft. Force levels required to move the shaft were measured at approximately $800 \mathrm{lb}$ and the use of a high-power servo actuator was indicated.

Boiler outlet pressure was initially selected as the control parameter. This pressure would be sensed, and any error from the set point (700 psi) would be used to change feedpump stroke and correct this error. For this reason, the initial concept selected was a hydraulic system that used servo valves to apply pressure to a power piston. The power piston was used to vary the pump displacement. A control analysis indicated that the use of only the boiler outlet pressure as the main control parameter would result in larger pressure fluctuations or even instability.

To eliminate these problems, it was decided to use a predicted organic-flow demand signal as the primary input to the feedpump control and retain the boiler-outlet pressure signal as a secondary or trim input. This control concept utilized an electrohydraulic servo actuator (Figure 3.104). An input voltage, $V_{W F}$, representing flow demand and any pressure-error signal voltage, was applied to a solenoid (1). The solenoid armature displaced a pilot valve (2) with a force proportional to solenoid current. Displacing the pilot valve from null caused the actuator.(3) to move and change feedpump displacement: Also, the motion was transmitted through feedback links (4), (5), (6) to provide a restoring force, returning the pilot valve to null. The solenoid coil and feedback linkage were matched so that pump displacement was a linear function of input current. Initial testing of the unit showed high hysteresis and breakaway amounting to 6 percent of the input signal. This was slightly higher than the 4 percent quoted by the vendor, Servotronics, Inc. 


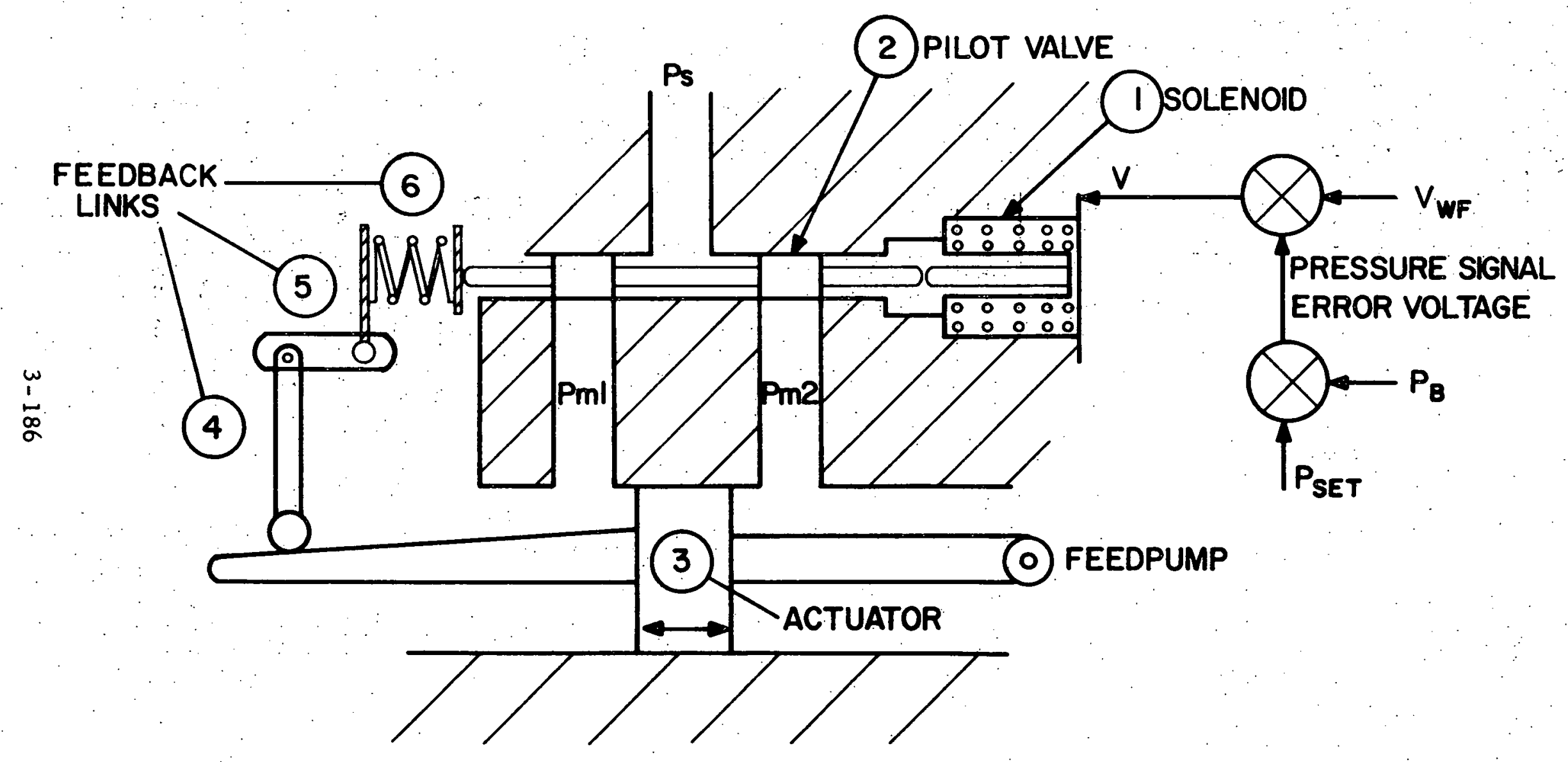

Figure 3.104 Feedpump Electrohydraulic Control Schematic 
An additional electrical feedback loop was added to allow much higher gain to overcome breakaway forces. Actuator displacement was detected with a linear variable-differential transformer, and this feedback signal was compared to the input signal representing desired displacement. A block diagram of this is shown in Figure 3.105. Thi,s method overrode the "loose" mechanical feedback link, and the test data showed hysteresis was reduced to 0.3 percent, and breakaway 0.1 percent, of the input signal, as shown in Figure 3.106. A closed-loop frequency-response test showed the control to be stable with a flat response, within $\pm 3 \mathrm{db}$, of approximately 2.5 cycles. In addition, a signal representing expander speed was used in the stroke control circuit to compensate for pump volumetric efficiency dropoff at higher speeds.

This final control system was installed in the preprototype system. Some trouble was encountered with a 5- filter used in the servo valve system. It would occasionally plug, causing intermittent operation. Time was not available to try a coarser. filter or to have the vendor solve the problem.

\subsection{TRANSMISSION EVALUATION}

Several transmissions were available for use with the organic Rankine-cycle powerplant. After evaluating various designs, two transmissions were considered suitable for the preprototype system. One transmission had been previously designed by Dana Corporation specifically for the application under a subcontract. The other transmission was a standard Ford C-4 automatic transmission. 


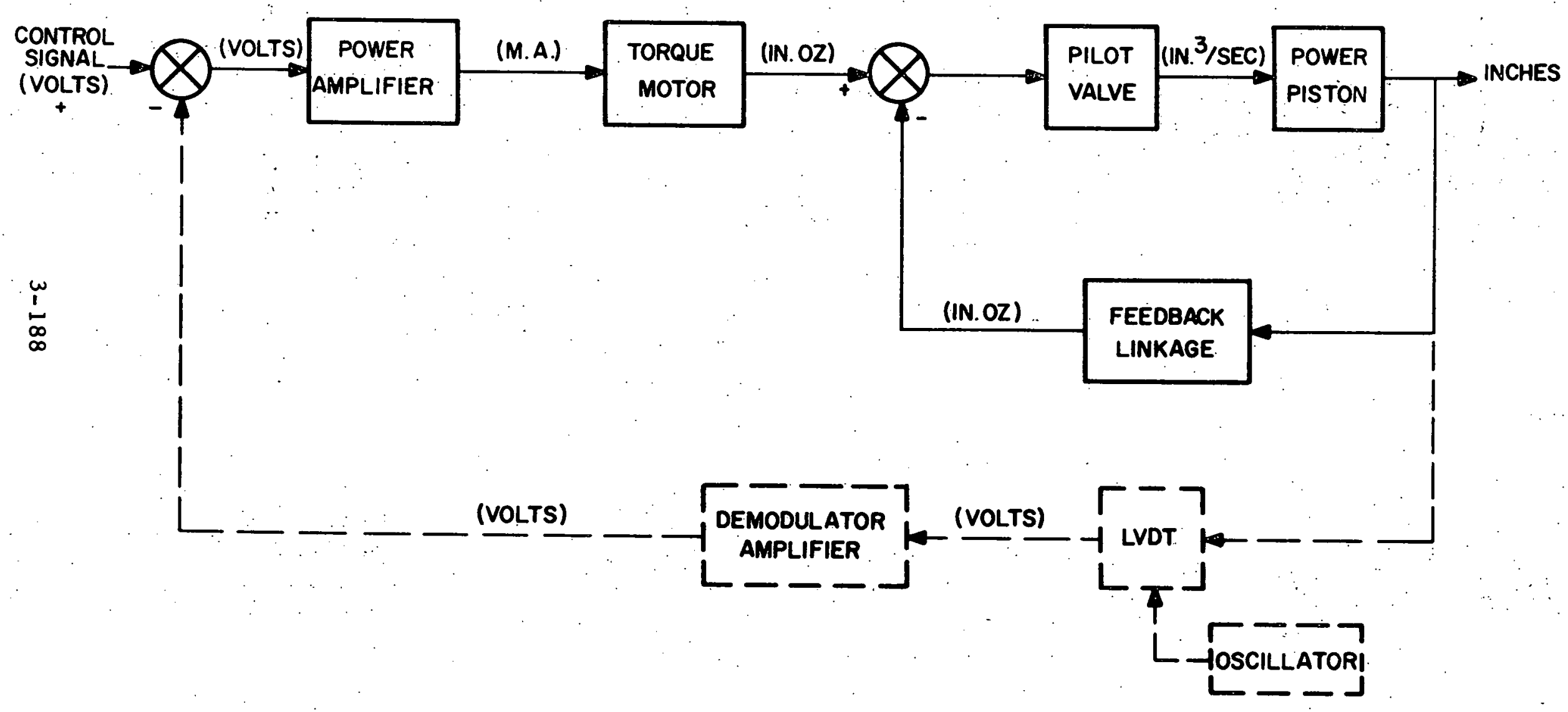

Figure 3. 105. Feedpump Stroke Control Block Diagram. (Electrical position feedback shown as dashed lines.) 


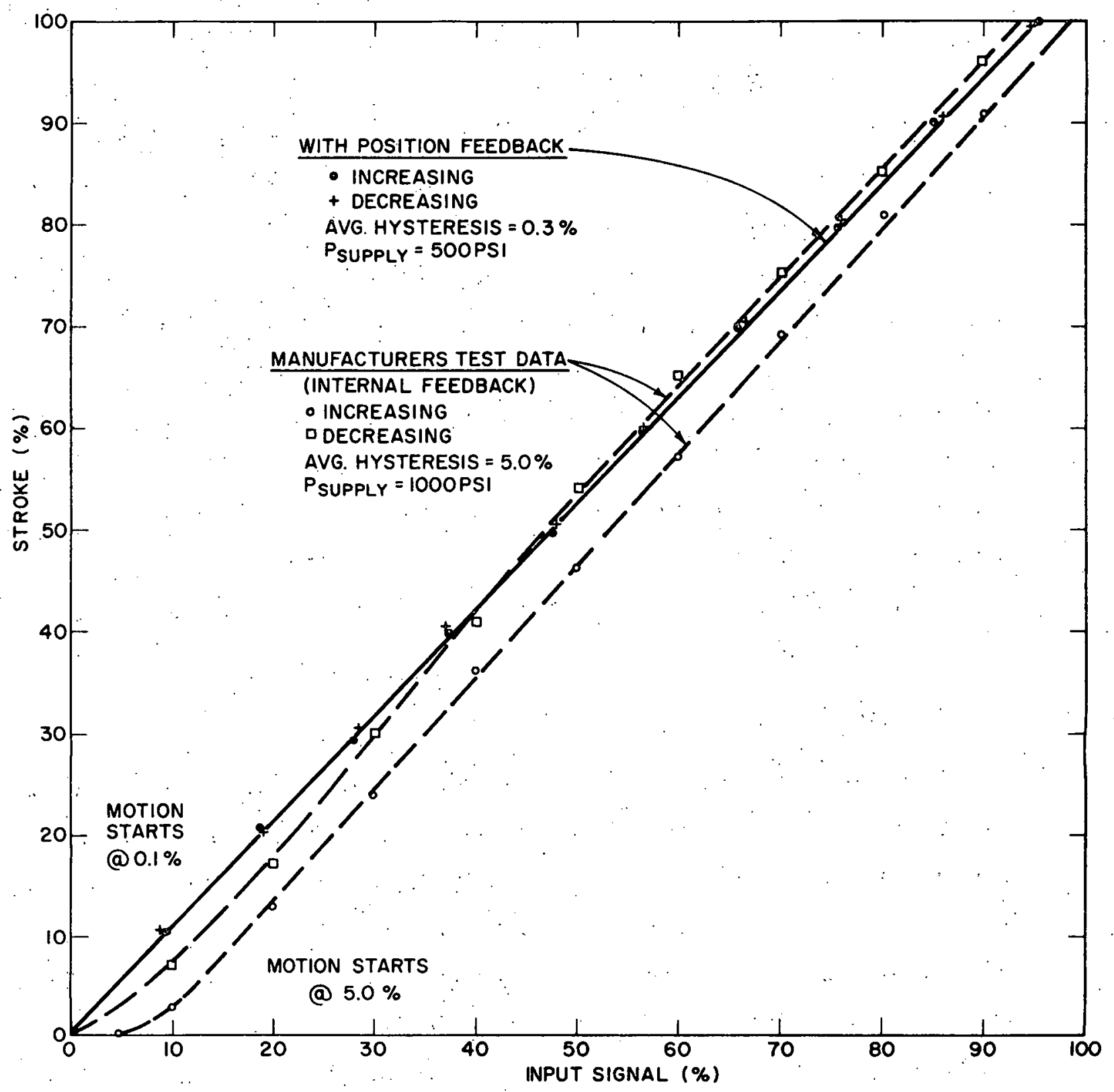

Figure 3.106 Feedpump Actuator Hysteresis with External Electrical Position Feedback. 


\subsubsection{Dana Transmission}

This transmission was a two-speed unit with a hydraulically ope rated slipping wet clutch. The slipping clutch was used to permit the expander to operate during low-speed operation of the vehicle, including idle. Above a speed of $8 \mathrm{mph}$, the clutch locked up and the transmission operated as a direct-coupled unit, which resulted in high-efficiency operation due to the desirable torque characteristics of the Rankine-cycle expander with variable cutoff intake valving. A control system was also designed for the low-speed slipping mode of operation, as well as to provide the desired shifting between the twospeed ratios. Since this was a special transmission and would have required considerable development, it was not considered for the preprototype system.

\subsubsection{Ford C-4 Transmission}

The Ford Motor Company, the subcontractor on this task, selected the standard Ford C-4 automatic transmission. This transmission is a three-speed unit with a 10-1/4 in. torque converter. Because of the low expander speed, a step-up gear was required between the expander and transmission. A gear ratio of 2.7 was chosen for the step-up gear. The torque converter stall-speed characteristics limited to $800 \mathrm{rpm}$ the lowest speed at which the expander was required to operate at the maximum intake ratio.

The selected transmission characteristics are summarized below:

\section{Type}

Torque Converter Diameter

Speedup Gear Ratio

Transmission Gear Ratios

Rear Axle Ratio
Standard Ford C-4 Automatic

Transmission (Three-Speed)

$10-1 / 4$ in.

$1: 2.70$

$2.46,1.46,1.00$

3. $5: 1$ 
A 1972 Ford Galaxie could travel at $107 \mathrm{mph}$ at an expander speed of $1800 \mathrm{rpm}$ with this transmission-driveline.

The torque converter-transmission characteristics were provided by FOMOCO to Thermo Electron for use with the vehicle performance and fuel economy estimates. The characteristics of the torque converter are given in Figure 3.107 and the shift point data in Figure 3.108. These characteristics provide slightly better fuel economy than the Dana two-speed transmission, but poorer acceleration performance.

The speedup gear coupled to the transmission is illustrated in Figure 3.109. Because of the expander torque fluctuations, the design included a simple pendulum detuner, which reduced the driveline torque fluctuation to an acceptable level. A complete analys is of the pendulum detuner was carried out by FOMOCO in preparation of this design.

The three-speed automatic transmission with the torque converter was incorporated into the data reduction program; vehicle performance and fuel economy calculations were all performed using this unit. The original gear-shift data provided by FOMOCO were not optimum. Following a review of these results, a new recommendation was provided by FOMOCO with acceptable results.

\subsubsection{Comparison of Transmission Units}

A summary of the calculated results is presented in Table 3.19. These results included the latest estimates for the accessory and auxiliàry loads on the system. The two-speed Dana transmission provided better acceleration performance than the conventional 


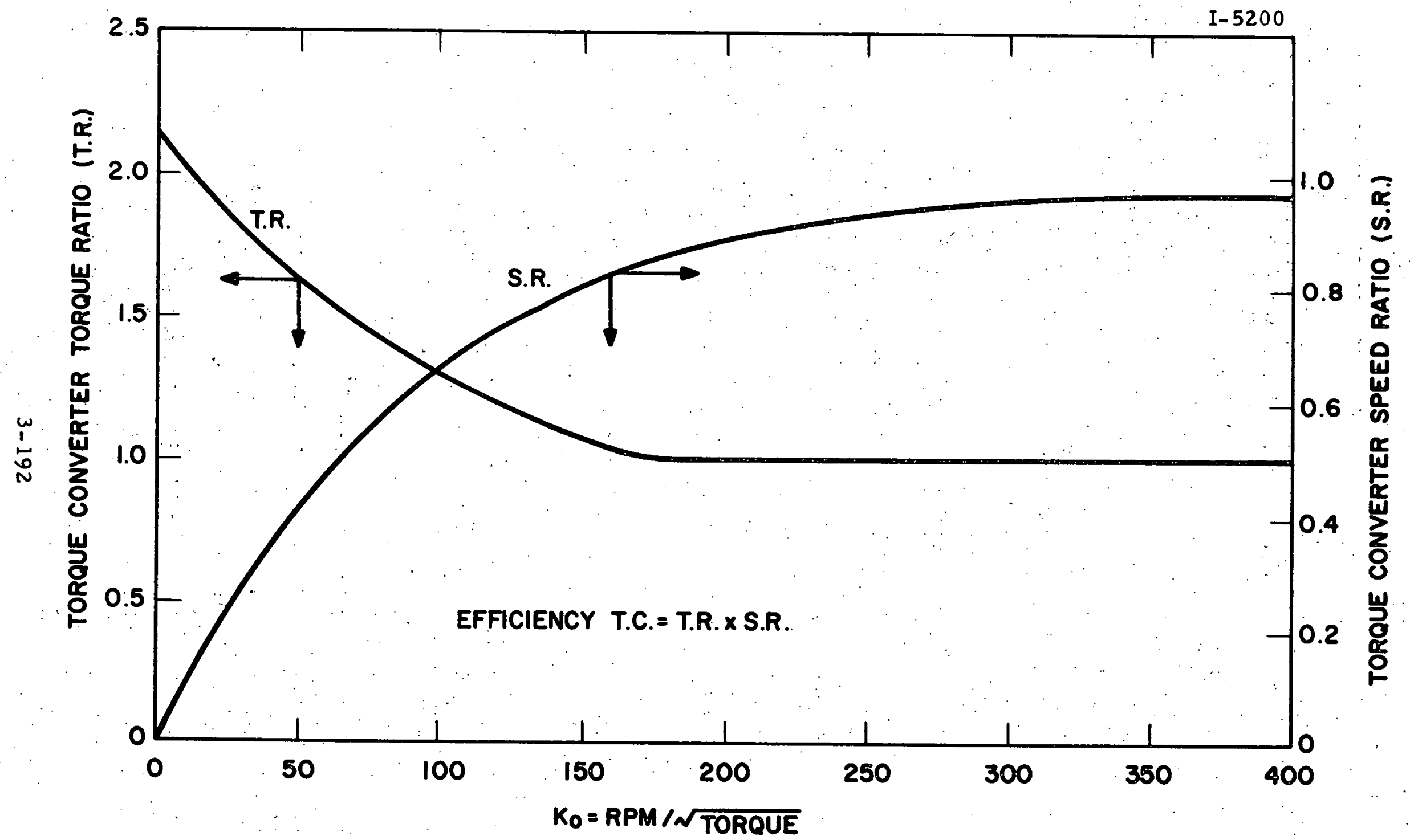

Figure 3.107. Torque Converter Characteristics, 10-1/4" Diameter Converter 
A. 1665

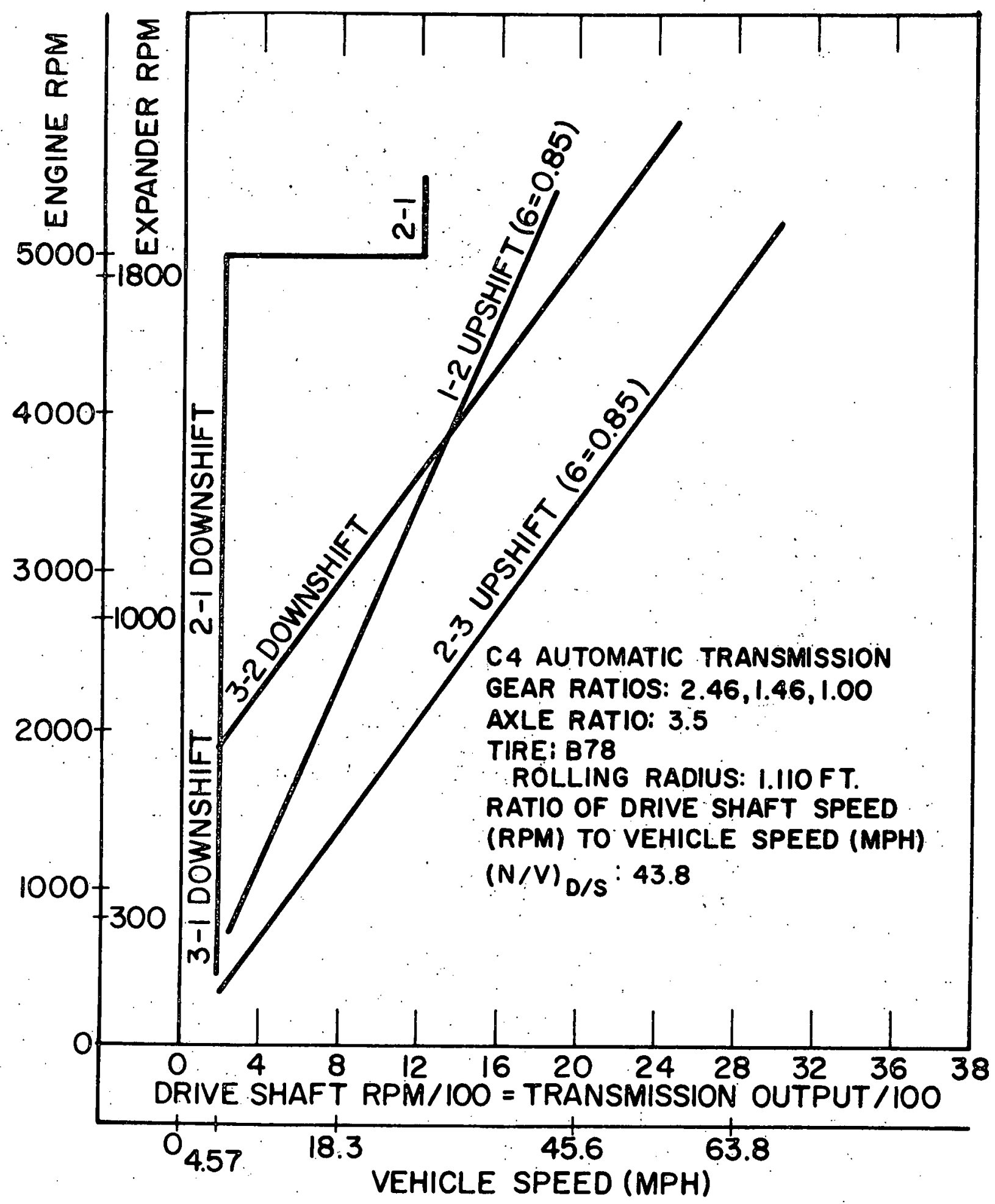

Figure 3.108 Transmission Shift Map 


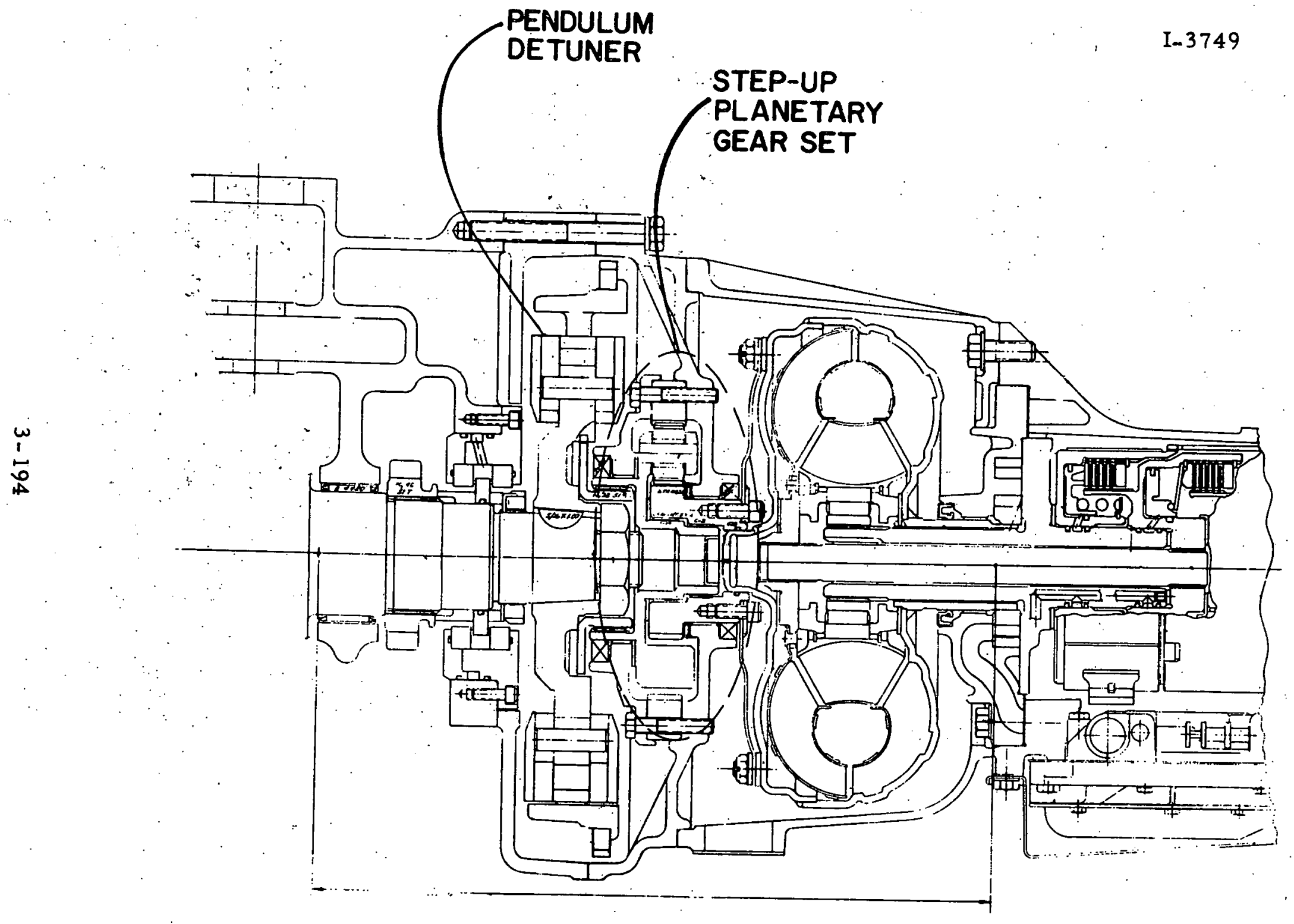

Figure 3.109 Assembly Drawing Ilustrating Step-up Gear and Torque Converter 
TABLE 3.19

SUMMARY OF VEHICLE PERFORMANCE PREDICTIONS FOR TWO TYPES OF TRANSMISSIONS
Ambient Temperature
$=85^{\circ} \mathrm{F}$
Test Weight, Acceleration and Fuel Economy $=4,576$ lb
Test Weight, Gradability
$=5,276 \mathrm{Ib}$

\begin{tabular}{|c|c|c|c|}
\hline & & \multicolumn{2}{|c|}{$\begin{array}{c}\text { FOMOCO Three-Speed } \\
\text { Automatic }\end{array}$} \\
\cline { 2 - 4 } & $\begin{array}{c}\text { Dana } \\
\text { Two-Speed } \\
\text { Transmission }\end{array}$ & $\begin{array}{c}\text { Shift at } \\
\text { Converter } \\
\text { Speed } \\
\text { Ratio }=0.85\end{array}$ & $\begin{array}{c}\text { Shift at } \\
\text { Converter } \\
\text { Speed } \\
\text { Ratio }=0.97\end{array}$ \\
Acceleration Times & $13.4 \mathrm{sec}$ & $16.2 \mathrm{sec}$ & $15.1 \mathrm{sec}$ \\
$0 \rightarrow 60 \mathrm{mph}$ & $15.0 \mathrm{sec}$ & $19.8 \mathrm{sec}$ & $18.4 \mathrm{sec}$ \\
$25 \rightarrow 70 \mathrm{mph}$ & $14.5 \mathrm{sec}$ & $15.5 \mathrm{sec}$ & $15.0 \mathrm{sec}$ \\
DOT Passing & $35.3 \%$ & $53.4 \%$ & $53.4 \%$ \\
Gradability & $34.6 \%$ & $44.3 \%$ & $44.3 \%$ \\
$0 \mathrm{mph}$ & $26.8 \%$ & $26.7 \%$ & $27.0 \%$ \\
$10 \mathrm{mph}$ & $19.8 \%$ & $17.8 \%$ & $19.0 \%$ \\
$20 \mathrm{mph}$ & $11.3 \%$ & $8.9 \%$ & $9.9 \%$ \\
$30 \mathrm{mph}$ & $6.8 \%$ & $5.0 \%$ & $5.0 \%$ \\
$50 \mathrm{mph}$ & 1 & $\ddots$ & \\
$70 \mathrm{mph}$ & $15.4 \mathrm{mpg}$ & $18.8 \mathrm{mpg}$ & $18.8 \mathrm{mpg}$ \\
Fuel Economy & $13.5 \mathrm{mpg}$ & $14.7 \mathrm{mpg}$ & $14.7 \mathrm{mpg}$ \\
$30 \mathrm{mph}$ Steady Speed & $10.3 \mathrm{mpg}$ & $10.5 \mathrm{mpg}$ & $10.5 \mathrm{mpg}$ \\
$50 \mathrm{mph}$ Steady Speed & $10.8 \mathrm{mpg}$ & $11.2 \mathrm{mpg}$ & $11.2 \mathrm{mpg}$ \\
$70 \mathrm{mph}$ Steady Speed & $8.6 \mathrm{mpg}$ & $8.5 \mathrm{mpg}$ & $8.8 \mathrm{mpg}$ \\
Federal Urban Cycle & $11.4 \mathrm{mpg}$ & $11.4 \mathrm{mpg}$ & $11.6 \mathrm{mpg}$ \\
FOMOCO Urban Cycle & & & \\
FOMOCO Suburban & & & \\
Cycle & & & \\
\hline
\end{tabular}

*3.

Accessory and auxiliary loads were slightly less for these calculations than for the calculations with the FOMOCO three-speed transmission. 
three-speed automatic. The fuel economy with the conventional threespeed automatic was slightly better than with the Dana transmission. The conventional three-speed automatic had better low-speed gradability, whereas the Dana two-speed had better high-speed gradability.

Due to both the better fuel economy and the lack of development required for the Ford C-4 transmission, it was selected as the system transmission. 


\section{COMPACT CAR DESIGN}

The energy crisis showed the need for automotive powerplants that would give maximum fuel economy. Since the trend was toward more compact cars, an advanced Rankine-cycle prototype system was designed and analyzed, with emphasis on improving fuel economy while maintaining exhaust emissions below one-half the federal emission standards defined in the 1970 Clean Air Act. A compact car with either an internal combustion engine (ICE) or a Rankine-cycle power plant gives better fuel economy than a full-size car due to the lower vehicle weight and the reduced acceleration performance requirements for smaller vehicles. In addition, the condenser performance of a Rankine-cycle powerplant in a compact car is greatly improved because morefrontal a rea per engine horsepower is avallable than in a fullsize car.

\section{1 SYSTEM DESCRIPTION}

The objective was to design a prototype engine for a compact car with performance comparable to that of a 1974 Ford Pinto. The design was based on information generated from the preprototype system development program.

The major considerations for the system design were:

- Road load fuel economy rather than acceleration performance

- Preprototype data and learning to be used to maximize system performance and design

- Improved component integration and packaging relative to the preprototype system 
The final configuration and specifications of the system designed for the compact car are given in Table 4.1. There were various design and packaging options considered and analyzed before a choice was made on which configuration to use for each of the components. Table 4.2 is a listing of the component design and packaging options that were considered. The final configurations are shown packaged in a Pinto engine compartment in Figures 4.1 and 4.2 . The main differences between this configuration and the preprototype configuration are that the expander and vapor generator are mounted side by side instead of on top of each other, resulting in easier maintenance, and the condenser and regenerator are packaged as a single unit. In addition, the fan is mounted in front of the condenser, which results in lower fan power due to the increased air density at the fan inlet.

The following sections discuss the various options in detail and provide the basis for selecting the final component design.

\subsubsection{Working Fluid}

The organic working fluid chosen for the compact car design system is Fluorinol-50. The major reasons for choosing Fluorinol-50 Instead of Fluorinol-85 a re:

- Higher water content results in lower-volume flow rate.

- Smaller component sizes resulting from reduced flow rates lead to reduced weight of the system.

- The thermal stability of Fluorinol-50 is greater than that for Fluorinol-85. This permits the use of a peak cycle temperature of $650^{\circ} \mathrm{F}$ using Fluorinol -50 , instead of $625^{\circ} \mathrm{F}$ as with 
TABLE 4.1

PROTOTYPE (COMPACT CAR) SYSTEM CHARACTERISTICS

\section{Design Point Conditions}

Reference Car

Auto. Weight

Expander Gross Shaft Power

Expander. Speed

Firing Rate

Working Fluid.

Freezing Point (First

Formation of Ice)

Ice Point (Completely Frozen)

Minimum Pumping Temperature

Peak Cycle Temperáture

Peak Pressure
1974 Ford Pinto:

$2543 \mathrm{lb}$

$60 \mathrm{hp}$

$2000 \mathrm{rpm}$

$1.06 \times 10^{6} \mathrm{Btu} / \mathrm{hr}$

Fluorinol-50

$-9^{\circ} \mathrm{F}$

$-82^{\circ} \mathrm{F}$

$-28^{\circ} \mathrm{F}$

$650^{\circ} \mathrm{F}$

800 psia 
TABLE 4.2

COMPONENT DESIGN AND PACKAGING OPTIONS

\begin{tabular}{|c|c|c|}
\hline Component & Design Options & Packaging Options \\
\hline Vapor Generator & Radial or Axial & $\begin{array}{l}\text { Front Packaged or Rear } \\
\text { Packaged }\end{array}$ \\
\hline Regenerator & Plate Fin & \multirow{2}{*}{$\begin{array}{l}\text { Separate Plate Fin Unit, } \\
\text { Integrated Condenser- } \\
\text { Regenerator, Vehicle } \\
\text { Mounted or Engine Mounted }\end{array}$} \\
\hline Condenser & $\begin{array}{l}\text { Plate Fin or } \\
\text { Intermediate } \\
\text { Water Cooled }\end{array}$ & \\
\hline $\begin{array}{l}\text { Condenser Fan } \\
\text { Drive }\end{array}$ & $\begin{array}{l}\text { Varidrive or } \\
\text { Electric }\end{array}$ & $\begin{array}{l}\text { Front of Condenser or } \\
\text { Rear of Condenser }\end{array}$ \\
\hline Expander & $\begin{array}{l}2,3 \text { or } 4 \\
\text { Cylinder }\end{array}$ & $\begin{array}{l}\text { Radial, In-line, or } \mathrm{V} \\
\text { Configuration with } \\
\text { Integrated Feedpump }\end{array}$ \\
\hline Feedpump & $\begin{array}{l}3 \text { or } 5 \\
\text { Cylinder }\end{array}$ & $\begin{array}{l}\text { Radial or In-line Integrated } \\
\text { "with Expander }\end{array}$ \\
\hline
\end{tabular}




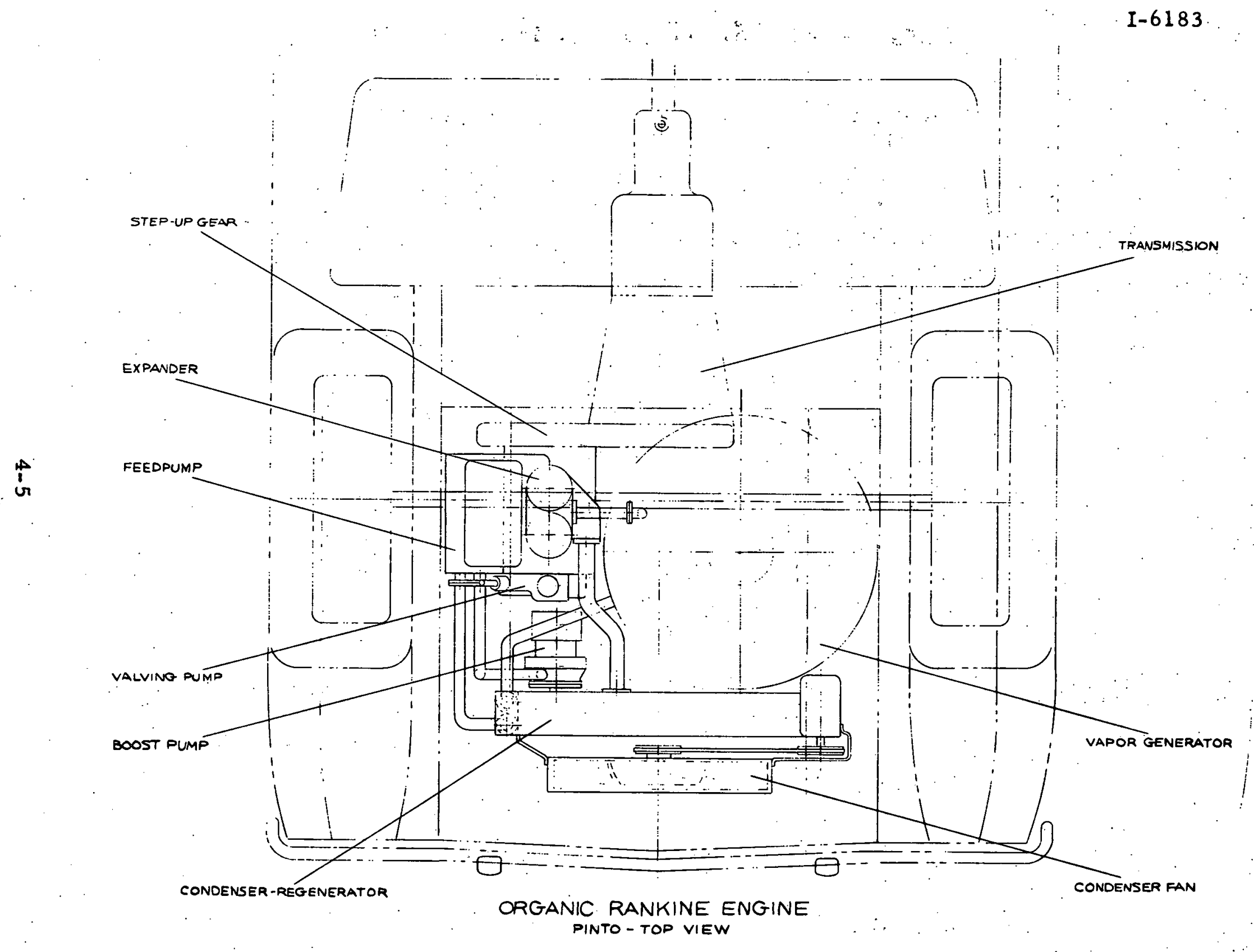

Figure 4.1 Organic Rankine Engine (Pinto-Top View) 


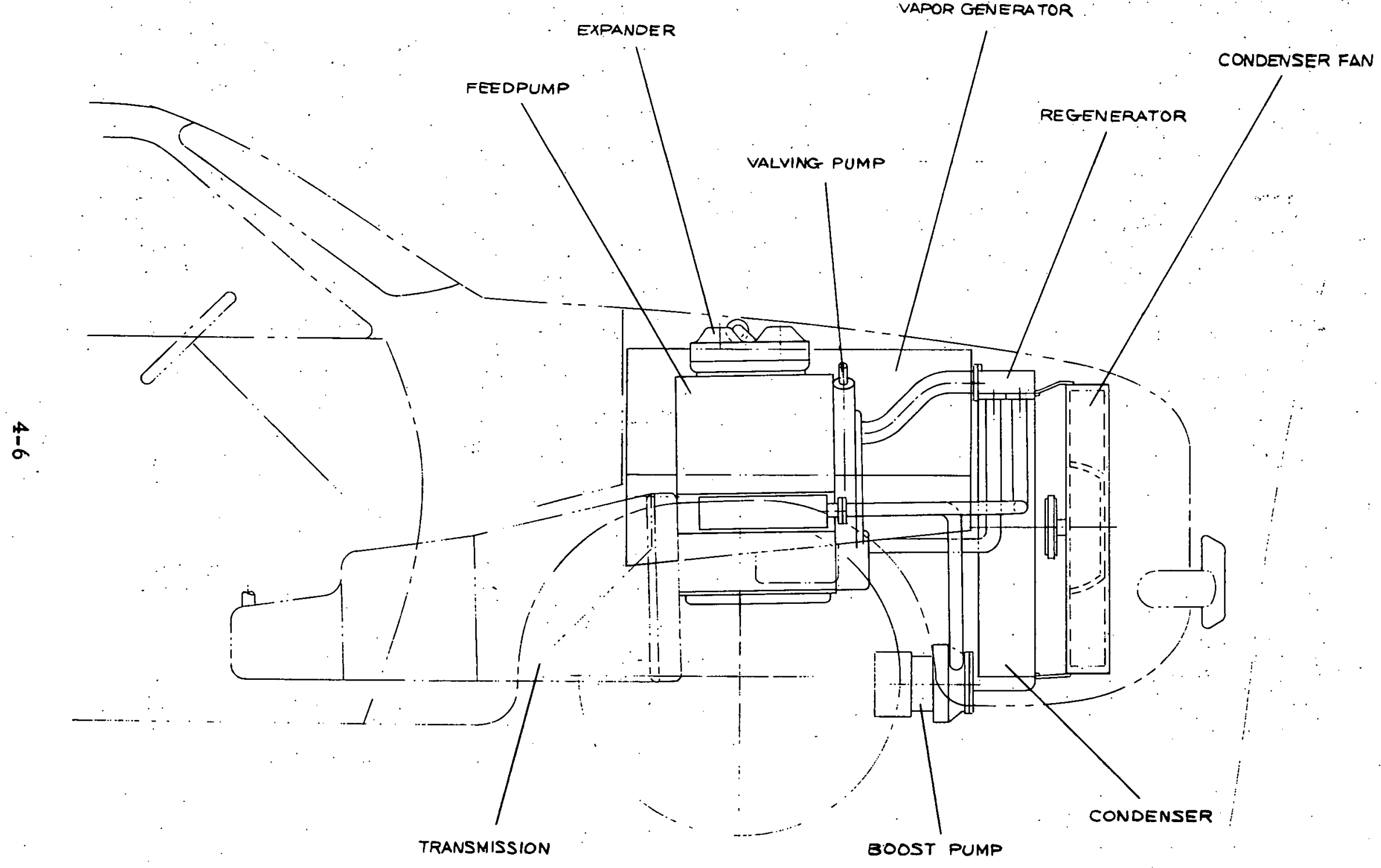

Figire 4.2 Organic Rankine Engine (Plnte - Side Vlew) 
Fluorino1-85. This results in a higher cycle efficiency for the higher temperature. It does have a higher freezing point than Fluorinol-85 $\left(-82^{\circ} \mathrm{F}\right)$, but this freezing point refers to the condition when ice crystals start to form. Fluorinol-50 can still be pumped at $-28^{\circ} \mathrm{F}$ and does not freeze solid until its temperature is $-82^{\circ} \mathrm{F}$. A freezing temperature of $-28^{\circ} \mathrm{F}$ is adequate for cold-weather starting.

\subsubsection{Expander-Feedpump Assembly. Design}

The selection and design of the expander is probably the single most important task of the compact car design. The expander is the largest component with the least packaging flexibility. Consequently, once the type of expander is selected and its placement decided, the rest of the components are "fit around" the expander.

\subsubsection{Selection of Expander-Feedpump Configuration}

All radial, horizontally opposed, and "V"' expanders were eliminated from consideration for the following reasons:

- Relatively complex manifolding is required.

- Drainage of liquid under startup conditions can be a severe problem, particularly with the bottom cylinders of radial expanders.

- Integration with the other components of the system is generally more difficult with other than in-line geometries.

This left two-; three-, and four-cylinder in-line expanders for consideration. Expanders with more than four cylinders can be eliminated on the grounds of complexity: In addition, the bore becomes 
so small that leakages and heat losses are unacceptable. There are three remaining factors to consider in the selection of the number of cylinders:

- Dynamic balance

- Acceptable torque fluctuation level

- Expander bulk

In regard to dynamic balance, the smallest number of cylinders that will give perfect balance (primary and secondary forces and moments) is six. In two-, three-, and four-cylinder units, a counterrotating shaft is required for primary-moment balance. With such a counter-rotating shaft, the two-cylinder unit would have a secondaryforce imbalance, and the three- and four-cylinder units would have a secondary-moment imbalance. The unbalanced force in the twocylinder unit is proportional to twice the reciprocating mass, and the unbalanced moment in the four-cylinder unit is proportional to twice the reciprocating mass multiplied by the distance between cylinder centers. Although the two-cylinder expander might be at some disadvantage, with respect to the three- or four-cylinder expander, its imbalance is still one-half that of a four-cylinder, four-stroke IC engine of the same bore and stroke. The top speed of the expander is likely to be about one-half that of the IC engine. One can conclude, then, that the choice of the number of cylinders need not be governed by balance considerations:'

The following point relative to torque fluctuations can be made. First; the four-stroke, four-cylinder diesel engine is successfully employed in passenger automobiles, and the torque fluctuations are 
likely to be worse than in a two-cylinder organic Rankine-cycle expander operating at modest inlet pressures. Second, flywheels and/or pendulum detuners can reduce torque fluctuations, and their bulk and complexity can be balanced against an increase in the number of cylinders. Again, it would appear that torque fluctuations would not rule out a two-cylinder expander in favor of three or four cylinders.

The remaining consideration is expander bulk, and to evaluate this a dimensional analysis was performed. In this analysis, the following factors. were held constant:

- Horsepower.

- Pressure drop through the inlet valve (BICERI-type valiving assumed)

- "Crank angle occupied by inlet valve during opening (constant intake ratio)

The following assumptions were made:

$1=$ length $\sim$ bore $\mathrm{x}$ number of cylinder $\mathrm{s}$

h $=$ height $\sim$ bore

$\mathbf{w}=$ width $\sim$ bore

This analysis indicated that a four-cylinder expander would occupy only 70 percent of the volume that a two-cylinder would occupy, but would be 40 percent longer. The packaging studies indicated that the length of the expander was always the dominating dimension. As a" result of this analysis, as well as using a fewer number of parts, a two-cylinder in-line configuration was chosen. The major design considerations for the expander are given in Table 4.3. 
TABLE 4.3

\section{EXPANDER DESIGN CONSIDERATIONS}

- Number of Cylinders - 2, in-line

- Bore - 3.25 in.

- Stroke $-3.0 \mathrm{in}$.

- Rated Speed - 2,000 rpm

- Rated Power - $60 \mathrm{hp}$

- Valving - Intake - BICERI variable cutoff Exhaust - Uniflow, through piston-controlled ports

- Lubrication - Dry sump with metered oil injection to bearings

- Bearings - Roller type, antifriction

- Crankshaft - Machined alloy steel, case hardened with detachable counterweights

- Connecting Rods - Aluminum alloy forging, split big end

- Piston - Aluminum alloy casting, hard anodized skirt

- Cylinder Block - Aluminum alloy sand casting

- Cylinder Liners - Cast iron

- Cylinder Head - Aluminum alloy 
One of the basic design goals was to attempt to integrate components of the Rankine system, reducing the overall bulk and complexity of the engine.' Since a counter-rotating shaft parallel to the crankshaft was required for primary-moment balance, an in-line variable-displacement. feedpump mechanlsm was designed to operate from eccentrics incorporated into the counter-rotating shaft. This allows the feedpump to be incorporated into the expander cylinder block casting. A three-cylinder in-line design was chosen for the feedpump. The feedpump design characteristics are:

- Number of Cylinders - 3, in-line

$\therefore$ Bore -1.20

- Stroke - 0.4 (maximum, continuously variable to zero)

- Rated speed - 2,000 rpm

- Flow - 4.6. gpm (maximum) at 1,000 rpm

- Valving - Spring-loaded flapper valve, inlet and outlet

\section{1. 3 Expander and Feedpump Detall Design}

Figures $4.3 ; 4.4$, and 4.5 show the expander-feedpump assembly. The pump and distributor of the BICERI valving system are housed in an aluminum casting bolted to the front (nondrive end) of the main expander casting. The BICERI valve pump is driven off the front of the crankshaft, and the distributor is driven through a right-angle hellcal gear arrangement off the counter-rotating balance shaft.

Lubrication is of the dry sump type with a plunger-type metering pump for delivering small quantities of oll to the various bearings. 


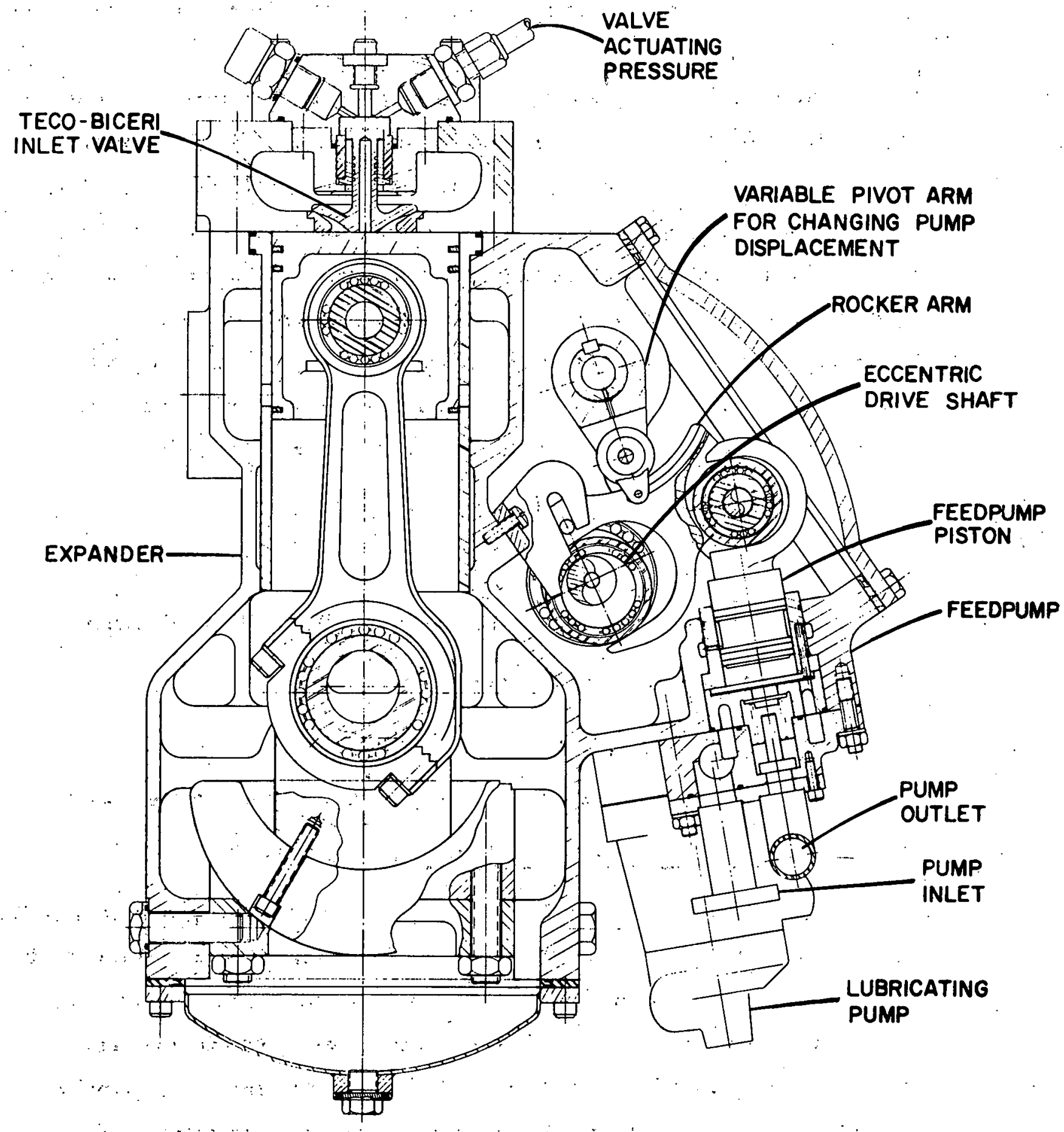

Figure 4.3 Front Section of Expander and Feedpump 


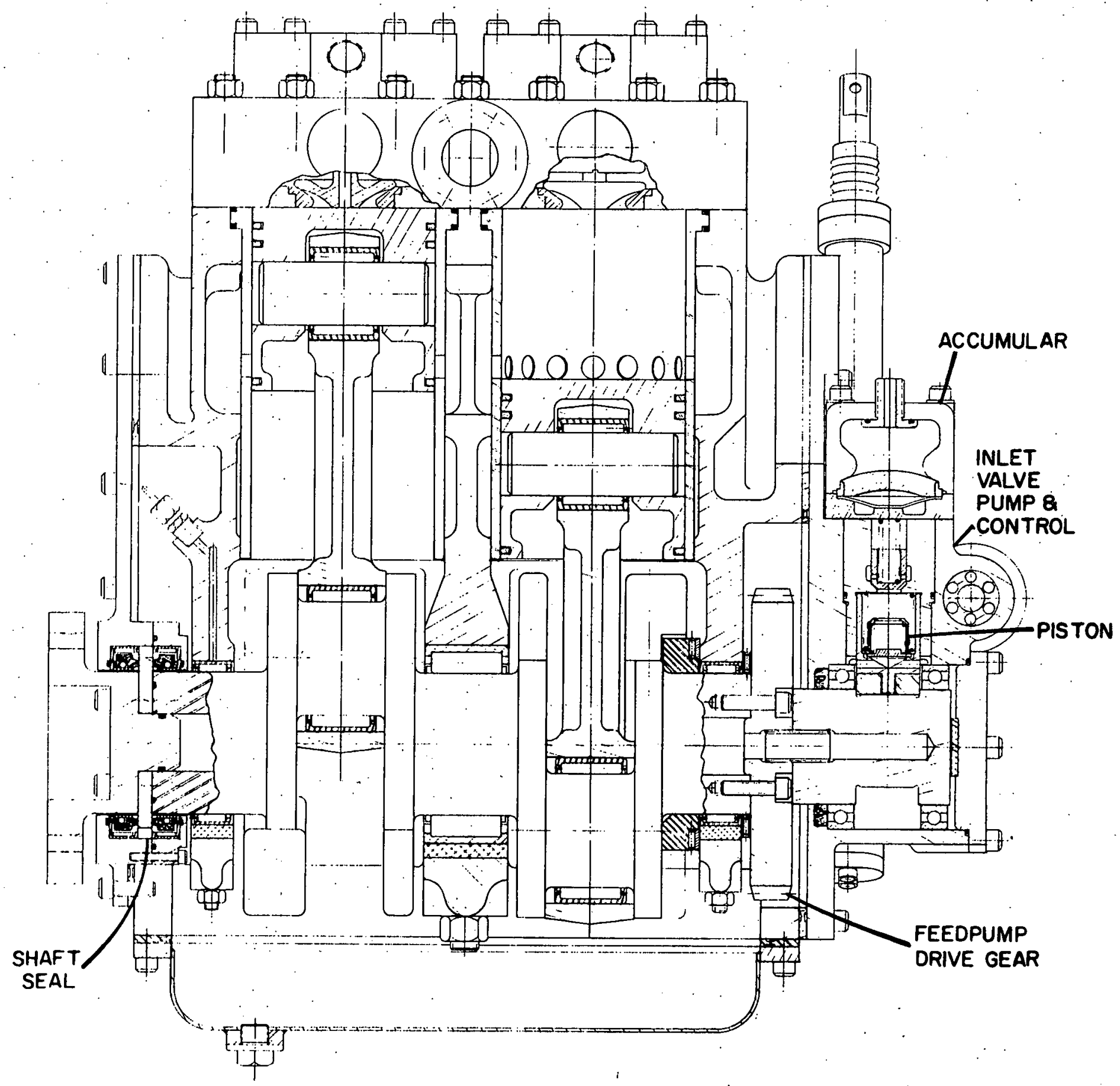

Figure 4.4 Longitudinal Section through Expander 


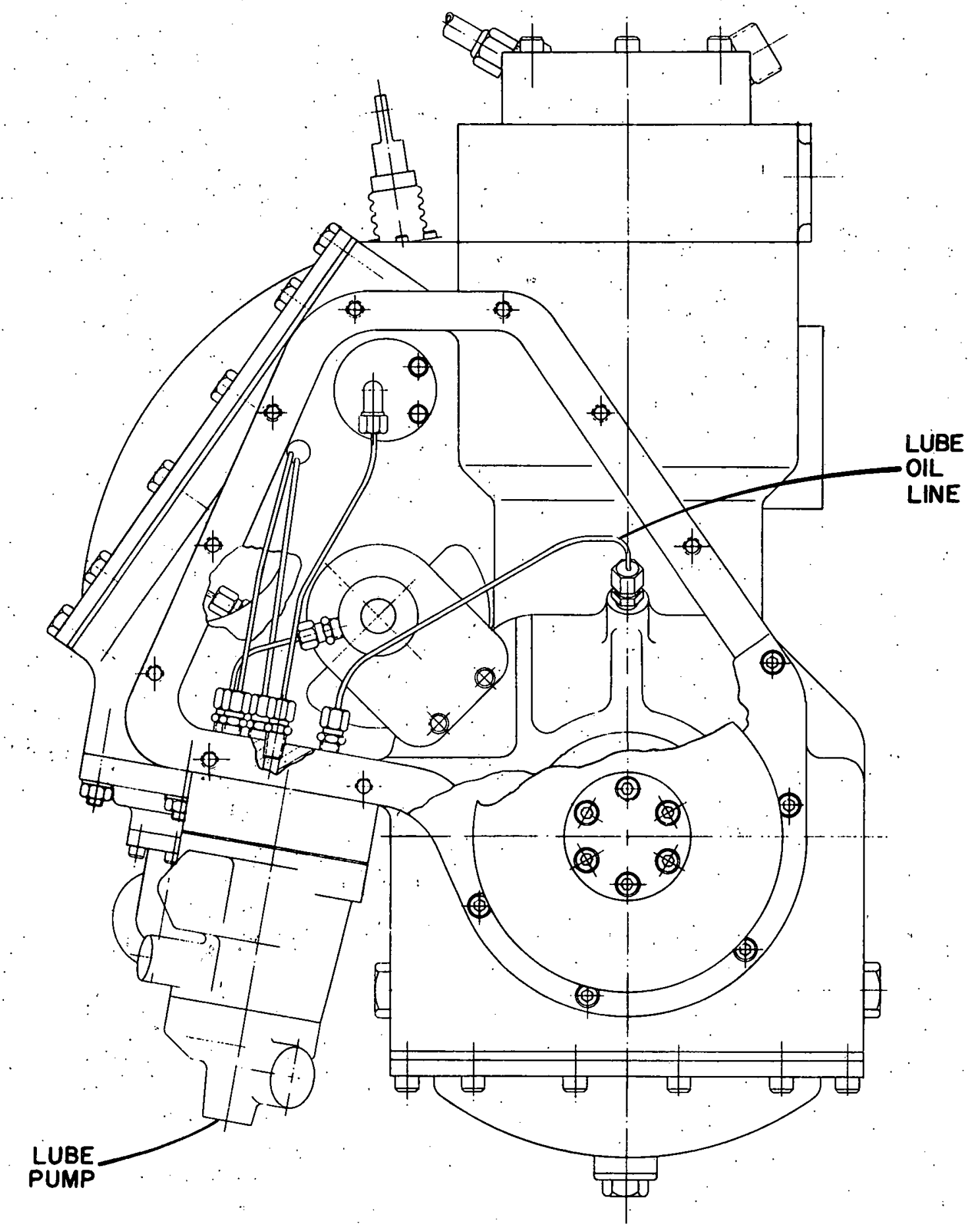

Figure $4.5^{\circ}$ Section Showing Lube Oil Pump and Connections 
The pump is a standard Saab unit used on their two-stroke cycle automobile engine. It is driven off the rear of the counter-rotating shaft through a right-angle helical drive and supplies a small quantity of oil sequentially at seven outlet ports at a rate of one cycle per 80 engine revolutions. Three of these outlets lead to the three main bearings, two lead to the counter-rotating shaft, and two lead to the pump pirot shaft. These shafts are drilled so that ofl is distributed to the various bearings. An oil reservoir of about one quart capacity supplies oil to the lube pump and makeup oil to the BICERI pump crankcase.: Lubrication of the drive gears for the counter-rotating shaft is by leakage from the drive end of the BICERI rotor. Oll collecting in the crankcase returns to the sump. It is anticipated that the oil rates will be low enough so that no oll need be returned to the reservolr until the engine has warmed up, and any working fluid that might have collected in the sump has evaporated.

The arrangement of the expander itself is very similar to the V-4 expander. Aluminum is used instead of iron in the cylinder block and cylinder head, and the pistons are anodized aluminum running on castiron liners. The porting in the liners has been changed from rectangular slots to circles, in view of problems with rings encountered in the V-4 design. The connecting rods are forged aluminum and split at the big end. The crankshaft is case-hardened alloy steel and, in contrast with the V-4 (which had a cast steel crankshaft), is machined from a solid bar with bolt-on counterweights. This was done because the steel foundry recommended an investment casting, rather than a sand casting, due to the smaller size, and it was felt that the cost was not justified for the quantity likely to be built. 
The bearings were slized by ratioing loads from the V-4 expander. The bearing loads were then evaluated at $1.000 \mathrm{rpm}$ and an IMEP of 154 psi by Torrington Company, taking into account not only pressure versus crank angle, but also rotating and reciprocating loads. They concluded that all of the bearings (wrist pin, crank pin, and the three mains) should have lives in excess of $1000 \mathrm{hr}$. Since the conditions for sizing were much more severe than average driving, it is felt that the bearings will have the required 3500-hr life. All three main bearing caps are aluminum forgings with a steel beam section under each cap to provide stiffness. The center main support beam is tied into the cylinder block casting with a bolt on each side to provide additional stiffness.

Unlike the V-4 expander, this unit has only one shaft seal, and it is of the same type as previously used.

The three-cylinder variable-displacement feedpump is shown in Figures 4.3 and 4.6 . The main features of the feedpump are shown in Figure 4.3 . The pistons are reciprocated by eccentrics on the counterrotating balance shaft operating through rocker arms with a variable pivot point. The piston and valving are very similar to previous Thermo Electron designs. In contrast with previous pumps, the only bearing that rotates at crankshaft speed is the eccentric bearing. The remaining bearings operate at almost static conditions, and ultimately might be replaced by simpler solid rubbing surfaces. Again, in contrast with the radial pump design, the load on the eccentric bearing varies with the pump delivery; at low flow rates the load on this bearing is considerably reduced, whereas in the radial design the bearing load was only a function of the pump discharge pressure and 


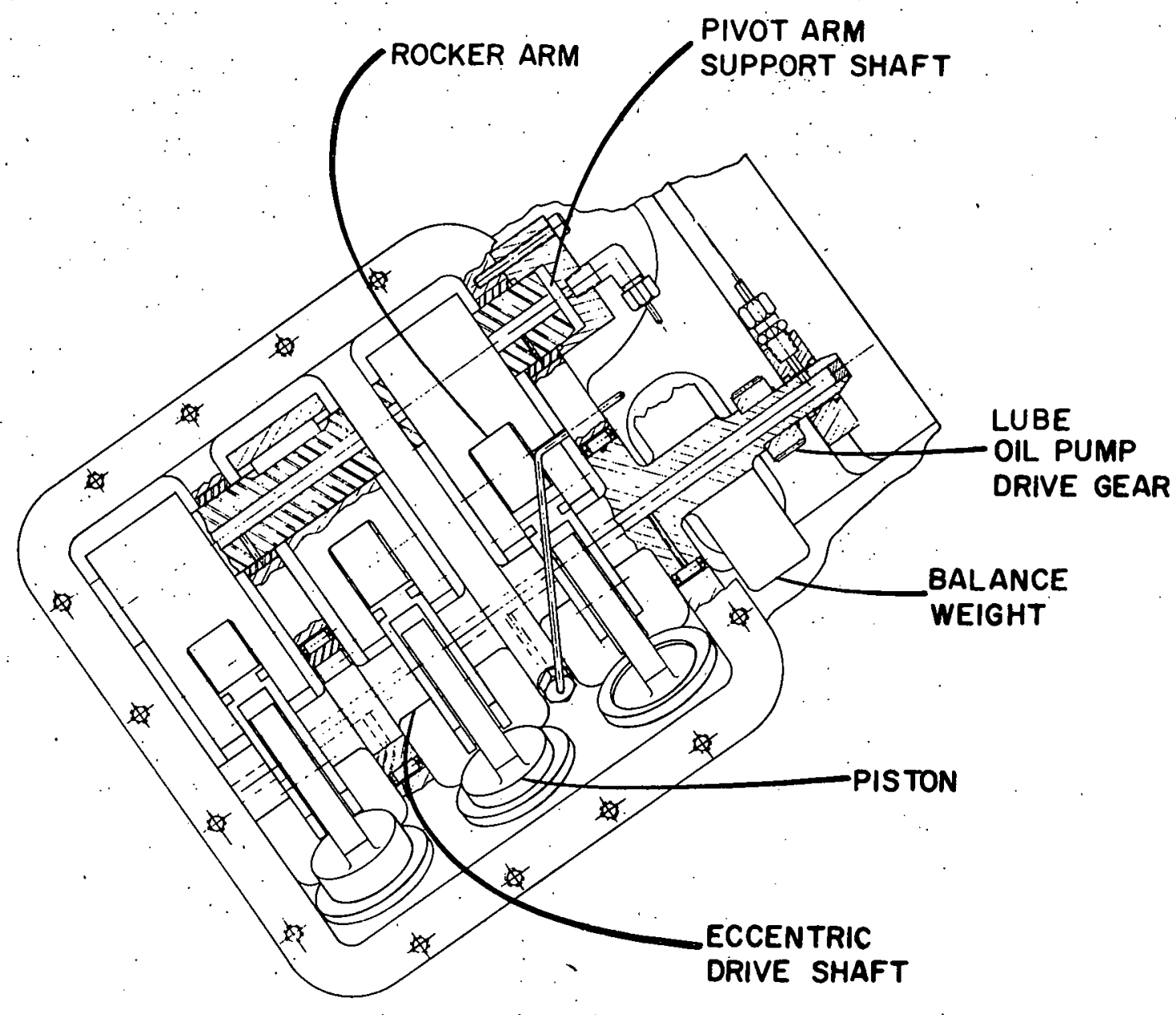

Figure 4.6 Feedpump. Detail Showing Pump.with Cover Removed 
not the pump displacement. Another important advantage of this design is that the force required to change the pump displacement is small compared to the radial pump design. The radial feedpump had inletand outlet-flow passages cast into the pump housing. This was done to reduce the overall diameter of the pump, which was the critical dimen sion. In this design, the porting has been moved to the cylinder head for two reasons: to simplify the block casting, and to reduce heat transfer from the block to the intake liquid, which has the effect of increasing the boost pump requirement. Plston and liner materials and construction are simllar to the radial preprototype pump. Positive piston return without springs is provided because return springs increase the bulk of the pump considerably and also increase the loads on all the bearings.

Figure 4.6 shows the view of the feedpump looking into the flange that bolts to the expander. The eccentric drive shaft can be seen in this view; located at one end of the shaft is a gear that drives the lube oll pump. Also mounted on this shaft near this gear is the balance weight required for the pump. The feedpump-displacement control and expander-cutoff control have been joined by a mechanical linkage, as shown in Figure 4.7. This simplifies the control function by eliminating the necessity for electronic sensors on cutoff control and logic to position the feedpump-control servo mechanism. The elimination of the hydraulic servo for positioning the feedpump should reduce the parasitic losses.

\subsubsection{Compact Car Burner/Vapor Generator}

The burner/vapor generator design used for the compact car is patterned after the burner/vapor generator used for the full-size car 


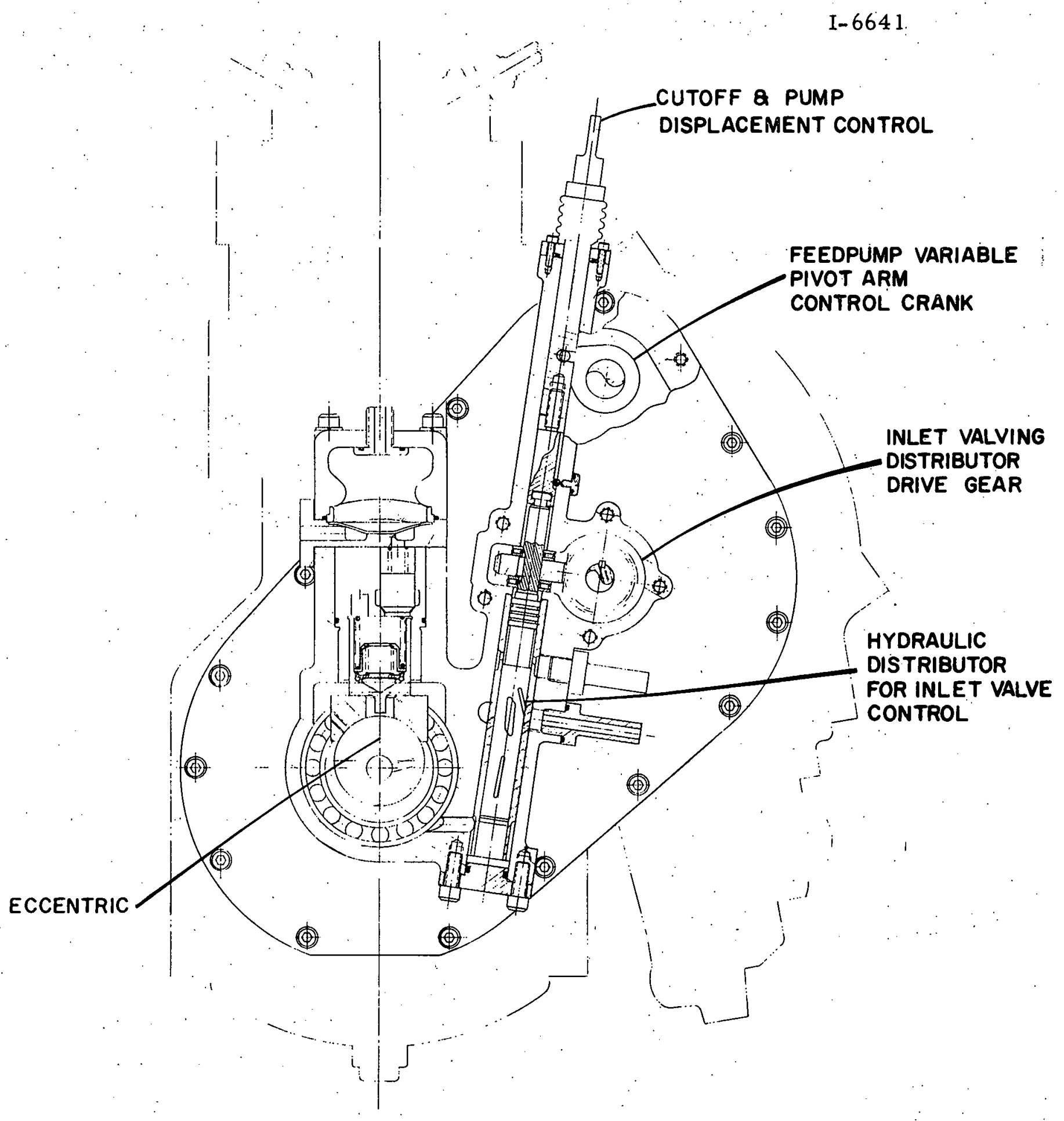

Figure 4.7 Section Showing Inlet Valving Pump and Distributor with Feedpump Control 
and described in Section 3.7. The sizes of the components have been reduced to reflect the reduced firing and heat transfer rates, but the design draws heavily on the previous development experience. A conceptual drawing of the burner/vapor generator is shown in Figure 4.8. Design point characteristics are shown in Table 4.4.

The compact càr vapor ganerator requires three stages. The inner two coils are plain tubing, whereas the outer coil is externally finned. No internal finning is used in this design. The main design features for each stage are given in Table 4.5. The arrangement is again cross. parallel/cross-counter flow with the working fluid entering the outer coil, crossing over to the inner, and exiting from the center coil. The vapor generator housing was redesigned to include an integral duct for EGR. This duct channels exhaust gas directly to the EGR metering shutter without requiring external connections.

The combustion air distribution system remains essentially the same as that used in the preprototype combustor. Air, mixed with recirculated exhaust gas, is introduced into the combustion zone from three directions: radially inward, and along the vertical axis above and below the fuel atomizing cup. The air for the radially inward; or reverse, jet is fed to a circular sheet-metal duct by six one-inch diameter tubes, which extend across the combustion zone and also serve as part of the support structure for the combustor. This duct, which is actually composed of a number of overlapping segments to accommodate expansion, is located in the vertical center of the combustion zone concentric with the fuel atomizing cup. It is closed at the top, bottom, and outer diameter; the inside diameter is faced with a series of perforated metal sheets through which the air flows. The 


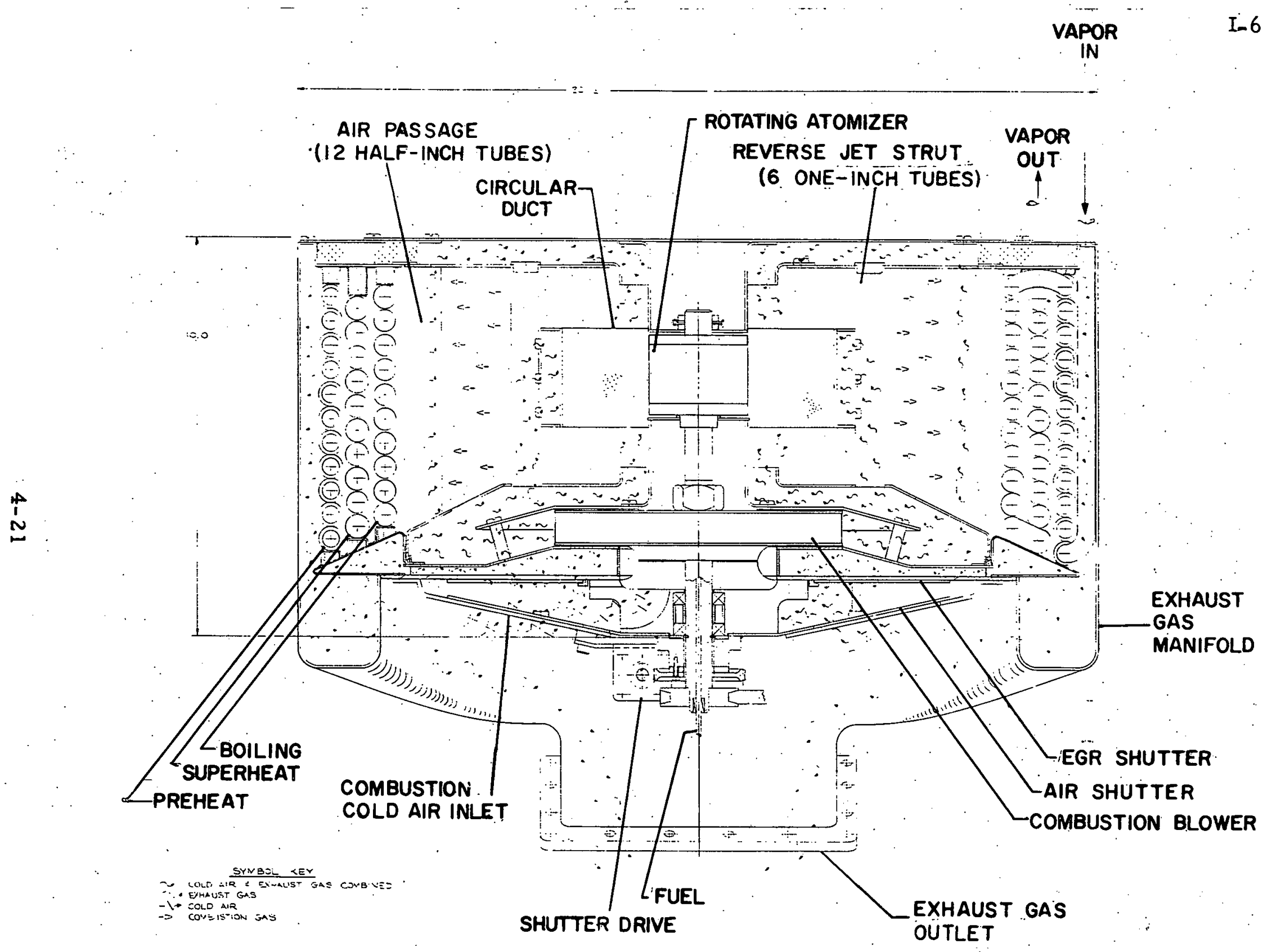

Figure 4.8 Layout of Combustor/Vapor Generator 
TABLE 4.4

DESIGN POINT CHARACTERISTICS OF

BURNER/VAPOR GENERATOR

BURNER .

- Performance Characteristics

Combustion Rate

Fuel Type

$1.05 \times 10^{6} \mathrm{Btu} / \mathrm{hr}$

Fuel Flow Rate

EPA Gasoline

Airflow Rate

Combustor Pressure Drop

$53 \mathrm{lbm} / \mathrm{hr}$

Control Pressure Drop

$1000 \mathrm{lbm} / \mathrm{hr}$

Combustion Gas Adiabatic Temperature

3.5 in. $-W . C$

Combustion Space Rate

2 in. $-W C$

$3200^{\circ} \mathrm{F}$
$1.8 \times 10^{6} \mathrm{Btu} / \mathrm{hr}-\mathrm{ft}^{2}$

- Salient Features

Rotary Atomizer

Radial Flow Combustor with Reverse Flow Secondary Air

Variable EGR, from $60 \%$ at idle to $0 \%$ at maximum firing rate

- Dimensions

Diameter

15 in.

Height

8.5 in.

Weight (including control shutter)

$40 \mathrm{lb}$

VAPOR GENERATOR

- Performance Characteristics

Heat Transfer Rate

Efficiency at $100 \%$ Load

Fluorinol-50

Flow Rate

Inlet Temperature

Inlet Pressure

Outlet Temperature

$8.4 \times 10^{5} \mathrm{Btu} / \mathrm{hr}$ $80 \%$

Outlet Pressure

$23701 \mathrm{bm} / \mathrm{hr}$

$27.6^{\circ} \mathrm{F}$

950. psia

$650^{\circ} \mathrm{F}$

800 psia

Gas-Side Pressure Drop

2.5 in. $-W C$

Exhaust System Pressure Drop

1 in. $-W C$ 
TABLE 4.5

STAGE-WISE CHARACTERISTICS OF VAPOR GENERATOR

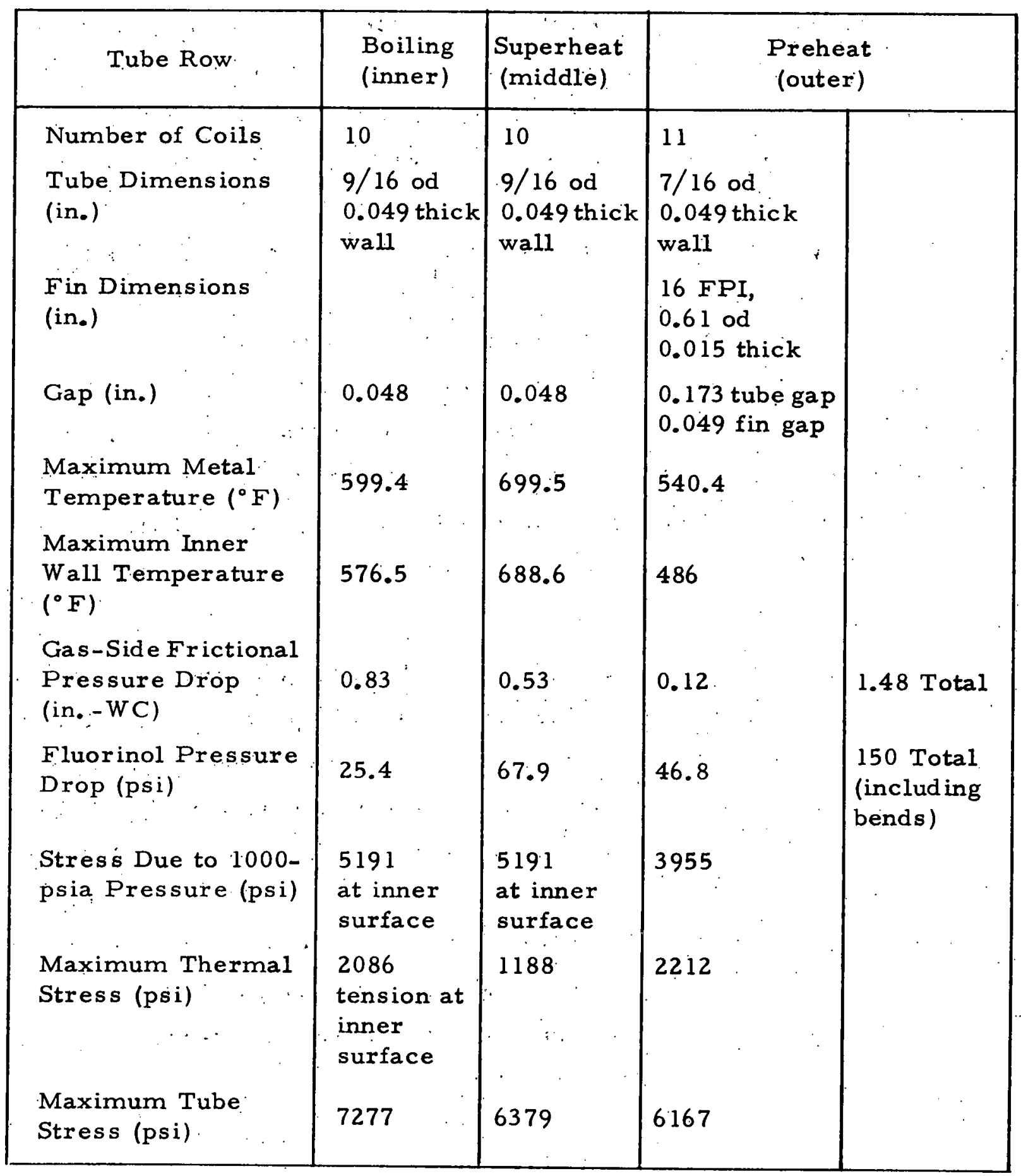


perforated facing serves to distribute the air from the reverse side and, more importantly, to intercept and vaporize any large fuel droplets thrown from the atomizing cup. The air for the bottom side is directed over the blower diffuser and through a short tube into the combustion zone. The air for the top vertical side must cross the combustion zone. This passage:is provided by twelve $1 / 2$-inch diameter tubes located around the outside diameter of the combustor. These tubes are used also as part of the support structure of the combustor. The air flows through a chamber, formed by the top of the combustion chamber liner and the top cover plate of the burner, and into the combustion zone through a tube identical to the one at the bottom. A small amount of air is also introduced into this top chamber through the six one-inch diameter tubes that feed the reverse jet. This flow serves to cool the tubes and represents about 5 percent of the total flow. The flow rate is controlled by orifice plates tack welded over the top of the tubes.

The components of the burner have been sized to provide the same airflow split as in the full-size car burner - 50 percent to the reverse flow duct and 25 percent to each of the two vertical jets. Although experience with the large combustor has indicated that the flow split between the reverse jet and the two vertical jets is not critical and may vary considerably without adverse effects on emission levels, the same is not true of the flows to the vertical jets. If the two flows are not nearly equal, flame asymmetry and quenching along the chamber walls may result. To assure a symmetric flow pattern, a means of regulating the flow to the bottom jet was provided. 
Calculations of bearing loads; as well as experience with the large combustor, has shown that a pair of ball bearings at the combustor blower inlet is sufficient to support the shaft that drives the combus tion blower and atomizing cup, and that no bearings are required in the combustion zone.

To prevent premature vaporization of the fuel before its entry into the atomizer, a pressure-rellef valve has been designed into the end of the fuel line. This valve has a cracking pressure of $20 \mathrm{psig}$ and assures that, even at the minimum firing level, the fuel will be under pressure throughout the fuel delivery system. As an added precaution, the fuel line has been relocated. It now passes directly through the hollow center of the blower and atomizer drive shaft. This is the shortest possible route for the fuel, much shorter han that used previously, and it is also well protected from the hottest parts of the burner.

The basic operating principle of the air and EGR shutters remains the same; however, some details of construçtion have been changed. The shape of the air shutter has been changed from flat to conical. The shutter, rather than being a separate assembly, now rotates about the hub that holds the blower bearings. This change provides better centering of the shutter, eliminates a source of air leakage, and provides for the widest practical spacing of the blower support bearings. Connections between the burner and vapor generator are now made with gasketed flanges, using ceramic fiber insulation as the gasketing material. The blower characteristics for the burner/vapor generator are given in Table 4.6 . 


\section{TABLE 4.6}

DESIGN POINT CHARACTERISTICS OF COMBUSTION BLOWER

Blower Performance

Total Airflow (lbm/hr)

1000

Inlet Temperature $165^{\circ} \mathrm{F}$

Inlet Pressure

14.7 psia

EGR

0

Static Pressure Rise

9 in. $-W C$

Speed

$6000 \mathrm{rpm}$

Static Efficiency

$60 \%$

Shaft Hors epower

0.62

\section{Blower Design}

Blower Type.

Manufacturer and Number

Number of Blades

Diameter

Inlet Diameter

Height

Discharge Height

Weight
Mixed Flow

Rotron F-4

19

6 in.

5 in.

$2-1 / 8$ in.

0.86 in.

10 oz 


\subsubsection{Compact Car Condenser/Regenerator and Fan}

The condenser and the regenerator are similar to the components used on the full-size automotive preprototype system and described in Sections 3.4.1 and 3.3.1. They are, of course, smaller. The major change has been the incorporation of the regenerator into the inlet header of the condenser. The use of some common housing components has resulted in a savings of space and weight. The plumbing is also simplified by the elimination of the condenser-to-regenerator connection and its associated pressure drop.

Since the condenser and regenerator are designed as a single brazed assembly, they must be of the same material. Since a steel condenser, because of its low fin efficiency, would be impractical, aluminum was chosen; the regenerator, therefore, must also be of aluminum. Although the liquid-side pressures of the regenerator are fairly high, stress analysis indicates that, for sufficiently thick fins, stresses are within acceptable levels for the working temperatures that will be encountered.

The preliminary design is shown in Figure 4.9. The design point characteristics are shown in Table 4.7.

The compact car condenser requires 36 percent of the flow of the full-size automotive condenser. The alr-side pressure drop is also less. One of the full-size automotive fans, operating at the reduced speed of $2460 \mathrm{rpm}$, would provide the air required at $85^{\circ} \mathrm{F}$ ambient temperature. The fans were designed to provide a radial component to the exit velocity of the air. This was done to provide as unrestricted a flow as possible to the air as it passed around the expander directly 
I- 6648
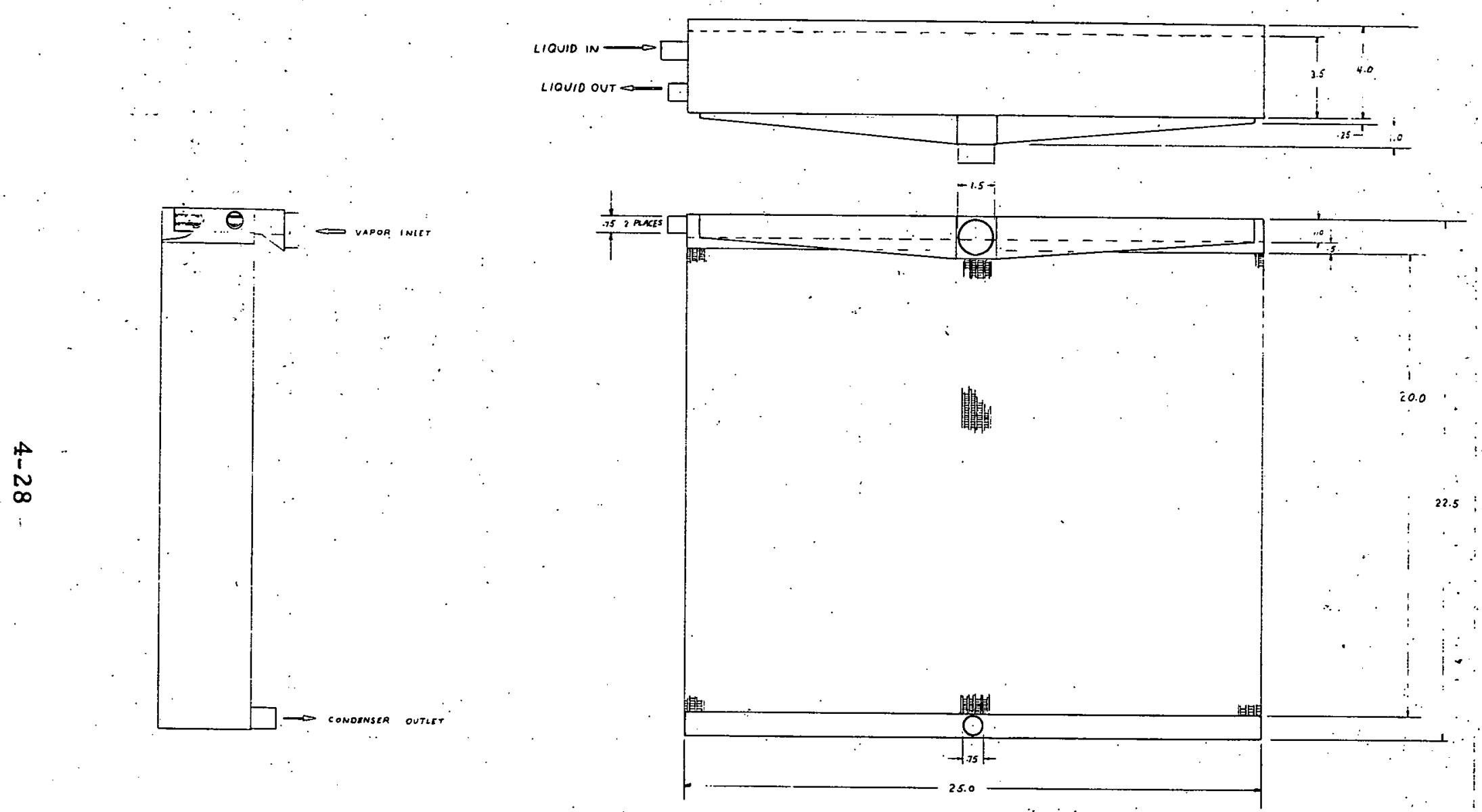

Figure 4:9 Condenser-Regenerator Assembly, Compact Car Engine 
TABLE 4.7

DESIGN POINT CHARACTERISTICS OF CONDENSER/REGENERATOR

A. PERFORMANCE CHARACTERISTICS

1. Regenerator

Flow Rate, Fluorinol-50

Rate of Heat Transfer

Fluorinol-50 Conditions

Liquid: Inlet Temperature

Inlet Pressure

Outlet Temperature

Outlet Pressure

Vapor: Inlet Temperature

Inlet Pressure

Outlet Temperature

Outlet Pressure

Regenerator Effectiveness

2. Condenser

Heat Transfer Rate

Fluorinol-50 Conditions

Flow Rate

Condensing Temperature

Condensing Pressure

Inlet Temperature

Inlet Pressure

Exit Temperature

Exit Pressure

Air Conditions

Flow Rate

Design Ambient Temperature

Core Pressure Drop

Condenser Effectiveness
$2370 \mathrm{lbm} / \mathrm{hr}$

$91,800 \mathrm{Btu} / \mathrm{hr}$

$203^{\circ} \mathrm{F}$

970 psia

$276^{\circ} \mathrm{F}$

950 psia

$380^{\circ} \mathrm{F}$

34 psia

$259^{\circ} \mathrm{F}$

33 psia

0.70

$67.1,500 \mathrm{Btu} / \mathrm{hr}$

$2370 \mathrm{lbm} / \mathrm{hr}$

$212^{\circ} \mathrm{F}$

31.8

$259^{\circ} \mathrm{F}$

33 psia

$203^{\circ} \mathrm{F}$

30.5 psia

$27,4001 \mathrm{bm} / \mathrm{hr}$

$85^{\circ} \mathrm{F}$

3 in. $-W C$

0.80 
TABLE 4.7 (continued)

$A-1609 b$

\title{
DESIGN POINT CHARACTERISTICS OF CONDENSER/REGENERATOR
}

B. PHYSICAL CHARACTERISTICS

1. Overall Dimensions and Characteristics

Overall Dimensions

Material

Total Weight

$25 \times 22.5 \times 4$ in. 6951 Aluminum $47 \mathrm{lbm}$

\section{Regenerator}

Type of Exchanger

Two-pass cross-

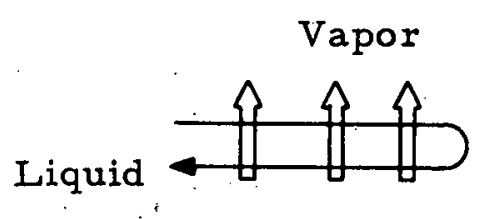 \\ counterflow \\ Transfer Area \\ Film Transfer Coefficient \\ Overall Fin Efficiency \\ imensions \\ Core Weight \\ Liquid-Side Characteristics \\ Number of Passes \\ Number of Parallel Passages \\ Surface Characteristics \\ $3-1 / 2 \times 1 \times 24$ in. \\ $2.41 \mathrm{bm}$ \\ Two \\ Two \\ 0.1-in. high \\ lanced fin \\ $18.5 \mathrm{fins} / \mathrm{in}$. \\ UAP No. U-407665 \\ $7.37 \mathrm{ft}^{2}$ \\ $1906 \mathrm{Btu} / \mathrm{hr}-\mathrm{ft}^{2}-{ }^{\circ} \mathrm{F}$ \\ 0.75 \\ Vapor-Side Characteristics \\ Number of Passes \\ Number of Parallel Passages \\ Surface Characteristics \\ One \\ Three \\ 0.233 in. high \\ ruffled fin \\ 24 fins/in. \\ UAP No. U-405649
}


TABLE 4.7 (continued)

DESIGN POINT CHARACTERISTICS OF CONDENSER/REGENERATOR

Transfer Area

Film Transfer Coefficient

Overall Fin Efficiency
$25.1 \mathrm{ft}^{2}$ $103 \mathrm{Btu} / \mathrm{hr}-\mathrm{ft}^{2}-^{\circ} \mathrm{F}$ .0 .85

Crossflow

Condensing Fluorinol

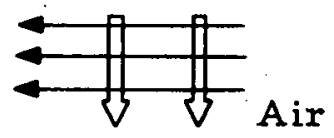

Core Dimensions

Core Weight

Fluorinol-50 Side Characteristics

Number of Parallel Circuits

Surface Characteristics

Transfer Area

Condensing Transfer Coefficient

Overall Fin Efficiency

Air-Side Characteristics

Frontal Area

Surface Characteristics

Transfer Area

Film Transfer Coefficient

Overall $F$ in Efficiency
$20 \times 25 \times 4$ in.

$33.1 \mathrm{lb}$

60

0.050-in. high straight fin 20 fins/in. $125.3 \mathrm{ft}^{2}$ $318 \mathrm{Btu} / \mathrm{hr}-\mathrm{ft}^{2}-{ }^{\circ} \mathrm{F}$ 0.99

$3.47 \mathrm{ft}^{2}$ 0.326 -in. high perforated fin 22 fins/in. Garret $A$ iResearch 22R-.326-Perf(-13)0.004 (AL)

$576.4 \mathrm{ft}^{2}$ $27.7 \mathrm{Btu} / \mathrm{hr}-\mathrm{ft}^{2}-{ }^{\circ} \mathrm{F}$ 0.92 
behind the fans. As the compact car fan is to be located in front of the condenser, it must develop truly axial flow. In all other respects, the fan would be identical. Specifications for the required fan are given in Table 4.8.

\subsection{IMPROVEMENTS REIATIVE TO THE PREPROTOTYPE SYSTEM} AND PERFORMANCE PROJECTIONS

Many improvements in performance are inherent in the compact car, mainly because the system size is greatly reduced. Another improvement is due to the change in water content of the organic working fluid from Fluorinol-85 to Fluorinol-50. The third major improvement in performance and system integrity is due mainly to component and overall system design.

Specifically, the improvements of the compact car design relative. to the preprototype system are listed below:

- Improved SFC with Fluorinol-50 due to higher cycle temperature

- Reduced component size due to reduced flow rate

- Reduced system weight due to using aluminum expander and regenerator instead of steel

- Reduced number of parts, e.g., two-cylinder expander, three-cylinder pump, one fan

- One shaft seal instead of two

- Improved intake valve design

- Integrated expander, feedpump; intake valve, and hydraulic pump 
TABLE 4.8

DESIGN POINT CHARACTERISTICS OF CONDENSER FAN

\section{Design Point Performance}

Total Flow $(1 \mathrm{bm} / \mathrm{hr})$

Inlet Temperature

Inlet Pres sure

Airflow (ft ${ }^{3} / \mathrm{min}$ )

Speed

Pressure Rise (total)

Pressure Rise (static)

Fan Shaft Power

Efficiency

\section{Fan Design}

Type

Tip Diameter

Number of Blades

Material

Fan Drive
27,400

$85^{\circ} \mathrm{F}$

14.7 psia

6270

2460 rpm

2.0 in. $-W C$

1.2 in. - WC

$2.9 \mathrm{hp}$

$69 \%$

Tube Axial

$20 \mathrm{in.}$

17
Aluminum Alloy
Belt driven by
electric motor 
- Integrated cutoff and feedpump controls

- Reduced parasitics

- Integrated regenerator and condenser

- Electrically driven condenser fan with energy storage for transient

- Elimination of relative motion between components, no flex lines

- Improved packaging and flexible configuration

Performance projections, mainly fuel economy, have been established for the compact car design. Data have been gathered from test experience gained on the preprototype system, as well as information avallable on current ICE powerplants. Fuel economy performance was computed on the following basis:

- Drive power based on Ford correlation for Pinto

- Accessory power based on requirement at an $85^{\circ} \mathrm{F}$ ambient

- Expander and feedpump efficiencies based on existing component test data

- Powerplant weight $100 \mathrm{lb}$ in excess of ICE

Fuel economy data for the organic Rankine-cycle system powered Pinto are given in Figure 4.10. The 60-Expander horsepower system. shows fuel economy as a function of vehicle speed for various transmission configurations. A peak steady-speed fuel economy of $40 \mathrm{mpg}$ is achlevable with the four-speed transmission for speeds up to approximately $30 \mathrm{mph}$. 


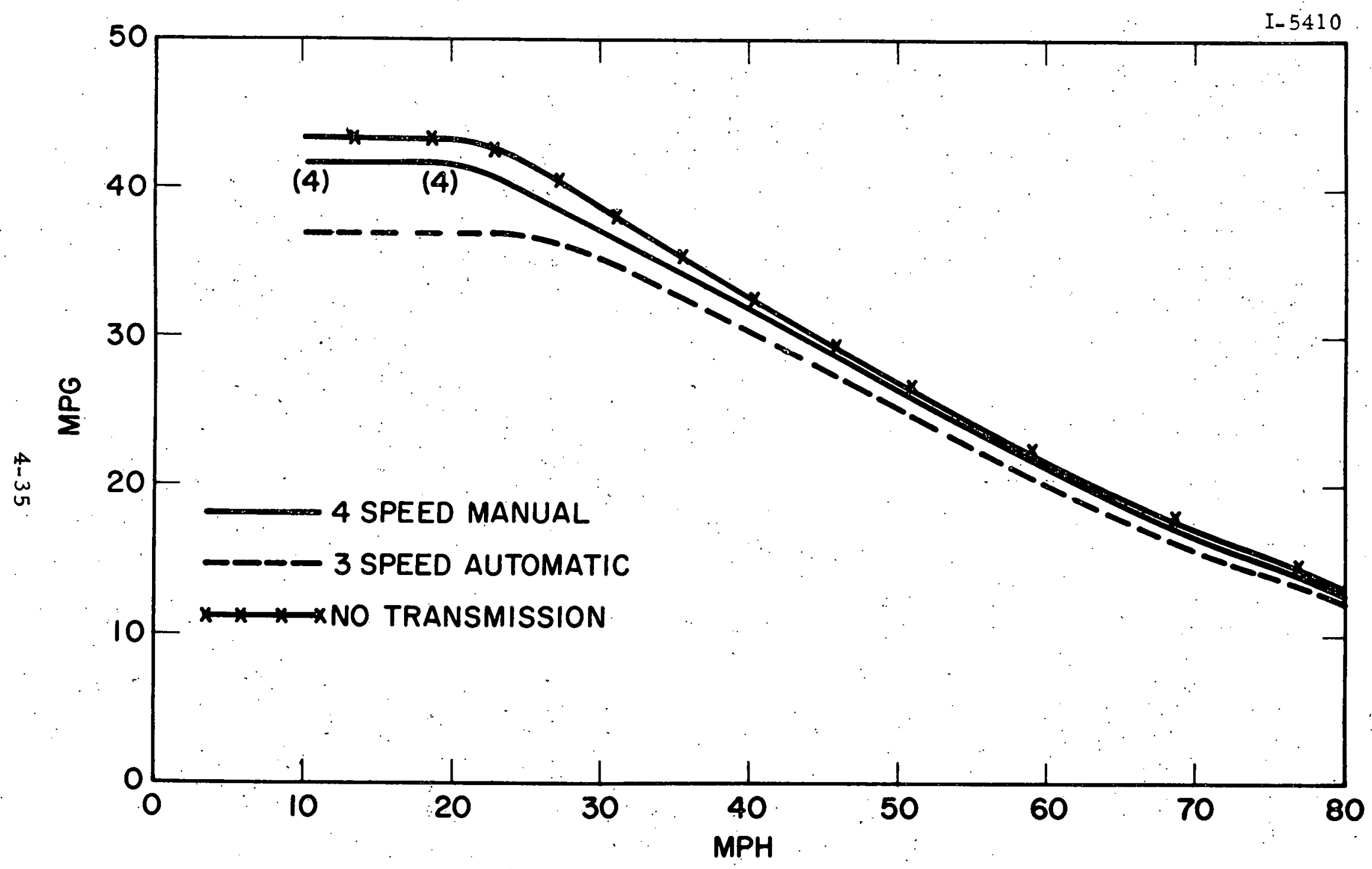

Figure 4.10 Compact Cax Fuel Economy Projections 
Fuel economy for two vehicles at different test weights, specifically the Pinto type and the Subaru type, both with a four-speed standard transmission and Rankine-cycle powerplant, are compared in Figure 4.11 at an ambient of $85^{\circ} \mathrm{F}$.

One of the goals for the prototype system was emission levels less than one-half the federal standards. Since the prototype combustion 8 ystem was not built and tested, there is no data available to show that this goal could be met positively. . However, the prototype combustion system was a scaled-down version of the preprototype system, and it should have the same emission characteristics. The HC and $C O$ emissions for the preprototype system were well below the goals for the prototype system and would pose no problem. The NO emissions were about 69 percent of the federal standard, or about 38 percent above the goal for the prototype system. The fuel economy improvement for the compact car is projected to be between 30 and 50 percent higher than the full-size (preprototype) car. This should reduce the NO emissions sufficiently to meet the goal.

A performance comparison between a Pinto with an ICE and a Pinto with an organic Rankine engine on a $0-$ to $60-\mathrm{mph}$ acceleration condition shows that the ICE takes $16.5 \mathrm{sec}$, whereas the organic Rankine engine takes 19.1 sec. The performance comparison was made with both vehicles utllizing the four-speed standard transmission.

The performance projections of the organic Rankine-cycle powerplant for a compact car; as well as improvements relative to the larger preprototype system, both in performance and design, make it a feasible alternate automotive powerplant. 


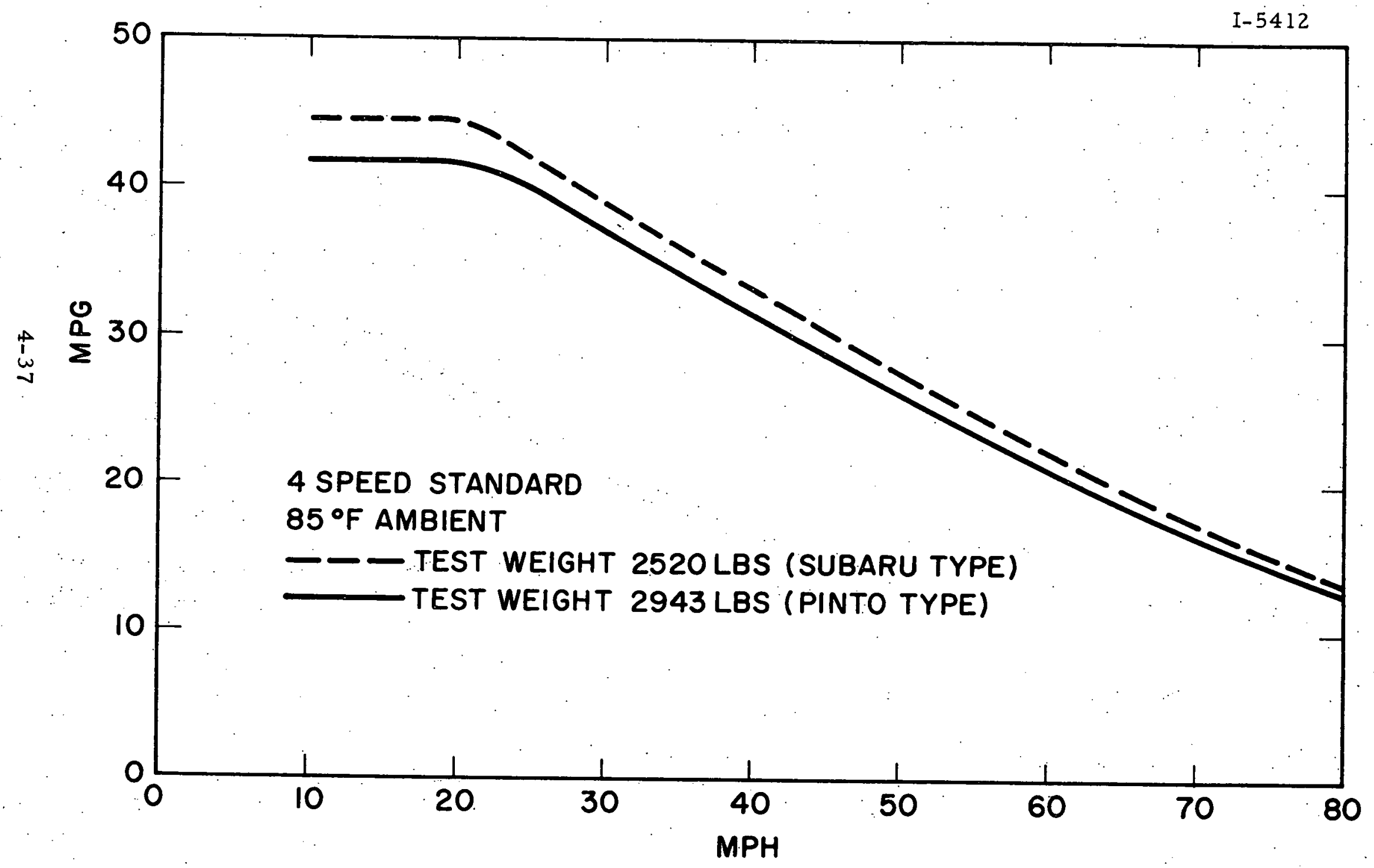

Figure 4.11 Fuel Economy - Effect of Weight 


\section{REFERENCES}

1. 'Preprototype Engine and Four-Cylinder Expander Quallfication Test Plan for the Rankine-Cycle Automotive Engine Program, " Thermo Electron Report No. TE4157-46-74, November 1973.

2. "Preprototype Engine System Characterization Test Plan for the Rankine-Cycle Automotive Engine Program," Thermo Electron Report No. TE4157-135-74, June 1974.

3. 'Rankine-Cycle Power System with Organic-Based Working Fluid and Reciprocating Expander for Automobile Propulsion, "Thermo Electron Report No. 4134-71-72, May 1972.

4. 'Design and Development of an Automobile Propulsion System Utilizing a Rankine-Cycle Engine," Thermo Electron Report No. TE4157-97-73, May 1973.

5. "Condenser and Fan Development for Rankine-Cycle Engines," Report No. EPA-460/3-73-007, AiResearch Manufacturing Company, November 1973.

6. R. Sakhuja and A. Vasilakis, "Low Emission Combustion Deyelopment for Automotive Rankine-Cycle Engines," SAE Paper 730672 , June 18-22, 1973.

7. E. A. Mayer, 'Control System Study for a Rankine-Cycle Automotive Powerplant Organic Reciprocating System, "' Bendix Research Laboratory, Report No. 6524, April. 1973. 


\section{APPENDIX A}

\section{ROAD LOAD FUEL ECONOMY CALCULATIONS}

A data reduction program was used, which had as input the temperatures, pressures, flow rates, and power measurements from the preprototype system tests, and calculated component efficiencies, emissions, pressure drops, and road load fuel economy. This program was called the Road Load Data Reduction Program. The following is a discussion of the calculations used in this program to derive fuel economy (mpg) for the system.

Figure A. 1 is a schematic of the power train and system losses as they occur in the system and are handled by the computer program. The starting point for calculating fuel economy is the dynamometer horsepower (HP DYN), which measures the expander power minus the engine-driven ORCS auxiliaries such as the condenser fans, the hydraulic valve pump, and the feedpump.

The system power is then calculated by subtracting the ORCS a uxlliaries not driven by the expander from the dynamometer power. These a uxiliaries consist of the combustion system and the boost pump.

\section{A. 1 COMBUSTION SYSTEM POWER REQUIREMENT}

The combustion system consisted of the following items:

1. Burner-Boiler Blower-Motor

2. Fuel Cup Atomizing Power

3. Fuel Pump 


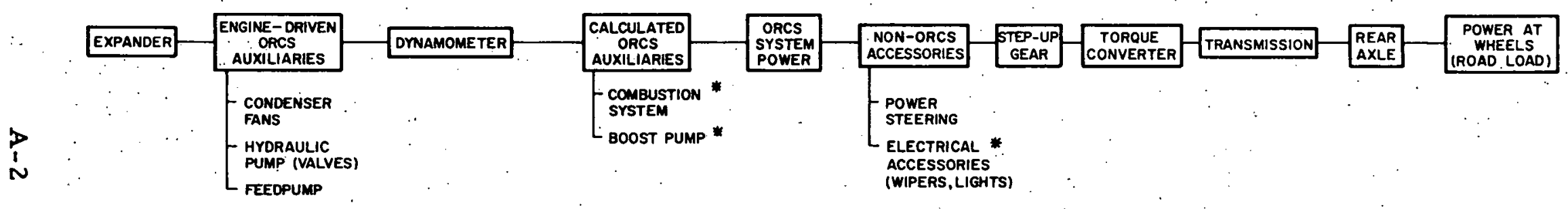

* includes alternator

Figure A.1 Preprototype System Computer Program Schematic 
Ignition work was considered negliglble since the ignitors would be shut off shortly after startup.

\section{A. 1.1 Blower-Motor}

The combustion blower-motor combination was tested and the power consumption of the unit was obtained as a function of pressure drop and flow. In separate tests, the pressure drop through the burnerboller was measured. The characteristic curve of the burner-boller was combined with the power consumption data of the blower-motor. This resulted in the curve drawn in Figure A.2. The curve shows the power, corrected for temperature and pressure, as a function of volume flow. The actual power is obtained as follows:

$$
\mathrm{HP}_{\mathrm{B}}=(\mathrm{HP} / \sigma) \times \sigma
$$

where

$$
\begin{aligned}
& \sigma=17.35 \mathrm{P} / \mathrm{T} \\
& \mathrm{P}=\text { pressure in inches of mercury } \\
& \mathrm{T}=\text { temperature }{ }^{\circ} \mathrm{R}
\end{aligned}
$$

\section{A. 1.2 Fuel Cup Atomizer Power}

A fuel atomizing cup was set up with a small motor and the power consumption was measured as a function of cup speed (normal operation was at $5000 \mathrm{rpm}$ ). These data are plotted in Figure A. 3.

\section{A. 1.3 Fuel Pump Work}

The work required for the fuel pump was calculated using the standard equation for flow work:

$$
\text { A-3 }
$$




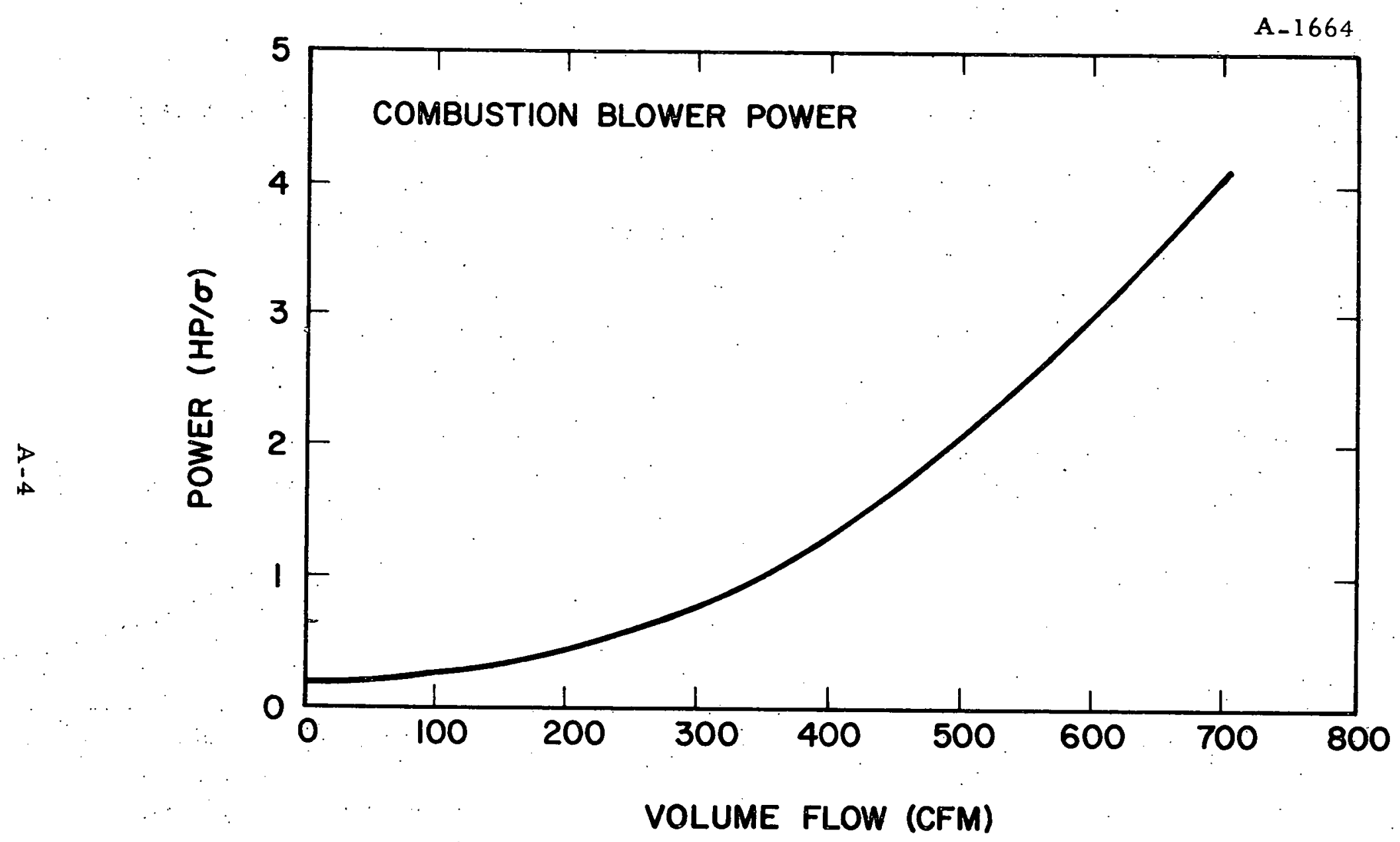

Figure A.2 Burner-Boiler Blower Power Consumption 
$A=1666$

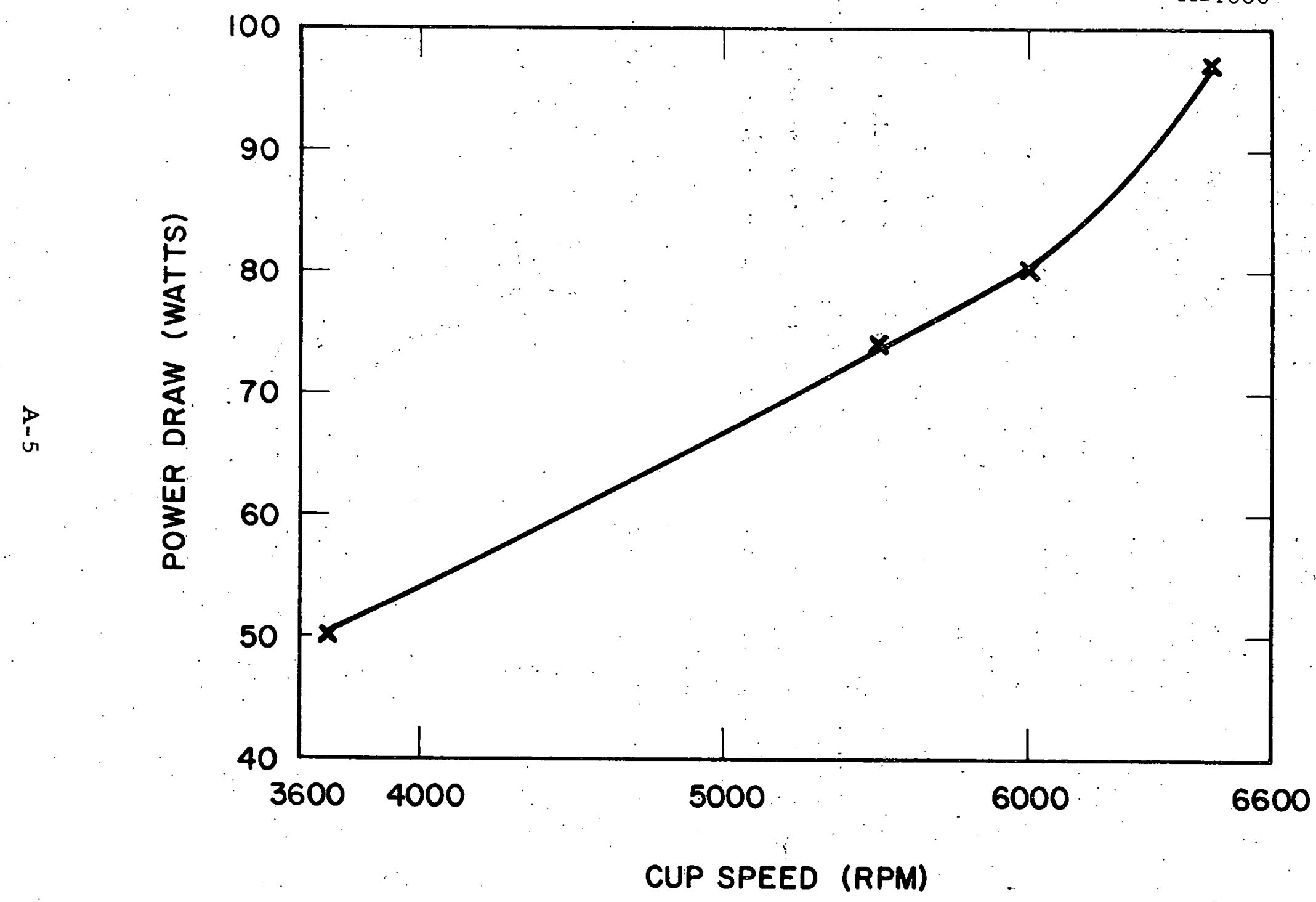

Figure A. 3 Fuel Cup Work as a Function of Cup Speed 


$$
\mathrm{HP}_{\mathrm{F}}=\left[\left(\frac{\mathrm{M}_{\mathrm{F}}}{\rho_{\mathrm{f}} \times 3600}\right) \Delta \mathrm{P}\right] / 550 \times \eta_{\mathrm{MP}} \text { (hp) }
$$

where

$$
\begin{aligned}
& \dot{M}_{F}=\text { fuel flow }(\mathrm{lb} / \mathrm{hr}) \\
& \rho_{\mathrm{f}}=\text { fuel density }\left(\mathrm{lb} / \mathrm{ft}^{3}\right) \\
& \Delta \mathrm{P}=\text { pressure drop across the pump }\left(\mathrm{lb} / \mathrm{ft}^{2}\right) \\
& \eta_{\mathrm{MP}}=\text { combination of the motor-pump efficiency } \eta_{\mathrm{MP}}=0.45
\end{aligned}
$$

A. 2 BOOST PUMP REQUIREMENTS

The power consumption of the boost pump was obtained by direct measurement of volts and amps to the motor since the actual boost pump motor was used in the preprototype system tests. If the vehicle speed wa below $45 \mathrm{mph}$, the boost pump power was zero; above $45 \mathrm{mph}$ the boost pump power was included in the calculation.

\section{A. 3 NET ORCS POWER}

Using all the preceding information, the net power of the ORCS can be obtained:

$$
H_{N E T}=\dot{H} P_{D Y N}-\left(H P_{B}+H P_{C}+H P_{F}+H P_{B P}\right) /\left(\eta_{A L T} \times \eta_{B}\right)
$$

where

$$
\begin{aligned}
& \mathrm{HP}_{\mathrm{NET}}= \text { net ORCS power used to calculate } \mathrm{BSFC} \text { and cycle } \\
& \text { efficiency } \\
& \mathrm{HP}=\text { power measured at the dynamometer } \\
& \mathrm{HP}=\text { combustion blower power } \\
& \mathrm{HP}_{\mathrm{C}}= \text { fuel cup power requirement } \\
& \mathrm{HP}_{\mathrm{F}}=\text { fuel pump power requirement }
\end{aligned}
$$




$$
\begin{aligned}
& \mathrm{HP}_{\mathrm{BP}}=\text { boost pump power requirement } \\
& \eta_{\mathrm{ALT}} \quad=\text { alternate efficiency (defined in later section) } \\
& \eta_{\mathrm{B}} \quad=\text { alternate belt and chain efficiency }=0.9604
\end{aligned}
$$

\section{A. 4 POWER TRAIN INPUT POWER}

The power input to the drive train can be calculated by subtract. Ing the non-ORCS accessories from the net system power.

\section{A. 5 POWER STEERING}

Figure A. 4 shows the power steering requirements for the vehicle as a function of expander speed.

\section{A. 6 ELECTRICAL ACCESSORIES}

Ford Motor Company supplled Thermo Electron with estimates of accessory loads. They estimated 0.6 horsepower would be required for lights, wipers, startup, etc. This makes the drive input power:

$$
{ }_{\mathrm{HP}}^{\mathrm{HP}}=\mathrm{HP}_{\mathrm{NET}}-\left[\mathrm{HP}{ }_{\mathrm{PS}}+\mathrm{HP}_{\mathrm{ACC}} /\left(\eta_{\mathrm{ALT}} \times \eta_{\mathrm{B}}\right)\right]
$$

where

$$
\begin{aligned}
{ }_{\mathrm{HPS}}= & \text { power steering power } \\
\mathrm{HP}_{\mathrm{ACC}}= & \text { electrical accessories }(0.6 \mathrm{HP}) \\
\eta_{\mathrm{ALT}}= & \text { alternator efficiency. Figure A. } 5 \text { gives the alternator } \\
& \text { efficiency as a function of load }
\end{aligned}
$$

\section{A. 7 DRIVELINE REQUIREMENTS}

\section{A.7.1 Step-up Gear}

The step-up gear has a ratio of $2.7: 1$ and an estimated efficiency of 98.8 percent. This makes the input speed to the torque converter: 


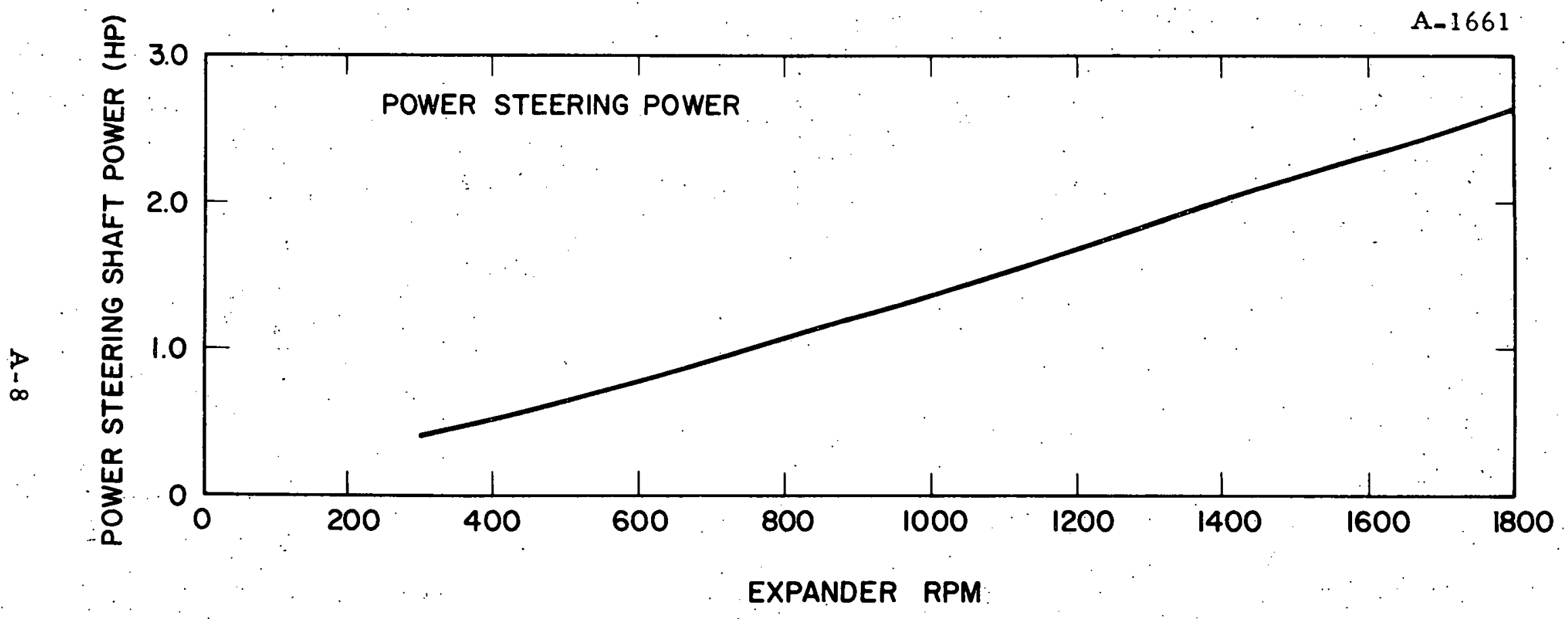

Figure A. 4 Power Steering Power as a Function of Expander RPM 


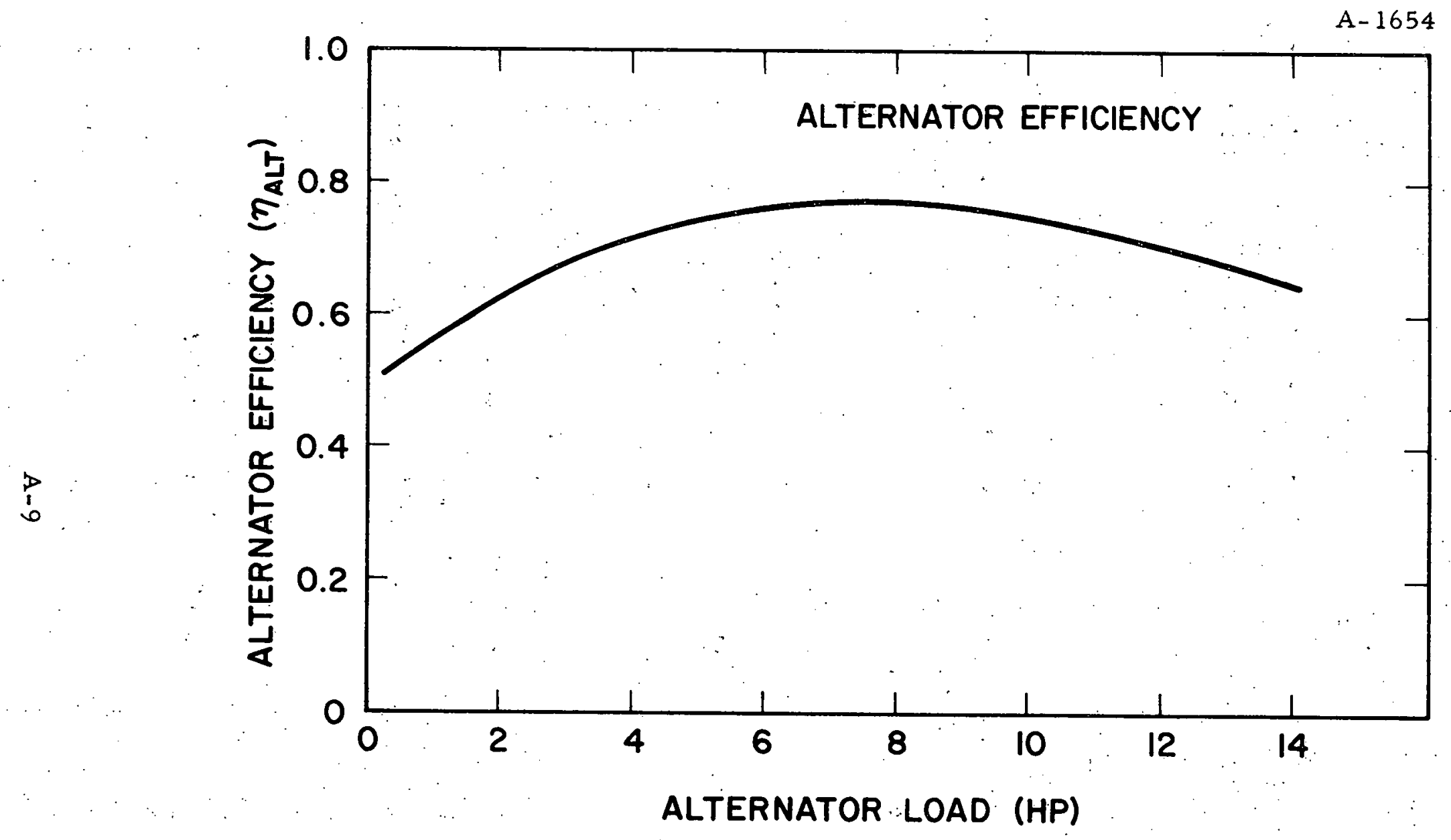

Figure A.5 Alternator Efficiency as a Function of Load 


$$
\mathrm{N}_{\mathrm{TCI}}=2.7 \times \mathrm{N}_{\mathrm{EX}}
$$

where

$$
\begin{aligned}
& \mathrm{N}_{\mathrm{EX}}=\text { expander speed } \\
& \mathrm{N}_{\mathrm{TCI}} \quad=\text { step-up gear output or torque converter input speed }
\end{aligned}
$$

The power out of the step-up gear and into the torque converter is:

$$
H_{\mathrm{TCI}}=\mathrm{HP}_{\mathrm{DR}} \times 0.988
$$

\section{A.7.2. Torque Converter}

The torque converter characteristic curve is shown in Figure A. 6. Plotted in this figure are both the converter efflciency and the speed ratio as a function of the parameter $K_{1}$, where $K_{1}$ is a function with the following definition:

$$
\begin{aligned}
& \mathrm{K}_{1}=\mathrm{N}_{\mathrm{TCI}} / \sqrt{\mathrm{T}_{1}} \\
& \mathrm{~T}_{1} \text { (Input Torque) }=\mathrm{HP}_{\mathrm{TCI}} \times 5252 / \mathrm{N}_{\mathrm{TCI}} \text { (ft-lbf) }
\end{aligned}
$$

The output speed and power of the torque converter 1s:

$$
\mathrm{N}_{\mathrm{TCO}}=\mathrm{N}_{\mathrm{TCI}} \times \mathrm{SR} \text { and } \mathrm{HP}_{\mathrm{TCO}}=\mathrm{HP}_{\mathrm{TCI}} \times \eta_{\mathrm{TC}}
$$

where

$$
\begin{aligned}
& \mathrm{SR} \\
& \mathrm{N}_{\mathrm{TCO}}=\text { torque converter output speed (rpm) } \\
& \mathrm{HP}_{\mathrm{TCO}}=\text { torque converter power output (hp) } \\
& \eta_{\mathrm{TC}} \quad=\text { torque converter efficiency defined in Figure A. } 6
\end{aligned}
$$

\section{A. 7.3 Transmission}

The power and speed out of the transmission are:

$$
\mathrm{HP}_{\text {TRANS }}={ }_{\mathrm{HP}}{ }_{\mathrm{TCO}}{ }^{\mathrm{x}} \eta_{\mathrm{TRANS}}
$$


A- 1651

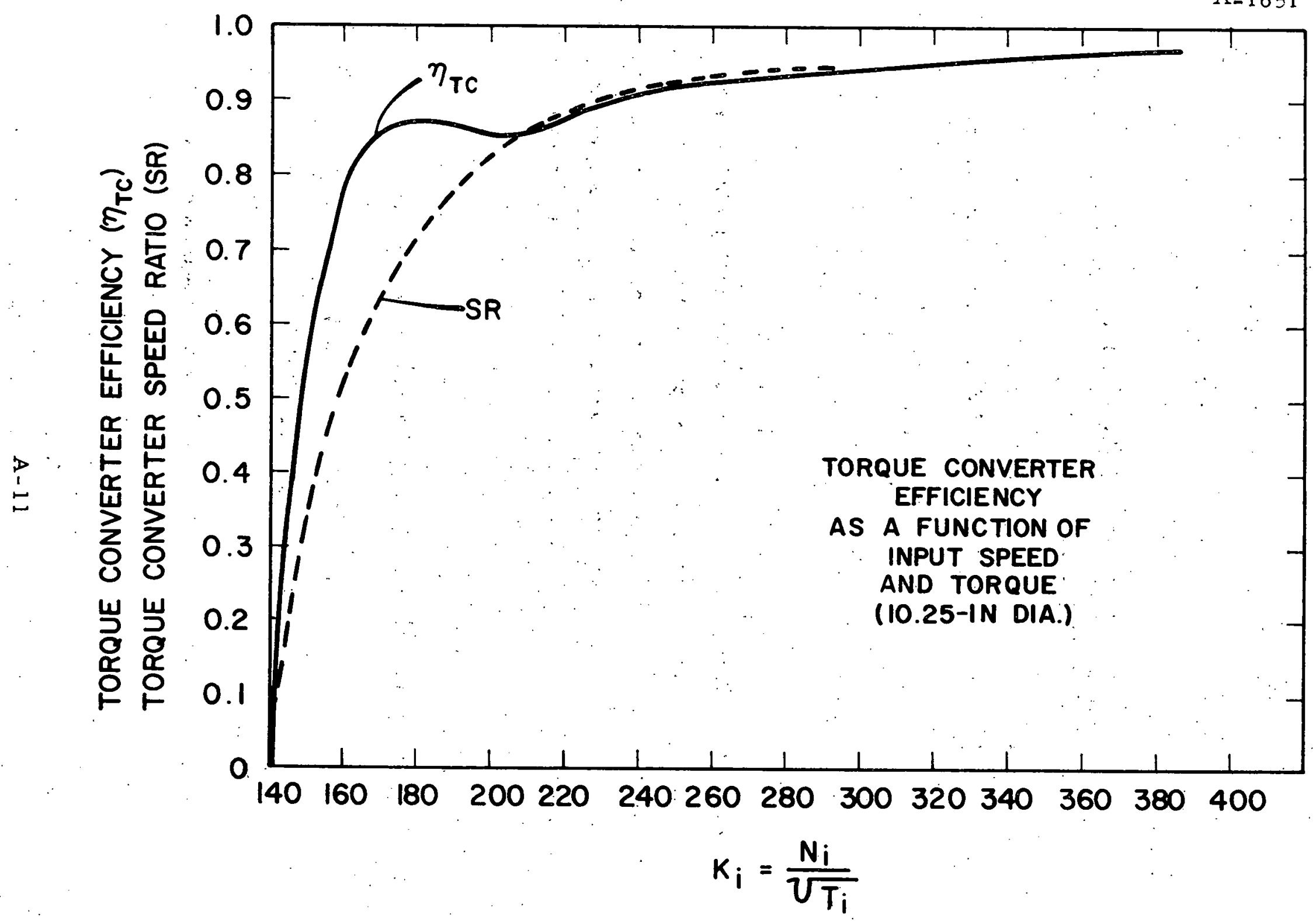

Figure A. 6 Torque Converter Characteristics 


$$
\begin{aligned}
\mathrm{HP}_{\text {TRANS }} & =\mathrm{HP}_{\mathrm{TCO}} \times \eta_{\text {TRANS }} \\
\mathrm{N}_{\text {TRANS }} & =\mathrm{N}_{\mathrm{TCO}} / \mathrm{TGR}
\end{aligned}
$$

where

$$
\begin{aligned}
& \eta_{\text {TRANS }}=\text { transmission gearbox efficiency } \\
& \text { TGR = transmission gearbox speed ratio }
\end{aligned}
$$

For the Road Load Data Reduction Program, the following values were used for the efficiency and speed ratio of the transmission:

\begin{tabular}{ccc} 
Gear & $\eta_{\text {TRANS }}$ & TGR \\
\hline 1 & 0.96 & 2.46 \\
2 & 0.97 & 1.46 \\
3 & 0.98 & 1.0
\end{tabular}

Subsequently, Thermo Electron received more refined information on a specific gearbox transmission. The speed ratios remain the same, however; the gearbox efficiencies for the different gears are shown in Figure A.7. All road.load data were reduced using the preceding table, whereas all the non-road load data used the efficiencies in Figure A. 7.

\section{A. 7.4 Rear Axle}

The output power and speed of the rear axle are:

$$
\begin{aligned}
\mathrm{HP}_{\mathrm{W}} & =\eta_{\mathrm{RA}} \times \mathrm{HP}_{\text {TRANS }} \\
\mathrm{N}_{\mathrm{W}} & =\mathrm{N}_{\mathrm{TRANS}} / \mathrm{RAR}
\end{aligned}
$$

where

$$
H P_{W}=\text { horsepower at the wheels; } 1 \text {,e., road load power }
$$




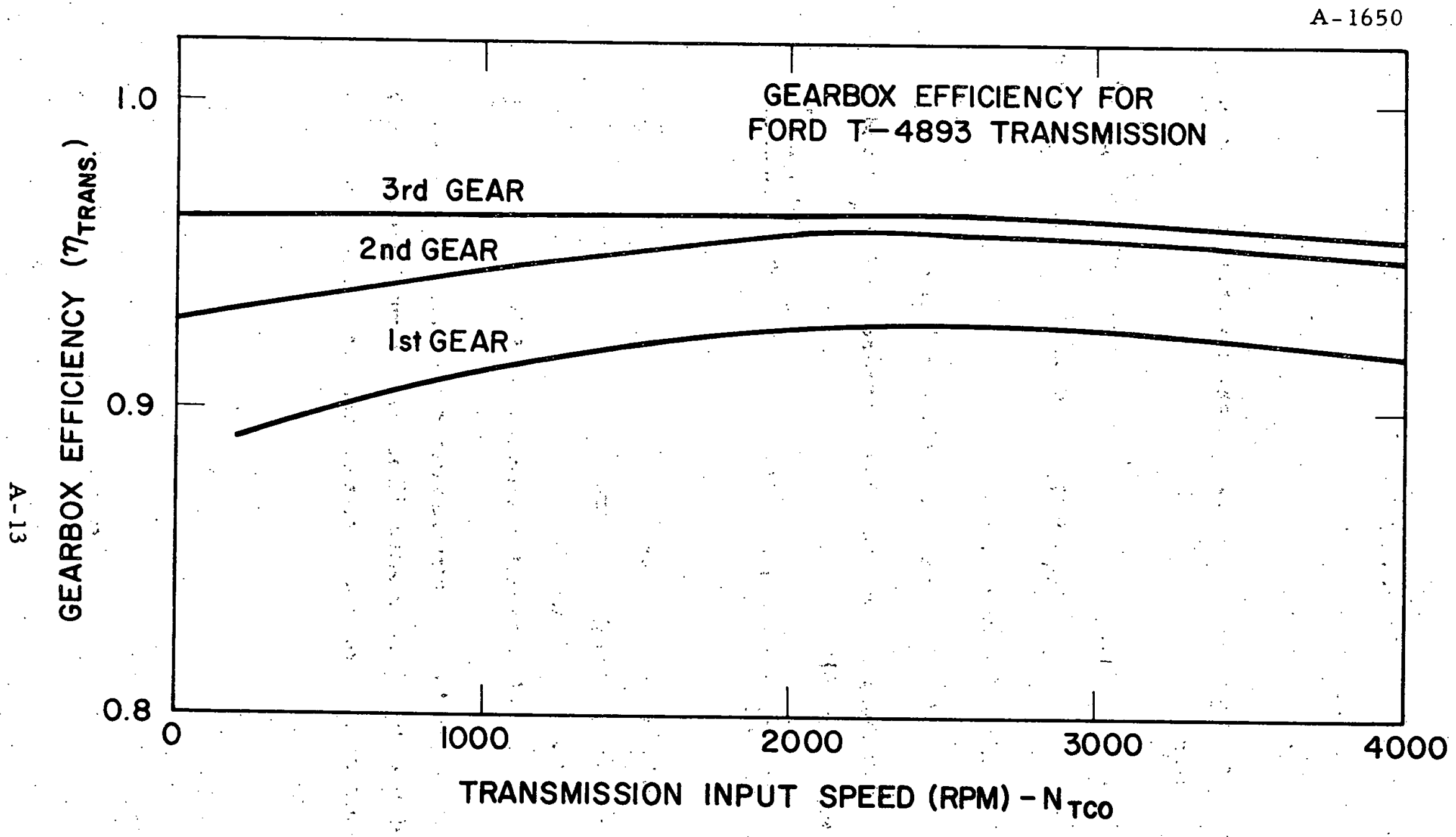

Figüre A.7 Transmission Gearbox Efficiency 
$\eta_{\mathrm{RA}}=$ rear axle efficiency $=0.965$

RAR = rear axle ratio $=3.5$

\section{A. 8 ROAD LOAD POWER}

Summarizing the previous calculations, the equation for road load power becomes:

$$
\begin{aligned}
H P_{R L} & =H P_{W}=\left\{H P_{D Y N}-\left[\left(H P_{B}+H P_{C}+H P_{F}+H P_{B P}\right) /\left(\eta_{A L T} \times \eta_{B}\right)\right]\right. \\
& -\left(H P_{P S}+{ }^{H P}{ }_{A C C} /\left(\eta_{A L T} \times \eta_{B}\right)\right\} \times 0.988 \times \eta_{T C} \times \eta_{\text {TRANS }} \times \eta_{R A}
\end{aligned}
$$

The speed (rpm) of the rear wheels is:

$$
\mathrm{NW}=\mathrm{N}_{\mathrm{EX}} \times 2.7 \times \mathrm{SR} /(\mathrm{TGR} \times \mathrm{RAR})
$$

The relationshlp between road load horsepower. $\left(H_{R L}\right)$ and vehicle speed is as follows:

$$
\mathrm{HP}_{\mathrm{RL}}=\frac{\mathrm{V}}{550}\left[\frac{\mathrm{W}}{65}\left(1+1.4 \times 10^{-3} \mathrm{~V}+1.2 \times 10^{-5} \mathrm{v}^{2}\right)+\frac{\rho \mathrm{C}_{\mathrm{d}^{A}} \mathrm{v}^{3}}{2}\right]
$$

where

$\mathrm{V}=$ yehicle speed $(\mathrm{ft} / \mathrm{sec})$

$\mathrm{W}=$ yehicle weight $(4576 \mathrm{lbm})$

$\rho=a i r \operatorname{density}\left(s \operatorname{lugs} / \mathrm{ft}^{3}\right.$ )

$C_{d} A=d r a g$ coefficient $x$ frontal a rea $\left(12 \mathrm{ft}^{2}\right)$

The data reduction program required the vehicle speed as a function of road load horsepower. This was accomplished by curve fitting the preceding equation. A plot of the curve fit is shown in Figure A. 8. 


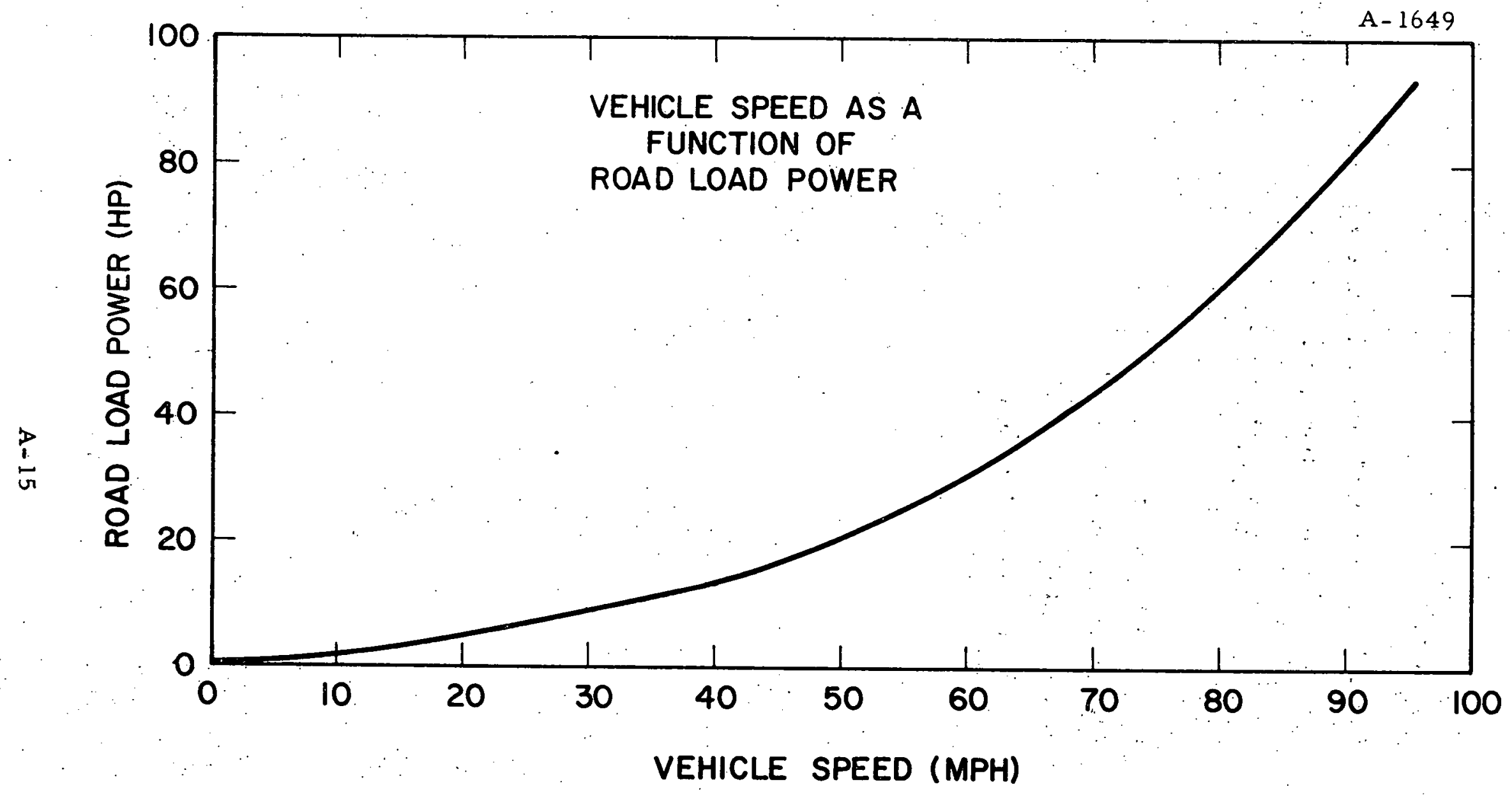

Figure A.8 Road Load Curve 


\section{A. 9 FUEL ECONOMY}

Using Figure A. 8, the vehicle speed (mph) can be obtained from the road load power. The fuel economy was then calculated as follows:

$$
M P G=N_{V} /\left(M_{F}+L P G\right)
$$

where

$$
\begin{aligned}
& M P G=\text { fuel economy (mpg) } \\
& N_{V}=\text { vehicle speed }(\mathrm{mph}) \\
& M_{F}=\text { fuel flow }(\mathrm{lb} / \mathrm{hr}) \\
& \mathrm{LPG}=\text { fuel density }(6.35 \mathrm{lbm} / \mathrm{gal})
\end{aligned}
$$




\section{APPENDIX B}

\section{IDEAL CYCLE MODEL FÓR EXPANDER}

The model used to evaluate the maximum work available from the cycle is presented along with the derivation of the work equations. This model was utilized to evaluate the effects on efficiency of changes in clearance volume and exhaust-valve closing volume: It is especially useful in determining the penalties or benefits in efficiency when running the expander uniflow (very low clearance volume and, therefore, high compression ratios with relatively high exhaust-valve closing volumes) as compared to running the expander with auxiliary exhaust valving (high clearance volume and low exhaust-valve closing volume). Overall, the model is a very useful tool in determining the maximum work and, therefore, the maximum efficiency that can be expected from the expander under various operating conditions. The symbols for the physical quantities used in the model are given in Table B. 1 .

B. 1 Case $1\left(m_{6}-m_{R E S} \leq m_{N E T}\right)$

Case 1 defines the model and work equations developed for the condition where the inlet valve closes after inlet conditions are achieved. Point 1 on the PV (pressure-volume) diagram shown below designates the inlet valve closing, which occurs after the inlet conditions (shown by $\mathrm{Pl}$ in the PV diagram) have been achieved.

Besides the condition of residual mass in the cylinder, Case 1 also covers the condition of overcompression as shown by the dotted lines in the PV diagram. 
TABLE B. 1

SYMBOLS FOR PHYSICAL QUANTITIES

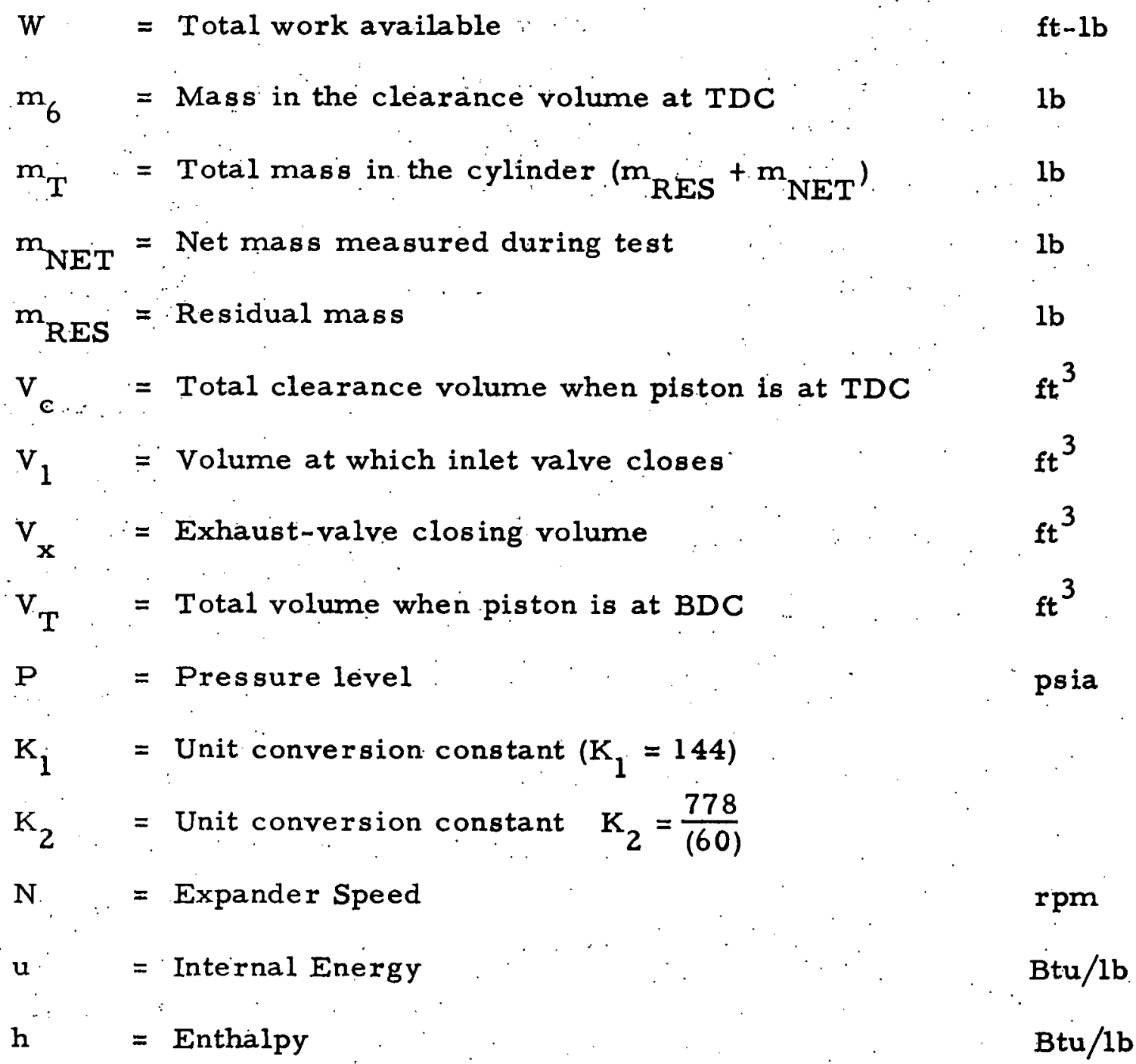

\section{B-2}




\section{Thermo

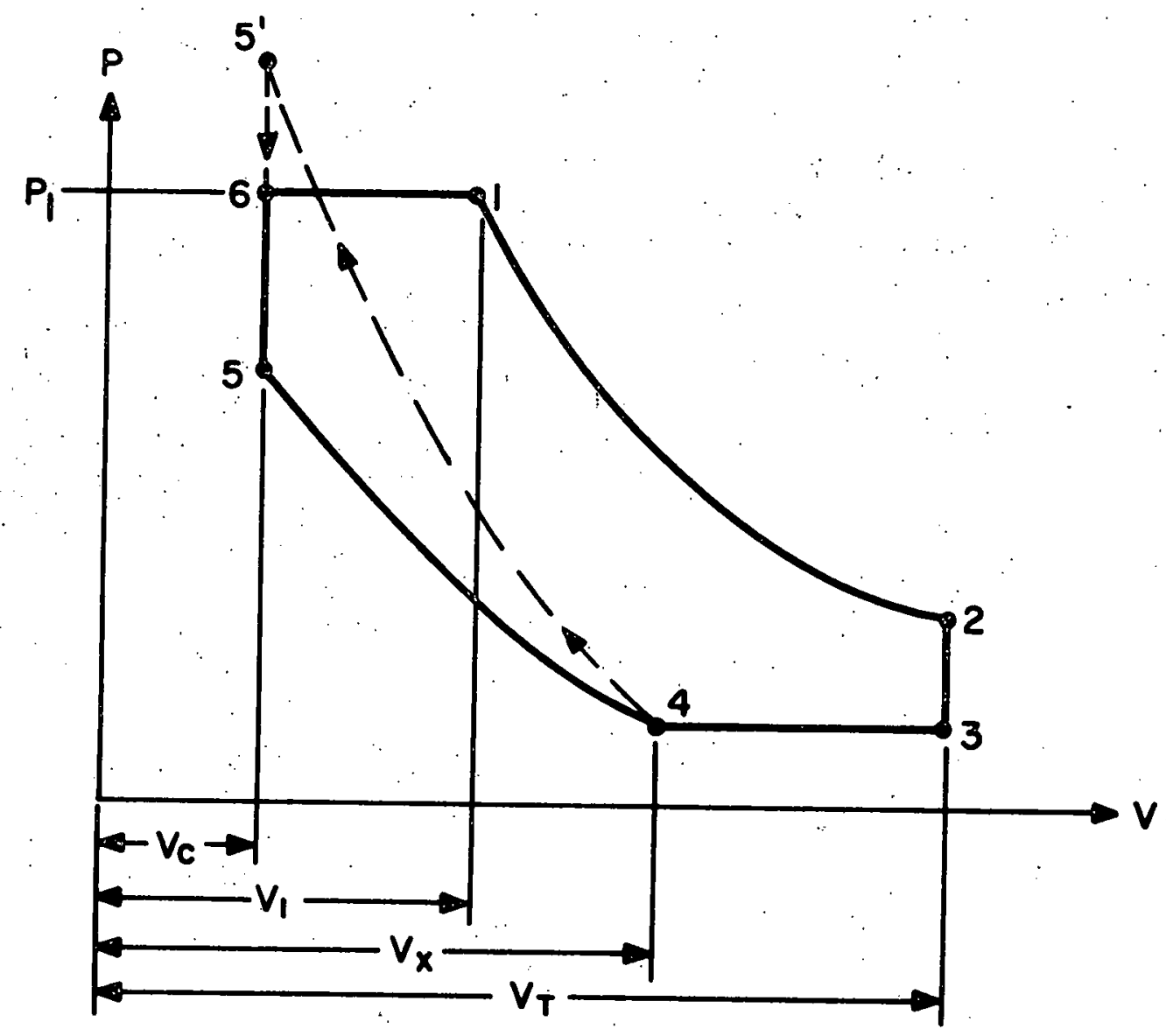

The work equation is as follows:

$W=K_{1} P_{1}\left(V_{1}-V_{c}\right)+K_{2} m_{T}\left(u_{1}-u_{2}\right)-K_{1} P_{3}\left(V_{T}-V_{x}\right)-K_{2} m_{R E S}\left(u_{5}-u_{4}\right)$,

since $h=u+P V$

and $\quad u=h-P V$

The equation for total work available from the model without overcompression becomes:

$W=K_{2}\left[m_{T}\left(h_{1}-h_{2}\right)+m_{R E S}\left(h_{4}-h_{5}\right)\right]+K_{1}\left[V_{T}\left(P_{2}-P_{3}\right)+V_{c}\left(P_{5}-P_{1}\right)\right]$ 
The equation for total work available with overcompression is:

$$
\begin{aligned}
& W=K_{2}\left[m_{T}\left(h_{1}-h_{2}\right)+m_{R E S}\left(h_{4}-h_{5}{ }^{\prime}\right)\right]+K_{1}\left[V_{T}\left(P_{2}-P_{3}\right)+V_{c}\left(P_{5}-P_{1}\right)\right] \\
& \because .2 \text { Case } 2\left(m_{6}-m_{R E S}>m_{N E T}\right)
\end{aligned}
$$

Case 2 defines the model and work equations developed for the condition where the inlet valve closes before inlet conditions are achieved. Point $6^{\prime}$ on the following PV diagram designates the inlet valve closing, which occurs before the inlet conditions have been achieved.

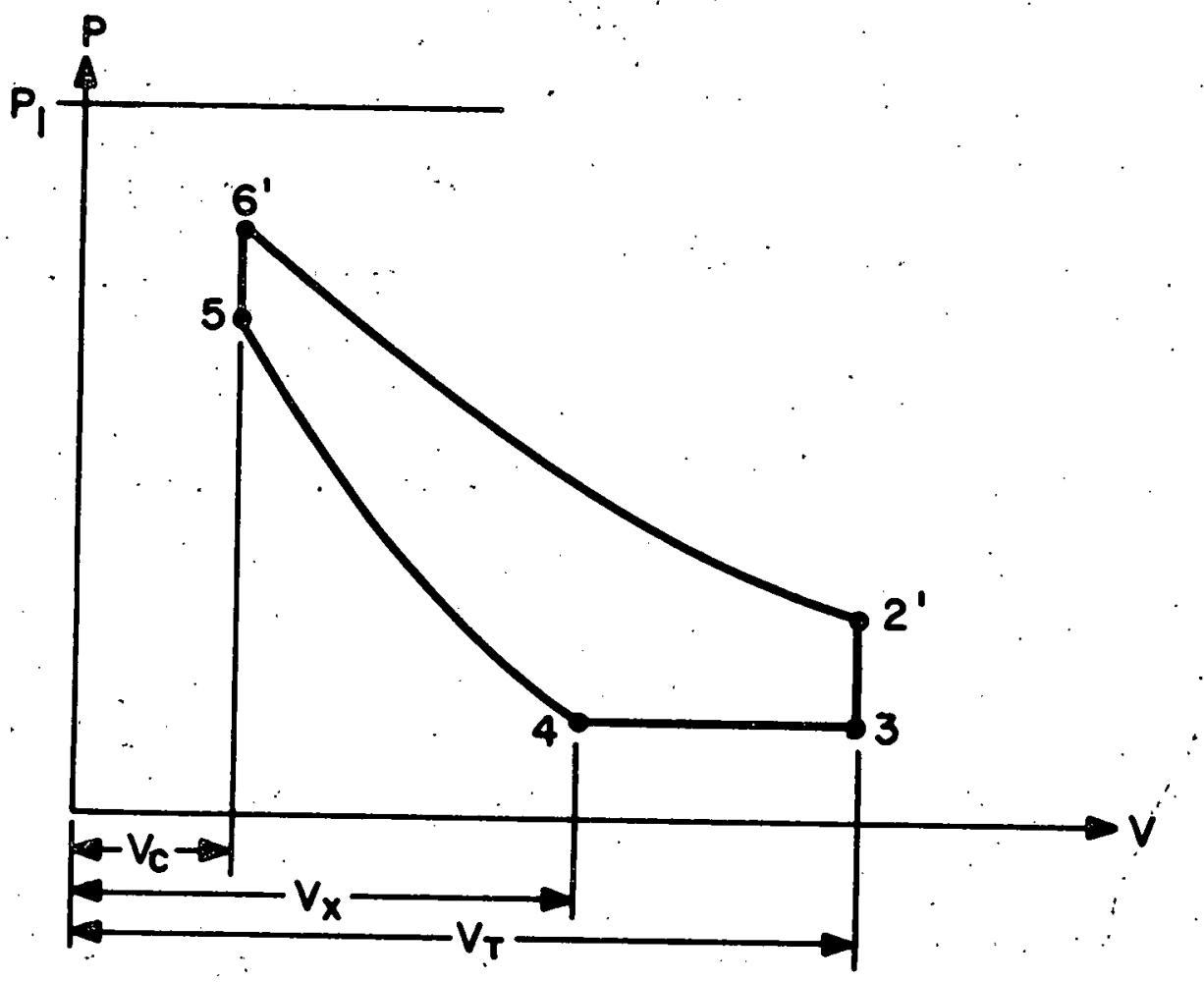

The equation for total work available is:

$$
\mathrm{W}=\mathrm{K}_{2}\left[\mathrm{~m}_{\mathrm{T}}\left(\mathrm{h}_{6}^{\prime}-\mathrm{h}_{2}^{\prime}\right)+\mathrm{m}_{\mathrm{RES}}\left(\mathrm{h}_{4}^{\prime}-\mathrm{h}_{5}\right)\right]+\mathrm{K}_{1}\left[\mathrm{~V}_{\mathrm{T}}\left(\mathrm{P}_{2}^{\prime}-\mathrm{P}_{3}\right)+\mathrm{V}_{\mathrm{c}}\left(\mathrm{P}_{5}-\mathrm{P}_{6}^{\prime}\right)\right]
$$

